\title{
Radiation dosimetry in vascular radiology : organ and effective dose to patients and staff
}

Citation for published version (APA):

Kicken, P. J. H. (1996). Radiation dosimetry in vascular radiology : organ and effective dose to patients and staff. [Doctoral Thesis, Maastricht University]. Universiteit Maastricht. https://doi.org/10.26481/dis.19960620pk

Document status and date:

Published: 01/01/1996

DOI:

10.26481/dis.19960620pk

Document Version:

Publisher's PDF, also known as Version of record

\section{Please check the document version of this publication:}

- A submitted manuscript is the version of the article upon submission and before peer-review. There can be important differences between the submitted version and the official published version of record.

People interested in the research are advised to contact the author for the final version of the publication, or visit the DOI to the publisher's website.

- The final author version and the galley proof are versions of the publication after peer review.

- The final published version features the final layout of the paper including the volume, issue and page numbers.

Link to publication

\footnotetext{
General rights rights.

- You may freely distribute the URL identifying the publication in the public portal. please follow below link for the End User Agreement:

www.umlib.nl/taverne-license

Take down policy

If you believe that this document breaches copyright please contact us at:

repository@maastrichtuniversity.nl

providing details and we will investigate your claim.
}

Copyright and moral rights for the publications made accessible in the public portal are retained by the authors and/or other copyright owners and it is a condition of accessing publications that users recognise and abide by the legal requirements associated with these

- Users may download and print one copy of any publication from the public portal for the purpose of private study or research.

- You may not further distribute the material or use it for any profit-making activity or commercial gain

If the publication is distributed under the terms of Article $25 \mathrm{fa}$ of the Dutch Copyright Act, indicated by the "Taverne" license above, 
RADIATION DOSIMETRY IN VASCULAR RADIOLOGY:

ORGAN AND EFFECTIVE DOSE TO PATIENTS AND STAFF 
aan

Paulatte.

"Thomas en Cécile

ISBN 9052782172

P.J.H. Kicken, Mastricht, the Netherlands, 1996.

All rights are reserved. No part of this publication may be reproduced, stored in a retrieval system, transmitted in any form or by any means, or republished in any form, without permission in writing from the copyright owner.

The work described in this thesis was financially supported by the former Dutch Ministry of Welfare, Health, and Cultural Affairs (The Hague), the Dutch Ministry of Social Affairs and Employment (The Hague), and the University Hospital Maastricht. 


\title{
Radiation dosimetry in vascular radiology: Organ and effective dose to patients and staff
}

\author{
PROEFSCHRIFT \\ ter verkrijginging van de graad van doctor \\ aan de Rijksuniversiteit Limburg te Maastricht, \\ op gezag van de Rector Magnificus, Prof. Mr. M.J. Cohen, \\ volgens het besluit van het College van Dekanen, \\ in het openbaar te verdedigen \\ op donderdag 20 juni 1996 om 14.00 uur
}

door

Peter Joseph Hubert Kicken 


\section{Promotores:}

Prof. dr. J.M.A. van Engelshoven

Prof. dr. J.J. Broerse (Rijksuniversiteit Leiden)

\section{Co-promotor:}

Dr. G.J. Kemerink

\section{Beoordelingscommissie:}

Prof. dr. A. Hasman (voorzitter)

Dr. L.B. Beentjes (Katholieke Universiteit Nijmegen)

Prof. dr. P.J.E.H.M. Kitslaar

Dr. J. Zoetelief (TNO, CSD Rijswijk) 


\section{CONTENTS}

1. Introduction

1.1 Purpose of this study

1.2 Scope of this study

1.3 Contents and structure of this thesis

2. Basic concepts of radiation quantities and risks

2.1 Introduction

2.2 Quantities and units in dosimetry

2.3 Effects and risks of $\mathrm{X}$-rays

3. Radiological protection and radiation doses

3.1 Introduction

3.2 Objectives of radiological protection

3.3 General principles of radiological protection

3.4 Radiological protection in radiology in the Netherlands

3.5 General information about radiation exposures in diagnostic radiology

3.6 General information about radiation doses in vascular radiology

4 Arteriography and interventional vascular radiology

4.1 Arteriography

4.2 Interventional vascular radiology

4.3 Vascular imaging techniques

4.4 Diagnostic imaging systems in the University Hospital Maastricht, the De Wever Hospital Heerlen, and the Maasland Hospital Sittard

4.5 Exposure conditions to patients in the University Hospital Maastriclat, the De Wever Hospital Heerlen, and the Maasland Hospital Sittard

4.6 Occupational exposure conditions in the University Hospital Maastricht, the De Wever Hospital Heerlen, and the Maasland Hospital Sittard

5 Vascular radiology in the Netherlands in 1992: a quantitative approach

5.1 Introduction

5.2 Methods: questionnaire to 165 hospitals

5.3 Results of the questionnaire

5.4 Discussion

5.5 Conclusion

6 Methods and techniques to assess the radiation dose to patients and staff

6.1 Introduction

6.2 Dosimetric methods to quantify organ doses

6.3 Automatic recording of technique parameters and dose-area product

6.4 Dosimetric approach for patients

6.5 Dosimetry techniques applied for occupational exposure 
7. Exposure conditions of patients in vascular radiology: collected data about technique parameters, dose-area product, patient characteristics and effective dose estimates

7.1 Introduction

7.2 Dose-area product and technique parameters for arteriography and percutaneous transluminal angioplasty procedures in the Universiry Hospital Maastricht, the De Wever Hospital Heerlen, and the Maasland Hospital Sittard

7.3 Characterisation of the patient

7.4 Effective dose estimates for the patient, using published data on E/DAP-ratios

7.5. Correlation analysis

8 Quantitative data about patient exposure conditions and dose estimates for selected procedures in the University Hospital Maastricht

8.1. Introduction

8.2 Quantification of patient radiation exposure conditions in arteriography of the pelvis and lower limbs

8.3 Organ doses and effective dose to patients in arteriography of the pelvis and lower limbs

8.4 Quantification of patient radiation exposure conditions in abdominal arteriography

8.5 Organ doses and effective dose to patients in abdominal arteriography

8.6 Comparison of results of this study with dose estimates obtained from previously published data

9 Entrance doses and effective dose to occupationally exposed persons in arteriography and interventional endovascular radiology.

9.1 Introduction

9.2 Dose measurement procedures to assess occupational exposures

9.3 Entrance doses to occupationally exposed persons in the University Hospital Maastricht, the De Wever Hospital Heerlen, and the Maasland Hospital Sittard

9.4 Effectiveness of 0.5 - $\mathrm{mm}$-thick lead-equivalent aprons in vascular radiology

9.5 Effective dose estimates for occupationally exposed persons

10 Conclusions and recommendations for dose control

10.1 Introduction

10.2 Results inferred for patients

10.3 Results inferred for occupationally exposed persons

10.4. Recommendations

\section{Appendices:}
A Thermoluminescence dosimetry
B Distribution of red marrow in peripheral bones
C. Lead aprons
D Effective dose to the patient as a function of the X-ray bearn direction

\section{References}

Samenvatting

Acknowledgement 


\section{Chapter 1}

\section{Introduction}

Vascular radiology involves imaging' of the vascular system for diagnostic and therapeutic purposes, using various modalities such as X-ray techniques, (doppler) ultrasound and magnetic resonance imaging. X-rays may cause adverse biological effects to patients and staff. Generally, prolonged flluoroscopic times and multiple series of radiographic and/or digital images are required, resulting in relatively high radiation doses to patients and staff. Due to significant variations in the use of $X$-ray equipment, exposure conditions and radiation doses may vary widely. However, to date, few studies into these radiation exposures have been conducted. Therefore, we performed a study with the following purposes.

\subsection{Purpose of this study}

Objectives of this study into radiation exposures in vascular radiology were:

1. to quantify the doses to patients;

2. to quantify the occupational doses;

3. to compare occupationall doses with legally established dose limits;

4. to derive simple measurement procedures to estimate medical and occupational doses;

5. to derive measures to optimise radiological protection of the patient and staff.

\subsection{Scope of this study}

This thesis describes the design and results of a study into the radiation dose to patients and personnel during vascular radiology. Radiation doses have been quantified for three main groups of procedures:

I. Intra-arterial arteriography, comprising digital subtraction angiography (DSA), serial cut film radiography, or both techniques. Procedures were classified into:

a. pelvis/lower limbs arteriography.

b. abdominal arteriography

c. thoracic arteriography

d. arteriography of the upper limbs

e. cerebral arteriography

I Imaging of the vascular system by using $\mathrm{X}$-rays comprises fiuoroscopy for real-time imaging of the vessels and the catheter, and film radiography and digital imaging for diagnostic and recording purposes. 
II. Intra-venous digital subtraction arteriography (IV-DSA):

a. pelvis/lower limbs IV-DSA

b. abdominal IV-DSA

c. thoracic IV-DSA

III. Interventional endovascular procedures:

a. percutaneous transluminal angioplasty in the lower limbs

b. percutaneous transhuminal angioplasty in the abdomen.

Quantitative data on medical exposure conditions and occupational exposures are given for all above-mentioned procedures. Details on fluoroscopy and imaging are given for procedures in groups Ia, Ib, IIa, and IIb. Data on occupational exposures are giwen for the operator and the first assistant for procedures in groups I and III. Dose measurements were performed in the anglography rooms in three Dutch hospitals: the University Hospital Maastricht, the De Wever Hospital Heerlen and the Maasland Hospital Sittard. Dose estimates in the University Hospital Maastricht and the De Wever Hospitall were associated with the $X$-ray tube in undercouch positions. Initial measurements in the Maasland Hospital were performed with overcouch X-ray tube positions. After a deliberate change of the protocol, the dosimetric study was continued with undercouch $\mathrm{X}$-ray tube applications. For extrapolation of the results from the present study, a survey to the extent of vascular radiology in the Netherlands was conducted in 1992.

\subsection{Contents and structure of this thesis}

Basic data on radiation quantities, biological effects and risks due to exposures to ionising radiation are given in Chapter 2 . In Chapter 3 radiological protection, and medical and occupational exposures to $\mathrm{X}$-rays in diagnostic radiology are introduced. Literature data about radiation exposures in vascular radiology are reviewed. In Chapter 4, a description is given of vascular radiology, seen from the view point of radiological protection. This chapter comprises data on $X$-ray equipment, imaging systems, and exposure conditions to patients and staff in the three hospitals, mentioned before. A survey to the number and types of vascular radiology procedures, characteristics of equipment, and occupational exposure conditions in the Netherlands is reported in Chapter 5 . The design of the study into the radiation exposure of patients and personnel is described in Chapter 6. In Chapter 7. measurement results of an automated, real-time monitoring system, developed for this study by the Department of Radiology of the University Hospital Maastricht, are presented. This chapter also comprises characteristic data on the patients. In Chapter 8 , details on radiodiagnostic views in selected arteriography procedures, results of Monte Carlo organ dose calculations, and estimates for the effective dose are given. Quantitative data on occupational exposures, derived from numerous measurements with thermoluminescent dosemeters, are discussed in Chapter 9. Concluding remarks and recommendations to optimise radiological protection in vascular radiology are given im Chapter 10. 


\section{Chapter 2}

\section{Basic concepts of radiation quantities and risks}

\section{$2.1 \quad$ Introduction}

The discovery of X-ray photoluminescence by Röntgen in 1895 [RO95] was followed by the recognition of chemical and physical effects such as the pliotographic effect and ionisation. Soon after the very early applications there was evidence of detrimental biological effects as well. Reddening of the skin and ulceration (at high dose levels) even became a method for dosage control in radiation therapy in the early $20^{\text {th }}$ century [TA89]. Only one year after the discovery of X-rays, Becquerel discovered radioactivity. In a long history of research, scientists such as $M$. and P. Curie, E. Rutherford, P. Villard, E. Chadwick, $\mathbb{L}$. Gray and many others have contributed to the understanding of the properties of radioactive substances and ionising radiation. In the fields of radiation application and protection, it was soon concluded that coherent systems of measurements, quantities and units were indispensable. On an international level, this has resulted in the establishing of a number of commissions and advisory boards. In the field of metrology, the International Commission on Radiation Units and Measurements (ICRU) has become the leading institution.

\subsection{Quantities and units in dosimetry}

In diagnostic radiology and in radiological protection, various quantities are used to describe the radiation field or the radiation energy transferred to the imaging system and to the human body. An ellementary description of $X$-ray fields comprises quantitative data on the number, direction and energy of the photons. Radiation fields can be characterised by radiometric quantities, such as fluence rate and energy fluence rate, as defined by ICRU [IC80]. The ionisation process, which is elementary related to the interaction of radiation with matter, can be characterised by interaction coefficients, such as cross sections, linear energy transfer and mass energy absorption coefficients [IC80].

In assessments of risks of exposure to ionising radiation, differences in relative biological effectiveness of various types of radiation as well as differences in radiosensitivity of human tissues should be taken into account. It is obvious that primary physical quantities do not account for these factors. Therefore, in order to be of practical value in radiological protection, primary physical quantities have to be "translated" into heal th physics quantities, in which differences and similarities of the biological response to different types of exposures have been incorporated. Due to advancements in radiobiology and epidemiology, organ specific risk estimates can change, and indeed have changed in the past. Eventually, new insights in risks are followed by modifications in the relationship between physical quantities and health physics quantities. 
To restrict the risks associated with the exposure ro ionising radiation, systems of dose limits have been introduced and applied. Quantities used in this system are called limiting quanities. To assess the radiation exposure in terms of limiting quantites, a number of operationall quantities have been defined, such as ambient dose equivalent and personal dose equivalent. These quantities, measurable with radiation measurement devices, provide a sufficiently conservative assessment of limiting quantities to ensure the absence of underestimates [1C88, IC92, IC93].

Definitions of a number of quantities and units which are applicable to quantify medical and occupational radiation exposures are given below. Fundamental definitions of physical radiation quantities are given in ICRU Report 43 [IC88], of operational quantities in ICRU Report 47 and Report 51 [1C92, 1C93], and of radiation protection quantities in Publication 60 of the International Commission on Radiological Protection [IC91]. Since we did not apply operational quantities in this study, these quantities are not included in the following summary.

\section{Absorbed dose}

The physical quantity absorbed dose, $\mathrm{D}$, is the quotient of $\mathrm{d} \epsilon_{\text {mean }}$ by $\mathrm{d} m$, where $\mathrm{d} \epsilon_{\text {mean }}$ is the mean energy imparted by ionising radiation to matter of mass d $m$ [IC80, IC93].

$$
\mathrm{D}=\mathrm{d} \epsilon_{\text {mean }} / \mathrm{d} m
$$

The mean energy imparted, $\epsilon_{\text {mean }}$, is the mathematical expectation value of the energy imparted $\epsilon$. The energy imparted, $\epsilon$, by ionising radiation to matter in a volume is [IC93]:

$$
E=R_{\mathrm{int}}-R_{\mathrm{oes}}+\Sigma Q
$$

where

$\mathbf{R}_{\text {in }}=$ the radiant energy incident on the volume, i.e. the sum of the energies (excluding rest energies) of al! those charged and uncharged ionising particles which enter the volume;

$R_{\text {оut }}=$ the radiant energy emerging from the volume, i.e. the sum of the energies (excluding rest energies) of all those charged and uncharged ionsing particles which leave the volume;

$\mathrm{EQ}=$ the sum of all changes of the rest mass energy of nuclei and elementary particles in any muclear transformations which occur in the volume.

The energy imparted results from random discrete energy deposition events by individual ionising particles and their secondaries. The quantity $\epsilon$ is therefore stochastic [NC91]. Consequently, $e$ varies discontinuously in space. A definition of absorbed dose in terms of the differential quotient $\mathrm{d} / \mathrm{dm}$ would be of little practical value, since its numerical value would have an unpredictable stochastic character. By using the averaged imparted energy instead, the nature of the absorbed dose is non-stochastic and is, in general, a continuous function [GR85]. 
The mean value of $\epsilon\left(\epsilon_{\operatorname{men}}\right)$ is derived from

where

$$
E_{\text {mean }}=\int_{0}^{\infty} \epsilon f_{V}(\epsilon) d \epsilon
$$

$f_{v}(\epsilon)=\quad$ the normalised probability distribution function of $\epsilon$, with $V$ the volume containing mass $m$ [NC91].

The absorbed dose is defined at a given position in the irradiated object and is a nonstochastic quantity. Because of the discrete manner in which energy is imparted, the limiting process of $\mathrm{V} \rightarrow 0$ is obviously an idealisation. The volume $\mathrm{V}$ should at all times contain a large number of atoms [NC91]. Specification of the absorbed dose should include the medium in which the absorbed dose has been determined. In the Systeme International d'Unités (SI system) the absorbed dose is expressed with the units Joule $\cdot \mathrm{kg}^{\text {* }}$ 1. The special SI unit of absorbed dose is the gray $(G y) ; 1$ gray is equal to $1 \mathrm{~J} \cdot \mathrm{kg}^{-1}$. The former special unit was the rad ( $1 \mathrm{rad}=0.01 \mathrm{~Gy})$.

\section{Absorbed dose in biological tissue}

In radiological protection the quantity absorbed dose refers in general to the absorbed dose in a biological tissue. For radiological protection ICRP has detined the absorbed dose in biological tissue, $\mathrm{D}_{\mathbb{T}, \mathbb{R}}$, as the amount of energy imparted to a tissue or organ $\mathbb{T}$ by ionising radiation of cype $\mathrm{R}\left(\mathrm{E}_{\text {impartes, } \mathrm{R}}\right)$, divided by the mass of the irradiated tissue or organ $\left(\mathrm{m}_{\mathrm{Y}}\right)[\mathrm{IC} 91]$.

$$
\mathrm{D}_{\mathrm{T}, \mathbb{R}}=\mathrm{E}_{\text {imparted, }, \mathrm{R}} / \mathrm{m}_{\mathrm{T}}
$$

In other words, $D_{T, R}$ is the average dose in a tissue or organ. The tissue or organ as well as the type of radiation must be specified. In this thesis the quantity "absorbed dose in biological tissue" is referred to as "tissue dose", "organ dose", or "dose" for short. Presupposing a linear dose-effect relationship, the average absorbed dose in a tissue is especially useful as an indicator for the probability of stochastic effects. The special SI unit of absorbed dose in tissue is the gray (Gy); 1 gray is equal to $1 \mathrm{~J} \cdot \mathrm{kg}^{\text {. }}$. The traditional unit was the rad ( $1 \mathrm{rad}=0.01 \mathrm{~Gy})$.

\section{Equivalent dose}

The quantity equiwalen dose, $\mathrm{H}_{\mathrm{T}}$, introduced by ICRP for application in radiological protection [IC91], is defined as the tissue dose $D_{T . R}$ weighted for the biological effectiveness of the radiation quality of interest. The equivalent dose is derived by multiplying the tissue dose with a so-called radiation weighting factor $\left(w_{R}\right)$. Contributions of different radiation types have to be totalised.

$$
H_{T}=\Sigma_{R}\left(w_{R} \cdot D_{T, R}\right)
$$

The radiation weighting factor depends on the type and energy of the radiation incident on the body. Radiation weighting factors have been selected to be representative for the relative biological effectiveness in inducing stochastic effects at a low dose level. The value of $w_{R}$ for $X$-rays has been set to unity. Consequently, the numerical value of $H_{\mathrm{T}}$ is equal to the numerical value of $\mathrm{D}_{\mathbb{T} R}$ for all medical diagnostic applications of $\mathrm{X}$-rays. 
The special S.1.-unit of equivalen dose is the sievert $(S v)$, 1 sievert is equal to $1 \mathrm{~J} \cdot \mathrm{kg}^{-1}$. The quantity equivalent dose is the successor of the quantiry dose equivalen which was introduced by ICRP in 1977 [1C77]. Alhough these quantities show some differences, in radiology they may be regarded as similar. The special $S$. I- unit and former unit of the superseded quantity dose equivalent are the sievert and the rem, respectively (1 rem $=$ $0.01 \$ Y)$.

In diagnostic radiology, radiation energy is imparted to internal organs and tissues. Generally, only a small number of organs is directly exposed to the primary $\mathrm{X}$-ray beam. The majority of organs will receive scattered radiation from the directly exposed tissues, system components such as the aperture and the table top, or air. As a general rule, organ dose contributions due to scattered radiation are much lower than the dose due to the primary radiation. Organ doses depend on the body part being examined, the examination type, and the features of the X-ray equipment and imaging system. Obviously, the radiation dose also depends, directly or indirecty, on the weight, height, gender and age of the patient, and on the skill and attitude of the operator. Due to the relatively snall radiation field and the high attenuation of the impinging $X$-rays inside the body, organ equivalent doses may vary between a fraction of a microsievert up to tens of millisieverts. For example, normalised to entrance dose, an anterior-posterior chest examination $(80 \mathrm{kV}$, $4 \mathrm{~mm}$ Al) may result in $0.4 \mathrm{mSv} / \mathrm{mGy}$ equivalent dose to the lungs, and $0.002 \mathrm{mSv} / \mathrm{mGy}$ to the lower large intestine. A posterior-anterior examination of the abdomen $(80 \mathrm{kV}, 4$ $\mathrm{mm} \mathrm{Al}$ ) may result in a normalised equivallent dose of $0.009 \mathrm{mSv} / \mathrm{mGy}$ to the lungs, and $0.2 \mathrm{mSv} / \mathrm{mGy}$ to the lower large intestine (data derived with XDOSE [LE94]).

\section{Effective dose}

In the past it was recognised that radiation doses have to be presented in a comprehensive way. Comparison of radiation risks and determination of the efficiency of protection measures are hardly feasible, if the dosimetric information merely comprises a (long) list of equivalent organ doses. Inhomogeneous exposure conditions and internal contaminations $\ddot{n}$ particular asked for a different approach. To be able to compare various, nonuniform exposures, resulting in different distributions of organ doses, ICRP introduced in 1977 the quantity effective dose equivalent [IC77], which was defined in 1978 [1C78]. In 1991 this quantity was superseded by the effective dose.

The health physics quantity effective dose, $\mathrm{E}$, is defined by ICRP [IC91] as the sum of the weighted equivalent doses in all tissues and organs of the body. The weighting accounts for differences in the relative probability of stochastic effects in various organs and tissues.

where

$$
\mathrm{E}=\mathrm{\Sigma}_{\mathrm{T}}\left(\mathrm{w}_{\mathrm{T}} \cdot \mathrm{H}_{\mathrm{T}}\right)
$$

$w_{T}$ is a so-called tissue weighting factor for tissue $T_{*}$

$\mathrm{H}_{\mathrm{T}}$ is the equivalent dose of tissue $\mathrm{T}$, thereby

$$
\mathrm{E}=\Sigma_{\mathrm{T}}\left(w_{\mathrm{T}} \cdot \mathrm{E}_{\mathrm{R}}\left(w_{\mathrm{R}} \cdot \mathrm{D}_{\mathrm{T}, \mathrm{R}}\right)\right)
$$

Numerical values for tissue weighting factors depend only on the organ or tissue, not on the quality of the radiation. Tissue weighting factors refer to a reference population of equal numbers of males and females, in a wide range of ages. Numerical values for tissue 
weighting factors for 12 organs have been defined in ICRP Publication 60 (see Table 2.1). In addition, various organs have been inciuded in a remainder group. As mentioned before, the numerical value of $w_{R}$ is equal to $I$ for diagnostic medical $X$-ray applications. Consequently, under these circumstances the effective dose can be calculated as:

$$
\mathrm{E}=\Sigma_{\mathrm{T}}\left(\mathrm{w}_{\mathrm{T}} \cdot \mathrm{D}_{\mathrm{T}}\right)
$$

If remainder organs are exposed the effective dose is computed as:

$$
E=\Sigma_{\mathrm{T}}\left(w_{\mathrm{T}} \cdot \mathrm{D}_{\mathrm{T}}\right)+w_{\text {peraindef }} \cdot \Sigma_{\mathrm{r}}\left(\mathrm{m}_{\mathrm{r}} \cdot \mathrm{D}_{\mathrm{r}}\right) / \Sigma_{\mathrm{r}} \mathrm{m}_{\mathrm{r}}
$$

where

$\mathrm{w}_{\text {remainster }}=0.05$

$\mathrm{m}_{\mathrm{r}}$ is the mass of remainder tissue $r$ (see foomote in Table 2.1)

By its definition, $\mathrm{E}$ is related to stochastic effects of radiation in man, associated with exposures to low dose levels only. The special S.I.-unit of effective dose is the sievert (Sv); 1 sievert is equal to $1 \mathrm{~J} \cdot \mathrm{kg}^{-1}$. The special S.I.-unit and former special unit of the superseded quantity effective dose equivalent are the sievert and the rem respectively (1 rem $=0.01 \mathrm{~Sv}$.

Table 2.1 Tissue weighting factors ${ }^{\mathrm{A}}$

\begin{tabular}{ll}
\hline Tissue or organ & $\begin{array}{l}\text { Tissue weighting } \\
\text { factor, } w_{\mathrm{T}}\end{array}$ \\
\hline Gonads & 0.20 \\
Red bone marrow, colon , lung, stomach & 0.12 \\
Bladder, breast, liver, oesophagus, thyroid & 0.05 \\
Skin, bone surface & 0.01 \\
Remainder & 0.05
\end{tabular}

"Source: ICRP Publication 60 [IC91]; "Colon = descending colon, sigmoid and rectum. Colon is equal to "lower large intestine" as applied in ICRP Publication 26; "For calculation purposes. ICRP proposed to include the following tissues and organs in Remainder (figures in brackets refer to the mass (kg) of the male and female reference man respectively [1C75]: adrenals $(0.014,0.014)$, brain $(1.4,1.2)$, upper lange intestine $(0.2), 0.20)$. small intestine $(0.64,0.60)$. kidneys $(0.31,0.275)$, muscle $(28,17)$, pancreas $(0.1,0.085)$, spleen $(0.18,0.15)$, thymus $(0.02,0.02)$ and uterus $(-0.08)$.

\section{Kerma}

The physical quantity kema, $\mathrm{K}$, was first defined by ICRU in 1962 [IC62]. In ICRU Report 43 [IC 88] kerma is defined as the quotient of $\mathrm{d} E_{\mathrm{tr}}$ by $\mathrm{d} m$, where $\mathrm{d} E_{\mathrm{tr}}$ is the sum of the initial kinetic energies of all the charged particles liberated by uncharged ionising radiation in a volume element of a specified material and $\mathrm{d} m$ is the mass of the matter in that volume element.

$$
\mathrm{K}=\mathrm{d} E_{\mathrm{tr}} / \mathrm{d} m
$$

Kerma the name of this quantity was originally derived from "kinetic energy released in material" [IC62], was introduced in order to take the nature of the interaction process of uncharged particles with matter into account. Uncharged radiations, such as photons and 
neutrons, transfer energy in a two-stage process. In the first stage, the uncharged radiation transfers energy to a charged particle, originating of the irradiated material. In the second stage, this charged particle interacts with a (large) number of atoms, thereby imparting its kinetic energy to the material. With respect to its nature of interaction, uncharged ionising radiation is called "indirectly ionising radiation". The quantity kerma is related to the first stage of this interaction process. The specification of kerma should comprise information on the characteristics of the medium in which the kerma has been determined.

For calibration purposes of radiation measuring systems the quantity air kerma, measu-

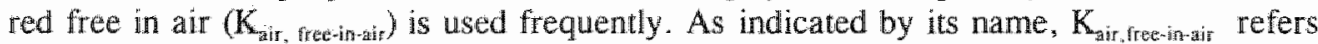
to conditions in which the kerma in air has been determined with no significant contributions of scattered radiation originating in other materials. In actual determinations of $\mathrm{K}$ the mass element should be so small that its introduction should not disturb the field of the indirectly ionising radiation. For mono-energetic photons, the air kerma $\left(\mathbb{K}_{\text {air }}\right)$ can be derived from the following equation [1C92]

$$
\mathbb{K}_{\text {air }}=160.2210^{-4} \cdot\left(\mu_{\mathrm{tr}} / \rho\right) \cdot \mathrm{E} \cdot \phi
$$

where

$\mathrm{K}_{\mathrm{air}}=$ the kerma in air, free in air [mGy]

$\mu_{\mathrm{gr}} / p=$ the mass energy transfer coefficient of photons with energy $\mathrm{E}$ in air $\left[\mathrm{cm}^{2} \mathrm{~g}^{-1}\right]$

$\mathrm{E}=$ the photon energy [MeV]

$\phi=$ the fluence $\left[\mathrm{cm}^{-2}\right]$

The Dutch National Standard Laboratory (NMi) applies the quantity $K_{\text {ait. }}$ ire-in-air to calibrate radiation monitoring devices. If these instruments are used to determine the absorbed dose, conversion factors must be applied.

Under the condition of charged particle equilibrium (CPE), and if the production of bremsstrahlung is considered to be negligible, the absorbed dose $\mathrm{D}_{\mathrm{m}}$ is related

to $\mathrm{K}_{\text {air, free-ith-xir }}$ as:

$$
\mathrm{D}_{\mathrm{m}}=\left[\left(\mu_{\mathrm{tul}} / \rho\right)_{\mathrm{in}} /\left(\mu_{\mathrm{en}} / \rho\right)_{\text {nir }}\right] \cdot \mathbb{K}_{\text {airo, frec-in-air }}
$$

where

$\left(\mu_{\text {iti }} / \rho\right)_{\text {in }}$ and $\left(\mu_{\mathrm{vin}} / \rho\right)_{\text {air }}$ are the mass energy absorption coefficients of the material $m$ and air respectively.

Since both conditions are generally met in medical radiology, the numerical values of

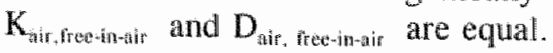

Under CPE conditions the sum of energies of charged particles entering and leaving the volume of interest (excluding rest energy) are equal [IC 80]. CPE will generally exist in a unitorm medium at a point which lies beyond the maximum range for the secondary charged particles from the boundaries of the medium. CPE will generally not exist near the interface between two dissimilar media [KA78]. In the low photon energy range, as encountered in medical radiology, ranges of secondary electrons produced by the primary interaction process are less than approximately $10 \mathrm{mg} \cdot \mathrm{cm}^{-2}$ (adapted from US70), which 
corresponds to approximately $0.01 \mathrm{~cm}$ in soft tissue and $8 \mathrm{~cm}$ in air. The special S.I. -unit of kerma is the gray (Gy); 1 gray is equal to $\mathrm{l} J \cdot \mathrm{kg}^{-5}$.

\section{Dose-area product}

The quantity dose-area product, DAP, is related the quantity exposure-area product, as introduced in the 1960s by Carlsson [CA63, CA65]. DAP is equal to the dose in air in a plane, integrated over the area of interest defined by the variables $x$ and $y$.

$$
D A P=\int_{x-\operatorname{man}}^{x-\max } \int_{y-\min }^{y-\max } D(x, y) d x d y
$$

Dose area product meters have been in use for more than three decades in Germany. and for some time in the United Kingdom, the Scandinavian countries and the United States of America [PY94]. DAP measurements, carried out with specially designed devices, provide data on the absorbed dose at a reference distance to the focus and the area of the exposed surface at this distance, perpendicular to the central axis of the X-ray beam. Disregarding absorption and scattering of radiation in air the dose rate is approximately inversely quadratically related to the distance from the focus of the $X$-ray tube. Since the cross. section of the beam is quadratically related to the focal distance, the product of dose with area is constant, independent of the reference distance from the focus. Taking advantage of this phenomenon one can indirectly determine DAP, free in air (i.e. without back scatter radiation from the patient), at the skin entrance position by measurement of DAP close to the focus. Descriptions of the determination of DAP by using dedicated systems such as a Diamentor transmission ionisation chamber can be found elsewhere [PY78, SH82, WA89].

The relevance of the quantity dose-area product for diagnostic radiology lies partially in its relation to the quantity effective dose (E). Various authors have described a reasonable relationship between DAP en $E$ for simple examinations [LE92a]. Furthermore, this quantity can be measured quite easily and may, combined with data on e.g. fluoroscopy time and patient characteristics, provide useful data for intercomparison of the performance of X-ray systems and/or individual operators. The unit of dose-area product is gray times square meters $\left(\mathrm{Gy} \cdot \mathrm{m}^{2}\right)$; the sub-unit milligray times square centimetres $\left(\mathrm{mGy} \cdot \mathrm{cm}^{2}\right)$ is also used.

\section{Other radiation dose and risk quantities}

To improve the accuracy of dose assessments and risk estimations, other quantities were derived in the past. These quantities take account of differences in the type of effects involved, or differences in groups of exposed people, such as male versus female, or young versus old people. For example, to make a distinction between somatic and hereditary effects, the quantity somatically effective dose equivalent (SED) has been introduced by Beentjes [BE84]. Beninson and Sowby [BE85] derived age and sex dependent weighting factors to estimate the effective dose equivalent under medical exposure conditions. Huda et al. [HU89, HU90] developed Population Irradiation Factors (PIFs) to adjust for differences in age and sex distributions. Some investigators expressed the radiation exposure to patients directly in terms of the calculated fatal risk instead of in a dosimetric quantiry [BE84, WA88]. In the early sixties, the quantity mean energy imparted was introduced by Carlsson [CA63] to assess somatic risks in radiology. This quantity has been commented on and applied by a number of other investigators [CA65, HA83, MA93, PE93, PY78, SH84, WA89a]. For some common examinations of the trunk and head, Carlsson [CA86] 
derived ratios of the effective dose equivalent to the mean energy imparted as well as to the absorbed dose. Shrimpton [SH86] concluded that the total energy imparted and effective dose equivalent agree within a factor of about two to three. Huda [HU91] stated that, compared with the effective dose equivalent, the correlation between energy imparted and effective dose is weaker. This difference was ascribed to changes in the lissue weighting factors.

\section{Comparison of the quantinies effective dose and effective dose equivalent}

At a first glance the quantities effective dose, $\mathrm{E}$, and effective dose equivalent, $\mathrm{H}_{\mathrm{E}}$, look very similar. However, it should be stressed that, although both quantities have been defined for the same purpose, the philosophies behind these quantities are different. To start with, the quantity equivalent dose, used in the determination of $\mathrm{E}$, and the quantity dose equivalent, used in the determination of $\mathrm{H}_{\mathrm{E}}$, are dissimilar. The calculation of the dose equivalent is based on information related to the radiation inside the tissue only. whereas equivalent doses are computed by means of the radiation weighting factor, which is related to the type and energy of the radiation incident on the body. For X-ray exposures these differences are insignificant however and are not explored any further here. Secondly, $E$ is defined as a measure for health detriment to exposed populations, whereas the former quantity $\mathrm{H}_{\mathbb{E}}$ was defined to provide a measure for the risks of fatal cancer and hereditary effects for workers. In addition to these differences it is noted that the number of explicitly specified tissues at risk in $\mathrm{H}_{\mathrm{L}}$ was equal to six, whereas $\mathrm{E}$ comprises twelve specified tissues. Furthermore, new insights in radiation effects are reflected in risk estimates and have changed the weighting factors accordingly.

Several investigators have discussed the relationship between $\mathbb{E}$ and $\mathrm{H}_{\mathrm{E}}$. Huda et al. [HU91] concluded that $\mathrm{E} / \mathrm{H}_{\mathrm{E}}$ ratios for skull, chest, and pelvic $\mathrm{X}$-ray examinations are equal to $0.3,0.8$ and 1.1 respectively. For abdominal examinations ratios were equal to about unity in PA-projections, and about two for AP-projections. From data presented by Sevomaa et a1. [SE92] it was derived that $\mathrm{E} / \mathrm{H}_{\mathrm{E}}$ ratios in $\mathrm{AP}$ - and lateral examinations of the chest, spine and abdomen in male phantoms vary between 0.8 to 1.4. Zankl et al. [ZA92] derived $\mathrm{E} / \mathrm{H}_{\mathrm{E}}$ ratios of 0.5 and 0.75 for examinations of the thorax with $A P$ and PA views respectively. The 1993 Report of the United Nations Scientific Committee on the Effects of Atomic Radiation [UN93] concluded that, although $\mathrm{E} / \mathrm{H}_{\mathrm{E}}$ values for specific types of diagnostic examinations may deviate from unity, computed results of $\mathrm{E}$ and $\mathrm{H}_{\mathrm{E}}$ for diagnostic $X$-ray examinations as a whole should be fairly similar.

In ICRP Publication 60 [1C91] dissimilarities in both quantities have been considered as well. Given the uncertainties in dose assessment procedures and dose-risks relationship, ICRP does not recommend that attempts should be made to correct earlier values of $H_{E}$.

\section{Additional notes on the effective dose}

The effective dose accounts for stochastic effects in a reference population of equal numbers of male and fernale persons of a wide range of ages; the tissue weighting factors apply to workers, to the whole population, and to either sex [IC91]. Tissue weighting factors do not account for (potential) differences in sensitivity to radiation induced effects related to race, social class, occupation etc. Various investigators have pointed out that age distributions of patients do not match those of the reference group $1 \mathrm{BE} 84, \mathrm{BE} 85$, HU89, NR93, WA88, WA88b].

Since radiation sensitivity for stochastic effects is related to age and sex, the quantity effective dose can only be used with restrictions to estimate potential health detriment in 
medical applications of radiation [DR93. NR93]. Another difficulty is that because of their health status, patients may respond differenty to lonising radiation than the base population [UN93]. Nevertheless, published data on medical radiation doses are expressed. quite frequently in the quantity effective dose, or the formerly used quantity effective dose equivalent. Although it is recognised that the effective dose will underestimate the detriment from paediatric exposure by about a factor two and overestimate that from geriatric exposure by at least a factor five, NRPB recommends to use effective dose in cases in which several organs are exposed to assess the detriment from diagnostic medical exposures [NR93]. On the other hand, Drexler et al. [DR93] stated that E in its present definition should not be regarded as a quantity of any importance in medical applications. To improve the accuracy of risk assessments, age- and sex-specific organ risk factors should be used. However, it is recognised that it would be extrenely confusing to have different sets of tissue weighting factors and hence different quantities to replace effective dose for subgroups of the general population [NR93].

The quantity effective dose has been used in this thesis to quantify radiation doses to patients and to occupationally exposed persons.

\subsection{Effects and risks of $X$-rays}

\subsubsection{Introduction}

$\mathrm{X}$-rays may interact with matter by various processes. The most important interaction processes in diagnostic applications of X-rays are the Compton effect, photoelectric effect and coherent (Raleigh) scattering. The Compton effect and photoelectric effect involve energy transter to an electron and result in the ionisation of the atom. Coherent scatier results in a change of the direction of the photon without loss of energy. The relative contributions of these interaction processes depend on the energy of the $X$-rays and the atomic composition of the exposed material. After the transfer of energy of the $X$-ray photon to an electron, this electron usually interacts with other electrons, thereby leading up to a cascade-reaction in which excited atoms, ions and "free" electrons will be produced.

The process of ionisation changes chemical and physical properties of atoms and molecules, and thus may modify and damage cells or parts of cells in exposed biological. tissues. If cellular damage occurs and biological repair mechanisms fail, this may result in modification of the genetic code, loss of cell function and even cell death. If loss of cell. function or cell killing occurs on a large scale, this may lead to loss of tissue function and to early death of the exposed individual.

A genetically modified cell, which has maintained its reproduction capabilities, may result in a malignant neoplasm in the exposed person. If, on the other hand, the biological function of the cell is to transfer genetic information to human offspring (germ cell), modification of the cell nucleus may result in adverse effects in the progeny of exposed persons. Effects which become manifest in exposed persons themselves, such as nonmalignant damage to the skin, or early death by cancer induction, are called "somatic effects". Effects which become manifest in the progeny are called "hereditary effects". In addition to the above-mentioned categories (hereditary effects and somatic effects), biological effects that are of importance in radiological protection can be calegorised in 
two other groups. Depending on the nature of their relationship to the absorbed dose, these biological effects are classified as deterministic or as stochastic effects.

\subsubsection{Deterministic effects}

Deterministic effects comprise somatic effects introduced by loss of cell functions and/or cell killing. These effects become manifest only in exposed persons. Consequently, deterministic effects are classified as somatic effects. Deterministic effects do not occur below certain threshold dose levels. A threshold dose generally denotes the amount of radiation that is required to cause a specific effect in at least one to five percent of the exposed persons [1C84]. Threshold doses depend on the type of effect considered and the exposure conditions. For example, the threshold dose for erythema of the skin in a single exposure is approximately 6 to $8 \mathrm{~Gy}$, whereas the threshold dose for temporary sterility of a male is estimated to be 0.15 Gy for a single brief exposure [IC84]. Above the threshold level, the severity of the harm of an effect will increase with increasing radiation dose. The magnitude of the effect to the health of the exposed person depends on the type of the effect and on the dose. A more extensive description on characteristics (effect dependency on e.g. dose rate, type of exposure, linear energy transfer and tissue kinetics) and classification (early effects versus late effects) can be found in ICRP Publication 41 [IC84]. A number of deterministic effects and associated threshold dose levels are listed in Table 2.2.

Table 2.2 Estimated values of thresholld dose levels for deterministic effects in adults ${ }^{a}$

\begin{tabular}{|c|c|c|c|}
\hline Tissue and effect & $\begin{array}{l}\text { Organ dose } \\
\text { received in a } \\
\text { single brief } \\
\text { exposure } \\
\text { [Gy] }\end{array}$ & $\begin{array}{l}\text { Organ dose } \\
\text { received in } \\
\text { a protracted } \\
\text { exposure } \\
\text { [Gy] }\end{array}$ & $\begin{array}{l}\text { Amnual dose } \\
\text { rate (protracted } \\
\text { exposure } \\
\text { for many years) } \\
{\left[G y \cdot \mathrm{yr}^{-1}\right]}\end{array}$ \\
\hline \multicolumn{4}{|l|}{ Eye lens } \\
\hline Detectable opacy & $0.5-2.0$ & 5 & $>0.1$ \\
\hline Visuall impaiment & $5,2-10^{b}$ & $>8$ & $>0.15$ \\
\hline \multicolumn{4}{|l|}{ Red bone marrow } \\
\hline $\begin{array}{l}\text { Depression of } \\
\text { Maematopoiesis }\end{array}$ & 0.5 & $\mathrm{nat}^{c}$ & $>0.4$ \\
\hline Futal aplasia & 1.5 & nat & $>1$ \\
\hline \multicolumn{2}{|l|}{ Ovaries } & 6 & $>0.2$ \\
\hline \multicolumn{4}{|l|}{ Tesves } \\
\hline Temporary sterility & 0.15 & na & 0.4 \\
\hline Permanent sterility & $3.5,3.5-6^{\mathrm{b}}$ & na & 2 \\
\hline
\end{tabular}

\footnotetext{
"Source: ICRP Publication 41 [IC84]; "Source: ICRP Publication 60 [1C91]; " na denotes "not applicable"
} for this condition; the dose threshold depends on dose rate rather than on total dose.

\subsubsection{Stochastic effects}

The term stochastic effects refers to effects which result from the proliferation of a cel] with modified genetic material in its nucleus. If this cell is part of a body tissue, a somatic stochastic effect may become manifest; if the function of this cell is associated with propagation, a hereditary effect may become manifest. Stochastic effects are considered to 
behave with an all-ormone response. If a stochastic effect becomes manifest, differentiation into severity is not relevant, since in general its severity increases in time with early death as a possible outcome [1C91]. Although the severity of a stochastic effect is not related to the magnitude of the exposure, its induction probability is. This insight has consequences for the concept of dose-effect relation. In the case of deterministic effects the dose-effect relationship is related to the introduced effects themselves, whereas in the case of stochastic effects the dose-effect relationship is related to the probability of induction or expression of the effect.

Dose-effect relationships for stochastic effects have been derived from data on animal experiments, groups of patients, occupationally exposed persons, and survivors of the atomic bombing of Hiroshima and Nagasaki. Consensus on quantitative models concerning dose-effect relationships has not been reached yet, due to problems in the assessment of the radiation dose, epidemiological research (e.g. incomplete follow up period of groups), transformation of results of animal experiments to men, in combination with the nonspecific character of radiation induced effects, and a lack of scientific knowledge in areas of biological interaction processes and propagation mechanisms. The fact that the greater part of dose-effect data refer to high dose and high dose rates is another complicating factor in the determination of reliable risk factors for low dose and low dose rate exposure conditions.

Compiled data on exposures and effects are frequently reviewed by a number of international and national bodies, such as the ICRP, BEIR-committee, NCRP and UNSCEAR and the Health Council of the Netherlands [BE90, GE91, IC91, IC91a, NC90, UN86, UN88, UN93]. To illustrate the order of magnitude of risks, Table 2.3 lists probability coefficients for fatal cancer for individual organs as published in ICRP Publication 60 [IC91]. These estimates are denoted to be representative for a population of workers of equal numbers of men and women and for a whole population, comprising equall numbers of both sexes, both of a wide range of ages. A comprehensive description of the assessment of risk factors for various stochastic effects has been published in an issue of the Annals of the ICRP [IC91a].

It should be noted that hereditary effects of ionising radiation in men have not been affirmed yet. However, results of in vitro studies and animal experiments suggest that hereditary effects might occur. To be on the safe side, it is assumed in radiological protection that modifications in human germ cells will indeed be transferred to subsequent: generations [1C91]. Quantitative estimates for anticipated genetic effects are given in the Tables 2.3 and 2.4 .

For radiological protection purposes, ICRP introduced a new risk measure, the aggregated detriment, in its Publication 60 [IC91]. The aggregated detriment includes four components of attributable detriment: the probability of tatal cancer, the weighted probability of non-fatal cancer, the probability of severe hereditary effects and the relative length of loss of life. The contributions of non-fatal cancers are related to the average lethality factor of the cancer concerned. The relative length of loss of life has been introduced as a multiplication factor to take account for the relative number of years lost by early death and the relative number of years of impaired life. According to ICRP 60 [IC91] the nonfatal somatic detriment adds about 20 to $30 \%$ to the fatal detriment for a wide range of dose distributions. The aggregated detriment is used to derive numerical values of the tissue weighting factor, which is applied in calculations of the effective dose. The aggregated detriment for individual organs and tissues is presented in Table 2.4. These data are 
denoted to be representative for a population of workers and for a whole population, both comprising equal numbers of both sexes and a wide range of ages.

Table 2.3 Estimated probability coefficients of fatal cancer for individual tissues and organs and probability coefficients of severe hereditary effects for populations of equal numbers of both sexes ${ }^{s}$

\begin{tabular}{|c|c|c|}
\hline Tissue or organ & $\begin{array}{l}\text { whole population } \\
{\left[10^{-5} \mathrm{msv}^{-1}\right.}\end{array}$ & $\begin{array}{l}\text { workers } \\
{\left[10^{-5} \mathrm{mSv}^{-1}\right]}\end{array}$ \\
\hline \multicolumn{3}{|c|}{ Somatic faul stochastic effects (malignancies): } \\
\hline Bladder & 0.30 & 0.24 \\
\hline Bone marrow & 0.50 & 0.40 \\
\hline Bone surface & 0.05 & 0.04 \\
\hline Breast & 0.20 & 0.16 \\
\hline Collon & 0.85 & 0.68 \\
\hline Liver & 0.15 & 0.12 \\
\hline Lung & 0.85 & 0.68 \\
\hline Oesophagus & 0.30 & 0.24 \\
\hline Ovary & 0.10 & 0.08 \\
\hline Skin & 0.02 & 0.02 \\
\hline Slomach & 1.10 & 0.88 \\
\hline Thyroid & 0.08 & 0.06 \\
\hline Remainder & 0.50 & 0.40 \\
\hline Tolal: & 5.00 & 4.00 \\
\hline \multicolumn{3}{|c|}{ Severe hereditary disonders: } \\
\hline Gonads & 1.00 & 0.6 \\
\hline
\end{tabular}

"Source: ICRP Publication 60 [IC91].

Tissue weiglting factors (Table 2.1), estimates for the probabilities of stochastic risks (Table 2.3), and the aggregated detriment (Table 2.4) for individual organs and tissues are presented together in Table 2.5. This table shows some small numerical analomies for the probability coefficient and the associated detriment for the organs lung, oesophagus, and stomach [BR95]. It also follows from Table 2.5 that, because of the rounding off procedure used (see footnote e of Table 2.5), derived values for $w_{\mathrm{T}}$ differ from relative detriments. For instance, $w_{\mathrm{T}}$-values for the liver, oesophagus, skin, and thyroid are about a factor of two higher than the corresponding relative detriments. As illustrated by the organs colon and liver, relative contributions of some tissues to the effective dose are affected signiticantly. Whereas the ratio of detriments for these organs is equal to 6.3 , the ratio of the corresponding $w_{T}$-values is only 2.4 .

In the foregoing description, attention is given to deleterious effects of radiation. It should be noted that a number of papers have been published on beneficial effects of low doses of radiation as well. A beneficial or stimulative effect at low doses of an agent known to be toxic at high doses is called hormesis [WE93]. Recently, a review on the subject radiation hormesis has been given by Loken and Feinendegen [LO93] and van Wyngaarden and Pauwels [WY95]. Quantitative data on hormesis can be found in a special issue of Health Physics [HE87]. Consensus on the existence of hormesis has not yet been reached. There- 
fore, in line with the international and national approach to radiological protection, this phenomenon has been disregarded in this thesis.

Table 2.4 Aggregated detriment for individual organs and tissues for popalations of equal numbers of both sexes

\begin{tabular}{|c|c|c|}
\hline Tissue/organ & $\begin{array}{l}\text { whole population } \\
{\left[10^{\circ} \mathrm{mS}\right]}\end{array}$ & $\begin{array}{l}\text { workers } \\
{\left[10^{-3} \mathrm{mSv}\right]}\end{array}$ \\
\hline \multicolumn{3}{|c|}{ Fatal and non-fanal malignancies: } \\
\hline Bladder & 0.29 & 0.24 \\
\hline Bone marrow & 1.04 & 0.83 \\
\hline Bone surface & 0.07 & 0.06 \\
\hline Breast & 0.36 & 0.29 \\
\hline Colon & 1.03 & 0.82 \\
\hline Liver & 0.16 & 0.13 \\
\hline Lung & 0.80 & 0.64 \\
\hline Oesophagus & 0.24 & 0.19 \\
\hline Ovary & 0.15 & 0.12 \\
\hline Skin & 0.04 & 0.03 \\
\hline Stomach & 1.00 & 0.80 \\
\hline Thyroic & 0.15 & 0.12 \\
\hline Remainder & 0.59 & $0.4 \pi$ \\
\hline \multicolumn{3}{|c|}{ Severe heredivary effects: } \\
\hline Gonads & 1.33 & 0.80 \\
\hline Total & 7.3 & 5.6 \\
\hline
\end{tabular}

"Source: ICRP Publication 60 [IC9I].

Age at exposure

As mentioned before, in the quantity effective dose differences in radiation, sensitivities associated with the patient's age and sex are not included explicitly "Age and sex-specific risk data are schematically presented in Figure 2.1. This figure comprises aggregated risk factors for the population of the United Kingdom [NR93], and excess lifetime mortality risk factors for the population of the United States of America [IC91]. Both risk lactors are associated with acute uniform single exposures to low LET radiation at the indicated age (low LET radiation: radiation with linear energy transfer less than $10 \mathrm{keV} \cdot \mu \mathrm{m}^{-1}$, including $x$ and gamma radiations of all energies). In these publications it is stated that average excess lifetime mortality for males and females are equal to $7.7 \%$ and $8.1 \%$ per sievert respectively; averaged over both sexes and all ages, the aggregated detriment is estimated to be $8 \%$ per sievert. Figure $2 . \mathbb{1}$ clearly demonstrates the relatively high risk factors for young people and the low risk factors for the elderly. Also, gender-specific differences are indicated. Figure 2.1 also shows that risk data sets from different sources may show inconsistencies (indicated mortality risks are higher than aggregated risks). 
Table 2.5 Tissue weighting factors, $\mathrm{w}_{\mathrm{T}}$, derived from aggregated detriment estinates, associated with stochastic radiation rishs for worker populations of equal numbers of both sexes ${ }^{*}$

\begin{tabular}{|c|c|c|c|c|}
\hline Tissue or organ & $\begin{array}{l}\text { Risk" } \\
{\left[10^{s} \mathrm{mSv}\right]}\end{array}$ & $\begin{array}{l}\text { Detriment } \\
{\left[10^{-5} \mathrm{~ms} \mathrm{v}^{-1}\right]}\end{array}$ & $\begin{array}{l}\text { Rel. } \\
\text { detriment }\end{array}$ & $w_{T}^{*}$ \\
\hline \multicolumn{5}{|c|}{ Somatic fatal stochastic effects (malignancies): } \\
\hline Bladder & 0.24 & 0.24 & 0.04 & 0.05 \\
\hline Bone marrow & 0.40 & 0.83 & 0.15 & 0.12 \\
\hline Bone surface & 0.04 & 0.06 & 0.01 & 0.01 \\
\hline Bireast & 0.16 & 0.29 & 0.05 & 0.05 \\
\hline Colon & 0.68 & 0.82 & 0.15 & 0.12 \\
\hline Gonthads & 0.08 & 0.12 & 0.02 & \\
\hline Liver & 0.12 & 0.13 & 0.02 & 0.05 \\
\hline Luing & 0.68 & 0.64 & 0.11 & 0.12 \\
\hline Oesophagus & 0.24 & 0.19 & 0.03 & 0.05 \\
\hline Skin & 0.02 & 0.03 & 0.00 & 0.01 \\
\hline Stomach & 0.88 & 0.80 & 0.14 & 0.12 \\
\hline Thyroid & 0.06 & 0.12 & 0.02 & 0.05 \\
\hline Remainder & 0.40 & 0.47 & 0.08 & 0.05 \\
\hline \multicolumn{5}{|c|}{ Severe hereditary disorders: } \\
\hline Gonads & 0.6 & 0.80 & 0.14 & $0.20^{5}$ \\
\hline Total & na. & 5.6 & 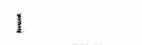 & 1 \\
\hline
\end{tabular}

"Source: ICRP Pulalication 60 [IC91]; ${ }^{\circ}$ Sex-averaged estimated probability coefficients of fatal cancer for individual tissues and organs, and probability coefficients of severe hereditary effects; "Aggregated detriment for individual organs and tissues; "Relative detriment. Ratio of the aggregated detriment to organ

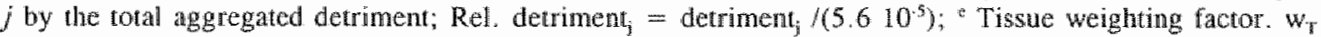
is equal to the rellative detriment, rounded to $0.01,0.05,0.12$ or 0.20 ; "Estimated probability for malignancies is equal to half of that for the ovaries. Risks for radiation induced malignancy of the testes are insignificantly small; $w_{T}$ for the gonadls is derived from the sum of the relative detriments for malignancies and hereditary effects.

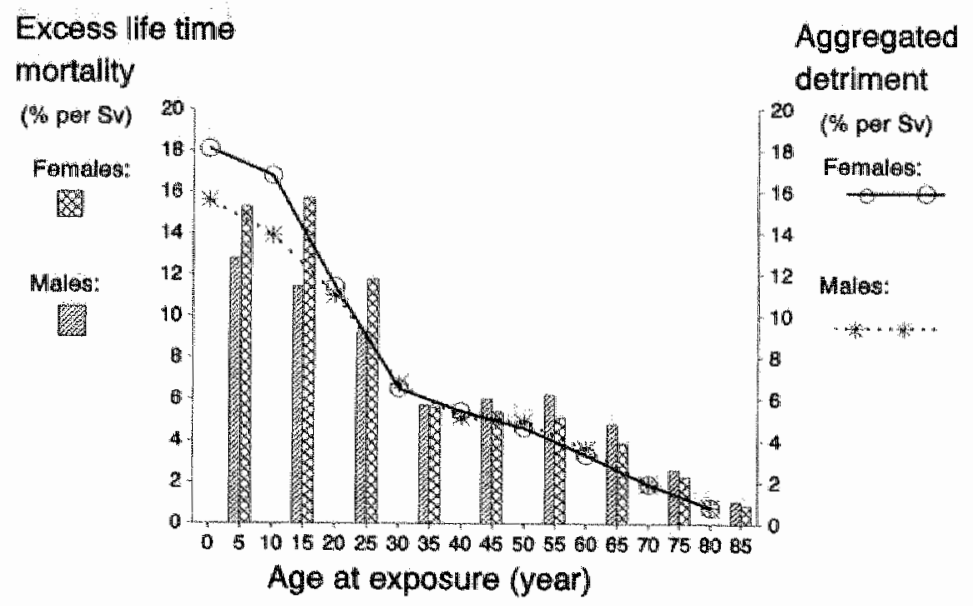

Figure 2.1 Variation with age at exposure of sex-specific radiation risk factors for total aggregated detriment [NR93], and for mortality [1C91], associated with single exposures. 


\section{Chapter 3}

\section{Radiological protection and radiation doses}

\subsection{Introduction}

In the early days of diagnostic radiology, fluoroscopy involved considerable levels of exposure to the physician, thereby increasing the risk of detrimental effects. Damage to the skin was the first radiation effect noted after exposure to $X$-rays [IC91b]. It became obvious that applications of ionising radiation were not only associated with beneficial results to society but also could do harm to exposed individuals. Visible effects in exposed persons and a growing insight in radiobiology resulted in an awareness of a need for a systematic approach to radiological protection. To coordinate radiological protection measures, the International Commission on Radiological Protection (ICRP) was established at the Second International Congress of Radiology in 1928. From 1928 to 1950 the ICRP was functioning under the name of International X-ray and Radium Protection Commission [IC59]. On an international level, health physics has been covered for a long time by the International Commission on Radiological Protection (ICRP). National health physics societies have been assembled in the International Radiation Protection Association (IRPA). Quite a number of other commissions have been set up within the frame of special applications or based on social economical terms.

ICRP has a long history in issuing recommendations to provide an adequate level of protection to the hazards of ionising radiation. In 1955, ICRP published its first recommendations in the British Journal of Radiology [IC55]. From the beginning, ICRP not only considered medical applications of X-rays and radioactive sources, but other types of exposure to ionising radiation as well. To improve the accessibility, recommendations were issued by a general publisher. Until 1994, the very first recommendations were followed up by 60 reports, comprising recommendations and a variety of data on radiological protection measures, effects, handling of sources, dosimetry elc. Since Publication no 1, ICRP has gained and maintained the status of the most respected authority in the field of international bodies on radiological protection. ICRP recommendations have been used by other international bodies and by national authorities to develop a systematic approach to radiological protection. This thesis follows this approach and uses ICRP recommendations as a guideline to describe generally adopted principles of radiological protection.

In an episode of nearly one hundred years numerous investigations on physical interaction processes and biological mechanisms have been carried out. Since its foundations in 1955, the United Nations Scientific Committee on the Effects of Atomic Radiation (UNSCEAR) has compiled and evaluated published data on sources and effects of all kinds of jonising radiation. In the last two decades, scientific data have been summarised by UNSCEAR in five reports [UN82, UN86, UN88, UN93, UN94]. 
Although dose response relationships in the low dose and low dose rate region have not been firmly established yet, and although epidemiological data do not exclude zero effects at (very) low doses, it is assumed in radiological protection that (i) the probability of induction of stochastic effects increases linearly proportional with increasing dose, and that (ii) no threshold limit exists for these types of effects. Application of this so-called linear dose-effect hypothesis is restricted to the low dose, low dose rate region. This condition is met in almost any exposure condition associated with "normal" applications of radiation sources as well as in environmental or technology enhanced exposures. Based on the linear dose-effect hypothesis, it is further assurned that the potential for manifestation of adverse stochastic effects in large exposed groups is dependent on the total dose, calculated as the sum of the radiation dose to all individuals of that group. This quantity is called the collective dose (it is noted that the numerical result of this summation is equal to the multiplication of the mean dose and the number of exposed persons).

\subsection{Objectives of radiological protection}

Taking the characteristics of adverse effects of ionising radiation and the dose levels at which these effects occur into account, the primary objectives of radiological protection are:

- to prevent the occurrence of acute and chronic deterministic effects, and

- to reduce the occurrence of stochastic effects to a justifiable level.

Basically, these objectives are applicable to all individuals exposed, including radiological workers, patients, volunteers in biomedical experiments, and members of the public.

\subsection{General principles of radiologicall protection}

In its Publication 60, ICRP recommended a system for proposed and continuing practices involving radiation sources. This system comprises the following three principles:

- Justification of a practice: No practice should be adapted if its (estimated) radiation detriment offsets its (expected) benefit to exposed individuals or to society.

- Optimisation of protection. The magnitude of individual doses, number of persons exposed and the likelihood of potential exposures should all be kept as low as reasonably achievable, economic and social factors taken into account. The process of optimisation should include any particular source within a practice.

- Individual dose limits and risk limits. The doses to individuals of the combination of all relevant practices should be subject to dose limits. However, dose limits should not be applied to medical exposures of patients. In practices where there will be a potential for exposure but no certainty that it will occur, the potential exposure should be subject to some control of risk.

This system has been adopted by a number of international and national bodies. It is used as a framework to develop and apply guidelines for radiological protection, related to specified types of radiation applications and to various types of exposure conditions. In the field of radiological protection in medical diagnostic X-ray applications the same principles apply as stated before: 
- Justification:

According to ICRP guidelines, medical investigations should be justified before being put into practice. All the exposures, including oceupational, public and potential exposures should be taken into account. Justification should not only apply to classes of investigations, but also to individual patient investigations. It is explicitly stated that case by case justification is not necessary for simple diagnostic procedures, based on common indications.

- Optimisation of protection:

Optimisation of protection, formerly addressed by ICRP as ALARA (as low as reasonably achievable), should be given special attention. ICRP states that there is a considerable scope for dose reduction in diagnostic radiology. ICRP has acdressed optimisation in radiological protection in Publication 55 [IC89]. In line with ICRP recommendations, NCRP has issued a report on the implementation of the principles of ALARA for medical and dental personnel [NC90].

- Dose limits:

Dose limits should be applied to all persons (potentially) exposed, except to the patient. In ICRP 60 it is considered that, if the practice is justified and if the protection is optimised, the dose in the patient will be as low as compatible with the medical purpose, and application of dose limits could increase the patient's detriment.

In applications of the system of protection decisions have to be made on justification and optimisation, and actual and potential doses have to be compared with dose limits. It is obvious that all three activities necessitate reliable insight in dose levels associated with the (proposed) practice. Especially in complex applications of medical X-ray systems, involving fluoroscopy and varying numbers of radiodiagnostic projection, associated doses are not well known.

\subsection{Radiological protection in radiology in the Netherlands}

Dutch legislation concerning exposures to ionising radiation has been laid down in the Atomic Energy Act of 1963 (Kemenergiewet). The Alomic Energy Act provides a framework of measures, which are described in detail in regulations (algemene maatregelen van bestuur en ministeriêle besluilen). Dutch legislation concerning exposure to the general public, workers, individuals of the public as well as to patients, is based on directives of the European Atomic Energy Community (Euratom), founded by the European Community in 1958. Each member state of the European Conmunity (EC) is obliged to implement EC-directives in their national legislation system. EC member states may, up to some level, extend or adapt EC-directives in order to take national, historical and current developments into account. The general idea of the EC approach is that a solid basic set of elementary rules will be incorporated in national legislations. A unified lay out of the system of legislation in the member states is not explicitly stated as a goal, but harmonisation of national legislation could be hoped for as a spin-off result.

EC-directives, published as CEC Basic Safety Standards or CEC Basic Safety Standards amendments, incorporate in large parts the recommendations of the ICRP. On an international level EC-Commissions provide liaison to other advisory bodies such as the International Atomic Energy Agency (IAEA), the World Health Organisation (WHO) and the Organisation for Economic Cooperation and Development (OECD). 
Current Dutch obligations with respect to medical diagnostic applications of $X$-ray systems are based on the Atomic Energy Act and its regulations. By adapting the regulation "Besluit stralenbescherming Kenenergiewe" (Staatsblad 1993 (317), 25 May 1993), Dutch legislation concerning radiological protection in the field of medical applications of ionising radiations lately has been conformed to EC-directive 1984 [EC84]. In the adapted regulations, medical radiation applications have been made subject to the principle of justification for categories of applications as well as for patient examinations, on a caseby-case approach, if appropriate. It should be noted, however, that practical guidelines to justify these radiation exposures are not available. In recent granted licences for medical $X-$ ray applications, it is explicitly stated that these applications must be performed by a qualified physician.

Usually, radiation risks to the individual patient associated with $X$-ray diagnosis are limited to stochastic effects. This risk is small in comparison with the benefit of the examination. Therefore, in general, X-ray examinations of individual patients are justified on medical evidence. Optimisation of protection has already been explicitly included in Dutch regulations for a number of years. Optimisation applies to all applications of radiation sources, including medical $X$-ray systems. Although optimisation of protection seems to be less complex than justification, there is no evidence in the literature that quantitative approaches of optimisation in medical applications have been adopted on a large scalle. In order to assist with implementing optimisation procedures, ICRP provided recommendations on three optimisation procedures for radiological protection in its Publication 55 [1C89]: cost-benefit analysis, multi-autribute utility analysis and multi-criteria outranking analysis. It should be noted that quantitative optimisation, for instance as outhined in ICRP Publication 55 [IC89], requires reliable estimates for exposures and consensus on monetary values for attributed risks to occupationally exposed persons, to the population and to the patient. Only few data on proposed monetary values have been published yet. It is obvious that the positive results of a radiation application should be expressed on a quantitative base as well.

It should be stressed that the low frequency of quantitative optimisation procedures does not necessarily mean that protection measures are insufficient. The foregoing merely states that the approach of optimisation may be inadequate. In conclusion, one may observe that there is a discrepancy between legal obligations and general practice.

Exposed persons, excluding the patient, are subject to a system of dose limits, which has been laid down in the Atomic Energy act. Table 3.1 lists current dose limits for workers and individuals of the public as formulated in 1986. In addition to justification and optimisation, one has to assure that the exposures to $X$-ray's do not exceed these limits. Due to inherent protection measures in imaging systems and ease of structural shielding, these limits can be met relatively easily in modern departments of radiology. It is expected that in a few years, current dose limits as presented in Table 3.1, will be superseded. To what extent new dose limits will deviate from the current levels is unknown, since at least four processes are involved:

- In 1991 ICRP presented in its Publication 60 a new system for dose limitation [IC91]. Parts of this system will be incorporated in the Dutch legislation.

- Due to the adaption of the general approach to risk control, Dutch authorities try to incorporate a system of risk control instead of dose control in legislation.

- Ongoing experimental and epidemiological research provides data on exposures and effects that can change estimated values for risks factors.

- The European Community currently updates the CEC Basic Safety Standards. 
Implementation of the 1990 recommendations of the ICRP in EC-drectives and Atomie Energy Act, and extrapolation of the current discussions will probably result in decreased annual effective dose limits in Dutch legislation for occupational exposure $\left(20 \mathrm{mSv} \cdot \mathrm{y}^{-1}\right)$ and for nonoccupational exposure, during stay on premises $\left(2 \mathrm{mSv} \cdot \mathrm{y}^{-1}\right)$

Except for the effective dose, dose limits applied in this thesis are equal to those reported in Table 3.1 (column "workers, students"). As an annual limit for the effective dose 20 $\mathrm{mSV}$ was used.

Table 3.1 Dose limits for persons exposed to ionising radiations according to the Dutch Atomic Energy Act ${ }^{9}$

\begin{tabular}{|c|c|c|}
\hline $\begin{array}{c}\text { Exposure condition } \\
\text { (organ/tissue) }\end{array}$ & $\begin{array}{l}\text { workers } s^{\text {th }} \text {, students } \\
{\left[\mathrm{mSv} \cdot \mathrm{y}^{-1}\right]}\end{array}$ & $\begin{array}{l}\text { members of the } \\
\text { general public } \\
{\left[\mathrm{mSv} \cdot \mathrm{y}^{\prime}\right]}\end{array}$ \\
\hline \multicolumn{3}{|l|}{ Dose equivallent: } \\
\hline Total body & 50 & 5 \\
\hline Eye Lens & 150 & .15 \\
\hline \multicolumn{3}{|l|}{ Skin, hand, lower arm, } \\
\hline Abdomen of women & 13. $\mathrm{mSv}$ in 13 weeks & - \\
\hline \multicolumn{3}{|l|}{ Fenus (from declaration of } \\
\hline Other organs and tissues & 500 & 50 \\
\hline \multicolumn{3}{|l|}{ Source related exposure } \\
\hline \multicolumn{2}{|l|}{$\begin{array}{l}\text { Nonoccupational exposure at home } \\
\text { during care of patients }\end{array}$} & 0.1 \\
\hline \multicolumn{3}{|c|}{ 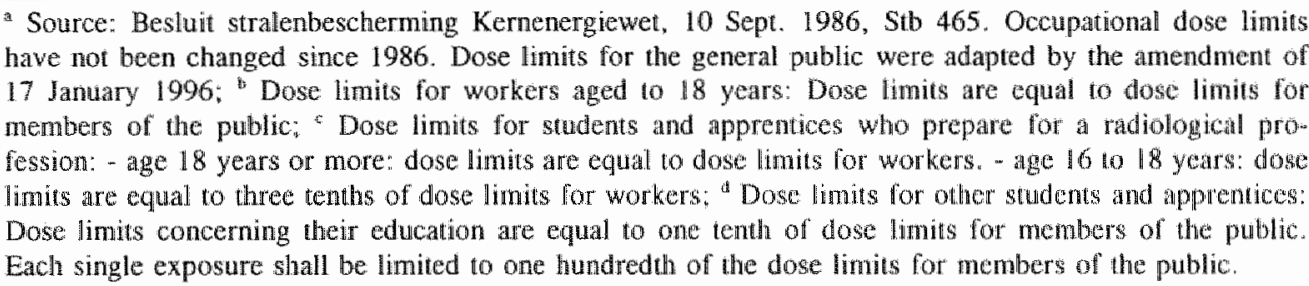 } \\
\hline
\end{tabular}

\subsection{General information about radiation exposures in diagnostic radiology}

Medical and occupational radiation exposures arising from diagnostic $X$-ray examinations have been assessed by various investigators. A thorough compilation of results and conclusions can be found in subsequent reports of the United Nations Scientific Committee on the Effects of Atomic Radiation (UNSCEAR) in 1958, 1962, 1972, 1977, 1982, 1988 and 1993. The following sections presents selected dosimetry data. References include dose quantities as used by the original authors. The reader is referred to Chapter 2 for additional information on quantities. Details on frequencies and dose data for angiography are included in other chapters. 


\subsubsection{Radiation dose to the patient}

Annual frequencies of diagnostic medical $X$-ray examinations vary from approx. 1200 per 1000 inhabitants in Japan to approx. 20 in Ghana and Nigeria. In developed countries with more than one physician per 1000 inhabitants, the mean annual number of $X$-ray examinations is estimated to be 800 per 1000 inhabitants, varying between about 1000 in Japan and Canada and 500 in Sweden, Spain and the United Kingdom [BE91].

UNSCEAR reported in 1993 that in developed countries (health-care level $I$; more than one physician per 1000 habitants) the annual number of diagnostic X-ray examinations per 1000 inhabitants slightly had increased from 820 in $1970-1979$ to 890 in 1985-1990, whereas angiography, on the other hand, had increased from 1.6 to 7.1 per 1000 inhabitants. In the Netherlands the reported frequency of diagnostic examinations decreased in these periods slightly from 570 to 530 per 1000 inhabitants [UN93]. Reported minimum, mean and maximum annual frequencies per 1000 inhabitants for some different types of diagnostic medical examinations are listed in Table 3.2.

Table 3.2 Ammual frequency of diagnostic medical X-ray examinations per 1000 inhabitants (Afreq), in 11 countries of health care level I in the 1980s"

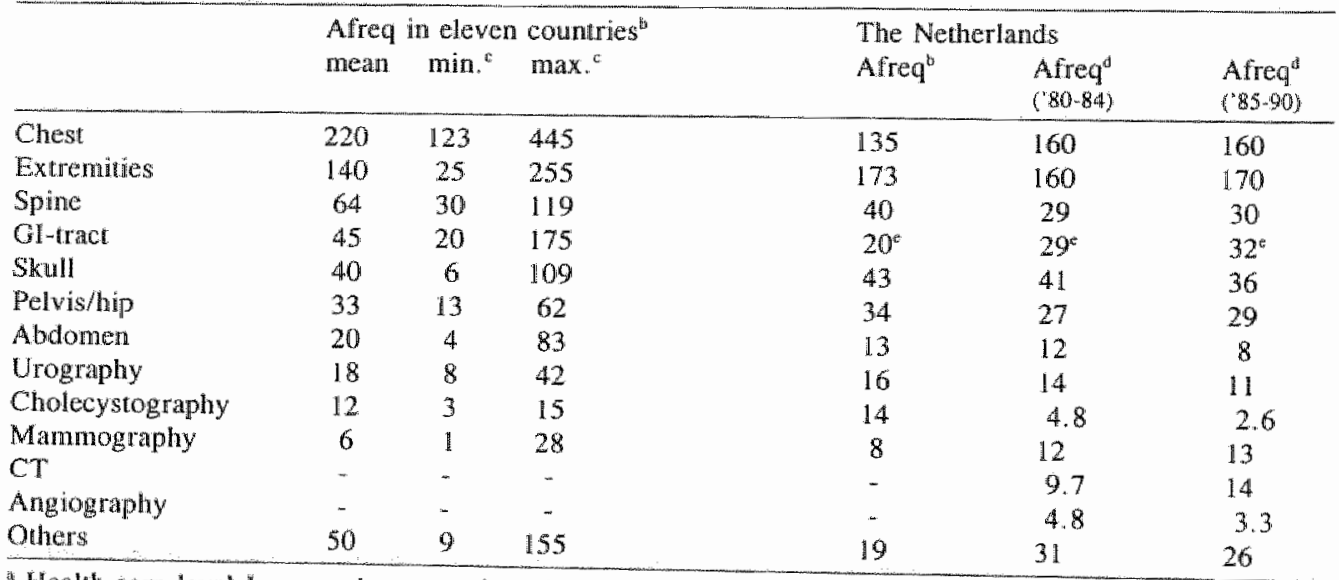

"Health care level 1: more than one physician per 1000 inhabitants;" Source: Bennett B.G. [BE9]]. Datla reler to the early $1980 \mathrm{~s} ;{ }^{\circ} \mathrm{Min}$. and max. refer to the lower and upper figures of reported means; "Source: UNSCEAR 1993 [UN931; " Unspecified in [BE91]. Sum of upper tract and lower tract in [UN93].

The data in Table 3.2 refer to eleven countries with more than one physician per 1000 inhabitants. For comparison, relative frequencies of these types of examinations in the Netherlands have been included separately. It should be noted that dissimilarities exist in published data on frequencies in the Netherlands (e.g. spine, cholecystography).

Bennett [BE91] presented estimated values for the mean effective dose equivalent per examination for various examination types in six countries. The average effective dose equivalent has been listed is Table 3.3 , minimum values and maximum values for the average have been included, too. Intercomparison of mean values per examination type shows considerable variations between countries, sometimes as much as an order of
magnitude. 
Table 3.3 Mean effective dose equivalent to patients per X-ray examination in six developed countries ( $\mathrm{mSv}$ * examination $\left.{ }^{-4}\right)$

\begin{tabular}{|c|c|c|c|c|}
\hline & $\operatorname{six} c o$ & nories & & UK \\
\hline & mean $^{2}$ & $\min ^{2}$ & $\max ^{*}$ & mean \\
\hline Chest & 0.15 & 0.05 & 0.4 & 0.07 \\
\hline Extremities & 0.1 & - & - & 0.1 \\
\hline Spine & 0.8 & 0.4 & 2.5 & 1.3 \\
\hline GI-tract & 5.0 & 1.6 & 10.2 & $4-8$ \\
\hline Skull & 0.2 & 0.09 & 1.4 & 0.15 \\
\hline Pelwis/hip & 1.3 & 0.3 & 3.2 & 1.3 \\
\hline Abdomen & 1.1 & 0.3 & 2.6 & 1.4 \\
\hline Urography & 3.5 & 0.7 & 10.4 & 4.4 \\
\hline Cholecystography & 1.5 & 0.6 & 7.2 & 0.95 \\
\hline Mammography & - & - & - & 0.2 .1 \\
\hline
\end{tabular}

"Source: Bennert B.G. [BE91]; countries: France, Italy, Japan, Spain, former USSR, US. Min. and max. refer to the lower and upper figures of reported means; "Source: UNSCEAR reporl 1993 [UN93].

Surveys of patient exposures in the United Kingdom showed very large ranges in mean effective doses per examination type [SH86]. Estimated range factors of the effective dose equivalent per examination for various "simple" examination types varied between 28 for the thoracic spine and 460 for the chest (range factor is maximum/minimum ratio). For six types of "complex" procedures the range factors are estimated to be 11 for barium enema and 58 for combined cholangiography/cholecystography procedures [SH86].

It is worthwhile to note that the range factor per examination type, calculated over half of the examinations between the 25-percentile and 75-percentile, varies between 2 and 4 only. These figures show that the patient radiation dose in the majority of the examinations is quite similar. Graphical presentations of effective dose equivalents [SH86] clearly illustrate that large range factors are introduced by a relatively small number of examinations.

By quantification of inter- and intra-hospital wariations, Harrison and co-workers [HA83] showed that there were considerable variations within one hospital as well as significant differences between hospitals. Intercomparison of mean entrance skin doses due to X-ray examinations of the hand, chest, skull lumbar spine, and barium meal examin ations showed ranges by actor 3 to 4 [HA83].

Using data presented in the 1993 UNSCEAR Report [UN93], the average effective dose equivalents, the annual frequency and the collective patient dose associated with various bypes of X-ray examinations in countries of healih care level I have been summarised for the 1980 s in Table 3.4. The total number of people in health care level 1 in 1990 is estimated to be 1350 million (approximately $25 \%$ of the total population of the world). The number of radiologists in health care level I countries is estimated to be 0.072 per 1000 habitants [UN93]. Table 3.4 shows that estimated mean doses due to angiography are relatively high. However, due to its low frequency the contribution of angiography to the collective dose is estimated to be $5 \%$. The larger part of the collective dose is associated with upper GI tract examinations $(23 \%)$, computed tomography (18\%) and chest mass miniature (14\%). 
Table 3.4 Fequenciss, average effective dose equivalent and collective dose equivalent to patients associated with X-ray exammations in the 1980s in contries of Health-care Level $I^{2,3}$

\begin{tabular}{|c|c|c|c|c|c|}
\hline Examination & \multirow{2}{*}{$\begin{array}{l}\text { Average } \\
\text { effective } \\
\text { dose } \\
\text { equivalent } \\
\text { (mSw } \\
\text { examination) }\end{array}$} & \multirow{2}{*}{$\begin{array}{l}\text { Annual } \\
\text { frequency } \\
\text { per } 1000 \\
\text { inhabitants }\end{array}$} & \multicolumn{3}{|c|}{ Annal collective effective dose equivalent } \\
\hline Skull & & & & & \\
\hline Chest radiography & $\begin{array}{l}0.16 \\
0.14\end{array}$ & 40 & 6.4 & 8560 & 0.7 \\
\hline Chest fluorascopy & $\begin{array}{l}0.14 \\
0.98\end{array}$ & $\begin{array}{r}171 \\
33\end{array}$ & 23.9 & 31500 & 2 \\
\hline Chest mass miniat. & $\begin{array}{l}0.98 \\
0.52\end{array}$ & $\begin{array}{r}33 \\
260\end{array}$ & 32.3 & 43100 & 3 \\
\hline Mammography & 1.0 & $\begin{array}{r}260 \\
12\end{array}$ & 135 & 182000 & 14 \\
\hline Extremines & 0.06 & $\begin{array}{r}12 \\
121\end{array}$ & 12.0 & 17000 & 1 \\
\hline Lumbosacral spine & 1,7 & $\begin{array}{r}121 \\
54\end{array}$ & 7.3 & 10600 & 0.8 \\
\hline Pelvis & 1.2 & $\begin{array}{l}54 \\
21\end{array}$ & 91.8 & 122000 & 10 \\
\hline Hip/femul & 0.92 & $\begin{array}{l}21 \\
12\end{array}$ & 25.2 & 32800 & 3 \\
\hline Abdomen & 1.1 & $\begin{array}{l}12 \\
32\end{array}$ & 11.0 & 15300 & 1 \\
\hline Upper GI tract & 4.1 & $\begin{array}{l}32 \\
52\end{array}$ & 35.2 & 44700 & 4 \\
\hline Lower Gi tract & 7.2 & $\begin{array}{l}52 \\
11\end{array}$ & 213 & 285000 & 23 \\
\hline Urography & 3.1 & $\begin{array}{l}1.1 \\
14\end{array}$ & 79.2 & 112000 & 9 \\
\hline Comp tomography & 4.3 & $\begin{array}{l}14 \\
39\end{array}$ & 43.4 & 58200 & 5 \\
\hline Angiography & 6.8 & $\begin{array}{r}39 \\
6\end{array}$ & 167.7 & 224000 & 18 \\
\hline \multirow{2}{*}{\multicolumn{2}{|c|}{ Total (rounded figures) }} & & 40.8 & 57300 & 5 \\
\hline & & 890 & 920 & 1260000 & $100 \%$ \\
\hline
\end{tabular}

"Source: UNSCEAR report 1993 [UN93]; Health-care level I: more than one physician per 1000 labitants: "Derived from data given in annex C [UN93]

\subsubsection{Occupational exposures}

Estimates of occupational exposures heavily depend on readings of personal dosemeters. There is, especially in radiology, a considerable potential for drawing erroneous conclusions. Due to the non-uniformity of the radiation field, the relatively low energy of $\mathrm{X}$ rays, and the use of protective clothing, the relation between effective dose and dosemeter reading depends on the location of the dosemeter on the body. It is particularly important 10 know if the dosemeter is located underneath or on the protective lead apron. If the personal dosemeter is worn on the apron, the dosemeter reading could be as much as 10 to 20 times higher than the effective dose [UN93]. This ratio depends on features of the $X$ ray system (e.g. tube high voltage, filtration, beam direction), work procedures (e.g. distance and body orientation to the patient) and characteristics of the lead aprons (attenuation and shape) as well. Other sources of inaccuracy are differences in the definition of the dose threshold level and in the recording of doses below the threshold level. Also differences in monitoring procedures in various countries may increase the overall inaccuracy.

Three examples of reported data on occupational exposures are summarised below. In comparing dose data for various countries one should recognise the potential sources of variation mentioned above. This has been illustrated in Table 3.5 , which comprises data as published in UNSCEAR Report 1993 [UN93]. 
Using data from the Canadian National Dose Registry. Ashmore and comorkers [AS91] estimated the average annual whole-body dose in 1988 to 1560 radiologists and 9300 technicians in diagnostic applications to be $0.19 \mathrm{mSv}$ and $0.12 \mathrm{mSv}$ respectively: for 120 radiologists and 570 technicians in therapeutic applications mean annual doses were estimated to be $0.26 \mathrm{mSv}$ and $0.70 \mathrm{mSv}$ respectively. Exposures below the single dosemeter reporting threshold level of $0.2 \mathrm{mSw}$ were not included in the summation to derive mean values.

Based on a sample of 94 radiologists and 890 radiographers in the North West Region of the UK, Pratt and Sweeney [PA91] estimated the average annual whole-body dose in 1986 to be $0.57 \mathrm{mSv} \cdot \mathrm{y}^{-1}$ and $0.36 \mathrm{mSv} \cdot \mathrm{y}^{-1}$ respectively.

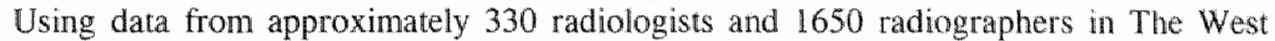
Midlands and some other regions in the UK, as recorded by the Regional Radiation Physics and Protection Service, Roberts and co-workers estimated the mean ammal dose in 1989 to be $0.24 \mathrm{mSv} \cdot \mathrm{y}^{-1}$ and $0.04 \mathrm{mSv} \cdot \mathrm{y}^{-1}$ respectively [R091]. Until 1986, dose measurement results below the threshold level of single dosemeters $(0.2 \mathrm{mSv})$ were added as a figure of 0.2 in the total sum. From 1986, doses below the detection threshold of single dosemeters $(0.15 \mathrm{mSv})$ are recorded as zero in the annual totals. This change in recording strategy resulted in a significant reduction of the mean annual dose. For example in 1986-1987, the mean annual dose to all hospital staff changed from about 2 $\mathrm{mSv}$ to $0.09 \mathrm{mSv}$.

Table 3.5 Occupational exposures in radiology (mSv * $y^{-11}$ )

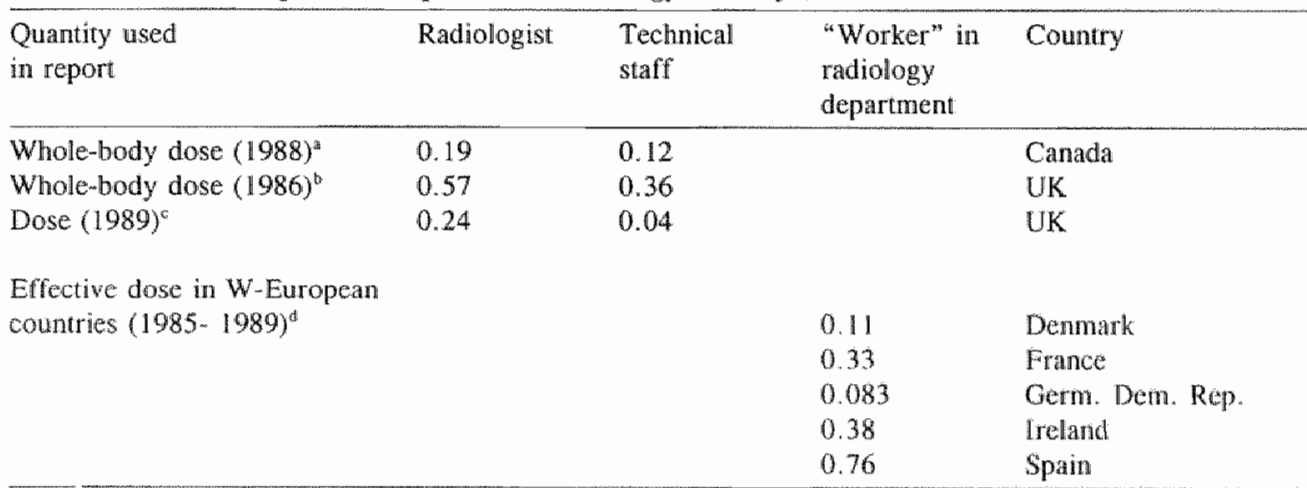

"Source [AS91]; "Source [PA91]; "Source [R091]: "Sounce [UN93]. Other countries: 1.31 mSW in Argentina; $0.05 \mathrm{mSv}$ in Australia; $0.76 \mathrm{mSv}$ in Brazil: $1.84 \mathrm{mSv}$ in China; $0.68 \mathrm{mSv}$ in Crechoslovakia; $0.19 \mathrm{mSw}$ in Finland; $0.21 \mathrm{mSv}$ in Hungary; $0.34 \mathrm{mSv}$ in $1 \mathrm{ndia}: 1.67 \mathrm{mSv}$ in Indonesia; $3.45 \mathrm{mSv}$ in Peru.

The reviewed reports illustrate another problem encountered frequently in a literature search for dose data. All three authors used dose quantities ("whole-body dose" and "dose") which are not defined by international bodies, such as ICRP or ICRU. Moreover, they did not explain the quantities, thereby introducing a potential source for errois. 


\subsubsection{Dosimetry data on radiology in the Netherlands}

Timmermans and Beentjes [T192] collected data on the frequencies of medical diagnostic examinations in The Netherlands. Combined with estimated data on the somatic effective dose and the genetic effective dose for various types of examinations they estimated the mean annual effective dose associated with medical diagnostic examinations to be $0.5 \mathrm{mSv}$ (averaged over the totall population). In view of the high frequency of chest radiography and high doses in computed tomography $(\mathrm{CT})$, studies into the radiation dose to the patient and the image quality have recently been performed in the Netherlands [GE92. GE941. Typical walues for effective doses derived with phantoms are $85 \mu \mathrm{Sw}$ for conventional thorax examinations, and 1 to 2,18 and $24 \mathrm{mSw}$ for CT-examinations of the head, thorax and abdomen respectively. Data on the exposures of the Dutch population to all sources of ionising radiations in the 1980 s have been collected by Vaas and co-workers [V A91]. The total collective effective dose equivalent, due to all sources, including those of natural origins, is estimated to be $37200 \mathrm{man}$-sievert per anmum; the per caput dose is computed to be $2.6 \mathrm{mSv} \cdot \mathrm{y}^{-\frac{3}{}}$.

On the basis of the dose data given above, the contribution of medical exposures by diagnostic $X$-ray procedures to the total radiation exposure to members of the population is estimated to be about $20 \%$.

An estimate of the collective effective dose associated with occupational exposure in 1990 can be derived from data presented by van Winsen et al. [Wi92]. Medical diagnostic applications of X-ray systems (not including cardiology, dentistry and applications in operating theatres) resulted in a collective dose registered on personal dosemeters, worn by staff and technical assistants, of 3.2 man sievert. The sum of the doses of the dosem meters worn by personnel in all diagnostic applications of X-ray systems, including cardiology, dentistry and applications in operating theatres, is equal to 7.3 man. sievert. Assuming that all dosemeters have been wom above the protective lead apron, the collective effective doses are estimated to be approximately $5 \%$ to $10 \%$ of the totalised dose of the dosemeters [UN93]. Using a value of $10 \%$, the collective occupational dose due to medical diagnostic $X$-ray procedures is estimated to be approximately $0.3 \mathrm{man}$-sievert, or as 0.7 man - sievert if all applications are included. It is concluded from these data that the contribution of all occupational exposures in medical diagnostic X-ray applications to the total collective dose, due to all sources, is approximately $0.002 \%$.

Data on number of persons exposed, average values of dosemeter readings and the collective dose in the Netherlands are given in Table 3.6 [Wi92].

Table 3.6 Occupational exposure in medical X-ray applications in the Netherlands in $1990^{\text {* }}$

\begin{tabular}{|c|c|c|c|c|c|}
\hline & \multicolumn{2}{|c|}{ Number of persons } & \multicolumn{2}{|c|}{$\begin{array}{l}\text { Average dose of } \\
\text { dosemeters } \\
{\left[\mathrm{mSv} \cdot \mathrm{y}^{-1}\right]}\end{array}$} & \multirow{2}{*}{$\begin{array}{l}\text { Collective } \\
\text { dose of } \\
\text { dosemeters } \\
{\left[\mathrm{man} \cdot \mathrm{Sr} \cdot \mathrm{y}^{-1}\right]}\end{array}$} \\
\hline & Male & Female & Malle & Female & \\
\hline Dentistry & 1200 & 2100 & 0.15 & 0.05 & 0.29 \\
\hline Operating theatre & 450 & 550 & 0.22 & 0.07 & 0.14 \\
\hline Cardiology & 700 & 400 & 4.6 & 1.4 & 3.7 \\
\hline Other diagnostic procedures & 3000 & 4800 & 0.74 & 0.20 & 3.2 \\
\hline All diagnostic applications & 5400 & 7900 & 1.1 & 0.21 & 7.3 \\
\hline
\end{tabular}




\subsection{General information about radiation doses in vascular radiology}

Published data about radiation doses to patients and staff in vascular radiology are reviewed below in chronological order. To increase readability, dose data are presented in currently used quantities, effective dose (E), absorbed dose in skin at the $X$-ray beam entrance side $\left(\mathrm{D}_{\mathrm{ski}}\right)$, organ dose $\left(\mathrm{D}_{\text {organ }}\right)$, or dose-area product (DAP). An exception was made for the former quantity effective dose equivalent $\left(\mathbb{H}_{\mathrm{E}}\right)$. This quantiry has not been converted because various organ doses that are needed for effective dose calculations were not included in the papers reviewed. Besides, attempts lo correct earlier values are not recommended by ICRP [IC91]. Additional information about (dis)similarities between the quantities $\mathrm{E}$ and $\mathrm{H}_{\mathrm{E}}$ is given in Section 2.2. Acronyms used to indicate the $\mathrm{X}-\mathrm{ray}$ beam direction are explained in Table D.2 (appendix D).

As some descriptions of callibration and dose measurement procedures were incomplete, various reported exposure data were ambiguous with respect to the absorbing medium (air or skin; free-in-air or backscatter inclusive). In this review, entrance skin doses were derived by multiplying reported exposure data by the conversion factor $10 \mu \mathrm{Gy} \cdot \mathrm{mR}^{-1}$. Dose-area products were derived by multiplication of reported exposure-area products by the conversion factor $0.00877 \mathrm{~Gy} \cdot \mathrm{cm}^{2} \cdot \mathrm{R}^{-1} \cdot \mathrm{cm}^{2}$.

\subsubsection{Radiation doses to patients}

This subsection comprises dosimetric data about cerebral, thoracic, abdominal and peripheral angiography, followed by a remaining group of some other diagnostic and interventional vascular procedures. Quantitative dose data are summarised in Table 3.7.

\section{Cerebral angiography:}

In 1982, Möller and Fehretz [MO80] reported that doses to the eye lens of patients undergoing conventional cerebral arteriography, comprising AP and LAT views, were between $33 \mathrm{mGy}$ and $81 \mathrm{mGy}$, depending on the number of films taken.

Pavlicek et al. [PA82] compared doses to various tissues of patients undergoing IVDSA (undercouch $X$-ray tube) and conventional angiography of cerebral vessels (overcouch $X$-ray tube). For IV-DSA, the skin dose was $37 \mathrm{mGy}$ (range 10-80 mGy), averaged over 52 procedures. For conventional procedures, the skin dose was $230 \mathrm{mGy}$ (range 50 $500 \mathrm{mGy}$ ), averaged over 45 procedures. On average, fluoroscopy contributed $36 \%$ and $70 \%$ of the skin exposure in DSA and conventional procedure respectively. It should be noted that average skin dose (in the paper denoted as "average skin exposure") was not defined explicitly. Taking the position and direction of each single view into account, the authors estimated the dose to bone marrow, thyroid and eye lens. The marrow dose from IV-DSA was estimated to be $0.55 \mathrm{mGy}$, from conventional angiography to be $11.5 \mathrm{mGy}$. The thyroid dose from IV-DSA was estimated to be $7.4 \mathrm{mGy}$, from conventional angiography to be $87 \mathrm{mGy}$. Doses to the eye lens were $0.15 \mathrm{mGy}$ for IV-DSA and $3.2 \mathrm{mGy}$ for conventional angiography. It was noted that the average fluoroscopy time was a factor of 10 smaller in IV-DSA than in conventional angiography. The authors stated that it could be expected that the decrease in fluoroscopy time could even be more in instifutions without a resident training programme. Referring to dose estimates for red marrow and the eye lens, it was stated that the number of patients examined with IV-DSA could increase by a factor of approximately 20 without any increase in population dose. However, it should be noted here that this statement is not very solid, as this would 
implicate that the effective dose (equivalent) by IV-DSA was a factor of 20 smaller compared with conventional angiography.

Maccia et al. [MA88] estimated the nation-wide mean effective dose equivalent for cerrebral angiography for France (1982) to be $12 \mathrm{mSv}$ (mean number of films, 46; mean fluoroscopy time, $8.0 \mathrm{~min}$ ). Dose assessment procedures were not described. Although, figures about AP-versus PA-projections were not given, it was explicilly stated that a high proportion of X-ray systems in France were used with overcouch tubes.

Passariello et al. [PA83a] measured entrance doses to an anthropomorphic phantom by simulating AP-, LAO and RAO-exposure conditions for IV-DSA and conventional (film) cerebral angiography of the same vascular region. The ratio of the entrance dose from IVDSA by the entrance dose from conventional angiography was calculated to be 0.7 . The corresponding ratio of eye lens doses was reported to be 1.8 . Because of inadequately described data and discussion, we judged the results as inconclusive.

Plunkett et al. [PL 86] measured dose-area products in cerebral angiography. Because of skewed data distributions, the authors presented median values instead of means. Median values for DAP for various procedure types were calculated to be: IV-DSA for atherosclerotic cerebrovascular disease, $16 \mathrm{~Gy} \cdot \mathrm{cm}^{2}$ (range $3-37 \mathrm{~Gy} \cdot \mathrm{cm}^{2} ; \mathrm{n}=50$ ); IV-DSA for postoperative evaluation of carotid endarterectomy, $6.5 \mathrm{~Gy} \cdot \mathrm{cm}^{2}$ (range 0.8-18 $\mathrm{Gy} \cdot \mathrm{cm}^{2} ; \mathrm{n}=26$ ); conventional angiography for atherosclerotic cerebrovascular disease, 28 Gy $\cdot \mathrm{cm}^{2}$ (range 5-50 Gy $\mathrm{cm}^{2} ; n=44$ ); conventional angiography for evaluation of an intracranial mass lesion $19 \mathrm{~Gy} \cdot \mathrm{cm}^{2}$ (range $7-52 \mathrm{~Gy} \cdot \mathrm{cm}^{2} ; \mathrm{n}=15$ ); and for procedures comprising both conventional and IA-DSA cerebral angiography, $50 \mathrm{~Gy} \cdot \mathrm{cm}^{2}$ (range 12-91 Gy $\left.\cdot \mathrm{cm}^{2}, \mathrm{n}=14\right)$. During fluoroscopy and IV-DSA no grid was applied; based on literature data, the authors claimed a dose reduction of $50 \%$. High exposures to patients who required a combined conventional and IA-DSA examination were associated with prolonged fluoroscopy times (median 17.5 min, whilst median values varied between 0.8 and 1.3 min for IV-DSA, and between 6.1 and 11.2 min for conventional angiography). The median contributions of fluoroscopy to the radiation dose in IV-DSA and conventional angiography were estimated to be $6 \%$ and $37 \%$ respectively.

Casselden [CA88] measured doses to the eye lenses during cerebral angiography by using thermoluminescent dosemeters. In IA-DSA arteriography of 10 patients, on average comprising 148 images per patient (PA-direction) and 7.4 min fluoroscopy, the mean dose to the lens was estimated to be $3.3 \mathrm{mGy}$. The entrance dose to the eye lens was estimated to be $196 \mathrm{mGy}$ by simulating exposure conditions during conventional cerebral angiograpliy, comprising $42 \mathrm{AP}$-views and $10 \mathrm{~min}$ fluoroscopy. The author was concerned that multiple-wessel angiography and interventional procedures, requiring more imaging sequences than the average number of frames collected in this study, would even result in larger doses to the eye lens.

Thijssen et al. [TH88] measured entrance doses to the eye lens of patients $(n=27)$ in cerebral arteriography, using DSA imaging (PA direction) and serial cut films (AP direction). From measurements with thermoluminescent dosemeters, average doses to the eye lens were estimated to be $0.9 \mathrm{mSv}$ for DSA. and $81 \mathrm{mSv}$ for films; mean doses to the thyroid were $6.1 \mathrm{mSv}$ for DSA, and $22 \mathrm{mSv}$ for films.

In a paper on cost-utility analyses by Wall and Russell [WA88] the average effective dose equivalent estimate for cerebral angiography in the UK was reported to be $4 \mathrm{mSw}$.

Mustafa and Janeczek [MU89] determined the mean DAP for carotid DSA (undercouch X-ray tube system), comprising RAO, LAO and Towne's views, to be $1.1 \mathrm{~Gy} \cdot \mathrm{cm}^{2}$. A total of 20 frames was acquired for each view, with air kerma of $4.35 \mu \mathrm{G} y /$ frame at the 
image input screen surface, and 3 to 7 s fluoroscopy previewing. Mean doses to the thyroid and eye lens were estimated to be $21 \mathrm{mGy}$ and $4.7 \mathrm{mGy}$ respectively. The highest skin dose was equal to $185 \mathrm{mGy}$.

Howe et al. [HO91】 presented entrance skin exposures (ESE) and effective dose equivalents $\left(\mathrm{H}_{\mathrm{E}}\right)$ for cerebral arteriography. Results were inferred from themoluminescent dose measurements in simulated exposure conditions. As the calibration procedure was not described, the meaning of ESE could not be traced. Taking circumstantial data presented into account, we have converted ESE (in R) to absorbed dose in skin at the entrance position ( $D_{\text {skin }}$ in $\mathrm{mGy}$ ), according to $\mathrm{D}_{\text {s } \mathrm{k} \text { in }}=10 \times \mathrm{xSE}$. The following estimates were inferred for fluoroscopy (PA): Iumbar spine (40 s): $\mathrm{D}_{\text {skin }} 40 \mathrm{mGy}, \mathrm{H}_{\mathrm{E}} 0.65 \mathrm{mSv}$; upper chest (600 s): $\mathrm{D}_{\text {skin }} 312 \mathrm{mGy}, \mathrm{H}_{\mathrm{E}} 7.1 \mathrm{mSv}$. Dose contributions from radiography were reported to be: LAO-aortic arch (13 films): $\mathrm{D}_{\text {skin }} 213 \mathrm{mGy}, \mathrm{H}_{\mathrm{E}} 9.7 \mathrm{mSv}$. LLAT+RLATneck region ( $2 \times 6$ films): $D_{\text {skin }} 22 \mathrm{mGy}, H_{\mathrm{E}} 0.33 \mathrm{mSv}$. LAO+RAO- head $(2 \times 7$ films): $\mathrm{D}_{\text {skinhead }} 96 \mathrm{mGy}, \mathrm{H}_{\mathrm{Es} \text {, haxd }} 1.8 \mathrm{mSv}, \mathrm{D}_{\text {skin, neck }} 18 \mathrm{mGy}, \mathrm{H}_{\mathrm{E} \text {, neck }} 1.3 \mathrm{mSw}$. Using estimates for organ doses involved in the assessment of $\mathrm{H}_{\mathrm{E}}$, the authors estimated mean $\mathrm{H}_{\mathrm{k}}$ for cerebral arteriography to be $21 \mathrm{mSv}$. From these data it follows that fluoroscopy accounted for $37 \%$ of $\mathrm{H}_{\mathrm{E}}$.

Feygelman et al. [FE92] estimated mean $\mathrm{H}_{\mathbb{E}}$ in cerebral angiography to be $11 \mathrm{mSiv}$ (10 patients). The results refer to angiography performed on an overcouch $\mathrm{X}$-ray system, comprising both DSA and radiography. $H_{\mathbb{1}}$ was calculated from the entrance dose, $\mathrm{X}$-ray entrance field, and published DAP to $\mathrm{H}_{\mathbb{E}}$ conversion factors. Contributions of fluoroscopy views for different parts of the body were apparently taken into account. However, the method applied was not explained in detail. The mean contribution of fluoroscopy was calculated to be $7.1 \mathrm{mSv}(67 \%)$, of serial cut film $2.8 \mathrm{mSv}(26 \%)$, and of DSA $0.7 \mathrm{mSv}$ $(7 \%)$. Average values for parameters were: fluoroscopy time, $10.4 \mathrm{~min}$; serial cult films. $28 \mathrm{AP}$ and $28 \mathrm{LAT}$; number of DSA-frames, 53. Mean tube high voltage settings for fluoroscopy and radiography were $80 \mathrm{kV}$, for DSA $68 \mathrm{kV}$. Fluoroscopy high voltage settings were weighted relative to the fluoroscopy time prior to being averaged. $X$-tay beam filtration was $2.5 \mathrm{~mm}$ Al. Mean entrance skin doses were calculated to be $271 \mathrm{mGy}$ for fluoroscopy, $88 \mathrm{mGy}$ for AP films, $18 \mathrm{mGy}$ for LAT films, and $25 \mathrm{mGy}$ for AP-DSA.

Steel and Temperton [ST93] collected data about angiography procedures, comprising both serial cut film angiography and DSA imaging. Depending on the choice of the "anatomical program" and the field size of the input screen of the image intensifier, dose rates at the input screen varied between 6 and $31 \mu \mathrm{Gy}$ per DSA frame and between 0.3 and $0.7 \mu \mathrm{Gy} \cdot \mathrm{s}^{-1}$ for fluoroscopy. A water phantom $\left(20 \times 20 \times 20 \mathrm{~cm}^{3}\right)$ was used to determine entrance dose rates to the patient. These dose rates were estimated to be 7 to $10 \mathrm{mGy}$ per DSA frame, and 280 to $460 \mu \mathrm{Gy} \cdot \mathrm{s}^{-1}$ for fluoroscopy. From measurement results for 32 cerebral angiography procedures (mean fluoroscopy time, 3.9 min (range 1.2 - 12 min); mean number of images, 78 (range 47-115)), average dose-area product was calculated to be $27.4 \mathrm{~Gy} \cdot \mathrm{cm}^{2}$ (range $9.4-80 \mathrm{~Gy} \cdot \mathrm{cm}^{2}$ ). By using published dose conversion factors, the authors calculated the average $H_{E}$ to be $4 \mathrm{mSv}$ (range $1-12 \mathrm{mSv}$ ). The position of the $\mathrm{X}$ ray nube (overcouch or undercouch) was not described. From their results an E/DAPconversion coefficient of $0.15 \mathrm{mSv} \cdot \mathrm{Gy}^{-1} \cdot \mathrm{cm}^{-2}$ was derived.

Fisher and co-workers [F[95] estimated median DAP for cerebral arteriography with an overcouch $X$-ray tube system $\left(\mathrm{n}=33\right.$ ), to be $73 \mathrm{~Gy} \cdot \mathrm{cm}^{2}$ (range $3-200 \mathrm{~Gy} \cdot \mathrm{cm}^{2}$ ). Median for fluoroscopy time, 17 min (range, 0.5-56 min); median number of series, $12(2-19)$; median number of frames, 184 (40-480). The imaging mode applied was not described. However, considering the number of images reported, DSA imaging may be assumed. 
Marshall et al. [MA95a] reported dose measurements performed in 90 cerebral DSA angiography procedures, using an undercouch $X$-ray system. Mean doses to the eye lens. and the thyroid were $11 \mathrm{mGy}$ and $5.6 \mathrm{mGy}$ respectively (mean number of DSA-frames, 122; mean fluoroscopy time, $4.7 \mathrm{~min}$ ). Mean DAP was equal to $49 \mathrm{~Gy} \cdot \mathrm{cm}^{2}$, entrance skin dose was estimated to be $150 \mathrm{mGy}$. Data pertaining to a four vessel study fleft and right carotid and vertebral arteries) were used for further analysis and for estimation of the effective dose. The mean effective dose to the patient was calculated to be $3.6 \mathrm{mSv}$ (corresponding mean DAP, $42 \mathrm{~Gy} \cdot \mathrm{cm}^{2}$ ). Fluoroscopy accounted for $14 \%$ of total DAP and for $22 \%$ of the effective dose. The higher contribution of fluoroscopy to the effective dose was attributed to extended fluoroscopy times for the chest region, containing more radiosensitive tissues than the head. The overall E/DAP-conversion factor derived in that study was equal to $0.087 \mathrm{mSv} \cdot \mathrm{Gy}^{-1} \cdot \mathrm{cm}^{-2}$.

\section{Thoracic aneriography}

Maccia et al. MA88] estimated the nation-wide mean effective dose equivalent for thoracic angiography in France (1982) to be $5 \mathrm{mSv}$ (mean number of films, 24, mean fluoroscopy time, $7.6 \mathrm{~min}$ ).

\section{Abdominal arteriography}

In 1982, Kauffinann et al. [KA82] estimated average DAP for renal arteriography $(n=56)$ to be $31 \mathrm{~Gy} \cdot \mathrm{cm}^{2}$.

Mean effective dose equivalent for abdominal angiography in France (1982) was estimated to be $20 \mathrm{mSv}$ [MA88]; the average number of films was 38 , mean fluoroscopy time, $5.0 \mathrm{~min}$.

In a paper by Wall and Russell [WA88], mean $\mathrm{H}_{\mathrm{E}}$ for abdominal angiography in the UK was reported to be $6 \mathrm{mSv}$.

Steel and Temperton [ST93] performed measurements for hepatic $(n=12)$ and renal arteriography; mean effective dose equivalents to the patient were estimated to be $23 \mathrm{mSv}$ and $16 \mathrm{mSv}$ respectively. The ratio of the mean effective dose to mean DAP was calculated to be $0.17 \mathrm{mSy} \cdot \mathrm{Gy}^{-1} \mathrm{~cm}^{-2}$ for both procedure types.

\section{Thoracic-abdominal arteriography}

Fisher and coworkers [F195] estimated median DAP for thoracic and abdominal angiography procedures $(n=21)$, performed with an undercouch $X$-ray tube system, to be 33 $\mathrm{Gy} \cdot \mathrm{cm}^{2}$ (range 11-130 $\mathrm{Gy} \cdot \mathrm{cm}^{2}$ ). The median for fluoroscopy time was 6.1 min (range, 1.2-68 min); median number of series, 3 (2-11); median number of frames, 1.15 (48-232). The imaging mode applied was not described. However, considering the number of images reported. DSA imaging may be assumed.

\section{Peripheral arteriography}

Kauffmann et al. [KA82] estimated mean DAP for femoral aorto-arteriography to be 20
$\mathrm{~Gy} \cdot \mathrm{cm}^{2}([\mathrm{n}=124)$.

Passariello et al. [PA83a] measured entrance doses to an anthropomorphic phantom by simulating exposure conditions for IV-DSA and conventional (film) peripheral angiography. The ratio of the dose from IV-DSA and the dose from conventional angiography was calculated to be 0.5 for the abdominal region, and 0.33 for the legs. 
Maccia et al. [MA88] summarised data about radiology in France in 1982. Mean elfective dose equivalents, mean number of films, and fluoroscopy time for inferior limbs were estimated to be $10 \mathrm{mSv}, 14$ films, and 1.3 min respectively.

Wall and Russell [WA88] reported the average effective dose equivalent for peripherall anglography procedures in the UK to be $4 \mathrm{mSv}$.

Howe et al. [HO91] presented estimates for entrance skin exposures (ESE) and effective dose equivalents $\left(H_{E}\right)$ for peripheral arteriography (see also cerebral arteriography for additional remarks). The following results were obtained for PA-fluoroscopy (lumbar spine region, $40 \mathrm{~s}$ ): $\mathrm{D}_{\text {skin }} 41 \mathrm{mGy}, \mathrm{H}_{\mathrm{E}} 0.5 \mathrm{mSv}$. Dose estimates for AP-radiography were: abdominal region ( 5 films): $\mathbb{D}_{\text {skin }} 89 \mathrm{mGy}, \mathrm{H}_{\mathrm{r}} 2.6 \mathrm{mSv}$; pelvic region ( 5 films): $\mathrm{D}_{\text {skin }} 31$ $\mathrm{mGy}, \mathrm{H}_{\mathrm{E}} 7.5 \mathrm{mSv}$; thigh (5 films): $\mathrm{D}_{\mathrm{skim}} 5 \mathrm{mGy}, \mathrm{H}_{\mathrm{E}} 0.9 \mathrm{mSv}$. In all, average $\mathrm{H}_{\mathrm{E}}$ for peripheral arteriography was estimated to be $12 \mathrm{mSv}$.

Steel and Temperton [ST93] collected data about various angiography procedures (see also cerebral arteriography). From measurement results for 31 peripheral angiography procedures (mean fluoroscopy time $3.7 \mathrm{~min}$ (range $1.2-19 \mathrm{~min}$ ), mean number of imag$\mathrm{es}, 66$ (range 24-107)), the average DAP was calculated to be $43 \mathrm{~Gy} \cdot \mathrm{cm}^{2}$ (range 13-122 Gy $\cdot \mathrm{cm}^{2}$ ). Taking into account that about $50 \%$ of total DAP could be attributed to exposures to the pelvis, the authors calculated mean $\mathrm{H}_{\mathrm{E}}$ to be $4 \mathrm{mSv}$ (range 1 - $16 \mathrm{mSv}$ ). An E/DAP-conversion coefficient of $0.09 \mathrm{mSv} \cdot \mathrm{Gy}^{-1} \mathrm{~cm}^{-2}$ was derived from their results.

Fisher and coworkers [FI95] characterised patient exposures for undercouch $\mathrm{X}$-ray tube peripheral angiography procedures $(n=11)$. The median value for the fluoroscopy time was $7.9 \mathrm{~min}$ (range 2.7-17 min); median number of series, 9 (range 3u11); median number of frames, 179 (range 36-277); median DAP, $71 \mathrm{~Gy} \cdot \mathrm{cm}^{2}$ (range 34-202 Gy $\cdot \mathrm{cm}^{2}$ ). It should be noted that the imaging modes applied (DSA or films) were not explicitly mentioned. However, from presented values for "frames" it was assumed that DSA was used.

Castellano et al. [CA95] assessed the effective dose to average patients in 17 bifemoral arteriography procedures. Procedures were performed on an undercouch X-ray tube system, with a discrete stepping tube stand and a filmless digital imaging acquisition system with $40 \mathrm{~cm}$ image intensifier. Mean total DAP per procedure was calculated to be $13 \mathrm{~Gy} \cdot \mathrm{cm}^{2}$. Using DAP data and various dose conversion factors, taking the position of the X-ray beam for three main stages of the procedure into account, the authors derived a mean effective dose of $3.1 \mathrm{mSv}$. The authors stated that the catheter manipulation stage contributed $55 \%$ to the effective dose, while fluoroscopy previewing and the DSA images acquisition stage accounted for $23 \%$ and $22 \%$ respectively. It should be noted here that. compared with DSA, the relative contribution of fluoroscopy previewing, which is needed for adjustment and programming of the stepping device, appears to be quite high. The authors gave no additional comments about this subject. The highest entrance doses; calculated as the sum of the dose contributions of these three imaging stages, were obtained for the abdominal region. Averaged over all procedures, the mean entrance dose to the abdomen was estimated to be $25 \mathrm{mGy}$. From their results the E/DAPaconversion coefficient was estimated to be $0.24 \mathrm{mSv} \cdot \mathrm{Gy}{ }^{-1} \cdot \mathrm{cm}^{-2}$.

\section{Remaining group of vascular and interventional procedures}

Kauffmann et al. [KA82] estimated DAP for phlebography to be $4.6 \mathrm{~Gy} \cdot \mathrm{cm}^{2}$. DAP for PTA of limb vessels was estimated to be $11 \mathrm{~Gy} \cdot \mathrm{cm}^{2}$, DAP for renal embolisation 82 Gy $\cdot \mathrm{cm}^{2}$.

Maccia et al. [MA88] reported the mean effective dose equivalent for phlebography in France (1982) to be $11 \mathrm{mSw}$ (10 films, $3.0 \mathrm{~min}$ ). 
From a small sample of PTA- and embolisation procedures, Fisher and co-workers [FI95] estimated median DAP-values to be $69 \mathrm{~Gy} \cdot \mathrm{cm}^{2}$ (range $22-151 \mathrm{~Gy} \cdot \mathrm{cm}^{2} ; \mathrm{n}=6$ ) and 122 Gy $\mathrm{cm}^{2}$ (range $34-287 \mathrm{~Gy} \cdot \mathrm{cm}^{2} ; \mathrm{n}=9$ ) respectively.

In 36 angiography procedures for imaging of tumours in the upper and lower extremily, radiation exposures due to IA-DSA and conventional arteriography were compared on a one-to-one basis by Lee et al. [LE86]. The authors estimated the mean skin entrance doses per procedure to be $54 \mathrm{mGy}$ for LA-DSA, and as 56 mGy for conventional arteriography. However, by multiplying reported mean numbers of images taken (frames, 32 ; films, 15$)$ by corresponding dose data ( $850 \mu \mathrm{Gy} /$ frame and $1750 \mu \mathrm{Gy} / \mathrm{film})$, we calculated entrance doses to be $27 \mathrm{mGy}$ for IA-DSA and $26 \mathrm{mGy}$ for films. As the meaning and the method applied to assess the skin entrance dose were not described in full cletail, the data presented in that paper are questionable.

Berthelsen and Cederblad [BE91b] determined the effective dose equivalent to patients. in five embolisation procedures of cerebral vessels (undercouch $X$-ray abe system) by using a dose-area product meter, and DAP to energy imparted conversion factors. These procedures comprised prolonged fluoroscopy times (range 26 to $90 \mathrm{~min}$ ), 5-16 DSA series, and 0-4 serial cut film series. Effective dose equivalents were calculated to be in the range of 6 to $43 \mathrm{mSv}$ (mean $23 \mathrm{mSv}$ ). Highest measured entrance dose determined for individual patients, varied between 170 and $1400 \mathrm{mGy}$ (mean $680 \mathrm{mGy}$ ). The doses to the most exposed eye and to the thyroid were measured to be $22-139$ mGy (mean $90 \mathrm{mGy}$ ), and 5-10 mGy (mean $8.2 \mathrm{mGy}$ ).

\section{Concluding remarks about data on patient dosimetry}

A surprisingly large number of papers still refer to AP-exposure conditions of the patient [MO80, PL86, CA88, TH88, HO91, FE92, FI95]. Already in 1978, Rosenbaum et al. [RO78] reported that radiation doses to the lens of the eye of the patient from radiographs could be reduced by a factor of $50-100$ by using PA instead of AP projections, without loss of image quality. These authors even referred to earlier publications (1971) denoting similar conclusions. In 1981, Gray et al. [GR81] published organ doses for 24 diagnostic examination projections, normalised to entrance doses. The authors concluded: "Significant reduction in dose to specific organs is possible by properly choosing the projections (anteroposterior vs. posteroanterior)". In a paper on lumbar spine radiology [TS90] the advantages of PA views over AP views with respect to both imaging quality and to doses to radiosensitive lissues were discussed. More recently, Marshall and co-workers [MA94] studied the effect of PA views versus AP views in abdominal examinations. From data obtained for various image intensifiers with input screen diameters between 14 and $40 \mathrm{~cm}$, and for $35 \times 35 \mathrm{~cm}^{2}$ films, it was concluded that effective doses for PA views were between 2 to 5 times lower for males, and between 2.6 to 5.9 times lower for females, than those for $\mathrm{AP}$ views. In addition to literature data, relatively high effective doses for $\mathrm{AP}$ views are reported in this thesis (Table 6.6, and appendix D) by using commercially available sofware [HA94, LE94]. In summary, although the benefit of PA views over AP views has been noticed for some time now, many studies still refer to AP projections, indicating a relatively large number of overcouch $X$-ray tube systems.

It should also be noted that various investigators have expressed their concern about the radiation dose to the patient because of specific features of DSA systems. Casselden [CA88] remarked that after the introduction of DSA, more images were acquired per sequence than was normal practice with conventional technique. Taylor et al. [TA89a] noticed that radiation doses to patients from DSA were appreciable, and could even 
exceed those for conventional angiography. It was argued that high dose levels were caused by system capabilities which encouraged the acquisition of large numbers of images. According to these authors "the fact that there is no need to reload him changers means that there is no significant penalty in terms of time, effort or expenses in performing additional runs". Steete and Temperton [SE93] also expressed their concern about the large number of multiple DSA images that can be acquired very rapidly.

As can be seen in Table 3.7, there is a broad range of dose estimates. Some authors also explicitly remarked on the wide ranges in dose results found in their studies [PA82. PL85]. Large variation per procedure type were associated both with the experience of the operator [PL85], and with patient characteristics [PA82, PL85].

Contributions from fluoroscopy to total exposure, expressed by means of the effective dose (equivalent) or the entrance dose, were quite high. Reported estimates for contributions of fluoroscopy for IV-DSA were equal to. 36\% [PA82], and 6\% [PL86]; for IA-DSA angiography 70\% [PA82], 22\% [MA95a], and 55\%-78\% [CA95]; for conventional angiography 70\% [PA82], 37\% [PL86], and 37\% [HO91]; and for combined DSA and conventional angiography $27 \%$ [PL86], and 67\% [FE92]

Data about the contribution of angiography to collective doses are very limited. Maccia [MA88] estimated relative frequencies of angiography and phlebography in France (1982) to be $0.8 \%$ and $0.3 \%$ of all diagnostic examinations. The relative contribution of angiography to the collective effective dose equivalent from diagnostic radiology was estimated to be $9.7 \%$ (6.5\% was contributed to abdominal angiography); contribution by phlebography was estimated to be 1\%. Padovani et al. [PA87] estimated the frequency of angiography, relative to all radiodiagnostic procedures in North-east Italy (1983) to be $0.3 \%$. In a review paper by Contento et al. [CO88], relative frequencies of different types of X-ray examinations per 1000 inhabitants were presented. It is useful to note that, whereas the ratio for total X-ray examinations in the UK, France and NE Italy were found to be $1: 1.9: 1.5$, corresponding ratios for angiography were estimated to be $1: 6,4: 1.1$.

In summary, patient doses from angiography procedures have been addressed in various papers. However, in coherence with other investigators [MU89, ST93, MA95a] it should be noted that in a time span of about 20 years relatively few data about medical exposures in vascular radiology have been made available. Most of the literature data reviewed are associated with cerebral arteriography. As shown in the review, studies performed in the 1980 th were focused on entrance doses [MO80, PA82, PA83a, LE86, CA88, TH88, MU89], rather than on effective dose equivalent. Only a small number of papers comprising dose-area product data may be useful for future dosimetric studies IKA82, PL86, F[95]. Conclusions drawn in some papers were not well-founded [PA82, PA83a, LE86]. Some papers denoting effective dose equivalents did not refer to the original work [MA88, WA88]. From 1991 onwards, some estimates for effective dose (equivalent) have emerged [HO91, FE92, ST93, MA95a, CA95]. Because of the large variation in exposures to the patient, and hence the complexity of the dose assessment procedure, these papers show differences in the dosimetric approach and in the extent of descriptive data. In all, it is concluded that only a limited amount of data have been published, useful for a general approach for optimisation of radiological protection in vascular radiology. 
Table 3.7 Dose estimates for patients in wascular radiology ${ }^{a}$

\begin{tabular}{|c|c|c|c|c|c|c|c|c|}
\hline $\begin{array}{l}\text { Procedore } \\
\text { Lit. } \\
\text { source }\end{array}$ & $\begin{array}{l}\text { Imaging } \\
\text { mode }\end{array}$ & $\begin{array}{l}\text { Tubet } \\
\text { pos. }\end{array}$ & $\begin{array}{l}\mathrm{D}_{\text {eye }} \\
{[\mathrm{mOy}]}\end{array}$ & $\begin{array}{l}D_{\text {skit }} \\
{[m G y]}\end{array}$ & $\begin{array}{l}\mathrm{D}_{\text {thys }} \\
\text { [mGy] }\end{array}$ & $\begin{array}{l}\mathrm{H}_{E} \\
{[\mathrm{mSv}]}\end{array}$ & $\begin{array}{l}\text { E } \\
{[\mathrm{mSN}]}\end{array}$ & $\begin{array}{l}\text { DAP } \\
{\left[G y \cdot \mathrm{cm}^{2}\right]}\end{array}$ \\
\hline \multicolumn{9}{|l|}{ Cerebral } \\
\hline MOBO & film & $A P$ & $33-81$ & - & - & - & $\cdots$ & - \\
\hline PA82 & IV-DSA & under & 0.15 & 37 & 7.4 & - & - & - \\
\hline PA82 & $\mathrm{film}$ & over & 3.2 & 230 & 87 & - & - & - \\
\hline MA8 8 & - & und $^{c}$ & 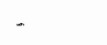 & - & - & 12 & - & - \\
\hline PL86 & IV-DSA & $\mathrm{PA}$ & - & - & - & - & - & $7-17\{\text { med }\}^{d}$ \\
\hline PL86 & $\mathrm{flm}$ & $\mathbb{A P}$ & - & - & - & - & - & $19-28\{\mathrm{med}\}$ \\
\hline PL 86 & $D S A+f i m$ & $A P$ & $\approx$ & - & - & - & - & $50\{$ med $\}$ \\
\hline CA88 & IA-DSA & $\mathrm{PA}$ & 3.3 & - & - & - & - & - \\
\hline CA88 & film & A.P & 196 & - & - & - & - & - \\
\hline TH88 & $1 A-D S A$ & $P A$ & 0.9 & - & 6.1 & - & - & - \\
\hline TH88 & film & $\mathrm{AP}$ & 81 & - & 22 & - & - & - \\
\hline WAB8 & - & - & - & - & - & 4 & - & - \\
\hline MU89 & DSA & PA & 4.7 & 185 & 21 & 。 & - & 1.1 \\
\hline $\mathrm{HO} 91$ & film & $P A$ & - & 312 & - & 21 & - & - \\
\hline FE92 & $\mathrm{DSA}+$ film & over & - & 271 & - & 11 & - & - \\
\hline ST93 & DSA & - & - & - & - & 4 & - & 27 \\
\hline $\mathbb{F} 195$ & DSA & over & - & - & - & - & - & 73 \\
\hline MA95a & DSA & under & 11 & 150 & 5.6 & - & 4 & 49 \\
\hline \multicolumn{9}{|l|}{ Thoracic } \\
\hline MA88 & 。 & $u n d^{c}$ & - & - & - & 5 & - & - \\
\hline \multicolumn{9}{|l|}{ Abdominal } \\
\hline KA82 & - & - & - & $\infty$ & - & - & - & 31 \\
\hline MA88 & - & und $^{\mathrm{c}}$ & - & - & - & 20 & - & - \\
\hline WA88 & - & - & - & - & - & 6 & - & - \\
\hline 5793 & DSA & - & - & - & - & $16,23^{c}$ & - & \\
\hline \multicolumn{9}{|c|}{ Thoracic/abdominal } \\
\hline \multirow{2}{*}{\multicolumn{7}{|c|}{ Peripheral }} & - & $33\{$ med $\}$ \\
\hline & & - & - & - & - & - & - & 20 \\
\hline $\begin{array}{l}\text { KA82 } \\
\text { MA88 }\end{array}$ & - & und $^{c}$ & - & - & - & 10 & - & - \\
\hline WA 88 & .. & - & - & - & - & 4 & - & - \\
\hline HO9! & fillm & $A P$ & $\therefore$ & 89 & . & 12 & - & - \\
\hline $5 T 93$ & DSA & - & - & - & $*$ & 4 & - & 43 \\
\hline FI95 & DSA & over & - & - & - & - & - & $7 \|\{$ med $\}$ \\
\hline CA95 & DSA & under & 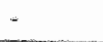 & 25 & - & * & 3 & 13 \\
\hline
\end{tabular}

in " $\sim$ " denotes that this information was not included; "AP" refers to anterior posterior and "PA" to poster" hor anterior beam direction. AP may be considered as similar to overcouch and PA to undercouch $X$-ray mile positions; "A high proportion of the $X$-ray systems were used with overcouch tubes, " (med) denotes median value instead of artithmetic mean; " Renal angiography $16 \mathrm{mSv}$, hepatic angiography $23 \mathrm{mSv}$.

\subsubsection{Radiation doses to staff}

This subsection comprises information about occupational exposures in vascular radiology. In most cases, radiation exposures to the operator exceeds those to assisting personnel (see Chapter 9). Therefore, in order to condense the following review, attention has been focused on the dose to the operator. Dose data for various locations on the outside of the body of the operator are summarised in Table 3.8. As it was realised that much can be 
learned from other radiodiagnostic examinations involving fluoroscopy, a number of papers containing relevant information for dosimetry in anglography procedures have been reviewed as well. Data about dose rates near the patient table for angiographic and nonangiographic procedures are summarised in Table 3.9 .

\section{Dose data referring to angiography procedures}

In 1972, Riley et al. [R172] reported about measured entrance doses for operators performing various angiography procedures, including abdominal, cerebral, and peripheral procedures. Vascular imaging was performed with an undertable fluoroscopy X-ray tube system, with two separate $X$-ray tube and film changer systems. Contrast media were injected manually. In order to determine the relative contributions of radiography and fluoroscopy to the total exposure, two sets of thermoluminescent dosemeters were used for each person. For cerebral angiography $(n=26)$, mean skin doses per procedure were estimated to be $60 \mu \mathrm{Gy}$ to the forehead, $70 \mu \mathrm{Gy}$ to the neck, $110 \mu \mathrm{Gy}$ to the elbow, and $75 \mu \mathrm{Gy}$ to the hand. For 20 abdominal angiography procedures, mean skin doses per procedure were estimated to be $270 \mu \mathrm{Gy}$ to the forehead, $215 \mu \mathrm{Gy}$ to the neck, $205 \mu \mathrm{Gy}$ to the elbow, and $200 \mu$ Gy to the hand. For both cerebral and abdominal angiography procedures it was determined that $92 \%$ of the exposure to the operator was due to radiography. For peripheral angiography $(n=9)$, mean skin doses per procedure were estimated to be $120 \mu \mathrm{Gy}$ to the forehead, $110 \mu \mathrm{Gy}$ to the neck, $135 \mu \mathrm{Gy}$ to the elbow, and $130 \mu \mathrm{Gy}$ to the hand. Doses correlated well with the total tube load for radiography (total mAs). In other procedures, which do not require the presence of the operator near the patient during radiography, good correlation was found for total fluoroscopy time and dose to the forehead. In an additional study [RI72], comprising four abdominal procedures with contrast medium injected by means of a remotely-triggered injector, average radiation closes to the operator were reduced to $10 \mu \mathrm{Sv}$ or less. The authors recommended that "manual injection of contrast material should be avoided whenever possible." Furthermore, it was stated that "radiologists should use automatic remotely-triggered equipment to inject contrast medium. They should stand at least $2 \mathrm{~m}$ from the patient when in the room during radiography". Also, concern was expressed about new equipment with overtable tubes, which could increase scattered doses to the eye lens of the operitor.

Santen et al. [SA75] measured entrance doses to the hand and neck of operators, exposed to scattered $X$-rays in various types of angiography procedures. Procedures were performed with an undertable X-ray tube angiography system. From data oblained in 80 aortography (AA), 25 selective renal arteriography (SRA), and 25 selective vertebral arteriography (SVA) procedures, mean fluoroscopy time and the mean number of radiographs were estimated to be for AA: $1.1 \mathrm{~min}, 0.4$ films; SRA: $2.4 \mathrm{~min}, 3.2 \mathrm{lilms}$; SVA:5.0 min, 1.3 films. Occupational exposures associated with fluoroscopy and serial cut film radiography were derived separately in 88 procedures. It was derived from data presented by the authors that mean entrance doses to the forehead were equal to $2 \mu G y$ for AA, $150 \mu \mathrm{Gy}$ for SRA, and $48 \mu \mathrm{Gy}$ for SVA. Mean entrance doses to the hand were equal to $4 \mu \mathrm{Gy}$ for $\mathrm{AA}, 32 \mu \mathrm{Gy}$ for SRA, and $11 \mu \mathrm{Gy}$ for SVA. Mean doses to the hands, resulting from fluoroscopy were estimated to be $3.3 \mu \mathrm{Gy} \cdot \mathrm{min}^{-1}$ for $\mathrm{AA}$, and 1.1 $\mu \mathrm{Gy} \cdot \mathrm{min}^{-1}$ for SRA. Mean hand doses per radiograph were estimated to be 2.7 $\mu \mathrm{Gy} \cdot$ film $\mathrm{m}^{-1}$ for SRA, and $0.6 \mu \mathrm{Gy} \cdot$ film $\mathrm{m}^{-1}$ for SVA. Mean doses to the forehead, resulting from fluoroscopy were estimated to be $1.7 \mu \mathrm{Gy} \cdot \mathrm{min}^{-1}$ for AA and SRA, and 0.8 $\mu \mathrm{Gy} \cdot \mathrm{min}^{-1}$ for SVA; mean forehead doses per film were estimated to be $13 \mu \mathrm{Gy} \cdot \mathrm{film}^{-1}$ for SRA, and $2.4 \mu \mathrm{Gy} \cdot \mathrm{film}^{-1}$ for SVA. The authors stated that exposures associated with 
radiography were high because contrast medium was manually injected, with the operator standing beside the patient table.

Lackner et al. [LA78] performed entrance dose measurements to the operator for 56 abdominal and peripheral arteriography procedures (overcouch tube system). Because of the reported distance of the operator from the patient, 0.6-1 $\mathrm{m}$, both for fluoroscopy and radiography, we assumed that contrast medium was imjected manually. From a comparison of entrance doses per unit time with data obtained in 134 cardio-angiography procedures, the authors concluded that relatively high doses from noncardiovascular imaging were caused by obsolescent system features (e.g. kerma rate at input screen of image intensifier was reported to be $0.87 \mu \mathrm{G} y \cdot \mathrm{s}^{-1}$; kerma rate for the cardio-system was $0.26 \mu \mathrm{Gy} \cdot \mathrm{s}^{-1}$ ). Median entrance doses to the operator were $420 \mu \mathrm{Gy}$ to the forehead and $130 \mu \mathrm{Gy}$ to the hand. In order to reduce occupational exposures, the authors advocated the use of remote controlled contraste medium injection systems.

Entrance doses to operators in 18 cerebral arteriography procedures, performed on an undercouch $X$-ray tube system, were reported by Chopp et al. [CH80]. Mean fluoroscopy time was 6.2 min, average number of films 79. Mean doses to the forehead, thyroid and wrist were estimated to be $31 \mu \mathrm{Gy}, 28 \mu \mathrm{Gy}$, and $22 \mu \mathrm{Gy}$ respectively. Injection of contrast medium (manually or by power system) was not described.

Law [LA85] reported on dose measurements that were performed pair-wise on the wrist (on the arm near the patient and X-ray beam) and the "head" (forehead or on thyroid collar) of the operator during various angiography procedures. The ratio of the sum doses to the wrist and the head was calculated to be 2.7 . X-ray tube position and contrast medium administration were not described.

Tryhus et al. [TR87] determined entrance doses to operators for 10 cerebral and 14 abdominal arteriography procedures. All procedures were performed with power contrast medium injectors, using an undercouch fuoroscopy X-ray system and two overtable tubes for radiography and DSA. Mean entrance doses for cerebral angiography were estimated to be $26 \mu \mathrm{Gy}$ for the eyes, $41 \mu \mathrm{Gy}$ for the thyroid, and $71 \mu \mathrm{Gy}$ for the hand. Mean entrance doses for abdominal angiography were estimated to be $52 \mu \mathrm{Gy}$ for the eyes, 75 $\mu \mathrm{Gy}$ for the thyroid, and $130 \mu \mathrm{Gy}$ for the hand, excluding one abdominal procedure in which the dose to the hand was $3 \mathrm{mGy}$. Higher doses during abdominal procedures were related to increased scatter from patient tissue and the closer proximity of the radiologist to the $X$-ray wabe than during cerebral angiography. Doses to the eyes, thyroid and hand were only weakly correlated with fluoroscopy time. From measurement results, the author's concluded that the apron $(0.5 \mathrm{~mm}$ lead equivalent) reduced gonadal dose by a factor of 7411 . As will be discussed in section 9.4, this result is probably incorrect.

In a study on entrance doses to angiographers in a Dutch hospital in 1987 [KI88], comprising 123 procedures, the mean dose to the chest region (on the apron) of operators was estimated to be $67 \mu \mathrm{Sv}$. On the basis of measurements performed during eight procedures, it was estimated that entrance doses to the most exposed hand were equal to about three times the dose to the chest. Entrance doses to the chest for unspecified IV-DSA were $56 \mu \mathrm{Gy}(\mathrm{n}=32)$, for unspecified IA-DSA procedures $61 \mu \mathrm{Gy}(\mathrm{n}=54)$, and for PTA
procedures $68 \mu \mathrm{Gy}(\mathrm{n}=14)$.

Britton and Wholey [BR88] measured doses to the unprotected eye lens of operators in cerebral angiography (undertable $X$-ray tube system). For IV-DSA procedures $(n=65)$, the lens dose was estimated to be $9 \mu \mathrm{Gy}$ (range 4-16 $\mu \mathrm{Gy}$ ); mean dose rate to the forehead during fluoroscopy was $8.9 \mu \mathrm{Gy} \cdot \mathrm{min}^{-1}$ (range $4-14 \mu \mathrm{Gy} \cdot \mathrm{min}^{-1}$ ). IV-DSA studies were performed with power injection of contrast material. From measurements in 45 intra- 
arterial procedures (femoral approach), the mean doses to the lens were calculated to be $58 \mu \mathrm{Gy}$ from fiuoroscopy (mean fluoroscopy time 8.8 min; mean dose rate 9.0 $\mu \mathrm{Gy}-\mathrm{min}^{-1}$ ), and $130 \mu \mathrm{Gy}$ from IA-DSA imaging (hand injecton of contrast material). The authors concluded that the use of pressure injectors rather than hand injection would eliminate the dose due to filming, which was found to account for $75 \%$ of the total dose. The authors also concluded that judicious use of fluoroscopy controls, as well as experience in catheterisation would reduce the occupational exposure. This was illustrated by longer fluoroscopy times for residents (mean $11.7 \mathrm{~min}$ ) compared with staff radiologists (mean 4 min).

Berthelsen and Cederblad [BE91b] determined the effective dose equivalent to operators in embolisation procedures of cerebral vessels (undercouch $X$-ray system). For five procedures, with fluoroscopy times varying between 26 and $90 \mathrm{~min}$, number of film series between 0 and 4 , and number of DSA series berween 5 and 16 , estimates for $H_{E}$ were calculated to be ranging from 10 to $26 \mu \mathrm{Sv}$ (mean $17 \mu \mathrm{S} v$ ). Entrance doses to the eyes, neck, and most exposed hand were estimated to be 40-210 $\mu$ Gy (mean 115 $\mu \mathrm{Gy}$ ), 50-120 $\mu \mathrm{Gy}$ (mean $75 \mu \mathrm{Gy}$ ), 30-190 $\mu \mathrm{Gy}$ (mean $115 \mu \mathrm{Gy}$ ) respectively. With references to published data, and taking into account that personnel wore $0.35 \mathrm{~mm}$ lead aprons, the authors calculated $\mathrm{H}_{\mathrm{E}}$ to be about $20 \%$ of the neck dose.

Boone and Levin [BO91] simulated exposures near an angiography system in both PA and AP geometries for a supine patient. A 200 -mm-thick perspex phantom, a field of view of $30 \times 30 \mathrm{~cm}^{2}$ and air kerma rate of $0.44 \mu \mathrm{Gy} \cdot \mathrm{s}^{-1}$ at the irnage intensifier entrance screen (behind the grid), were used to perform measurements at various distances and for different tube high voltage settings. At $50 \mathrm{~cm}$ from the central beam axis, the PA/AP dose rate ratio for the lower legs of the operator was about 8 . Above the waist AP/PA dose rate ratios varied from 3 (at $140 \mathrm{~cm}$ ) to 5 (at $160 \mathrm{~cm}$ ), which illustrates once more the increased exposure level to the unprotected arms, neck and head of the operator in AP views. It was also shown that, as the automatic brightness control of the system kept the kerma rate at the image intensifier constant, the scatter dose rate decreased with increasing tube high woltage. Scatter dose ratios for 70,80 and $90 \mathrm{kV}$ were calculated to be about 1.3:1:0.8. The authors noted that the results confirmed the rule of thumb: in fluoroscopy, the radiologist's exposure at a distance of $1 \mathrm{~m}$ is roughly one thousand h of the patient"s entrance exposure.

Fisher at al [F[95] examined the association between the fluoroscopy time, number of series, number of frames, and dose-area product with the entrance doses to the hand and the neck for various angiography and interwentional procedures. Cerebral arteriography was performed on an overcouch tube system, whilst other procedures were performed on an undercouch $\mathrm{X}$-ray tube system. Conrelations were found to be very weak for the hand $(r<0.21)$ and weak for the neck $(r<0.62)$. The authors concluded that occupational dose data could not be derived from technique parameters. It should be noted here that, although the authors stated explicilly that dose data were skewed and deviated from a normal distribution, the Pearson correlation coefficient was applied. Furthermore, judging from the number of observations reported, it must be concluded that correlation analysis was performed without discriminating between overcouch and undercouch tube positions. This implies that conclusions drawn by the authors about associations may be invalid. Median values for the dose to the hand and the neck were estimated to be $230 \mu \mathrm{Gy}$ and $175 \mu \mathrm{Gy}$ for cerebral angiography $(\mathrm{n}=33), 65 \mu \mathrm{Gy}$ and $55 \mu \mathrm{Gy}$ for thoracic and abdominal angiography $(\mathrm{n}=21), 145 \mu \mathrm{Gy}$ and $75 \mu \mathrm{Gy}$ for peripheral angiography $(\mathrm{n}=11)$, $500 \mu \mathrm{Gy}$ and $210 \mu \mathrm{Gy}$ for PTA $(\mathrm{n}=6)$, and $250 \mu \mathrm{Gy}$ and $240 \mu \mathrm{Gy}$ for embolisation 
procedures $(n=9)$. Ratios of means for occupational exposures for interventional procedures and means for angiography were found to be approximately 1.5. In one cerebra! angiography procedure the dose to the hand was measured to be as high as $6.3 \mathrm{mGy}$. The authors stated that no explanation was found, which indicates that incidentally unnoticed higtt exposures can occur in daily practice. It was also stated that differences between the dose to the hand and the neck, and the position of the X-ray tube (undercouch or overcouch) were found to be statistically significant $(p<0.01)$.

Table $3.8 \quad$ Dose estimates for operators in wascular radiology

\begin{tabular}{|c|c|c|c|c|c|c|c|c|c|}
\hline \multirow{2}{*}{$\begin{array}{l}\text { Procedure } \\
\text { Lit. } \\
\text { source }\end{array}$} & \multirow[b]{2}{*}{$\begin{array}{l}\text { Imaging } \\
\text { mode }\end{array}$} & \multirow[b]{2}{*}{$\begin{array}{l}\text { Tubet } \\
\text { pos. }\end{array}$} & \multirow[b]{2}{*}{$\begin{array}{l}\operatorname{Inj}_{,}{ }^{8} \\
\text { sysit. }\end{array}$} & \multicolumn{5}{|c|}{ Mean dose per procedure } & \\
\hline & & & & $\begin{array}{l}D_{\text {eye }} \\
{[\mu \mathrm{G} y]}\end{array}$ & $\begin{array}{l}D_{\text {nerdk }} \\
{[\mu \mathrm{Cy}]}\end{array}$ & $\begin{array}{l}D_{\text {hiand }} \\
\lfloor\mu G y\rfloor\end{array}$ & $\begin{array}{l}\mathrm{H}_{E} \\
{[\mu \mathrm{Sv}]}\end{array}$ & $\begin{array}{l}\mathrm{E} \\
\lfloor\mu \mathrm{Sv}]\end{array}$ & \\
\hline \multicolumn{10}{|c|}{ Cerebral arteriography } \\
\hline $\mathbb{R} 172$ & film & under & man & 60 & 70 & 75 & - & - & \\
\hline SA75 & film & under & man & 48 & - & 11 & . & - & \\
\hline $\mathrm{CH} 80$ & film & under & - & 31 & 28 & 22 & - & - & \\
\hline $\operatorname{TR} 87$ & $\mathrm{film}+\mathrm{DSA}$ & under & rem & 26 & 41 & 71 & - & - & \\
\hline BR88 & W-DSA & under & rem & 9 & - & - & - & - & \\
\hline BR88 & $I A-D S A$ & under & man & 188 & - & - & - & - & \\
\hline Flos & DSA & over & - & - & 175 & 230 & - & - & $\{m e d\}^{e}$ \\
\hline MA95a & DSA & under & $\operatorname{man}$ & 14 & 11 & 19 & - & 0.55 & \\
\hline \multicolumn{10}{|c|}{ Abdominal arteriography } \\
\hline $\mathrm{RI} 72$ & film & under & $\operatorname{man}$ & 270 & 215 & 200 & - & - & \\
\hline RI72 & film & under & $\mathrm{rem}$ & $<10$ & $<10$ & $<10$ & - & - & \\
\hline SA75 & film & under & - & 2 & - & 4 & - & - & \\
\hline SA75: & film & under & $\operatorname{man}$ & 150 & - & 32 & - & - & \\
\hline TR87 & film $m$ DSA & under & $\mathrm{rem}$ & 52 & 75 & 130 & - & - & \\
\hline \multicolumn{10}{|c|}{ Thoracictabdominal art. } \\
\hline \multirow{2}{*}{\multicolumn{3}{|c|}{ Abdomina/peripherat art. }} & - & - & 55 & 65 & $\sim$ & - & $\{$ med $\}$ \\
\hline LA78 & film & over & $\operatorname{man}^{n}$ & 420 & . & & - & .. & \\
\hline \multirow{2}{*}{\multicolumn{10}{|c|}{$\begin{array}{l}\text { Peripheral arreriography } \\
\text { RI72 film }\end{array}$}} \\
\hline $\mathrm{RI} 72$ & fillm & under & mant & 120 & 110 & 130 & - & & \\
\hline 195 & $\operatorname{DSA}$ & under & - & - & 75 & 145 & - & - & $\{$ med $\}$ \\
\hline \multicolumn{10}{|c|}{$\begin{array}{l}\text { Angiography (nor specified) } \\
\text { K188 }\end{array}$} \\
\hline $\mathrm{K} 188$ & NODSA & $=$ & 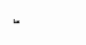 & - & 56 & - & - & - & \\
\hline K.L88 & $1 \mathrm{~A} \cdot \mathrm{DSA}$ & - & - & - & $6 !$ & 190 & - & - & \\
\hline \multicolumn{10}{|c|}{$\begin{array}{l}\text { Endo vasc. intervenwional procedures } \\
\text { BEglb(emb) DSA }+ \text { film }\end{array}$} \\
\hline $\begin{array}{l}\text { BEgl b(emb) } \\
\text { F195 (PTA) }\end{array}$ & DSA+film & under & $\therefore$ & 115 & $\begin{array}{r}75 \\
210\end{array}$ & $\begin{array}{l}115 \\
500\end{array}$ & - & - & $\{\mathrm{med}\}$ \\
\hline $\begin{array}{l}\text { F195 (PTA) } \\
\text { K188 (PTA) }\end{array}$ & DSA & $\begin{array}{l}\text { under } \\
-\end{array}$ & - & - & 68 & - & - & - & \\
\hline FI95 (enb) & $\begin{array}{l}\text { DSA } \\
\text { DSA }\end{array}$ & - & - & - & 240 & 250 & - & - & $\{$ med $\}$ \\
\hline
\end{tabular}

"film" denotes sertal cut film angiography; " "under" " "DSA" denotes digital subtraction angiography; tube positions respectively; "s "ing " ministration of contrast medium by means of manual injection of contrast medium; "rem" denotes adthat the authors provided medians instead af remote controlled power injection system; " med\} denotes Selective renal arteriography; " manual injectioneans; "Aortography. Radiography data not described; 8 
Marshall et al. [MA95a] performed dose measurements for staff in 90 cerebral DSA angiography procedures, using an undercouch $\mathrm{X}$-ray system. Contrast nuedium was injected manually. Dose measurements were performed with thermoluminescent dosemeters and with electronic personal dosemeters $(n=30)$. Siaff wore $0.35 \mathrm{~mm}$ lead equivalence protective aprons. The entrance dose for operators at the chest above the apron was measured to be $11 \mu \mathrm{Gy}$ per procedure (averaged over all cerebral plus embolisation procedures performed). From measurements performed for cerebral arterial embolisations it was inferred that doses at chest height were about a factor of two higher than for cerebral angiography. It was noted that this increase in dose correlated well with the increase in DAP. Average doses for operators, combined both for angiography and embolisation procedures were estimated to be $14 \mu \mathrm{Gy}$ for the forehead, and $19 \mu \mathrm{G} y$ for the most exposed hand. By dividing the dose at chest height in front of the apron by a factor of 20 , the authors estimated the mean effective dose for cerebral angiography to be $0.55 \mu \mathrm{Sv}$. As mean DAP was equal to $49 \mathrm{~Gy} \cdot \mathrm{cm}^{2}$, this would implicate a DAP to effective dose conversion factor of $0.01 \mu \mathrm{Sw} \cdot \mathrm{Gy}^{-1} \cdot \mathrm{cm}^{-2}$.

\section{Occupational doses to operators in non-angiography procedures}

The relationship between dose rate from scattered radiation and field size was found to be linear, both for overcouch X-ray tube positions [FO79, MA92] and for undercouch X-ray tube positions [MA92].

Den Boer and Mohr [BO76] measured spatial distributions of scattered radiation near a cardio-vascular X-ray system (undertable tube) for different technical parameters. By using the conversion factor $8.77 \mu \mathrm{Gy} / \mathrm{mR}$, we converted presented exposure rates to absorbed dose rates in air. At tube high voltage of $90 \mathrm{kV}$, tube current $1 \mathrm{~mA}$, and field size $8.5 \times 11 \mathrm{~cm}^{2}$, dose rates close to the patient table varied from $0.7-7.2 \mu \mathrm{Gy} \cdot \mathrm{min}^{-1}$, depending on the projection angle and the theight from the floor. The authors calculated correction factors for tube high voltage settings of $60,70,80,90,100$ and $110 \mathrm{kV}$, to be $0.2,0.38,0.7,1,1.3$, and 1.65 respectively. It should be noted that these findings are contradicting with the results by Boone [BO91]. Probably, dose rates by Den Boer were obtained by fixed $\mathrm{mA}$-values. Taking into account that modern imaging systems have automatic exposure controls, one should use Boone's data for daily practice.

Forster and Mohr [FO79] investigated the radiation dose rate around an overcouch urological fluoroscopy system. At tube high voltage setting of $84 \mathrm{kV}$, wbe current $1 \mathrm{~mA}$. and beam size $20 \times 20 \mathrm{~cm}^{2}$, dose rates at positions $35 \mathrm{~cm}$ lateral from the table, $135 \mathrm{~cm}$ above the floor, were measured to be about 5.7-11 $\mu \mathrm{Gy} \cdot \mathrm{min}^{-1}$, depending on the position; at $35 \mathrm{~cm}$ lateral from the table, dose rates at $50 \mathrm{~cm}, 100 \mathrm{~cm}$ and $150 \mathrm{~cm}$ above the floor were equal to about $0.7 \mu \mathrm{Gy}$ " $\min ^{-1}, 7 \mu \mathrm{Gy} \cdot \mathrm{min}^{-1}$, and $11 \mu \mathrm{Gy} \cdot \mathrm{min}^{-1}$ respectively.

Cruikshank et al. [CR80a] measured finger doses to two operators performing percutaneous cholangiography procedures (undercouch X-ray tube system). Initial differences between individual doses per unit fluoroscopy time $(940 \mu \mathrm{Sv} / \mathrm{min}$ and $240 \mu \mathrm{Sv} / \mathrm{min})$ were attributed to differences in the sizes of the X-ray field applied (full screen versus $10 \times 10$ $\mathrm{cm}^{2}$ ). In a second stage during which both operators attempted to cone the field to $10 \times 10$ $\mathrm{cm}^{2}$, corresponding finger dose rates were $370 \mu \mathrm{Sv} / \mathrm{min}$ and $300 \mu \mathrm{Sv} / \mathrm{min}$. As other technique parameters remained essentially unattered, the authors associated this dose reduction (about $3 \mathrm{x}$ ) with the more careful attention that was paid to field size settings.

Gustafsson and Lunderquist [GU81] reported about TLD measurements at the forehead, neck and fingers of operators during percutaneous transhepatic cholangiography (undercouch fluoroscopy $X$-ray tube system). Estimated average doses for 10 procedures were 
calculated to be $50 \mu \mathrm{Gy}$ to the forehead, $40 \mu \mathrm{G} y$ to the neck, and $1500 \mu \mathrm{Gy}$ and $550 \mu \mathrm{Gy}$ to the left and right hand respectively. Mean fluoroscopy ime was 13 min. It follows that corresponding ratios of means are equal to $3.8 \mu \mathrm{Gy} \cdot \mathrm{min}^{-1}$ for the forehead, 3.1 $\mu \mathrm{Gy}$ - min ${ }^{-1}$ for the neck, $115 \mu \mathrm{G} y \cdot \mathrm{min}^{-1}$ for the hand close to the $\mathrm{X}$-ray beam. Generally, radiography was performed with personnel outside of the operating area. A rough method was used to estimate effective dose equivalents. The authors concluded that about $60 \%$ of the effective dose came from the radiation exposure to the unshielded head and neck region. The authors explained considerably higher eye lens doses found by other investigators by high exposure rates at image intensifier screens and manual injection of contrast material during radiography in those hospitals.

Faulkner and Moore [FA82] measured radiation dose levels at waist and chest level in the immediate vicinity of an X-ray system, both with undercouch and overcouch tube positions. For tube high voltage and tube current settings of $80 \mathrm{kV}$ and $1 \mathrm{~mA}$ (field size $12 \times 10 \mathrm{~cm}^{2}$ ), dose rates for overcouch wabe position waried between $50 \mu \mathrm{Gy} \cdot \mathrm{min}^{* 1}$ at very close distance, and $10 \mu \mathrm{Gy} \cdot \mathrm{min}^{-1}$ at $0.5 \mathrm{~m}$ from the table. Dose rates for undercouch tube position, at $0.5 \mathrm{~m}$ from the table, were equal to $8 \mu \mathrm{Gy} \cdot \mathrm{min}^{-1}$ at waist level, and about 2 $\mu \mathrm{Gy}$ " $\mathrm{min}^{-1}$ at chest level. The authors stated that "increasing the tube potential may not lead to a higher personal dose if tube current is reduced appropriately". It should be noted that this statement contradicts results obtained by Boone [BO91].

Law [LA85] reported about dose measurements performed on the wrist (on the arm near the patient and $X$-ray beam) and the head/neck region (forehead or on thyroid collar) of radiologists in a number of different diagnostic procedures. Ratios of the wrist dose by the dose to the head varied between about 1 and 14, indicating a large variation in the relationship between these measurement positions.

Kicken et al. [KI88a] measured entrance doses to various measurement positions on the body of occupationally exposed personnel in two cardiac catheterisation rooms (both equipped with an undertable X-ray tube system). Measurement results obtained in 1250 procedures were normalised to DAP. Averaged over both hospitals, dose rates to the operator were found to be equal to $2.8 \mu \mathrm{Gy} \cdot \mathrm{Gy}^{-1} \cdot \mathrm{cm}^{-2}$ for the eye lens and thyroid, 3.7 $\mu \mathrm{Gy} \cdot \mathrm{Gy}^{-1} \cdot \mathrm{cm}^{-2}$ for the lower leg, $2.3 \mu \mathrm{Gy} \cdot \mathrm{Gy}^{-1} \cdot \mathrm{cm}^{-2}$ for the hand close to the $\mathrm{X}$-ray beam. and $0.7 \mu \mathrm{Gy} \cdot \mathrm{Gy}^{-1} \cdot \mathrm{cm}^{-2}$ for the other hand. On the basis of filmbadge dosemeter data, the overall effective energy of scattered radiation near the patient table was estimated to be $35 \mathrm{keV}$.

For a standard fluoroscopy table with overcouch tube, Inglis et al. [IN89] estimated the entrance dose rates for the hands of experienced operators for percutaneous nephrolithotomy to be $51 \mu \mathrm{Gy} \cdot \min ^{-1}$ and $78 \mu \mathrm{Gy} \cdot \mathrm{min}^{-1}$ for the left middle and left index finger respectively ( $\mathrm{n}=55,75-80 \mathrm{kV}$, about $1.5 \mathrm{~mA}$, mean fuoroscopy time 4.4 min (range 1.2 $-12.5 \mathrm{~min})$ ).

McParland and co-workers [MC90] measured entrance doses to operators in two cardiology catheterisation rooms, both equipped with undercouch $X$-ray ribe systems. Entrance doses obtained in 43 procedures were normalised to the workload (integrated tube current). Averaged over both hospitals, dose rates were estimated to be 0.65 $\mu \mathrm{Gy} \cdot \mathrm{mA}^{-1} \cdot \mathrm{min}^{-1}$ for the forehead, and $0.55 \mu \mathrm{Gy} \cdot \mathrm{mA}^{-1} \cdot \mathrm{min}^{-1}$ for the thyroid. In one hospital entrance doses at the chest and wrist were estimated to be $0.6 \mu \mathrm{Gy} \cdot \mathrm{mA}^{-1} \cdot \mathrm{min}^{-1}$, and $0.75 \mu \mathrm{Gy} \cdot \mathrm{mA}^{-1} \cdot \mathrm{min}^{-1}$ respectively, whereas results in the other hospital were equal to $30 \mu \mathrm{Gy} \cdot \mathrm{mA}^{-1} \cdot \min ^{-1}$ for the chest, and $37 \mu \mathrm{Gy} \cdot \mathrm{mA}^{-1} \cdot \mathrm{min}^{-1}$ for the wrist. The authors explained these large difference by the finding that operators in the latter hospital worked considerably closer to the patient. 
Ramsdale et al. [RA90a] noted a trend towards equipping $X$-ray systems with overconch $X$-ray tubes instead of the more conventional undercouch arrangement. From TLD measurement results for operators in percutaneous nephrolithotomy procedures with an overcouch system (mean fluoroscopy time 22 min; $n=42$ ), mean doses were estimated to be $520 \mu \mathrm{Gy}$ and $280 \mu \mathrm{Gy}$ for the left and right hand respectively, $320 \mu \mathrm{Gy}$ for the eye, and $270 \mu \mathrm{Gy}$ for the neck. The authors reported that hand doses were in good agreement with the results by Law et al. [LA89], obtained for similar exposure conditions; left hand and neck doses were about a factor of 6 above those reported by Lowe et al. [LO86], which were determined for an undercouch $X$-ray tube system.

Vehmas et al. [VE91] reported finger doses associated with fluoroscopy during percutaneous nephrostomy, performed on an angiography system with undercouch tube. The average dose was equal to $190 \mu$ Gy per procedure $(n=21$; mean fluoroscopy time $12 \mathrm{~min}$; mean DAP 8.0 (range $0.4-24$ ) $\mathrm{Gy} \cdot \mathrm{cm}^{2}$ ). From these results the ratio of hand dose by fluoroscopy time, and the ratio of hand dose by DAP were calculated to be $16 \mu \mathrm{Gy} \cdot \mathrm{min}^{-1}$, and $24 \mu \mathrm{Gy} \cdot \mathrm{Gy}^{-1} \cdot \mathrm{cm}^{-2}$ respectively. In a subsequent paper by Vehmas and Tikkanen [VE92] about this study, mean and median dose rates to the hand of the operator in 27 procedures were calculated to be $20 \mu \mathrm{Gy} \cdot \mathrm{min}^{-1}$ and $8 \mu \mathrm{Gy} \cdot \mathrm{min}^{-1}$ respectively. The frequency distribution was found to be skewed. The range of dose rates was wide, differences of several hundred-times were obtained. The Spearman rank correlation coefficient was used to quantify associations between the doses rates to the hands and shoulders. Correlations between most measurement positions showed statistically significant correlations, with the exception of the left hand and right hand, and the right hand and the left shoulder. In all, it was concluded that the correlation between shoulder and thand doses was uncertain, and that finger doses should be used on both hands.

Felmlee et al. [FE91] investigated hand doses with TLD ring badges during 30 interventionall non-vascular radiology procedures, performed with an undertable $X$-ray tube system. The average hand dose was $1500 \mu \mathrm{Gy}$ (range $0-5500 \mu \mathrm{Gy}$ ). From a statistical analysis, the authors concluded that hand doses did not correlate linearly with fluoroscopy time. From scatter radiation measurements, it was observed that hand dose rates decreased by about a factor of two at $5 \mathrm{~cm}$ displacement from the border of the $X$-ray field and by a factor of three at $10 \mathrm{~cm}$ displacement.

From means for entrance doses and the fluoroscopy time for percutaneous nephrolithotony procedures performed on an overcouch $X$-ray tube system (n $=42$ ), presented by Page and Walker [PA92], the entrance dose per unit fuoroscopy time was calculated to be $15 \mu \mathrm{Gy} \cdot \mathrm{min}^{-1}$ for the eye, $13 \mu \mathrm{Gy} \cdot \mathrm{min}^{-1}$ for the thyroid, $24 \mu \mathrm{Gy} \cdot \mathrm{min}^{-1}$ for the left hand, and $13 \mu \mathrm{Gy} \cdot \mathrm{min}^{-1}$ for the right hand. These relatively low dose rates were associated with the use of small fields, and the intermittently use of the light beam diaphragm to check the position of the $X$-ray field to ensure that the operator's fingers never strayed into the primary beam.

Vehmas [VE93] investigated operators' finger doses during 39 percutaneous drainage procedures (undercouch X-ray tube system). The author used the Spearman's rank correlation to derive a positive correlation between DAP and finger doses to the left and right hand. Also, a positive correlation between hand doses and fluoroscopy time was found. According to Vehmas, conflicting conclusions found by Felmlee et al. [FE91] resulted from inappropriate statistical methods used by Felmlee. Vehmas noted that frequency distributions in both studies were skewed, thereby necessitating the use of distribution-free statistics. 


\begin{tabular}{|c|c|c|c|c|c|c|c|c|}
\hline $\begin{array}{l}\text { Procedure } \\
\text { Lit. } \\
\text { source }\end{array}$ & $\begin{array}{l}\text { Imgang } \\
\text { mode }\end{array}$ & $\begin{array}{l}\text { Tube } \\
\text { position }\end{array}$ & $\begin{array}{l}\text { Dose to } \\
\text { Un- } \\
\text { spec }\end{array}$ & $\begin{array}{l}\text { Fore } \\
\text { head }\end{array}$ & Merk & Hand & Leg & Unit \\
\hline \multicolumn{9}{|c|}{$\frac{\text { source }}{\text { Cerebral antertography }}$} \\
\hline SA75 & nuoro & undler & - & 0.8 & $=$ & - & - & $\mu G y=\min ^{-1}$ \\
\hline $\begin{array}{l}\text { SA75 } \\
\text { BR8 } 88\end{array}$ & fitm & ander & - & 2.4 & - & 0.6 & - & $\mu \mathrm{Gy} \cdot \mathrm{fim} \mathrm{m}^{-2}$ \\
\hline $\begin{array}{l}\text { BR88 } \\
\text { Abdowinal artat }\end{array}$ & fluoro & under & - & 9.0 & - & - & - & $\mu \mathrm{Gy} \cdot \mathrm{min}^{-\frac{1}{3}}$ \\
\hline \multicolumn{9}{|c|}{$\begin{array}{l}\text { BR88 fluoro } \\
\text { Abdominal artariography }\end{array}$} \\
\hline $\begin{array}{l}\text { SA75 } \\
\text { SA75 }\end{array}$ & fivoro & monder & - & 1.7 & - & $\begin{array}{l}3.3 \\
1.1\end{array}$ & - & $\begin{array}{l}\mu \mathrm{Gy} \cdot \min ^{-1} \\
\mu \mathrm{Gy} \cdot \min ^{-1}\end{array}$ \\
\hline $\begin{array}{l}\text { SA75 } \\
\text { SA75 }\end{array}$ & nlluoro & under & 。 & 1.7 & - & 2.7 & 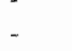 & $\mu \mathrm{Gy} \cdot \mathrm{fllm}^{-1}$ \\
\hline \multicolumn{7}{|c|}{$\begin{array}{l}\text { 3A75 film } \\
\text { Cardio-roscular systems }\end{array}$} & & \\
\hline $\mathrm{BO} 076$ & fluor & under & .747 & - & - & - & . & $\mu G y \cdot \min ^{-1}$ \\
\hline K.188 & Fluorotcine & under & - & 2.8 & 28 & 2.3 & 3.7 & $\mu \mathrm{Gy} \cdot \mathrm{G} y^{-1} \cdot \mathrm{cm}^{-2}$ \\
\hline MC90 & fluotcine & under & - & .65 & .55 & $8-37$ & - & $\mu G y \cdot \operatorname{mA}^{-1}-\min ^{-4}$ \\
\hline \multicolumn{9}{|c|}{$\begin{array}{l}\text { MCoo fluotecine } \\
\text { Angiography systent }\end{array}$} \\
\hline$B O 91^{i 6}$ & fuoro & aver & 1 & - & - & $\sim$ & - & $\mu G y \cdot m G y$ \\
\hline \multicolumn{9}{|c|}{$\begin{array}{l}\text { BO9 } 1^{\text {A }} \text { fuoro } \\
\text { Urology sysiems }\end{array}$} \\
\hline \multicolumn{9}{|c|}{$\begin{array}{l}\text { Fo79 ituoro } \\
\text { Nephrolithotonyy }\end{array}$} \\
\hline IN89 & fluoro & over & - & - & - & 78 & " & $\mu G y \cdot \min ^{-1}$ \\
\hline VE91 & fluoro & under & - & $\cdots$ & - & 16 & - & $\mu \mathrm{Gy} \cdot \min { }^{\prime}$ \\
\hline VB91 & fluoro & under & - & - & - & 24 & - & $\mu \mathrm{Gy} \cdot \mathrm{Gy} y^{4} \cdot \mathrm{cm}^{2}$ \\
\hline VE92 & fluiora & under & - & . & - & 20 & - & $\mu \mathrm{Gy} \cdot \min ^{-1}$ \\
\hline PA92 & fluoro & over & - & 15 & 13 & 24 & - & ${ }_{\mu} \mathrm{Gy} \cdot \mathrm{min}^{-4}$ \\
\hline \multicolumn{9}{|c|}{$\begin{array}{l}\text { PA92 } 2 \text { finoro } \\
\text { Non vascular procedures }\end{array}$} \\
\hline CR80a(PTC) & fluoro & wnder & - & - & - & 240 & - & $\mu \mathrm{G} y \cdot \mathrm{mini}^{-1}$ \\
\hline CR80a(PTC) & fluoro & under & - & - & - & 940 & - & $\mu G y \cdot \min$ \\
\hline GU81 (PTC) & fluoro & under & - & 3.8 & 3.1 & 115 & - & $\mu \mathrm{Cy} \cdot \min ^{-1}$ \\
\hline \multicolumn{9}{|c|}{ Unspecifed system } \\
\hline FA82 & nuoro & over & - & - & 10 & - & - & $\mu \mathrm{Gy} \cdot \min ^{-1}$ \\
\hline FA82 & flworo & under & - & - & 2 & - & - & $\mu \mathrm{Gy} \cdot \min ^{-1}$ \\
\hline
\end{tabular}

" " "denores that this information was not included: "under" refers to undercouch, and "over" to over.

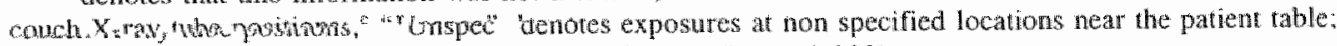
"scatter dose, relative to patient entrance dose $\left(D_{\text {seaser }}=D_{\text {equtsace }} / 1000\right)$.

\section{Concluding remarks about data on occupational exposures}

Published data show a wide variation in dose data for different parts of the body, as well as lor different types of procedures. Difierences in occupational exposures are both associated with features of the imaging equipment (e.g. overcouch versus undercouch $X$ ray tube systems, cut film versus DSA, and manual versus remote-controlled injection of contrast medium), as with the experience of the operator. It should be noted that some authors evaluated additional shieldings, that were attached to the patient table or ceiling mounted. To prevent a mixup of data, these data have not been included in this review.

Some authors noted that dose data distributions were skewed, with a small number of observations on the high dose sides. Because of non Gaussian dose distributions, various authors provided medians instead of means (generally, medians were smaller than means). Some authors investigated the correlation between occupational exposures and technique parameters, such as fluoroscopy cime, dose-area product, and total tube load. As noted by 
Vehmas [VE93], results of correlation analysis with statistical methods applicable for normal distributed data are suspect.

Various authors expressed their concern about relatively high occupational exposures resulting from overcouch systems, or at least illustrated differences between dose levels for overcouch wersus undercouch X-ray tube systems [RI72, GU81, FA82, LA89, B091, F[95].

For some time now, investigators have given attention to increased dose levels to the operator associated with manual injection of contrast medium for radiography [RI72, SA75, LA78, BR88]. Relative contributions of radiography to the total exposure have been reported as high as $92 \%$ [RI72] and 75\% [BR88]. In spite of the recommendations made by the authors to introduce remotely controlled power injection systems, manual injection has been in use up to now [LO93, MA95a, this thesis].

Beside the position of the $\mathrm{X}$-ray tube and contrast medium administration, other sources of variation were introduced to explain differences between occupational dose data, such as the distance of the operator from the patient [MC90], diaphragm setting [CR 80a, BR88, PA92], system features [LA78], and experience of the operator [BR88]. 


\section{Chapter 4}

\section{Arteriography and interventional vascular radiology}

In this chapter medical procedures and equipment applied in arteriography and interventional vascular radiology are described. It only includes information pertaining to the radiation exposure of patient and personnel. In order to provide insight in the variations in exposure conditions, general characteristics of angiography are covered as well. Since exposure conditions depend on the technique of contrast medium administration, this technique is also described. The general descriptive sections are mainly based on information published in textbooks and literature [BU94, CU90, JO87, LA90, PH86, WH90, WO891. To increase readability, case-by-case references to these sources are not included.

Since this thesis does not deal with cardiology, descriptions of these specialistic procedures have not been included.

\subsection{Arteriography}

\subsubsection{Introduction}

The vascular system can be investigated with various imaging methods, such as radiography, computed tomography (CT), radionuclide imaging, ultrasound and magnetic resonance imaging (MRI). In radiography, contrast is caused by local differences in the attenuation of $X$-rays in the body. Since the $X$-ray attenuation in a blood vessel and its surrounding tissue are quite similar, blood vessels are not seen on a plain radiograph. Injection of a contrast medium, presently always an iodine compound that increases the attenuation of $X$-rays, is necessary to visualise the vascular system ( $X$-raty angiography). $X$-ray angiography, $C T$ and radionuclide imaging involve the application of ionising radiation, resulting in a radiation dose to the patient. In X-ray angiography and CT the radiation source is located outside the patient's body. In radionuclide imaging, radiopharmaceuticals, preferably enitting gamma radiation in the energy range of approximately 80 to $300 \mathrm{keV}$, are introduced into the vascular system. The emitted radiation is used to produce images with a so-called gamma-camera. In ultrasound and MRI non-ionising radiation imaging techniques are applied. There is no hard evidence that any physiological change is produced in patients by exposure to ultrasound during diagnostic examinations [NC83, NC92]. Current scientific data on adverse health effects indicate that, although knowledge is limited in this area, the long term risks of MRI examinations are less than those associated with alternative diagnostic methods which involve exposure to ionizing radiation [KA90, NH91, NR91].

According to the principles of justification as described in Chapter 2, aspects such as patient risk and discomfort, cost of the procedure, test characteristics, and the relevance 
of the diagnostic information to be gained, should be properly weighed when choosing which imaging modallity should be used.

In the medical literature on $X$-ray angiography, imaging of arteries is refered to as arteriography and imaging of veins as phebography or venography. However, in daily practice as well as in the literature, the term angiography is (incorrectly) used as a synonym for arteriography. Arteriography may be performed by arterial as well as by venous injections of contrast medium. Phlebography, on the other hand, nearly always requires contrast medium injection in a vein.

In common practice the term conventional angiography refers to imaging of arteries by using a serial cut film changer after injection of a bolus of contrast medium into the arterial vascular system. Digital subtraction angiography (DSA) refers to imaging of arteries by using a digital subtraction system after injection of a bolus of contrast medium into the arterial vascular system (Intra-Arterial DSA, or IA-DSA) or venous vascular system (Intra-Venous DSA, or IV-DSA). Advantages and disadvantages of conventional angiography, IA-DSA and IV-DSA have been discussed by Carmody [CA86a], Dawson [DA88] and Jeans [JE90].

The contrast medium can be administrated through a needle into a (superficial) blood vessel or through a catheter being positioned more deeply in the vascular system. If a small branch far from the main vessel has to be examined, the catheterisation is called "selective", since the position of the catheter tip is located near that branch and the flow of contrast fluid enables imaging of one or only a few small vessels.

A scheme for the classification of $X$-ray angiography examinations is provided in Table 4.1. Five different criteria are given: (i) the anatomical region, (ii) the method of contrast administration, (iii) the type of blood vessel to be imaged, (iv) the position of the catheter tip, and (iv) the imaging technique.

Characterisation of angiographic views of single blood vessels generally includes the direction of the $\mathrm{X}$-ray beam as well. Rotation of the X-ray tube housing and image receptor carrier around the length axis of the patient results in anterior-posterior, posterior-anterior, lateral or oblique projections. Angulation of the X-ray housing results in caudal-cranial or cranial-caudal projection.

For various types of phlebography procedures a radiographic tilting table is required. As the so-called "universal angiography systems" generally do not provide a tilting patient support option, these procedures are usually carried out in generall fluoroscopy rooms, equipped with a spot film or a digital subtraction imaging system. Phlebography procedures that are not performed in an angiography room have not been included in this study.

\subsubsection{Arteriography, a brief description of the procedure}

Four different stages are recognised in arteriographic procedures:

(i) patient preparation.,

(ii) catheterisation,

(iii) imaging of the vascular system, and

(iv) follow-up treatment.

Stage two is associated with fluoroscopy and stage three with the photographic or digital imaging of the vascular system. Depending on the diagnostic information one wants to obtain, these stages can be repeated severat times. As the $X$-ray system is applied 
Table 4.1 Classification criferia for angingraphic examinations

\begin{tabular}{|c|c|c|}
\hline Criteria & Additional information & Nomenclature \\
\hline $\begin{array}{l}\text { - Regional position } \\
\text { of the blood vessel }\end{array}$ & $\begin{array}{l}\text { - head, neck } \\
\text { - upper limbs } \\
\text { - thorax } \\
\text { - abdomen, pelvic } \\
\text { - iliac/lower limbs }\end{array}$ & $\begin{array}{l}\text { - cerebral } \\
\text { - peripheral } \\
\text { - Uhoracic } \\
\text { - abdoninal } \\
\text { - peripheral }\end{array}$ \\
\hline - Puncrure sile & $\begin{array}{l}\text { - artery } \\
\text { - vein }\end{array}$ & $\begin{array}{l}\text { - intra-arterial } \\
\text { - intrawenous }\end{array}$ \\
\hline $\begin{array}{l}\text { - Type of the blood } \\
\text { vessel imaged }\end{array}$ & $\begin{array}{l}\text { - artery } \\
\text { - wein }\end{array}$ & $\begin{array}{l}\text { - arteriography } \\
\text { - phlebography, or } \\
\text { kenography }\end{array}$ \\
\hline $\begin{array}{l}\text { - Position of the } \\
\text { catheter tip }\end{array}$ & $\begin{array}{l}\text { - in main vessel } \\
\text { - in branch of main vessel } \\
\text { - in (small) branch }\end{array}$ & $\begin{array}{l}\text { - nonselective: } \\
\text { - selective } \\
\text { - superselective }\end{array}$ \\
\hline - Imaging system. & $\begin{array}{l}\text { - photographic } \\
\text { - digital } \\
\text { - digital subtraction }\end{array}$ & $\begin{array}{l}\text { - conventional } \\
\text { - DSI } \\
\text { - DSA (DVI })\end{array}$ \\
\hline
\end{tabular}

"Usually the prefix "nonselective" is not used; "DVI is a trade name used by Philipss; (DVI=digital vascular imaging).

infrequently in the stages one and four, only the stages two and three are relevant concerning radiation protection.

Arteriographic procedures may involve two, three or four occupationally exposed persons. In a complex procedure the angiographic team usually exists of one operator (a radiologist), one first assistant (a radiologist-trainee or a radiographer), one circulating assistant (radiographer) and one other radiographer. Depending on the complexity of the procedure and the skill of the team members involved, the auxiliary activities are performed by one to three persons. In the following paragraph a short description is given of the stages (ii) and (iii). Additional information on patient exposure conditions and occupationall exposure conditions is provided in the sections 4.5 and 4.6 respectively.

\section{(ii) Cathererisation}

The radiologist punctures a blood vessel with a specially designed needle and introduces a guide-wire (a thin metal wire) through this needle into the blood vessel system. The positioning of this guide-wire, which will be used to guide a hollow catheter, may involve fluoroscopic control. Subsequently, the needle is removed and a hollow catheter is pushed over this guide-wire and introduced in the blood vessel. After positioning the catheter in the vascular system the guide-wire is removed and the catheter is advanced to its final position. This catheterisation technique is reffered to as the Seldinger technique. Movements of the catheter are guided by short or protracted periods of fluoroscopy. To facilitate catheter positioning, parts of the vascular system are sometimes visualised in the fluoroscopic image by manual administration of small quantities of contrast medium through the catheter. Repeated catheterisation activities comprise repositioning of the catheter tip and/or the introduction of a new guide-wire to replace a catheter or to intro- 
duce a new one. The duration of the fluoroscopic actions depends on various factors such as the anatomy and the condition of the vascular system of the patient, the desired location of the catheter tip, characteristics of the guide-wire and the catheter, and the experience of the operator.

\section{(iii) Imaging of the vascular system}

Vascular imaging is performed with a serial cut film system, a DSA systen or with both systems. Quite regularly, fluoroscopic previewing of the body region is required. Contrast medium is usually administered with a power driven injector, which is connected to the film changer control unit or DSA system. During vascular imaging (serial cut film or DSA) all personnel stay behind protective barriers in the control room, if a power driven contrast medium injector is applied. However, occupational exposure may occur if contrast medium is injected manually, in which case the operator stays next to the patient, approximately at the same location as during fluoroscopy. Nonvolatile imaging techniques are described in section 4.3 .

\subsubsection{Contrast medium administration for $\mathrm{X}$-ray arteriography}

The quality of the vascular image depends on the characteristics and quality of the imaging system, but also on the quantity and concentration of contrast medium, the location of the injection, the injection speed and the timing of imaging with respect to contrast medium administration. For example, a rapid injection through a selectively placed catheter in the artery that is to be imaged, shows a high peak in the time-contrast density curve, whereas a tardy injection through a non-selectively placed catheter would show a broader and lower peak. A venous injection, or a slow non-selective arterial injection would show a very broad and low peak, resulting in a poor image of the arterial system or in no vascular image at all. The injection speed of contrast medium and the total dose administered depend on the position of the catheter tip (e.g. abdominal aorta, carotid artery, peripheral vein) and the imaging system applied (cut film, DSA). Contrast medium can be administered in the arteries and veins through a catheter or through a needle, referred to as a catheterisation and a needle puncture respectively. In the following paragraphs contrast injection is described briefly.

\section{Common femoral artery needle puncture}

For a femoral needle puncture approach, the patient lies on the table in supine position. Normally, a retrograde puncture of the femoral artery is performed in the groin, directly under the ligament of poupart, using a stainless steel or teflon coated needle of approximately 8 to $10 \mathrm{~cm}$. This approach is used for peripheral arteriography of one leg.

Common femoral artery catheterisation

The common femoral artery is a large vessel close to the body surface and wasilly accessible for puncturing in the groin, as described above. It is most frequently used for arterial catheterisation, giving access to the aorta and all its branches in the neck, upper and lower limbs. After insertion of the catheter in the artery, the catheter is usually directed towards the head (retrograde catheterisation) or in special cases towards the foot (antegrade catheterisation).

\section{Brachial artery catheterisation}

In a brachial approach the patient lies supine on the table support with the arm abducted to $90^{\circ}$ at the shoulder. The brachial artery lies even closer to the skin surface than the femoral artery; its much smaller diameter is a disadvantage, however. To insert a cathe- 
ter, the brachial artery is punctured above the elbow region. Catheterisation of the brachial artery gives access to the aorta and its branches including the lower extremities The brachial artery can also be catheterised in an antegrade candal direction to image blood vessels in the lower arm or hand.

\section{Axillary artery catheterisation}

The axillary artery is punctured over the neck of the humerus to insert a catheter. The diameter of the axillary artery is larger than the diameter of the brachial artery but smaller than the femoral artery. With the patient in supine position, the arm abducted to $90^{\circ}$ at the shoulder and flexed at the elbow. and the hand behind the head the axillary artery is easy to catheterise. Essentially, the axillary approach gives access to the same vessels as the brachial approach.

Abdominal aorta needle puncture

For translumbar aortography (TLA) the abdominal aorta is punctured with the patient in prone position. TLA procedures have been performed quite frequently in the past, but nowadays the Seldinger technique and IV-DSA are preferred, and TLA is more or less obsolete.

Catheterisation of the median antecubital vein, jugular vein or subclavian vein

In IV-DSA examinations a catheter is introduced in the median antecubital vein (elbow region), or alternatively in a jugular vein (neck region) or subclavian vein.

\subsubsection{Indications and contra-indications to arteriography}

There is a wide range of indications for $\mathrm{X}$-ray arteriography including diagnosing and staging of occlusive arteriosclerotic arterial disease, bone and soft-tissue tumours. Although reported radiation doses to the patients are high, radiation exposure has not been described explicitly as a contra-indication to arteriography.

Contra-indications to arteriography are always relative. This means that, provided that the potential benefit is larger than the risk of the procedure, and if the same information cannot be obtained from a noninvasive procedure, that the angiographic examination will be performed. Depending on the patient's condition and known history on reactions to the contrast medium, the radiologist can choose from various approaches and imaging techni-
ques to minimise the risk.

\subsection{Interventional vascular radiology}

Interventional vascular radiology encompasses various techniques in which diagnostic vascular imaging procedures are used to support therapeutic measures. Some interventional vascular radiological procedures are an alternative to surgery, whereas other proceinterventional vascular as an enlargement of the set of medical possibilities. In general, conditions of the blood vessel systerm incorporate angiographic examinations to define the technique. Some interventional sechniques at the start and at the end of the interventional venous or arterial blood and/or measuring require additional actions, such as sampling of

Interventional vascular radiology comprises various procedure types, such as:

- Percutaneous transluminal angioplasty (PTA). The most frequently performed interventional vascular procedure is percutaneous transluminal angioplasty, also known as Dotter 
procedure. After the introduction and placement of a balloon ditation catheter, stenosis or occlusion can be treated in a number of arteries, such as illac arteries, femoral artery and renal artery.

- Stent placement. In an increasing number of cases, stents (flexible, expandable tubes) are used to keep the vessel open after a Doter procedure, or to strengthen the vessel wall at the location of an aneurysm.

- Embolisation. Embolisation involves the injection of an occlusive material via a catheter in an artery into block blood flow. For example, infertility due to incompetence of venous walves may be corrected for by interruption (embolisation) of the spermatic vein.

- Selective intra-arterial drug treatment. Selective intra-arterial drug treatment involves the application of a drug via a selectively placed catheter in various arteries such as the renal artery, mesenteric artery and brachial artery.

- (Re)placement of barriers. Placement and replacement of barriers involves the introduction of a "foreign" body in the blood vessel system.

Generally, interventional vascular radiology requires at least the same features of the $X$ ray system, patient support system, imaging system, catheterisation equipment and contrast media as angiography does. Without further elaborating on this point, it may be clear, however, that interventional vascular radiology is more complex than $X$-ray angiography and requires additional equipment and skill of the catheterisation team. In general, interventional vascular radiology is more time consuming and involves longer fluoroscopy time than angiography. However, in interventional vascular procedures the number of radiographs or DSA-images are generally smaller than in angiography.

This study comprises data on percutaneous transluminal angioplasty procedures. The frequencies of other types of interventional vascullar procedures were too low to be used to derive reliable data on exposure conditions.

\subsection{Vascular imaging techniques}

Vascular radiology is based on the enhancement of the radiographic image of a blood vessel by temporary, partially replacing the blood by a radiomopaque fluid. In conventional angiography, photographic images are made, using large cut lilms or high speed roll films. To enhance the photographic vascular image, photographic subtraction is used. One film is exposed immediately before injection of the contrast medium or after injection but before the contrast fluid arrives. Subsequently, a number of films is exposed during the passing of the contrast medium. Afterwards, a positive subtraction mask is made of the first film. In the subtraction process, radiographs, taken upon arrival of the contrast medium are matched with the positive mask film. The image of all tissues will "disappear", except the blood vessels containing contrast fluid. Consequently, the resulting subtracted radiograph shows only the opacified blood vessel(s). Advancements in computer technologies and diagnostic imaging systems offered the opportunity to perform this subtraction process by electronical means. More than a decade ago, real time digital subtraction systems (DSA systems) were introduced. These systems have made the original analog subtraction more or less obsolete.

A modern angiography room occupies an operating area of at least $50 \mathrm{~m}^{2}$, with additional rooms for storage of equipment (e.g. a DSA computer). Immediate access to a nearby fill $\mathrm{m}$ development room is required if conventional techniques are applied. If digital imaging systems are used, a hard copy producing system (e.g. a laser imager) is required. 
Control panels for remote control of the $X$-ray system, the imaging systems and the automatic high pressure contrast injector as well as a mamual control panel for digital imaging systems should be located in a shielded area, with a good view and easy access to the operating theatre.

Universal angiography systems facilitate a wide range of projection sites and projection angles. High flexibility in X-ray beam positioning are featured in so-called C-arm and Uarm systerns, having an X-ray ube mounted on one side of the arm and one or more invaging systems, including an image intensifier, opposite to the other arm. Various recording devices, such as a video pick-up system, a video camera, a photospot or cinefuorography may be attached to the image intensifier. A large number of angiography systems comprises serial cut film devices, which are interchangeably mounted with the image intensifier. By rotating and angulating the $\mathrm{C}$ - or $\mathrm{U}$-arm a wide range of projections are covered. Due to system limitations, some systems can only be applied in overcouch tube position or in undercouch tube position. In $\mathrm{C}$-arm and U-arm carrier systems the focus to film distance (source-image-distance, SID) is fixed at approximately $100 \mathrm{~cm}$, whereas the distance of the focus to the input screen of the image intensifier may be varied from approximately 90 io $120 \mathrm{~cm}$.

Some types of angiographic procedures can be performed with general fluoroscopy imaging systems, extended with hard copy imaging devices. Generally, these systems comprise a movable patient support, mounted on a robust stand, which incorporates a large field image intensifier and a facillity for plain film radiography. The X-ray nube is mounted on a fixed carrier, vertically moveable over the image entrance field area. Obviously, these systems provide less flexibility than C-arm or U-arm systems and are not applicable to all angiographic procedures.

Some angiography rooms, especially rooms which are in use for cardiowascular examinations, are equipped with biplane facilities. These systens provide two $X$-ray systems which can be used independently as well as simultanerously to accomplish imaging in two perpendicular directions at the same time, thus providing 3-dimensional information with a potential for reducing the amount of contrast fluid needed.

A 12-pulse or high frequency high voltage generator is applied for high quality imaging. Specially designed, high duty $\mathrm{X}$-ray tubes with dual focal spots are used. A 10 to 12-degree anode larget angle is required to cover a field of $35 \mathrm{~cm} \times 35 \mathrm{~cm}$ at $100 \mathrm{~cm}$ source-image distance.

Image intensifiers have large input fields (e.g. 14" or 16"). Magnification can be performed in two ways. Geometrical magnification is accomplished by varying the sourceto-object distance relative to the source-to-image distance. Electronical magnification is accomplished by selecting a small input screen area (e.g. 6") in a multi-modal image intensifier. Since the area of the output image screen of the image intensifier is constant, the output image of a small input screen image has to be more magnified than the output image of the large input screen image, thus providing more details. Modern imaging intensifier systems have up to three input screen sizes, e.g. 6", $10^{\prime \prime}$ and $14^{\prime \prime}$.

Nonvolatile images may be produced by using several types of imaging systems. Depending on the type of system applied, angiography can be classified into two groups: conventional angiography and digital angiography. Conventional angiography comprises radiographic techniques, such as (serial) cut film radiography, spot film radiography, roll film radiography (e.g. photospor), and cine radiography. Digital angiography comprises digital imaging techniques, such as digital subtraction angiography (DSA), and digital spot imaging (DSI). In Figure 4.1 a scheme is presented showing various imaging methods 
applied in angiography. Some outhines of serial cur film angiography and DSA are given in the following paragraphs.

\section{Serial cut film angiography}

In daily practice the term conventional angiography is used to refer to serial cul film imaging techniques, using a Schonander AOT or a PUCK cut film changer, with films of approximately $35 \mathrm{~cm} \times 35 \mathrm{~cm}$. The film changer system comprises a removable film storage cassette (maximum cassette capacity in a PUCK system is 20 films), a high speed film transport device, a removable output cassette and a rare earth screen. Upon arrival of the contrast medium in the blood vessel that is to be examined, a series of films is exposed. The number of films taken varies between 1 and approximately 10 per series; the filming speed is usually set between 0.3 and 3 films per second. Some angiographic systems are equipped with a programmable stepping facility. Following the contrast medium in the vascular system, these systems provide a means to produce a sequence of series of images after one single bolus contrast medium injection. In the course of the diagnostic examination, the films are used for catheterisation purposes. Afterwards, a selected subset is used for medical recording purposes. In some examinations, film subtraction techniques may still be applied.

\section{Digital Subtraction angiography (DSA)}

In digital subtraction angiography, a high resolution video camera records the output-screen of the image intensifier. The video image is digitised and directed to a dedicated computer system. Digitised images are stored in data matrices (256)256 to $1024 \times 1024$ pixels). Analog to digital conversion results in 8 to 16 bits data samples. The image rate may vary between 0.3 and 5 images per second. To enhance the visibility of the vessels several techniques are available. A frequently used technique is mask subtraction. Before the arrival of the contrast medium in the blood vessel to be examined, one image or a few images are made, to provide a so-called "mask" image. These "test images" are made for automatic or manual settings of the tube high voltage and tube load. Upon arrival of the contrast medium a sequence of approximately 5 to 30 images is made. Afterwards or in real time, depending on system features, the mask image is digitally subtracted from the image sequence, resulting in images of the blood vessel with time dependent contrast. Bone structures and other tissues which obscure the blood vessel system are more or less removed in the subtraction process.

For medical recording a subset of the subtracted images is selected and printed via e.g. a llaser imager. In general the anatomical information of the images is used. Time dependent contrast flow, giving insight in the functional characteristics, is of secondary importance. DSA of the extremities sometimes may require an additional absorber (brass, copper or aluminium) in the primary beam to enhance the image quality. To compensate for wide variations in patient stature, sometimes a so-called compensation or equalisation filter is placed extemal to the collimator assembly. Also, aluminium wedge bars or other absorbing materials may be placed next to the patient's body to reduce local differences in the $X$-ray beam at the image intensifier, thus avoiding or limiting overexposure of the image at body boundaries.

The term "Digital Subtraction Angiography" (DSA) is interchangeable with the term "Digital Vascular Imaging" (DVI). 


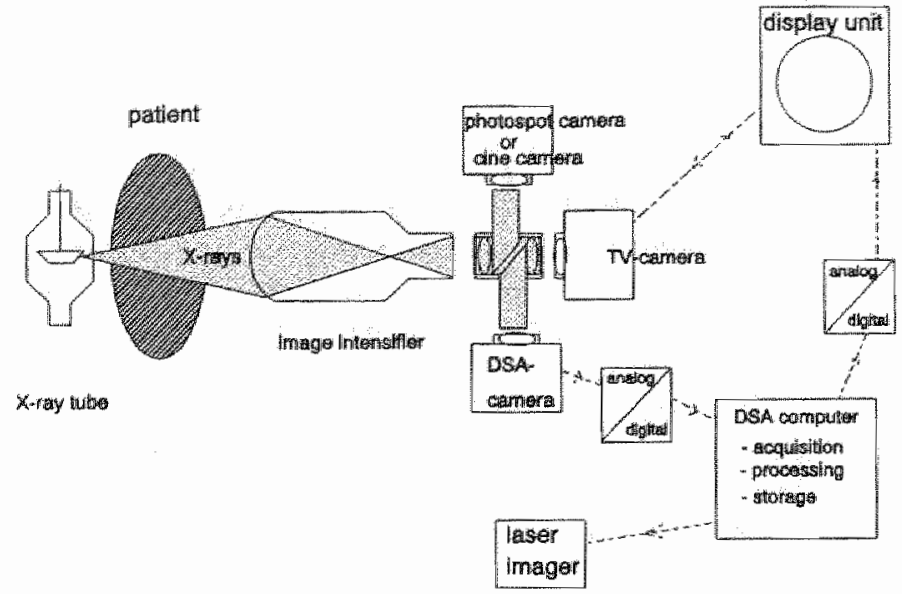

Figure 4.1 Diagram of image intensifier applications.

\subsection{Diagnostic imaging systems in the University Hospital Maastricht, the De Wever Hospital Heerlen, and the Maasland Hospital Sittard}

\subsubsection{Diagnostic imaging systems in the University Hospital Maastricht}

The angiographic suite in the University Hospital Maastricht (azM) comprised two separate diagnostic $X$-ray systems: (i) a universal angiographic system, and (ii) a ceiling mounted $\mathrm{X}$-ray tube. The ceiling mounted $\mathrm{X}$-ray system was used very infrequently for selective cut film angiography of hands and feet only. Therefore, this system has been excluded from the scope of this study. A diagram of the universal angiographic system, a Diagnost Arc (Philips. Medical Systems, Best, The Netheralnds) is given in Figure 4.2. The Philips Diagnost Are comprised an $X$-ray beam carrier (floor to celling column supporting a $C$-shaped arm), an $X$-ray tube unit, an image intensifier sub-system with $T V$ chain, a filn changer and an add-on DSA-unit. The film changer unit and image intensifier were both coupled to the C-arm on a revolving head, opposite the $\mathrm{X}$-ray lube [PH85, PH85a]. For posterior-anterior projections in conventional angiography, an automatic stepping facility could be used in combination with the film changer. Up to four steps could be made with the beam carrier in every run (i.e. five positions), the step length was fixed at $22 \mathrm{~cm}$. In a test run, test exposures could be made and high voltage, tube load and diaphragm could be set for each individual position. Settings were automat"cally stored for the subsequent exposure run. Components of the system are listed in Table 4.2. Data on the dose rate at the entrance screen of the image intensifier are summarised in Table 4.3 . 


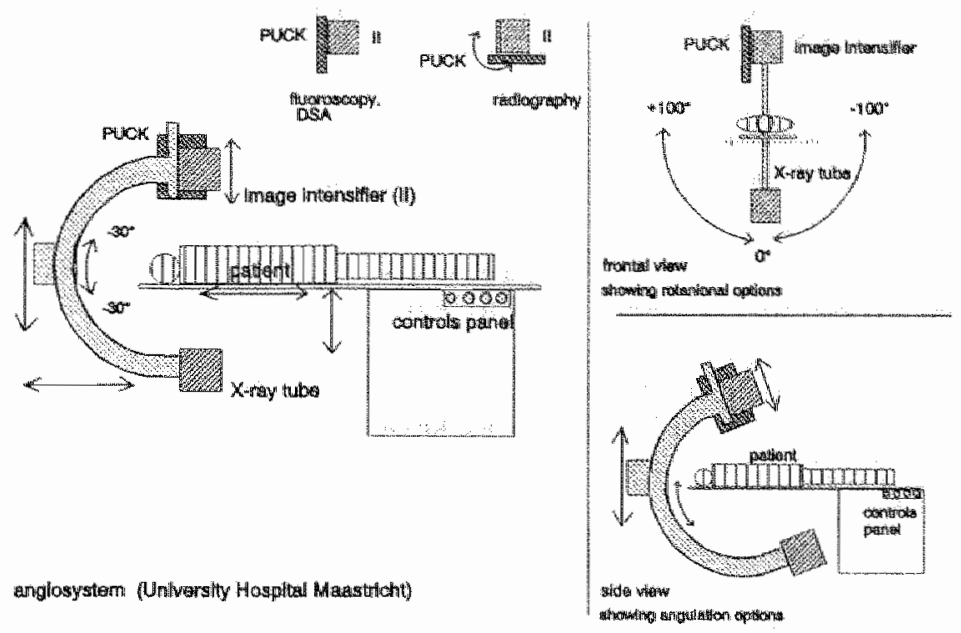

Figure 4.2. Universal Angiographic System in the University Hospital Maastricht.

Table 4.2 Universal Angiographic System in the University Hospital Maastricht.

\begin{tabular}{|c|c|}
\hline System components & Type and features \\
\hline Stand & $\begin{array}{l}\text { Philips, Diagnost Arc (1987); Max. long. and lat. movement of C-arm, } 178 \mathrm{~cm} \\
\text { and } 69 \mathrm{~cm} \text {, resp.; Max. rotation: }-100^{\circ} / 100^{\circ} \text {; max. angulation: }-40^{\circ} / 440^{\circ} \text {. }\end{array}$ \\
\hline Generator & Philips, Maximus CM 100 (1987). 12 pulse generator; $\max .1000 \mathrm{mAs}$. \\
\hline $\mathrm{X}$-ray tube & $\begin{array}{l}\text { Philips, SRM } 15 / 50(1989,1992) ; \text { total beam filltration: } 4.5 \mathrm{~mm} \text { Al-eq; First- } \\
\text { half-value layer: } 3.2 \mathrm{~mm} \text { Al at } 70 \mathrm{kV} ; 3.6 \mathrm{~mm} \text { Al at } 80 \mathrm{kV} \text {.: Maximal beam } \\
\text { diameter at } 100 \mathrm{~cm} \text { from the focus: } 35 \mathrm{~cm} \text {. }\end{array}$ \\
\hline Patient support & Philips, Angiodiagnosi (1987). \\
\hline Patient table & $\begin{array}{l}\text { Philips. Angio } 3 \text { (1987); free overhang: } 205 \mathrm{~cm} \text {, Vert., long, and lat. mowement } \\
\text { ranges are } 29,35 \text { and } 12 \mathrm{~cm} \text {, resp; X-ray attenuation equals } 0.91 .0 \mathrm{~mm} \\
\text { aluminium equivalen. }\end{array}$ \\
\hline Image intensifier & $\begin{array}{l}\text { Philips trimode } 6 ", 10 " \text { en } 14 "(1992) \text {; Camera tube: Plumbicon (1987); Orid: } \\
\text { carbon fiber, } 441 / \mathrm{cm} \text {, ratio } 10,1_{83}=100 \mathrm{~cm} ; \text { SID: } 85 \text { to } 110 \mathrm{~cm} \text {; Min. paticnt- } \\
\text { image receptor-distance: } 10 \mathrm{~cm} \text {. }\end{array}$ \\
\hline TV-chain & Philips, XTV-6 (1987). \\
\hline DSA & $\begin{array}{l}\text { Technicare, DR } 960-\mathrm{B} \text { (General Electric) (1986): } 515 \times 512 \text { matrices; Max frame } \\
\text { rate: } 3.3 \mathrm{~s}^{-3} \text {. Manual setting of frame rate, HV and mAs; Hard copies of DSA- } \\
\text { frames on } 35 \times 43 \text { film (6-frame division mode, or single frame mode) (Laser } \\
\text { Imager, } 3 \mathrm{M} \text { ). }\end{array}$ \\
\hline Radiography system & $\begin{array}{l}\text { PUCK UD4 } 35 / 35 \text { serial cut film changer ( } 1987 \text {; Max. film capacity: } 20 \text { per } \\
\text { cassette. Max. speed } 3 \text { films } \cdot \mathrm{s}^{-1} \text {, Intensify screen: Titan U lgadolinium/ } \\
\text { lanthanum] ; lanex regular } 400 \text {; Grid: carbon fiber, } 601 / \mathrm{cm} \text {, ratio } 10, \mathrm{f}_{40}=100 \\
\mathrm{~cm} \text {; SID: } 100 \mathrm{~cm} \text {; Min. patient-film-distance: } 5 \mathrm{~cm} \text {. }\end{array}$ \\
\hline
\end{tabular}


Trable 4,3 Dose rate during fluorascopy of the Universall Angiographic System in the University Hespital Maastricht ${ }^{*}$

$\begin{array}{ll}\text { - no grid: } & \\ 14 " \text { mode: } & 0.21 \mu \mathrm{Gy} / \mathrm{s} \\ \text { 9" mode: } & 0.27 \mu \mathrm{Gy} / \mathrm{s} \\ \text { 6" mode: } & 0.44 \mu \mathrm{Gy} / \mathrm{s} \\ \text { - with grid: } & \\ 14^{\prime \prime} \text { mode: } & 0.60 \mu \mathrm{Gy} / \mathrm{s} \\ 9 " \text { mode: } & 0.81 \mu \mathrm{Gy} / \mathrm{s} \\ 6 \text { 6" mode: } & 1.14 \mu \mathrm{Gy} / \mathrm{s}\end{array}$

${ }^{3}$ Dose rate in air at inage intensifier entrance field, measured with a $1.5 \mathrm{~mm} \mathrm{Cu}$ absorber in the primary beam, with automatic settings of tube high woltage and tube current.

\subsubsection{Diagnostic imaging systems in the De Wever Hospital, Heerlen}

The angiographic suite in the De Wever Hospital in Heerlen comprised two separate diagnostic X-ray systems, a universal angiographic system (Philips Polydiagnost UPI), and a ceiling mounted $X$-ray tube. The ceiling mounted X-ray tube was applied very infrequently and has been excluded from the scope of this study. For conventional angiography the image intensifier was set to its maximum distance to the focus and the film changer unit was moved over a guidance system in the U-arm up to a position opposite to the X-ray tube, covering the image intensifier. A diagram of the universal angiographic system is given in Figure 4.3. Components of the system are listed in Table 4.4. Experimentally derived data and data from the manufacturer on the dose rate at the entrance screen of the image intensifier are summarised in Table 4.5.

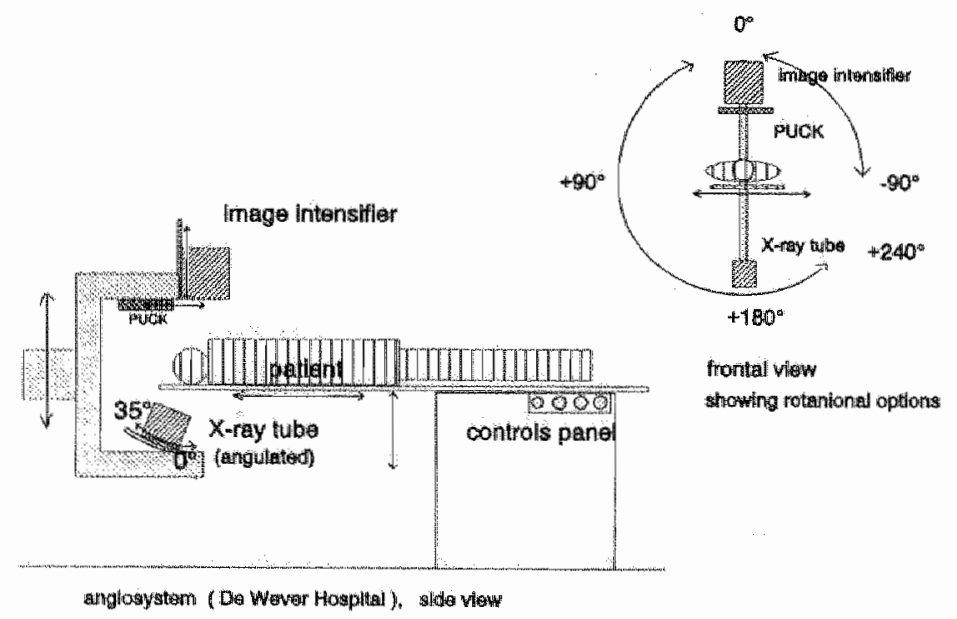

Figure 4.3 Universal Angiographic System in the De Wever Hospital (Heerlen). 
Table 4.4 Universal Angiographic System win the De Wever Hospital (Hearlen)

\begin{tabular}{|c|c|}
\hline System components & Type and featrares \\
\hline Stand (fixed) & 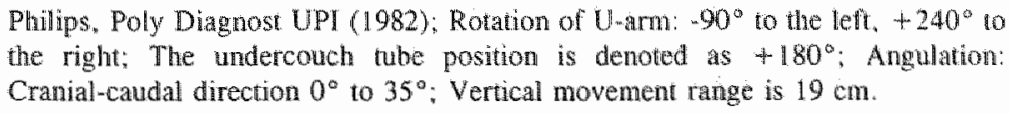 \\
\hline Generator & Philips, Super Maximus 100 (1982), constant voltage \\
\hline$x$-ray tube & $\begin{array}{l}\text { Philips, SRM } 1550(1992) \text {; Total beam filtration: } 2.8 \mathrm{~mm} \text { Al-equiv, Firs hall } \\
\text { value layer: } 2.9 \mathrm{~mm} \mathrm{Al} \text { at } 80 \mathrm{kV} \text {. }\end{array}$ \\
\hline Patient support & Philips, Amgiodiagnost 2U (1982). \\
\hline Pattent table & $\begin{array}{l}\text { Philips, Angio } 2 / 2 \mathrm{u}(1982) \text {; Vert., long. and lat. movement range is } 32,108 \text { and } \\
42 \mathrm{~cm} \text {, resp. }\end{array}$ \\
\hline Image intensifier & 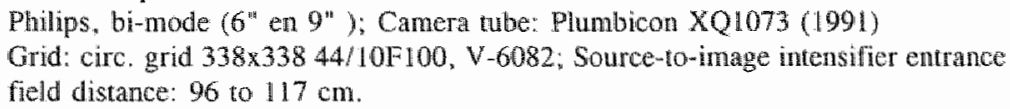 \\
\hline TV-chain & Philips, XTV-4 (1982, updated 1987). \\
\hline DSA & Philips, DVIL vascular $(1987)$. \\
\hline Radiography system & $\begin{array}{l}\text { PUCK, serial film changer (1980); Intensify screen: Curix MR-400; Grid: } \\
338 \times 33844 / 10 \mathrm{~F} 100 \text {, P-2455; Maximum capacity of film changer is } 20 \text { films } \\
\left(35 \times 35 \mathrm{~cm}^{2}\right) \text {; Focus-fim distance is } 95 \mathrm{~cm} \text {. }\end{array}$ \\
\hline
\end{tabular}

The system enabled automatic setting of tube high voltage and tube load to obtain an adequate intensity of the DSA images produced. At the start of a DSA run, a series of one to five test frames was taken. The image intensity was determined in a central, circular field of variable diameter, manually adjusted by the technical staff. Frame rate, tube high voltage and tube load could be set automatically using preprogrammed information by selecting from a number of options for various types of angiography. In cranial-caudal projections, carried out by moving the $\mathrm{X}$-ray housing over a concave guidance system, the image receptor plane (image intensifier or film) stayed parallel to the U-arm, resulting in a geometric distortion of the image obtained. Contrary to the angiographic system in the azM hospital, this system did not facilitate automatic stepping.

Table 4.5 Dose rate of the Universal Angiographic System in the De Wever Hospitall (Heerlen)

\begin{tabular}{|c|c|c|}
\hline linaging mode & \multicolumn{2}{|c|}{$X$-ray output (dose rate at image intensitier entratho fie ld) } \\
\hline \multicolumn{3}{|l|}{ fluoroscopy $(\mathrm{DI}-1)^{\mathrm{a}}$} \\
\hline 9 modle: & $0.37 \mu \mathrm{Gy} / \mathrm{s}(42 \mu \mathrm{R} / \mathrm{s})^{\mathrm{b}}$ & $0.9 \mu \mathrm{G} y / \mathrm{s}$ \\
\hline 6" nodle: & $0.48 \mu \mathrm{Gy} / \mathrm{s}(55 \mu \mathrm{R} / \mathrm{s})^{\mathrm{h}}$ & $1.1 \mu \mathrm{G} y / \mathrm{s}^{\mathrm{c}}$ \\
\hline \multicolumn{3}{|l|}{ DSA (DI): } \\
\hline 9" node: & $9 \mu \mathrm{G} y /$ frame & \\
\hline
\end{tabular}

auto settings for high voltage (HV) and tube current (I): HV $\cdot 1^{0.42}=70$, derived from HV-l curve XG-7302; " data from manufacturer: "experimentally derived data.

\subsubsection{Diagnostic imaging systems in the Maasland Hospital, Sittard}

The angiographic suite in the Maasland Hospital in Sittard, comprised a universal angiographic system (Philips Poly Diagnost UPI). All angiographic procedures, except anglography of the lower extremities, were carried out with the universal system. An- 
giography of the lower extremities was generally performed in a general fluoroscopy room with DSA facilies (not described in this thesis). The universal systems in the Maasland Hospital and in the De Wever Hospital was basically the same (see section 4.4.2).

Due to technical limitations of the film changer, conventional angiography was restricted to overcouch tube positions. Limitations of the $X$-ray beam carrier restricted caudal-cranial DSA-angiography of the supine patient with undercouch tube position to $10^{\circ}$ at maximum. System components are listed in Table 4.6 .

Table 4.6 Universal Angiographic System in the Maasland Hospital (Sittard)

\begin{tabular}{|c|c|}
\hline System components & Type and foatures \\
\hline Stand. & Philips, Poly Diagnost UPI (1983). \\
\hline Generator & Philips, Optimus M200 (1983), constant volsage. \\
\hline$X$-ray rube & $\begin{array}{l}\text { Philips, SRM } 35100(1988) \text {; total beam filtration: } 2,8 \mathrm{~mm} \text { Al eq.: First hallevalue } \\
\text { layer: } 2.9 \mathrm{~mm} \mathrm{Al} \text { at } 80 \mathrm{kV} \text {. }\end{array}$ \\
\hline Patient supportt & Philips, Angiodiagnost $20(1983)$. \\
\hline Flofting table top & Philips, Angio $2 / 2 \mathrm{u}(1983) ; 2 \mathrm{~mm}$ Al-equivalent. \\
\hline Image mensifier & $\begin{array}{l}\text { Philips, bi-modal }\left(6,5^{\text {an }} \text { and } 9^{\prime \prime}\right)(1990) \text {; camera tube: Plumbicon XQ1072 (1984); } \\
\text { grid: circular grid } 338 \times 338 \text { N4, R 12, Folo0 (1990) }\end{array}$ \\
\hline TV chain & Philips, XTV-4 (1983). \\
\hline $\operatorname{DSA}$ & Philips, DVI-2, vascular $(1984)$. \\
\hline Radiography & $\begin{array}{l}\text { PUCK-U } 35 \times 35 \text {, flm changer ( } 1983) \text {; intenstier screen: KODAK, Lane Regular; } \\
\text { grid: } 338 \times 33844 / 10 \mathrm{~F}(1983) \text {. }\end{array}$ \\
\hline
\end{tabular}

Data on the dose rate at the entrance screen of the image intensifier are summarised in Table 4.7.

It should be noted that in the De Wever Hospital the X-ray tube was used in an undercouch position (except for cerebral angiography), whereas in the Maasland Hospital the $X$-ray rube was initially used in the overcouch position.

Table 4.7 Dose rate of the Uniwersal Angiographic System in the Maasland Hospital (Sittard)

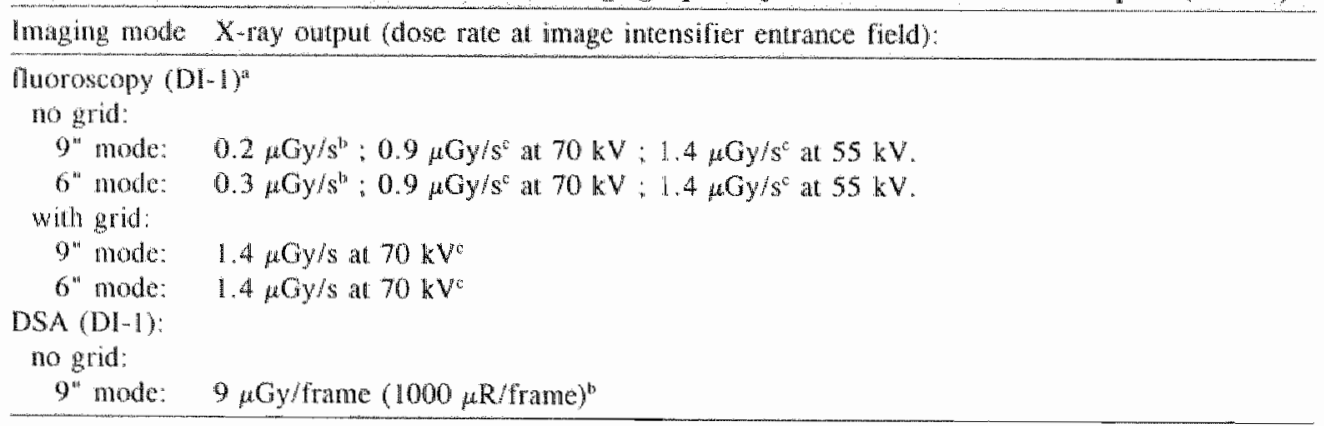

"auto settings high voltage and wube current: D type; ${ }^{\mathrm{b}}$ data from manufacturer; ${ }^{\text {e experimentally derived }}$ data. 


\subsection{Exposure conditions to patients in the University Hospital Maastricht, the De Wever Hospital Heerlen, and the Maasland Hospital Sittard}

In this section a general description is given of relevant conditions during fluoroscopy and imaging in the catheterisation and imaging stages as described in section 4.1.2.

\section{Fluoroscopy}

Fluoroscopic imaging was performed in short or protracted periods during the catheterisation stage(s) and in the imaging stages. In the first catheterisation stage fluoroscopy was used for the positioning of the guide-wire, and for the positioning of the catheter. In the subsequent catheterisation stage(s) fluoroscopy was used for repositioning the catheter, and/or introduction of a new guide-wire, and/or replacement of the catheter or placement of a new catheter.

The duration of the fluoroscopic actions, the location and direction of the X-ray beam, the beam diaphragm settings and the choice of the image intensitier input screen depended on various factors such as the vascular anatomy, the condition of the vascular system, the desired location of the catheter tip, characteristics of the guide-wire and the catheter and the experience of the operator. Generally, tube high voltage and tube current were automatically controlled. Manual settings were required in a very few cases only. It is obvious that the tube high voltage and tube current depended on the mass and tissue composition of the imaged body region. The position of the $X$-ray beam could be varied between the iliac region and foot in lower limbs arteriography, and between the iliac region and the neck region in cerebral angiography. In thoracic and abdominal arteriography the X-ray beam was directed to the trunk region. In the catheterisation stage(s), the X-ray beam direction was usually posterior-anterior for undercouch systems and anterior-posterior for overcouch systems. In the imaging stage (DSA, cut film), previewing of the body region was quite regularly required, using the fluoroscopy facilities. The $\mathrm{X}$-ray beam direction and location during fluoroscopic previewing are identically to the imaging characteristics. Consequently, oblique and angulated fluoroscopic views could occur.

\section{Imaging of the vascular system}

Vascular imaging was performed with a serial cut film system, a DSA system or with both systems. High voltage and tube load settings were dependent on the mass and tissue composition of the imaged body region. The beam diaphragm settings were usually adapted to the region of interest, thus decreasing the contribution of scatter radiation in the image obtained. The focus-to-patient distance was normally set to its maximum. In most cases a large field image intensifier input screen (e.g. 14" in azM) was used in DSA. The X-ray beam direction depended on the system features (overcouch or undercouch system) and the vascular anatomy. Usually, anterior-posterior or posterior-anterior images were taken. Oblique images were taken if the image was obscured by other vessels or body structures, or to take a view in a prescribed direction of a turned vessel. In all three hospitals the $X$-ray systems did not feature a programmable stepping facility for DSA. As mentioned before, however, the X-ray system in the azM hospital facilitated a stepping system for serial cut film angiography. Additional absorbers or wedge bars were used rarely. 
Orientation of the patient"s body

The relative position of the patient"s bocly to the X-ray beam depended on the procedure to be performed. In azM, patients were nearly always in a supine position, with their head at the cranial side of the table support (the patient's head points to the X-ray bearn carrier, his feet to the table stand). In the De Wever Hospital and the Maasland Hospital the patient's head was directed to the beam carrier in vascular radiology of the trunk and/or neck region, whereas in lower limb arteriography and dotter procedures of the femoral vessels the feet were directed towards the carrier. Procedures with prone positioned patients were very rare.

\subsection{Occupational exposure conditions in the University Hospital Maastricht, the De Wever Hospital Heerlen, and the Maasland Hospital Sittard}

\subsubsection{Occupationally exposed persons}

Occupationally exposed persons were classified into four groups:

- group 1 (operator): A radiologists or radiologist-trainee (registrar) who conducted the medical procedure (catheterisation and imaging). Sometimes a non-radiologist was involved as a co-operator. Sterile working conditions had to be met.

- group 2 (first assistant): A radiologist, radiologist-trainee or a radiographer, supporting the operator (sterile working conditions). In complex procedures radiologists of group 1 . and group 2 sometimes interchanged. Also, if a radiologist-trainee performed the catheterisation and a racliologist supported as first assistant, they sometimes interchanged their activities and positions.

- group 3 (circulating assistants): One or more radiographers or other medical personnel providing additional support or handling medical equipment in the vicinity of the operating area (sterile conditions were not required). In most cases, support by circulating assistants was not required, except in PTA procedures.

- group 4 (technical assistants): One or more radiographers, operating remote controls and performing administrative tasks in the control room.

Table 4.8 Angiography teams in the three hospitals

\begin{tabular}{|c|c|c|c|}
\hline Group & $\begin{array}{l}\text { University Hosp. } \\
\text { Maastrich }\end{array}$ & $\begin{array}{l}\text { De Wever Hospital } \\
\text { Heerlen }\end{array}$ & $\begin{array}{l}\text { Maasland Hospital } \\
\text { Sittard }\end{array}$ \\
\hline Operator & $\begin{array}{l}\text { - radiologist, or } \\
\text { - registrar }\end{array}$ & $\begin{array}{l}\text { - radiologist, or } \\
\text { - registrar }\end{array}$ & - radiologist \\
\hline First assistant & $\begin{array}{l}\text { - rodiologist, } \\
\text { - registrar, or } \\
\text { - radiographer }\end{array}$ & $\begin{array}{l}\text { - radiologist, } \\
\text { - registrar, or } \\
\text { - radiographer }\end{array}$ & - radiographer \\
\hline $\begin{array}{l}\text { Circulating } \\
\text { assistant }\end{array}$ & $\begin{array}{l}\text { - radiograptier or } \\
\text { - member of an other } \\
\text { medical department }\end{array}$ & "radiographer & - radiographer \\
\hline
\end{tabular}

In simple procedures, one person could perform tasks of both group 3 and 4 . Due to the relatively great distance to the patient and limited exposure times, it was anticipated that 
the occupational exposure to persons of group 3 was low. The radiation dose to persons in group 4 was expected to be very low as well. since they remained behind the protective barrier between the operating area and the control room. Therefore, persons in groups 3 and 4 have not been included in this study. Table 4.8 summarises the professionils involved in the three hospitals separately.

If a radiologist-trainee and a radiologist were involved as the operator and the first assistant respectively, they sometimes switched their activities and positions. This mostly occurred if the catheterisation was complicated and required additional skill and experience, not yet provided by the radiologist-trainee. This could occur more than once in a procedure.

\subsubsection{Occupational exposure conditions}

The following paragraphs describe the exposure conditions during catheterisation and vascular imaging to the operator and to the first assistant. This description matches the information given in section 4.1.2. Specific system features and exposure conditions which are not common in all three hospital are denoted as (azM) for the University Hospital Maastricht, (DW) for the De Wever Hospital in Heerlen and (MA) for the Maasland Hospital in Sittard.

\section{Exposure conditions during catheterisation}

The positioning of the guide-wire and catheter usually involwed fluoroscopic imaging. Movements of the X-ray beam carrier, rotation and angulation of the $X$-ray tube housing. and movement of the patient table were carried out by means of a control panel fixed at the patient table, or manually. Fluoroscopic images were shown on a movable ceilingmounted video display unit. The display unit was positioned opposite to the operator (DW), diagonally opposite to the operator, near the distal end of the patient table (azM) or over the distal end of the patient table (MA).

\section{Operator}

To manipulate the guide-wire or the catheter the operator stood next to the patient table, close to the puncture site. Using the Seldinger approach, he usually stayed between the abdominal region and the thigh. Other positions occurred as well, however. For example in cerebral angiography in DW, the operator remained for some time near the head of the patient. To view the fluoroscopic images, the operator had to rotate his body slighty (azM, DW) or quite extremely (MA), turning the side of his body to the radiation source. The operator usually stayed on the left side of the supine patient (azM), or on the right side of the supine patient (DW, MA).

\section{First assistant}

- azM-hospital: The first assistant usually stayed opposite to the operator, on the other side of the patient table. The assistant had to rotate his body extremely to view the video monitor, thus exposing the side of his body to the radiation source. Sometimes, prolonged exposure of the back occurred. If lead aprons were worn, covering the front and sides of the body only, the radiation dose to the trunk could increase significantly.

- DW-hospital: Technical staff performing as first assistant remained at the same side of the patient as the operator did. The first assistant usually stayed at the distal end of the patient table. In this position he stood in the shadow field of the operator, and was there- 
fore exposed to a much lower radiation level. First assistance by a radiologist or registrar was provided from across the parient table.

- MA-hospital: Technical staff performing as first assistant stayed opposite to the operator, across the patient table. The first assistant was usually closer to the distal end of the patient table.

\section{Exposure conditions during imaging of the vascular system}

The operator and assistant stayed next to the patient table to control movements of the $X$ ray system and for fluoroscopic previewing. Compared to the catheterisation stage, the fluoroscopic actions were quite brief, consequently the occupational exposure to scattered radiation was low. Usually the control panel was fixed at the right side of the supine patient, thus the operator or assistant could stay at the right side as well. During remotely controlled contrast medium injections for DSA or cut film arteriography, all personnel stayed behind protective barriers ( $2 \mathrm{~mm}$ lead equivalent) in the control room. Occasionally, operating personnel stayed behind a mobile lead lined barrier ( $2 \mathrm{~mm}$ lead equivalent) in the operating room (azM). Close surveillance, for example for mentally handicapped or seriously ill patients, was required relatively infrequently. Significant occupational exposure in the imaging stage could occur if contrast medium was injected manually. In that case the operator stood next to the patient, approximately at the same location as during fluoroscopy. In azM and DW manual contrast medium injection was performed relatively infrequently, whereas in MA manual administration was the standard technique applied by one radiologist. In MA one operator stayed quite regularly at about 2 to $3 \mathrm{~m}$ distance to the patient even during application of the remotely controlled injection system. Due to the exposure to scattered radiation during the programming of the automatic stepping facility in lower limbs angiography, the contribution of fluoroscopic actions in the imaging stage was expected to be larger in azM than in DW and MA.

\section{Protecrive measures for persons near the patient table}

Protective barriers, fixed to the patient table to attenuate the scattered $\mathrm{X}$-ray, and movable ceiling-mounted facial lead glass shielding to protect the lens of the eyes, were not applied. All personnel in the operating room wore protective llead aprons. General information about aprons can be found in appendix $C$. Characteristics of the aprons worn by staff in the three hospitals involved in this study (azM, DW, MA) are summarised below:

- azM-hospital: Two types were used. Semi-closed aprons (Burlington Medical Supplies; $0.5 \mathrm{~mm} \mathrm{~Pb}$ eq.), and wrap-around aprons (Burlington Medical Supplies; $0.5 \mathrm{~mm}$ Pb-eq. at front side; $0.25 \mathrm{~mm}$ at back side, with $100 \%$ coverage).

- DW-hospital: Semi-closed aprons were used, protecting the front and both sides and partly covering the back, about $60 \%$ to $80 \%$, depending on body size (Burlington Medical Supplies; lead equivalent $0.5 \mathrm{~mm}$ at the front, and approximately $0.2 \mathrm{~mm}$ lead-equivalence at the back).

- MA-hospital: Two radiologist and one member of the technical staff wore semi closed aprons (Scantlex Medical AB, Taby, Sweden; $0.5 \mathrm{~mm}$ Pb-equivalent). One radiologist and all other technical staff wore wrap-around aprons (Delft Instruments/Scanflex; $0.25 \mathrm{~mm}$ $\mathrm{Pb}-\mathrm{eq}$.). Overlapping sections in the front area provided a vertical strip of approximately 5 to $15 \mathrm{~cm}$ wide with an effective thickness of $0.5 \mathrm{~mm} \mathrm{~Pb}-\mathrm{eq}$.

Although thyroid collars are generally recommended in heavy duty radiation conditions, thyroid collars were used rather infrequently. Some operators always used a thyroid collar 
(a2M), whereas other operators used them if complex and prolonged procedures were to be expected (azM, DW, MA) or did not use them at all (azM, DW, MA). The radiation attenuation of the thyroid collars was equal to $0.5 \mathrm{~mm}$ lead. Lead glasses were used very infrequently. Some persons favoured their "own" lead glasses. Consequently, a number of different "models" were in use. Generally, the radiation attenuation was equal to 0.5 or $0.75 \mathrm{~mm}$ lead equivalent. Due to limited flexibility, dexterity and sensitivity, lead rubber gloves were not in use in angiography and interwentional vascular radiology.

In summary, two or three imaging modes were applied: fluoroscopy, DSA, and/or serial cut film radiography. Exposure conditions could be associated both with undercouch and overcouch tube positions. In most cases, remote-controlled contrast medium injection systems were applied, with the operator and assistant standing behind a protective barrier. Generally, protective clothing was limited to lead aprons. 


\section{Chapter 5}

\section{Vascular radiology in the Netherlands in 1992: a quantitative approach ${ }^{1}$}

\subsection{Introduction}

Vascular radiological procedures are generally considered to cause relatively high radiation exposures to patients and personnel. However. quantitative data on the frequency of these procedures to calculate its contribution to the radiation exposure of the Dutch population are very limiked [KE90, BE90a, BE91a]. Therefore, we undertook a study to obtain more detailed data on the frequency of angiography and endovascular interventional procedures in the Netherlands in order to be able to extrapolate estimates for medical and occupational radiation exposure caused by wascular radiology, as derived in three hospitals [KI92a, KI93, K193a, KI93b], to the Dutch population.

\subsection{Methods: a questionnaire to 165 hospitals}

A questionnaire concerning quantitative information on angiography and interventional endovascular procedures in 1992 was directed to 165 hospitals in the Netherlands with a department of diagnostic radiology. The survey comprised three classes of questions. (1) General information: type of institution, number of beds, number of angiographic suites, number of radiologists performing angiographic procedures. (2) Information about X-ray equipment and examination technique: type and age of the imaging system, tube position, contrast medium injection method. (3) Number of vascular radiological procedures and related patients: procedure types were classified into four main groups (with subgroups): intra-arterial arteriography, intra-venous digital subtraction arteriography, phlebography and interventional endovascular procedures.

A three stage strategy was applied. First, mantgers of departments were informed that a survey was planned and were asked for their co-operation. Questionnaires were then sent to executive technicians, as mentioned in the letter. Finally, initial non-responders were contacted by telephone.

Nineteen hospitals which had responded were subsequently approached for more specific intormation concerning occupational radiation exposure conditions, such as the type and effective thickness of the protective lead aprons, the use of lead thyroid collars,

"This chapter is based on the publication: P.J. Kicken, G.J. Kemerink and J.M.A. van Engelshoven. Vascular radiology in the Netherlands in 1992: a quantitative approach. European Journal of Radiology. 1995; 19: 212-219 [K195]. Only minor editorial modifications were made. 
the position of the personal dosemeter and the position of personnel during non fluoroscopic imaging.

Statistical analysis has been performed with the SAS ${ }^{\circ}$ package [SA89]. The ShapiroWilk statistic was used to test the null hypothesis that data values were a random sample from a normal distribution. The nonparametric Kolmogorov-Smirnov two-sample test was used to compare non-normally distributed data sets.

\subsection{Results of the questionnaire}

\subsubsection{Response to the survey}

Of the $159(96 \%)$ hospitals which responded, 120 had an angiographic suite and 99 of them provided useful information about the hospital, $X$-ray equipment and current angiographic technique. Sixty-three hospitals provided data on the number of patients in relation to the type of examination. while 34 hospitals responded by listing the frequency of the various examination codes according to the Dutch health care reimbursement system [PO93]. Three hospitals of the group of 99 provided information which was partly related to patients and partly to examination codes.

The two resulting data sets, one based on patients and one on examination codes, pertaining to $52 \%$ and $28 \%$ respectively of all Dutch hospitals with angiographic facilities, have been analyzed separately. The results are presented in Table 5.1.

\subsubsection{Number of angiography rooms and radiologists}

In the estimation of the total numbers of angiographic suites and vascular radiologists in the Netherlands, the data obtained have been corrected for missing values using the method of Beentjes and Timmermans [BE91a]. In this method, the characteristics of the 21 non-responding general hospitals were assumed to be equal to those of the responding 99 hospitals, with the number of beds being a predictive parameter for the number of angiography rooms and vascular radiologists. Information on the number of beds has been obtained by the survey and was completed with published data [GE94a]. A nonparametric paired comparison test indicated that the distribution of the number of beds in 91. general hospitals which provided data on angiography rooms and radiologists was very similar to the distribution of the number of beds in 21 hospitals which did not respond (P-value per procedure type varied between 0.43 and 0.77 ). The scaling factor correcting for missing data in general hospitals amounted to 1.23, if approximated with the bed-ratio. For university hospitals no extrapolation was required.

\subsubsection{Number of patients and examination codes}

Table 5.1 shows that 60 (out of 112) general hospitals and three (out of eight) university hospitals provided data on patients for vascular imaging and/or endovascular interventional procedures; 30 general and four university hospitals provided data on examination codes (a patient procedure may comprise one to approximately five examination codes, an examination code generally refers to a well defined set of radiodiagnostic actions). These data sets have been extrapolated to all hospitals with angiography rooms in the Netherlands (120), using the number of beds as a scaling factor. Comparison of data sets associated with extrapolation indicate that the distributions of beds in responding and non- 
responding general hospitals were very similar. The scaling factor for general hospitals varies between 1.82 and 1.86 for patient data and between 3.52 and 3.81 for examination code data, depending on the classification group. For university hospitals scaling factors of 2.97 and 2.0 are found for patient data and examination data respectively. An alternative approach for extrapolation, based on the number of hospitals, results in nearly the same numerical value of the scaling factors.

Extrapolated results of the survey are presented in Tables 5.2 and 5.3. Patients and examinations have been classified into four main groups. For each group an estimate is given for the number of patients and the number of examinations in university hospitals, generenl hospitals and in all hospitals.

Table 5.1 Statistics on the results of a survey into vascular radiology in the Netherlands in 1992

\begin{tabular}{|c|c|c|c|c|}
\hline & Hospitals & Beds" & Anglo suites ${ }^{2}$ & Radiologists \\
\hline \multicolumn{5}{|l|}{ Survoy-response: } \\
\hline \multicolumn{5}{|l|}{ Patients: } \\
\hline Uniwersity hospitals & 3 & 2470 & 5 & 12 \\
\hline General hospitals & 60 & 23798 & 62 & 171 \\
\hline Both & 63 & 29147 & 67 & 183 \\
\hline \multicolumn{5}{|l|}{ Examination codes: } \\
\hline University hospitals & 4 & 3670 & 9 & 21 \\
\hline General hospitals & 30 & 12152 & 35 & 114 \\
\hline Bothi & 34 & 15822 & 44 & 119 \\
\hline \multicolumn{5}{|l|}{ Total response: } \\
\hline University hospilals & 8 & 7340 & 16 & 40 \\
\hline General hospitals & 91 & 35950 & 98 & 286 \\
\hline Both & 99 & 43290 & 114 & 326 \\
\hline \multicolumn{5}{|c|}{$\begin{array}{l}\text { Exronpolated resuls for angüography rooms and } \\
\text { radiologists in all hospitals with angiography suites }\end{array}$} \\
\hline University hospitals & 8 & 7340 & 16 & 40 \\
\hline General hospitals & 112 & 44315 & 120 & 315 \\
\hline Both & 120 & 51655 & 136 & 365 \\
\hline
\end{tabular}

"Number of hospitals with angiography rooms; "Number of beds in hospitals wuth angiography rooms; Number of angiography rooms; "Number of tadiologists who performed on average at least one examination per week; "One university and one general hospital provided general data (no data on patients or oxaminations); "Extrapolated lesults for all hospitals with angiography suites derived from the surveyresponse, using the number of beds as a scalling factor.

\subsubsection{Radiographic equipment}

The results of the survey show that angiography is accomplished with various methods: digital substraction angiography systems (DSA), conventional radiography (cut film techniques with PUCK or AOT serial film changer) and spot film systems. Digital spot imaging systems (DSI) were also mentioned a few times. The majority of hospitals applied PUCK film systems for conventional angiography (48 out of 52), only four hospitals still used AOT systems. The availability of the various imaging systems is shown in Table 5.4 and the age of the equipment in Table 5.5.

The response to the question concerning overcouch or undercouch X-ray tube application (response $=97$ hospitals) showed that in $38 \%$ of the hospitals, X-ray tubes are 
usually applied in an overcouch position, in $56 \%$ in undercouch position. In $6 \%$ of the hospitals there is no preference.

\subsubsection{Occupational exposure conditions}

The results of the survey of occupational exposure conditions in 19 hospitals have been summarised in Table 5.6. The hospitals in this group perform approximately $25 \%$ of all angiographic and interventional examinations in the Netherlands.

Table 5.2 Estimated number of patients for vascular radiology in the Netherlands in 1992 (datto from 60 hospitals extrapolated to 120 hospitals)

\begin{tabular}{lccc}
\hline Procedure type. & $\begin{array}{c}\text { Number of patients } \\
\text { University } \\
\text { hospitals }\end{array}$ & $\begin{array}{c}\text { General } \\
\text { hospitals }\end{array}$ & All hospials \\
\hline
\end{tabular}

Intra-arterial arteriography

Specified

Upper limbs

163

Cerebral

Thoracic

Abdominal.

Nliac/lower limbs

Abdominal, iliac/legs ${ }^{3}$

Toral specified

Unspecified ${ }^{\mathrm{X}}$

Total

Intravenous DSA arteriography:

Specified

Cerebrai

Thoracic

Abdominal

Hiacllegs

Abdominal, iliac/legss

Total specified

Unspecified

Total

\section{3}

431

1117

1694

0

4888

621

5509

\section{5 \\ 134}

273

582

0

1634

0

1634

193

4384

4577

Total

Interventional radiology:

Percutaneous transluminal angioplasty:

Abdominal region
lliac/legs
Abdominal, iliac/legs
Total specified
Unspecified
Total

Abdominall region

lhachlegs

Abdominal, iliac/legs

Unspecified $^{x}$

Total

$\begin{array}{rr}238 & 19 \\ 520 & 244 \\ 0 & 91 \\ 758 & 3550 \\ 0 & 674 \\ 758 & 422\end{array}$

1360

6334

1772

3696

16054

1697

30913

1175

32088

${ }^{3}$ Data from hospitals which could not differentiate beyond the level of this group; "Patient" refers to a vascular radiodiagnostic procedure, completed in one session and comprising one or more examinations. 
Table 5.3 Estimated number of examinations in vascular radiology in the Netherlands in 1992 (duta from about 30 hospitals extrapolated to 120 hospitals)

Examination Number of examinations

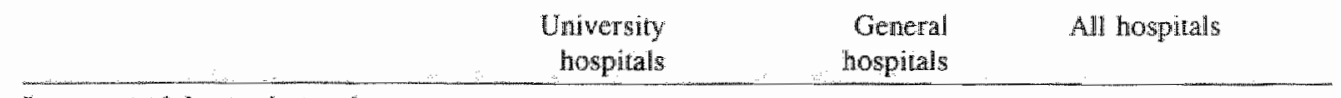

Intra-arterial arteriography

Specified

Upper limbs

506

1131

1637

Cerebrall

9198

6195

15393

Thoracic

1238

1920

3158

Abdominal

1210

11825

13035

Iliac/lower limbs

5190

14694

19884

Abdominal, iliac/legs ${ }^{\star}$

1374

3658

5032

18716

39423

58139

Unspecified

400

2640

3040

19116

42063

61179

Intravenous DSA arteriography

Specified

Cerebral

Thoracic

Abdominal

84

1594

1594

84
308

791

875

Iliacilegs:

510

1220

Abdominal, iliac/legs ${ }^{2}$

912

2589

Totall specified:

5127

5127

902

10503

11405

Unspecified

1451

Total

902

11954

1451

12856

Phlebography:

Total

1962

7805

9767

Interventional radiology:

Percutaneous transluminal angioplasty (specified)

Abdominall region $\quad 164$

Iliac/legs

1050
164777

724

Abdominal, uliac/legs

0

3827

Toual specified

1214

1010

1010

Unspecified ${ }^{2}$

0

4347

5561

Totall

1214

507

507

4854

6068

"Data from hospitals which could not differentiate beyond the level of this group; "Examination" refers 10 a defined set of radiodiagnostic actions (e.g. catheterisation, a PUCK series, a DSA-series), A patient procedure may comprise various examinations. 
Table 5.4 Avalability of various imaging systems in hospitals in the Netherlands (sample sixe = 98 hospitals) ${ }^{2}$

\section{Relative}

awailability

Hospitals with one type of imaging system:

DSA

CA

Spot film

Hospitals with two types of inaging systems:
$33 \%(36 \%)$

$17 \%(19 \%)$

$3 \%(5 \%)$

$17 \% \quad(15 \%)$

$13 \%(9 \%)$

$11 \%(12 \%)$

$7 \% \quad(5 \%)$

$68 \% \quad(64 \%)$

$53 \% \quad(52 \%)$

$34 \% \quad(30 \%)$

$23 \%(15 \%)$

$20 \% \quad(14 \%)$

$18 \% \quad(16 \%)$

DSA + conventional

"DSA, digital subtraction angiography; CA, conventional angiography (seriall cut film, $34 \mathrm{~cm} \times 34 \mathrm{~cm}$ ); Hospitals with only one angiography room in brackets. Out of 98 hospitals responding, 69 hospitals have one angiography room (August 1993).

Table 5.5 Age of equipment in angiography rooms in the Netherlands (sample size $=97$ hospitals)

\begin{tabular}{lll}
\hline & Age (years) & \\
& X-ray systems & Imaging systens \\
\hline Mean & $7 \cdot 1$ & 5.7 \\
25th percentile & 3 & 2 \\
Median & 6 & 5 \\
75 th percentile & 11 & 9 \\
Maximum & 22 & 17 \\
\hline
\end{tabular}

August 1993. 
Table 5.6 Occupational exposure conditions in angiograplity rooms in the Netherlands (sample size $=19$ hospitals)

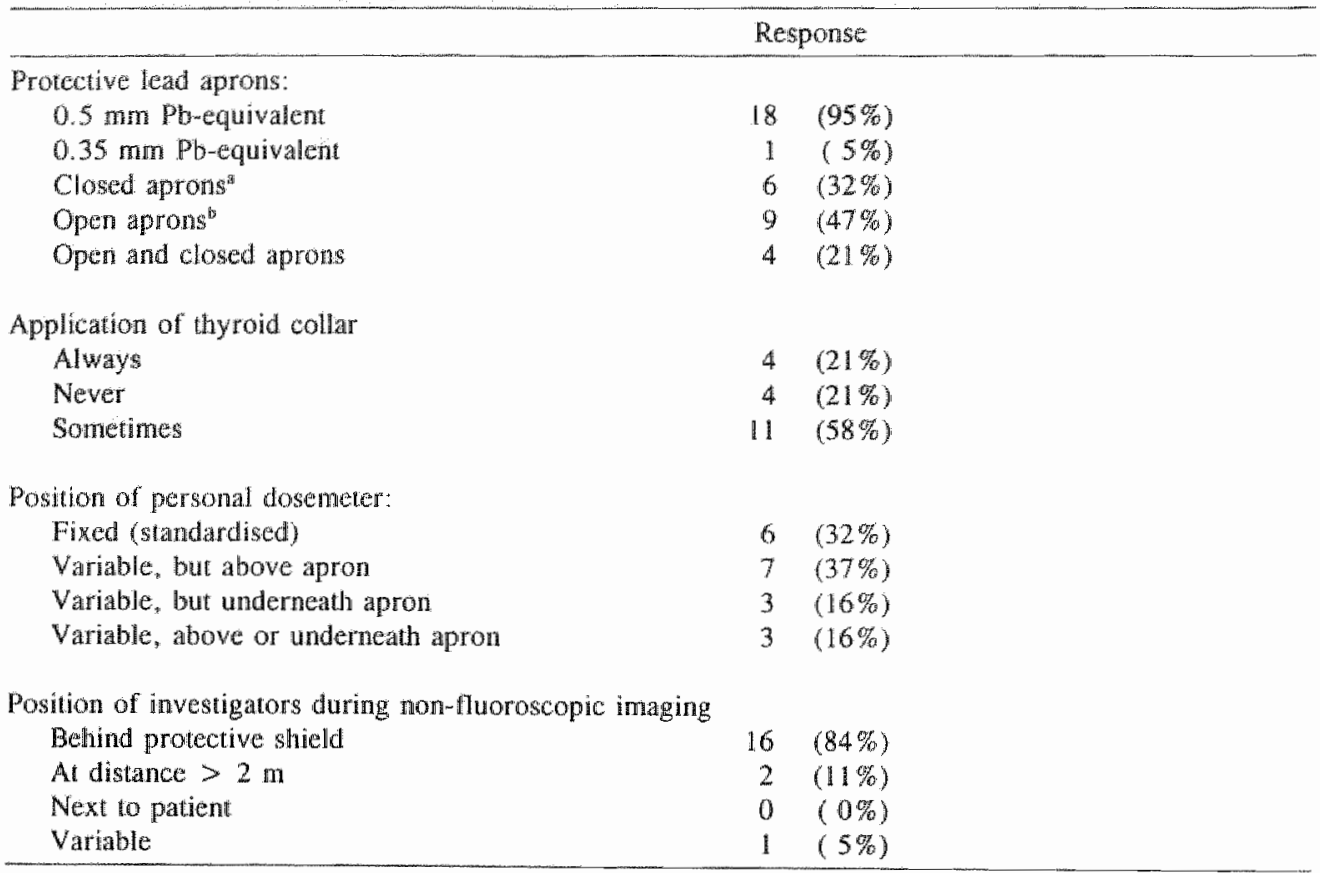

August 1993.

"Wrap-around aprons, protecting the front both sides and back of the body; "Aprons which protect the front and the sides of the body only.

Table 5.7 Average numbers of vascular examinations and interventional procedures performed per week in Dutclh hospitals with angiography rooms (1992)

\begin{tabular}{|c|c|c|c|c|}
\hline \multirow{2}{*}{$\begin{array}{l}\text { Frequency of } \\
\text { vascular } \\
\text { examination } \\
\text { (week') }\end{array}$} & \multicolumn{4}{|c|}{ Number of hospitals responding to the survey } \\
\hline & $\begin{array}{l}\text { Intra-art. } \\
\text { arteriography }\end{array}$ & $\begin{array}{l}\text { Intrayenous } \\
\text { DSA arteriography }\end{array}$ & Phlebography & $\begin{array}{l}\text { Interventionall } \\
\text { endovascular }\end{array}$ \\
\hline$<0.5$ & 1 & 17 & 25 & 30 \\
\hline$<1$ & 7 & 23 & 49 & 48 \\
\hline$<2$ & 19 & 33 & 57 & 68 \\
\hline$<5$ & 54 & 47 & 65 & 81 \\
\hline$\geq 5$ & 44 & 7 & 7 & $\mathbb{1}$ \\
\hline all $(>0)$ & 98 & 54 & 72 & 82 \\
\hline
\end{tabular}

Ninety-eight hospitals provided data on patients and/or examinations. The total number of hospitals with angiograplny suites is $₫ 20$. 
Table 5.8 Comparison of the results of a survey into vaseular radiology in the Netherlands (1992) with data of the RIS/NVwRD data filing system (1991)

\begin{tabular}{lllll}
\hline Examination & \multicolumn{2}{l}{ Radiodiagnostic examinations (estimate) } & Patient (estimate) \\
& Survey & RIS/NVvRD & Survey & RSSNvvRD \\
& $(1992)$ & $(1991)$ & $(1992)$ & $(1991)$ \\
\hline Total arteriography & 74035 & $63200-73200$ & 40975 & 44000 \\
- Intra-arterial & 61179 & & 32088 & 34000 \\
- Intravenous DSA & 12856 & & 8887 & 10000 \\
Phlebography & 9767 & $10000-11600$ & 4577 & 11000 \\
Perculaneous & 6068 & $5300-6200$ & 4982 & 5300 \\
transluminal & & & & \\
angioplasty (PTA) & & & & \\
\hline
\end{tabular}

${ }^{a}$ Data filing system on radiodiagnostic examinations (RIS), managed by the Dutch Society of Radiology (NVvRD) in which examinations are recorded according to the Dutch health care reimbursement system (COTG) (van der Poel, 1993). Estimated frequencies are derived by extrapolation the data sannple. For the left column a multiplication factor of 3,0 has been used; according to de Valois (1993) the figure of 5300 for PTA is quite realistic. The figures in the right column have been derived by multiplication with 3.57 (see text): ${ }^{\text {to }}$ Estimated values by de Valois, RIS/NVvRD data filing system (1993).

\subsection{Discussion}

The response rate to this survey was relatively high (Table 5.1), presumably because the list of items was kept very limited and self-explanatory and a three stage strategy was applied.

It should be noted that estimated frequencies of subgroups of angiography presented in Tables 5.2 and 5.3 may contain some inaccuracy since no guidance was provided to classify procedures comprising examinations of blood vessels in adjacent body regions. Because the survey addressed radiological procedures in the angiographic suite and a large number of phlebographic studies will be performed in non-angiographic suites the number of phlebography may be underestimated in the present survey.

In all, it was estimated that there are approximately 136 angiography rooms in the Netherlands, for a total population of 15 million people. Hospitals without angiography facilities appear to be relatively small. On average, these hospitals have 250 beds, whereas the responding hospitals with angiography facilities have 430 beds on average.

The total numbers of patients referred for angiography (arteriography plus phlebography) and interventional endovascular procedures are estimated to be 45500 and 5000 respectively (Table 5.2). Approximately 32100 patients were referred for intra-arterial arteriography, 8900 for intravenous DSA arteriography and 4600 for phlebography.

The total numbers of radiological examinations (arteriography plus phlebography) is estimated to be 83000 , the total number of interventional endovascular procedures as 6000 (Table 5.3). Approximately 61200 intra-arterial arteriography examinations, 12900 intrawenous DSA arteriography examinations and 9800 phlebography examinations have been carried out.

Tables 5.2 and 5.3 show that, on awerage, about two examinations are carried out per patient referred for an arteriographic procedure. The exact value depends on the type of vascular procedure. In interventional radiology the ratio of the number of examinations and the number of patients is 1.2 . 
The survey response shows that the annual number of angiographic or interventional endovascular procedures in some hospitals is quite small. With the simplification that the numbers of patients are equal to the numbers of examinations, hospitals were afterwards classified into groups with on average less than one half, one, two and five examinations per week. The results (Table 5.7) show that, in a number of hospitals, interventional radiology is performed rather infrequently.

A data sample of a filing system of radiodiagnostic examinations of the Dutch Society of Diagnostic Radiology (RIS-system) [VA92], made available by de Valois, has been used as a cross check on the results of the survey. The data sample on angiography of the RIS-system was part of a data group of 2.07 million radiological examinations (the total number of radiological examinations in the Netherlands in 1991, including ultrasound and MRI was estimated to be 8.24 million). The frequency of examinations using $X$-rays in 1991 was estimated to be 7.4 million by de Valois [VA92]. A similar figure (6.9 million $X$-ray examinations) was derived by extrapolating the results of Beentes and Timmermans [BE90a]. Using the estimated frequency of de Valois, a multiplication factor of 3.57 was derived, to extrapolate frequency data on angiography in his data sample to the whole population. A comparison (Table 5.8) shows that the frequencies of the number of vascular radiological procedures and of the patients undergoing these procedures are very similar. Only the estimated figures of patients with phlebography differ. Since the questionnaire did not differentiate between types of phlebography, the source of this dissimilarity is rather obscure, but it may be caused by the fact that the survey was particularly addressed to activities in the angiographic suite and most phlebograms are not made in an angiographic suite.

Using the estimated frequency of 7.4 million radiological examinations in 1991 [VA92] the relative contributions of diagnostic vascular radiology and endovascular procedures in medical diagnostic $X$-ray applications are calculated to be $1.1 \%$ and $0.08 \%$ respectively. Based on data obtained in an investigation of 50 randomly selected hospitals, van Kempen [KE90] estimated the frequency of these examinations, relative to all $X$-ray examinations in the years $1986-1988$, as $0.09 \%$ in general hospitals, $0.42 \%$ in university hospitals and $0.29 \%$ in regional hospitals, with a nation-wide average of $0.23 \%$. These figures are lower than the present results. Beentjes and Timmermans [BE90a] have reevaluated van Kempen's data, and obtained slightly different results.

In an overview of radiographic examinations in the Netherlands in 1984 by Beenijes and Timmermans [BE9]a], abdominal aortography and renal arteriography were estimated to be approximately $0.4 \%$. Extrapolation of data from the RIS-system (1991) results in $0.4 \%$, using the present results (1992) relative frequencies are estimated to be $0.2 \%$ $0.3 \%$.

Table 5.4 shows that $68 \%$ of all hospitals apply DSA systems, $53 \%$ apply conventional angiography and $34 \%$ apply spot film systems. As shown in Table 5.5 , the mean age of the X-ray equipment is about 7 years and the mean age of the imaging systems about 6 years. This age roughly corresponds with the date of the widespread introduction of DSA, while apparently most systems have not been replaced yet.

We were surprised to see that in a relatively large number of angiographic suites, $X$ ray tubes are applied in overcouch tube positions $(38 \%)$. This was not expected, because various investigators published dosimetric studies [FA82, UN88] showing that the overcouch tube position is associated with higher occupational radiation exposures than the undercouch position, leading to specific recommendations by ICRP and NCRP [IC90, NC90]. 
The survey shows that in $84 \%$ of the responding hospials, contrast media are injected preferentially with an electrically driven power injector. In $15 \%$ of the hospitals, contrast media are administered manually on a regular basis, in addition to the use of an automatic injection system. In one hospital manual injection is the preferred way. These data indicate that power injectors are now considered to be quite safe.

Table 5.6 shows that mearly all hospitals apply $0.5 \mathrm{~mm}$ Pb equivalent lead aprons. Aprons with no protection of the back are in use in approximately $50 \%$ of the hospitals. It is worth mentioning that, in order to prevent exposure to the unprotected back, special care should be taken in choosing an appropriate position for the fluoroscopy display unit [K193]. Standardisation of the application of lead thyroid collars has not been achieved yet. Only $30 \%$ of the hospitals use thyroid collars on a regular basis. Dosimetry studies [K193] show that thyroid collars can further reduce the effective dose of occupationally exposed persons, wearing a lead apron, by a factor of two. Therefore, it seems worthwhile introducing thyroid collars on a larger scale.

Standardisation in the position of wearing personal dosemeters has also not been achieved. We [KI93] as well as other authors [BU89, FA93, WE89] have addressed the issues of dosemeter location and conversion of dosemeter readings to effective dose estimates. It was concluded that the relation between effective dose and reading of the dosemeter heavily depends on the location of the dosemeter. Thus, as long as standardisation in wearing personal dosemeters has not been achieved and (national) dosimetry record keeping systems do not contain information on the dosemeter location, reliable effective dose estimates cannot be calculated from dosimetry data in these systems.

The survey clearly shows that in the majority of the hospitals, exposure of the radiollogist and his assistant(s) to scattered radiation is restricted to the period of fluoroscopy. Generally, during non-fluoroscopic imaging, investigators stay behind protective shielding or maintain adequate distance to the radiation source. This result is consistent with the wide-spread use of power injection systems for contrast media. It is concluded that estimates of (average) occupational exposure may be derived from data referring to fluoroscopy only.

\subsection{Conclusion}

Quantitative information about angiography and non-cardiac endovascular interventional procedures in the Netherlands in 1992 have been determined, combined with information about the available equipment and some aspects of the examination technique. This intormation will be used to extrapolate patient and personnel dose data (measured in three Dutch hospitals) to nationwide estimates. In the field of occupational radiation protection there still seem to be some possibilities for improvement: more extensive use of undercouch X-ray rube, wearing a thyroid collar and standardisation of the position of the personal dosemeter. 


\section{Chapter 6}

\section{Methods and techniques to assess the radiation dose to patients and staff ${ }^{2}$}

\subsection{Introduction}

Radiation doses to patients and personnel vary widely in vascular radiology. Arteriographic procedures may be limited to a small region (e.g. skull, pelvis or hand), or encompass the major part of the body (e.g. up to $70 \%$ in arteriography of aorto-iliac and peripheral vessels). In addition, various imaging methods are commonly used in patient examinations. Beam entrance location, beam direction, field size, focus-to-skin distance, beam quality, radiation intensity and exposure time vary considerably during arteriographic procedures. These characteristics are determined by the X-ray system used, some patient characteristics, the image quality required, and the diagnostic or therapeutical procedure that is carried out.

Due to relatively short distances, anisotropic distribution of the scattered radiation, and high attenuation by protective clothing and e.g. lead slabs, occupational exposures in vascular radiology can be characterised as a dynamic, non-uniform exposure to a spectrum of scattered, low energetic photons, mainly originating in the patient.

It therefore follows that, due to variable, non-uniform exposure conditions and the large inter- and intrawexamination variations, assessment of the medical and occupational dose is very difficult, and that reliable estimates for the radiation exposure require a large number of dose measurements and knowledge of the exposure conditions in relevant stages of the examination.

Although it is recognised that the quantity effective dose is not entrely appropriate in the evaluation of medical exposures to ionising radiation, it is nevertheless used to express the radiation dose, both to patients and occupationally exposed personnel. The effective dose is not directly measurable by instruments, but has to be derived from dose estimates for organs and tissues, multiplied by their corresponding lissue weighting factor (see Table 2.1). Dosimetric methods are discussed in the following sections.

\subsection{Dosimetric methods to quantify organ doses}

Three dosimetric techniques can be applied to estimate organ doses: in situ dose measurements, phantom measurements, and Monte Carlo calculations. Some features and drawbacks of these techniques are discussed.

\footnotetext{
Part of this chapter is based on the publication: Pierre I. Kicken, Gerrit J. Kemerink, Peter J. Vaessen. Jef $J$. Ackermans. An automated measurement system for characterisation of patient exposure during angiography. Radiation Protection Dosimetry. 1992,43(1/4):165-169 [K192]
} 
In situ dose measurements

Generally, in situ measurements of the radition dose to internal tissues are infeasible in vascular radiology. Even measurements of entrance doses are rather complex or not possible at all. For example, in interventional diagnostic procedures sterile conditions are required. Dosemeters attached to the patient cannot be removed, nor can other dosemeters be added in the course of the examination. Therefore, patient entrance dose data derived from TLD measurements are integrated doses, resulting from various imaging modes (e.g. fluoroscopy, DSA, serial cut film radiography) and diagnostic views. Decomposition of the TLD-dose in entrance dose estimates for relevant diagnostic views is virtually impossible. Obviously, in situ dose measurements for occupationally exposed persons are entirely out of the question.

\section{Dose measurements in phantoms}

If exposure conditions show small variations and are easy to characterise, organ doses can be estimated from dose measurements inside and on the surface of anthropomorphic phantoms, such as the Rando phantom. Detailed descriptions of phantoms are provided in ICRU Report 48 [IC92a]. Dosimetric studies in anthropomorphic phantoms are very time consuming, and, by its nature, must be restricted to a limited set of different exposure conditions and phantom characteristics. As a consequence, extrapolation of these experimentally derived data to complex, clinical exposure condifions may result in unreliable dose estimates.

\section{Monte Carlo organ dose calculations}

Monte Carlo organ dose methods comprise mathematical descriptions of the human body and statistical computational techniques to allow for the stochastic nature of the interactions of ionising radiation with matter. Taking advantage of the flexibility of software programming techniques, several software packages have been developed TDR90, 1085, KR86, RE94]. The National Radiological Protection Board (NRPB) in the United Kingdom [JO85] uses a hermaphrodite adult phantom, whereas the Gesellschaft fur Strahlen- und Umweltschutz (GSF) in Germany has developed a mate and a fenale adult phantom [KR86, DR90]. Age-specific phantoms, which provide adaptable descriptions for the mass and dimension of the body and internal organs, have been introduced by Yamaguchi [YA94] and Veit [VE89, VE93a]. A review of computational models has been presented by Zankl [ZA93]. Quite recently, NRPB [HA94] and Le Heron [LE94] have issued a software package, including an extended organ dose data set, for atssessments of doses to adult patients in diagnostic radiology. Organ doses and effective doses have been made available for the NRPB-hermaphrodite phantom for X-ray spectra in the range of 50 $\mathrm{kV}$ to $120 \mathrm{kV}$ tube high voltage, and from $2 \mathrm{~mm} \mathrm{All}$ to $5 \mathrm{~mm}$ Al total beam filtration. In the Netherlands, at the TNO, Centre for Radiological Protection and Dosimetry (TNO) whe general purpose Monte Carlo Code MCNP [BR86, BR91] is being used for Monte Carlo simulation of radiation transport to study dose distributions in diagnostic radiology. Recently, organ doses related to chest radiography have been calculated for male and female phantoms developed by GSF [SC94, SC95].

Unfortunately, Monte Carlo organ dose data sets for medical exposures in diagnostic radiology [DR90, HA94,JO85, KE80] are of limited use for angiography, since typical values for focus-to-skin distance, projection site, field size and beam direction are usually different from those in more common radiographic examinations. Also, organ dose clata are not available at all for many angiographic projections. 


\subsection{Automatic recording of technique parameters and dose-area product}

\subsubsection{An automatic system for recording exposure conditions}

Since the number of diagnostic views in arteriography is quite large, and exposure parameters of single angiographic examinations will often deviate from average values, it was anticipated that a large number of procedures had to be monitored to derive representative sets of exposure data for angiographic procedures. Therefore, we developed and applied a dedicated system for automatic, real-time recording of relevant technique parameters of the X-ray system and the close-area product (DAP). This system has been applied in three hospitals, the University Hospital Maastricht (azM), the De Wever Hospital Heerlen (DW), and the Maasland Hospital Sittard (MA). Acquired data have been used (i) to quantify the exposure condition to the patien, and (ii) to characterise the occupational exposure conditions.

The angiography rooms in all three hospitals comprised two $X$-ray systems: the angiography system and a ceiling mounted $X$-ray tube. As it was determined within a few months that patient procedures which involved imaging by means of the ceiling mounted system were carried out rather infrequently, these procedures have been excluded from the acquired data set. The following description is focused on the angiograpliy systems.

The real-time monitoring system consisted of an IBM compatible personal computer, extended with analog-digital convertors and digital inputoutput channels. The system was further equipped with a dose-area product meter (Diamentor M-3, PTW/Freiburg, Germany), connected to the $\mathrm{PC}$ via a serial $\mathrm{RS}-2320$ interface. The flat transmission ionisation chamber was fitted on the $X$-ray output window of the angiographic $X$-ray systems. The dose-area product meter measures the product of dose rate, exposure time and the area of the beam cross section. Combined with additional information, this is a measure for the entrance dose to the patient. In the range of diagnostic applications, the accuracy of the dose-area product is almost independent of the dose rate, field size and beam quality [WA89]. Therefore, dose-area product meters are applicable in angiography. A list of components is given in Table 6.1. All electronic input channels were scanned by software polling. Software for system control, data acquisition and processing was developed in our department, using the programming language C. Off-line data processing was carried out by means of the database system DBASE IV. Statistical analyses were performed with the software package SAS [SA89]. A diagram of the system is presented in Figure 6.1.

Data pertaining to examinations were stored recordwise in ASCII-files, which are easily accessible by (statistical) sofware packages. Single records contained descriptive data or measured results of system parameters for a single projection. Records with descriptive data started with a code, identifying its type of information. In order to reduce the amount of data, technical parameters were sampled and averaged unless the imaging stopped, or unless one technical parameter deviated more than $10 \%$ from its current average, indicating a significant change in the current projection. If this occurred the cumulated DAP, as well as average or cumulated values for the technical parameters belonging to the last projection were calculated and stored. Subsequently, a new record was opened and a new measurement series started. The number of data records for a single examination depended on the complexiry of the catheterisation and the number of diagnostic views (range found in the azM hospital for $95 \%$ of all procedures: 10 to about 200 records per procedure; maximum 850 ). 
Table 6.1 System Components of the Angiographic Monitoring System

Hardware

1 Olivetti M24 Personal Compuer (PC/XT, IBM-compatible)

(8087 math co-processor, $20 \mathrm{Mb}$ harddisk, real time clock)

1 Digital l/O-board, memory mapped, 40 channels; (PCl-20087W-1/Burr Brown)

1 Analog digital convertor board (memory mapped, 16 singlewended channels.

12- bit resolution, conversion time $25 \mu$ s, multi range signal input,

(PCl-20089W-1/Burr Brown)

I Matrix printer (Epson compatible)

1 Diamentor $\mathrm{M}-3$ (PTW/Freiburg)

2 transmission ionisation chambers (dimensions: $21 \mathrm{~cm} \times 21.5 \mathrm{~cm} \times 1.7 \mathrm{~cm}$ )

Sofrutare

Data acquisition and processing software (developed by azM)

Real-time recorded parameters of the angiographic X-ray systems are listed in Table 6.2. Parameters, preceded by the character "s" were measured directly by means of low level analog or digital signals; parameters preceded by the character "d" were indirectly derived from measured results.

Additional data on the anatomical position of the diagnostic images were taken from data sheets filled out by technical staff. The patient's age and sex, the operator's name, and the procedure type were entered manually in the course of the medical examination. Data on height and weight were asked from the patient by the radiographer, in a number of cases this information was not obtained. Data on age were taken from the medical record.

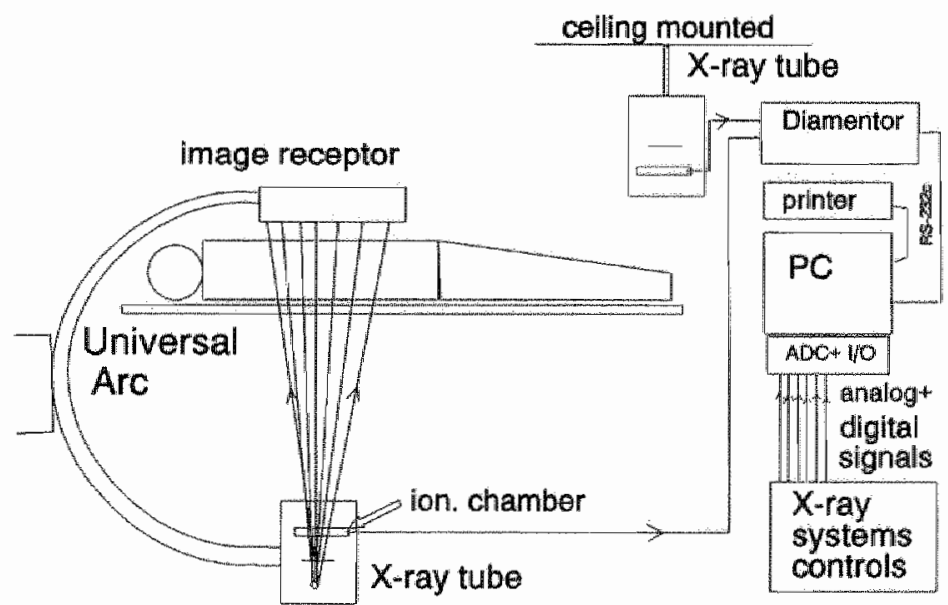

Figure 6.1 Diagram of the real-time monitoring system.

After installation of the transmission ionisation chamber, the response of the dose-area product meter was checked for various sizes and shapes of the X-ray beam. Dose measurements were performed with a $30 \mathrm{ml}$ ionisation chamber (PM-30, Capintec Inc., Pittsburgh, USA), connected to an electrometer (Capintec 192 A, Capintec Inc.), with a 
calibration factor traceable to the Dutch Standards Institute (NMi). The cross section area of the beam was determined from simultaneously exposed radiographs. For nonrectangularly shaped $X$-ray beams, the cross section was derived as the ratio of the mass of the exposed area of the film to the mass of a rectangular exposed film area, multiplied by the area of the rectangle. Quality control of the dose-area product was performed in all three hospitals at the start and end of the data acquisition period. Measured DAP-values deviated less than $5 \%$ from the dose measured in the centre, multiplied by the beam cross section.

Table 6.2 Real-time Recordled Parameters of the Angiographic X-Ray Systems in the three hospitals

\begin{tabular}{|c|c|c|c|}
\hline Technical Parameter & $2 \mathrm{a} \mathrm{M}$ & DW & MA \\
\hline (s) Tube high voltage & $y$ & $y^{\prime}$ & y \\
\hline (s) Rectangular diaphragm & $y$ & $y$ & y \\
\hline (s) Iris diaphragm & y & na & na \\
\hline (s) Imaging mode (fluoro, dsa, ca) & $y$ & $y$ & $y$ \\
\hline (s) Longinudinal position of $\mathrm{X}$-ray source & $y$ & in & $n$ \\
\hline (s) Lateral position of table top & n. & y & $\mathrm{y}$ \\
\hline (s) Vertical position of table top & $n$ & $y$ & y \\
\hline (s) Vertical position of focus & $\mathbf{n}$ & $y$ & $y$ \\
\hline (s) Distance of focus-10-imaging system & $\mathrm{n}$ & $y$ & $y$ \\
\hline (s) Angle of rotation of X-ray source & $y$ & $y$ & y \\
\hline (s) Angle of angulation of $X$-ray source & $y$ & $y$ & $y$ \\
\hline (s) Geometrical enlargement factor & $y$ & na & na \\
\hline (s) Isocentre & y & na & na \\
\hline (s) Image intensitier (azM: $6,10,14 ; \mathrm{DW}, \mathrm{MA}: 6,9$ inch) & y & $y^{y}$ & $y$ \\
\hline (s) Tube current & $y$ & y & y \\
\hline (s) Tube load (mAs) & $y$ & $y$ & y \\
\hline (d) Focus-skin-distance & $y$ & y & y \\
\hline (d) Fluoroscopy time & $y$ & y & y \\
\hline (d) Number of DSA frames per series & $\mathrm{y}$ & y & y \\
\hline (d) Number of CA films per series & $y$ & y & y \\
\hline (s) Dostonarea product & y & y & $y$ \\
\hline
\end{tabular}

$(s)=$ analog or digital signal provided; $(d)=$ data derived from other information; $y=$ yes, data awailable; $\mathrm{n}=$ no, data not available; wa $=$ not applicable.

\section{Selection and compression of recorded data}

Since in a single examination different imaging techniques were applied and various diagnostic projections were used with any of these techniques, angiographic examinations were characterised by a number of data sets detailing the $X$-ray exposure for relevant stages of the angiographic procedure. It was anticipated that, due to limitations of personnel and computer resources, the number of different diagnostic views that could be handled in additional Monte Carlo organ dose calculations would be restricted. Therefore, we aimed to characterise the patient exposure conditions with a consistent data set, that was as small as possible. In this data set exposure conditions were related to mathematical phantoms and their 3-dimensional co-ordinate system, as used in MC-computational dosimetry by GSF and TNO. Results for selected groups of procedures are given in Chapler 8. 
In order to obtain a quantitative description of the exposure conditions, the very large amount of data acquired in this study has been sorted and compressed. For selected types of procedures a subset was derived, according to the criteria that weight, height and the quotient of weight and height of the patient did not differ more than $20 \%$ from the anatomical data of the GSF-phantoms ADAM and EVA [KR86]. From this subset, a subgroup was selected containing procedures in which usage data on DSA. cut film radiography (PUCK) and fluoroscopy showed high simillarity with average values for the subset. Selection criteria were chosen to exclude extreme procedures. Data records of this subgroup were labelled according to their anatomical position and projection angle. Data records which contributed less than $0.1 \%$ to the total dose-area product were deleted. Single procedures were merged into a very condensed data file, containing average values for technique factors (imaging mode, tube high voltage, field size, focus-to-skin distance, $X$-ray beam direction), totalised data on DAP, total entrance dose free in air, fluoroscopy time and the number of images per diagnostic view. Average values for technique parameters (T-parm) per view were derived by calculating weighted means, using the dosearea product (DAP) for weighting, according to:

$$
\text { mean T-parm } \text { weighed }_{1}=\Sigma_{\mathrm{i}}\left(\mathrm{DAP} \cdot \mathrm{T}-\mathrm{parm}_{\mathrm{i}}\right) / \Sigma_{\mathrm{i}} \mathrm{DAP}
$$

where $i=$ record number.

The rationale for using weighted instead of unweighted calculation of the mean, in which all data records would contribute equally, is found in the large variations in DAP per record. For example, DAP values in single data records during fluoroscopy in peripheral arteriography varied between about $0.0 \rrbracket$ and $9 \mathrm{~Gy} \cdot \mathrm{cm}^{2}$.

\subsubsection{Resullts of a pillot study}

In a pilot study, performed in the University Hospital Maastricht in 1991, patient exposure conditions were determined for various procedure types. Some results are shown in Table 6.3 and Table 6.4. It can be easily gathered from these data that the total DAP per procedure type and the relative contributions of fluoroscopy . DSA and CA vary considerably. DAP values for single examinations vary between 1 and $120 \mathrm{~Gy} . \mathrm{cm}^{2}$. On average, con ventional arteriography by means of serial cut films (CA) contributed about $25 \%$ to the total DAP per examination; DSA and fluoroscopy each about 40\%. In IV DSA, fluoroscopy accounted for only $10 \%$ of the total DAP.

The number of diagnostic projections and the number of images are given for DSA and CA separately in Table 6.4. Typical values for the fluoroscopy time are included as well. On average, three to four different. DSA projections were used, resulting in about 60 DSA-frames per examination. For CA the maximal mean number of different projections amounted up to five, the maximal mean number of fillms up to 25 .

In this pilot-study, TL dose measurements were performed to check the accuracy of the entrance dose estimates. In six patient examinations, TLDs were attached on the table top, underneath the supine patient (about 100 TLDs per examination). Dose estimates were derived for various body regions, using measured DAP-values, measured diaphragm settings, estimates for the focus-to-skin distance and for the longitudinal $X$-ray field position for each imaging mode separately. These dose estimates were compared with 
TLD measurement results. Good agrement was found in all cases (differences relative to TLD doses, were smaller than $30 \%$.

Table 6.3 Results of a pilot-study: dose-area product, DAP, per examination and mean relative contributions of fluoroscopy, DSA, and conventional angiography (CA) in the University Hospitall Maastricht

\begin{tabular}{|c|c|c|c|c|c|c|c|}
\hline \multirow[t]{2}{*}{ Procedure } & \multirow{2}{*}{$\begin{array}{l}\text { No. } \\
\text { of } \\
\text { exam. }\end{array}$} & \multicolumn{3}{|c|}{$D A P\left(G y \cdot \mathrm{cm}^{2}\right)$} & \multicolumn{3}{|c|}{ Relative contribution } \\
\hline & & Mean & Med & Range & fluor. & DSA & $\mathrm{CA}$ \\
\hline Aorto-iliac + one leg & 34 & 13 & 10 & $2-52$ & $35 \%$ & $40 \%$ & $25 \%$ \\
\hline Aorto iliac + wo leges & 7 & 32 & 23 & 19.68 & $45 \%$ & $30 \%$ & $25 \%$ \\
\hline Selec. Cerebr. Angio & 21 & 59 & 51 & $12-120$ & $40 \%$ & $35 \%$ & $25 \%$ \\
\hline PTC (perc trans.chol.) & 12 & 23 & 27 & 1. -48 & $90 \%$ & - & $10 \%$ \\
\hline IV-DSA abdomen & 8 & 57 & 57 & $31-89$ & $10 \%$ & $90 \%$ & - \\
\hline IV-DSA aorto-il. thighs & 22 & 47 & 45 & $16-100$ & $10 \%$ & $90 \%$ & - \\
\hline
\end{tabular}

Table 6.4 Number of diagnostic projections $\left(\mathbf{n}_{\mathrm{DSA}}, \mathbf{n}_{\mathrm{CA}}\right)$, diagnostic images $\left(\mathbf{n}_{\mathrm{DSA}-\mathrm{frames}}, \mathbf{n}_{\mathrm{CA} \cdot \mathrm{flims}}\right)$ and fluoroscopy time (mean, \pm 1 SD)

\begin{tabular}{|c|c|c|c|c|c|c|}
\hline \multirow[t]{2}{*}{ Procedure } & \multirow{2}{*}{$\begin{array}{l}\text { No. } \\
\text { of } \\
\text { exam. }\end{array}$} & \multirow[t]{2}{*}{$\mathrm{n}_{\mathrm{DSA} A} \mathrm{n}_{\mathrm{DSS} A}$} & \multirow{2}{*}{$\begin{array}{l}\mathbf{n}_{C A} \\
\text { frames }\end{array}$} & \multirow[t]{2}{*}{$\mathrm{n}_{\mathrm{CA}-}$} & \multirow{2}{*}{ films } & \multirow[b]{2}{*}{$(\min )$} \\
\hline & & & & & & \\
\hline Aorto-iliac + one leg & 34 & $3.2 \pm 1.2$ & $53 \pm 30$ & 5 & $12 \pm 8$ & $2.9 \pm 1$ \\
\hline Aorto-illac + two legs & 7 & $3.3 \pm 0.8$ & $53 \pm 23$ & 5 & $14 \pm 2$ & $4.5 \pm 1$ \\
\hline Selec. Cerebr. Angio & 21 & $4.1 \pm 4.5$ & $69 \pm 73$ & $3 \pm 3.5$ & $25 \pm 27$ & $15 \pm 10$ \\
\hline $\operatorname{PTC}$ & 12 & - & - & 1 & $2 \pm 1$ & $10 \pm 7$ \\
\hline IV-DSA abdomen & 8 & $3.4 \pm 0.9$ & $62 \pm 16$ & - & - & $1.0 \pm 0.5$ \\
\hline IV-DSA ilact thighs & 22 & $4.0 \pm 0.9$ & $71 \pm 18$ & - & - & $1.2 \pm 0.4$ \\
\hline
\end{tabular}

\subsection{Dosimetric approach for patients}

As mentioned before, assessments of organ doses 10 patients were based on results of Monte Carlo (MC) dose calculations. Entrance doses for patients were indirectly derived. from recorded data on dosemarea product and technique parameters. Application of TLDs as a primary tool for routine assessment of the entrance doses was also considered. However, it was concluded and indeed confirmed in our pilot-study, that this approach would be impractical, because it requires very large numbers of TLDs. In addition, it was anticipated that the use of TLDs in selected stages of the examination would be hardly compatible with the sterile conditions generally required in vascular radiology.

Assessment of the entrance dose

The absorbed dose free-in-air at the beam entrance position at the patient was derived from measurements of the dose-area product, field size, and focus-to-skin distance, according to:

Entrance dose $($ in Gy $)=\operatorname{DAP} \times(1 / \mathrm{AREA}) \times(1 / \mathbb{F S D})^{2}$ 
where $D A P=$ dose-area product $\left(\mathrm{Gy} \cdot \mathrm{cm}^{2}\right), \mathrm{AREA}=$ field size at $1 \mathrm{~m}$ distance from the focus $\left(\mathrm{cm}^{2}\right)$, and FSD $=$ focus-to-skin distance $(\mathrm{m})$.

The field size was determined continuously in real time by the recording system for all three imaging modes. Because of the presence of an iris draphragm that blocks the edges of the rectangular aperture, allowances have been made in off-line data compression processing. It is estimated that the inaccuracy in the derived field size is less than $10 \%$.

In the azM hospital, focus-to-skin distances were derived in real time from electronic data on the focus-to-image distance, the geometrical enlargement factor (magnification referring to a reference point), and the distance of the reference point (isocentre) from the table top. In the DW hospital and MA hospital, focus-to-skin distances were estimated from real-time recorded data on the vertical positions of the table top and the focus, and the lateral position of the patient support. The patient was represented by a semicylindrical volume (cut in half along the longitudinal axis), with the flat surface positioned on the table support (radius $=20 \mathrm{~cm}$ ).

The derived entrance dose is equal to the air kerma, free in air; backscatter radiation from the patient's body is not included. The dose measurement procedure was checked with the same ionisation chamber as used for dose-area-product quality control.

Since the patient support in undercouch tube positions is between the focus and the patient, allowances had to be made for its radiation attenuation. As it was anticipated that the position of the X-ray tube could be derived from technical parameters (e.g. the angle of rotation), correction factors were implemented in off-line data processing activities instead of using different DAP calibration factors. Besides, using different sets of DAP calibration factors in real-time measurements would distort the quantification of occupational exposure conditions.

\section{Assessment of the effective dose for patients}

\section{Merhod 1}

Effective dose estimates for the patient were derived from entrance dose estimates, combined with Monte Carlo (MC) organ dose data. MC dose data were made available by GSF, Neuherberg, Germany, and TNO, Rijswijk, The Netherlands. On request, these institutions performed $\mathrm{MC}$ organ dose calculations for selected types of arteriography procedures. Calculated MC organ dose data were normalised to entrance air absorbed dose, free in air [DR90], or to dose-area product [SC94a]. Full details on effective dose calculations, based on MC data, are given in Chapter 8.

\section{Method 2}

In addition to MC organ dose calculations (method 1), a second approach was used to obtain (rough) estimates for the effective dose to patients. This was accomplished by multiplying DAP data, obtained from clinical measurements in this study, by E/DAPratios for full diagnostic procedures. E/DAP-ratios were taken from literature, or derived from published data on $\mathrm{E}$ and DAP. These ratios are summarised in Table 6.5.

Using the software package XDOSE a second set of E/DAP-ratios was inferred. These data refer to single diagnostic views. Results are given in Table 6.6. As this alternative approach was intended to be a relatively simple calculation procedure, the dependence of E/DAP-ratios on the tube high voltage, beam filtration, field size, and patient's dimensions and sex, have not been taken into account. 
Table 6.5 Ratios of effective dose to DAP (published data)

\begin{tabular}{|c|c|}
\hline Procedure type & $\mathrm{E} / \mathrm{DAP}\left[\mathrm{mSv} \cdot \mathrm{Gy}^{-3} \cdot \mathrm{cm}^{-2}\right]$ \\
\hline Barium enema & $0.3^{\text {mag9 }}$ \\
\hline Barium mest & $0.2^{[\text {HNa }}$ \\
\hline Chest, PA & $0.15^{\text {MMas }}$ \\
\hline Cardiac, fluor, PA & 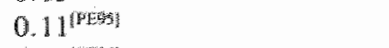 \\
\hline Cardiac, x-ray, $P A$ & $0.15^{(\text {EES })}$ \\
\hline Abdomen, AP & 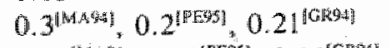 \\
\hline Abdomen, $\mathrm{PA}$ & 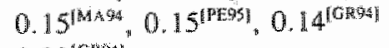 \\
\hline Lumbar spine, AP & 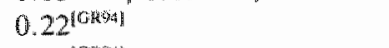 \\
\hline Pelvis, $A$ & 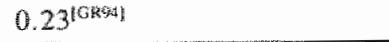 \\
\hline
\end{tabular}

Typical sex-averaged data for $\mathbb{H V}$ is about $80 \mathrm{kV}$ and $3-4 \mathrm{~mm}$ Al total beam filtration.

Table 6.6 Ratios of effective dose to DAP (derived from XDOSE)

\begin{tabular}{lll}
\hline X-ray examination & $\begin{array}{l}\mathrm{E} D \mathrm{AP}\left[\mathrm{mSV} \cdot \mathrm{Gy}^{2} \cdot \mathrm{cm}^{2}\right] \\
\mathrm{AP}\end{array}$ & 0.03 \\
\hline Head & 0.04 & 0.03 \\
Cerwical spine & 0.26 & $?$ \\
Chest & 0.24 & 0.15 \\
Heart & 0.15 & 0.17 \\
Upper stomach & 0.56 & 0.26 \\
Stomach & 0.45 & 0.19 \\
Kidneys & 0.25 & 0.15 \\
Small intestine & 0.24 & 0.19 \\
Abdomen & 0.24 & 0.15 \\
Pelvis & 0.26 & 0.26
\end{tabular}

"Calculated results for a hermaphrodite phantom, using XDOSE (HV $=80 \mathrm{kV}$; filtration $=4 \mathrm{~mm} \mathrm{Al}$ ) [HA94, LE94].

Data presented in the Tables 6.5 and 6.6 were derived as typical values for about $80 \mathrm{kV}$, and 3-4 mm Al filtration, averaged for male and female patients. Using these data and taking AP and PA exposures into account, approximated values for E/DAP-ratios were derived for all main procedure types included in Table 7.1. IV-DSA procedures have been included separately because of obvious differences in IV-DSA and IA-arterial arteriography of the iliac and lower limbs region. The results are given in Table 6.7. The quotients of AP-ratios and PA-ratios vary between 1.5 and 2. It should be noted, for comparative purposes, that computed results by Yamaguchi [YA94] show that, for adults exposed to $45 \mathrm{keV}$ photons, the AP/PA-ratio of the effective dose per unit air kerma is equal 10 1.8. Taking an additional correction factor of 0.8 for PA projections (see footnote a of Table 6.7) into account, results presented in Table 6.7 were compared with available literature data about vascular radiology (section 3.6.1). Good agreement was found for cerebral arteriography (our estimate for PA $0.08 \mathrm{mSv} \cdot \mathrm{Gy}^{-1} \cdot \mathrm{cm}^{-2}$, versus 0.09 $\mathrm{mSv} \cdot \mathrm{Gy}^{-1} \cdot \mathrm{cm}^{-2}$ for PA [CA95], and $0.15 \mathrm{mSv} \cdot \mathrm{Gy}^{-1} \cdot \mathrm{cm}^{-2}$ AP/PA not specified [ST93]), abdominal arteriography (our estimate for PA $0.16 \mathrm{mSv} \cdot \mathrm{Gy}^{-1} \cdot \mathrm{cm}^{-2}$, versus 0.17 $\mathrm{mSV} \cdot \mathrm{Gy}^{-1} \cdot \mathrm{cm}^{-2} \mathrm{AP} / \mathrm{PA}$ not specified [ST93]), and iliac and lower limbs arteriography (our estimate for PA $0.08 \mathrm{mSv} \cdot \mathrm{Gy}^{-1} \cdot \mathrm{cm}^{-2}$, versus $0.09 \mathrm{mSv} \cdot \mathrm{Gy}^{-1} \cdot \mathrm{cm}^{-2}$ AP/PA not specified [ST93]). Only the E/DAP ratio by Castellano [CA95] for PA-iliac and lower 
limbs arteriography procedures $\left(0.24 \mathrm{mSv} \cdot \mathrm{Gy}^{-1} \cdot \mathrm{cm}^{-2}\right)$ differed from the conversion coefficients given in Table 6.7 .

Table 6.7 Estimated ratios of effective dose to DAP applicable in vascular radiology"

\begin{tabular}{|c|c|c|}
\hline$X$-ray examination & $\begin{array}{l}\text { E/DA } \\
{[\mathrm{m} S \mathrm{~V}}\end{array}$ & \\
\hline & $\mathrm{AP}$ & PA \\
\hline Cerebral anteriographyb & 0.2 & 0.1 \\
\hline Upper extremity arteriography & 0.2 & 0.15 \\
\hline Thoracic arteriography & 0.2 & 0.15 \\
\hline Abdominal areriography & 0.3 & 0.2 \\
\hline lliac and lower Jimbs anteriographyc & 0.15 & 0.1 \\
\hline IV-DSA iliac and lower limbs ${ }^{\mathrm{d}}$ & 0.3 & 0.2 \\
\hline PTA & 0.3 & 0.2 \\
\hline
\end{tabular}

${ }^{2}$ In order to estimate effective doses for procedures with undercouch tube positions, allowances have to be made for the radiation attenuation in the patient support. This can be accomplished by multiplying the DAP value by an additional factor of 0.8 (note: first-HVL at $80 \mathrm{kV}$ was $3.6 \mathrm{~mm} \mathrm{Al}$ in azM, and $2.9 \mathrm{~mm}$ Al in DW and MA); It is assumed that in a substantial number of cerebrall views the thy oid is directly exposed to the primary beam; "These procedures comprise exposures to the lower limbs (thighs, lower leg and

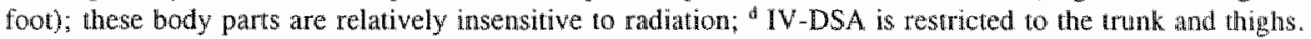

\subsection{Dosimetry techniques applied for occupational exposure}

In current Dutch legislation, occupational dose limits are expressed in the quantities effective dose equivalent, $\mathrm{H}_{E}$, and dose equivalent, $H$, to the lens of the eye, skin, hand, forearm, foot and ankle (see section 3.1). These quantities have been superseded on an international level in 1991 [IC91] by the quantities effective dose, $\mathrm{E}$, and equivalent dose. $\mathrm{H}_{\mathrm{T}}$ respectively. Differences in philosophy and computational methods for $\mathrm{H}_{\mathrm{E}}, \mathrm{E}, \mathrm{H}$ and $\mathrm{H}_{\mathrm{T}}$ are discussed in Chapter 2. Since it is anticipated that in the near future in Dutch legislation effective dose and equivalent dose will be applied, these quantities have been used in this thesis.

In order to estimate the quantities dose equivalent and effective dose, various thermoluminescent dosemeters (comprising TLD-100 elements) were attached at appropriate places on the body. Dosemeters were changed after each patient procedure.

\subsubsection{Thermoluminescence dosimetry in the study of occupational exposures in vascular radiology}

A general introduction to thermoluminescence dosimetry (TL dosimetry) and descriptions of TL dosimetric procedures applied in this study can be found in appendix A.

\section{Dosemeter}

Dose measurements have been carried out with commercially available extruded chips of LiF, doped with small quantities of magnesium and titanium (TLD-100, Harshaw). The energy response of Lif and tissue are relatively similar. Two types of dosemeters were 
used. As indicated by their names, "body-dosemeters" were worn on the body, and "ringdosemeters" were worn on the hands.

Each "body-dosemeter" comprised two TLD-100 elements, dust-proof sealed in thin sachets $(5 \mathrm{~cm} \times 2.5 \mathrm{~cm}$ ). The backing material consisted of a strip of thin paper (about 80 $\mu \mathrm{m})$, covered with a layer of dry glie. A thin polyester/polyethylene foil was used as front cover (12 $\mu \mathrm{m}$ polyester; $50 \mu \mathrm{m}$ polyethylene).

Each ringdosemeter contained one TLD-100 element. The TLD was placed in a plastic ring and covered, dust-proof and waterproof, by a piece of paper $\left(80 \mathrm{~g} / \mathrm{m}^{2}\right)$ and a thin, aluminized, plastic foil $(50 \mu \mathrm{m})$. Ringdosemeters were immersed in alcohol during five minutes before use in order to maintain sterile working conditions, .

\section{TLD readout}

In order to obtain the integrated TL-signal, TLDs were read out by means of a manual TLD-reader (Harshaw 4000B, Harshaw, Solon, USA), featuring plancher heating and a programmable temperature control unit. The readout cycle comprised a pre-read out temperature of $150{ }^{\circ} \mathrm{C}(5 \mathrm{~s})$, followed by a TL-acquisition period, in which the temperature increased to $230^{\circ} \mathrm{C}$ (temperature rate $=25^{\circ} \mathrm{C} / \mathrm{s}$ ). This temperature level was maintained during $7 \mathrm{~s}$. All TL-signals were stored in an IBM-compatible personal computer, and visually checked afterwards for irregularities (shape and position of TL-peaks).

\section{Selection of TLDs}

To be able to use calibration factors for groups of TLDs, a subset, matching the criterion that the TL response was within the range of $95 \%$ to $105 \%$ of the arithmetic mean, was selected from a batch of more than one thousand TL elements. These selected elements were processed batchwise throughout the various stages in this study. By using a homogeneous group of TLDs instead of individually calibrated TLDs, the administrative tasks and probability of handling errors were reduced substantially. The loss of precision was considered to be acceptable.

\section{Annealing}

Annealing was carried out for batches of about 100 TLDs, placed on an aluminium holder and covered by a thin aluminium capping. The annealing process involwed high temperature $\left(400^{\circ} \mathrm{C}, 60 \mathrm{~min}\right)$ and low temperature annealing $\left(105^{\circ} \mathrm{C}, 90 \mathrm{~min}\right)$. To obtain a high degree of reproducibility, annealing procedures were performed strictly according to a local protocol. It should be noted that the low temperature annealing at $105^{\circ} \mathrm{C}$ during 90 minutes deviated from the "standard" procedure $\left(80^{\circ} \mathrm{C}\right.$ during 24 hours). Experimentally, no drawbacks were found. This alternative method was applied to reduce the preparation time and to maintain a high throughput.

\section{Calibration}

Calibration of dosemeters was carried out essentially free in air, with the TL elements and a reference ionisation chamber placed in the centre of an X-ray field (Polymobil. Siemens, Erlangen. Germany; high frequency voltage generator; $H V, 73 \mathrm{kV}$; totai beam filtration, $2.8 \mathrm{~mm} \mathrm{Al}$; first-HVL, $2.7 \mathrm{~mm} \mathrm{Al}$ at $73 \mathrm{kV}$; focus-TLD-distance, $92 \mathrm{~cm}$. TLDs were placed with their square surfaces perpendicular to the ceniral beam axis. To improve the reliability, a test exposure was performed at the start of each calibration procedure; the constancy of the ionisation chamber system was checked each week by means of a ${ }^{90} \mathrm{Sr} /{ }^{90} \mathrm{Y}$ radiation source. Calibration factors derived for "body-dosemeters" were also 
assigned to ringdosemeters. TL elements to be used for calibration purposes (six elements) and for background correction (six elements) were taken randomly out of the batch. The read-out process was usually performed one week after the annealing procedure. As discussed by others [CH82, DR85, PR81] and confirmed by our own experiments, fading of the TL-signal was negligible $(<<5 \%)$.

In the diagnostic dose range the relationship between the TL-signal and the radiation dose is linear. Therefore, the following simple relationship could be applied:

$$
T L_{\text {mmearn, cal }}=\mathrm{C} \cdot \mathrm{K}_{\text {cal }}+\mathrm{TL}_{\text {mean, baxkground }}
$$

where

$\mathrm{c}=$ calibration factor (TL-response per unit of kerma),

$\mathrm{K}_{\text {cal. }}$ = air-kerma, measured during calibration,

$\mathrm{TL}_{\text {mean, background }}=$ average TL-signal of the non-exposed TLDs,

$\mathrm{TL}_{\text {atean, cal }}=$ average TL-signal of TLDs exposed during the calibration procedure.

In order to estimate the air-kerma of the applied TL-element $i, \mathrm{~K}_{\mathrm{i}}$, the following relationship was used:

$$
\mathrm{K}_{\mathrm{i}}=1 / \mathrm{c} \cdot\left(\mathrm{TL}_{\mathrm{i}}-\mathrm{TL}_{\text {mean, background }}\right)
$$

with $c$ and $T L_{\text {incan, background }}$ derived in the callibration process.

\subsubsection{Dosimetric approach to estimate entrance dose and effective doses to personnel}

\section{Entrance dose estimates}

In order to compare occupational doses with legally established deterministic dose limits for the eye lens, thyroid, hands, and for the feet, ankles, and lower legs (see section 3.4), dosemeters were attached to the front of the skuil, neck, fingers and lower legs respectively.

In order to estimate entrance skin doses from TLD air kerma measurements, allowances had to be made for differences in mass energy absorbtion coefficients $\left(\mu_{\mathrm{en}} / \rho\right)$ of tissue and air (see Chapter 2$)$. As the ratio of $\left(\mu_{\mathrm{en}} / \rho\right)_{\text {tissue }}$ and $\left(\mu_{\mathrm{en}} / \rho\right)_{\text {air }}$ is about 1.06 for diagnostic $X$-ray spectra [J085], the doses to the eye lens, hand, and lower extremities were derived by multiplying the kerma, measured by dosemeters worn on these positions by 1.06 .

\section{Effective dose calculations}

In order to calculate the effective dose, dose estimates for internal organs and for skin were multiplied by tissue weighting factors.

Organ doses were derived by multiplication of so-called dose conversion coefficients (DCCs) with the air kerma, free-in-air, at the body entrance position. Because DCC data. directly applicable to occupational exposure conditions in vascular radiology were not available, we deriwed own estimates, based on two DCC data sets. One data set comprised published DCCs for exposures to patients in $\mathbb{X}$-ray examinations [DR93]. The other data set was madle available by TNO Rijswijk [SC95a]. These characteristics and dissimilarities of both data sets are discussed later in this section. 
Taking account of the characteristics of the occupational exposure conditions and the exposure conditions associated with the DCC data set available at the start of this study [DR90], the body of occupationally exposed persons was divided into eleven regions: head, neck, upper arms $(2 x)$, hands plus forearms $(2 x)$, thorax, abdomen, both thighs, lower legs plus feet $(2 x)$. Organ dose from occupational exposures of the regions head, neck, thorax, and abdomen were associated with published DCCs for radiodiagnostic films of the skull, cervical spine, lungs, and abdomen plus pelvis [DR9o]. Three regions, namely the thorax, the abdomen, and the thighs, were assumed to be fully covered by a lead apron. Except for five tissues (red marrow, bone surface, skin, muscle, and oesophagus), each organ comprised in the effective dose calculations was assigned to a single region. As shown in Table 6.11 , the other five tissues were assigned to four regions (oesophagus) or to eleven regions. As the tissue weighting factor of red marrow is relatively high ( $w_{\text {sed natrow }}=0.12$; see Table 2.1 ), the distribution of red marrow over the regions considered could have a serious impact on dose estimates. Therefore, a literature review was undertaken (see appendix B). In addition to the measurement positions as mentioned before, dosemeters were also worn on the upper arms, the back, the sternum and on the abdomen (see Figure 6.2). Various measurements on the trunk were performed both on and underneath the lead apron.

Tissue weighting factors $\left(\mathrm{w}_{\mathrm{T}}\right)$ were taken from ICRP Publication 60 [IC91]. Tissue weighting factors for remainder organs were computed with use of organ masses as listed in ICRP Publication 23 [IC75]. The results, given in Table 6.9, show that the remainder organ "muscle" clearly dominates. Since tissue weighting factors defined by ICRP [IC91], do not discriminate between males and females, a hermaphrodite person was assumed for effective dose estimations. Except for the female breasts and uterus, sex-averaged DCC data were used. As values for $w_{\text {breas }}$ and $w_{\text {utrals }}$ are sex-averaged values, and as these tissues are absent in males, DCC data for females were used in our dose calculations. This approach resulted in a sex-averaged estimate for the effective dose.

It was recognised that organ doses depend on the effective energy of the scattered $X$ rays and therefore on the tube high voltage. However, to simplify dose calculations, all DCC data were related to a fixed tube high voltage setting of $80 \mathrm{kV}$. This typical value was derived from real-time recorded wbe high voltage settings during fluoroscopy in about 900 procedures (see Table 7.5 ).

During catheterisation, X-ray exposures to the body of the operator mainly varied from lateral exposures to the left side (RLAT) to frontal (anterior-posterior, AP) directions. Other exposure conditions, for instance, oblique, lateral of the right side, and posterioranterior occurred less frequently. Deviations from uniform AP-exposure conditions have been confirmed by entrance dose measurements. Measurement results showed that dose levels for the lleft and right sides of the body were significantly different (e.g Table 9.4). Ratios of doses to the left side by doses to the front of the trunk (see Figure 9.5) varied between 1.5 and 2.5. However, because of limitations and characteristics of the DCC data sets available, our calculations of occupational exposures were based on AP-exposure conditions, both for the operator and the assistant. (Clarification: DCC data for AP views of the head were nearly similar to those for lateral views; lateral views of the cervical spine comprised scattered radiation to the thyroid only, and were judged as unrealistic considering occupational exposures, DCCs for lateral views of the chest were judged as unrealistically small; lat/oblique views of the abdomen and pelvic region were not provided). 


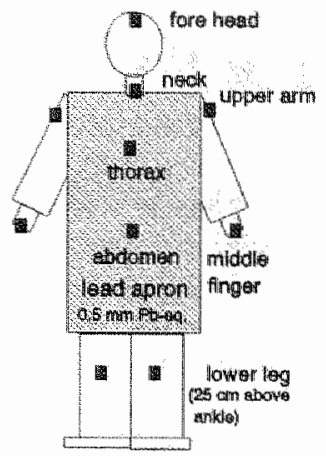

Figure 6.2 Diagram of dose measurement positions

Table 6.8 Mass and tissue weighting factor for remainder organs and tissues, $w_{\text {rem }}$ argase used in effective dose calculations

\begin{tabular}{lrrr}
\hline $\begin{array}{l}\text { Remainder organs } \\
\text { and tissues }\end{array}$ & $\begin{array}{c}\text { Mass }_{\text {raate }} \\
(\mathrm{g})\end{array}$ & \multicolumn{1}{c}{$\begin{array}{c}\text { Mass }_{\text {remale }} \\
(\mathrm{g})\end{array}$} & W $_{\text {rent. organ }}{ }^{\circ}$ \\
\hline Adrenals & 14 & 14 & $2.9 \mathrm{E}-5$ \\
Brain & 1400 & 1200 & $2.7 \mathrm{E}-3$ \\
Upper large intestine & 210 & 200 & $4.3 \mathrm{E}-4$ \\
Small intestine & 640 & 600 & $1.3 \mathrm{E}-3$ \\
Kidney & 310 & 275 & $6.0 \mathrm{E}-4$ \\
Muscle & 28000 & 17000 & $4.4 \mathrm{E}-2$ \\
Pancreas & 100 & 85 & $1.9 \mathrm{E}-4$ \\
Spleen & 180 & 150 & $3.4 \mathrm{E}-4$ \\
Thymus & 20 & 20 & $4.2 \mathrm{E}-5$ \\
Uterus & - & 80 & $1.0 \mathrm{E}-4$ \\
\hline
\end{tabular}

Source: ICRP Publication 23 [IC75]; ${ }^{\text {D }}$ Upper large intestine $=$ caecum + ascending colon + transverse colon; "Mean values for males and fernales. $w_{\text {rem, orean }}=0.05 \cdot$ mass $_{j}$ " $\left(\Sigma_{j} \text { mass }\right\}^{-1}$. The sum value of column $w_{\text {reen orgat }}$ is equal to 0.0497 ; the difference with the weighting factor for remainder tissucs defined by ICRP-60 ( $w_{\text {rema organ }}=0.05$ )。 is negligible.

Entrance doses obtained from measurements in the centres of the thorax and abdomen were multiplied by a factor 1.5 in order to allow for underestimation of actual entrance doses to the trunk. This factor was used to allow both for the increase in the entrance doses at the side of the body (ratio 1.5 to 2.5), and for the decrease in DCC-values for oblique exposures. The $E_{\mathrm{AP}} / \mathrm{E}_{45^{\circ} \text { oblique }}$-ratio was estimated to be 1.3-1.5 (photon energy range of 45 to $60 \mathrm{keV}$ ), by using $\mathrm{E} / \mathrm{K}_{\mathrm{air}}$-ratios for $\mathrm{AP}$ - and lateral exposures, presented by Yamaguchi [YA94] and Zankl [ZA92]. As shown in Table 9.6, entrance doses to the forehead of operators in the MA hospital were significantly lower than corresponding doses to the left side of the head. Consistent with the mean dose estimates for the front and left side of the head $\left(D_{\text {iefi }} / D_{\text {irom }}\right.$-ratio is 4$)$ and taking into account that DCCs for lateral and PA exposures of the head are similar, allowances for effective dose estimations were made by multiplying entrance doses to the forehead of operators by a factor of 4 . 
Table 6.9 Sex-averaged organ dose conversion coefficient, DCC, compiled for various regions, resulting from $\mathrm{AP}$ expossures to $\mathrm{X}$-rays generated at $80 \mathrm{kV}$, derived from anthropomorphic phantoms ADAM and EVA

\begin{tabular}{|c|c|c|c|c|c|c|c|c|}
\hline \multirow[b]{2}{*}{$\begin{array}{l}\text { Organ } \\
\text { tissue }\end{array}$} & \multicolumn{4}{|c|}{ DCC-estimates by TNO } & \multicolumn{4}{|c|}{ DCC-estimates by GSE } \\
\hline & $\begin{array}{l}\text { Regions } \\
\text { head }\end{array}$ & neck. & thorax & abdomen & $\begin{array}{l}\text { Regions } \\
\text { head }\end{array}$ & neck & thorax & abdomen \\
\hline Gonads & .6 & - & - & 0.79 & - & - & - & 0.68 \\
\hline Red narrow & 0.026 & 0,002 & 0.046 & 0.12 & 0.03 & 0.02 & 0.04 & 0.05 \\
\hline Colon (LLI) & - & - & - & 0.45 & - & - & - & 0.34 \\
\hline Lungs & * & - & 0.54 & - & - & - & 0.37 & 0.01 \\
\hline Stomach & - & - & - & 0.77 & - & - & 0.10 & 0.48 \\
\hline Badder & . & - & . & 0.74 & - & - & - & $0.65^{c}$ \\
\hline Breast & - & $\ldots$ & 1.0 & - & - & -. & 0.97 & - \\
\hline Liver & - & - & - & 0.55 & - & - & 0.13 & 0.28 \\
\hline Oesoplxagus & 0.007 & 0.035 & 0.20 & 0.002 & 0.01 & 0.29 & 0.15 & 0.01 \\
\hline Thyroid & - & 1.0 & - & - & 0.61 & 0.90 & 0.12 & - \\
\hline Skin & 0.051 & 0.009 & 0.098 & 0.14 & 0.06 & 0.02 & 0.09 & 0.12 \\
\hline Bone surface & 0.19 & 0.003 & 0.16 & 0.16 & 0.13 & 0.08 & 0.15 & 0.10 \\
\hline Adrenalls & - & - & - & 0.15 & - & - & 0.07 & 0.07 \\
\hline Brain & 0.24 & “ & - & - & 0.19 & 0.07 & - & - \\
\hline U.L. intest. & - & - & - & 0.60 & - & . & - & 0.44 \\
\hline Small intest. & - & 。 & - & 0.49 & - & - & - & 0.37 \\
\hline Kidneys & - & - & - & 0.15 & - & - & 0.02 & 0.10 \\
\hline Muscle & 0.014 & 0.007 & 0.099 & 0.20 & 0.01 & 0.02 & 0.07 & 0.12 \\
\hline Pancreas & - & - & - & 0.38 & - & - & 0.08 & 0.21 \\
\hline Spleen & - & - & - & 0.29 & - & - & 0.06 & 0.11 \\
\hline Thymus & - & - & 0.98 & - & - & 0.01 & 0.86 & - \\
\hline Uterus & - & - & - & 0.49 & - & - & - & 0.40 \\
\hline Entrance dose & & & & & 1.13 & 1.13 & 1.24 & 1.29 \\
\hline
\end{tabular}

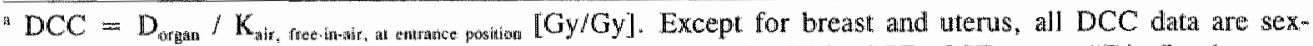
averaged values. Sources: TNO: personal communication [SC95a], GSF: GSF-report "Die Bestimmung von Organdosen in der Röntgendiagnostik" [DR93]. Head: AP view of skull. Neck: AP wiew of cervical spine. Thorax: AP view of lumgs. Abdomen: $A P$ views of abdomen and pelvis. $\mathrm{DCC}_{\text {batomen }}=$ maximuma

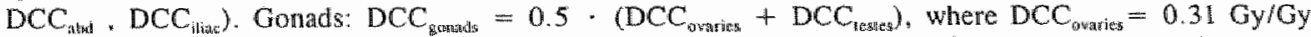

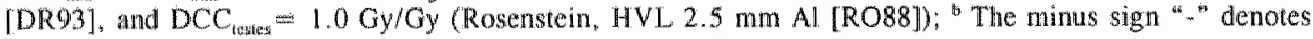
that DCC-value was not provided; "Personal communication Zankl, 1995.

In DCC data sets provided by GSF and TNO, organ doses were normalised to air kerma, free-in-air, at the body entrance position. Because our dose measurements were performed with dosemeters worn on the body, allowances had to be made for backscatter. Backscatter factors were derived from DCC data for the skin at the entrance site, as provided by GSF [DR93]. Our own experiments with TLDs showed that, at the $99 \%$ confidence lewell, backscatter of copper was less than 3\% [K192a], Paix [PA83] obserwed that the backscatter of lead was less than or nearly similar to the backscatter of copper. Therefore, no backscatter corrections were made for TLDs on the outside of lead aprons.

The radiation attenuation factor by lead aprons was experimentally estimated to be 200 (see section 9.4). In our effective dose calculations it was anticipated that, because of high attenuation by protective clothing, the effective photon energy of the impinging radiation would increase, and organ doses and the effective dose would also increase. Seuntjes et al. [SE87] concluded that by changing the beam filtration from $2-4 \mathrm{~mm} \mathrm{Al}$ to $4 \mathrm{~mm} \mathrm{Al}+0.5$ $\mathrm{mm} \mathrm{Cu}$, the effective photon energy increased from about $45 \mathrm{keV}$ to $58 \mathrm{keV}$. We assumed 
that $0.5 \mathrm{~mm}$ lead "filtration" would increase the effective energy 10 about $60 \mathrm{keV}$. By interpolating data for AP exposure conditions presented by Yamaguchi [YA94] it was derived that, to allow for this phenomenon, the effective dose had to be multiplied by a factor of about 1.5. In our effective dose calculations, this "effective dose enhancemen" factor was combined with the attenuation factor of lead aprons (200), resulting in an effective attenuation factor for organ doses in the trunk and thighs of 130 .

Attenuation factors for lead aprons were derived experimentally, and nor with use of Monte Carlo calculations, because these calculations would have required very lengthy computer processing times. For instance, Monte Carlo organ dose calcultations by TNO took about 25 hours for each exposure condition. To obtain DCCs for exposed organs, protected by aprons with an attenuation factor of 130 , with similar statistical confidence levels as for the nonprotected body, processing times would increase with about a factor 17000. It is obvious that this approach was considered to be impractical.

In summary, estimates for the effective dose, E, were derived according to:

$$
\mathrm{E}=\Sigma_{\mathrm{reg}} \Sigma_{\mathrm{T}}\left(\mathrm{w}_{\mathrm{T}} \cdot \mathrm{w}_{\mathrm{R}} \cdot \mathrm{DCC}_{\mathrm{T}, \mathrm{reg}} \cdot \mathrm{K}_{\mathrm{reg}} \cdot \mathrm{obl} \cdot \mathrm{Att}_{\mathrm{reg}}\right)
$$

where

$w_{\mathrm{T}}=\quad$ Tissue weighting factor for specified organ (i) or remainder organ (j), according to ICRP 60 (see Table 2.1 in this thesis). For remainder organ $j$, the tissue weighting factor, $w_{j}$, was calculated to be $0.05 \cdot m_{\mathrm{j}} / \Sigma_{\mathrm{j}} \mathrm{m}_{\mathrm{j}}$, where $\mathrm{m}_{\mathrm{j}}$ was the mass of organ $j$.

$w_{1}$ was calculated for males and females separately. Since $w_{T}$ values are not sex-specific, $w_{j}$ was taken as the mean value for both sexes (see Table 6.8).

$\mathrm{w}_{\mathrm{R}}=\quad$ Radiation weighting factor. For exposures in radiology $w_{\mathrm{R}}$ is unity.

$\mathrm{DCC}_{\mathrm{T}, \mathrm{reg}}=$ Dose conversion factor for organ $T$ in region reg. $\mathrm{DCC}_{\mathrm{T}, \mathrm{esg}}$-values were provided by TNO, or taken from [DR93]. DCC, $\mathrm{Deg}_{\mathrm{T}}$-values used in our dose calculations are given in Table 6.11.

$K_{\text {reg }}=\quad$ Air kerma, free-in-air, for region reg. $K_{\text {reg }}$ was derived from TLD measurements. Allowances were made for backscatter for the thead, upper arm, hand,

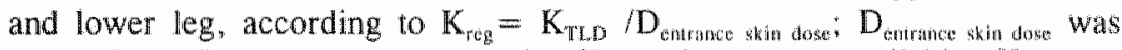
taken from [DR93], or set to unity if no data were available. $K_{\text {reg }}$ was assumed to be uniform for the whole region. If TLD measurement results were not available, $K_{\text {reg }}$ was inferred from air kerma estimates for surrounding regions.

$\mathrm{obl}=\quad$ Correction factor to make allowances for non AP exposures, obl $=1.5$ or the abdomen and thorax; obl $=4$ for the head of operators in the MA hospital (stage 1); obl $=1$ for all other exposures.

$\mathrm{Att}_{\mathrm{Teg}}=$ Attenuation factor, used to allow for the dose reduction by lead aprons. Att $=1 / 130$ for the regions thorax, abdomen, and thighs; $\mathrm{Att}_{\mathrm{reg}}=1$ for other regions. 
Characteristics of DCCs provided by TNO 1SC95al and by GSF IDR931:

\section{Characteristics of TWO data sets:}

DCC data made avalable by TNO comprised calculated organ doses per unit air kerma, free-in-air, at body entrance positions. DCCs were obtained by Monte Carlo simulation of radiation transport, using the MCNP $3 \mathrm{~B} 3$ code [SC94, SC95a]. Calculations were performed for AP-irradiation geometries for the GSF-phantoms ADAM and EVA, using broad unidirectional photon beams, generated at $80 \mathrm{kV}$ (beam filtration, $2.5 \mathrm{~mm} \mathrm{Al}$; frstHVL, $2.8 \mathrm{~mm} \mathrm{Al}$; second $\mathrm{HVL}, 4.2 \mathrm{~mm}$ Al). Both phantoms were divided in several sections, corresponding with the regions listed before. DCCs were calculated for organs listed in ICRP Publication 60 [IC91]. Before the start of the computations, organs and tissues were designated to single sections. As noted before, five tissues (red marrow, skin, bone surface, muscle, and oesophagus) extended into more than one section. These tissues were divided into subcompartments, each corresponding with a single section. For each section, energies imparted to the organs and subcompartments located in that section were computed. Imparted energies to organs and subcompartments outside that region were set to zero. It should be noted that the energy imparted to a single organ accounts for both the primary radiation impinging on the section and the scatter radiation originating anywhere in the phantom. Mean organ doses were calculated from imparted energy and the total mass of the organ/tissue considered. By dividing derived mean organ doses by calculated air kermas, DCCs were computed. Results for various regions, expressed as sex-averaged DCCs are given in Table 6.9 .

\section{Characteristics of GSF-data sets:}

DCC data published by Drexler et al. [DR93] are associated with "simple" radiographic views, both for male (ADAM) and female patients (EVA). We used DCC data for APviews of the skull, cervical spine, lungs, abdomen and iliac region, at tube voltage settings of $80 \mathrm{kV}$ (beam filtration $2.5 \mathrm{~mm} \mathrm{Al}$; focus-skin-distance $85 \mathrm{~cm}$; focus-film distance 115 $\mathrm{cm}$ ). Sex-averaged results for various regions are given in Table 6.9. It should be noted that GSF-data do not comprise exposures to the arms and legs.

Dissimilarities berween exposure conditions and exposure models by TNO and GSF, and consequences for the estimation of effective doses:

- Actual occupational exposures resulted from a volume source (the patient) located at about 0.3. $101.5 \mathrm{~m}$ from the person. In Monte Carlo calculations by GSF a point source (the focus) was used with a focus-skin-distance of $0.85 \mathrm{~m}$; TNO used a broad parallel. beam. Because of differences in source geometry and source-to-organ distances, DCCs by GSF will probably underestimate the actual organ doses. On the other hand, DCC data by TNO may overestimate actuall doses.

- Basically, in our model it was assumed that the contribution from each single region to the effective dose could be accounted for independently from the exposures to other regions. This approach required that doses to all organs included in effective dose calculations could be determined for each single region. The summing up of dose contributions associated with an appropriate set of these views could be regarded as similar to our approach, because various diagnostic views used by GSF more or less corresponded with the regions applied in our calculations, and because all organs required were involved in the calculations by GSF. 
As X-ray field sizes used by GSF for views of the trunk were smaller than the cortesponding body regions exposed in our study, exposure to some tissues was only partially accounted for. For example, for AP-abdominal films $\left(30 \times 40 \mathrm{~cm}^{2}\right)$ the exposed skin surface at the entrance side was calculated to be about $650 \mathrm{~cm}^{2}$, whereas the sexaveraged skin surface at the entrance side of our region "abdomen" was calculated to be about 1350 $\mathrm{cm}^{2}$. Due to this discrepancy, calculated imparted energies to some organs, and hence some DCC-values derived by GSF will be too small.

Calculations by TNO were based on a uniform, total body exposure. These calculations included dose contributions to organs in a single region due to scatter radiation originating outside that region. However, the approach by TNO did not take account of the dose to organs or parts of organs outside of the region considered, resulting from scatter radiation originating in that region (these doses were set to zero). As a consequence, doses to organs located in the region considered will be overestimated, whereas the dose to other organs will be underestimated.

Table 6.10 shows that differences between DCC data sets by TNO and GSF for the regions head and thorax are relatively small. It should be noted that the $\mathrm{DCC}_{\text {thyrain }}$ values for the AP view of the head by GSF were quite high $\left(\mathrm{DCC}_{\text {thyr,ADAM}}, 0.85 \mathrm{~Gy} / \mathrm{Gy}\right.$; $D C C_{\text {thyr,EvA }}, 0.37 \mathrm{~Gy} / \mathrm{Gy}$ ). The $\mathrm{DCC}_{\text {thyrraid }}$ was excluded as it was clear from this value that the thyroid was partly exposed to the primary beam, instead of exposed vo scatter radiation only. Also, $\mathrm{DCC}_{\mathrm{brain}}$ by GSF, resulting from exposure to the neck was associated with partial exposure to the primary beam. Consequently this DCC was excluded too. Differences between DCCs by GSF and TNO for the neck region are partly due to differences in the positions and sizes of the X-ray fields. For AP-views of the thorax and abdomen, GSF computed DCCs for various organs in the abdomen and thorax respectively. However, as the exact positions of the GSF-views were not described, it was not possible to discriminate between (1) partial exposures, and (2) exposures due to scatter. In our calculations, DCCs for organs outside of the region considered were ser to zero.

In order to be able to make allowances for differences between GSF and TNO data sets, TNO performed additional Monte Carlo calculations for two other exposure models for the region "abdomen" of the phantom ADAM (see Table 6.10). Exposure model 2 readily approximated our exposure model. With exposure model 3, the exposure geometry used by GSF was simulated. From Table 6.10 it follows that results obtained by TNOexposure model 3 and results by GSF are quite similar.

Taking the characteristics of the exposure calculation models by GSF and TNO into account, DCCs used in this study $\left(\mathrm{DCC}_{\text {siudy }}\right)$ were derived according to:

- region head: $\mathrm{DCC}_{\text {study }}$ were set equal to DCC TNo

- region neck: Except for the thyroid, all other $\mathrm{DCC}_{\text {study }}$ walues were set equal to wwo times $\mathrm{DCC}_{\mathrm{TNO}} . \mathrm{DCC}_{\mathrm{xtudy}}$ for the thyroid was set equal to $\mathrm{DCC}$ TNo. A multiplication factor of two was used to allow for the neck hole of the apron, which extended some centimetres in the thorax region. It was assumed that the regional masses and the relative depths of the tissues in the neck hole area, were similar to corresponding data for the neck region. This area was accounted for in the thorax region in the TNO exposure model.

- region thorax: $\mathrm{DCC}_{\text {study }}$ were set equal to $\mathrm{DCC}_{\mathrm{TNo}}$; if $\mathrm{DCC}_{\mathrm{TN}}$ and $\mathrm{DCC}_{\mathrm{GSF}}$ differed by more than $10 \%, \mathrm{DCC}_{\text {sudy }}$ were set equal to the mean of these DCCs. 
- region abdomen: $\mathrm{DCC}_{\text {grudy }}$ were set equal to TNO-xposure model 2 , except for red marrow, skin, and bone surface. As adapted GSF-data for these tissues indicated that DCCs could be higher than those obtained from TNO-exposure model 2 , numerical values assigned to these three DCCs were set equal to adapted GSF data.

- regions lower leg, upper arm, and hand: $\mathrm{DCC}_{\text {suaty }}$ were set equal to $\mathrm{DCC}_{\mathrm{TNO}}$.

Final results are summarised in Table 6.11.

Table 6.10 Comparison of organ dose conversion coefficients, DCCs, for ADAM derived from various exposure models, simulating exposures to the abdominal region at a generating potential of $80 \mathrm{kV}^{\mathrm{r}}$

\begin{tabular}{|c|c|c|c|c|c|}
\hline \multirow[t]{2}{*}{$\begin{array}{l}\text { Organ } \\
\text { tissue }\end{array}$} & \multicolumn{3}{|c|}{$\begin{array}{l}\text { Exposure models } \\
\text { TNO }\end{array}$} & \multirow[t]{2}{*}{$\begin{array}{l}\text { Exposure } \\
\text { model GSF }\end{array}$} & \multirow{2}{*}{$\begin{array}{l}\text { DCC used } \\
\text { in this } \\
\text { study }\end{array}$} \\
\hline & 1 & 2 & 3 & & \\
\hline Testes & $b^{b}$ & 0.11 & 0.056 & - & $\alpha^{\prime}$ \\
\hline Red marrow & 0.12 & 0.062 & 0.044 & $0.05(0.07)$ & 0.07 \\
\hline Colon(LLD) & 0.44 & 0.39 & $0.30^{\circ}$ & 0.32 & 0.39 \\
\hline Lungs & - & 0.016 & 0.011 & $<0.01$ & 0.00 \\
\hline Stomith & 0.76 & 0.62 & 0,49 & $0.42(0.46)$ & 0.62 \\
\hline Bladder & 0.72 & 0.70 & 0.59 & 0.63 & 0.70 \\
\hline Liver & 0.57 & 0.35 & 0.25 & $0.23(<0.30)$ & 0.35 \\
\hline Oesophagus & 0.003 & 0.008 & 0.004 & 0.01 & 0.08 \\
\hline Thyroid & - & - & - & - & 0 \\
\hline Skin & 0.15 & 0.11 & 0.082 & $0.11(0.15)$ & 0.15 \\
\hline Bone surface & 0.18 & 0.091 & 0.062 & $0.09(0.11)$ & 0.11 \\
\hline Adrenals & 0.14 & 0.070 & 0.058 & $0.06(0.07)$ & 0.07 \\
\hline Brain & - & - & - & - & 0 \\
\hline U.1. intest. & 0.59 & 0.55 & 0.45 & 0.42 & 0.55 \\
\hline Small intest. & 0.48 & 0.45 & 0.37 & 0.35 & 0.45 \\
\hline Kidneys & 0.14 & 0.11 & 0.083 & $0.09(0.11)$ & 0.11 \\
\hline Muscle & 0.19 & 0.16 & 0.12 & $0.11(0.14)$ & 0.16 \\
\hline Pancreas & 0.37 & 0.26 & 0.20 & 0.18 & 0.26 \\
\hline Spleen & 0.26 & 0.17 & 0.11 & 0.09 & 0.17 \\
\hline Thy mus & - & 0.003 & 0.003 & $<0.01$ & 0 \\
\hline
\end{tabular}

"DCC = mean organ dose / air kerma, freeminair [Gy/Gy]. TNO exposure models 1-3 (Source: personal communication [SC95a]): Model 1: Broad undirectional AP beam; HV, $80 \mathrm{kV}$; beam filtration, $2.5 \mathrm{~mm}$ Al. Model 2: Narrow unidirectional AP beam; HV, $80 \mathrm{kV}$; filtration, $2.5 \mathrm{~mm}$ Al. Field size similar to the region "abdomen". Model 3: Diverging AP beam; HV, $80 \mathrm{kV}$; filtrattion, $2.5 \mathrm{~mm} \mathrm{AI}$ : FSD, $0.85 \mathrm{~m}$ (simulating GSF exposure model). GSF Exposure model (Source: GSF-report "Die Bestimmung von Organdosen in der Röntgendiagnostik" $[D R 93]) . D C C=$ maximum( $D C C_{\text {aldonten }}, D C C_{\text {ithae }}$ ) for AP abdominal and iliac radiographs respecively; $80 \mathrm{kV}, 2.5 \mathrm{~mm} \mathrm{~A} ; \mathrm{FSD} 0.85 \mathrm{~m}$. DCC-values in parentheses are own estimates, derived from original DCC-values by GSF, corrected for geometrical discrepancies, due to limited field sizes. "The minus sign "w" denotes that DCC-value was not provided. "As denoted in a rootnote of Table $6.9, \mathrm{DCC}_{\text {tesses }}$ was set to $1 \mathrm{~Gy} / \mathrm{Gy}$. 
Table 6.11 Sex-averaged organ dose conversion coefficient, DCC, and effective dose conversion coefficient, $\mathrm{ECC}$, for occupationally exposed persons in vascular rodiology

\begin{tabular}{|c|c|c|c|c|c|c|c|c|c|}
\hline $\begin{array}{l}\text { Organ } \\
\text { tissue }\end{array}$ & $\begin{array}{l}\text { Regions } \\
\text { head }\end{array}$ & neck & thorax & $\begin{array}{l}\text { ab- } \\
\text { domen }\end{array}$ & Ihighs & $\begin{array}{l}\text { lower } \\
\text { leg }\end{array}$ & $\begin{array}{l}\text { upper } \\
\text { arm }\end{array}$ & hand & Sum \\
\hline \multicolumn{10}{|c|}{ Organ dose conversion coefficient per region $(G y / G y)$} \\
\hline Gonads & - & - & - & 0.79 & -. & - & - & - & 0.79 \\
\hline Red marrow & 0.026 & 0.004 & 0.04 & 0.07 & 0.007 & - & 0.004 & - & 0.16 \\
\hline Colon & - & - & - & 0.40 & - & - & - & - & 0.40 \\
\hline Lungs & - & - & 0.46 & - & - & - & - & - & 0.46 \\
\hline Stomach & - & - & - & 0.63 & - & - & - & - & 0.63 \\
\hline Bladder & - & - & . & 0.73 & - & - & - & - & 0.73 \\
\hline Breast & - & - & 1.0 & - & - & - & - & - & 1.0 \\
\hline Liver & - & - & - & 0.34 & $\omega$ & - & - & - & 0.34 \\
\hline Oesophagus & 0.007 & 0.070 & 0.18 & 0.005 & $\infty$ & . & . & . & 0.26 \\
\hline Thyroid & - & 1.0 & - & - & - & - & - & - & 1.0 \\
\hline Skin & 0.051 & 0.018 & 0.098 & 0.14 & 0.20 & 0.055 & 0.015 & 0.025 & 0.70 \\
\hline Bone surface & 0.19 & 0.006 & 0.16 & 0.10 & 0.28 & 0.075 & 0.056 & 0.063 & 1.1 \\
\hline Adrenals & - & - & - & 0.08 & - & - & - & - & 0.08 \\
\hline Brain & 0.24 & - & 。 & - & $\infty$ & . & - & - & 0.24 \\
\hline U.1. intest. & - & - & - & 0.56 & - & - & - & - & 0.56 \\
\hline Small intest. & - & -. & - & 0.46 & - & . & . & . & 0.46 \\
\hline Kidneys & - & - & - & 0.12 & - & - & - & - & 0.12 \\
\hline Muscle & 0.014 & 0.014 & 0.085 & 0.17 & 0.15 & 0.026 & 0.003 & 0.007 & 0.51 \\
\hline Pancreas & - & - & - & 0.27 & - & - & - & - & 0.27 \\
\hline Spleen & $\therefore$ & - & - & 0.19 & - & - & - & - & 0.19 \\
\hline Thymus & - & - & 0.92 & - & - & - & - & - & 0.92 \\
\hline Uterus & - & - & - & 0.45 & - & - & - & - & 0.45 \\
\hline
\end{tabular}

Effective dose conversion coefficient per region (Sw/Gy)

$\mathbb{E} C C=\begin{array}{lllllllll}0.007 & 0.055 & 0.125 & 0.355 & 0.012 & 0.002 & 0.001 & 0.001 & 0.56\end{array}$

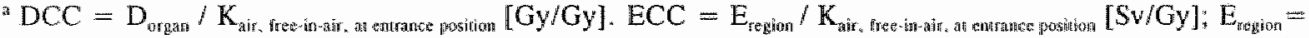
$\Sigma_{T} w_{T} \cdot D C C_{T, r e g e n}$. Except for breast and urerus, all DCC data are sex-averaged values. Column "sump": summation of DCC and ECC-data for the head, neck, thorax, abdomen, thighs, lower leg (2x), upper arm $(2 x)$, and hand $(2 x)$; "To allow for the neck hole, DCCs for red marrow, oesophagus, skin, bone surface and muscle were multiplied by two.

In conclusion, methods applied for the assessment of the effective dose to patients and staff comprise real-time recordings of technique parameters, measurements of the dosearea product, the determination of entrance doses, and Monte Carlo organ dose calculations. Effective dose estimates for the patient were inferred as the sum value of various diagnostic views, which were defined by means of the recorded technique parameters. E/DAP-ratios were derived from diterature data in order to estimate effective doses to patients undergoing vascular examination types that were not studied in detail. The effective dose to staff was calculated as the sum value of contributions from various exposed regions. The entrance dose to these regions was measured with themoluminescent dosemeters. 


\section{Chapter 7}

\section{Exposure conditions of patients in vascular radiology: collected data about technique parameters, dose-area product, patient characteristics and effective dose estimates}

\subsection{Introduction}

Measurement results obtained with the real-time monitoring system, characteristics of the patient, and estimates for the effective dose are discussed for three hospitals: the University Hospital Maastricht (azM), the De Wever Hospital Heerlen (DW), and the Maasland Hospital Sittard (MA). In the course of this study, procedures were classified. according to the anatomical region being investigated and the imaging technique applied. To be able to discuss the collected data in a comprehensive way, procedures have been designated to six main groups (see Table 7.1 ).

The main groups 1 to 5 are composed of intra-arterial arteriography (LA-art) and intravenous DSA procedures (IV-DSA). IA-arteriography comprises conventional radiography. IA-DSA, or both imaging techniques. Main group 6 comprises interventional endovascular procedures. Vascular imaging in the latter procedures is performed with intra-arterial arteriography.

Various procedures could not be classified because of conflicting characteristics. For cxample, procedures which comprised diagnostic imaging of arteries in both the upper and lower part of the body have been excluded from the data set. Condensing the data discussed in this section, various subgroups have been merged, based on the main group they belonged to, and taking similarities in the dose-area product into account. General data on measurements performed in the three hospitals are given in Table 7.2.

In the MA hospital, dosimetric data have been acquired in two periods. In the first period, measurements were performed with overcouch tube geometry. Since it was anticipated that the radiation exposure both to the worker and the patient could be decreased by changing to undertable tube position, a trial was started with the $X$-ray tube in undercouch position. The dose consequences of this change were investigated in the second period. Due to limitations of the imaging system, serial cut film imaging (PUCK) had to be performed in both measuring periods with the $X$-ray tube in the overcouch position.

\section{Computation of mean values}

Typical values per procedure for technique parameters with changeable settings, such as tube high voltage and beam size, have been inferred as the weighted mean, using DAP per 
data record for weighting (see Section 6.3.1). Means and other statistics per procedura type have been computed from these rypical data.

Table 7.1 Types of arteriography and interventional endovascular procedures

\begin{tabular}{|c|c|}
\hline $\operatorname{Code}^{\mathrm{a}}$ & Procedure type \\
\hline \multicolumn{2}{|c|}{ 1. CEREBRAL (CA): } \\
\hline CAI & IA arteriography of cerebral vessels (one side) \\
\hline CA2 2 & IA arteriography of cerebral vessels (two sides) \\
\hline CAiv & IV-DSA of cerebral arteries \\
\hline \multicolumn{2}{|c|}{ 2. UPPER EXTREMITIES: } \\
\hline EA & IA arteriography of vessels in the upper extremities \\
\hline \multicolumn{2}{|c|}{ 3. THORACIC (TA): } \\
\hline TAA & IA arteriography of thoracic vessels \\
\hline TAiv & IV-DSA of thoracic arteries \\
\hline \multicolumn{2}{|c|}{ 4. ABDOMINAL (AA): } \\
\hline AAA & IA arteriography of abdominal vessels \\
\hline $\mathrm{AAB}$ & Selective IA arteriography of abdominal vessels \\
\hline AAiv & IV.DSA of abdominal vessels \\
\hline \multicolumn{2}{|c|}{ 5. PERIPHERAL (PA): } \\
\hline PAn & $\begin{array}{l}\text { IA arteriography of iliac and peripheral vessels in one leg, simple needle } \\
\text { puncture in the femoral artery }\end{array}$ \\
\hline PAs & IA arteriography of iliac and peripheral vessels, Seldinger catheterisation \\
\hline PAiv & IV-DSA of iliac and peripheral anteries \\
\hline \multicolumn{2}{|c|}{ 6. PERCUTANEOUS } \\
\hline \multicolumn{2}{|c|}{ TRANSLUMINAL ANGIOPLASTY (PTA): } \\
\hline PTAa & PTA of abdominal aorta \\
\hline PTAP & PTA of iliac and peripheral arteries \\
\hline PTAI & PTA of one renal artery \\
\hline
\end{tabular}

"These character codes are used throughout this chapter to ideruify different procedure types. Procedures in the MA hospital with overcouch X-ray tube positions are denoted with "../over"; undercouch tube positions with ".../under". If the position of the X-ray tube is not mentioned, the procedures were carried out with undercouch tube positions.

\section{Selection of data discussed in this chapter}

\section{az, M hospital}

In total, data were collected for 988 procedures, comprising 923 angiography and 65 endovascular interventional procedures. About 200 procedures, which were judged as unclassifiable or unreliable, or which were designated in groups with a low number of observations $(<4)$ were deleted from the data set. This section comprises data on 784 procedures.

\section{DW hospital}

Data were collected for 147 procedures. After the exclusion of nonvascular procedures and vascular procedures with less than 3 observations, the remaining group of 118 procedures comprised 91 angiography procedures and 27 PTA procedures. 


\section{MA hospital}

Dosimetric data on IV-DSA procedures and peripheral arteriography procedures in MA were not recorded, because the majority of these procedures were performed in an other diagnostic room, comprising a different type of X-ray equipment. Of 173 angiographic and PTA procedures (142 in the first period and 31 in the second period), six procedures have been excluded from the dose assessment procedure, because of matching errors, or suspected malfunction of the automated monitoring system. Four procedures could not be classified into one of the main groups. Furthermore, a retrospective analysis of recorded data on the angle of rotation of the U-arm showed that four procedures in the second measurement period were carried out with the $X$-ray tube in the overtable position during fluoroscopy. These procedures were excluded as well. The remaining group contained data about 159 procedures.

\section{Statistics:}

The evaluation of the data soon showed that the collected data were usually not distributed normally. This means that the arithmetic mean and standard deviation are of limited use. However, in order to achieve a comprehensive picture, the data presented in this chapter are characterised by mean values. With respect to further analyses, statistics (minimum, maximum, various percentiles, quartiles, and standard errors) on technique parameters, DAP and effective dose are given elsewhere [KI95c].

Table 7.2 Measurements in angiography rooms in three hospitals axM, DW and MA

\begin{tabular}{|c|c|c|c|}
\hline & $\mathrm{azM}$ & DW & MA \\
\hline - Measuring period & May'91-June'93 & Feb'92-Jul'92 & $\begin{array}{l}\text { Aug'92-Mar'93 } \\
\text { Mar'93-Jun'93 }\end{array}$ \\
\hline \multicolumn{4}{|l|}{$\begin{array}{l}\text { - Number of procedures } \\
\text { performed per year: }\end{array}$} \\
\hline arteriography & 400 & 500 & 250 \\
\hline . intervent. vasc. & 60 & 70 & 50 \\
\hline - other procedures & 50 & 120 & 50 \\
\hline \multicolumn{4}{|l|}{$\begin{array}{l}\text { Total number of } \\
\text { procedures monitored, } \\
\text { compiled in this study }\end{array}$} \\
\hline & $988^{b 3}$ & 147 & $\begin{aligned} 142 & \text { (period 1) } \\
31 & \text { (period 2) }\end{aligned}$ \\
\hline \multicolumn{4}{|l|}{$\begin{array}{l}\text { Number of procedures } \\
\text { discussed in this } \\
\text { chapter: }\end{array}$} \\
\hline arteriography & 754 & 91 & 139 \\
\hline intervent. vase. & 30 & 27 & 20 \\
\hline fotal & 784 & 118 & 159 \\
\hline
\end{tabular}

\footnotetext{
"All procedures. except procedures in the first period in MA, have been carried out with undercouch Xray tube positions; "The relatively large difference in the numbers of observations (988) and procedures discussed (784) in the azM hospital reflects the large range and complexity in vascular procedures carried out (i.e. many procedures could not be classified into any group of Table 7.1).
} 


\subsection{Dose-area product and technique parameters for arteriography and percutaneous transluminal angioplasty procedures in the University Hospital Maastricht, the De Wever Hospital Heerlen, and the Maasland Hospital Sittard}

Table 7.3 characterises the use of the imaging systems in the three hospitals, azM, DW and MA, for various types of procedures. Concise descriptions of arteriography and. endovascular radiology can be found in Chapter 4 .

The data comprised in Table 7.3 are illustrated for IA-arteriography of cerebral vessels at one side (CA1) in the azM hospital:

This study involved 43 procedures. Mean fluonoscopy time was 8.9 minutes. Vascular imaging was performed with DSA in 40 procedures $(93 \%)$, in which, on average, $5 \mathbb{A}$ DSA series were made, comprising 82 DSA-frames per procedure. In 7 procedures $(16 \%)$ vascular imaging was performed with serial cut radiography (PUCK). On average, these procedures comprised 4 series, resulting in 28 films per procedure. It should be noted that, as both DSA and radiography were applied in some procedures, the sum value of the relative frequencies for DSA and radiography exceeds $100 \%$.

Similarities and dissimilarities of the characteristic data presented in Table 7.3 are briefly discussed below.

\section{Fluoroscopy}

Mean fluoroscopy times per procedure type varied from about 1 to 15 minutes. Mean fluoroscopy times were very short in IV-DSA procedures (about $1 \mathrm{~min}$ ). Prolonged fluoroscopy ( $>$ about $10 \mathrm{~min}$ ) was associated with PTA procedures and selective catheterisation in abdominal and in cerebral arteriography. Comparison of fluoroscopy shows that cerebral arteriography in azM involved more lengthy fluoroscopy actions than in DW and MA. On the other hand, PTA procedures in azM required less fluoroscopic imaging (exception: PTAr1 in DW). Maximum fluoroscopy times per hospital were equal to 50 minutes, 65 and 45 minutes for azM, DW and MA respectively (not shown in Table 7.3).

\section{DSA}

In DW and MA, vascular imaging procedures always involved DSA. Depending on the procedure type, DSA was used in $25 \%$ to $100 \%$ of the IA-art. procedures in azM. Low frequencies were found in selective catheterisation in abdominal arteriography (AAB) and in PTA of abdominal vessels. Averaged over all procedures in azM, DSA imaging was performed in $87 \%$ of the procedures (not shown in Table 7.3 ).

In azM, the mean number of DSA-series varied from about 2 to 7 , on average comprising about 25 to 115 DSA-frames. In DW and MA 3 to about 11 DSA-series were performed, comprising about 45 to about 145 DSA-frames in DW, and 40 to $170 \mathrm{DSA}$ frames in MA. Due to large differences in the use of serial cut film imaging (PUCK), intercomparison of DSA data in these three hospitals is difficult. Maximum number of DSA-frames per procedure in azM, DW and MA were equal to 250, 220 and 320 respectively (not shown in Table 7.3). 
Table 7.3

Mean fuoroscopy time, DSA and serial cut film radiography (PUCK) in arteriography and PTA procedures ${ }^{\mathrm{S}}$

\begin{tabular}{|c|c|c|c|c|c|c|c|c|}
\hline $\begin{array}{l}\text { Procedure } \\
\text { type }^{\text {b }}\end{array}$ & $\begin{array}{l}\text { No. } \\
\text { of } \\
\text { proc. }\end{array}$ & $\begin{array}{l}\text { Fluoro. } \\
\text { time } \\
\text { (min) }\end{array}$ & $\begin{array}{l}\text { DSA } \\
\text { Rel. } \\
\text { freq. } \\
(\%)\end{array}$ & $\begin{array}{l}\text { No. } \\
\text { of } \\
\text { series }\end{array}$ & $\begin{array}{l}\text { No. } \\
\text { of } \\
\text { frames }\end{array}$ & $\begin{array}{l}\text { PUCK } \\
\text { Rel. } \\
\text { freq. } \\
(\%)\end{array}$ & $\begin{array}{l}\text { No. } \\
\text { of } \\
\text { series }\end{array}$ & $\begin{array}{l}\text { No. } \\
\text { of } \\
\text { frllns. }\end{array}$ \\
\hline \multicolumn{9}{|c|}{ acM hospilat: } \\
\hline $\mathrm{CAl}$ & 43 & 8.9 & 93 & 5 & 82 & 16 & 4 & 28 \\
\hline $\mathrm{CA} 2$ & 67 & 13.7 & 96 & 7 & $\mathbb{1 1 5}$ & 16 & 4 & 26 \\
\hline CAIW & 25 & 1.2 & 100 & 3 & 49 & 0 & & . \\
\hline $\mathrm{EA}$ & 6 & 14.3 & 67 & 4 & 60 & 67 & 3 & 26 \\
\hline TAA & 33 & 4.6 & 70 & 3 & 49 & 48 & 3 & 19 \\
\hline TAiv & 24 & 1.4 & 100 & 3 & 57 & 0 & . & . \\
\hline AAA & 96 & 5.4 & 58 & 2 & 23 & 100 & 2 & 14 \\
\hline $\mathrm{AAB}$ & 24 & 14.8 & 25 & 2 & 37 & 100 & 2 & 30 \\
\hline Aiv & 32 & 0.7 & 100 & 3 & 49 & 0 & . & . \\
\hline PAn & 164 & 3.1 & 93 & 3 & 60 & 93 & 5 & 15 \\
\hline PAs & 88 & 5.2 & 99 & 4 & 71 & 95 & 5 & 15 \\
\hline PAiv & 152 & 1.1 & 100 & 4 & 70 & 0 & . & \\
\hline PTA Ad & 18 & 9.1 & 44 & 2 & 38 & 94 & 3 & 12 \\
\hline PTAP & 7 & 9.6 & 29 & 3 & 35 & 100 & 3 & 13 \\
\hline PTAr! & 5 & 12.8 & 80 & 3 & 32 & 100 & 3 & 15 \\
\hline
\end{tabular}

DW hospiral:

$\begin{array}{lrrrrrr}\text { CA. } & 8 & 6.4 & 100 & 5 & 93 & \\ \text { CA2 } & 13 & 7.9 & 100 & 9 & 125 & \\ \text { EA } & 9 & 3.8 & 100 & 5 & 74 & \\ \text { AAA } & 4 & 2.2 & 100 & 3 & 47 & \\ \text { AAAiv } & 18 & 1.9 & 100 & 4 & 76 & \\ \text { PAn } & 32 & 3.5 & 100 & 10 & 145 & \\ \text { PAs } & 7 & 4.2 & 100 & 7 & 105 & 57 \\ \text { PTAa } & 11 & 12.6 & 100 & 6 & 64 & \\ \text { PTAp } & 13 & 12.1 & 100 & 6 & 69 & \\ \text { PTArl } & 3 & 26.3 & 100 & 4 & 52\end{array}$

MA hospiral:

$\begin{array}{lrrrrrrrr}\text { CAl/over } & 31 & 6.5 & 100 & 7 & 116 & 0 & . & . \\ \text { CA2/over } & 58 & 9.4 & 100 & 10 & 169 & 0 & . & \text {. } \\ \text { CA2-under } & 19 & 8.2 & 100 & 10 & 167 & 0 & . & \text {. } \\ \text { EA/over } & 5 & 2.6 & 100 & 3 & 40 & 0 & . & 18 \\ \text { AAA/over } & 13 & 4.4 & 100 & 4 & 71 & 38 & 2 & 6 \\ \text { AAA-under } & 5 & 5.5 & 100 & 5 & 75 & 40 & 6 & 21 \\ \text { AAB/over } & 8 & 9.1 & 100 & 3 & 61 & 63 & 2 & 8 \\ \text { PTAa/over } & 17 & 15.1 & 100 & 4 & 46 & 100 & 1 & 8 \\ \text { PTAp-tunder } & 3 & 6.3 & 100 & 3 & 47 & 0 & . & \end{array}$

"Means were computed for those procedures, which comprised the indicated imaging mode. Statistics on procedure types with small numbers of observations (e.g. less than 10) should be interpreted as indicative, onlly. The character "," denotes that this data is not applicable; "See Table 7. I for explanation of procedure codes; "Rel. freq. = ratio of procedures with applications of the indicated imaging mode, to the total number procedures of the specified type. 


\section{Serial cut film (PUCK)}

PUCK imaging was performed in $16 \%$ to $100 \%$ of the procedures in a $\mathrm{M}$, in about $50 \%$ of the peripheral arteriography procedures in DW, and in $40 \%$ to $100 \%$ of the abdominal arteriography and PTA procedures in MA. Averaged over all procedures in azM, PUCK imaging was performed in $54 \%$ of the procedures (not shown in Table 7.3 ).

Radiographic imaging inwolved on average 2 to 5 PUCK-series, composed of about 10 to 30 films in azM. In DW, PUCK-imaging was performed in peripheral arteriography only (2 series, 11 films). In MA, PUCK-imaging was applied in abdominal arteriography and PTA-abdomen (overcouch tube positions). The mean number of series per procedure type varied between 1 and 6 , with on average 6 to 18 films per procedure type.

PUCK imaging in MA during PTA with the X-ray tube in the undercouch position (second period) was hampered because of limitations of the imaging systems. As an alternative, imaging was performed with DSA. Since only three PTA procedures could be included in the data set discussed, these data should be considered as indicative only.

\section{Dose-area product (DAP)}

Means for DAP and mean relative contributions of the imaging systems (fluoroscopy, DSA, and serial cut film) to DAP are presented in Table 7.4. This table shows, for instance, that mean DAP for cerebral arteriography of vessels at one side (CA1) in azM was equal to $32 \mathrm{~Gy} \cdot \mathrm{cm}^{2}$. For these procedures, the mean value for relative contributions from fluoroscopy per procedure, averaged over 43 procedures (see Table 7.3 ), was $37 \%$. If DSA imaging was applied (40 procedures; $40=0.93 \times 43$, Table 7.3 ), the mean of relative contributions of DSA to total DAP was $60 \%$. If serial cut films (PUCK) were taken ( 7 procedures; $7=0.16 \times 43$, Table 7.3 ), the mean contribution of radiography to total DAP was equal to $43 \%$. Overall means for DSA and PUCK per procedure type can be found by multiplying the relative frequency of each type by their corresponding relative contributions to total DAP.

It should be noted that average contributions were calculated as the arithmetic mean for the relative contribution per procedure. Average means were not calculated from mean total DAP and mean DAP per imaging mode to prevent that, especially for small groups, single procedures with very high DAP values could have a large influence on this statistic.

Table 7.4 shows that mean DAP per procedure type (roundoff unit is five), varied from about 15 to $75 \mathrm{~Gy} \cdot \mathrm{cm}^{2}$ in azM, from 20 to $85 \mathrm{~Gy} \cdot \mathrm{cm}^{2}$ in DW (exception: PTAr 1 ), and from 20 to $60 \mathrm{~Gy} \cdot \mathrm{cm}^{2}$ in MA (EA procedures exclusive). It should be noted that DAP data for arteriography of the upper limbs (EA) in MA were "very" small.

On average, high DAP values were associated with sellective abdominall arteriography procedures in azM and MA, with PTA of the renalis artery (PTAr1) in azM and DW, and with IV-DSA abdominal procedures in DW.

DAP data collected during fluoroscopy in azM for intra-arterial arteriography procedures were compared with DAP data for IV-DSA procedures. Awerage DAP for fluoroscopy per procedure for intra-aterial arteriography was estimated to be about 4 limes the average DAP value for IV-DSA. 
Table 7.4 Mean dose-area product (DAP) and relative contributions of imaging systems to DAP for arteriography and PTA procedures

\begin{tabular}{lllll}
\hline Procedure & DAP & Mean relative contribution to DAP & \\
type & $\left(\mathrm{Gy} \cdot \mathrm{cm}^{2}\right)$ & Fluoroscopy & DSA & PUCK \\
\hline
\end{tabular}

atM hospiral:

CAL
CAiv
EA

TAA

TAiv 20

AAA $\quad 38$

AAB $\quad 68$

Aiv 32

PAn 13

PAs $\quad 32$

PAIV 36

PTAA 31

PTAP 19

PTArl 76

DW hospilal:

$\begin{array}{lr}\text { CA1 } & 35 \\ \text { CA2 } & 43 \\ \text { EA } & 20 \\ \text { AAA } & 39 \\ \text { AAiv } & 8 \\ \text { PAn } & 61 \\ \text { PAs } & 60 \\ \text { PTAa } & 87 \\ \text { PTAp } & 76 \\ \text { PTArl } & 109\end{array}$

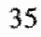

43

20

39

81

61

60

87

76

109

MA hospital:

CAl rover

CA2 hover

CA2 -under

EA lover

AAA lover

AAA -under

AAB / over

PTAa/over

PTAa-under

$37 \%$
$40 \%$
$21 \%$
$60 \%$
$38 \%$
$15 \%$
$37 \%$
$49 \%$
$9 \%$
$34 \%$
$38 \%$
$10 \%$
$60 \%$
$72 \%$
$54 \%$

$11 \%$

$13 \%$

$21 \%$

$14 \%$

$7 \%$

$8 \%$

$16 \%$

$33 \%$

$35 \%$

$48 \%$

$24 \%$

$21 \%$

$21 \%$

$24 \%$

$20 \%$

$23 \%$

$32 \%$

$45 \%$

$34 \%$
$43 \%$

$29 \%$

$58 \%$

$79 \%$

$33 \%$

$27 \%$

$59 \% \quad 44 \%$

$85 \%$

$37 \%$

$32 \%$

$91 \%$

$31 \%$

$32 \%$

$90 \%$

$32 \%$

$28 \%$

$30 \%$

$41 \%$

$43 \%$

$40 \%$

$32 \%$

$27 \%$

$20 \%$

$22 \%$

$89 \%$

$87 \%$

$79 \%$

$86 \%$

$93 \%$

$92 \%$

$76 \%$

$67 \%$

$65 \%$

$52 \%$

$76 \%$

$79 \%$

$79 \%$

$76 \%$

$70 \%$

$76 \%$

$27 \%$

$49 \%$

$31 \%$

$66 \%$

"See Table 7.1 for explanation of procedure codes, and Table 7.3 for numbers of observations and explanations of calculation procedures. As mean relative contributions were computed for those procedures, which comprised the indicated imaging mode, the sum value of mean relative contributions from fluoroscopy. DSA and PUCK can exceed 100\%.

Mean relative contributions of fuoroscopy to DAP in azM varied from $10 \%$ in IV-DSA in the abdominal region and in IV-DSA of the lower limbs, to $70 \%$ in PTA of the lower limbs. Depending on the procedure type, DSA imaging caused about $30 \%$ to $90 \%$ of DAP, serial cut film arteriography contributed about $20 \%$ to $50 \%$. 
In the DW hospital, mean relative contributions of fuoroscopy varied from about $5 \%$ to $10 \%$ in IV-DSA of abdominal vessels and lower limbs arteriography, up to $35 \%$ in PTA procedures. On average, DSA imaging produced about $65 \%$ to $95 \%$ of DAP, serial cut film in peripheral arteriography contributed about $15 \%$.

In the MA hospital, mean relative contributions of fluoroscopy varied from about $15 \%$ in upper limbs arteriography to $45 \%$ in PTA of abdominal vessels. DSA imaging caused about $30 \%$ to $80 \%$ of DAP, serial cut film $20 \%$ to $30 \%$, if applied.

Averaged over all procedures which comprised the indicated imaging mode, the relative contributions to DAP by fluoroscopy, DSA and PUCK are estimated to be $32 \%, 59 \%$ and $38 \%$ in azM, as $17 \%, 83 \%$ and $13 \%$ in $\mathrm{DW}$, and as $25 \%, 70 \%$ and $24 \%$ in $\mathrm{MA}$ respectively. The relative contributions of the imaging modes to the sum values of DAP for these hospitals are given in Table 7.6. The differences show that evaluation of reported results requires that calculation procedures applied are known.

DAP associated with single procedures waried widely. For instance, DAP for CAI in azM varied from $8.4 \mathrm{~Gy} \cdot \mathrm{cm}^{2}$ to $111 \mathrm{~Gy} \cdot \mathrm{cm}^{2}$. Considering all procedures included in Table 7.4. DAP per procedure in azM varied from $0.3 \mathrm{~Gy} \cdot \mathrm{cm}^{2}$ to $250 \mathrm{~Gy} \cdot \mathrm{cm}^{2}$, in DW from about $7 \mathrm{~Gy} \cdot \mathrm{cm}^{2}$ to $225 \mathrm{~Gy} \cdot \mathrm{cm}^{2}$, and in $\mathrm{MA}$ from about $2 \mathrm{~Gy} \cdot \mathrm{cm}^{2}$ to $125 \mathrm{~Gy} \cdot \mathrm{cm}^{2}$ [K195c]. Ratios of maximum to minimum DAP-values, calculated per procedure type, varied from 5 to about 45 (160 in PAn, and 1035 in upper limbs arteriography, EA) in azM, from 4 to about 30 in DW, and from about 2 to 10 in MA. After excluding procedures with very low and very high DAP values (DAP-values lless than the P10-value, and DAP-values above the P90-value of the procedure type in a hospital were deleted), these subgroups, comprising $80 \%$ of the procedures per procedure type, showed small range factors. The majority of P90/P10-ratios varied in azM from 3 to 6 (exception: 23 in upper limbs arteriography); in DW from about 2 to 5 (exception: 12 for PTAp); in MA from about 2 to 5 . This indicates that DAP, associated with the large majority of the procedures, in all three hospitals differed little from the average value of their respective procedure types.

Comparison of DAP-data pertaining to the three hospitals indicates significant differences in the exposures to the patient. In peripheral arteriography (PAn) and PTA (PTAa) major differences are found between azM and DW. Higl DAP for PAn in DW are related to DSA-imaging (estimates for DAP flucrascopy are nearly the same in azM and DW). Differences in PTA procedures are associated with both fluoroscopy and imaging.

\section{Tube high voltage}

Table 7.5 indicates that in azM the average tube high voltage for fluotoscopy varied from about $70 \mathrm{kV}$ to $95 \mathrm{kV}$, for DSA from about $65 \mathrm{kV}$ to $80 \mathrm{kV}$, for PUCK from $60 \mathrm{kV}$ to 75 $\mathrm{kV}$. In DW the tube high voltage in fluoroscopy varied from about $70 \mathrm{kV}$ to $85 \mathrm{kV}$, in DSA from about $60 \mathrm{kV}$ to $85 \mathrm{kV}$, and in PUCK applications the tube high voltage was 62 $\mathrm{kV}$. In MA the tube high voltage for fluoroscopy varied from about $75 \mathrm{kV}$ to $90 \mathrm{kV}(68$ $\mathrm{kV}$ in upper extremity art.), in DSA from about $60 \mathrm{kV}$ to $75 \mathrm{kV}$. In PUCK imaging in MA the tube high voltages was equal to about $70 \mathrm{kV}$. 
Table 7.5 Mean tube high woltage and field size of the primary beam, derived for arteriography and PT procedures"

\begin{tabular}{|c|c|c|c|c|c|c|}
\hline \multirow{2}{*}{$\begin{array}{l}\text { Procedure } \\
\text { type }\end{array}$} & \multicolumn{3}{|c|}{ Tube high wollage (KV) } & \multicolumn{3}{|c|}{ Field size at I wn from focus $\left(\mathrm{cm}^{2}\right)$} \\
\hline & Filuoro & $D S A$ & PUCK & Flworo & $D S A$ & PUCK \\
\hline \multicolumn{7}{|l|}{ awh hospital. } \\
\hline CAl & 76 & 73 & 68 & 370 & 390 & 680 \\
\hline $\mathrm{CA} 2$ & 76 & 71 & 68 & 390 & 450 & 710 \\
\hline CAiv & 74 & 67 & . & 680 & 610 & \\
\hline EA & 69 & 63 & 61 & 490 & 650 & 620 \\
\hline TAA & 80 & 72 & 75 & 540 & 680 & 820 \\
\hline TAiv & 71 & 67 & & 830 & 770 & . \\
\hline AAA & 83 & 82 & 76 & 570 & 600 & 870 \\
\hline AAB & 84 & 75 & 74 & 470 & 730 & 970 \\
\hline AAiv & 76 & 75 & & 930 & 960 & . \\
\hline PAn & 73 & 64 & 61 & 630 & 590 & 630 \\
\hline PAs & 80 & 67 & 66 & 690 & 840 & 870 \\
\hline PAiv & 77 & 73 & & 980 & 990 & \\
\hline PrAa & 86 & 70 & 74 & 480 & 750 & 680 \\
\hline PTAP & 83 & 68 & 64 & 340 & 450 & 520 \\
\hline PTArl & 95 & 78 & 76 & 500 & 640 & 790 \\
\hline \multicolumn{7}{|l|}{ DW hospital: } \\
\hline $\mathrm{CA}_{1}$ & 75 & 66 & . & 310 & 500 & . \\
\hline $\mathrm{CA} 2$ & 75 & 64 & . & 330 & 460 & . \\
\hline $\mathbb{E A}$ & 69 & 58 & . & 300 & 340 & . \\
\hline AAA & 79 & 63 & . & 490 & 560 & . \\
\hline AAiv & 82 & 69 & . & 530 & 550 & . \\
\hline PAn & 78 & 63 & & 410 & 400 & . \\
\hline PAs & 84 & 65 & 62 & 400 & 440 & 1330 \\
\hline PTAa & 82 & 70 & . & 350 & 450 & . \\
\hline PTAp & 79 & 66 & . & 300 & 360 & \\
\hline PTARI & 74 & 65 & 63 & 280 & 330 & 630 \\
\hline \multicolumn{7}{|l|}{ MA hospital: } \\
\hline CAl lover & 75 & 62 & . & 270 & 310 & . \\
\hline CA2 /over & 75 & 66 & . & 300 & 360 & . \\
\hline CA2 under & 75 & 63 & . & 290 & 340 & . \\
\hline EA fover & 67 & 59 & . & 330 & 350 & \\
\hline AAA lover & 86 & 73 & 72 & 360 & 440 & 760 \\
\hline AAA under & 87 & 71 & 71 & 400 & 480 & 760 \\
\hline AAB /over & 90 & 77 & 66 & 340 & 460 & 1030 \\
\hline PTAalover & 84 & 71 & 69 & 250 & 340 & 1010 \\
\hline PT:Aa-under & 87 & 73 & . & 230 & 450 & \\
\hline
\end{tabular}

"See Table 7.3 for explanation of footnotes.

Mean wube high woltages per procedure during fluoroscopy in azM, DW and MA were all three estimated to be $78 \mathrm{kV}$ (ranges: 55 to $105 \mathrm{kV}$ in azM; 57 to $100 \mathrm{kV}$ in DW; and 66 to $99 \mathrm{kV}$ in MA). For DSA-imaging means were estimated to be $70 \mathrm{kV}$ in azM (range 49 to $115 \mathrm{kV}$ ), $65 \mathrm{kV}$ in DW (range 54 to $85 \mathrm{kV}$ ), and $66 \mathrm{kV}$ in MA (range 59 to $92 \mathrm{kV}$ ). On average, PUCK-imaging required tube high voltage settings of $68 \mathrm{kV}$ in azM (range 50 to $96 \mathrm{kV}$; data not presented in Table 7.5 ), $62 \mathrm{kV}$ in DW, and $69 \mathrm{kV}$ (range 57 to 89 $\mathrm{kV}$ : data not presented in Table 7.5) in MA. 
Comparison of tube high voltage settings shows relatively good agreement. On average. tube high voltage (HV) in azM is equal or somewhat lower in lluoroscopy, but higher in DSA. It should be noted that HV setting in DSA in azM is performed manually and in DW and MA automatically.

\section{Field size}

Average field sizes of the primary beam for different procedure types are given in Table 7.5. Field sizes were derived by multiplication of the longitudinal and lateral field lengths, at $1 \mathrm{~m}$ from the focus. In the azM hospital, average field sizes for fluoroscopy and DSA varied from about 400 to $1000 \mathrm{~cm}^{2}$, for PUCK from 500 to $950 \mathrm{~cm}^{2}$. In DW average field sizes for fluoroscopy and DSA varied from about 300 to $550 \mathrm{~cm}^{2}$; the average PUCK field size in peripheral arteriography was estimated to be $1330 \mathrm{~cm}^{2}$. In MA average field sizes varied from about 250 to $400 \mathrm{~cm}^{2}$ for fluoroscopy, from 300 to $500 \mathrm{~cm}^{2}$ for DSA. and from 750 to $1050 \mathrm{~cm}^{2}$ for PUCK.

These data show considerable differences in field sizes in fluoroscopy and DSA in azM on one side, and DW and MA on the other side. These differences are associated with the

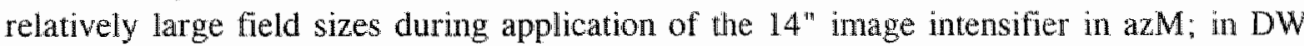
and MA the maximum field size of the image intensifier is $9^{\prime \prime}$. Without further study it is not clear whether there is a net benefit to the patient in using a large image intensifier in the procedure types compared.

For comparative purposes, relative contributions to DAP per imaging intensifier input screen are given in Table 7.6. These data show that the 6" image intensifier is relatively often used in DSA imaging in the MA hospital.

Table 7.6 Relative contribution to DAP for various imaging intensifier sizes

\begin{tabular}{|c|c|c|c|c|c|}
\hline \multirow{2}{*}{$\begin{array}{l}\text { Hospital } \\
\text { lmaging } \\
\text { mode }\end{array}$} & \multicolumn{4}{|c|}{$\begin{array}{l}\text { Relative contribution to DAP } \\
\text { per image intensifier imput screen (II) }\end{array}$} & \multirow{2}{*}{$\begin{array}{l}\text { Relative } \\
\text { contrib. } \\
\text { to DAP per } \\
\text { imaging } \\
\text { mode }\end{array}$} \\
\hline & $6^{\mathrm{e}}$ & $9^{n}$ & $10^{\text {nt }}$ & $14^{\text {mn }}$ & \\
\hline \multicolumn{6}{|l|}{$a z M:$} \\
\hline Fluoroscopy & $6 \%$ & $\mathrm{ab}^{\mathrm{b}}$ & $24 \%$ & $70 \%$ & $39 \%$ \\
\hline $\operatorname{DSA}$ & $10 \%$ & - & $16 \%$ & $74 \%$ & $46 \%$ \\
\hline \multicolumn{6}{|l|}{ DWH. } \\
\hline Fluoroscopy & $16 \%$ & $84 \%$ & ж & - & $20 \%$ \\
\hline DSA & $7 \%$ & $93 \%$ & - & - & $79 \%$ \\
\hline \multicolumn{6}{|l|}{ MA: } \\
\hline Fluoroscopy & $13 \%$ & $87 \%$ & - & $\sim$ & $26 \%$ \\
\hline $\operatorname{DSA}$ & $29 \%$ & $71 \%$ & - & - & $66 \%$ \\
\hline
\end{tabular}

${ }^{3}$ Relative contributions of image intensifier sereens per hospital were inferred as the ratio of the sum value of DAP per image intensifier screen to the total sum of DAP per imaging mode, multiplied by $100 \%$. Relative contributions per imaging mode, per hospital, are given in the column at the right side. Relaive contributions of serial cut film (PUCK) were equal to $15 \%$ for azM, $1 \%$ for DW, and $8 \%$ for $\mathrm{MA}$; " denotes "not applicable". 
Dependence of technique parameters on undercouch and overcouch tube positions in the MA hospital

Comparison of recorded data on technique parameters in the MA hospital for "undercouch X-ray tube positions" in cerebral and abdominal procedures, with corresponding "overcouch X-ray tube positions", showed that these technique parameters were quite similar in both positions. Switching from overtable to undertable positions had no quantitative effect on fluoroscopy time and DSA imaging.

\subsection{Characterisation of the patient}

The radiation risk to the patient, caused by medical X-ray examinations, depends on many factors. Relevant patient related factors are sex, age, and body size. The factors sex and age have been discussed in Chapter 2. Due to characteristics of X-ray imaging, the radiation dose depends on the body size. In order to produce high quality images, only small variations in the radiation intensity at the input plane of the imaging system are tolerable. This is achieved by adapting the tube high voltage, tube current and exposure time. Settings of these technique parameters depend on the radiation attenuation in the patient. Consequently, the intensity and effective energy of the X-ray photons at the entrance side of the patient are related to the mass of the body part that is being examined. According to Lindskoug [L192], differences in the size and shape of the patient cause variations in absorbed doses of more than two orders of magnitude. He states that these sources are even strong enough to dominate other sources of variability. Therefore, data on the size of the patient are required to evaluate measurement results. In this study weight and height of the patient were recorded. Wall and Shrimpton [WA89a] investigated the correlation between entrance dose and body shape, using the factors weight, $\exp \left(\right.$ weight/height) ${ }^{1 / 2}$, and $(70 / \text { weight })^{2}$. Lindskoug [L192] introduced the concept of the "equivalent cylindrical diameter". Both in [WA89a] and in [LI92] it was concluded that the correlations between entrance dose and these factors were weak. As it was not a primary goal in this study to establish a relationship between dose and body size, we characterised the patient body in a relatively simple manner, by calculating the ratio of weight to height.

\section{Statistics on age, weight, and height}

Table 7.7 presents data on all patients comprised in this study in the three hospitals. On average, the height and weight were equal to $174 \mathrm{~cm}$ and $74 \mathrm{~kg}$ for male patients, and to $163 \mathrm{~cm}$ and $68 \mathrm{~kg}$ for female patients. About $90 \%$ of both male and female patients had a length within about -10 to $+10 \mathrm{~cm}$, and a body mass within about -18 to $+18 \mathrm{~kg}$ of their respective mean values. As a measure for the size of the body, the ratio of weight to height was calculated. The mean weight/height ratio was $43 \mathrm{~kg} / \mathrm{m}$ and $41 \mathrm{~kg} / \mathrm{m}$ for males and females respectively. Excluding extremely large and small patients, typical ranges for arteriography patients (taking the 1 - and 99-percentile values as representative boundary values) were derived for height, weight and the weight/height-ratio (not shown in Table 7.7). Height varied from 150 to $179 \mathrm{~cm}$ for females, and from 158 to $189 \mathrm{~cm}$ for males. Weight varied between 43 and $105 \mathrm{~kg}$ for females, and between 48 and $100 \mathrm{~kg}$ for males. Weight/height-ratios varied from 21 to $88 \mathrm{~kg} / \mathrm{m}$, and from 21 to $84 \mathrm{~kg} / \mathrm{m}$ for females and males respectively. 
On average, both male and female patients were 60 years old. Only $5 \%$ of the patients was younger than about 30 years. Seventy five percent was over 50 years old.

The data of the three groups of patients examined in the three hospitals were analysed. The null hypothesis that data were random samples from normal distributions had to be rejected for the following data: age of males; age, weight, and weight/height ratio of females (Shapiro-Wilk statistics $P<.05$; SAS statistical software [SA89]). Using the nonparametric k-sample Kruskal-Wallis comparison test [SA89], the distributions of age, weight, height and weightheight ratio for these three hospitals, were compared. It was concluded that differences between these three hospitals were not statistically significant $(\mathrm{p}<.05)$.

Table 7.7 Height, weight, ratios of height to weight, and age for female and male patients in arteriography in three hospitals ${ }^{a}$

\begin{tabular}{|c|c|c|c|c|c|c|c|c|c|c|c|c|}
\hline & $\mathrm{N}$ & MIN & PS & P10 & $\mathrm{P} 25$ & P75 & $\mathrm{P} 90$ & P95 & MAX & MEDIAN & MEAN & SEM \\
\hline \multicolumn{13}{|c|}{ Height (cm): } \\
\hline Female & 527 & 132 & 154 & 155 & 160 & 168 & 170 & 172 & 185 & 164 & 163 & $<0.5$ \\
\hline Male & 831 & 130 & 162 & 165 & 170 & 178 & 183 & 185 & 194 & 174 & 174 & $<0.5$ \\
\hline \multicolumn{13}{|c|}{ Weight $(\mathrm{kg})$ : } \\
\hline Female & 5114 & 40 & 50 & 52 & 58 & 76 & 85 & 90 & 108 & 66 & 68 & 1 \\
\hline Male & 806 & 43 & 57 & 60 & 67 & 82 & 88 & 91 & 127 & 74 & 74 & $<0.5$ \\
\hline \multicolumn{13}{|c|}{ Weightheight $(\mathrm{kg} / \mathrm{m})$ : } \\
\hline Female & 513 & 25 & 31 & 33 & 36 & 47 & 51 & 55 & 65 & $4 \|$ & 41 & $<0.5$ \\
\hline Male & 805 & 26 & 34 & 36 & 39 & 46 & 50 & 52 & 69 & 43 & 43 & $<0.5$ \\
\hline \multicolumn{13}{|l|}{ Age $(y):$} \\
\hline Female & 563 & 19 & 30 & 36 & 50 & 72 & 80 & 83 & 93 & 63 & 60 & 1 \\
\hline Male & 867 & 16 & 33 & 41 & 51 & 69 & 75 & 79 & 90 & 62 & 60 & $<0.5$ \\
\hline
\end{tabular}

${ }^{3} \mathrm{~N}$ represents the number of patients. P5, P10, P25, P75, P90, and P95 denote 5-, 10-, 25-, 75-, 90 - and 95-percentile values respectively. SEM denotes the standard error of the mean; Sample sizes for height, weight and age differ because of missing data.

From a nonparametric comparison of height and weight of patients for ten different procedure types, it was concluded that differences between procedure types were not statistically significant. However, the factor "age" did show some differences. As can be seen in Table 7.8, patients referred for simple needle punctures for arteriography of one leg (PAn) were relatively old (mean age is 67 years for males, and 75 for females). On the other hand, patients in the groups abdominal arteriography (AA), cerebral arteriography (CA), and upper limbs arteriography (EA) were relatively young; mean ages for males were 54,59 and 53 years respectively, and mean age for females were 57,54 and 44 years respectively.

It should be stressed that one should carefully examine patient characteristics before getting to a general description. This is illustrated by a sample of patients referred for phlebography of the spermatic vein $(n=18)$. These patients, also designated to the group of angiography patients, deviated significantly with respect to age (mean $=34$ years, $\min =23$ years, $\max .=49$ years), whereas statistics on height and weight were ecual to corresponding statistics of the other groups. 
Table 7.8 Age of malle and female parients in arteriography in three hospitals

\begin{tabular}{|c|c|c|c|c|c|c|c|c|c|c|c|c|}
\hline \multirow{2}{*}{$\begin{array}{l}\text { Gender } \\
\text { Procedure } \\
\text { rype }\end{array}$} & \multicolumn{12}{|c|}{ Agt $(y)$} \\
\hline & $\mathbb{N}$ & MIN & PS & $\mathrm{P} 10$ & $P 25$ & P75 & P90 & $\mathrm{P} 95$ & MAX & MEDIAN & MEAN & SEM \\
\hline \multicolumn{13}{|l|}{ Females: } \\
\hline $\mathrm{CA}$ & 121 & 19 & 26 & 32 & 41 & 68 & 72 & 76 & 82 & 5 & 54 & 1 \\
\hline $\mathrm{EA}$ & 23 & 19 & 24 & 26 & 30 & 61 & 68 & 70 & 80 & 40 & 44 & 3 \\
\hline $\mathrm{TA}$ & 21 & 33 & 35 & 40 & 55 & 71 & 72 & 77 & 79 & 68 & 62 & 3 \\
\hline$A A A$ & 89 & 29 & 30 & 35 & 50 & 68 & 72 & 78 & 82 & 58 & 57 & 1 \\
\hline AAIY & 19 & 29 & 29 & 35 & 44 & 71 & 80 & 90 & 90 & 59 & 58 & 4 \\
\hline PAn & 93 & 26 & 55 & 65 & 69 & 82 & 87 & 88 & 92 & 78 & 75 & 1 \\
\hline PAs & 36 & 47 & 49 & 50 & 54 & 78 & 84 & 85 & 86 & 69 & 67 & 2 \\
\hline $\mathbb{P A i v}$ & 38 & 28 & 30 & 43 & 55 & 72 & 75 & 81 & 82 & 66 & 63 & 2 \\
\hline PTA & 41 & 22 & 38 & 43 & 53 & 76 & 81 & 85 & 88 & 64 & 63 & 2 \\
\hline \multicolumn{13}{|l|}{ Males: } \\
\hline$C A$ & 170 & 16 & 31 & 39 & 51 & 68 & 75 & 77 & 84 & 61 & 59 & 1 \\
\hline $\mathrm{EA}$ & 23 & 34 & 34 & 34 & 43 & 63 & 66 & 73 & 74 & 52 & 53 & 3 \\
\hline TA & 25 & 36 & 43 & 45 & 55 & 67 & 71 & 72 & 74 & 62 & 60 & 2 \\
\hline$A A A$ & 95 & 17 & 22 & 32 & 45 & 66 & 72 & 78 & 90 & 56 & 54 & 2 \\
\hline AAiv & 46 & 34 & 43 & 49 & 54 & 70 & 75 & 78 & 79 & 65 & 62 & 2 \\
\hline PAn & 114 & 30 & 45 & 54 & 60 & 75 & 81 & 84 & 90 & 68 & 67 & 1 \\
\hline PAs & 79 & 38 & 49 & 51 & 58 & 71 & 79 & 82 & 83 & 64 & 64 & 1 \\
\hline PAiv & 114 & 37 & 44 & 48 & 55 & 70 & 74 & 80 & 83 & 64 & 62 & 1 \\
\hline PTA & 89 & 34 & 44 & 46 & 52 & 67 & 73 & 35 & 77 & 60 & 60 & 1 \\
\hline
\end{tabular}

"N represents the number of patients. P5, P10, P25, P75, P90, and P95 denote 5-, 10-, 25-, 75-, 90 and 95-percentile values respectively. SEM denotes the standard error of the mean; "See Table 7.1 for explanation of procedure codes.

Mean values for age, height, weight, and weight/height ratio were computed for each single combination of sex, procedure type, and hospital (criterion: group size $>20$ ). It was inferred that mean walues for height of males and females varied between 172 to 177 $\mathrm{cm}$, and between 161 to $166 \mathrm{~cm}$ respectively. Mean values for weight of males varied between 71 and $83 \mathrm{~kg}$, of females between $64 \mathrm{~kg}$ and $71 \mathrm{~kg}$. Mean values for ratios of weight to height for males and females varied between 39 and $47 \mathrm{~kg} / \mathrm{m}$.

In conclusion, the data presented in Table 7.7 and Table 7.8 show that patients referred for vascular radiology and interventional endovascular procedures are relatively old. Considering the large differences found in stochastic risks for the elderly, compared with the "average member of the general public" (see Figure 2.1), applications of the quantity effective dose as defined by ICRP [IC91]] should be used with care.

Data on height and weight seem to indicate that current dimensions of phantoms applied in Monte Carlo organ dose calculations are relatively small. On average, patients are taller (female: $3 \mathrm{~cm}$, male : $4 \mathrm{~cm}$ ), and heavier (female: $8 \mathrm{~kg}$; male $4 \mathrm{~kg}$ ) than the Monte Carlo phantom. Using the average weight/height-ratios of 41 and $43 \mathrm{~kg} / \mathrm{m}$ for female and male patients, it follows that patients are slightly obese, compared with MC phantoms. 


\subsection{Effective dose estimates for the patient, using published data on E/DAP-ratios}

Using a very simple method, estimates for the effective dose to patients (E) will be derived for every procedure type encompassed in this study. These estimates are computed by multiplying collected DAP-data by E/DAP-ratios. The next chapter will presented detailed dose calculations, comprising quantitative data for various diagnostic view/s and Monte Carlo organ doses per view, for a number of selected procedure types. In order to assess the accuracy of the rough estimates for E, based on E/DAP-ratios, these estimates will be compared with these more elaborated estimates for $\mathbb{E}$ (Chapter 8).

Ratios of $E$ to DAP, derived from published data on $E$ and DAP, and from calculated results using XDOSE, are summarised in Section 6.4 (Table 6.7). Average results of DAP-measurements for various types of arteriographic and interventional endovascular procedures are given in Table 7.4.

PA- and AP-exposure geometries were taken into account separately, as far as these conditions could be inferred from easily availabie data on system features, medical examination protocols and DAP-results. In azM all procedures were carried out with undercouch X-ray tube positions. PUCK imaging in DW was performed with overcouch tube positions; fluoroscopy and DSA imaging was assumed to be carried out with undercouch $\mathrm{X}$-ray tube. No allowances have been made for fluoroscopic pre-viewing associated with overcouch PUCK imaging. Overcouch tube position was assumed for all diagnostic views in the first period in MA. In the second period fluoroscopy and DSA was carried out with undercouch tube, PUCK-imaging with overcouch tube positions.

In order to estimate the effective dose for procedures with undercouch tube positions, allowances were made for the radiation attenuation in the patient support by multiplying the DAP value by 0.8 (note: first-HVL at $80 \mathrm{kV}$ was $3.6 \mathrm{~mm} \mathrm{Al}$ in azM, and $2.9 \mathrm{~mm} \mathrm{AI}$ in DW and MA).

The accuracy of estimates for E mainly depends on the error in the E/DAP-ratio. Errors in collected. DAP-data, estimated to be about $5 \%$, are of no significance in this context. As can be seen in Section 6.4, the range of estimated E/DAP-ratios for vascular radiology is quite small $\left(0.1\right.$ to $\left.0.3 \mathrm{mSv} \cdot \mathrm{Gy} \cdot \mathrm{cm}^{-2}\right)$. It is highly probable that more elaborated dose estimation procedures will result in a larger range of dose conversion factors. It follows that the variation in effective doses to the patient may be greater than indicated in this section.

Results presented in Table 7.9 show that mean effective doses to patients per procedure type vary between about 1 and $18 \mathrm{mSv}$. Upper levels of effective doses per procedure type vary between about $5 \mathrm{mSv}$ and $40 \mathrm{mSv}$. Except for some types of PTA-procedure in azM and DW (PTAr in azM, PTAa and PTAp in DW), and abdominal arteriography in MA (AAA/over), differences in median and mean values per procedure type were quite small (less than $1 \mathrm{mSv}$ ). Effective dose estimates per procedure type and per hospital are discussed in the following paragraph. 
Truble 7.9 Effectwe dose estimates for patienis in arteriographic and interventional endovascular procedures, inferred from DAP and E/DAP ratios $^{3}$

\begin{tabular}{|c|c|c|c|c|c|c|c|c|c|}
\hline \multirow[t]{3}{*}{$\begin{array}{l}\text { Procedure } \\
\text { type }\end{array}$} & \multicolumn{3}{|c|}{ azM hospital } & \multicolumn{3}{|c|}{ DW Rospital } & \multicolumn{3}{|c|}{ MA hospinal } \\
\hline & \multirow{2}{*}{$\begin{array}{l}\text { No. } \\
\text { of } \\
\text { proc. }\end{array}$} & \multicolumn{2}{|c|}{$\begin{array}{l}\text { Effective dose } \\
\text { (mSv) }\end{array}$} & \multirow{2}{*}{$\begin{array}{l}\text { No. } \\
\text { of } \\
\text { proc. }\end{array}$} & \multicolumn{2}{|c|}{$\begin{array}{l}\text { Effeciwe dose } \\
(\mathrm{m} S \mathrm{~s})\end{array}$} & \multirow{2}{*}{$\begin{array}{l}\text { No. } \\
\text { of } \\
\text { proc. }\end{array}$} & \multicolumn{2}{|c|}{$\begin{array}{l}\text { Effecrive do } \\
(\mathrm{mSw})\end{array}$} \\
\hline & & Mean & Max & & Mean & Max. & & Mean & $\operatorname{Max}$ \\
\hline \multicolumn{10}{|c|}{ Arteriography: } \\
\hline CAL & 43 & 2.6 & 9 & 8 & 2.8 & 6 & . & & \\
\hline CAl/over & & & & . & & & 31 & 4.3 & 10 \\
\hline $\mathrm{CA}_{2}$ & 67 & 3.7 & 20 & 13 & 3.4 & 7 & 19 & 3.0 & 4 \\
\hline CA2/over & & & . & & . & & 58 & 7.9 & 22 \\
\hline CAIV & 25 & 1.1 & 4 & . & . & . & & & : \\
\hline $\mathbb{E A}$ & 6 & 3.3 & 9 & 9 & 2.4 & 5 & 5 & 0.9 & 2 \\
\hline TAA & 33 & 3.7 & 11 & - & . & . & & . & . \\
\hline TAiv & 24 & 2.4 & 10 & . & & . & : & $\therefore$ & . \\
\hline AAA & 96 & 6.0 & .27 & 4 & 6.3 & 9 & 5 & 6.8 & 9 \\
\hline AAA/over & & & & . & . & . & 13 & 13.4 & 38 \\
\hline$A A B$ & 24 & 10.8 & 26 & . & . & . & . & . & \\
\hline AAB/over & . & & & & . & - & 8 & 18.3 & 28 \\
\hline AAIV & 32 & 5.0 & 16 & 18 & 13.0 & 27 & . & 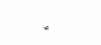 & . \\
\hline PAn & 164 & 1.0 & 4 & 32 & 4.9 & 11 & . & " & . \\
\hline PAs & 88 & 2.6 & 11 & 7 & 5.0 & 8 & . & . & \\
\hline PAily & 152 & 5.7 & 15 & . & . & . & . & . & \\
\hline
\end{tabular}

Interventional procedures:

\begin{tabular}{|c|c|c|c|c|c|c|c|c|}
\hline PTAa & 18 & 4.9 & 9 & 11 & 14.0 & 36 & 3 & 4.8 \\
\hline PTAa/over & & & . & . & & & 17 & 11.0 \\
\hline PTAP & 7 & 3.0 & 5 & 13 & 12.1 & 36 & . & . \\
\hline PTArl & 5 & 12.2 & 18 & 3 & 17.4 & 29 & & \\
\hline
\end{tabular}

"E/DAP-ratios and DAP-data are given in Table 6.7 and Table 7.4 respectively; "See Table 7.1 for explanation of the procedure codes: ". / /over" denotes procedures with overcouch X-ray tube geometry.

Comparison of $E$ in various procedure types in the three hospital azM, DW and $M A$

- In cerebral arteriography of vessels at one side (CA1), mean effective doses in azM and DW are equal $(E=2.6-2.8 \mathrm{mSv})$. In overcouch wbe geometry procedures in $\mathrm{MA}$ (CA1/over), the effective dose is a factor of about 1.6 higher $(\mathrm{E}=4.3 \mathrm{mSv}$ ) than in undercouch geometry in azM and DW (CA1).

- Arteriography of cerebral vessels at both sides (CA2) results in an effective dose of about $3.4 \mathrm{mSv}$ (range, undercouch tube geometry $3.0-3.7 \mathrm{mSv}$ ). Procedures in MA show that in overcouch tube geometry procedures (CA2/over) the mean effective dose is a factor of 2.6 bigher than in undercouch geometry procedures (CA2) (7.9 versus $3.0 \mathrm{mSv}$ ). - The effective dose from IV-DSA cerebral procedures (CAiv) is significantly lower than from IA-cerebral arteriography (CA1, CA2) (1.1 $\mathrm{mSv}$ versus 2.6 to $3.7 \mathrm{mSv}$ )

- The same conclusion holds for IV-DSA thoracic arteriography (TAiv) and IA-thoracic arteriography (TAA) (IV-DSA $2.4 \mathrm{mSv}$, versus IA-art. $3.7 \mathrm{mSv}$ ).

- Averages for $\mathrm{E}$ for non-selective IA-abdoninal arteriography (AAA) are equal to about $6 \mathrm{mSv}$. On average, overcouch tube positions (AAA/over) result in effective doses twice as high as undercouch tube positions (AAA). 
In undercouch tube geometries, effective doses associated with selective 1 A-abdominal arteriography $(\mathrm{AAB})$ are a factor of about $1.8(1.8=10.8 / 6)$ higher than non-selective $1 \mathrm{~A}$ abdominal procedures (AAA). Effective doses from overcouch tube positions (AAB/over) are a factor of about 1.6 higher than from undercouch tube positions (AAB).

The average effective dose from IV-DSA abdominal arteriography in azM (AAiv) is about as high as from LA-abdominal arteriography (AAA), whereas in DW IV-DSA abdominal procedures (AAiv) result in a mean effective dose twice as high as IA-art. procedures (AAA) (DW: IV-DSA $13 \mathrm{mSv}$, IA-art. $6.3 \mathrm{mSv}$ ).

- Peripheral arteriography of the iliac region and one leg, using the simple needle puncture technique, (PAn) results in azM in a mean effective dose of about $1 \mathrm{mSv}$; in DW the effective dose is estimated to be about $5 \mathrm{mSv}$.

The effective dose associated with Seldinger catheterisation for vascular imaging of the iliac region and both legs in azM, (PAs) is estimated to be about a factor of 2.5 higher than the simple needle approach for vascular imaging of one leg. In DW no differences are found between these techniques. Comparison of azM with $D W$ shows that $E$ in $D W$ is higher than in azM. In azM, IV-DSA arteriography of both legs (PAiv) is about a factor of 2 higher than for IA-arteriography (PAs) (IV-DSA: $5.7 \mathrm{mSv}$, IA-art.: $2.6 \mathrm{mSv}$ ).

- Effective doses associated with PTA procedures in azM (5 mSv) are lower than in DW. The mean effective dose from PTA of renal arteries (PTAr1) is relatively high in both hospitals. Data collected in MA indicate a high effective dose for overcouch tube geometries.

Comparison of $\mathrm{E}$ for arteriography of the abdominal (AAA), iliac and lower legs regions (PAs, PAn) with E for corresponding PTA procedures (PTAa, PTAp) show relatively small differences only.

As mentioned in the introductory part of this chapter, procedures which could not be designated unambiguously to a defimed group were excluded from the data set discussed. In the following paragraph estimates for typical and maximal values for $\mathbb{E}$ have been derived based on all DAP-data collected.

- Maximum and typical values for E/DAP-ratios of 0.2 and $0.15 \mathrm{mSv} \cdot \mathrm{Gy}^{-1} \cdot \mathrm{cm}^{-2}$ respectively, were used for undercouch X-ray tube geometries in azM and DW, and 0.3 and 0.2 $\mathrm{mSv} \cdot \mathrm{Gy} \mathrm{y}^{-1} \cdot \mathrm{cm}^{-2}$ respectively, for overcouch geometries in MA in the first period.

- The upper level and mean value for DAP in 988 procedures in azM were equal to 250 $\mathrm{Gy} \cdot \mathrm{cm}^{2}$ and $35 \mathrm{~Gy} \cdot \mathrm{cm}^{2}$ respectively. Maximum and mean values in 125 procedures in DW were equal to $122 \mathrm{~Gy} \cdot \mathrm{cm}^{2}$ and $60 \mathrm{~Gy} \cdot \mathrm{cm}^{2}$ respectively. From data collected in both period 1 and 2 in MA the maximal and mean values for 173 procedures were estimated to be $128 \mathrm{~Gy} \cdot \mathrm{cm}^{2}$ and $35 \mathrm{~Gy} \cdot \mathrm{cm}^{2}$ respectively.

From the data described above, maximum effective doses for azM, DW and MA were estimated to be $50 \mathrm{mSv}, 25 \mathrm{mSv}$ and $38 \mathrm{mSv}$ respectively; mean effective doses for azM, DW and MA were estimated to be $5 \mathrm{mSv}, 9 \mathrm{mSv}$ and $7 \mathrm{mSv}$ respectively. If, at worst, the highest possible DAP-value $\left(250 \mathrm{~Gy} \cdot \mathrm{cm}^{2}\right.$ ) resulted from vascular imaging of the prone patient with overcouch $X$-ray tube positions (AP views and/or lateral views), the elfective dose to the patient would be $75 \mathrm{mSw}$. 


\subsection{Correlation analysüs}

In this section the associations between patient age and size versus the fluoroscopy time and dose-area product are discussed. As the results of the Shapiro-Wilk test statistic [SA88] showed that a relatively large number of groups of observation could not be considered as random samples from normal distributions, the Spearman rank-order correlation coefficient $r_{5}$ has been used to quantify the strength of association between observed variables. Compared with the most powerful parametric measure, the Pearson product-moment correlation coefficient, the efficiency of the Spearman rank correlation coefficient is about $91 \%$ [S188].

Computed $r_{5}$-values, the significance probability under the null hypothesis that there is no association, and the number of paired observations are given in tables 7.10 to 7.12 . Associations of variables are discussed below. It should be stressed that conclusions are only valid within the ranges of variables as given in this chapter.

The purpose of this correlation analysis is to investigate whether some relations that are expected on the basis of general consiclerations are supported by experimental results. For instance, the correlation between age and fluoroscopy time may indicate differences or similarities in the conditions of blood vessels as a function of age. The correlation between patient size, quantified by weight/height-ratios, and dose-area product may indicate that the $X$-ray output depends on the size of the patient (slender, normal, obese).

\section{Patient age}

Table 7.10 shows that weak or no correlations were found between the patient age and the variables height, weight and weight/height-ratio. Older patients tend to be somewhat smaller. "The height-weight correlation for females $\left(r_{s}=0.24\right)$ is weaker than for males $\left(r_{s}\right.$ $=0.46)$. However, both figures are relatively small, indicating that the patient weight is not strongly correlated with the height.

Table 7.10 Spearman rank correlation coefficients for age and height versus weight, height and weight/height-ratio

\begin{tabular}{|c|c|c|c|c|c|}
\hline & & & Weight & Height & Ratio $_{\text {we cighther hight }}$ \\
\hline \multirow[t]{6}{*}{ Age } & \multirow[t]{3}{*}{ Male } & $r_{s}$ & -0.07 & -0.15 & -0.01 \\
\hline & & $\mathrm{p}$ & 0.05 & $<0.01$ & 0.71 \\
\hline & & $\mathrm{n}$ & 738 & 759 & 727 \\
\hline & \multirow[t]{3}{*}{ Female } & $\mathbb{1}_{s}$ & 0.09 & -0.17 & 0.13 \\
\hline & & $\mathrm{p}$ & 0.04 & $<0.01$ & $<0.01$ \\
\hline & & $\mathrm{n}$ & 467 & 476 & 460 \\
\hline \multirow[t]{6}{*}{ Height } & \multirow[t]{3}{*}{ Mate } & $r_{s}$ & 0.46 & 1 & 0.24 \\
\hline & & $\mathrm{p}$ & $<.01$ & . & $<.01$ \\
\hline & & $\mathrm{n}$ & 727 & . & 727 \\
\hline & \multirow[t]{3}{*}{ Female } & $r_{s}$ & 0.24 & $i$ & 0.08 \\
\hline & & $\mathrm{p}$ & $<.01$ & . & 0.10 \\
\hline & & $\mathrm{n}$ & 460 & . & 460 \\
\hline
\end{tabular}

\footnotetext{
$r_{\mathrm{s}}=$ Spearman rank correlation coefficien; $p=$ Significance probability under the null hypothesis that $r_{\mathrm{s}}$ is zero: $\mathrm{n}=$ Number of paired observations.
} 
It is concluded from Table 7.11 that the wariables age and fuoroscopy time are not associated, or that existing associations are small compared with other sources of variations. Apart from the procedure type TAiv (females), the same conclusion holds for the association between age and dose-area product. Apparently, the difficulty of the angiographic procedure does not strongly depend on age.

Table 7.11 Spearman rank correlation coefficients for age versus furoroscopy time and diase-areat product for selected types of vascular procedures ${ }^{\mathrm{a}}$

$\begin{array}{rlllll}\text { Proc type } \rightarrow \text { AA AAiv CA PAn PAs PAiv } & \text { PA }\end{array}$

Flioroscopy time

\begin{tabular}{|c|c|c|c|c|c|c|c|c|c|}
\hline \multirow[t]{6}{*}{ Age } & \multirow[t]{2}{*}{ Male } & $F_{8}$ & 0.18 & -.04 & 0.04 & 0.08 & 0.04 & $\cdots .11$ & 0.18 \\
\hline & & $\mathrm{p}$ & 0.13 & 0.87 & 0.72 & 0.48 & 0.78 & 0.23 & 0.57 \\
\hline & \multirow{4}{*}{ Female } & n & 70 & 24 & 87 & 85 & 60 & 112 & 13 \\
\hline & & $r_{s}$ & 0.23 & . & 0.31 & 0.01 & 0.11 & 0.30 & 0.50 \\
\hline & & $p$ & 0.06 & . & 0.01 & 0.94 & 0.58 & 0.08 & 0.11 \\
\hline & & $n$ & 65 & . & 64 & 75 & 28 & 36 & 12 \\
\hline
\end{tabular}

Dose-area product

\begin{tabular}{llrrrrrrr} 
Age Male & $\mathrm{r}_{\mathrm{s}}$ & 0.33 & 0.25 & -.05 & -.08 & 0.18 & -.02 & 0.24 \\
& $\mathrm{p}$ & $<.01$ & 0.25 & 0.67 & 0.44 & 0.18 & 0.76 & 0.44 \\
& $\mathrm{n}$ & 70 & 24 & 87 & 89 & 60 & 113 & 13 \\
Female & $\mathrm{r}_{\mathrm{s}}$ & 0.35 &. & 0.27 & -.10 & 0.18 & 0.24 & 0.79 \\
& $\mathrm{p}$ & $<.01$ &. & 0.03 & 0.39 & 0.35 & 0.15 & $<.01$ \\
& $\mathrm{n}$ & 65 &. & 67 & 75 & 28 & 38 & 12 \\
\hline
\end{tabular}

\footnotetext{
"See Table 7.1 for explanation of procedure codes; $r_{s}=$ Spearman rank correlation coefficient; $p=$ Significance probability under the null hypothesis that there is no association; $n=$ Number of paired observations.
}

\section{Patient body size}

The association between the patient body size and the X-ray output rate has been examined for various groups of procedures (see Table 7.12). The X-ray oulput rate was defined by three derived variables: (1) $\mathrm{DAP}_{\text {fluorascapy }}$ divided by the fluoroscopy time, (2) $\mathrm{DAP} \mathrm{P}_{\text {puck }}$ divided by the number of PUCK-films, (3) $\mathrm{DAP}_{\mathrm{DSA}}$ divided by the number of DSAframes. Patient body size was characterised by the ratio weight/height.

Table 7.12 shows large variations in calculated strength of association. The general picture can be summarised as follows:

- In cerebral arteriography (CA) weak associations are found between body size and fluoroscopy, whereas at the $5 \%$ significance level no associations are found for DSA. The statistical association between patient size and PUCK is not consistent for male and female patients.

- In intra-arterial abdominal arteriography (AA) and intravenous DSA abdominal arteriography (AAiv), body size and X-ray output rate, both in fluoroscopy and DSA are highly probably related. In AA procedures patient size and PUCK seems to be associated as well.

- In intra-arterial arteriography of the lower limbs (PAn and PAs), associations are found for patient size and both fluoroscopy and PUCK. No association was found for the patient size and DSA imaging. 
Intravenous DSA peripheral arteriography (AAiv, and PAiv) shows associations between patient size and both fluoroscopy and DSA.

Table 7.12 Spearman rank correlation for patient body size (weight/height-ratio) and the X-ray: output ${ }^{*, 6}$

\begin{tabular}{|c|c|c|c|c|c|c|c|c|c|}
\hline \multirow{2}{*}{$\begin{array}{l}\text { Patient } \\
\text { group }\end{array}$} & \multicolumn{3}{|c|}{ Fluoroscopy } & \multicolumn{3}{|l|}{ DSA } & \multicolumn{3}{|c|}{ Serial cur film } \\
\hline & $r_{s}$ & $\mathrm{p}$ & $n$ & $\mathbb{r}_{5}$ & $\mathrm{p}$ & n & $r_{s}$ & $\mathrm{p}$ & $\mathrm{n}$ \\
\hline $\mathrm{CA}, \mathrm{M}$ & 0.47 & $<.01$ & 82 & 0.20 & 0.08 & 80 & 0.68 & $<.01$ & 15 \\
\hline $\mathbb{C A}, \mathbb{F}$ & 0.38 & $<.01$ & 58 & 0.24 & 0.07 & 57 & 0.44 & 0.18 & 11 \\
\hline$A, M$ & 0.43 & $<.01$ & 66 & 0.46 & $<.01$ & 36 & 0.53 & $<.01$ & 66 \\
\hline $\mathrm{AA}, \mathrm{F}$ & 0.66 & $<.01$ & 61 & 0.35 & 0.05 & 31 & 0.51 & $<.01$ & 61 \\
\hline AAir, M & 0.52 & 0.01 & 24. & 0.68 & $<.01$ & 24 & . & & \\
\hline PAn,$M$ & 0.42 & $<.01$ & 71 & 0.15 & 0.21 & 73 & 0.57 & $<.01$ & 69 \\
\hline PAn , F & 0.45 & $<.01$ & 65 & 0.22 & 0.10 & 57 & 0.49 & $<.01$ & 63 \\
\hline PAS,M & 0.60 & $<.01$ & 53 & 0.21 & 0.13 & 53 & 0.29 & 0.04 & 51 \\
\hline$P A S, F$ & 0.64 & $<.01$ & 27 & -.15 & 0.45 & 26 & 0.58 & $<0.1$ & 25 \\
\hline PAiv, ML & 0.50 & $<.01$ & 88 & 0.47 & $<.01$ & 88 & . & . & . \\
\hline PAiv, F & 0.38 & 0.04 & 30 & 0.59 & $<.01$ & 32 & . & . & . \\
\hline
\end{tabular}

X-ray output rate: Fluoroscopy: DAP fiuoroseny / fluoroscopy time. DSA: DAP Serial cut film: DAP fim / number of films. "Measure of association: $r_{s}=$ Spearman rank correlation coefficient. $\mathrm{p}=$ Significance probability under the null hypothesis that there is no association. $\mathrm{n}=$ Number of paited observations. $r_{5}$-values for paired groups with less than 11 observations are not included (denoted as $\left.{ }^{26}, "\right), " \mathrm{a} a, \mathrm{~b}$ at $=$ procedure type (see Table 7.1$), \mathrm{b}=$ gender $(\mathrm{F}=$ lemale, $\mathrm{M}=$ male).

In summary, it is concluded that patient size and $X$-ray output per unit time or per image taken are weakly correlated. At the $5 \%$ significance level no correlations are found for intra-arterial DSA-imaging at the iliac/lower leg region (PAn, PAs) and the head/neck region (CA). A positive correlation berween patient size and DAP per unit fluoroscopy time in intra-arterial arteriography was more or less expected since a substantial part of fluoroscopy is used to guide the catheter in vessels in the trunk region. Apparently, the major part of DSA-imaging in CA, PAs and PAn procedures involved imaging of the head/neck and lower limbs regions; the masses of these body parts are probably not (strongly) correlated with the mass of the trunk region. 


\section{Chapter 8}

\section{Quantitative data about patient exposure conditions and dose estimates for selected procedures in the University Hospital Maastricht}

\subsection{Introduction}

In this chapter the exposure conditions and estimates for the effective doses to patients are reported for two selected groups of arteriography procedures performed in the angiographic suite of the Department of Diagnostic Radiology of the University Hospital Maastricht (azM).

In the azM, to which about 850 patients are referred for angiographic procedures each year, three imaging techniques are applied: fluoroscopy, serial cut film arteriography, and digital subtraction arteriography (DSA). Serial cut film arteriography, also known as conventional arteriography (CA), is performed with a PUCK-film system. DSA techniques are applied both with intra-arterial (IA-DSA) and intravenous administration of contrast media (IV-DSA). Features and characteristics of the $\mathrm{X}$-ray equipment and imaging system have been described in Section 4.3.

The automated monitoring system (see Section 6.3) was used to carry out measurements from June 1991 to June 1993. From collected data typical patient exposure conditions have been quantified in Section 8.2 for arteriography of the ilac region and the legs, and in Section 8.4 for abdominal arteriography. For the conversion of dose-area product data (DAP) to organ doses, calculations were performed by the Gesellschalt fur Strahlen- und Umweltforschung (Neuherberg), and by the TNO Centre for Radiological Protection and Dosimetry (Rijswijk). Results of Monte Carlo dose calculations for iliac and leg arteriography are given in Section 8.3, and for abdominal arteriograplyy in Section 8.5 .

A major task in the analysis of the information obtained with the automated datat acquisition system was data sorting and compression. An umpression of the degree of data reduction is given in Table 8.1. This table shows that, for example for peripheral arteriography with percutaneous needle punctures (PAn) complete data records were obtained for 167 procedures, comprising 8800 data records (for both male and female patients); the total DAP-value was $2100 \mathrm{~Gy} \cdot \mathrm{cm}^{2}$. From these data records a reference group was selected that comprised data about procedures with average use characteristics of the X-ray system and patients with size similar to the anatomical dimensions of the GSF-phantoms. This reference group comprised 67 procedures and about 3600 data records (total DAP $=796 \mathrm{~Gy} \cdot \mathrm{cm}^{2}$ ). In the process of data compression, the number of views was reduced to 69 (total DAP $\left.=794 \mathrm{~Gy} \cdot \mathrm{cm}^{2}\right)$. This data set was further reduced by deleting a number of less significant views (data records with $\mathrm{DAP}<0.05 \mathrm{~Gy} \cdot \mathrm{cm}^{2}$ ) and 
by not discriminating between oblique and/or angulated views of the foot and the lower leg regions. The final number of views was equal to 36 (18 for male and 18 for female patients) with total-DAP equal to $792 \mathrm{~Gy} \cdot \mathrm{cm}^{2}$. These final results are based on $40 \%$ of the procedures available, comprising $38 \%$ of total DAP. In this last process of condengation, information was lost which was associated with only about $0.5 \%$ of the total DAP. The final descriptions of views in three types of peripheral arteriography were merged, resulting in 39 views for male, and 37 views for female patients.

Dosimetric data associated with six types of abdominal arteriography procedures (AA), which are discussed in this chapter, were obtained for 152 procedures (total DAP $=6300$ $\mathrm{Gy} \cdot \mathrm{cm}^{2}$ ). From these procedures a reference group was derived that comprised 129 procedures with tolal DAP of $5200 \mathrm{~Gy} \cdot \mathrm{cm}^{2}$. After deleting infrequently applied wiews and merging the remaining data, the final results for abdominal arteriography, as presented in Section 8.3. comprised 33 views, which were associated with $4970 \mathrm{~Gy} \cdot \mathrm{cm}^{2}$.

Table 8.1 Selection and compression of recorded data in peripheral and abdominal arteriography ${ }^{a}$

\begin{tabular}{|c|c|c|c|c|c|c|c|c|}
\hline \multirow{3}{*}{$\begin{array}{l}\text { Proc. } \\
\text { type }^{\text {. }}\end{array}$} & \multicolumn{3}{|c|}{ All data } & \multicolumn{5}{|c|}{ Reference group } \\
\hline & \multirow{2}{*}{$\begin{array}{l}\text { No. } \\
\text { of } \\
\text { proc }\end{array}$} & \multirow{2}{*}{$\begin{array}{l}\text { No. } \\
\text { of } \\
\text { rec. }\end{array}$} & \multirow{2}{*}{ DAP } & \multirow{2}{*}{$\begin{array}{l}\text { No. } \\
\text { of } \\
\text { proc }\end{array}$} & \multirow{2}{*}{$\begin{array}{l}\text { No. } \\
\text { of } \\
\text { rec }\end{array}$} & \multirow[t]{2}{*}{ DAP } & \multicolumn{2}{|c|}{ Selected views } \\
\hline & & & & & & & $\begin{array}{l}\text { No. } \\
\text { of } \\
\text { views }\end{array}$ & DAP \\
\hline PAn & 167 & 8800 & 2100 & 67 & 3600 & 796 & 36 & 792 \\
\hline PAs & 89 & 5800 & 2900 & 42 & 2600 & 1169 & 3.8 & 1153 \\
\hline PAiv & 151 & 3300 & 5400 & 75 & 1600 & 2642 & 23 & 2618 \\
\hline $\mathrm{AA}$ & 152 & 5400 & 6300 & 129 & 4600 & 5200 & 33 & 4970 \\
\hline
\end{tabular}

"No. of proc $=$ number of procedures; No. of rec. $=$ number of data records. DAP $=$ total dose-area product (in $\mathrm{Gy} \cdot \mathrm{cm}^{2}$ ) associated with selected data. No. of wiews = number of wiews, derived from the reference group; ${ }^{P A n}=$ peripheral arteriography with needle puncture. $P A S=$ peripheral arteriography with Seldinger approach. $P A i v=$ peripheral arteriography with $I V \cdot D S A . A A=$ abdominal arteriography, including various intra-arterial arteriography types and IV-DSA procedures.

\subsection{Quantification of patient radiation exposure conditions in arteriography of the pelvis and lower limbs (peripheral arteriography, PA)}

\subsubsection{Introduction}

Generally, arteriography of aorto-iliac vessels and peripheral vessels of the lower limbs (hereafter referred to as "peripheral arteriography") is performed in patients with arterial occlusive disease for planning of medical treatment in order to prevent limb amputation. Data about medical radiation doses associated with arteriography of the lower limbs are scarse. This is probably due to the complex nature of this procedure as well as to the complex dose measurements that are to be applied. A third explanation may be the expectation that -since extremities are involved- the effective dose to the patient will be small. In peripheral arteriography, various areas of the lower part of the body are exposed in several diagnostic views, applying a large number of different projection angles, beam 
sizes and other varying technical parameters. In this section, the medical procedure and the dosimetric approach are briefly described, and the exposure conditions to patients in peripheral arteriography are quantified.

\subsubsection{Arteriography of the pelvis and lower limbs}

This study comprises three methods for diagnostic imaging of the vessels in the iliac region and lower limbs:

\section{Intravenous Digital Subtraction Arteriography (PAiv)}

For arteriography of the aorta-iliac vessels and blood vessels in the upper legs, contrast medium was administered intravenously to the supine patient through a needle in the basilic vein (Figure 8.1). Fluoroscopy was used for accurate patient positioning and to optimise the IV-DSA views. Usually, two IV-DSA series of the abdomen/pelvis and two IV-DSA series of the pelvis/upper legs were obtained. Additional series were taken if necessary.

\section{Seldinger catheterisation (PAS)}

For imaging of the arteries in the iliac region and in both legs, contrast medium was administered to the supine patient via a catheter, inserted into the femoral artery , with its tip positioned in the abdominal aorta, just below the renal arteries (Figure 8.2). Patients were examined with serial cut films (CA) and one or more intra-arterial DSA (IA-DSA) series of the pelvis, upper legs, knees, lower legs or feet region. Fluoroscopy was used for catheter positioning, for visual control in selecting various IA-DSA views and as a programming tool for the automatic stepping facility of the serial cut film system. Figure 8.3 illustrates a film series with the automatic stepping facility.

\section{Percutaneous Needle Puncture (PAn)}

For arteriography of the external iliac vessel and peripheral vessels in one leg, contrast medium was administered to the supine patient via a needle $(10 \mathrm{~cm}$ ) punctured in the femoral artery. Patients were examined with serial cut film arteriography , followed by one or more IA-DSA series of the lower pelvis, upper leg, knee and the lower leg region (Figure 8.4). Fluoroscopy was mainly used as a programming tool for the automatic stepping facility of the imaging system and for visual control in selecting various wiews.

As shown in Figure 8.1 to 8.4 , posterior-anterior views of the supine patient were obtained with the Xray tube in the undercouch position. Oblique projections were encountered during DSA and during thuoroscopic previewing of the iliac/groin/femoral region, and of the foot (not shown in the drawings).

Translumbar aortography (TLA) for visualisation of aorta-iliac and peripheral vessels of both legs was not included in this study, since this procedure is performed very rarely nowadays. 


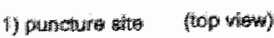

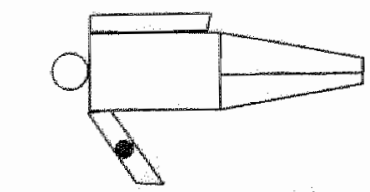

2y Heglons stom for DS

(lop vitew)

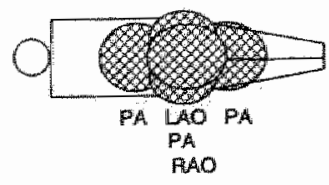

2a) PA D D V VW
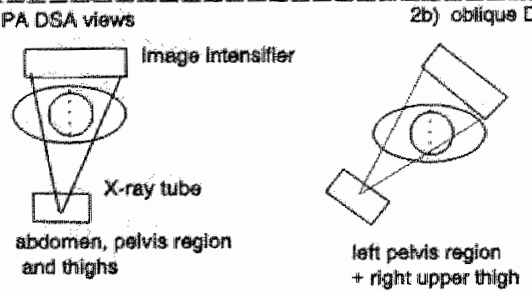

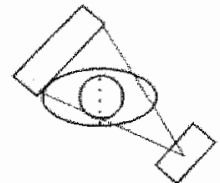

righti polvis roglion + late upper sting

Figure 8.1 Diagram of puncture site and exposed body areas during. IV-DSA of iliac and peripheral vessels (patient supine, undercouch tube).

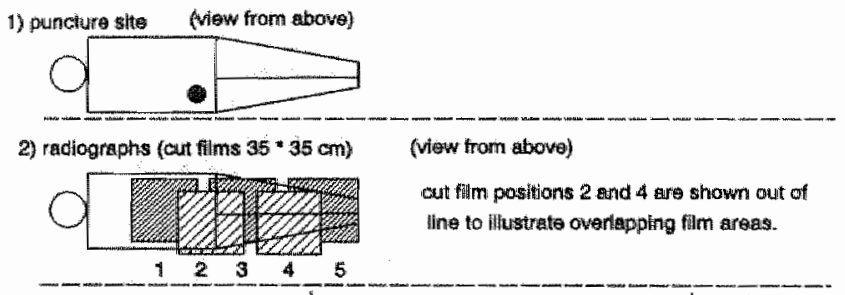

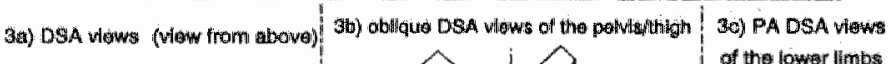
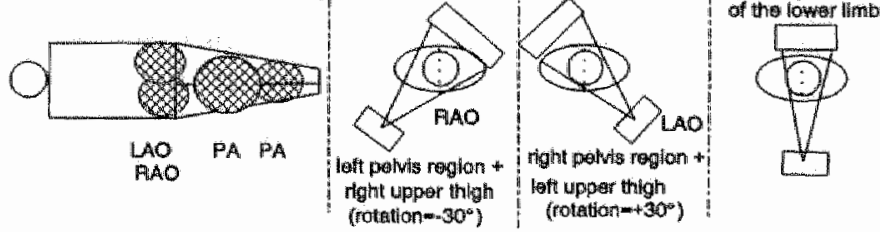

Figure 8.2 Diagram of puncture site and exposed body areas during serial cut film arteriography and IA-DSA of aorto-iliac and peripheral vessels in both legs (patient supine, undercouch tube, Seldinger catheterisation). 


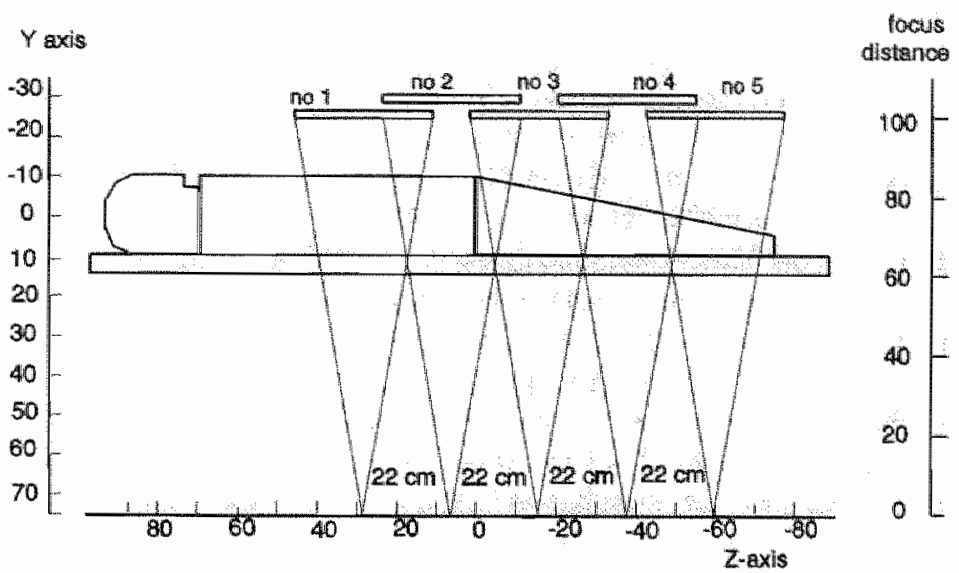

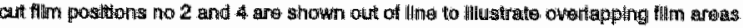

Figure 8.3 Diagram of serial cut film imaging in peripheral arteriography. applying the automatic stepping facillity (parient supine, undercouch tube, Seldinger catheterisation).

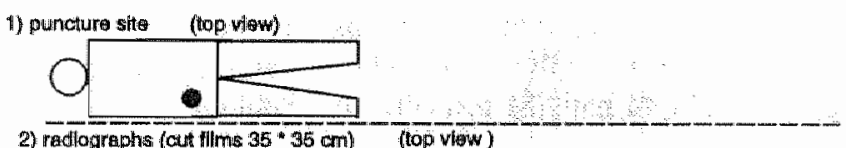

2) radographs (cut tilms $35 * 35$ cht) (top visw)

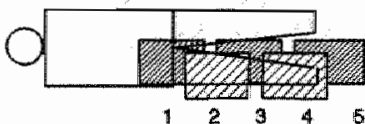

out filim posittons: 2 and 4 aro shown out of

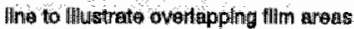

3) DISA views (top view)

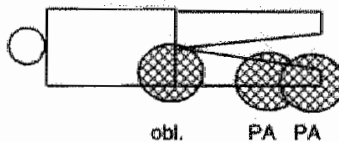

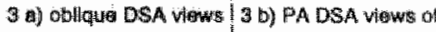
of the fight thith

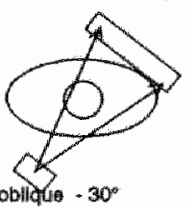

tho lower mitas

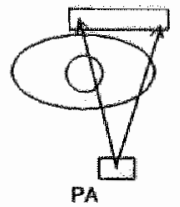

Figure 8.4 Diagram of puncture site and exposed body areas during serial cut film arteriography snd DSA of iliac vessels and peripheral vessels of one leg (patient supine, undercouch tube, percutaneous needle puncture in groin). 


\subsubsection{Dose measurements, selection and compression of recorded data}

Dose measurements and recordings of system parameters for peripheral arteriography were performed according to the method described in Section 6.3. From all data available, a subset was derived, according to the criteria that weight, height and the weight/heightratio of the patient should not differ more than $20 \%$ from the anatomical data of the GSFphantoms ADAM and EVA, used for Monte Carlo organ dose calculations [KR86]. In addition, the following selection criteria were used: number of DSA-series within $1 / 3$ and 3 times the mean; number of film-series within 0.8 and 1.3 times the mean value; DAPvalue for DSA, film and fluoroscopy with $1 / 6$ and 6 times the mean DAP. Selection criteria were chosen more or less arbitrarily, just to exclude "abnormal" procedures. These relatively broad ranges reflect the large variance in "normal" procedures. Results of the selection procedure are summarised in Table 8.1. Data records of the subgroup (hereafter referred bo as "reference group") were labelled according to their anatomical position and projection angle (Figures 8.1 - 8.4 show schematic representations of various views). As explained in Section 6.3, weighted average values for technique parameters per view were derived by using the dose-area product for weighting. Entrance doses, derived from dose-area product data, refer to the quantity air kerma, free-in-air, at the skin entrance position.

\subsubsection{Results and discussion}

About $35 \%$ of all procedures carried out in the angiography suite in the azM were classiffed as peripheral arteriography. Data about height, weight and age have been recorded for 362,346 and 643 patients respectively (Table 8.2).

Table 8.2 Age, weight and height of male and female patients in three types of peripheral arteriography in $1990-1993$

\begin{tabular}{|c|c|c|c|c|c|c|c|c|c|c|}
\hline \multicolumn{2}{|c|}{$\begin{array}{l}\text { Procedure } \\
\text { type }\end{array}$} & \multicolumn{2}{|c|}{$\begin{array}{l}\text { Age [y] } \\
\text { All: }\end{array}$} & \multirow{2}{*}{$\frac{\text { ref.gre }}{\text { MEAN }}$} & \multicolumn{2}{|c|}{$\begin{array}{l}\text { Weight [kg] } \\
\text { All }\end{array}$} & \multirow{2}{*}{$\frac{\text { ref. gr. }}{\text { MEAN }}$} & \multicolumn{2}{|c|}{$\begin{array}{l}\text { Helight }[\mathrm{cm}] \\
\text { All }\end{array}$} & \multirow{2}{*}{$\frac{\text { ref.gr. }}{M E A N}$} \\
\hline & gender & $\mathbb{N}$ & $\mathrm{MEAN}$ & & $\vec{N}$ & MEAN & & $N$ & MEAN & \\
\hline \multirow[t]{2}{*}{ All } & male & 454 & 64 & - & 222 & 76 & - & 234 & 172 & - \\
\hline & female & 189 & 70 & - & 124 & 68 & - & 128 & 163 & - \\
\hline PAn & male & 146 & 66 & 67 & 80 & 75 & 71 & 82 & 172 & 172 \\
\hline PAs & male & 88 & 64 & 66 & 54 & 77 & 74 & 55 & 174 & 174 \\
\hline PAiv & male & 220 & 62 & 62 & 88 & 76 & 72 & 97 & 172 & 173 \\
\hline PAn & female & 92 & 75 & 78 & 65 & 68 & 62 & 66 & 163 & 162 \\
\hline PAs & fenale & 38 & 67 & 67 & 26 & 70 & 62 & 28 & 164 & 163 \\
\hline PAir & female & 59 & 63 & 59 & 33 & 68 & 62 & 34 & 164 & 162 \\
\hline
\end{tabular}

" $P A n=$ percutaneous needle puncture, $P A s=$ Seldinger catheterisation, $P A i v=$ intravenous digital subtraction anteriography; " $A l l=$ patients with full data about gender, age, weight, height ard dosimetry; "ref. $g r$. = reference group, a representative subset of patients (see Section 8.2 .3 ). Number of male patiens in ref. gr.: $\mathrm{PAn}=40, \mathrm{PAs}=32$. PAiv $=58$. Number of female patients in ref. gr.: $\mathrm{PAn}=27$, $\mathrm{PAs}=10$, PAiv $=17$.

$\mathrm{N}=$ number of procedures: MEAN = arihnetic average; - = data not computed. 
Statistics on the number of imaging series, the total number of images and the fluoroscopy time per procedure are given in Table 8.3. Generally, only one imaging series was acquired at each location. However, if the diagnostic information obtained in a single run was judged as insufficient, the series was repeated at the same location. Resulis of DAP measurements, including relative contributions of different imaging techniques, are summarised in Table 8.4. Table 8.2 to 8.4 also present average values for patients of the reference group. It should be noted that all statistics in the higher indexed tables in Section 8.2 are derived from procedures of the reference group.

Results of a survey into non-cardiovascular radiology in the Netherlands in 1992 [K 195]. showed that $44 \%$ to $53 \%$ of these procedures were classified as peripheral arteriography, compared to $35 \%$ in the University Hospital Mastricht (azM). These data indicate that peripheral angiography is performed quite frequently. Of all peripheral arteriography procedures in the azM hospital, $70 \%$ were carried out on males. The relative numbers of males in percutaneous needle punctures (PAn-procedures) was equal to $61 \%$, in Seldinger procedures (PAs) to $70 \%$ and in IV-DSA procedures (PAiv) to $78 \%$.

Table 8.3 Fluoroscopy time, DSA-imaging and serial cut film radiography, in peripheral arteriography

\begin{tabular}{lrrrrrrr}
\hline $\begin{array}{l}\text { Procedure } \\
\text { type }\end{array}$ & $\begin{array}{c}\text { All patients } \\
\text { b }\end{array}$ & PIO & P90 & MAX & MED MEAN & STD & ref. group \\
N MEAN
\end{tabular}

\section{Fluoroscopy time [min]:}

$\begin{array}{lrrrrrrrrr}\text { all } & 448 & 0.7 & 5.3 & 17.8 & 2.5 & 2.8 & 2.3 & - & \\ \text { PAn } & 186 & 1.8 & 4.6 & 11.0 & 2.9 & 3.1 & 1.3 & 67 & 3.1 \\ \text { PAs } & 94 & 2.5 & 7.8 & 17.8 & 4.2 & 5.2 & 3.1 & 42 & 4.8 \\ \text { PAiv } & 168 & 0.5 & 1.8 & 4.1 & 1.0 & 1.1 & 0.6 & 75 & 1.2\end{array}$

\section{Number of DSA-series:}

$\begin{array}{lrrrrrrrrr}\text { all } & 455 & 2 & 5 & 11 & 4 & 3.6 & 1.4 & - & -5 \\ \text { PAn } & 190 & 2 & 5 & 9 & 3 & 3.2 & 1.4 & 67 & 3.5 \\ \text { PAs } & 94 & 3 & 5 & 8 & 4 & 3.8 & 1.4 & 42 & 4.1 \\ \text { PAiv } & 171 & 3 & 5 & 11 & 4 & 4.0 & 1.1 & 75 & 4.0\end{array}$

\section{Number of DSA-frames:}

$\begin{array}{lrrrrrrrrr}\text { all } & 455 & 33 & 95 & 204 & 61 & 63.6 & 27.2 & - & 61 \\ \text { PAn } & 190 & 25 & 88 & 151 & 54 & 55.2 & 26.7 & 67 & 61 \\ \text { PAs } & 94 & 34 & 110 & 168 & 65 & 69.2 & 30.0 & 42 & 75 \\ \text { PAiv } & 171 & 43 & 96 & 204 & 70 & 69.7 & 23.4 & 75 & 70\end{array}$

Number of film-series:

$\begin{array}{lrrrrrrrrr}\text { PAn } & 190 & 1 & 5 & 10 & 5 & 4.3 & 2.1 & 67 & 5.0 \\ \text { PAs } & 94 & 1 & 5 & 13 & 5 & 4.7 & 2.1 & 42 & 5.0\end{array}$

\section{Number of filnus:}

\begin{tabular}{lrrrrrrrrr} 
PAn & 190 & 8 & 16 & 54 & 14 & 13.5 & 6.4 & 67 & 13.5 \\
PAs & 94 & 10 & 15 & 39 & 14 & 13.8 & 5.4 & 42 & 13.6 \\
\hline
\end{tabular}

a.b.c See Table 8.2 for footnotes. Statistics (additional): $N=$ number of procedures, $P 10, P 90=10,90$. percentile value, $\mathrm{MAX}=$ maximum, $\mathrm{MED}=$ median; $\mathrm{STD}=$ standard deviation. Serial cut film radiography is not applied in IV-DSA (PAiv). 
Table 8.4

Dose-area proflucts and the relative contributions of fuoroscopy, DSA and serial cut films per procedure

\begin{tabular}{|c|c|c|c|c|c|c|c|}
\hline Procedure & All patients & & & & & & ref, group ${ }^{c}$ \\
\hline gender & P10 & P9o & $M A X$ & MEDIAN & MEAN & STD & $N$ MEAN \\
\hline
\end{tabular}

Doste-area product $\left(\mathrm{Gy} \cdot \mathrm{cm}^{2}\right)$ :

\begin{tabular}{|c|c|c|c|c|c|c|c|c|c|c|}
\hline \multicolumn{11}{|c|}{ Dost-area prod } \\
\hline all & mate & $304^{\circ}$ & 7.6 & 54 & 137 & 24 & 29 & 20 & - & \\
\hline & female & 151 & 6.5 & 40 & 87 & 17 & 22 & 16 & - & \\
\hline PAn & malle & 109 & 5.6 & 22 & 51 & 10 & 13 & 8 & 40 & 13 \\
\hline PAs & male & 64 & 14.1 & 62 & 137 & 28 & 34 & 23 & 32 & 30 \\
\hline PAiv & male & 131 & 21.3 & 59 & 104 & 38 & 39 & 16 & 58 & 38 \\
\hline PAn & fermale: & 81 & 5.6 & 30 & 48 & 10 & 144 & 10 & 27 & 更 \\
\hline PAs & remale & 30 & 13.1 & 55 & 84 & 24 & 30 & 19 & 10 & 0 \\
\hline PAiv & female & 40 & 14.9 & 45 & 87 & 30 & 32 & 16 & 17 & \\
\hline
\end{tabular}

Relative contribution of fluoroscopy to dose-area product $(\%)$ :

$\begin{array}{lrrrrrrrrr}\text { all all } & 455 & 6 & 48 & 89 & 24 & 26 & 17 & - & \\ \text { PAn all } & 190 & 17 & 50 & 89 & 33 & 34 & 13 & 67 & 33 \\ \text { PAs all } & 94 & 20 & 61 & 78 & 35 & 38 & 15 & 42 & 35 \\ \text { PAiv all } & 171 & 4 & 18 & 28 & 9 & 10 & 5 & 75 & 11\end{array}$

Rellative contribution of DSA to dose-area product (\%):

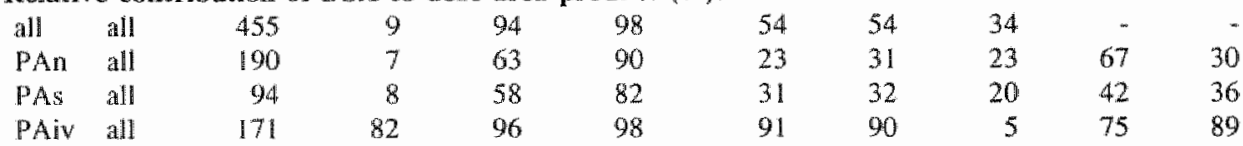

Relative contribution of serial cut films to dose-area product $(\%)$ :

$\begin{array}{lrrrrrrrrr}\text { PAn all } & 190 & 10 & 59 & 73 & 36 & 35 & 19 & 67 & 38 \\ \text { PAs all } & 94 & 11 & 52 & 65 & 28 & 30 & 16 & 42 & 29\end{array}$

a.b See Table 8.3 for foomotes. Statistics on relative contributions were derived from dose-area product ratios for fluorcscopy/total, DSA/total and film/total, computed for single procedures.

Table 8.5 Mean relative fuoroscopy time for each disamostic view in peripherall arteriography (reference group) ${ }^{a}$

\begin{tabular}{|c|c|c|c|c|c|c|c|c|c|}
\hline \multirow{2}{*}{$\begin{array}{l}\text { Procedure } \\
\text { type } \\
\text { Gender }\end{array}$} & \multicolumn{8}{|c|}{ Diagnostic view } & \multirow{2}{*}{$\begin{array}{l}\text { Total } \\
\text { fuoro- } \\
\text { scopy } \\
\text { time } \\
\text { [min] }\end{array}$} \\
\hline & $\begin{array}{l}\text { Abdo- } \\
\text { men } \\
\text { (pa) }\end{array}$ & $\begin{array}{l}\text { Abdo- } \\
\text { mery } \\
\left(r=30^{\circ}\right)\end{array}$ & $\begin{array}{l}\text { Pelvis } \\
\text { (pa) }\end{array}$ & $\begin{array}{l}\text { Pelvis } \\
\text { thigh } \\
\left(r^{n}=30^{\circ}\right)\end{array}$ & $\begin{array}{l}\text { Thing } \\
\text { (pa) }\end{array}$ & $\begin{array}{l}\text { Knee } \\
\text { (pa) }\end{array}$ & $\begin{array}{l}\text { Lower } \\
\text { leg } \\
\text { (pa) }\end{array}$ & $\begin{array}{l}\text { Foot } \\
(p a+\operatorname{la})\end{array}$ & \\
\hline $\begin{array}{l}\text { PAn: } \\
\text { male }\end{array}$ & $2 \%$ & - & $28 \%$ & $3 \%$ & $13 \%$ & $9 \%$ & $13 \%$ & $32 \%$ & 3.1 \\
\hline $\mathrm{cm}$ & $2 \%$ & 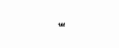 & $41 \%$ & $2 \%$ & $9 \%$ & 8 篮 & $10 \%$ & $28 \%$ & 3.0 \\
\hline $\begin{array}{l}\text { PAs: } \\
\text { male }\end{array}$ & $39 \%$ & 3䉓 & $23 \%$ & $3 \%$ & $10 \%$ & $9 \%$ & $7 \%$ & $7 \%$ & 4.7 \\
\hline fem. & $54 \%$ & - & $21 \%$ & - & $8 \%$ & $5 \%$ & $4 \%$ & $8 \%$ & 5.1 \\
\hline $\begin{array}{l}\text { PAiv: } \\
\text { male }\end{array}$ & $33 \%$ & $2 \%$ & $46 \%$ & $3 \%$ & $12 \%$ & $4 \%$ & - & - & 1.2 \\
\hline fem. & $27 \%$ & - & $42 \%$ & $1 \%$ & $26 \%$ & $4 \%$ & - & - & 1.0 \\
\hline
\end{tabular}

"See Table $8.2 ;$ " For easy reference, figures were rounded to integer values." "Denotes that frequency data were less than $1 \%$, or not applicable. Oblique wiews in the abdomen and pelvis regions are denoted by $" r=30^{\circ}$. 
Table 8.6 Mean relative number of DSA frames and mean relative muniter of serial cul films at different anatomical locations during peripheral arteriography (reference group)

\begin{tabular}{|c|c|c|c|c|c|c|c|c|c|}
\hline \multirow{2}{*}{$\begin{array}{l}\text { Imaging } \\
\text { system } \\
\text { Procedure } \\
\text { type } \\
\text { Gender }\end{array}$} & \multicolumn{2}{|c|}{ Diagnostic viewb } & \multirow[b]{2}{*}{$\begin{array}{l}\text { Pelvis } \\
\text { (pa) }\end{array}$} & \multirow[b]{2}{*}{$\begin{array}{l}\text { Pelyis } \\
\text { thigh } \\
\left(\mathrm{r}=30^{\circ}\right)\end{array}$} & \multirow[b]{2}{*}{$\begin{array}{l}\text { Thigh } \\
\text { (pa) }\end{array}$} & \multirow[b]{2}{*}{$\begin{array}{l}\text { Knee } \\
\text { (pa) } \\
\end{array}$} & \multirow[b]{2}{*}{$\begin{array}{l}\text { Lower } \\
\text { leg } \\
\text { (pa) }\end{array}$} & \multirow[b]{2}{*}{$\begin{array}{l}\text { Foot } \\
(p a+1 a t)\end{array}$} & \multirow{2}{*}{$\begin{array}{l}\text { Toual } \\
\text { mumber } \\
\text { of } \\
\text { frames }\end{array}$} \\
\hline & $\begin{array}{l}\text { Abdo- } \\
\text { men } \\
\text { (pa) }\end{array}$ & $\begin{array}{l}\text { Abdo- } \\
\text { men } \\
\left(r=30^{3}\right)\end{array}$ & & & & & & & \\
\hline \multicolumn{10}{|l|}{ DSA-frame: } \\
\hline \multicolumn{10}{|l|}{ PAn: } \\
\hline male & $-\approx$ & - & $2 \%$ & $5 \%$ & $1 \%$ & $5 \%$ & $25 \%$ & $64 \%$ & 61 \\
\hline fen. & - & - & $1 \%$ & $6 \%$ & $3 \%$ & $5 \%$ & $26 \%$ & $60 \%$ & 61 \\
\hline \multicolumn{10}{|l|}{ PAS: } \\
\hline male & $1 \%$ & $5 \%$ & $6 \%$ & $3 \%$ & $15 \%$ & $23 \%$ & $21 \%$ & $25 \%$ & 75 \\
\hline fem. & $4 \%$ & - & $4 \%$ & - & $23 \%$ & $18 \%$ & $8 \%$ & $43 \%$ & 77 \\
\hline \multicolumn{10}{|l|}{ PAiv: } \\
\hline male & $32 \%$ & $3 \%$ & $44 \%$ & $2 \%$ & $15 \%$ & $4 \%$ & - & - & 71 \\
\hline fem. & $29 \%$ & - & $42 \%$ & $\llbracket \%$ & $26 \%$ & $4 \%$ & - & . & 67 \\
\hline \multicolumn{10}{|l|}{ Films: } \\
\hline $\begin{array}{l}\text { PAn: } \\
\text { male, fem. } \\
\text { PAs: }\end{array}$ & - & - & $22 \%$ & - & $22 \%$ & $22 \%$ & $22{ }^{*}$ & $13^{*}$ & 14 \\
\hline $\begin{array}{l}\text { male, fem, } \\
\text { PAiv: }\end{array}$ & $22 \%$ & - & $22 \%$ & - & $22 \%$ & $22 \%$ & $13 \%$ & . & 14 \\
\hline male, fem. & - & - & - & - & - & - & - & $\cdots$ & - \\
\hline
\end{tabular}

n.ils See Table 8.5 for footnotes.

Talble 8.7 Dose-area products of diagnostic views as a function of rotation and angulation, relative to the total dose-area product (reference group)

\begin{tabular}{|c|c|c|c|c|c|c|c|c|c|c|}
\hline \multirow{2}{*}{$\begin{array}{l}\text { Procedure } \\
\text { rype } \\
\text { imaging } \\
\text { mode }\end{array}$} & \multicolumn{2}{|c|}{ Rotation } & \multirow[b]{2}{*}{$16-25^{\circ}$} & \multirow[b]{2}{*}{$26-35^{\circ}$} & \multirow[b]{2}{*}{$>35^{\circ}$} & \multirow[b]{2}{*}{ sum } & \multicolumn{2}{|c|}{ Angulation } & \multirow[b]{2}{*}{$16 m 30^{\circ}$} & \multirow[b]{2}{*}{ sum } \\
\hline & $\leq 5^{\circ}$ & $6.15^{\circ}$ & & & & & $0.5^{\circ}$ & $6-15^{\circ}$ & & \\
\hline \multicolumn{11}{|l|}{ PAn: } \\
\hline fluoro: & $27 \%$ & $2 \%$ & $1 \%$ & $1 \%$ & - & $31 \%$ & $30 \%$ & $1 \%$ & $<$ & $31 \%$ \\
\hline DSA & $15 \%$ & $10 \%$ & $7 \%$ & $6 \%$ & - & $38 \%$ & $30 \%$ & $6 \%$ & $2 \%$ & $38 \%$ \\
\hline films: & $31 \%$ & - & ш & - & - & $31 \%$ & $31 \%$ & . & . & 31\% \\
\hline total: & $73 \%$ & $12 \%$ & $8 \%$ & $7 \%$ & $0 \%$ & $100 \%$ & $91 \%$ & $7 \%$ & $2 \%$ & $100 \%$ \\
\hline \multicolumn{11}{|l|}{ PAs: } \\
\hline fluoro: & $32 \%$ & $1 \%$ & $1 \%$ & $<1 \%$ & - & $34 \%$ & $34 \%$ & $1 \%$ & - & $35 \%$ \\
\hline DSA: & $31 \%$ & $4 \%$ & $4 \%$ & $3 \%$ & - & $42 \%$ & $37 \%$ & $4 \%$ & $1 \%$ & $42 \%$ \\
\hline films: & $24 \%$ & - & . & - & - & $24 \%$ & $23 \%$ & $*$ & . & $23 \%$ \\
\hline total: & $87 \%$ & $5 \%$ & $5 \%$ & $3 \%$ & $0 \%$ & $100 \%$ & $94 \%$ & $5 \%$ & $1 \%$ & $100 \%$ \\
\hline \multicolumn{11}{|l|}{ PAiv: } \\
\hline fluoro: & $10 \%$ & $1 \%$ & $<1 \%$ & $<1 \%$ & $<1 \%$ & $11 \%$ & $84 \%$ & $5 \%$ & - & $89 \%$ \\
\hline DSA: & $83 \%$ & $1 \%$ & $3 \%$ & $2 \%$ & - & $89 \%$ & $i 1 \%$ & $<$ & - & $11 \%$ \\
\hline flims: & - & - & - & - & - & - & $\approx$ & - & - & - \\
\hline total: & $93 \%$ & $2 \%$ & $3 \%$ & $2 \%$ & $0 \%$ & $100 \%$ & $95 \%$ & $5 \%$ & $0 \%$ & $100 \%$ \\
\hline
\end{tabular}

"See Table 8.2. Relative dose-area producs have been calculated as average values for all male and female patients in the reference group. Due to rounding errors, summation of single contributions may yield results differing from the given sum values; "fluoro" denotes fluoroscopy; "DSA" denotes IA-DSA or IV-DSA, depending on the procedure type; "films" refers to serial cut film radiography. 
Table 8.8 Mean nelative dose-area product (DAP) for various diagnosic views during peripheral arteriography (reference group) ${ }^{2}$

\begin{tabular}{|c|c|c|c|c|c|c|c|c|c|}
\hline $\begin{array}{l}\text { Imaging } \\
\text { systen }^{\circ} \\
\text { Gender }\end{array}$ & $\begin{array}{l}\text { Diag } \\
\text { abd. } \\
\text { (pa) }\end{array}$ & $\begin{array}{l}\text { iic view } \\
\text { abd. } \\
\left(30^{\circ}\right)\end{array}$ & $\begin{array}{l}\text { pelwis } \\
\text { (pa) }\end{array}$ & $\begin{array}{l}\text { pelv./ } \\
\text { thigh } \\
\left(30^{\circ}\right)\end{array}$ & $\begin{array}{l}\text { thigh } \\
\text { (pa) }\end{array}$ & $\begin{array}{l}\text { knec } \\
\text { (pa) }\end{array}$ & $\begin{array}{l}\text { lower } \\
\text { leg } \\
\text { (pa) }\end{array}$ & $\begin{array}{l}\text { foot } \\
\text { (all) }\end{array}$ & $\begin{array}{l}\text { Total } \\
\text { DAP } \\
{[\%]} \\
\left.\left[\mathrm{Gy}^{\mathrm{N}}\right] \mathrm{cm}^{2}\right]\end{array}$ \\
\hline \multicolumn{10}{|c|}{$\begin{array}{l}\text { Peripheral arteriography of one leg (PAn): } \\
\text { fluoro: }\end{array}$} \\
\hline male & $0.5 \%$ & $-{ }^{c}$ & $13 \%$ & $2.3 \%$ & $5.1 \%$ & $2.7 \%$ & $2.5 \%$ & $4.9 \%$ & $31 \%$ \\
\hline female & $1.1 \%$ & - & $20 \%$ & $0.9 \%$ & $3.0 \%$ & $2.2 \%$ & $1.3 \%$ & $3.2 \%$ & $32 \%$ \\
\hline \multicolumn{10}{|l|}{ DSA: } \\
\hline male & - & - & $4.2 \%$ & $12 \%$ & $0.5 \%$ & $1.6 \%$ & $4.2 \%$ & $17 \%$ & $39 \%$ \\
\hline female & - & 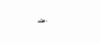 & $3.1 \%$ & $11 \%$ & $1.7 \%$ & $0.7 \%$ & $6.8 \%$ & $1 \rrbracket \%$ & $34 \%$ \\
\hline \multicolumn{10}{|l|}{ nilms: } \\
\hline male &. & - & $14 \%$ & - & $6.9 \%$ & $4.4 \%$ & $2.8 \%$ & $2.4 \%$ & $31 \%$ \\
\hline $\begin{array}{l}\text { female } \\
\text { total: }\end{array}$ & - & - & $15 \%$ & \multicolumn{6}{|c|}{ total: } \\
\hline male & $1 \%$ & - & $31 \%$ & $14 \%$ & $13 \%$ & $9 \%$ & $10 \%$ & $24 \%$ & 13.0 \\
\hline female & $1 \%$ & - & $38 \%$ & $12 \%$ & $13 \%$ & $8 \%$ & $10 \%$ & $16 \%$ & 10.3 \\
\hline
\end{tabular}

Peripheral arteriography of two legs, Seldinger catheterisation (PAs):

huoro:

\begin{tabular}{|c|c|c|c|c|c|c|c|c|c|}
\hline male & $17 \%$ & $0.8 \%$ & $8.6 \%$ & $0.8 \%$ & $2.8 \%$ & $1.8 \%$ & $1.2 \mathrm{w}$ & $1.3 \%$ & $34 \%$ \\
\hline female & $25 \%$ & - & $7.1 \%$ & - & $3.5 \%$ & $1.2 \%$ & $0.9 \%$ & $1.8 \%$ & 40 㵖 \\
\hline \multicolumn{10}{|l|}{ DSA: } \\
\hline male & $2.5 \%$ & $7.6 \%$ & $6.6 \%$ & $3.1 \%$ & $5.7 \%$ & $7.2 \%$ & $6.2 \%$ & $4.7 \%$ & $47 \%$ \\
\hline temale & $6.4 \%$ & - & $3.9 \%$ & - & $6.0 \%$ & $3.3 \%$ & $++11 \%$ & $+t+$ & $3.2 \%$ \\
\hline \multicolumn{10}{|l|}{ films: } \\
\hline male & $8.4 \%$ & - & $6.1 \%$ & - & $3.8 \%$ & $2.7 \%$ & $1.6 \%$ & - & $23 \%$ \\
\hline female & $11 \%$ & - & $8.8 \%$ & - & $4.9 \%$ & $3.5 \%$ & $2.1 \%$ & . & $30 \%$ \\
\hline \multicolumn{6}{|l|}{ total: } & & $9 \%$ & $6 \%$ & \\
\hline female & $42 \%$ & - & $20 \%$ & $3 \%$ & $14 \%$ & $8 \%$ & $f+16 \%$ & $+t+$ & \\
\hline
\end{tabular}

Intravenows peripheral arteriography (PAiv):

fluoro:

\begin{tabular}{|c|c|c|c|c|c|c|c|c|c|c|}
\hline male & $3,11 \%$ & $0.4 \%$ & $4.7 \%$ & $0.3 \%$ & $1.1 \%$ & $0.3 \%$ & - & . & $10 \%$ & \\
\hline fermale & $3.7 \%$ & - & $5.5 \%$ & $0.2 \%$ & $1.8 \%$ & $0.3 \%$ & - & . & $12 \%$ & \\
\hline \multicolumn{11}{|l|}{ DSA: } \\
\hline mate & $36 \%$ & $4.2 \%$ & $39 \%$ & $2.1 \%$ & $6.9 \%$ & $0.9 \%$ & - & - & $90 \%$ & \\
\hline female & $36 \%$ & - & $34 \%$ & $2.2 \%$ & $13 \%$ & $3.8 \%$ & - & - & $89 \%$ & \\
\hline \multicolumn{8}{|l|}{ total: } & & & \\
\hline fernale & $40 \%$ & $4 \%$ & $40 \%$ & $2 \%$ & $15 \%$ & $4 \%$ & - & . & & 26.9 \\
\hline
\end{tabular}

"Relative dose-area products were computed as average values for patients included in the reference group (see Section 8.2.3). As data have been derived from a sub-dataset, the total average walues and the relative contributions of the imaging modes may differ somewhat from the data presented in Table 8.4.

"fluoro" denotes fluoroscopy; "DSA" denores IA-DSA or IV-DSA, depending on the procedire type; "filmus" refers to serial cut film radiography. "the "_" sign denotes that diagnostic views were nor applicable or dosimetry data were not available. 
Table 8.9 Mean relative entrance dose $\left(\mathrm{RD}_{\text {iatrasse }}\right)^{\text {a.6. }}$ for different projections during peripheral arteriography (reference group)

\begin{tabular}{|c|c|c|c|c|c|c|c|c|}
\hline $\begin{array}{l}\text { Imaging } \\
5 y \text { steme } \\
\text { Gender }\end{array}$ & $\begin{array}{l}\text { Diagnostic view } \\
\text { abd. abd. } \\
\text { (pa) }\left(30^{\circ}\right)\end{array}$ & $\begin{array}{l}\text { pelvis } \\
\text { (pa) }\end{array}$ & $\begin{array}{l}\text { pelv. } \\
\text { thigh } \\
\left(30^{\circ}\right)\end{array}$ & $\begin{array}{l}\text { thigh } \\
\text { (pa) }\end{array}$ & $\begin{array}{l}\text { knee } \\
\text { (pa) }\end{array}$ & $\begin{array}{l}\text { lower } \\
\text { (pa) }\end{array}$ & $\begin{array}{l}\text { foot } \\
\text { leg } \\
\text { (ail) }\end{array}$ & $\begin{array}{l}\text { Menn } \\
\text { rotal } \\
\text { entrance } \\
\text { dose } \\
{[\%]}\end{array}$ \\
\hline
\end{tabular}

\section{Peripheral arteriography of one leg (PAn):}

fluoro:

\begin{tabular}{|c|c|c|c|c|c|c|c|c|c|}
\hline male & $1.7 \%$ & -4 & $15 \%$ & $1.9 \%$ & $7.2 \%$ & $2.8 \%$ & $28 \%$ & $5.2 \%$ & $37 \%$ \\
\hline fem. & $1.8 \%$ & - & $28 \%$ & $0.7 \%$ & $2.4 \%$ & $1.9 \%$ & $1.1 \%$ & $3.4 \%$ & $39 \%$ \\
\hline \multicolumn{10}{|l|}{ DSA: } \\
\hline male & - & - & $3.2 \%$ & $11 \%$ & $0.6 \%$ & $1.8 \%$ & $4.7 \%$ & $16 \%$ & $37 \%$ \\
\hline fem. & - & - & $2.4 \%$ & $8.7 \%$ & $1.6 \%$ & 0.78 & $6.7 \%$ & $10 \%$ & $30 \%$ \\
\hline \multicolumn{10}{|l|}{ films: } \\
\hline mate & - & - & $9.9 \%$ & . & $6.2 \%$ & $4.7 \%$ & $3.5 \%$ & $2.5 \%$ & $27 \%$ \\
\hline fem. & . & - & $12 \%$ & - & 7.4 & $5.5 \%$ & $3.9 \%$ & $2.2 \%$ & $31 \mathrm{w}$ \\
\hline \multicolumn{10}{|l|}{ total* } \\
\hline male & $2 \%$ & - & $38 \%$ & $13 \%$ & $14 \%$ & $9 \%$ & $11 \%$ & $24 \%$ & 54.2 \\
\hline fem. & $2 \%$ & .. & $42 \%$ & $9 \%$ & $1 \|$ 思 & $8 \%$ & $13 \%$ & $16 \%$ & 41.6 \\
\hline
\end{tabular}

Peripheral arteriography of two legs (PAs):

\section{fluoro:}

\begin{tabular}{|c|c|c|c|c|c|c|c|c|c|}
\hline male & $24 \%$ & $0.7 \%$ & $15 \%$ & $1.1 \%$ & $3.1 \%$ & $1.5 \%$ & $1.0 \%$ & $0.9 \%$ & $47 \%$ \\
\hline fem. & $48 \%$ & - & $9.5 \%$ & 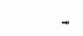 & $2.0 \%$ & $0.7 \%$ & $0.8 \%$ & $0.9 \%$ & $62 \%$ \\
\hline \multicolumn{10}{|l|}{ DSA: } \\
\hline male & $3.5 \%$ & $5.7 \%$ & $4.9 \%$ & $3.5 \%$ & $3.8 \%$ & $4.7 \%$ & $4.5 \%$ & $4.2 \%$ & $35 \%$ \\
\hline fem. & $2.8 \%$ & - & $2.9 \%$ & - & $4.0 \%$ & $2.7 \%$ & $t+7.6$ & $\%++$ & $20 \%$ \\
\hline \multicolumn{10}{|l|}{ fillms: } \\
\hline male & $7.2 \%$ & - & $4.6 \%$ & - & $3.0 \%$ & $2.2 \%$ & $1.5 \%$ & - & $19 \%$ \\
\hline $\begin{array}{l}\text { fem. } \\
\text { total: }\end{array}$ & $6.9 \%$ & - & $4.8 \%$ & - & $2.9 \%$ & $2.1 \%$ & $1.3 \%$ & - & $18 \%$ \\
\hline male & $35 \%$ & $6 \%$ & $25 \%$ & $1 \%$ & $10 \%$ & $9 \%$ & $7 \%$ & $5 \%$ & \\
\hline fem. & $58 \%$ & 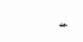 & 179 & $4 \%$ & $9 \%$ & $6 \%$ & +\|\|$\%$ & $+4+$ & \\
\hline
\end{tabular}

Intrawenous peripheral arteriography (PAiv):

\section{nworo:}

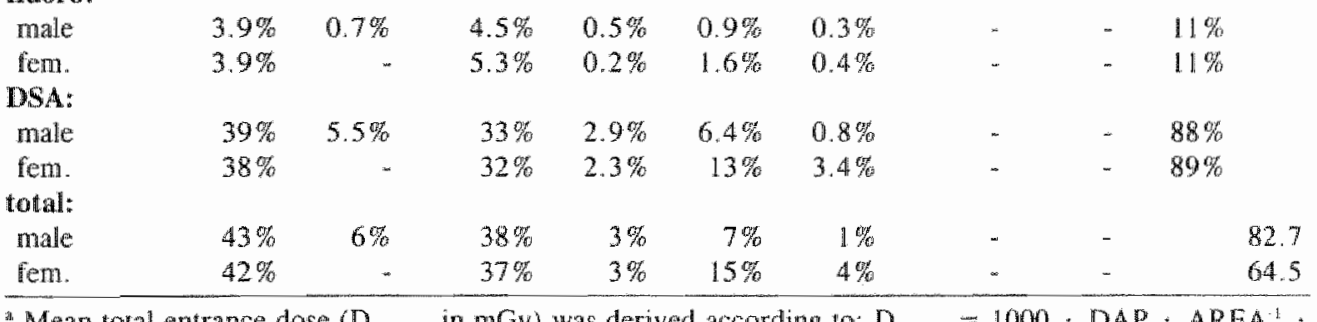

"Mean total entrance dose $\left(D_{\text {surance }}\right.$ in $\left.\mathrm{MGy}\right)$ was derived according to: $\mathrm{D}_{\text {enuane }}=1000 \cdot \mathrm{DAP} \cdot \mathrm{AREA}^{1}$. $F S D^{2}$, where $D A P=$ dose area product $\left(G y \cdot \mathrm{cm}^{2}\right), A R E A=$ field size at $1 \mathrm{~m}$ from the focus $\left(\mathrm{cm}^{2}\right)$, and

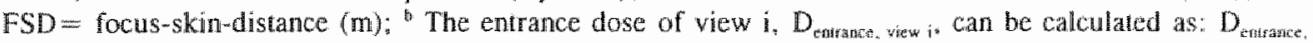

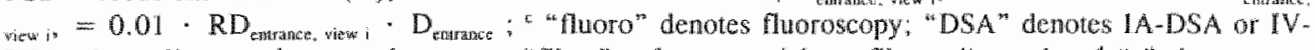
DSA, depending on the procedure type; "films" refers to serial cut film radiography; " "., denotes not applicable, or dosimetry data were not available. 


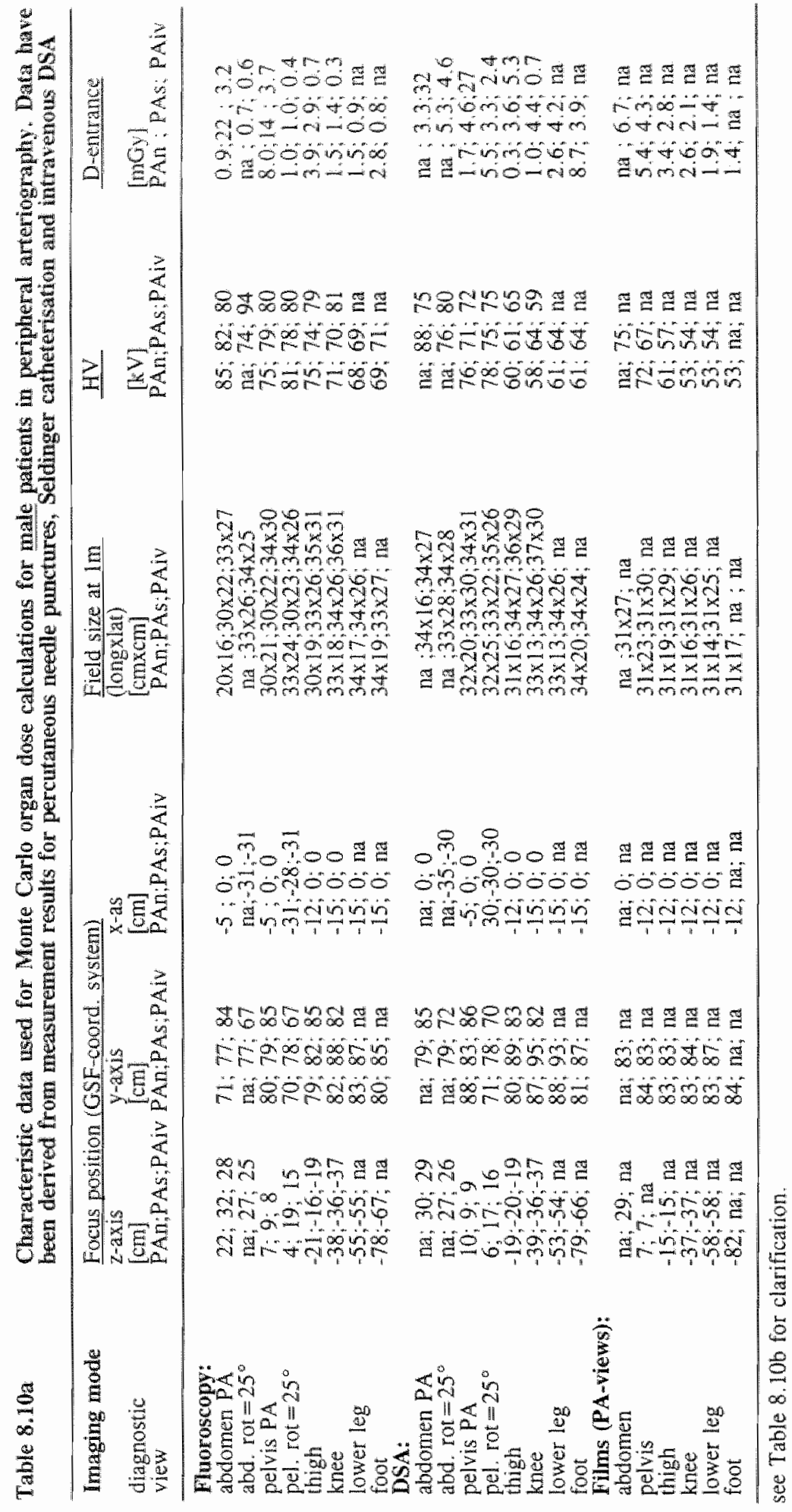




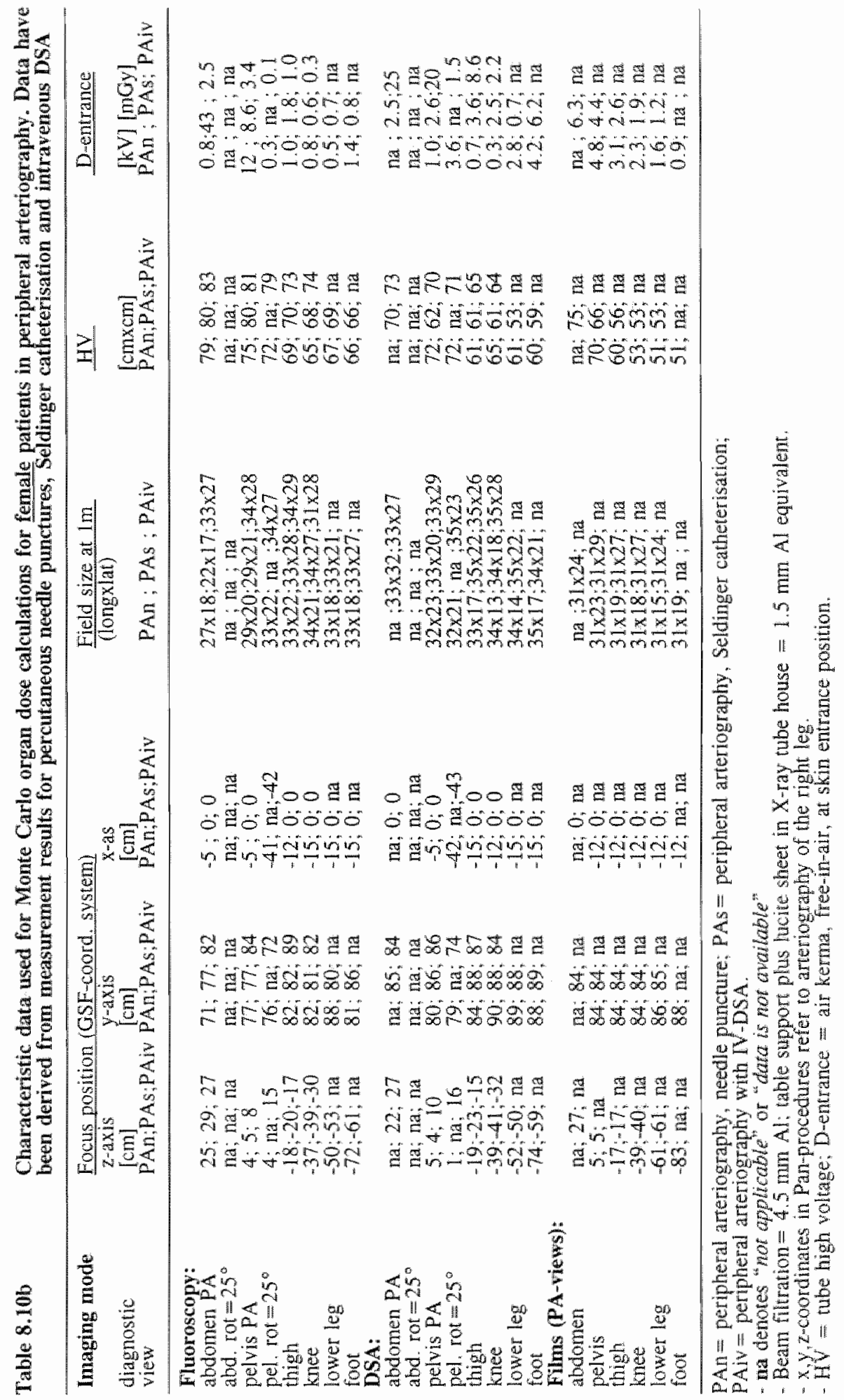




\section{Diagnosic views}

Measurement results of more than 450 clinical applications of the automated monitoring system have been used to derive quantitative descriptions of the exposure conditions to the patient in peripheral arteriography. The following parameters have been derived for each selected diagnostic view: tube high voltage, field size, focus-position, rotation and angulation of the X-ray beam, dose-area product (DAP), and entrance dose. Information about DSA-imaging and radiography in selected views is given in Table 8.6, fluoroscopy is covered in Table 8.5. Mean relative DAP values for various locations during arteriography of one leg (PAn), Seldinger catheterisation (PAs) and IV-DSA (PAiv) are given in Table 8.8. Relative contributions of fluoroscopy, DSA and serial cut films to DAP-total are included separately for each selected diagnostic view. Estimates for the entrance dose are given in Table 8.9. Table 8.7 provides data about the relative contribution of the dose-area product as a function of the projection angle (rotation and angulation). Data needed as input for Monte Carlo organ dose calculation have been summarised in Table $8.10 \mathrm{a} / \mathrm{b}$. The focus position has been described with the same coordinate systern as applied for the GSF-phantoms.

\section{Patient weight and height}

Mean weight and mean height of male patients were calculated to be $76 \mathrm{~kg}$ ( $\sigma=14 \mathrm{~kg}$, $\mathrm{n}=222)$ and $172 \mathrm{~cm}(\sigma=11 \mathrm{~cm}, \mathrm{n}=234)$, mean weight and height of female patients to be $68 \mathrm{~kg}(\sigma=11, \mathrm{n}=124)$ and $163 \mathrm{~cm}(\sigma=5 \mathrm{~cm}, \mathrm{n}=128)$. These data show some differences with GSF sex-specific phantoms ADAM and EVA, which have been designed to $70.5 \mathrm{~kg}$ and $170 \mathrm{~cm}$ for males, and $59.2 \mathrm{~kg}$ and $160 \mathrm{~cm}$ for females; the reference adult man [1C75], has been defined with a body mass and length of $70 \mathrm{~kg}$ and $170 \mathrm{~cm}$ for males, and $58 \mathrm{~kg}$ and $160 \mathrm{~cm}$ for females. The Shapiro-Wilk test statistic showed that the data about weight and height may be regarded as random samples from nomal distributions. Consequently, the two-sided $99 \%-c o n f i d e n c e$ interval for the means $(m)$ of weight and height, calculated to be $\mathrm{m} \pm 2.576 \cdot \sigma / \sqrt{\mathrm{n}}$, are equal to $74-78 \mathrm{~kg}$, and $170-174 \mathrm{~cm}$ respecively for males, and to be $65-71 \mathrm{~kg}$, and $162-164 \mathrm{~cm}$ respectively for females. It is concluded that, nowadays, patients referred to a radiologist for problems concerning peripheral vessels are talle than the anthropomorphic GSF-phantoms applied to calculate organ doses

Means for the weight of females in the large sample and females in the reference group differ, data about length for females and data about weight and length for male patients show good agreement (see Table 8.2). Tables 8.3 and 8.4 show that on average, apart from the dose-area product for female patients in Seldinger catheterisation, usage characteristics of the imaging system for the groups "all patients" and "reference group" were quite similar. It is concluded that the reference group can be regarded as fairly representative for the group "all patients".

\section{Patient age}

Table 8.2 indicates that patients referred to the radiologist for peripheral arteriography were relatively old: ninety percent of all patients was older than 48 years. On average, females were 70 years old, males were 64 years old. These data clearly demonstrate that this group was older than the reference population, used by ICRP to derive the tissue weighting lactor, applied for effective dose calculations. As the potential for hereditary effects in the elderly patient is relatively low, and fatal cancer risks for elderly people due to exposure to ionising radiation seem to be lower than in the reference population (see 
Figure 2.1), it might be anticipated that effective doses derived for these pattents overestimate the potential detriment. This dissimilarity has already been addressed in literature [DR93, NR90]. No adjustments will be made in this thesis.

\section{Dose-area product}

Table 8.4 shows that dose-area products (DAP) for peripheral arteriography varied considerably. In this study a range factor (ratio of maximum by minimum) of 100 was found. DAP varied between 1.4 and $137 \mathrm{~Gy} \cdot \mathrm{cm}^{2}$ (the minimum value $1.4 \mathrm{~Gy} \cdot \mathrm{cn}^{2}$ is nor included in Table 8.4). However, considering the three main types PAs, PAn and PAiv separately, the range factor per procedure type is reduced to 20,35 and 25 respectively.

The relative contributions of fluoroscopy, DSA and CA in DAP varied considerably as well. In the intra-arterial approach ( $\mathrm{PAn}$ and PAs), film contributed about $30 \%$ to $35 \%$ to the total DAP per procedure, IA-DSA contributed $30 \%$ and fluoroscopy about $35 \%$. In IV-DSA procedures fluoroscopy accounted for $10 \%$ and DSA for $90 \%$ of the total DAP (films are not applied in IV-DSA procedures).

Table 8.4 illustrates that DAP values for IV-DSA were the highest, those for Seldinger catheterisation somewhat lower, while the lowest values were found for needle punciure arteriography. Differences in DAP are associated with differences in fluoroscopy time, mumber of images (DSA frames and/or films) and field size.

Table 8.8 shows that in the reference group the abdomen and pelvis, with many tissues of relatively high radiation sensitivity, had the highest exposure in terms of DAP. Averaged over male and female patients, the DAP to the lower trunk region, relative to the total DAP, was estimated to be about $50 \%$ in PAn-procedures, $60 \%$ in PAs , and $85 \%$ in PAiv procedures.

\section{Fluoroscopy}

The mean values for fluoroscopy time for PAn and PAs were 3.1 and 5.2 minutes respectively (Table 8.3). A corresponding difference was seen in the DAP associated with fluoroscopy: the mean DAP in PAs was about $12 \mathrm{~Gy} \cdot \mathrm{cm}^{2}$, about three times higher than the mean DAP during PAn $\left(4.4 \mathrm{~Gy} \cdot \mathrm{cm}^{2}\right)$. This difference is mainly associated with the technique of contrast medium administration. PAn is a relatively simple technique, which requires only a short time of fluoroscopy, whereas PAs is a complex technique, which requires relatively long fluoroscopy times for accurate positioning of the catheter tip. The contribution from fluoroscopy for positioning and for programming the stepping facility for serial cut film arteriography is small. The same conclusion is true for positioning the imaging system for DSA.

\section{Images}

On average, 3 to 4 DSA series were used, resulting in about 55 DSA-images per total procedure for PAn, 70 DSA-images for PAs, and 70 DSA-images for IV-DSA procedures. Some procedures required up to $200 \mathrm{DSA}$-images. The number of different film-series in PAn and PAs procedures was almost always 5, the number of films laken was 13 or 14 . In some exceptional cases up to about 50 films were needed.

Table 8.6 shows that in PAn and PAs procedures in the reference group the majority of DSA-frames was taken in the lower leg region, whereas in IV-DSA (PAiv) more than $70 \%$ of the DSA-frames were associated with the abdomen/pelvis region. 


\section{Field size}

Using the dose-area product for weighting, the average beam aperture settings were computed (see Section 6.3). Mean field sizes for complete procedures, derived as the product of the average longitudinal and lateral beam sizes, were calculated to be $800 \mathrm{~cm}^{2}$ $\left(32 \times 25 \mathrm{~cm}^{2}\right)$ for Seldinger catheterisation, $640 \mathrm{~cm}^{2}\left(32 \times 20 \mathrm{~cm}^{2}\right)$ for needle puncture and $990 \mathrm{~cm}^{2}\left(34 \times 29 \mathrm{~cm}^{2}\right)$ for IV-DSA procedures. Data about the aperture settings show that, in all three imaging modes, relatively expanded field sizes were used for views of the pelvic region. The field size decreased if images were taken of smaller parts of the patient's body (thigh, knee, lower leg in PAn-procedures). Because of its anatomical shape, relatively expanded field sizes were used for (oblique) images of the foot. Also, it was observed in clinical practice, that compared to $X$-ray imaging of body parts within or adjacent to the trunk, less attention was paid to "fine" adjustment of the $X$-ray field size in imaging of the foot.

\section{Entrance dose}

The mean entrance dose per location was calculated for PAn, PAs and PAiv separately (Table 8.9). Entrance doses have been expressed as a percentage of the sum of entrance doses (summed per sex over all locations and imaging modes). It is recognised that summing up doses associated with different body parts does not make sense from a dosimetric point of view. However, this method is useful to provide insight in the relation between the entrance dose and the dose-area product as presented in Table 8.8 (mean entrance dose estimates can easily be derived by multiplying the relative figures by the sum of the doses as given in the column "mean total entrance dose" in Table 8.9). This comparison has been performed because dose-area product data are generally more easily derived than entrance dose estimates.

From a comparison of DAP data presented in Table 8.8 and corresponding dose data in Table 8.9 it is concluded that relative contributions of single diagnostic views to total DAP and to total entrance dose are quite similar. It follows that, as a first approach, view specific relative contributions to DAP may be applied instead of the calculated entrance skin doses per location, to calculate organ doses from Monte Carlo organ dose conversion factors, specified for air kerma at skin entrance positions.

\section{Thube high woltage}

In daily practice, tube high voltage settings varied between $48 \mathrm{kV}$ and $110 \mathrm{kV}$. Computation of the relative contribution of DAP per high voltage setting to total DAP per imaging mode showed that $90 \%$ of the total DAP (from the 5-percentile to the 95 percentile value) was associated with tube high voltage settings between 65 and $93 \mathrm{kV}$ for fluoroscopy, between 60 and $79 \mathrm{kV}$ for DSA, and between 51 and $75 \mathrm{kV}$ for radiography. From a subset of data pertaining to the abdominal and pelvic region, the 5 - and 95 . percentile values were computed to be 69 and $94 \mathrm{kV}$ for fluoroscopy, 66 and 80 for DSA. and 66 and $75 \mathrm{kV}$ for radiography. These data indicate the preferred range of the technique parameter "tube high voltage" in Monte Carlo organ dose calculations.

\section{Focus-skin-distance}

Weighted average values for focus-to-patient distances (not presented in this section) have been estimated to be 56 to $74 \mathrm{~cm}$ in fluoroscopy, 62 to $80 \mathrm{~cm}$ in DSA and 68 to $72 \mathrm{~cm}$ in radiography. In the lower trunk region the average value for all projections (using $D A P$ for weighting) was equal to $69 \mathrm{~cm}$ for males and $68 \mathrm{~cm}$ for females. 


\section{Projection angle}

The relative contribution per diagnostic view to the total dose-area product was computed for different directions of the $\mathrm{X}$-ray beam, characterised by the angle of rotation in the transversal plane and the angulation in the axial plane. Table 8.7 shows that the contributions of rotated fluoroscopic views were very small, whereas rotated DSA-views contributed $6 \%$ to $23 \%$, depending on procedure type. The contribution of angulated views (angulation more than $5^{\circ}$ ) was quite small. Therefore, it was concluded that "angulation" could be excluded from the set of descriptive parameters.

Variability in DSA-imaging, serial cut film radiography, and fuoroscopy Additional data about peripheral arteriography were extracted from a local record keeping system. It was derived that DSA-examinations of the lower trunk region rabdomen and/or pelvis) were performed in $32 \%$ of the needle puncture procedures (PAn), in $55 \%$ of the Seldinger catheterisation procedures (PAs), and in every IV-DSA procedure (PAiv). In $33 \%$ of the PAs procedures only one DSA-series was taken from the iliac region, in $15 \%$ of the procedures two or more series were acquired. In PAn procedures the iliac region was examined in $31 \%$ of the cases, in $28 \%$ one series was acquired and in $4 \%$ two series. In IV-DSA, examination of the iliac region was performed in $96 \%$ of the procedures, in $71 \%$ one series, and in $25 \%$ at least two series were required. Selection of the DSA views was based upon information in the medical record and on medical findings in the course of the angiographic procedure.

On average, about 60 to 75 DSA-frames were taken per procedure. The relative number of DSA-frames per location varied between $1 \%$ and $65 \%$. These figures depend both on the relative frequency of a DSA-series per location and on the number of DSAframes taken at that location. Each DSA run required a minimum of about 5 DSA frames; in this study the highest number of DSA-frames for one single view was 35 .

Data about the fluoroscopy time are given in Table 8.5. The fluoroscopy time per location in PAn and in PAs deviated significantly. In PAn procedures about $30-43 \%$ of the total fluoroscopy time was spent in the trunk region, and about $40 \%$ in the lower leg and foot region. In PAs procedures $65 \%-75 \%$ of the fluoroscopy time was associated with the trunk region, and only about $11-14 \%$ with the lower leg and foot region.

Not shown in a table are the large variations in fluoroscopy time and the number of DSA. frames per anatomical position. These variations may be partly related to the patient (condition of blood vessels, blood flow) and partly to the skill of the operator. As data about the operating team have been recorded, statistical analysis of the relation between grade and usage of the imaging systems can be studied in future.

\subsection{Organ doses and effective dose to patients in arteriography of the pelvis and lower limbs}

\subsubsection{Introduction}

Exposure conditions derived for peripheral arteriography of supine palients, with undercouch tube geometry, have been described in Section 8.2. Published Monte Carlo organ dose data in diagnostic radiology [DR90, DR93a, HA94, JO85] do not match the exposure conditions encountered in peripheral arteriography. Therefore, new sets of Monte Carlo organ dose conversion coefficients had to be calculated. Results of these 
organ dose calculations performed by the Gesellschaft fur Strahlen- und Umweltforschung (GSF), Gemany, and effective dose estimates will be discussed in Section 8.3 .

\subsubsection{Monte Carlo organ dose calculations and effective dose estimations}

Monte Carlo dose calculation methods applied by GSF, have been described in various papers [KR86, ZA92, ZA95]. Usually, Monte Carlo (MC) organ dose calculations are performed with erect phantoms. MC dose calculations for peripheral arteriography were to be performed with phantoms, positioned supine on a patient support (see Figure 8.5 and 8.6). In order to increase the reliability, GSF modified the lower limb region of their phantoms. Firstly, the limbs were positioned on the table support (see Figure 8.7). Without modifications, the limbs would be positioned as indicated in Figure 8.5. Secondly, in MC dose calculations for percutaneous needle puncture procedures, the legs were placed apart, as shown in Figure 8.7.

From the collected exposure data, two subsets were extracted for Monte Carlo organ dose calculations: one for male and one for female patients (see Table $8.10 \mathrm{a} / \mathrm{b}$ ). Taking the relatively low radiosensitivity of tissues in the legs unto account, a number of wiews in this region were combined afterwards. Also, views in Seldinger catheterisation (PAs) and views in IV-DSA procedures (PAiv) have been combined. Views in percutaneous needle puncture procedures (PAn) could not easily be combined with views in the other two procedure types, due to differences in the field size and the position of the focus. Except for the maximum value of the X-ray beam size, technical parameter settings and xyzcoordinates have been expressed as multiples of five. In all, 39 views defined for male patients, and 37 views defined for female patients (Table 8.11) have been used as input data for MC organ dose calculations.

Effective doses were calculated for each diagnostic view separately. The required weighted organ doses were derived by multiplication of the entrance dose (see Table 8.11 ) with the MC organ dose conversion coelficients (Table 8.12-8.14) and the tissue weighting factor (Table 2.1).

\section{3 .3 Results}

Results of Monte Carlo organ dose calculations for the GSF-phantoms ADAM and EVA, placed in supine position on a table support with undercouch X-ray tube geometries are given in Tables 8.12 through 8.14. Computed results, presented as "organ dose conversion coefficient", DCC, show mean organ dose equivalents, relative to air kerma. free-in-air, at the beam entrance position (Sv/Gy). DCCs presented in these tables, originally comprising four decimal digits, were rounded to two decimal digits. Furthermore, all DCCs less than 0.01 Sv/Gy have been set to 0 (denoted as " $<$ "in the tables). Comparison of effective doses, computed with original DCCs and with DCCs presented in the tables, showed a small decrease of $1 \%$ to $2 \%$, depending on the procedure type. In order to condense the presented data, various views with DCCs less than $0.1 \mathrm{~Sv} / \mathrm{Gy}$ and with maximum differences of $0.01 \mathrm{~Sv} / \mathrm{Gy}$ for matching DCCs in other views have been listed in the footnotes of the tables. 


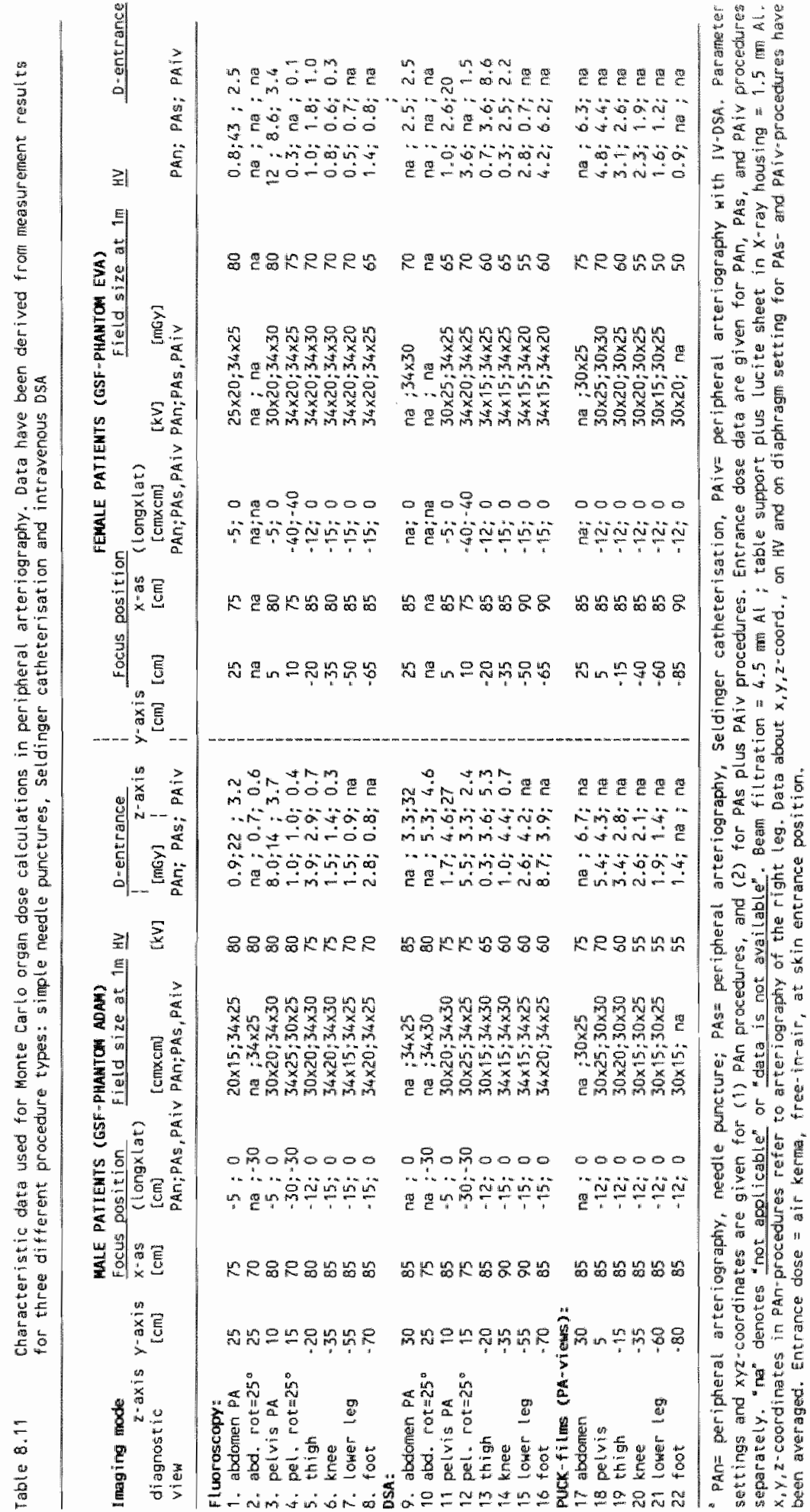




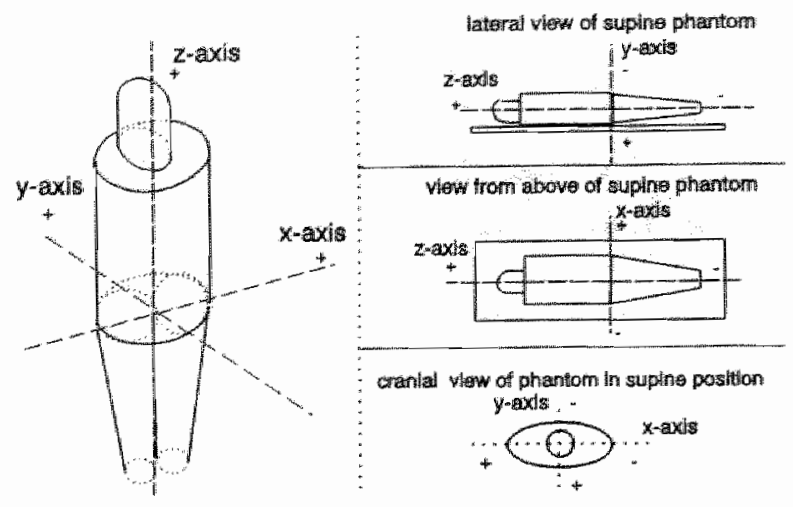

Figure 8.5 Diagram of the standard GSF Monte Carlo phantoms ADAM and EVA, and the phantom positioned supine on patient table.

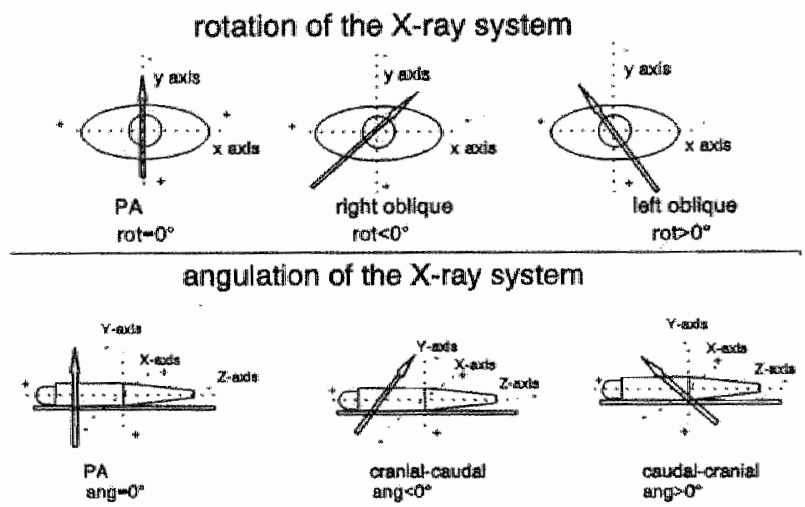

Figure 8.6 Diagram of rotation and angulation of the X-ray system with references to the 3 dimensional GSF-phantoms ADAM and EVA. Patient supine on table suppork, with underconch tube geometry for PA-views.

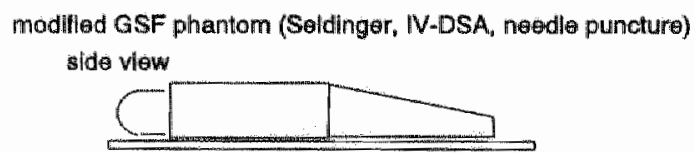

Vlew from above (Seldinger, IV-DSA)

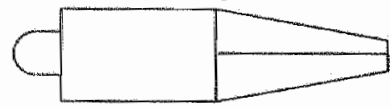

view from above (needle puncture)

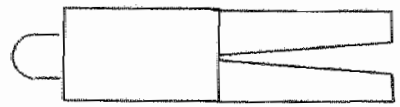

Figure 8.7 Diagram of modified GSF-phantoms for patients, supine on a patient support with closed legs and open legs geometry. 
Table 8.12 Organ dose per entrance dose conversion coefhicient (Sw/Gy) for intratvenous DSA peripheral arteriography

\begin{tabular}{|c|c|c|c|c|c|c|c|c|c|c|c|c|}
\hline \multicolumn{13}{|l|}{ Females } \\
\hline \multirow[t]{2}{*}{ Organ } & \multicolumn{12}{|c|}{ View No. ${ }^{b}$} \\
\hline & 1 & 2 & 3 & 4 & 5 & 6 & 9 & 10 & 11 & 12 & 13 & 14 \\
\hline Bladder & $<$ & na & .15 & .14 & $<$ & $<$ & .04 & nat & .14 & 12 & $<$ & $<$ \\
\hline Bone marrow & .08 & na & .04 & .12 & $<$ & $<$ & .17 & ma & .10 & .11 & $<$ & $<$ \\
\hline Bone surface & .09 & na & .06 & .13 & .16 & .13 & .20 & $\mathrm{max}$ & .13 & .12 & 12 & .12 \\
\hline Colon & .07 & ma & .09 & .13 & $<$ & $<$ & .15 & $\mathrm{ma}$ & .11 & .12 & $<$ & $<$ \\
\hline Liver & .03 & na & $<$ & .01 & $<$ & $<$ & .19 & nat & $<$ & $<$ & $<$ & $<$ \\
\hline Ovaries & .04 & na & .21 & .23 & $<$ & $<$ & .20 & nat & .23 & .21 & $<$ & $<$ \\
\hline Skin & .03 & nat & .05 & .06 & .12 & .10 & .07 & nat & .07 & .06 & .09 & .10 \\
\hline $\begin{array}{l}\text { Stomach } \\
\text {-remainder }\end{array}$ & .05 & กล & $<$ & $<$ & $<$ & $<$ & .14 & nat & $<$ & $<$ & $<$ & $<$ \\
\hline Adrenals & .04 & na & $<$ & $<$ & $<$ & $<$ & .48 & $\mathrm{ma}$ & $<$ & $<$ & $<$ & $<$ \\
\hline Kidneys & .50 & na & $<$ & .02 & $<$ & $<$ & .92 & na & $<$ & .01 & $<$ & $<$ \\
\hline Muscle & .03 & na & .06 & .09 & .10 & .07 & .09 & nat & .09 & .09 & .08 & .07 \\
\hline Pancrens & .06 & ma & $<$ & $<$ & $<$ & $<$ & .23 & na & $<$ & $<$ & $<$ & $<$ \\
\hline Small intest.. & .14 & na & .04 & .15 & $<$ & $<$ & .23 & $\mathrm{na}$ & .07 & .13 & $<$ & $<$ \\
\hline Spleen & .03 & na & $<$ & $<$ & $<$ & $<$ & .45 & na & $<$ & $<$ & $<$ & $<$ \\
\hline U.1. intest. & .10 & na & .02 & .15 & $<$ & $<$ & .19 & na & .04 & 13 & $<$ & $<$ \\
\hline Uterus & .03 & $\mathrm{na}$ & .21 & 21 & $<$ & $<$ & 16 & na & .21 & 19 & $<$ & $<$ \\
\hline
\end{tabular}

\begin{tabular}{|c|c|c|c|c|c|c|c|c|c|c|c|c|}
\hline \multirow[t]{2}{*}{$\begin{array}{l}\text { Males } \\
\text { Organ }\end{array}$} & \multicolumn{12}{|c|}{ View No. } \\
\hline & 1 & 2 & 3 & 4 & 5 & 6 & 9 & 10 & 11 & 12 & 13 & 14 \\
\hline Bladder & .02 & .02 & .17 & .12 & $<$ & $<$ & .01 & .03 & .16 & .12 & $<$ & $<$ \\
\hline Bone martow & .14 & .14 & .16 & 12 & $<$ & $<$ & 15 & .16 & .16 & .12 & $<$ & $<$ \\
\hline Bone surface & .14 & .14 & .16 & .11 & .20 & .19 & .18 & .17 & .16 & .12 & .18 & .15 \\
\hline Colon & .11 & .09 & .16 & .11 & $<$ & $<$ & .13 & .12 & .16 & 12 & $<$ & $<$ \\
\hline Liver & .05 & .04 & $<$ & $<$ & $<$ & $<$ & 16 & .05 & $<$ & $<$ & $<$ & $<$ \\
\hline Skin & .04 & .04 & .06 & .04 & .13 & .14 & .05 & .07 & .07 & .05 & .14 & .14 \\
\hline Stomach & .07 & .07 & $<$ & $<$ & $<$ & $<$ & .14 & .09 & $<$ & .02 & $<$ & $<$ \\
\hline $\begin{array}{l}\text { Testes } \\
\text {-remainder }\end{array}$ & $<$ & $<$ & .10 & .01 & .04 & $<$ & $<$ & $<$ & .11 & .02 & .04 & $<$ \\
\hline Adrenals & .07 & .08 & $<$ & $<$ & $<$ & $<$ & .66 & .12 & $<$ & $<$ & $<$ & $<$ \\
\hline Kidneys & .71 & .74 & .01 & .09 & $<$ & $<$ & .94 & .84 & .01 & .06 & $<$ & $<$ \\
\hline Muscle & .05 & .05 & .09 & .06 & .11 & .10 & .07 & .08 & .10 & .07 & .12 & .09 \\
\hline Pancreas & .11 & .11 & $<$ & $<$ & $<$ & $<$ & .26 & 16 & $<$ & .01 & $<$ & $<$ \\
\hline Small intest. & .21 & .19 & .15 & .16 & $<$ & $<$ & .24 & .21 & .16 & .15 & $<$ & $<$ \\
\hline Spleen & .08 & .16 & $<$ & $<$ & $<$ & $<$ & .26 & .32 & $<$ & .01 & $<$ & $<$ \\
\hline U.1. intest. & .15 & .12 & .09 & .09 & $<$ & $<$ & .18 & .14 & .10 & .08 & $<$ & $<$ \\
\hline
\end{tabular}

${ }^{a}$ Entrance dose = air kerma, free-in-air, at beam entrance position. The following tigsues and organs with dose conversion coefficients (DCC) less than $0.01 \mathrm{~Sv} / \mathrm{Gy}$ have been excluded from this table: breast (fem.). lung, oesophagus, thyroid, brain, and thymus. "na" : not applicable. "Quantitative descriptions of exposure conditions for single views are given in Table 8.11. ${ }^{~ A d d i t i o n a l ~ D C C ~ d a t a ~(d a t a ~ n o t ~ i n c l u d e d ~ i n ~}$ the table): Females: DCC-lung(view no.9) $=0.02$ Sv/Gy. Males: DCC-oesophagus (view no.9) $=0.02$ Sw/Gy; DCClung(view no. 9) $=0.04 \mathrm{~Sv} / \mathrm{Gy}$.

Original DCCs were used to compute the effective dose per entrance dose conversion coefficient (ECC) for each view. The results are given in Table 8.15. ECC-values vary between $0.0001 \mathrm{~Sv} / \mathrm{Gy}$ (film of the foot in PAn) and $0.116 \mathrm{~Sv} / \mathrm{Gy}$ (abdominal DSAimaging in PAs of female patients). 
Effective doses and relative contributions to the effective dose were calculated for various combinations of procedure type, gender, anatomical regions examined, and imaging mode. The results, considered as being representative to "normal sized" patients in "standard" procedures, are given in Table 8.16.

Table 8.13 Organ dose per entrance dlose conversion coefficient (Sv/Gy) for Seldinger catheterisation procedures in peripheral arteriography

\begin{tabular}{|c|c|c|c|c|c|}
\hline \multicolumn{6}{|l|}{ Females } \\
\hline \multirow{2}{*}{ Organ } & \multicolumn{5}{|c|}{ View No, ${ }^{b, c . d}$} \\
\hline & $7^{\mathrm{c}}$ & $8^{e}$ & 17 & 18 & 19 \\
\hline Bladder & $<$ & $<$ & .02 & .17 & $<$ \\
\hline Bone martow & $<$ & $<$ & .16 & .10 & $<$ \\
\hline Bone surface & .10 & .05 & .18 & .13 & .10 \\
\hline Colon & $<$ & $<$ & .14 & .12 & $<$ \\
\hline Liver & $<$ & $<$ & .12 & $<$ & $<$ \\
\hline Owaries & $<$ & $<$ & .18 & .25 & $<$ \\
\hline Skin & .08 & .06 & .05 & .07 & .08 \\
\hline \multicolumn{5}{|l|}{-remainder } & $<$ \\
\hline Adrenals & $<$ & $<$ & .29 & $<$ & $<$ \\
\hline Kidneys & $<$ & $<$ & .91 & $<$ & $<$ \\
\hline Muscle & .05 & .02 & .07 & .10 & .07 \\
\hline Pancreas & $<$ & $<$ & .21 & $<$ & $<$ \\
\hline Small intest. & $<$ & $<$ & .24 & .06 & $<$ \\
\hline Spleen < & $<$ & .24 & $<$ & $<$ & \\
\hline U. I. intest. & $<$ & $<$ & .19 & .04 & $<$ \\
\hline Uterus & $<$ & $<$ & .14 & .23 & $<$ \\
\hline \multicolumn{6}{|l|}{ Males } \\
\hline \multirow[t]{2}{*}{ Organ } & \multicolumn{2}{|c|}{ View No. } & & & \\
\hline & 7 & 8 & 17 & 18 & 19 \\
\hline Bladder & $<$ & $<$ & $<$ & .14 & $<$ \\
\hline Bone marrow & $<$ & $<$ & .11 & .08 & $<$ \\
\hline Bone surface & 12 & .06 & .14 & .1.1 & .14 \\
\hline Colon & $<$ & $<$ & .10 & .10 & $<$ \\
\hline Liver & $<$ & $<$ & .13 & $<$ & $<$ \\
\hline Skin & .10 & .06 & .04 & .06 & .12 \\
\hline Stomach & $<$ & $<$ & .11 & $<$ & $<$ \\
\hline $\begin{array}{l}\text { Testes } \\
\text { remainder }\end{array}$ & $<$ & $<$ & $<$ & .13 & .14 \\
\hline Adrenals & $<$ & $<$ & .54 & $<$ & $<$ \\
\hline Kidneys & $<$ & $<$ & .87 & $<$ & $<$ \\
\hline Muscle & .06 & .03 & .06 & .09 & .10 \\
\hline Pancreas & $<$ & $<$ & .21 & $<$ & $<$ \\
\hline Stmall intest. & $<$ & $<$ & .19 & .04 & $<$ \\
\hline Spleen & $<$ & $<$ & .22 & $<$ & $<$ \\
\hline U. 1. intest. & $<$ & $<$ & .14 & .03 & $<$ \\
\hline
\end{tabular}

i.tb See footnotes (a) and (b) in Table 8.12; ${ }^{\circ}$ DCCs for view nos. 1.6 and 9.14 are equall to DCCs for corresponding views in IV-DSA (see Table 8.12); ${ }^{1}$ Additional DCC data (data not included in the table): Fenales: DCC-lung(view no.17) $=0.01$ Sv/Gy. Males: DCC-lung(view no.17) $=0.02$ Sv/Gy, DCC. oesophagus (view no. 17) $=0.01 \mathrm{~Sv} / \mathrm{Gy}$; "DCC(view no.7) $=\mathrm{DCC}($ view no. 15$)=$ DCC(view no. 20$)$, DCC(view no. 8$)=D C C($ view no. 16$)=D C C$ (view no. 21 ). 
Table 8.14 Organ dose per entrance dose conversion coefficient ( $\mathrm{S} / \mathrm{Gy}$ ) for needle puncture procedures in peripherali arteriography"

\begin{tabular}{|c|c|c|c|c|c|c|c|c|c|c|c|c|}
\hline \\
\hline \multirow{2}{*}{$\begin{array}{c}\text { Femates } \\
\text { Organ }\end{array}$} & \multicolumn{12}{|c|}{ View No. bic } \\
\hline & 1 & 3 & 4 & 5 & 6 & 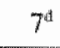 & $8^{d t}$ & 11 & 12 & $13^{\mathrm{d}}$ & 18 & 19 \\
\hline Bladder & $<$ & .15 & .13 & $<$ & $<$ & $<$ & $<$ & .13 & 11 & $<$ & .07 & $<$ \\
\hline Bone marr. & .09 & .06 & .10 & $<$ & $<$ & $<$ & $<$ & .06 & .09 & $<$ & .05 & $<$ \\
\hline Bone surf. & .09 & .08 & .11 & 08 & .06 & .05 & .02 & .09 & .10 & .06 & .09 & .06 \\
\hline Colon & .08 & .06 & .11 & $<$ & $<$ & $<$ & $<$ & .07 & .10 & $<$ & .03 & $<$ \\
\hline Liver & .10 & $<$ & $<$ & $<$ & $<$ & $<$ & $<$ & $<$ & $<$ & $<$ & $<$ & $<$ \\
\hline Ovaries & .04 & .17 & .18 & $<$ & $<$ & $<$ & $<$ & .19 & .17 & $<$ & .13 & $<$ \\
\hline $\begin{array}{l}\text { Skin } \\
\text {-remainder }\end{array}$ & .03 & .05 & .05 & .06 & .05 & .04 & .02 & .06 & .05 & .04 & .06 & .05 \\
\hline Kidneys & .45 & $<$ & .01 & $<$ & $<$ & $<$ & $<$ & $<$ & .01 & $<$ & $<$ & $<$ \\
\hline Muscle & .04 & .06 & .07 & .05 & .03 & .02 & $<$ & .08 & .07 & .04 & .07 & .05 \\
\hline Small int. & .15 & .04 & .113 & $<$ & $<$ & $<$ & $<$ & .04 & .12 & $<$ & .03 & $<$ \\
\hline U.I. int. & .14 & .05 & .13 & $<$ & $<$ & $<$ & $<$ & .04 & .12 & $<$ & .04 & $<$ \\
\hline Uterns & .04 & .22 & 19 & $<$ & $<$ & $<$ & $<$ & .19 & .17 & $<$ & .07 & $<$ \\
\hline
\end{tabular}

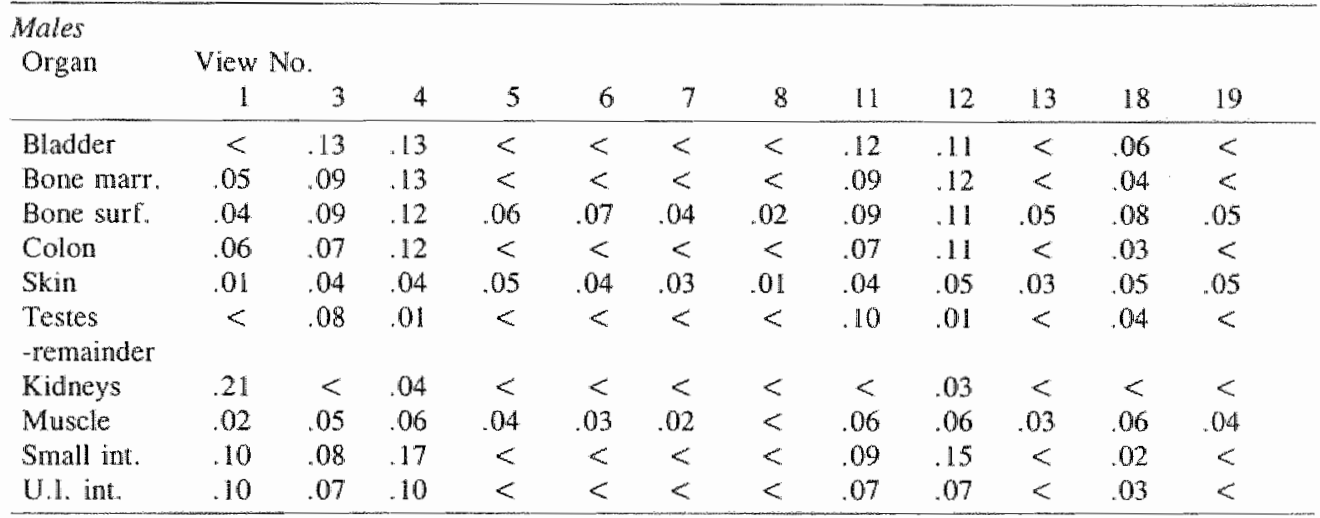

d.th See footnotes (a) and (b) in Table 8.12. In addition to the tissues excluded in Table 8. 12, the following tissues were exciuded: liver(males), stomach, adrenats, pancreas, and spleen" "Additional DCC data (Sv/Gy), data not included in the table: Females: DCC-adrenals(vicw no. I) $=0.04$ Sw/Gy. DCCstomach(view no. 1$)=0.0$. Sv/Gy, DCC-pancreas(view no. 1$)=0.05$ Sw/Gy. Males: DCC.liver(view no. I) $=0.02 \mathrm{~Sv} / \mathrm{Gy} ; \mathrm{DCC}$-stomach(wiew no. 4$)=0.01 \mathrm{~Sv} / \mathrm{Gy}, \mathrm{DCC}$-stomach(view no. $/ 2)=0.01 \mathrm{~Sv} / \mathrm{G} y . \mathrm{DCC}$. pancreas(view no.1) $=0.01$ Sv/Gy. ${ }^{D C C}($ view no.7) $=\operatorname{DCC}($ view no.15) $=\operatorname{DCC}($ view no.20). $\mathrm{DCC}($ view no. 8$)=\mathrm{DCC}($ view no. 15) $=\mathrm{DCC}($ view no.21), $\mathrm{DCC}$ (view no.13) $=\mathrm{DCC}($ view no. 14). As all DCCs of view no. 22 were less than 0.01 Sv/Gy, this view was excluded from the table. 
Table 8.15 Effective dose per entrance dose conwersion coeficient (Sw/Gy) in peripheral arteriography for needle punctures (PAn), Seldinger catheterisation (PAs) and intravenous DSA (PAiv)"

\begin{tabular}{|c|c|c|c|c|}
\hline \multirow{2}{*}{$\begin{array}{l}\text { Imaging mode } \\
\text { Diagnostic view }\end{array}$} & \multicolumn{2}{|c|}{ Male patients } & \multicolumn{2}{|c|}{ Female patients } \\
\hline & PAn & PAS and PAiv & PAn & PAs and PAiw \\
\hline \multicolumn{5}{|l|}{ Fluoroscopy: } \\
\hline 1. abdomen PA & .016 & .049 & .040 & .036 \\
\hline 2. $a b d \cdot r o t=25^{\circ}$ & - & .046 & - & - \\
\hline 3. pelvis PA & .045 & .074 & .062 & .069 \\
\hline 4. pel. rot $=25^{\circ}$ & .047 & .042 & .074 & .090 \\
\hline 5. thigh & .0044 & .018 & .0042 & .0085 \\
\hline 6. knee & .0028 & .0086 & .0025 & .0056 \\
\hline 7. lower leg & .0014 & .0044 & .0019 & .0038 \\
\hline 8. foot & .0006 & .0020 & .0009 & .0019 \\
\hline \multicolumn{5}{|l|}{ DSA: } \\
\hline 9. abdomen PA & - & .072 & - & .116 \\
\hline $10 \mathrm{abd}$. rot $=25^{\circ}$ & - & .057 & - & 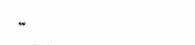 \\
\hline 11 pelyis PA & .049 & .076 & .065 & .085 \\
\hline 12 pel. rot $=25^{\circ}$ & .04 & .046 & .067 & .082 \\
\hline 13 thigh & .0032 & .017 & .0032 & .0063 \\
\hline 14 knee & .0023 & .0077 & .0022 & .0053 \\
\hline 15 lower leg & .0014 & .0043 & .0018 & .0036 \\
\hline 16 foot & .0006 & .0019 & .0009 & .0020 \\
\hline \multicolumn{5}{|c|}{ PUCK-films (PA-views): } \\
\hline 17 abdomen & - & .053 & - & .103 \\
\hline 18 pelwis & .024 & .060 & .045 & .092 \\
\hline 19 thigh & .0047 & .036 & .0036 & .0062 \\
\hline 20 kntee & .0019 & .0051 & .0019 & .0037 \\
\hline 2.1 lower leg & .0011 & .0029 & .0009 & .0020 \\
\hline $22 \mathrm{foot}$ & .0002 & - & .0001 & - \\
\hline
\end{tabular}
Qplican can be found in Table 8.11. "“" denotes "not applicable" or "data is not availlable". Beam filtration: $4.5 \mathrm{~mm}$ Al in X-ray beam $+1.5 \mathrm{~mm}$ for patient support. PAn- procedures refer to arteriography of the iliac region plus one leg. 
Table 8.16 Mean effective dose estinates for three types of peripheral arteriography procedures: needle punctures (PAn), seldinger catheterisation (PAs) and intravenows DSA (PAV)

\begin{tabular}{|c|c|c|c|c|c|c|}
\hline \multirow[b]{2}{*}{ Imanging mode } & \multicolumn{3}{|c|}{ Male patients } & \multicolumn{3}{|c|}{ Female patients } \\
\hline & PAn & PAs & PAiv & $\mathrm{PAn}$ & PAs & PAix \\
\hline $\begin{array}{l}\text { Mean effective dose (mSv) } \\
\text { for complete procedure: }\end{array}$ & 0.9 & 4.1 & 5.3 & 1.4 & 3.8 & 5.1 \\
\hline
\end{tabular}

Relative contributions $(\%)$

to the effective dose

for a complete procedure:

Irnaging mode

\begin{tabular}{lrrrrrr} 
Puoroscopy & $49 \%$ & $54 \%$ & $9 \%$ & $59 \%$ & $57 \%$ & $7 \%$ \\
DSA & $35 \%$ & $28 \%$ & $91 \%$ & $23 \%$ & $15 \%$ & $93 \%$ \\
films & $17 \%$ & $18 \%$ & - & $17 \%$ & $28 \%$ & - \\
Ansatomical regiom & $93 \%$ & $93 \%$ & $98 \%$ & $97 \%$ & $97 \%$ & $99 \%$ \\
$\begin{array}{l}\text { Trunk } \\
\text { Legs }\end{array}$ & $7 \%$ & $7 \%$ & $2 \%$ & $3 \%$ & $3 \%$ & $1 \%$ \\
$\quad \begin{array}{l}\text { Subspecification of } \\
\text { imaging mode in the }\end{array}$ & & & & & & \\
$\begin{array}{l}\text { trunk region } \\
\text { fluoroscopy }\end{array}$ & & & & & & \\
$\begin{array}{l}\text { DSA } \\
\text { films }\end{array}$ & $46 \%$ & $53 \%$ & $9 \%$ & $59 \%$ & $57 \%$ & $7 \%$ \\
\hline
\end{tabular}

" "." denotes "not applicable" or "data is not avadable" "Beam filtration: 4.5 mm $\mathrm{Al}$ in X-ray bean +1.5 mm for patient support. PAn- procedures refer to arteriography of the illiac region plus one leg. Sun values for subgroups can differ from listed totals due to rounding errors.

\subsubsection{Discussion}

\section{Organ dose and effective dose conversion coefficients}

Organ dose per entrance dose conversion coefficients (DCCs) vary between very small values (less than $0.0001 \mathrm{~Sv} / \mathrm{Gy}$ ) and about $0.9 \mathrm{Sw} / \mathrm{Gy}$. In the trunk region (e.g. view nos. $1-4,9-12$, and 17 and 18) DCCs wary between about 0.9 and $0.01 \mathrm{~Sv} / \mathrm{Gy}$. In the leg region, only DCCs for bone surface, skin and muscle are higher than $0.01 \mathrm{~Sv} / \mathrm{Gy}$. DCCs for the ovaries are systematically higher than DCCs for the testes. DCC-values for ovaries, exposed to the primary beam, are about $0.2 \mathrm{~Sv} / \mathrm{Gy}$, DCC-estimates for directly exposed testes about $0.1 \mathrm{~Sv} / \mathrm{Gy}$. It should be noted, however, that in clinical situations DCC values for exposed testes can be much higher. For instance, theoretically it can be shown that if the legs are spread, thereby not "protecting" the testes, and assuming a focus-patient distance of $75 \mathrm{~cm}$ and a focus-testes distance of $85 \mathrm{~cm}$, the DCC is about $0.8 \mathrm{Sw} / \mathrm{Gy}$.

Generally, DCCs for fluoroscopy of the trunk region are smaller than corresponding DCCs for DSA and film. This difference is associated with small fluoroscopy field sizes used in the catheterisation stage. Apparently, higher tube voltage settings in fluoroscopy do not fully compensate this effect.

Effective dose estimates per entrance dose conversion coefficients (ECC) shown in Table 8.15 clearly indicate the relative importance of the anatomical regions. ECCs for 
the trunk region vary between 0.02 and $0.08 \mathrm{~Sv} / \mathrm{Gy}$ for males, and between 0.04 and 0.12 for females. ECCs for the leg region are about ten to one hundred times smaller than ECCs for the trunk. ECCs for PAn procedures are systematically smaller than for PAs and PA-I procedures. This difference corresponds with smaller field sizes applied in PAn procedures. ECCs for views of the thigh in PAs and PAiv procedures of male patients (view nos 5,13 and 19) are higher than for females. This corresponds with exposures to the testes. The lower figures for ECC-thigh in PAn procedures for males result from exposure geometries in which the testes are not located in the primary $X$-ray beam.

\section{Estimates for the effective dose}

As shown in Table 8.16, mean effective doses for peripheral arteriography of normal sized patients are equall to $1 \mathrm{mSv}$ for needle puncture procedures (PAn), $4 \mathrm{mSv}$ for Seldinger catheterisation procedures (PAs), and $5 \mathrm{mSv}$ for intravenous DSA procedures (PAiv).

In intra-arterial arteriography, the major part of the effective dose was associated with fluoroscopy (about $50 \%$ for males, and about $60 \%$ for females). DSA and film radiography account in a varying ratio for the remaining part. It is concluded from these findings that a significant reduction of the effective dose can hardly be obtained from changes in one imaging mode only. Dose reduction has to be achieved by optimizing all imaging stages, preferably with emphasis on fluoroscopy actions because of its relatively. high contribution.

Contrary to intra-arterial arteriography, in IV-DSA procedures (PAiv) only about $10 \%$ of the effective dose resulted from fluoroscopy. It follows, that apart from using more efficient imaging systems, dose reduction has to be accomplished by decreasing the number of DSA-frames and/or using smaller DSA field sizes.

The relative contributions of the trunk and leg regions to the effective dose, quantified in Table 8.16, clearly show that the major part of the effective dose to the patient resulted from imaging actions in the trunk region (more than $90 \%$ ); only about $10 \%$ is associated with imaging of the $\operatorname{leg}(\mathrm{s})$. Compared with the contributions to the dose-area product (DAP) in intra-arterial procedures, this observation is quite dissimilar. Averaged over male and female patients the DAPS in the lower regions (thigh, knee, lower leg and foot) were estimated to be about $50 \%$ in PAn-procedures and $40 \%$ in PAs-procedures. In IVDSA procedures on the other hand, relative contributions of DAP and effective dose from. imaging of vessels in the legs were of the same order of magnitude (DAP $=14 \%$; crective dose $=8 \%$ ).

Mean E/DAP-ratios were calculated from DAP data presented in Table 8.4 (ref. group) and from final estimates for the mean effective dose (Table 8.16). Results vary between 0.07 for PAn-males, 0.14 for PAs-males, PAiw-males, and PAn-fiemales, and 0.19 $\mathrm{mSv} \cdot \mathrm{Gy} \mathrm{y}^{-1} \mathrm{~cm}^{-2}$ for PAs and PAix of remales. These findings indicate sex-average E/DAP-ratios of $0.1 \mathrm{mSv} \cdot \mathrm{Gy}^{-1} \cdot \mathrm{cm}^{-2}$ for needle puncture procedures (PAn), and 0.17 $\mathrm{mSV} \cdot \mathrm{Gy}^{-1} \cdot \mathrm{cm}^{-2}$ both for Seldinger catheterisation (PAs) and IV-DSA procedures (PAiv).

For comparison, it should be noted that the E/DAP-ratio for peripheral arteriography of supine patients, derived from literature data, was equal to $0.15 \mathrm{mSv} \cdot \mathrm{Gy}^{-1} \cdot \mathrm{cm}^{-2}$ (Table $6.7)$. 
If one does not account for DAP dependence on patient size, the maximum effective dose can be estimated by multiplying the derived sex-specific E/DAP ratios with maximum DAP data presented in Table 8.4, which show variations up to a factor of 4 from the mean. Consequently, maximum effective doses for PAn procedures are calculated to be 4 and $7 \mathrm{mSv}$ for males and females respectively, and $15-19 \mathrm{mSv}$ for PAs and PAiv procedures.

\subsection{Quantification of patient radiation dose exposure conditions in abdominal arteriography}

\subsubsection{Introduction}

Imaging of arteries in the abdominal and iliac region is called abdominal arteriography. Exposure conditions to patients are quantified for examinations in the Department of Diagnostic Radiology of the University Hospital Maastricht (azM). These data will be used in Section 8.5 to estimate the effective dose to the patient. Imaging systems applied in the azM are described in Section 4.3.

\subsubsection{Arteriography of the abdominal arteries}

This study comprises two methods for diagnostic imaging of the abdominal aorta and its branches:

\section{- Intravenous Digital Subtraction Arteriography (IV-DSA)}

In this procedure contrast medium was administered intravenously to the supine patient through a needle in the basilic vein. Fluoroscopy was used only to determine the position and the field of view for DSA-frames. Usually, one to three series of DSA-frames were taken per procedure, depending on the medical record and the findings in the course of the procedure.

\section{- Intra-arterial arteriography}

Contrast medium was administered to the supine patient via a catheter, inserted into the femoral artery, and placed in the aorta, with its tip near the renal arteries. Patients were examined with serial cut film arteriography and/or one or more series of DSA frames (IADSA). Fluoroscopy was used for catheter positioning, and for adjustment of the region of interest in serial cut film and DSA imaging. Selective catheterisations with the catheter tip manoeuvred in one of the branches of the aorta, were performed on clinical indications. Generally, selective catheterisation was more complex and required more fluoroscopy time than non-selective catheterisation. However, it should be noted that some non-selective catheterisation procedures were very time consuming as well.

Diagrams of frequently applied diagnostic views are given in Figure 8.8 and 8.9 . As these figures show, PA-views of supine patients were obtained with undertable X-ray rube positions. 

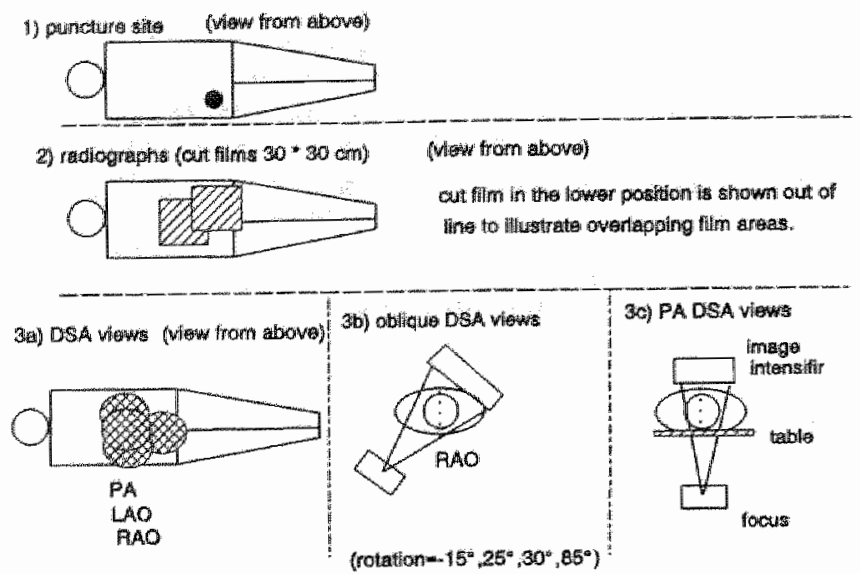

Figure 8.8 Diagram of puncture site and exposed body areas during serial cut film radiography and DSA.irtaging in intra-arterial abdominal arteriography, performed with Seldinger catheterisation of the supine patient, with undercouch tube geometry (PA, LAO, RAO, denote posterioranterior, left anterior oblique, and right anterior oblique views respecively).

1) punciure silta (top vlew)

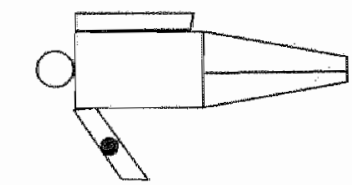

2.1) PADSA VIOW

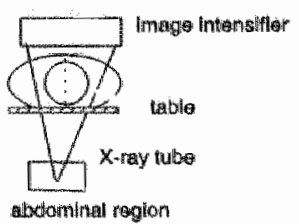

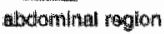

2) Reglons selectod for DSA

(top viow)

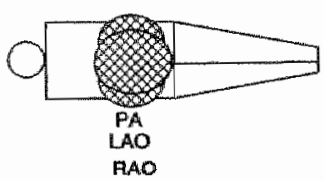

20) obltque DSA viows

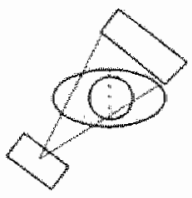

left rental artarias

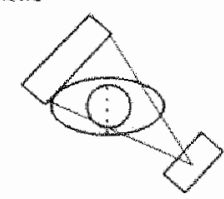

right ronal antorios

Figure 8.9 Diagram of puncture site and exposed body areas in intravenous abdominal arteriography of supine patients with undercouch tube geometry.

\subsubsection{Dose measurement, selection and compression of recorded data}

During this study, the X-ray system was equipped with the PC-based automated monitoring system which is described in Section 6.3. Using the same approach as applied 
for peripheral arteriography, a representative data set was derived from a large exposure data set for abdominal arteriography. Data selection was carried out according to the criteria that weight, height and the height/weight-ratio of the patient did not differ more than $30 \%$ from the corresponding data of the GSF-Monte Carlo phantoms ADAM and EVA [KR86]. In addition, the following selection criteria were used: number of DSAseries not less than $1 / 3$ and not more than 3 times the mean; number of film-series within 0.8 and 1.3 times the mean; dose-area products (DAP) for DSA, film, and fluoroscopy each within $1 / 10$ and 10 times the average values. These criteria were chosen arbitrarily, balancing between two opposing objectives: (1) to include as many procedures in the srudied data set as possible, and (2) to obtain typical exposure data for patients with body sizes, as similar as possible to the GSF phantoms. The resulting subgroup of procedures, trimmed for small and large anatomical sizes and for extreme radiation exposures, is referred to as "reference group". Using the DAP per data record for weighting, the resulting data set was condensed by merging data records of similar views, (see Section 6.3).

Intra-arterial abdominal arteriography procedures were classified into four groups:

- selective abdominal arteriography of the mesenteric artery and/or coeliac artery (AAMC),

- abdominal aortography, non selective (AAN),

- abdominal aortography, non selective, with blood sampling in aorta and in renal veins (AANB), and.

- abdominal arteriography, non selective, extended with selective catheterisation for renal arteriography (AAR).

Abdominal arteriography procedures which could not be designated unambiguouslly in one of these four groups, where classified as a remaining group (AXXX). The group AAia comprises all intra-arterial abdominal arteriography procedures performed. It should be noted that in Chapter 7, the three subgroups AAN, AANB and AAR were combined into subgroup AAA. Abdominal arteriography by means of intravenous DSA (IV-DSA) for maging of the aorta and renal arteries is denoted as AAiv.

\subsubsection{Results}

On average, intra-arterial abdominal arteriography procedures resulted in 68 data records per procedure (mimimum $=12$ and maximum $=230$ records), each record containing 19 items. The average number of data records in intravenous arteriography was 21 (minimum =9, maximum=71). Using the selection criterions mentioned in Section 8.4.3. exposure data for 129 procedures, stored in about 4600 data records, were selected from a large data set of 152 procedures. Selected data records (the reference group) have been merged and compressed into 33 data records, each representing a diagnostic view.

Table 8.17 contains statistics on the number of imaging series (serial cut film series and DSA-series), the total number of images (radiographs and DSA-images), and the fluoroscopy ume per procedure, both derived from all procedures monitored and from the reference group. Generally, only one imaging series was acquired at each location. However, if the diagnostic information obtained in a single run was not sufficient, the series was repeated. 
Table 8.17 Statisticy on inaging characteristics in abdominal arteriography

\begin{tabular}{|c|c|c|c|c|c|c|c|c|c|}
\hline \multicolumn{10}{|c|}{ Imaging modality } \\
\hline $\begin{array}{l}\text { Proc. } \\
\text { type }\end{array}$ & \multicolumn{2}{|c|}{ All patients } & $\mathrm{P} 90$ & $M A X$ & MEDIAN & MEAN & \multicolumn{3}{|c|}{ ref, group } \\
\hline \multicolumn{5}{|c|}{ Fluor oscopy time [min]: } & 13. & 14.8 & 2 & 11.5 & 14.7 \\
\hline $\begin{array}{l}\text { AAMC } \\
\text { AAN }\end{array}$ & 24 & 6 & 30 & 35 & $\begin{array}{r}13 \\
3\end{array}$ & $\begin{array}{r}14.0 \\
5.7\end{array}$ & 1 & $\begin{array}{r}18.3 \\
2.5\end{array}$ & 6.2 \\
\hline $\begin{array}{l}\text { AAN } \\
\text { AANB }\end{array}$ & 32 & 1 & 13 & 36 & 3 & 5.0 & 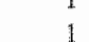 & 4.0 & 4.7 \\
\hline $\begin{array}{l}\text { AANB } \\
\text { AAR }\end{array}$ & 54 & 2 & 7 & 22 & $\begin{array}{l}4 \\
5\end{array}$ & 6.4 & $i$ & $\begin{array}{l}4.4 \\
5.2\end{array}$ & 5.1 \\
\hline $\begin{array}{l}\text { AAR } \\
\text { AXXX }\end{array}$ & 10 & 2 & 14 & 14 & 5 & 11.5 & 2 & 3.2 & ? \\
\hline $\begin{array}{l}\text { AXXX } \\
\text { AAia }\end{array}$ & 20 & 5 & 23 & 30 & $\begin{array}{c}9 \\
5\end{array}$ & 7.9 & 1 & - & . \\
\hline $\begin{array}{l}\text { AAir } \\
\text { AAiv }\end{array}$ & 140 & 2 & 21 & 36 & $\begin{array}{l}5 \\
1\end{array}$ & 0.7 & 0 & 0.7 & 0.7 \\
\hline \multirow{2}{*}{\multicolumn{10}{|c|}{ Number of film-series: }} \\
\hline & & & & & 2 & 2.2 & 0 & 2.0 & 2.3 \\
\hline $\begin{array}{l}\text { AAMC } \\
\text { AAN }\end{array}$ & 24 & 1 & 3 & $\begin{array}{l}4 \\
6\end{array}$ & 1 & 2.0 & 0 & 1.5 & 2.0 \\
\hline $\begin{array}{l}\text { AAN } \\
\text { AANB }\end{array}$ & 32 & 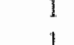 & 4 & $\begin{array}{l}6 \\
4\end{array}$ & $i$ & 1.4 & 0 & 1.0 & 1.4 \\
\hline AAR & 10 & 1 & 5 & 6 & 3 & 2.7 & 0 & 2.5 & 2.5 \\
\hline$A \times X X$ & 20 & 1 & 4 & 7 & 3 & 2.0 & 0 & - & - \\
\hline AAia & 140 & 1 & 4 & 7 & 2 & 2.0 & 0 & . & - \\
\hline \multicolumn{10}{|c|}{ Number of DSA-series: } \\
\hline AAMC & 6 & 1 & 3 & 3 & 2 & 2.0 & 0 & 2.0 & 2.2 \\
\hline AAN & 14 & 1 & 2 & 4 & 2 & 1.7 & 0 & 1.5 & 1.7 \\
\hline AANB & 40 & 1 & 3 & 4 & 2 & 1.8 & 0 & 2.0 & 1.8 \\
\hline AAR & 2 & 2 & 2 & 2 & 2 & 2.0 & 0 & - & - \\
\hline $\mathrm{AXXX}$ & 9 & 1 & 7 & 7 & 2 & 3.0 & 1 & - & - \\
\hline AAla & 71 & 1 & 3 & 7 & 2 & 2.0 & 0 & - & - \\
\hline AAiv & 32 & 2 & 3 & 5 & 3 & 2.7 & 0 & 3.0 & 2,8 \\
\hline \multicolumn{10}{|c|}{ Number of fillms: } \\
\hline $\mathrm{AAMC}$ & 24 & 15 & 45 & 60 & 30 & 30 & 2 & 30 & 32 \\
\hline$A A N$ & 32 & 9 & 20 & 25 & 12 & 13 & 1 & 13 & 13 \\
\hline AANB & 54 & 8 & 18 & 38 & 11 & 12 & I & 11 & $\llbracket 1$ \\
\hline AAR & 10 & 12 & 35 & 36 & 28 & 26 & 3 & 29 & 26 \\
\hline $\operatorname{AxXX}$ & 20 & 8 & 43 & 48 & 22 & 23 & 3 & - & - \\
\hline AAia & 140 & 8 & 33 & 60 & 13 & 18 & 1 & - & - \\
\hline \multicolumn{10}{|c|}{ Number of DSA-frames: } \\
\hline AAMC & 6 & 22 & 54 & 54 & 38 & 37 & 6 & 47 & 40 \\
\hline$A A N$ & 14 & 8 & 50 & 52 & 26 & 25 & 4 & 20 & 24 \\
\hline AANB & 40 & 9 & 33 & 50 & 25 & 22 & 2 & 24 & 22 \\
\hline AAR & 2 & 26 & 34 & 34 & 30 & 30 & 4 & . & - \\
\hline $\mathrm{AXXX}$ & 9 & 10 & 101 & 101 & 34 & 46 & 11 & - & * \\
\hline A Ain & 71 & 9 & 50 & 101 & 26 & 27 & 2 & - & * \\
\hline AAiv & 32 & 26 & 74 & 109 & 47 & 49 & 4 & 47 & 51 \\
\hline
\end{tabular}

"AAN = IA-abdominal aortography (non selective); $\mathrm{A} A \mathrm{NB}=1 \mathrm{~A}$-aottography, including sampling of blood in aorta and renal veins: $A . A R=\mathbb{A}$-arteriography of renal vessels; $A A M C=I A$-mesenteric and/or coeliac arteriography (selective); $A X X X=$ remaining group of $\mathbb{I A}$-abd. arteriography proc. $A A i a=$ all $I A$ abdominal arteriography procedures. AA I denotes intravenous DSA arteriography of the aorta and renal arieries. "Statistics for the reference group (see text) are given for: 26 for AAN-proc., 48 for AANBproc., 7 for AAR-proe., 20 for AAMC-proc, 29 for AAiv-proc. Within this combination of groups, DSAimaging was performed in 10 AAN proc. 36 AANB proc., 1 AAR proc., and 29 AA II procedures. Because of its low frequency. DSA in AAR was excluded from this table. Serial cut films were not applied in IV-DSA procedures (AAiv). P10, P90 $=10$, 90mpercentile value; MEAN $=$ arithmetic atverage; SEM - standard error of the mean. 
Table 8.18 provides the results of dose-area product measurements (DAP) for each procedure type separately, both for all patients and for the reference group; relative contributions of different imaging techniques are inciuded as well. Table 8.19 provides additional data derived from the group "all patients" on the relative contribution of the dose-area product as a function of projection angles (rotation in the transversal plane to obtain oblique or lateral views). Significant contributions of angulated views (angle more than $5^{\circ}$ ) were only found for DSA-15\% in AAN $(0.4 \%), D S A-15^{\circ}$ in $\mathrm{AANB}(1 \%), \mathrm{DSA}$ $\left(6^{\circ}-9^{\circ}\right)$ in $\mathrm{AA} I(11 \%)$ and $\mathrm{DSA}-18^{\circ}$ in $\mathrm{AA} I(1 \%)$. The term "angulation" refers to rotating movements of the C-arm in the plane through the longitudinal axis of the patient to provide caudal-cranial, or cranial-caudal views.

Table 8.18 Statistics on the dose-area product and the relative contributions of imaging modalities per patient procedure in abdominal arteriography

\begin{tabular}{lccccc}
\hline $\begin{array}{l}\text { Proc. } \\
\text { type }\end{array}$ & All patients & & & \multicolumn{2}{c}{ ref. group $^{\mathrm{b}}$} \\
\hline
\end{tabular}

Dose-area product $\left(\mathrm{Gy} \cdot \mathrm{cm}^{2}\right)$ :

$\begin{array}{lrrrrrrrrr}\text { AAMC } & 24 & 37 & 110 & 159 & 62 & 68 & 6 & 62 & 65 \\ \text { AAN } & 32 & 13 & 54 & 171 & 22 & 36 & 6 & 21 & 38 \\ \text { AANB } & 54 & 18 & 69 & 91 & 36 & 38 & 3 & 35 & 36 \\ \text { AAR } & 10 & 21 & 62 & 63 & 39 & 42 & 5 & 39 & 43 \\ \text { AXXX } & 21 & 32 & 138 & 210 & 49 & 68 & 11 & - & - \\ \text { AAi. } & 141 & 16 & 86 & 210 & 39 & 47 & 3 & 38 & 43 \\ \text { AAiv } & 32 & 12 & 59 & 99 & 28 & 32 & 3 & 29 & 33\end{array}$

Relative contribution of fluoroscopy in dose-area product (\%):

$\begin{array}{lrrrrrrrrr}\text { AAMC } & 24 & 26 & 72 & 85 & 49 & 49 & 4 & 46 & 47 \\ \text { AAN } & 32 & 20 & 52 & 79 & 34 & 37 & 3 & 37 & 39 \\ \text { AANB } & 54 & 22 & 57 & 84 & 32 & 36 & 2 & 31 & 35 \\ \text { AAR } & 10 & 22 & 61 & 62 & 41 & 42 & 5 & 37 & 34 \\ \text { AXXX } & 21 & 23 & 73 & 92 & 42 & 45 & 5 & - & - \\ \text { AAia } & 141 & 22 & 66 & 92 & 37 & 40 & 1 & 35 & 38 \\ \text { AAiv } & 32 & 5 & 14 & 36 & 8 & 9 & 1 & 8 & 8\end{array}$

Relative contribution of DSA in dose-area product $(\%)$ :

$\begin{array}{lrrrrrrrrr}\text { AAMC } & 6 & 21 & 42 & 42 & 32 & 32 & 4 & 29 & 30 \\ \text { AAN } & 14 & 18 & 65 & 65 & 41 & 39 & 5 & 34 & 37 \\ \text { AAMB } & 40 & 23 & 49 & 52 & 39 & 37 & 2 & 39 & 37 \\ \text { AAR } & 2 & 22 & 42 & 42 & 32 & 32 & 10 & - & - \\ \text { AXXX } & 9 & 8 & 52 & 52 & 38 & 33 & 5 & - & - \\ \text { AAlia } & 71 & 21 & 51 & 65 & 39 & 36 & 1 & 39 & 37 \\ \text { AAiw } & 32 & 86 & 95 & 97 & 92 & 91 & 1 & 92 & 92\end{array}$

Relative contribution of films in dose-area product $(\%)$ :

\begin{tabular}{lrllllllll} 
AAMC & 24 & 22 & 70 & 86 & 38 & 43 & 4 & 42 & 45 \\
AAN & 32 & 18 & 72 & 91 & 50 & 46 & 4 & 52 & 46 \\
AANB & 54 & 20 & 64 & 74 & 32 & 37 & 2 & 34 & 37 \\
AAR & 10 & 22 & 76 & 86 & 58 & 52 & 7 & 59 & 59 \\
AXXX & 20 & 15 & 74 & 99 & 39 & 43 & 5 & - & - \\
AAia & 140 & 20 & 70 & 99 & 38 & 42 & 2 & 39 & 43 \\
\hline
\end{tabular}

a. "See footnotes of Table 8.17.

Data derived from the reference group, used as input data for Monte Carlo organ dose calculations for males and females have been summarised in Table 8.20. This table 
comprises data about beam position and direction, field size, focus position, tube high voltage and entrance dose. Entrance dose estimates, derived from DAP measurement results, refer to the air kerma, free-in-air, at the beam entrance position. The position of the focus was derived by using the same $x y z$-coordinate system as applied for the GSFphantoms ADAM and EVA. This table also comprises data about the mean relative contribution per view to the total dose-area product, the mean fraction of the total fluoroscopy time, and the mean fraction of the number of films and DSA-frames. It should be noted that geometrical data and data about tube high voltage were rounded to multiples of five.

Table 8.19 Relative contribution to the dose-area product of various diagnostic views as a function of the rotation angle

\begin{tabular}{|c|c|c|c|c|c|c|c|c|}
\hline $\begin{array}{l}\text { Procedure } \\
\text { type }\end{array}$ & ig modle & $\begin{array}{l}\text { Rotation } \\
\leq 5^{\circ}\end{array}$ & $6-15^{\circ}$ & $16-25^{\circ}$ & $26-35^{\circ}$ & $36-45^{\circ}$ & $90^{\circ}$ & sum \\
\hline \multicolumn{9}{|l|}{ IA arteriography: } \\
\hline \multirow[t]{4}{*}{ AAN } & fluoro: & $42 \%$ & $.5 \%$ & $.5 \%$ & $.5 \%$ & . & - & $44 \%$ \\
\hline & DSA: & $14 \%$ & $3 \%$ & $4 \%$ & $2 \%$ & $1 \%$ & - & $24 \%$ \\
\hline & film: & $30 \%$ & 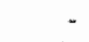 & $1 \%$ & $.6 \%$ & - & - & $32 \%$ \\
\hline & total: & $86 \%$ & $4 \%$ & $6 \%$ & $3 \%$ & $1 \%$ & - & $100 \%$ \\
\hline \multirow[t]{4}{*}{ AANB } & fluoro: & $32 \%$ & $2 \%$ & $2 \%$ & $.6 \%$ & - & - & $37 \%$ \\
\hline & DSA: & $5 \%$ & $9 \%$ & $12 \%$ & $5 \%$ & $.6 \%$ & $1 \%$ & $32 \%$ \\
\hline & film: & $31 \%$ & - & - & - & - & - & $31 \%$ \\
\hline & fotal: & $68 \%$ & $11 \%$ & $14 \%$ & $6 \%$ & $6 \%$ & $1 \%$ & $100 \%$ \\
\hline \multirow[t]{4}{*}{$A A R$} & fluoro: & $29 \%$ & $2 \%$ & $2 \%$ & - & 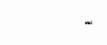 & - & $33 \%$ \\
\hline & DSA: & & - & $10 \%$ & - & - & - & $10 \%$ \\
\hline & film: & $50 \%$ & $5 \%$ & $2 \%$ & - & - & - & $57 \%$ \\
\hline & total: & $79 \%$ & $7 \%$ & $14 \%$ & - & - & - & $100 \%$ \\
\hline \multirow[t]{4}{*}{ AAMC } & fluoro: & $42 \%$ & - & - & - & - & $6 \%$ & $48 \%$ \\
\hline & DSA: & $6 \%$ & - & - & - & - & $3 \%$ & $9 \%$ \\
\hline & film: & $43 \%$ & - & - & - & - & - & $43 \%$ \\
\hline & total: & $91 \%$ & - & - & - & - & $9 \%$ & $100 \%$ \\
\hline \multirow[t]{3}{*}{ IV-DSA (AA I): } & fluoro: & $7 \%$ & $.1 \%$ & $.6 \%$ & .2 品 & - & - & $8 \%$ \\
\hline & DSA: & $81 \%$ & - & $6 \%$ & $4 \%$ & - & $1 \%$ & $92 \%$ \\
\hline & totall; & $88 \%$ & . & $7 \%$ & $4 \%$ & - & $1 \%$ & $100 \%$ \\
\hline
\end{tabular}

"See foomotes of Table 8.17. Relative contributions were calculated fron dose-area product data, summed over male and female patients for each group. Relative contributions are given for angles of rotation of the C-arm in the transaxial plane, providing oblique or lateral views. "sum" contains rounded figures. 
Table \$.20 Derived data about exposure conditions, used for Monte Carlo organ dose calculations in abdominal arteriography with undercouch tube geometry

\begin{tabular}{|c|c|c|c|c|c|c|c|c|c|c|}
\hline \multirow{2}{*}{$\begin{array}{l}\text { Inaging modle } \\
\text { diagnostic } \\
\text { view }\end{array}$} & \multirow[b]{2}{*}{ rot. ${ }^{b}$} & \multicolumn{3}{|c|}{ Focus positionen } & \multirow{2}{*}{$\begin{array}{l}\text { Fineld size" } \\
\text { at } 1 \mathrm{~m} \\
\text { (tongwat) } \\
\text { [croucom] }\end{array}$} & \multirow{2}{*}{$\begin{array}{l}\mathrm{WY} \\
{[\mathrm{k} y]}\end{array}$} & \multirow{2}{*}{$\begin{array}{l}\text { meten } \\
\text { dosect } \\
{[m G y]}\end{array}$} & \multirow{2}{*}{ 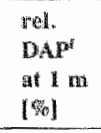 } & \multirow{2}{*}{$\begin{array}{l}\text { rel. } \\
\text { FLU } \\
{[\%]} \\
\end{array}$} & \multirow{2}{*}{$\begin{array}{l}\text { rel. } \\
\text { inag." } \\
\text { [\%] }\end{array}$} \\
\hline & & $\begin{array}{l}z- \\
\text { axis } \\
{[\mathrm{fm}]}\end{array}$ & $\begin{array}{l}y- \\
{[\mathrm{cm}]}\end{array}$ & $\begin{array}{l}\mathrm{x}- \\
\text { axis } \\
\text { [cri] }\end{array}$ & & & & & & \\
\hline \multicolumn{11}{|c|}{ MALE PATIENTS } \\
\hline \multicolumn{11}{|c|}{ Fluoroscopy: } \\
\hline abd. (mil) & $0^{\circ}$ & 30 & 75 & 0 & $25 \times 20$ & 85 & 7.4 & $25 \%$ & $79 \%$ & - \\
\hline$a b d .(m 2)$ & $20^{\circ}$ & 30 & 70 & 27 & $25 \times 25$ & 85 & 7.7 & $1 \%$ & $3 \%$ & - \\
\hline $\operatorname{abd}(\mathrm{m} 3)$ & $90^{\circ}$ & 30 & 0 & 80 & $25 \times 15$ & 1.05 & 11.8 & $1 \%$ & 2 & . \\
\hline abd. $(\mathrm{m} 4)$ & $0^{\circ}$ & 20 & 80 & 0 & $30 \times 20$ & 80 & 7.8 & $3 \%$ & $12 \%$ & . \\
\hline \multicolumn{11}{|l|}{ DSA: } \\
\hline abd. (m5) & $0^{\circ}$ & 30 & 80 & 0 & $34 \times 25$ & 80 & 1.3 & $20 \%$ & - & 419 \\
\hline abd. (m6) & $15^{\circ}$ & 30 & 80 & 30 & $20 \times 20$ & 85 & 2.2 & $4 \%$ & - & $9 \%$ \\
\hline abd. $(\mathrm{m} 7)$ & $25^{\circ}$ & 30 & 70 & 35 & $30 \times 25$ & 85 & 2.3 & $11 \%$ & - & $24 \%$ \\
\hline pelvis(m8) & $0^{\circ}$ & 10 & 80 & 0 & $34 \times 30$ & 75 & 1.0 & $9 \%$ & - & $25 \%$ \\
\hline \multicolumn{11}{|l|}{ Films: } \\
\hline$a b d .(m 9)$ & $0^{\circ}$ & 45 & 85 & 0 & $30 \times 30$ & 75 & 1.3 & $1 \%$ & - & $3 \%$ \\
\hline abd. $(\mathrm{m} / 0)$ & $0^{\circ}$ & 30 & 85 & 0 & $30 \times 30$ & 75 & 1.2 & $23 \%$ & - & $86 \%$ \\
\hline abd. (mll) & $0^{\circ}$ & 15 & 85 & 0 & $30 \times 30$ & 75 & 1.0 & $2 \%$ & - & $10 \%$ \\
\hline
\end{tabular}

FEMALE PATIENTS

\section{Fluoroscopy:}

\begin{tabular}{lrrrrrrrrrr} 
abd. (f1) & $0^{\circ}$ & 55 & 75 & 0 & $25 \times 15$ & 85 & 7.8 & $3 \%$ & $7 \%$ & - \\
abd. (f2) & $0^{\circ}$ & 40 & 80 & 0 & $20 \times 15$ & 80 & 7.4 & $5 \%$ & $13 \%$ & - \\
abd. (f3) & $0^{\circ}$ & 30 & 80 & 0 & $25 \times 20$ & 80 & 6.4 & $22 \%$ & $56 \%$ & - \\
abd. (f4) & $90^{\circ}$ & 30 & 5 & 75 & $20 \times 15$ & 95 & 11.7 & $2 \%$ & $5 \%$ & - \\
abd. (f5) & $25^{\circ}$ & 25 & 70 & 30 & $25 \times 25$ & 80 & 8.0 & $1 \%$ & $2 \%$ & - \\
abd. (f6) & $0^{\circ}$ & 15 & 75 & 0 & $25 \times 20$ & 75 & 5.6 & $3 \%$ & $9 \%$ & - \\
pelv. (f7) & $85^{\circ}$ & 10 & 5 & 70 & $25 \times 15$ & 95 & 12.6 & $1 \%$ & $3 \%$ & - \\
pelv. (f8) & $0^{\circ}$ & 5 & 75 & 0 & $15 \times 20$ & 75 & 6.2 & $3 \%$ & $6 \%$ & - \\
DSA: & & & & & & & & & \\
abd. (f9) & $0^{\circ}$ & 30 & 80 & 0 & $30 \times 30$ & 75 & 1.2 & $10 \%$ & - & $40 \%$ \\
abd. (f10) & $15^{\circ}$ & 30 & 80 & 0 & $20 \times 20$ & 80 & 2.2 & $3 \%$ & - & $10 \%$ \\
abd. (f11) & $30^{\circ}$ & 30 & 65 & 35 & $10 \times 10$ & 90 & 2.8 & $1 \%$ & - & $4 \%$ \\
abd. (f12) & $90^{\circ}$ & 30 & 0 & 75 & $25 \times 15$ & 90 & 3.4 & $2 \%$ & - & $7 \%$ \\
abd. (f13) & $25^{\circ}$ & 25 & 75 & 35 & $25 \times 25$ & 80 & 2.4 & $6 \%$ & - & $21 \%$ \\
pely.(f14) & $0^{\circ}$ & 15 & 80 & 0 & $34 \times 30$ & 75 & 0.8 & $2 \%$ & - & $8 \%$ \\
Films: & & & & & & & & & & \\
abd. (f15) & $15^{\circ}$ & 30 & 75 & 20 & $25 \times 20$ & 80 & 1.5 & $1 \%$ & - & $3 \%$ \\
abd. (f16) & $0^{\circ}$ & 25 & 85 & 0 & $30 \times 30$ & 75 & 1.1 & $34 \%$ & - & $93 \%$ \\
pely. (f117) & $0^{\circ}$ & 10 & 85 & 0 & $30 \times 25$ & 75 & 1.1 & $1 \%$ & - & $4 \%$ \\
\hline
\end{tabular}

"Data for males, were derived from 44 IA-ateriography and 21 IV-DSA procedures, for females from 57 IA-art and 8 IV-DSA procedures; "rot." denotes the angle of rotation. 0 " corresponds with PA-views of at supine patient (undercouch tube position); ${ }^{\circ} x, y, z$-coordinates refer to the GSF-phantoms ADAM and EVA: "field size were derived for a reference point at $1 \mathrm{~m}$ from the focus; "mean dose at $1 \mathrm{~m}$ " refers to the mean dose rate during fluoroscopy [mGy/min], to the mean dose per film [mGy/film], or to the mean dose per DSA-frame [mGy/frame]. Beam filtration $=4.5 \mathrm{~mm}$ Al: table susport plus window in X-ray housing $=1.5 \mathrm{~mm}$ Al-eq. Total $=6 \mathrm{~mm}$ Al-eq, " "rel. DAP" refers to the relative contribution of each diagnostic view to the total dose-area product; "rel. FLU" refers to the fluoroscopy time per wiew, relative to the total nuoroscopy time; "rel. ing." refers to the number of DSA-frames or films per diagnostic view, relative to the total number of DSA-frames or films respectively" $10-15^{\circ}$. 


\subsubsection{Discussion}

From results of an inquiry into the methods and the magnitude of non-cardiovascular radiology in the Netherlands in 1992 [K195], the number of intra-arterial (LA) abdominal arteriography procedures, relative to all IA-arteriography procedures, was estimated to be about $12 \%$ to $17 \%$; for IV-DSA procedures, the relative frequency of abdominal procedures was estimated to be $10 \%$ to $30 \%$. This relatively large uncertainty in the frequency of abdominal IV-DSA procedures is caused by a large proportion of undifferentiated abdominal and iliac/lower limb procedures. Because of this uncertainty, the frequency ratio of IA-procedures/IV-DSA procedures for abdominal arteriography could not be estimated better than 1.4 to 7 .

In the University Hospital Maastricht (azM), twenty-three percent of the IA-arteriography procedures was classified as abdominal arteriography, for IV.DSA the relative frequency was $14 \%$. The ratio of the numbers of intra-arterial procedures by intravenous procedures was equal to 3.8. The relative frequency of males in intra-arterial abdominal arteriography procedures was equal to $53 \%$, in intravenous DSA $74 \%$ (1990-1993).

It should be noted once more that statistics on technique parameters have been deriwed for selected procedures that meet the criteria for patient size and usage characteristics of the $X$-ray system. Procedures with extremly small or large numbers of images, fluotoscopy time and very obese or small patients were excluded from this group. Comparisons of means and medians of imaging characteristics and dose-area products pertaining to "all patients" and to the "reference group" can be carried out by using the data presented in Table 8.17 and 8.18 .

\section{Diagnostic Imaging:}

Table 8.17 shows that the fluoroscopy time per procedure varied between about 1 minute and 35 minutes. The mean fluoroscopy time in IV-DSA was about 40 seconds, about 5 minutes in non-selcctive intra-arteriography, and about 15 minutes in selective intraarteriography of the mesenteric and/or coeliac arteries. This large difference between IVDSA and intra-arterial arteriography is mainly associated with the techmique of contrast medium administration. Whereas intra-arterial arteriography is a complex technique, which requires a relatively large amount of fluoroscopy time for accurate positioning of the catheter tip, IV-DSA on the other hand is a relatively simple technique which requires only short times of fluoroscopy for previewing and adjustments of DSA-views.

Table 8.17 clearly demonstrates the wide variations in the application of the $X$-ray system in different types of abdominal arteriography and the variation within each type. It obvious that the frequencies of DSA- and filmmseries per procedure depend on the procedure type. Some IA-abdominal procedures involved DSA-imaging, whereas others involved film imaging only. In the majority of the procedures, both film- and DSAimaging were applied. Films were not applied in IV-DSA procedures. The number of film. series varied between 1 and 7, the number of films between 3 (not shown in Table 8.17) and 60 . The number of DSA-series varied between 1 and 7. The average number of DSAseries was 2 in IA-DSA, and 2.7 in IV-DSA. The total number of DSA-frames per procedure varied berween about 5 (not shown in Table 8.17) and 109. The large variability in fluoroscopy time and the number of DSA-frames is probably related to the 
broad range of pathologies, the patient (condition of blood vessels, blood low) and partly to the radiologist (grade of experience).

\section{Dose-area product.}

The dose-area product per patient procedure varied between about $5 \mathrm{~Gy} \cdot \mathrm{cm}^{2}$ (not shown in Table 8.18 ) and $210 \mathrm{~Gy} \cdot \mathrm{cm}^{2}$. This range factor of 40 , warying between 3 and 15 for selected procedure type, is relatively small. For instance, in peripheral arteriography a range factor of 100 was found, warying between 20 and 35 per procedure type (see Section 8.2.1).

It should be noted that, despite of the large difference in fluoroscopy time, the means for DAP in IV-DSA procedures and non-selective IA arteriography (AAN, AANB) were nearly the same (about $35 \mathrm{~Gy} \cdot \mathrm{cm}^{2}$ ). It is obvious that in IV-DSA more DSA-frames were required than in IA-DSA (see Table 8.17). Mean DAP $\left(68 \mathrm{~Gy} \cdot \mathrm{cm}^{2}\right.$ ) in selective arteriography of the mesenteric and coelac arteries (AAMC) was a factor of two higher than in non-selective procedures.

The mean relative contribution of fluoroscopy in IA-arteriography was about $35 \%$ (range: about $10 \%$ to $90 \%$ ). In IV-DSA, fluoroscopy contributed about $8 \%$ on average (range: about $5 \%$ to $36 \%$ ). Mean relative contributions of DSA and film in IAarteriography were equal to about $36 \%$ and $43 \%$ respectively. Relative contributions associated with DSA-imaging varied between $0 \%$ and $65 \%$ per procedure, filmcontributions varied between $0 \%$ and $99 \%$. This broad range in DAP-contribution per imaging mode clearly indicates large differences between angiography procedures of individual patients.

Generally speaking, variations in DAP will be both associated with differences in usage characteristics of the X-ray system such as fluoroscopy time and the number of images, and with differences in patient size.

The relative contributions of DAP from oblique projections to total DAP were computed as a function of the rotation of the X-ray stand in the transversal plane and the angulation in the axial plane. Table 8.19 shows that the contributions of rotated fluoroscopic views were very small, whereas rotated DSA-views contributed significantly. For example, in AANB procedures the relative contribution of rotated DSA views is estimated to be $27 \%$ of the total DAP. Significant contributions of rotated film-imaging were found in AAR-procedures. Contributions of angulated views (angulation more than $5^{\circ}$ ) were found to be quite small (see Table 8.19 , legend). It was concluded that the angle of angulation could be set to $0^{\circ}$.

\section{Field size:}

Mean field sizes were derived for a reference point at $1 \mathrm{~m}$ from the focus (data not shown in a table). In IV-DSA procedures the average field size was $950 \mathrm{~cm}^{2}\left(34 \times 28 \mathrm{~cm}^{2}\right)$, with only minor differences in fuoroscopy and DSA-imaging (differences less than $3 \%$ ). Averaged over all three imaging modes in intra-arterial arteriography, the mean field size was about $680 \mathrm{~cm}^{2}\left(27 \times 25 \mathrm{~cm}^{2}\right)$. The largest variation was found in AAMC-procedures, in which the mean field size was $390 \mathrm{~cm}^{2}\left(23 \times 17 \mathrm{~cm}^{2}\right)$ during fluoroscopy, $650 \mathrm{~cm}^{2}$ $\left(27 \times 24 \mathrm{~cm}^{2}\right)$ during DSA, and $990 \mathrm{~cm}^{2}\left(31 \times 32 \mathrm{~cm}^{2}\right)$ during film radiography. In the other types of IA-procedures, the mean field size during fluoroscopy was $500 \mathrm{~cm}^{2}$. Mean filin fielld sizes and mean DSA fields per type varied between 530 and $930 \mathrm{~cm}^{2}$ and between 630 and $780 \mathrm{~cm}^{2}$ respectively. 


\section{Tube high wollage:}

Tube high voltage varied between $66 \mathrm{kV}$ and $106 \mathrm{kV}$ (not shown in a table). For each imaging mode, the relative contribution of the DAP to the total DAP was computed par high voltage setting. Results showed that during fluoroscopy $90 \%$ of the total DAP (from the 5-percentile to the 95-percentile value) was associated with tube high voltage settings between $75 \mathrm{kV}$ and $97 \mathrm{kV}$ (median $=82 \mathrm{kV}$ ). During DSA-imaging, 90\% of DAP was associated with the high voltage range $71 \mathrm{kV}$ to $89 \mathrm{kV}$ (median $=79 \mathrm{kV}$ ); during serial cut film radiography $90 \%$ of the DAP resulted from tube high voltage settings between 72 $\mathrm{kV}$ to $78 \mathrm{kV}($ median $=76 \mathrm{kV})$.

\section{Quantitative data about exposure conditions:}

Derived quantitative exposure data on 28 diagnostic views (comprising fluoroscopy, DSA, serial cut films) have been compiled in Table 8.20 (from the originally derived set of diagnostic wiews, comprising 33 views, five views which contributed less than $0.5 \%$ each to the total DAP were excluded). The difference in the number of views in males $(n=11)$ and females $(n=17)$ is probably associated with the relatively small number of procedures. There is no evidence that the number of views depends on gender.

In all, it is concluded that PA-views in the abdominal region contributed about $70 \%$ to the total DAP per procedure: for male patients, PA-views contributed $68 \%$ (view no. m1, $\mathrm{m5}, \mathrm{ml0} ; \mathrm{z}$-coordinate $=30-25 \mathrm{~cm}$; rotation $=0^{\circ}$ ); for female patients $66 \%$ (view no. $\mathrm{P}$, 19, (16).

From the exposure data of the reference group (Table 8.20) the DAP per imaging modality, relative to the total DAP, is estimated to be: $30 \%$ for fluoroscopy, $44 \%$ for DSA and $26 \%$ for film radiography for male patients, and as $40 \%$ for fluoroscopy, $24 \%$ for DSA and $36 \%$ for female patients. These sex-specific differences are associated with differences in the relative number of selected procedures per procedure type. As shown in Table 8.20 (footnote a), the relative number of IV-DSA procedures for males is $32 \%$, whereas the relative number of IV-DSA proc. for females is only $13 \%$. It can easily be concluded from the preceding discussion that the low frequency of IV-DSA procedures for females corresponds indeed with a relatively low contribution of DSA, and high contributions of fluoroscopy and film.

Because of the selection criteria applied, the exposure data derived can be regarded as typical for the average patient, associated with an "average" procedure. Obviously, because of differences in patient body size, the quality of the blood vessels and catheterisation technique and imaging procedures applied, individual patient exposure conditions can differ significantly from the typical data derived in this study.

\subsection{Organ doses and effective dose to patients in abdominal arteriography}

\subsubsection{Introduction}

Exposure conditions for supine patients in abdominal arteriography with undercouch tube geometry have been described in Section 8.4. As published Monte Carlo organ dose data do not match these exposure conditions, the TNO Centre for Radiological Protection and Dosimetry (TNO.CSD) in Rijswijk has performed additional organ dose calculations. The 
term "organ dose" is used for short to denote "mean organ equivalent dose". Computational results and effective dose estimates are discussed in this section.

\subsubsection{Monte Carlo organ dose calculations and effective dose estimations}

Monte Carlo (MC) organ dose calculations by TNO [SC94, SC94all were performed with two phantoms, identical to the phantoms ADAM and EVA used by GSF [KR86]. It should be noted that $\mathrm{MC}$ data published by GSF represent organ doses, relative to the entrance dose (more precisely: relative to the air kerma, free-in-air, at the skin entrance position). However, as we recognised that data about the dose-area product (DAP) are generally more easily available than entrance dose data, we requested TNO to calculate organ doses, relative to the dose-area product. MC dose calculations by TNO were performed by simulating the interactions and energy depositions of $2,000,000$ photons for each single view. It required approximately ten hours processing time per view to track the history of such a large number of photons.

Due to limited resources, a subset of views was selected from the set of views quantified in Table 8.20. Taking the relative DAP of each view into consideration, nine views were selected: five for males $(\mathrm{ml}, \mathrm{m} 5, \mathrm{~m} 7, \mathrm{~m} 8$ and $\mathrm{m} 10$ ) and four for females ( $\mathrm{P} 3$, $19, \mathrm{f13}, \mathrm{f16}$ ). The sum of the mean relative DAPs of these selected views is equal to $88 \%$ for males, and $72 \%$ for females.

Two selected views could not be processed (wiew nos. $m l$ and $m 7$ ) because of limitations to the set of $\mathrm{X}$-ray spectra available. Organ dose estimates for these views were computed by interpolating results for nearby high voltage settings. In order to determine the high voltage dependence, organ dose calculations were performed for four different high voltage settings for one view (view no. $\mathrm{ml}$ ), namely $75 \mathrm{kV}, 80 \mathrm{kV}, 90 \mathrm{kV}$ and $100 \mathrm{kV}$.

Final results of Monte Carlo organ dose computations will be presented as "organ dose comversion coefficient", $\mathrm{DCC}_{\mathrm{DAp}}$, denoting the ratio of organ dose equivalent by dose-area product $\left(\mathrm{mSv} \cdot \mathrm{Gy}^{-1} \cdot \mathrm{cm}^{-2}\right)$. Using tissue weighting factors defined by ICRP (see Table 2.1), effective dose conversion factors per unit dose-area product $\mathrm{ECC}_{\text {dap }}$, were calculated for ach single diagnostic view. ECC $\mathrm{DAP}_{\mathrm{P}}$ for views which where not included in the subset of nine were estimated from published data about PA and rotated views of the abdominal region, presented in Section 6.4 and appendix D. Finally, effective doses were computed by summation for all views, the products of ECC calculations were carried out for five procedure types listed in Table 8.17 . Inaccuracies in the final results, due to arbitrary designations of values to $\mathrm{ECC}_{\mathrm{DAp}}$ for views that were not included in the subset used for Monte Carlo computations, have been addressed as well.

Because of high values for $\mathrm{DCC}_{\mathrm{DAP}}$ of some organs in the remaining group, some views could be a candidate for application of footnote 3 of Table 2 in ICRP Publication 60 [IC91], which reads as follow: "In those exceptional cases in which a single one of the remainder tissues or organs receives an equivalent dose in excess of the highest dose in any of the welve organs for which a weighting factor is specified, a weighting factor of 0.025 should be applied to that tissue or organ and a weighting factor of 0.025 to the average dose in the rest of the remainder as defined above.".

Effective doses were computed both with and without the application of this recommendation In order to evaluate its consequences. 


\subsubsection{Results and discussion}

\section{$D C C_{D A P}$ and $E C C_{D A P}$ Monie Carlo results}

Final results of Monte Carlo organ dose calculations, DCC given in Table 8.21. Results refer to supine positioned GSF-phantoms ADAM and EVA, witll undercouch $X$-ray tube geometries. Values for $\mathrm{DCC}_{\mathrm{DAP}}$ vary from less than 0.0001 $\mathrm{mSw} \cdot \mathrm{Gy}^{-1} \cdot \mathrm{cm}^{-2}$ to $2.6 \mathrm{mSv} \cdot \mathrm{Gy}^{-4} \cdot \mathrm{cm}^{-2}$. Data for views $\mathrm{m} 7$ and $\mathrm{fl} 3$ presented in this table. were calculated as mean values for LAO and RAO-projections, presented in Table 8.23. Results for $85 \mathrm{kV}$ were derived by linear interpolation between 80 and $90 \mathrm{kV}$. It should be noted that the range for effective dose conversion coefficients per view, ECC malle patients is quite small $\left(0.065\right.$ to $\left.0.109 \mathrm{mSv}-\mathrm{Gy}^{-1} \cdot \mathrm{cm}^{-2}\right)$. The same conclusion holds for female patients (range 0.132 to $0.225 \mathrm{mSw} \cdot \mathrm{Gy}^{-1} \cdot \mathrm{cm}^{-2}$ ). ECC $\mathrm{EAP}^{-v a l u e s}$ for females exceed $\mathrm{ECC}_{\mathrm{DAP}^{-\mathrm{v}}}$ values for males. This difference is mainly associated with the relatively high contribution of the ovaries to the effective dose for females.

\section{Dependence of tube high woltage}

$\mathrm{DCC}_{\mathrm{DAP}}$ and $\mathrm{ECC}_{\mathrm{DAP}}$ for male patients for one selected PA-wiew (view no. m1), performed with different tube high voltage settings ( $\mathrm{HV}$ ) are giwen in Table 8.22. Results show that both $\mathrm{DCC}_{\mathrm{DAp}}$ and $\mathrm{ECC}_{\mathrm{DAP}}$ increase from 75 to $90 \mathrm{kV}$; between 90 and $100 \mathrm{kV}$ no differences were found. It follows from these data that the minimum-maximum range of $\mathrm{ECC}_{\mathrm{DAP}}$ for $\mathrm{PA}$ views in the abdominal region, in dependence of $\mathrm{HV}$, is equal to about a factor of 2 . Table 8.23 shows that by increasing the tube high voltage from $80 \mathrm{kV}$ to 90 $\mathrm{kV}$ in oblique views, $\mathrm{ECC}_{\mathrm{DAP}}$ for males increased about $10 \%$ to $25 \%$. It should be noted that increased $\mathrm{ECC}_{\mathrm{DAp}}$-values for high tube high voltage (HV) do not indicate high effective doses at high $\mathrm{HV}$ settings. As pointed out by Drexler et al. [DR93] and many others, if HV settings are increased, the corresponding DAP-values decrease, which results in a decrease of the effective dose to the patient.

\section{Dependence of beam direction}

$\mathrm{DCC}_{\mathrm{DAP}}$ and $\mathrm{ECC}_{\mathrm{DAP}}$ pertaining to two oblique views ( $\mathrm{m} 7$ and $\mathrm{f} 13$ ) are given both for $\mathrm{LAO}$ - and for RAO-projection directions in Table 8.23. Data for male patients were calculated for 80 and $90 \mathrm{kV}$, data for females for $80 \mathrm{kV}$. DCC DAP and $\mathrm{ECC}_{\mathrm{DAP}}$ for $85 \mathrm{kV}$ for males were derived by interpolating results for 80 and $90 \mathrm{kV}$. Comparison of corresponding views shows that, due to non-symmetrical positions of organs, DCC vajues of various organs differ. Apart from $80 \mathrm{kV}$ for males, beam direction dependence was found for all projections. $\mathrm{ECC}_{\mathrm{DAP}}$ for $\mathrm{RAO}$-directions is about $10 \%$ higher than $\mathrm{ECC}_{\mathrm{DAP}}$ for $\mathrm{LAO}$-directions. This difference mainly results from increased values for DCC Da. for colon and stomach in RAO-projections; apparently the decrease in $\mathrm{DCC}_{\mathrm{DAP}}$ for liver only partly compensates this effect.

\section{Calculation of $E_{2}$ according to a specific recommendation in ICRP 60}

Estimates for the effective dose were derived both with and without application of the dose calculation rule included in footnote 3 of Table 2 in ICRP Publication 60 [IC91]. Litterally, footnote 3 only applies to exposure conditions where the dose of one single remaining organ exceeds the highest dose of the group of selected organs. In the diagnostic views included in Table 8.21 , generally two or more DCC DAp for remaining organs are higher than the highest $\mathrm{DCC}_{\mathrm{DAp}}$ of the selected organs. However, as other views could be a candidate for the application of footnote 3 , comparison has been carried 
out to determine the consequences of this approach. Table 8.24 provides the results of calculations, applying a tissue weighring factor of 0.025 to the remainder organ with the highest dose, and the mass weighted fraction of 0.025 to all other remainder organs. Comparison shows that ratios of effective dose calculations including foomote 3 , by effective doses without footnote 3, vary between about 1 and 1.5 . At $75 \mathrm{kV}$ for view no. $\mathrm{m} 1$, this ratio was even about $1.7(0.093 / 0.054)$. In conclusion, by applying foomote 3 . the effective dose estimate may increase with about $50 \%$. In this study footnote 3 was not applied. Firstly, because no single view, quantified in Table 8.21, fully met the application criterion. Secondly, it was expected that the sum values of organ doses, calculated by summation the contributions of single views in a procedure, would not meet the application criterion either. A third reason for not using this calculation rule is that the effective dose would no longer maintain its additive character. This aspect has recently been studied by Zankl [ZA95].

\section{Mean effective dose estimates}

Final results of the assessment of the mean effective dose to patients in abdominal arteriography are presented in Table 8.25. Depending on the procedure type, the mean effective dose was estimated to be about 3 to $12 \mathrm{mSv}$ per procedure. Comparison of relative effective dose contributions of the imaging modes involved, shows that fluoroscopy in intra-arterial arteriography amounted to 25-55\%. In IV-DSA, fluoroscopy contributed about $10 \%$.

As described in Section 8.5.2, additional organ dose calculations by TNO and the determination of ECC $\mathrm{DAs}_{\mathrm{P}}$ could only be performed for a set of selected views (9 out of 28). As described below, $\mathrm{ECC}_{\mathrm{DA}}$ for the remaining 19 views, accounting for $12 \%$ of mean DAP-male and $28 \%$ of mean DAP-female only, were derived indirectly. Since the $\mathrm{ECC}_{\mathrm{DAP}}$-values for these views were considered as less accurate, compared with TNO data, the contributions of these different data sources have been determined. Table 8.26 shows the contribution of $\mathrm{ECC}_{\mathrm{DAP}}$ based on results of $\mathrm{MC}$ calculations performed by TNO, relative to the final effective dose estimates. Relative contributions of the TNO data to the effective dose are estimated to be $60 \%$ to $96 \%$ for a complete procedure. Contributions of TNO data to the effective dose, associated with specified imaging modes vary between $30 \%$ and $100 \%$. It should be noted that the $30 \%$-contribution is of minor importance, because it is associated with fluoroscopy in IV-DSA procedures. The relatively low contributions of $35 \%$ and $40 \%$ in fluoroscopy during two intra-arterial abdominal procedures may attribute significantly to the inaccuracy. An analysis of the sensitivity of the effective dose was carried out by recalculating the eftective dose with adapted values for $\mathrm{ECC}_{\mathrm{DAP}}$ for the 19 remaining views. A range for the effective dose was derived by using for $\mathrm{ECC}_{\mathrm{DAP}}$ both a small value $\left(0.05 \mathrm{mSv} \cdot \mathrm{Gy}^{-1} \cdot \mathrm{cm}^{-2}\right.$, being about one half of the mean for males) and a large value $\left(0.3 \mathrm{mSv} \cdot \mathrm{Gy}^{-1} \cdot \mathrm{cm}^{-2}\right.$, being about two times the mean for females). Results are given in Table 8.27 .

Comparison of estimated low and high estimates for the effective dose with dose estimates presented in Table 8.25 , show that, if doses in Table 8.25 are used as reference values, overestimation may vary between about $3 \%$ (AAiv-procedures for males) to about $25 \%$ (AAiv- and AAN-procedures for females). Considering underestimation, it is very unlikely that estimated values underestimate the effective dose by more than about $20 \%$ $50 \%$, depending on the procedure type. Taking limited resources into considerations, it is concluded that the selected subset of views, used for additional calculations by TNO, is wery useful for dose estimation. 


\section{ECCIDAP-ratios for complete procedures}

From DAP data pertaining to the procedures selected for dose calculations (reference group) and from final estimates for the mean effective dose (Table 8.21), mean E/DAPratios were calculated for each single procedure type. Results, given in Table 8.28 , vary between 0.08 and $0.20 \mathrm{mSv} \cdot \mathrm{Gy}^{-1} \cdot \mathrm{cm}^{-2}$. These findings indicate that, averaged for the rocedures discussed, a sex-averaged E/DAP-ratio of $0.15 \mathrm{mSv} \cdot \mathrm{Gy}^{-1} \cdot \mathrm{cm}^{-2}$ may be onsidered as appropriate.

Table 8.21 Organ dose and effective dose per dosearea product conversion coefficients for abdominal arteriography

\begin{tabular}{|c|c|c|c|c|c|c|c|c|c|}
\hline \multicolumn{3}{|c|}{ Malies } & \multicolumn{7}{|c|}{ Females } \\
\hline View No. ${ }^{\text {ats }} \ldots>>$ & $\mathrm{ml}$ & $\mathrm{ms}$ & $\mathrm{m} 7$ & $\mathrm{~m} 8$ & $\mathrm{mi0}$ & $\mathrm{f}$ & f9 & $\mathrm{f} 13$ & 116 \\
\hline & pa & $\mathrm{pa}$ & obl & pa & pa. & pa & pa & obl & pa \\
\hline Organ & $85 \mathrm{kV}$ & $80 \mathrm{kV}$ & $85 \mathrm{kV}$ & $75 \mathrm{kV}$ & $75 \mathrm{kV}$ & $80 \mathrm{kV}$ & $75 \mathrm{kV}$ & $80 \mathrm{kV}$ & $75 \mathrm{kV}$ \\
\hline \multicolumn{10}{|c|}{ Organ dose per dose-area product $\left(\mathrm{nnSv} \cdot G y^{\prime} \cdot \mathrm{cm}^{2}\right)$} \\
\hline Bladder & 0.019 & 0.024 & 0.023 & 0.189 & 0.009 & 0.017 & 0.021 & 0.042 & 0.060 \\
\hline Bone marrow & 0.210 & 0.214 & 0.212 & 0.154 & 0.1124 & 0.200 & 0.211 & 0.260 & 0.283 \\
\hline Bone surface & 0.329 & 0.300 & 0.298 & 0.157 & 0.179 & 0.341 & 0.337 & 0.299 & 0.333 \\
\hline Breast & - & - & - & - & - & 0.017 & 0.037 & 0.006 & 0.013 \\
\hline Colon & 0.067 & 0.091 & 0.098 & 0.275 & 0.055 & 0.068 & 0.111 & 0.146 & 0.195 \\
\hline Liver & 0.221 & 0.277 & 0.333 & 0.004 & 0.221 & 0.336 & 0.512 & 0.254 & 0.350 \\
\hline Lung & 0.036 & 0.057 & 0.051 & $<$ & 0.030 & 0.067 & 0.149 & 0.024 & 0.046 \\
\hline Oesophagus & 0.022 & 0.030 & 0.029 & $<$ & 0.014 & 0.038 & 0.057 & 0.011 & 0.019 \\
\hline Ovaries & - & - & - & . & - & 0.075 & 0.100 & 0.252 & 0.435 \\
\hline Skin & 0.095 & 0.091 & 0.102 & 0.095 & 0.080 & 0.113 & 0.126 & 0.123 & 0.126 \\
\hline Stomach & 0.285 & 0.250 & 0.275 & 0.006 & 0.158 & 0.351 & 0.398 & 0.237 & 0.315 \\
\hline Testes & 0.001 & 0.001 & 0.002 & 0.088 & $<$ & - & - & - & - \\
\hline $\begin{array}{l}\text { Thyroid } \\
\text {-remainder }\end{array}$ & 0.001 & 0.001 & $<$ & $<$ & $<$ & $<$ & 0.003 & $<$ & $<$ \\
\hline Adrenals & 0.883 & 1.320 & 1.205 & 0.002 & 0.728 & 2.060 & 1.530 & 0.227 & 0.633 \\
\hline Brain & $<$ & $<$ & $<$ & $<$ & $<$ & $<$ & 0.001 & $<$ & 0.001 \\
\hline Kidneys & 2.445 & 1.840 & 2.085 & 0.014 & 1.260 & 2.580 & 2.180 & 2.195 & 1.880 \\
\hline Muscle & 0.145 & 0.128 & 0.147 & 0.113 & 0.092 & 0.157 & 0.177 & 0.161 & 0.177 \\
\hline Pancreas & 0.638 & 0.479 & 0.589 & 0.003 & 0.282 & 0.744 & 0.665 & 0.358 & 0.517 \\
\hline Smatl iniest. & 0.522 & 0.439 & 0.493 & 0.156 & 0.242 & 0.449 & 0.480 & 0.609 & 0.570 \\
\hline Spleen & 0.245 & 0.403 & 0.692 & 0.004 & 0.509 & 0.365 & 1.060 & 0.490 & 0.844 \\
\hline Thymus & 0,006 & 0.006 & 0.006 & $<$ & 0.003 & 0.009 & 0.011 & 0.002 & 0.009 \\
\hline U. I. intest. & 0.416 & 0.330 & 0.383 & 0.095 & 0.191 & 0.408 & 0.421 & 0.485 & 0.471 \\
\hline Uterns & - & - & - & - & - & 0.068 & 0.089 & 0.183 & 0.325 \\
\hline \multicolumn{10}{|c|}{ Effective dose per dose-area product $\left(\mathrm{mSv} \cdot \mathrm{Gy}^{-4} \cdot \mathrm{cm}^{-2}\right)$} \\
\hline E & $0.098^{2}$ & 0.102 & 0.109 & 0.088 & 0.065 & 0.132 & 0.171 & 0.160 & 0.225 \\
\hline
\end{tabular}

\section{Range of effecrive doses to the patient}

If the patient size and gender are not taken into consideration, maximum values for abdominal arteriography procedure types can be estimated by multiplying means for derived sex-specific E/DAP-ratios by maximum DAP data presented in Table 8.18. 
Maximum values calculated in this manner are $26 \mathrm{mSv}$ for $\mathrm{AAN}(0.15 \times 171) .27 \mathrm{mSv}$ for $A A M C(0.17 \times 159)$, and $13 \mathrm{mSv}$ for AAiv $(0.13 \times 99)$. The maximum value for all intraarterial procedures is estimated to be $36 \mathrm{mSv}(0.17 \times 210)$.

The inaccuracy in these estimates due to systematic errors, discussed in the preceding paragraphs, is very likely to be less than about $50 \%$.

Table 8.22 Tube high woltage dependence of organ dose and effective dose per dose-area prodiuct conversion coefficients for a pa view in abdominal arteriography of male patients

\begin{tabular}{|c|c|c|c|c|c|}
\hline \multirow[t]{2}{*}{ Organ } & \multicolumn{5}{|c|}{ Tube Migh voltage } \\
\hline & $75 \mathrm{kV}$ & $80 \mathrm{kV}$ & $85 \mathrm{kV}^{\mathrm{b}}$ & $90 \mathrm{kV}$ & $100 \mathrm{kV}$ \\
\hline \multicolumn{6}{|c|}{ Organ dose per dose-area product (mSv $\left.\cdot \mathrm{Gy} \cdot 1 \cdot \mathrm{cm}^{2}\right)$} \\
\hline Bladder & 0.008 & 0.015 & 0.019 & 0.023 & 0.023 \\
\hline Bone marrow & 0.124 & 0.185 & 0.210 & 0.236 & 0.216 \\
\hline Bone surface & 0.208 & 0.304 & 0.329 & 0.354 & 0.339 \\
\hline Colon & 0.033 & 0.057 & 0.067 & 0.076 & 0.075 \\
\hline Liver & 0.114 & 0.195 & 0.221 & 0.248 & 0.249 \\
\hline Lung & 0.016 & 0.031 & 0.036 & 0.042 & 0.039 \\
\hline Oesophagus & 0.008 & 0,018 & 0.022 & 0.025 & 0.025 \\
\hline Skin & 0.078 & 0.091 & 0.095 & 0.098 & 0.096 \\
\hline Stomach & 0.146 & 0.252 & 0.285 & 0.318 & 0.320 \\
\hline Thyroid & $<$ & 0.001 & 0.001 & 0.001 & $<$ \\
\hline \multicolumn{6}{|l|}{-remainder } \\
\hline Adrenalls & 0.541 & 0.809 & 0.883 & 0.957 & 0.944 \\
\hline Brain & $<$ & $<$ & $<$ & $<$ & $<$ \\
\hline Kidneys & 1.700 & 2.300 & 2.445 & 2.590 & 2.530 \\
\hline Muscle & 0.095 & 0.134 & 0.145 & 0.157 & 0.154 \\
\hline Pancreas & 0.341 & 0.564 & 0.638 & 0.712 & 0.715 \\
\hline Small intest. & 0.284 & 0.464 & 0.522 & 0.581 & 0.577 \\
\hline Spleen & 0.128 & 0.216 & 0.245 & 0.274 & 0.266 \\
\hline Thymus & 0.0002 & 0.004 & 0.006 & 0.007 & 0.005 \\
\hline U. 1. intest. & 0.221 & 0.368 & 0.416 & 0.465 & 0.467 \\
\hline \multicolumn{6}{|c|}{ Effective dose per dose-area product $\left(\mathrm{mSv} \cdot \mathrm{Gy}^{-1} \cdot \mathrm{cm}^{-2}\right)$} \\
\hline $\mathrm{E}$ & 0.054 & $0.087^{2}$ & 0.098 & 0.110 & 0.107 \\
\hline
\end{tabular}

"Diagnostic view is defined in Table 8.20 (view no. ml): "Data for $85 \mathrm{kV}$ were derived by interpolating $80 \mathrm{kV}$ and $90 \mathrm{kV}$ data: " $<$ " denotes "less than $0.001 \mathrm{mSw} \cdot \mathrm{Gy} " \cdot \mathrm{cm}^{2} "$. 
Table 8.23 Organ dose and effective dose per dosemarea product conversion coefficients for wo oblique views in abdominal arteriography

\begin{tabular}{|c|c|c|c|c|c|c|c|c|}
\hline \multirow[t]{4}{*}{ Organ } & \multicolumn{8}{|c|}{ View $\mathbb{N o}^{\text {ab }}$} \\
\hline & \multicolumn{6}{|c|}{ Males (vicw no. m7) } & \multicolumn{2}{|c|}{ Females (f 13 ) } \\
\hline & LAO & LAO & LAO & $\mathrm{RAO}$ & RAO & $\mathrm{RAO}$ & LAO & RAO \\
\hline & $80 \mathrm{kV}$ & $85 \mathrm{kV}^{2}$ & $90 \mathrm{kV}$ & $80 \mathrm{kV}$ & $85 \mathrm{kV}^{\mathrm{t}}$ & $90 \mathrm{kV}$ & $80 \mathrm{kV}$ & $80 \mathrm{kV}$ \\
\hline \multicolumn{9}{|c|}{ Organ dose per dose-area product $\left(\mathrm{msv} \cdot \mathrm{Gy} \cdot \mathrm{cm}^{2}\right)$} \\
\hline Bladder & 0.021 & 0.024 & 0.026 & 0.019 & 0.023 & 0.026 & 0.042 & 0.043 \\
\hline Bone manrow & 0.202 & 0.217 & 0.232 & 0.183 & 0.207 & 0.231 & 0.254 & 0.267 \\
\hline Bone surface & 0.299 & 0.306 & 0.313 & 0.270 & 0.291 & 0.312 & 0.291 & 0.307 \\
\hline Bteast & & - & - & - & - & - & 0.007 & 0.006 \\
\hline Colon & 0.076 & 0.081 & 0.086 & 0.101 & 0.115 & 0.130 & 0.119 & 0.173 \\
\hline Liver & 0.432 & 0.449 & 0.467 & 0.191 & 0.217 & 0.243 & 0.289 & 0.219 \\
\hline Lung & 0.050 & 0.053 & 0.056 & 0.042 & 0.049 & 0.056 & 0.023 & 0.025 \\
\hline Desophagus & 0.028 & 0.030 & 0.032 & 0.024 & 0.027 & 0.031 & 0.011 & 0.011 \\
\hline Ovaries & & - & - & - & - & - & 0.248 & 0.256 \\
\hline Skin & 0.102 & 0.103 & 0.105 & 0.096 & 0.100 & 0.105 & 0.119 & 0.128 \\
\hline Stomach & 0.198 & 0.212 & 0.227 & 0.298 & 0.338 & 0.379 & 0.194 & 0.280 \\
\hline $\begin{array}{l}\text { Testes } \\
\text { remainder }\end{array}$ & 0.002 & 0.002 & 0.002 & 0.002 & 0.002 & 0.002 & - & - \\
\hline Adremals & 1.190 & 1.225 & 1.260 & 1.090 & 1.185 & 1.280 & 0,220 & 0.234 \\
\hline Kidneys & 2.070 & 2.120 & 2.170 & 1.930 & 2.050 & 2.170 & 2.100 & 2.290 \\
\hline Muscle & 0.144 & 0.148 & 0.153 & 0.134 & 0.145 & 0.157 & 0.157 & 0.166 \\
\hline Pancreas & 0.459 & 0.484 & 0.510 & 0.621 & 0.695 & 0.769 & 0.320 & 0.396 \\
\hline Small intest. & 0.477 & 0.501 & 0.526 & 0.429 & 0.484 & 0.540 & 0.595 & 0.624 \\
\hline Spleen & 0.298 & 0.312 & 0.326 & 0.994 & 1.072 & 1.150 & 0.336 & 0.644 \\
\hline U. 1. intest. & 0.395 & 0.416 & 0.438 & 0.309 & 0.351 & 0.393 & 0.520 & 0.451 \\
\hline Uterus & . & - & - & & . & - & 0.180 & 0.186 \\
\hline
\end{tabular}

Effective dose per dose-area product ( $\left.m S v \cdot G y^{4}{ }^{\prime} \mathrm{cm}^{2}\right)$

\begin{tabular}{lllllllll}
$\mathrm{E}$ & 0.100 & 0.106 & 0.112 & 0.099 & 0.112 & 0.125 & 0.151 & 0.169 \\
\hline
\end{tabular}

"Diagnostic views $\mathrm{m} 7$ and $\mathrm{f} 13$ are defined in Table 8.20. LAO and RAO denote left anterior oblique and right anterior oblique views respectively. DCC for thyroid $(<0.002)$, brain $(<0.001)$, thy rnus $(<0.009)$,

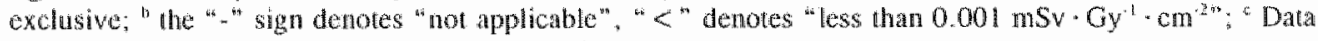
for $85 \mathrm{kV}$ were derived by interpolating $80 \mathrm{kV}$ and $90 \mathrm{kV}$ data.

Table 8.24 Effective dose per dose-area product conversion coefficients, $\mathrm{ECC}_{\mathrm{ba}}$, calculated both with and without the application of footnote 3, Table 2, ICRP Publication 60

\begin{tabular}{|c|c|c|c|c|c|c|c|c|c|}
\hline & Vlaw & & & & & & & & \\
\hline & $\mathrm{m} 1$ & $\mathrm{~ms}$ & $\mathrm{~m} 7$ & $\mathrm{~m} 8$ & $\mathrm{~m} 10$ & $B$ & $f 9$ & 113 & 116 \\
\hline & & pa & obd & pa & pa & pa & pa & obl & pa \\
\hline $\mathrm{ECC}_{\mathrm{B}, \mathrm{P}, \mathrm{P}}$ & $8.5 \mathrm{kV}$ & $80 \mathrm{kV}$ & $85 \mathrm{kV}$ & $75 \mathrm{kV}$ & $75 \mathrm{kV}$ & $80 \mathrm{kV}$ & $75 \mathrm{kV}$ & $80 \mathrm{kV}$ & $75 \mathrm{kV}$ \\
\hline excl. & 0.098 & 0.102 & 0.109 & 0.088 & 0.065 & 0.132 & 0.171 & 0.160 & 0.225 \\
\hline ind. & 0.156 & 0.145 & 0.157 & 0.086 & 0.094 & 0.192 & 0.221 & 0.211 & 0.267 \\
\hline
\end{tabular}

"excl $=$ lootnote 3 was nor applied; incl. = foomote 3 was applied. 
Table 8.25 Mean effective doses to patients and mean relative contribution to the effective dose per imaging mode in abdominal arteriography ${ }^{3}$

\begin{tabular}{|c|c|c|c|c|c|}
\hline \multirow{2}{*}{$\begin{array}{l}\text { Procedure } \\
\text { fype } \\
\text { Gender }\end{array}$} & \multirow{2}{*}{$\begin{array}{l}\text { No. } \\
\text { of } \\
\text { procedlures }\end{array}$} & \multirow{2}{*}{$\begin{array}{l}\text { Mean } \\
\text { effective } \\
\text { dose (mSv) }\end{array}$} & \multicolumn{2}{|c|}{$\begin{array}{l}\text { Relative contribution } \\
\text { to the effective dose }\end{array}$} & \multirow[b]{2}{*}{ Him } \\
\hline & & & Fluoro. & $\mathrm{DSA}$ & \\
\hline \multicolumn{6}{|l|}{ Males: } \\
\hline AAMC & 7 & 6.0 & $57 \%$ & - & $43 \%$ \\
\hline$A A N$ & 11 & 4.9 & $40 \%$ & $40 \%$ & $20 \%$ \\
\hline AANB & 24 & 3.3 & $40 \%$ & $38 \%$ & $22 \%$ \\
\hline AAR & 2 & 2.3 & $56 \%$ & - & $44 \%$ \\
\hline AAiw & 21 & 3.2 & $7 \%$ & $93 \%$ & . \\
\hline \multicolumn{6}{|l|}{ Females: } \\
\hline AAMC & 13 & 11.9 & $37 \%$ & $12 \%$ & $51 \%$ \\
\hline AAN & 15 & 5.3 & $43 \%$ & $8 \%$ & $49 \%$ \\
\hline AANB & 24 & 6.4 & $29 \%$ & $25 \%$ & $45 \%$ \\
\hline AAR & 5 & 7.1 & $24 \%$ & $76 \%$ & . \\
\hline AAiv & 8 & 4.7 & $10 \%$ & $90 \%$ & . \\
\hline
\end{tabular}

"beam filtration: $4.5 \mathrm{~mm}$ Al in X-ray beam $+1.5 \mathrm{~mm}$ for patient support. "¿" denotes "for applicoble". "AAMC = IA-mesenteric and/or coeliac arteriography (selective); AAN =IA-abdominal aontography, non selective; $A A N B=I A$-aortography, extended with blood sanspling in aorta and in rental veins; $A A R=1 A$. arteriography of renal vessels: AAiv $=$ intravenous DSA arteriog raphy of the aorta and renal arteries.

Table 8.26 Contributions of selected views to the mean total effective dose and mean effective doses per imaging mode in abdominal arteriography procedures ${ }^{\mathrm{a}}$

\begin{tabular}{|c|c|c|c|c|c|c|}
\hline \multirow[t]{2}{*}{$\begin{array}{l}\text { Procedure } \\
\text { types }\end{array}$} & \multirow[t]{2}{*}{$\begin{array}{l}\overline{\mathrm{E}} \\
\text { (mSviproc.) }\end{array}$} & \multirow[t]{2}{*}{$\begin{array}{l}\overline{\mathrm{E}}_{\text {for } 9 \text { seff views }} \\
\text { (mSv/proc.) }\end{array}$} & \multicolumn{4}{|c|}{$\begin{array}{l}\text { Relative contributions } \\
\text { of } 9 \text { selected views }\end{array}$} \\
\hline & & & total & fluor. & DSA & filln \\
\hline \multicolumn{7}{|l|}{ Males: } \\
\hline AAMC & 6.0 & 4.3 & $73 \%$ & $75 \%$ & - & $69 \%$ \\
\hline AAN & 4.9 & 4.1 & $86 \%$ & $83 \%$ & $93 \%$ & $78 \%$ \\
\hline AANB & 3.3 & 2.6 & $78 \%$ & $77 \%$ & 70 & $97 \%$ \\
\hline AAR & 2.3 & 2.0 & $87 \%$ & $77 \%$ & - & $100 \%$ \\
\hline AAiv & 3.2 & 3.1 & $96 \%$ & $71 \%$ & $99 \%$ & - \\
\hline \multicolumn{7}{|l|}{ Fenales: } \\
\hline$A A M C$ & 11.9 & 8.8 & $74 \%$ & $40 \%$ & $68 \%$ & $100 \%$ \\
\hline$A A N$ & 5.3 & 3.5 & $66 \%$ & $35 \%$ & $100 \%$ & $87 \%$ \\
\hline AANB & 6.4 & 4.8 & $76 \%$ & $63 \%$ & $59 \%$ & 94 \\
\hline AAR & 7.1 & 6.1 & $86 \%$ & $71 \%$ & - & $91 \%$ \\
\hline A Aiv & 4.7 & 2.9 & $60 \%$ & $30 \%$ & $64 \%$ & - \\
\hline
\end{tabular}

s.ti See foomotes of Table 8.25 . 
Table 8.27 Estimates for the mean effective doses in abdominall arteriography, using low and high values for $\mathrm{E} / \mathrm{OAP}$-ratios for non-gelected wiews"

\begin{tabular}{lll}
\hline $\begin{array}{l}\text { Procedure } \\
\text { rypec }\end{array}$ & $\begin{array}{l}\text { EE (mSw procedure) } \\
\text { EDAP }=0.05\end{array}$ & E/DAP $=0.3$ \\
\hline Males: & & \\
AAMC & 5.1 & 9.2 \\
AAN & 4.5 & 6.2 \\
AANB & 2.9 & 4.7 \\
AAR & 2.1 & 2.9 \\
AAiv & 3.2 & 3.5 \\
Females: & & \\
AAMC & 9.8 & 14 \\
AAN & 4.0 & 6.5 \\
AANB & 5.3 & 7.6 \\
AAR & 6.5 & 5.1 \\
AAiv & 3.4 &
\end{tabular}

* See footnotes of Table 8.25; "E/DAP-ratios in $\mathrm{mSv} \cdot \mathrm{Gy} \cdot \mathrm{cm}^{2}$.

Table 8.28 Mean ratio of effective dose by dose-area product for abdominall arteriography procedure $^{a}$

\begin{tabular}{lll}
$\begin{array}{l}\text { Procedure } \\
\text { type }\end{array}$ & $\begin{array}{l}\text { E/DAP-ratio }\left(\mathrm{mSv} \cdot \mathrm{Gy}^{1} \cdot \mathrm{cm}^{23}\right. \\
\text { Males }\end{array}$ & \begin{tabular}{l} 
Females \\
\hline AAMC
\end{tabular} \\
AAN & 0.14 & 0.19 \\
AANB & 0.10 & 0.20 \\
AAR & 0.09 & 0.18 \\
AAiv & 0.08 & 0.16 \\
\hline
\end{tabular}

a.th See foomotes of Table 8.25 .

\subsection{Discussion}

Conventional dose assessments for complex procedures generally comprise monitoring of a small number of measurable quantities, resulting in integrated values that are representative for the complete procedure [KA82, F[95]. Because of loss of differential information, effective dose estimates derived from these integrating measurements may be highly inaccurate. In this study, detailed measurements were performed. Collected data were used to produce Monte Carlo organ dose data sets, previously not available. The exposure data collected were used to derive reliable estimates for the mean effective dose to the patient, exposed to X-rays in PA-views.

Comparison of DAP to effective dose conversion factors (E/DAP-ratios) derived in this study with E/DAP ratios estimated from previously published data of calculated from a commercially available software package (see Table 3.7, [ST93, CA95], Tables 6.5-6.7 [GR94. HA94, LE94, MA94, PE95]) shows the following picture:

Peripheral arteriography:

- Mean ratios of E by DAP, derived in this study (see Section 8.3.4), vary between 0.07 and $0.19 \mathrm{mSv} \cdot \mathrm{Gy}^{-1} \cdot \mathrm{cm}^{-2}$ for intra-arterial procedures, and between 0.14 and 0.19 $\mathrm{mSv} \cdot \mathrm{Gy}^{-1} \cdot \mathrm{cm}^{-2}$ for intravenous procedures. 
- E/DAP-ratios derived from literature on peripheral vascular radiology (Table 3.7), were estimated to be $0.09 \mathrm{mSv} \cdot \mathrm{Gy}^{-1} \cdot \mathrm{cm}^{-2}$ [ST93] and $0.24 \mathrm{mSv} \cdot \mathrm{Gy}{ }^{-1} \cdot \mathrm{cm}^{2}$ [CA95]. E/DAPratios derived from other published data (Table 6.7), were estimated to be $0.1 \mathrm{mSv} \cdot \mathrm{Gy}^{*}$ ${ }^{1} \cdot \mathrm{cm}^{-2}$ for intra-arterial procedures and $0.2 \mathrm{mSv} \cdot \mathrm{Gy} \cdot \mathrm{cm}^{-2}$ for intravenous peripheral arteriography procedures (Table 6.7 ).

Abdominal arteriography:

- Averaged over various procedure types, a sex-averaged E/DAP-ratio of 0.15 $\mathrm{mSv} \cdot \mathrm{Gy}^{-1} \cdot \mathrm{cm}^{-2}$ was derived in this study.

- Castellano et al. [CA95] estimated E/DAP-ratio for hepatic and renal arteriography to be $0.17 \mathrm{mSv} \cdot \mathrm{Gy}^{-11} \cdot \mathrm{cm}^{-2}$ (Table 3.7), The E/DAP-ratio for abdominal arteriography derived from published non-specific abdominal arteriography data, was equal to 0.2 $\mathrm{mSv} \cdot \mathrm{Gy}^{-1} \cdot \mathrm{cm}^{2}$ (Table 6.7).

Resuits of a comparison of our effective dose estimates for peripheral and abdominal arteriography procedures with previously published data, as described in Section 3.6, are summarised below.

Peripheral arteriography:

- Other investigators estimated the mean effective dose to be $3 \mathrm{mSv}$ [CA95], $4 \mathrm{mSv}$ [WA88, ST93], $10 \mathrm{mSv}$ [MA88] or $12 \mathrm{mSv}$ [HO91].

- Our estimates for the mean effective dose to patients for intra-arterial procedures are equal to $1 \mathrm{mSv}$ for simple needle puncture arteriography procedures (sex-specific estimates are equal to 0.9 and $1.4 \mathrm{mSv}$ ), and $4 \mathrm{mSv}$ for Seldinger procedures (sex-specific estimates are equal to 3.8 and $4.1 \mathrm{mSv}$ ). The mean effective dose for intravenous procedures was estimated to be $5 \mathrm{mSv}$.

Abdominal arteriography:

- Published data about mean effective dose for abdominal arteriography were scarce. Only two references were found. Effective dose estimates were equal to $20 \mathrm{mSv}$ [MA88] and $6 \mathrm{mSv}$ [WA88].

- Our estimates for mean effective doses to patients vary between 2 and $12 \mathrm{mSv}$ for intraarterial procedures, and between 3 and $5 \mathrm{mSv}$ for intravenous procedures, depending on the procedure type and the gender.

In summary, taking the large variations in exposure conditions into accoum, good agreement was found for E/DAP-conversion factors obtained from detailed measurements performed in this study and E/DAP-conversion factors derived from published nonspecific data (Table 6.7), both for peripheral and abdominal arteriography. Some published effective dose estimates for peripheral angiography [WA88, ST93, CA95] show good agreement with our data. In all, it is concluded that, using an undercouch $X$-ray system, mean effective doses to the patient vary between 1 and $5 \mathrm{mSv}$ from peripheral arteriography, and between 2 and $12 \mathrm{mSv}$ from abdominal arteriography, depending on the procedure type. 


\section{Chapter 9}

\section{Entrance doses and effective dose to occupationally exposed persons in arteriography and interventional endovascular radiology}

\subsection{Introduction}

Thermoluminescent dosemeters (TLD) were used to infer occupational radiation doses to radiologist and assistants in vascular radiology in three hospitals: the University Hospital Maastrich (azM), the De Wever Hospital Heerlen (DW), and the Maasland Hospital Sittard (MA). Dosimetry techniques and computational methods for effective dose estimation can be found in Section 6.5. Background information on TL-dosimetry is provided in appendix A. Features of the imaging systems are summarised in Table 9.1. detailed descriptions are given in Section 3.4. Occupational exposure conditions are characterised in Section 3.6. Character codes used in this chapter to identify procedure types are given in Table 7.1 .

Entrance doses were obtained for various measurement positions on the body of occupationally exposed persons. Many distributions of these entrance doses are skewed, showing a long tail at high dose levels. The Shapiro-Wilk test [SA89] showed that, at a $5 \%$ significance level, the majority of doses obtained in this study could not be considered as random samples from normal distributions. Because of non-normal characteristics of dose distributions, shape parameters such as standard deviation and standard error are not given; dose estimates are characterised by the location parameters arithmetic mean, median, and maximum. Associations between variables are examined with distribution free test statistics, such as the Spearman rank correlation coefficient.

As shown in Table 9.1, diagnostic projections in azM were always carried out with the $X$ ray tube under the patient table. In DW, the $\mathrm{X}$-ray tube was generally used in undercouch positions too, but in some cases overcouch ube positions were applied as well. It was inferred from results of the real-time monitoring system (see Section 6.3) that in DW about $10 \%$ of the dose-area product, due to fluoroscopy, was associated with overcouch X-ray tube positions. Initially, all procedures in the MA hospital were carried out with overcouch tube positions; because of preliminary results of this work, undercouch tube positions were applied in a subsequent phase.

Due to system limitations, conventional arteriography (serial cut film inaging) in DW and MA was allways carried out with overcouch tube positions.

During radiographic imaging, personnel in all three hospitals stayed usually behind protective barriers, or at least at two meters distance from the patient. Therefore, only 
fluoroscopy during the catheterisation stage, and during fluoroscopic previewing. contributed to the occupational dose.

Table 9.1 Features of the angiography X-ray systems in three hospitals (summary)

\begin{tabular}{|c|c|c|c|}
\hline $\begin{array}{l}\text { Features of } \\
\text { X-ray system }\end{array}$ & $\begin{array}{l}\text { Hospitals } \\
\mathrm{azM}\end{array}$ & DW & MA \\
\hline - Type & $\begin{array}{l}\text { Philips, } \\
\text { Diagnost Arc }\end{array}$ & $\begin{array}{l}\text { Philips, } \\
\text { Poly Diagnost UPI }\end{array}$ & $\begin{array}{l}\text { Philips, } \\
\text { Poly Diagnost UPI }\end{array}$ \\
\hline - Gemerator & $\begin{array}{l}\text { Philips, } \\
\text { Maximus CM } 100 \\
\text { 12-pulse generator }\end{array}$ & $\begin{array}{l}\text { Philips, } \\
\text { Super Maximus } 100 \\
\text { const. volt. }\end{array}$ & $\begin{array}{l}\text { Philips, } \\
\text { Optimus M200 } \\
\text { const. voltage }\end{array}$ \\
\hline - Beam filltration & $4.5 \mathrm{~mm} \mathrm{Al}$ & $2.8 \mathrm{~mm} \mathrm{Al}$ & $2.8 \mathrm{~mm} \mathrm{Al}$ \\
\hline - First HVL at $80 \mathrm{kV}$ & $3.6 \mathrm{~mm} \mathrm{Al}$ & $2.9 \mathrm{~mm} \mathrm{Al}$ & $2.9 \mathrm{~mm} \mathrm{Al}$ \\
\hline - Stand & C-shape arm & U-shape arm & U-shape arm \\
\hline - Rotation & -90 to $+90^{\circ}$ & $-90^{\circ}$ to $240^{\circ}$ & $.90^{\circ} 10240^{\circ}$ \\
\hline - Angulation & $-40^{\circ} 10+40^{\circ}$ & $0^{\circ}$ to $35^{\circ}$ & $0^{\circ} 1035^{\circ}$ \\
\hline - Tube position & undercouch & undercouch & (1) overcouch: (2) undercotod? \\
\hline - Floating table & yes & yes & yes \\
\hline - Image intent. & $6^{n}, 10^{n}, 14^{n}$ & $6^{\prime \prime \prime}, 9^{\prime \prime}$ & $6^{\prime \prime}, 9^{11}$ \\
\hline - DSA systen & Technicare DR-960B & Philips DVI wascular & Philips DVI vascular \\
\hline $\begin{array}{l}\text { - Serial cut film } \\
\text { - Stepping facility }\end{array}$ & $\begin{array}{l}\text { PUCK UD } 435 \times 35 \mathrm{~cm} \\
\text { cut film }\end{array}$ & $\begin{array}{l}\text { PUCK U } 35 \times 35 \mathrm{~cm} \\
\text { no }\end{array}$ & $\begin{array}{l}\text { PUCK U } 35 \times 35 \mathrm{~cm} \\
\text { no }\end{array}$ \\
\hline
\end{tabular}

"aZM, DW and MA denote three hospitals, see the introductory part.

Dose measurement protocols are briefly described in Section 9.2. Results of entrance dose measurements are given in Section 9.3.1-9.3.3. Section 9.3.4 summarises overall mean and median values of entrance doses at various measurement locations, weighted for the anmual frequencies of the procedure types. Correlations between entrance doses and the Xray output during fluoroscopy are discussed in Section 9.3.5. Compliance of entrance dose estmates for personnel with established occupational dose limits has been demonstrated in Section 9.3.6. In Section 9.4 the effectiveness of 0.5 -mm-thick lead-equivalent aprons is examined. Finally, effective dose estimates are derived in great detal in Section 9.5. In various subsections of 9.5 , the relationships of effective doses with attenuation characteristics of aprons, with the $X$-ray output, and with entrance dose measurement positions are discussed as well.

\subsection{Dose measurement procedures to assess occupational exposures}

By applying different measurement protocols, various dosemeters (varying between five and sixty) were attached to the body of occupationally exposed persons. Each dosemeter comprised one or two thermoluminescent elements (TLD-100). Selection of measurement positions was based on the following criteria:

- Radiation sensitivity of tissues and organs.

- Potential dose level taking exposure geometry and protective clothing into account.

- Anticipated variation in dose levels at positions in the vicinity of the measurement position.

- Relevance of the position to be able to demonstrate compliance with dose limits. 
The construction and calibration procedure of the dosemeters are described in Section 6.5.1. TLDs were calibrated by means of the air kerma, free-in-air. As no additional correction factors were applied, dose measurements obtained in clinical practice include dose contributions from back scattered radiation.

Dose data were obtained from various combinations of measurements at the head, neck, upper arms, hands, chest, abdomen, back, thighs, and lower legs. Data about the measurement locations and the number of dosemeters applied per person are summarised in Table 9.2 .

Table 9.2 Entrance dose masurements with TLDs in the University Hospital Maastricht (azM), the De Wever Hospital Heerlen (DW), and the Maasland Hospital Sittard (MA)

\begin{tabular}{|c|c|c|c|c|c|c|c|c|c|}
\hline \multirow{2}{*}{$\begin{array}{l}\text { Position } \\
\text { of } \\
\text { Tl-dosemeter }\end{array}$} & \multicolumn{6}{|c|}{$\begin{array}{l}\text { Measurement protocols } \\
\text { azM }\end{array}$} & \multirow[t]{2}{*}{$\underline{\text { DW }}$} & \multicolumn{2}{|l|}{$\mathrm{MA}$} \\
\hline & 1 & 2 & $3^{3 b}$ & 4 & 5 & 6 & & 1 & II \\
\hline \multicolumn{10}{|l|}{ Head } \\
\hline forchead & $\mathrm{Y}$ & $Y$ & $-M$ & Y & $\mathrm{Y}$ & - & $Y$ & $\mathrm{Y}$ & $\mathrm{Y}$ \\
\hline sides & - & . & - & - & - & - & - & $-H Y$ & - \\
\hline \multicolumn{10}{|l|}{ Trunk, on aprion } \\
\hline neck & $Y$ & $\mathrm{Y}$ & $Y$ & $Y$ & $Y$ & - & $Y$ & $Y$ & $Y$ \\
\hline sternum & $Y$ & - & $Y$ & - & - & $\mathrm{Y}$ & - & - & - \\
\hline abdiomen & $Y$ & Y & $\mathrm{Y}$ & - & $-/ Y$ & $\mathrm{Y}$ & - & $-/ Y$ & $Y$ \\
\hline back & $\mathrm{Y}$ & - & - & - & $Y$ & $\mathrm{Y}$ & - & $-N$ & - \\
\hline . thighs & $Y$ & $\cdots$ & $\mathrm{Y}$ & - & - & - & - & - & - \\
\hline \multicolumn{10}{|l|}{ Trunk, under apron } \\
\hline . sternum & $Y$ & - & - & - & - & - & - & - & - \\
\hline abdomen & $Y$ & $Y$ & - & - & - & - & - & - & - \\
\hline . thighs & $Y$ & - & - & - & - & $*$ & - & - & - \\
\hline \multicolumn{10}{|l|}{ Upper extremities } \\
\hline middle fingers & $Y$ & $Y^{\prime \prime}$ & - & - & - & $\cdots$ & - & - & - \\
\hline ring fingers & $\mathrm{Y}$ & $\mathrm{Y}$ & $\mathrm{Y}$ & $\mathrm{Y}$ & Y & - & $Y$ & $Y$ & $\mathrm{Y}$ \\
\hline wrists & Y & $\mathrm{Y}$ & - & - & - & - & - & - & - \\
\hline elbows & $\mathrm{Y}$ & $\mathrm{Y}^{r}$ & - & - & - & - & - & - & - \\
\hline shoulder/upper arms & $Y$ & - & - & $Y$ & Y & $X^{\prime \prime}$ & $Y$ & $\mathrm{Y}$ & $Y$ \\
\hline \multicolumn{10}{|l|}{ Lower extremities } \\
\hline lower leggs & $Y$ & $Y$ & $\mathrm{Y}$ & $\mathrm{Y}^{\prime}$ & $Y$ & - & $Y$ & Y & $\mathrm{Y}$ \\
\hline Peirsonal dosemeter & Y & $Y$ & - & - & - & - & - & - & - \\
\hline $\begin{array}{l}\text { No. of dosemeters } \\
\text { per person, per procedure }\end{array}$ & 22 & 15 & 60 & 8 & 10 & 5 & 8 & 9 & 9 \\
\hline
\end{tabular}

" " $Y$ " denotes that dosemeters were applied; "-" denotes that no measurements were performed;

"Fout strips, each containing 26 dosemeters, were attached parallel to the vertical axis, at the front and left sides of both the trunk en left leg; "Owercauch $X$-ray tube positions were used in the first period; undercouch positions in the second period.

Initially, ring dosemeters were worn at the middle finger and the ring finger of both hands; later only one dosemeter was used for each hand. Ring dosemeters were worn under sterile gloves. The TL-element of the middle finger dosemeter was positioned at the dorsal side of the hand, of the ring finger dosemeter at the palmar side. The dose to the neck was inferred from dosemeters which were attached to the skin with adhesive tape, or from dosemeters, constructed as a small collar. Dosemeters were worn under or on the 
thyroid collar. It should be noted that dose estinates for the neck refer to occupational exposure conditions without thyroid collars. Apart from ring dosemeters and collar dosemeters, all dosemeters were fixed with adhesive tape. Body dosemeters were worn on the outside of sterile clothing. During the first two measurement periods in the azM, additional dosemeters were worn underneath the lead apron and on the personal dosemeter. In order to assess the entrance dose for the lower legs, dosemeters were attached at the front side of the trousers, about $20 \mathrm{~cm}$ or less above the ankle. It was ensured that the lead apron did not reduce the exposure level at that TLD measurement location.

Entrance doses were derived from TLD measurements, calibrated in terms of the air kerma, free-in-air, corrected for background radiation. According to Jones [J085], the dose was multiplied by the mean ratio of mass energy absorption coefficients of tissue and air for diagnostic exposures (1.06).

Statistics on doses presented in this chapter were derived without the use of lower detection levels. Because of inaccuracies in the background correction and differences in the sensitivity per TL-element, negative dose estimates occurred at very low dose levels. Obviously, negative doses have no physical meaning. However, from a statistical point of view unbiased results are to be preferred above truncated cose distributions.

\section{Missing value:}

A number of measurement resulis were lost due to handling errors and errors in the TLD readouts. Furthermore, in some procedures dosemeters were not provided for all measurement locations that were used in effective dose calculations.

In the first four periods in the azM, 61 of 2530 dose measurements (2\%) were judged as unreliable, another 53 dosemeters $(2 \%$ ) were not properly used. Of 1540 dose measurements in DW, 9 results $(0.6 \%)$ were unreliable; 71 dosemeters $(5 \%)$ were not properly used or were lost. Of 2490 dose measurements in the first period in MA, 13 results $(0.5 \%)$ were rejected as unreliable, and 17 dosemeters $(0.7 \%)$ were not used or were lost. In summary, about $1.3 \%$ of the dose estimates did not pass the quality check. and about $2.2 \%$ of the dosemeters were not properly used or were lost.

Missing and unreliable doses were replaced by dose estimates, inferred from doses measured at nearby locations. The average ratio of the dose at the location of the missing data by the dose at a nearby location was used to estimate the missing dose value. Average ratios were derived for operators and first assistants separately. Selection of the nearby location was based on the Spearman rank correlation coefficients, which were derived for each combination of two nearby locations. The completion of the dose data set has been discussed elsewhere [K193]. Comparison of means of the incomplete data set with means of corresponding locations of the completed data set showed deviations of $15 \%$ or less. This was judged as satisfactory. 


\subsection{Entrance doses to occupationally exposed persons in the University Hospital Maastricht, the De Wever Hospital Heerlen, and the Maasland Hospital Sittard}

The number of dose measurements and the annual frequencies of various procedure types are given in Table 9.3. The ratios of dose measurements and annual frequencies were used to estimate the annual occupational effective dose.

Table 9.3 Frequency of occupational dose measurements and annual frequency of procedure types in axM, DW, MA

\begin{tabular}{|c|c|c|c|c|}
\hline $\begin{array}{l}\text { Hospital } \\
\text { Procedure type } \\
\text { (+ procedure code) }\end{array}$ & $\begin{array}{l}\text { No. of } \mathrm{p} \\
\text { operator }\end{array}$ & $\begin{array}{l}\text { res with } m \\
\text { assistant }\end{array}$ & $\begin{array}{l}\text { ments }^{2} \\
\text { operator } \\
\text { /assistant }\end{array}$ & $\begin{array}{l}\text { Armeal no. } \\
\text { of proc. }\end{array}$ \\
\hline \multicolumn{5}{|l|}{$a z M:$} \\
\hline CA certbral anteriography & 27 & 25 & 12 & $102(20 \%)$ \\
\hline EA upper extr. art. & 3 & - & - & $16(3 \%)$ \\
\hline TA thoracic art. & 5 & 4 & 2 & $30(6 \%)$ \\
\hline AA abdominal arteriography & 20 & 17 & 5 & $103(20 \%)$ \\
\hline PAm iliac +limb art. (needle) & 21 & 16 & - & $99(19 \%)$ \\
\hline PAs illactlimbs art. (Seldinger) & 24 & 19 & 4 & $46(9 \%)$ \\
\hline Pl"A perc. trans angioplasty & 15 & 12 & 6 & $61(12 \%)$ \\
\hline \multicolumn{5}{|l|}{$D W:$} \\
\hline cerebral arieriography & 26 & 25 & - & $72(10 \%)$ \\
\hline EA upper extr. art. & 11 & 11 & . & $33(5 \%)$ \\
\hline TA thoracic art. & 3 & 2 & - & $23(3 \%)$ \\
\hline AA abdominal arteriography & 4 & 3 & - & $38(5 \%)$ \\
\hline PAr illac+limb ant. (needle) & 19 & - & - & $137(20 \%)$ \\
\hline PAs iliac+limbs art. (Seldinger) & 4 & 3 & - & $99(14 \%)$ \\
\hline AAiv IV-DSA aortatiliac vessels & 5 & $\mathbb{1}$ & 3 & $100(14 \%)$ \\
\hline PTA perc. trans. angioplasty & 25 & 26 & 3 & $72(10 \%)$ \\
\hline \multicolumn{5}{|l|}{$M A^{\prime}$} \\
\hline CAl cerebral art., one side & $26: 1$ & $26: 11$ & - & $139(39 \%)$ \\
\hline CA2 cerebral ant., two sides & $42: 17$ & $42 ; 17$ & - & 1 \\
\hline EA upper extr. art. & 4: 1 & $4 ; 1$ & - & $24(7 \%)$ \\
\hline AAA abdominal anteriography & $11: 5$ & $11 ; 5$ & .. & $41(12 \%)$ \\
\hline $\mathrm{AAB}$ abdominal art., selective & $8 ; 1$ & $8 ; 1$ & - & y \\
\hline PTA perc. trans. angioplasty & $18 ; 3$ & $18 ; 3$ & - & $53(15 \%)$ \\
\hline
\end{tabular}

"Measurement periods: azM: June'91 - June"93; DW: January-June 1992; MA: August 1992 - January 1993; "Reference periods: azM: June"92 June 93; DW: 1992; MA: 1992. Percentage values refer to the frequencies per type, relative to the total number of procedures carried out in the angiography room. As various types have been excluded from this able (e.g. phlebography vena cava, phlebography of the spermalic vein, percutaneous transhepatic cholangiography), the sum values of the percentages are smaller than 100\%: MA: data refer to procedures carried out in the angiography room only (room 9). The numbers of procedures are denoted as $x x y$, where $x x$ denotes the number of measurements in period $\mathrm{I}$, and $y y$ the number of measurements in period II.

As shown in Table 9.3, dose measurements were carried out during intra-arterial arteriography and during endovascular procedures. As noted before, the major part of the 
occupational exposures results from fluoroscopy. Since fluoroscopy is only used during very short periods during intravenous DSA, except for IV-DSA of the abdomen in DW. these procedures were not included in this study. Results of dose estimates for various body parts of occupationally exposed persons are summarised in Table 9.4 to 9.6 .

\subsubsection{Entrance dose estimates for occupationally exposed persons in the azM}

In the course of the dosimetry study project in the azM, two additional studies were carried out. One study was focused on hand dose measurements, the other study aimed at information about the dose level as a function of the height from the floor. Objectives. results and conclusions of these studies are described in the second part of this section.

Table 9.4 summarises the results of dose measurements in the azM for operators, first assistants, and for operators and assistants who switched their activities and positions. It should be noted again that dose data presented as "entrance dose" were inferred from $\mathrm{Tl}$ dosemeters which were calibrated in terms of air kerma, free-in-air; statistics were deriwed from measurement data, not corrected for backscatter, nor for negative results.

Comparison of median and mean values showed that means were nearly always larger, indicating a skewed dose distribution with a small number of high exposures. Except for a few cases, mean/median-ratios were less than two. The vast majority of maximum/median-ratios were between 1 and 10 .

Relatively high dose levels were found for the lower legs. This finding corresponds with the undertable $X$-ray tube geometry exposure conditions. Maximum dose values found in this study were equal to about $1100 \mu$ Gy per procedure. These high doses were inferred both for the lower legs and for the hands.

Dose levels on the forehead were less than doses to the neck (thyroid). Generally, forehead/neck-ratios were within the range of about 1 to 4 . Average dose levels at the neck and at the chest (sternum on the apron) were nearly equal. Abdomen/chest dose ratios varied between about 1 and 4. In summary, along the longitudinal axis, average ratios of dose levels, normalised to the neck dose, varied between a factor 0.3 for the forehead, and a factor of 1 to 4 for the front of the trunk.

Non-symmetrical exposures resulted in differences in doses at the body side close to the radiation source and the other side. Average dose ratios for the highly exposed upper arm and the other upper arm varied from about 3 to 15 . On average, the dose to the upper arm close to the imaging system was about a factor of 2 to 3 higher than the dose at the neck. Comparison of doses at both lower legs showed that these ratios were nearly always within a factor of 2 .

Average doses to the hands of operators and assistants were less than the doses to the lower legs. However, doses to the hands of operators and assistants who switched their activities and positions, were significantly higher. This finding indicates that in complex catheterisations, which more often lead to task switching, and during catheterisations performed by registrars, manual activities during fluoroscopy viewing were prolonged, and/or the hands were relatively close to the X-ray field. 
Table 9.4 Entrance dobe 3 tinates for occupationally exposed persons in the a.s $u^{*}$

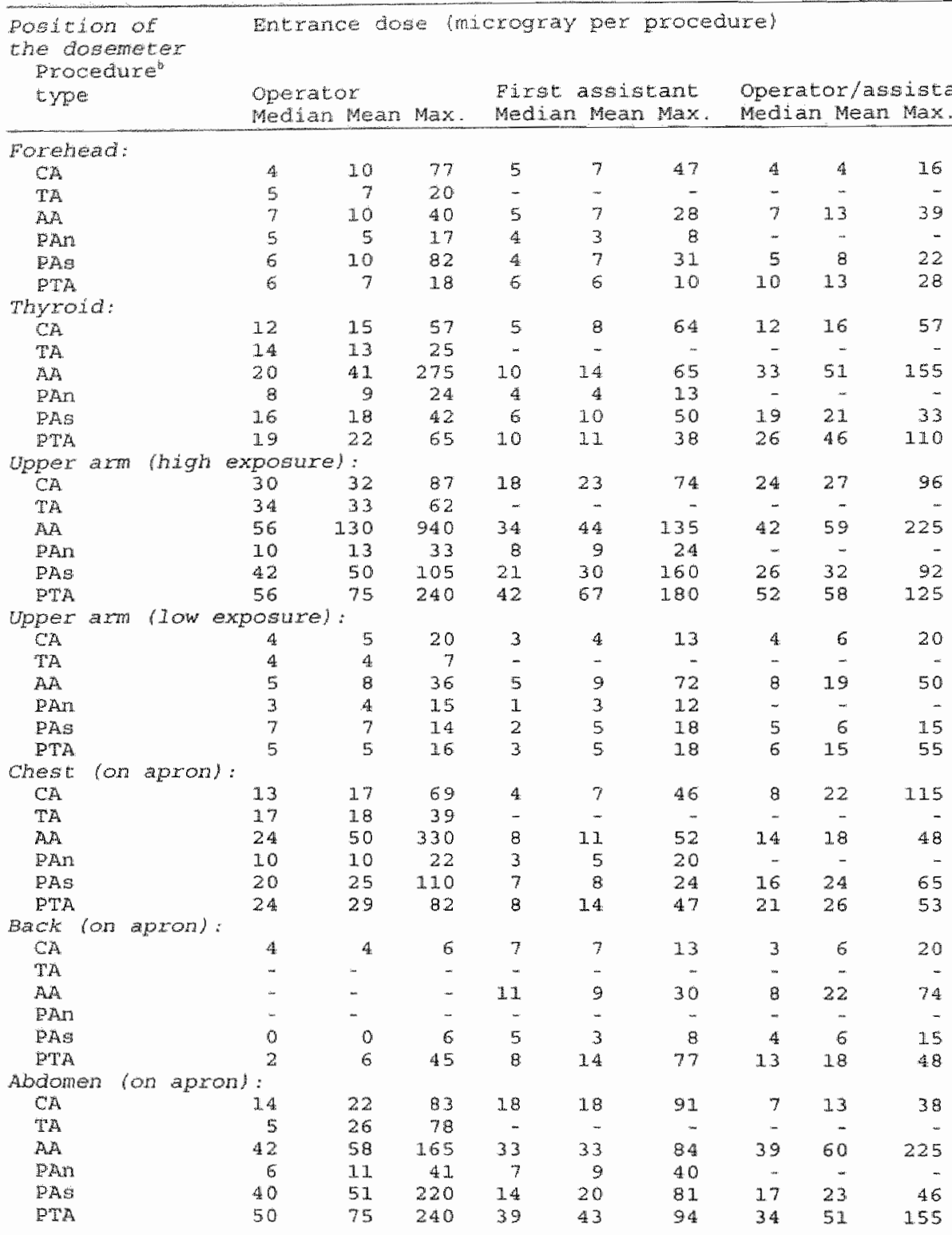

(continued on next page) 
Talle 9.4 Entrance dose stimate for occupationally exposed persons in the arM (continuation)

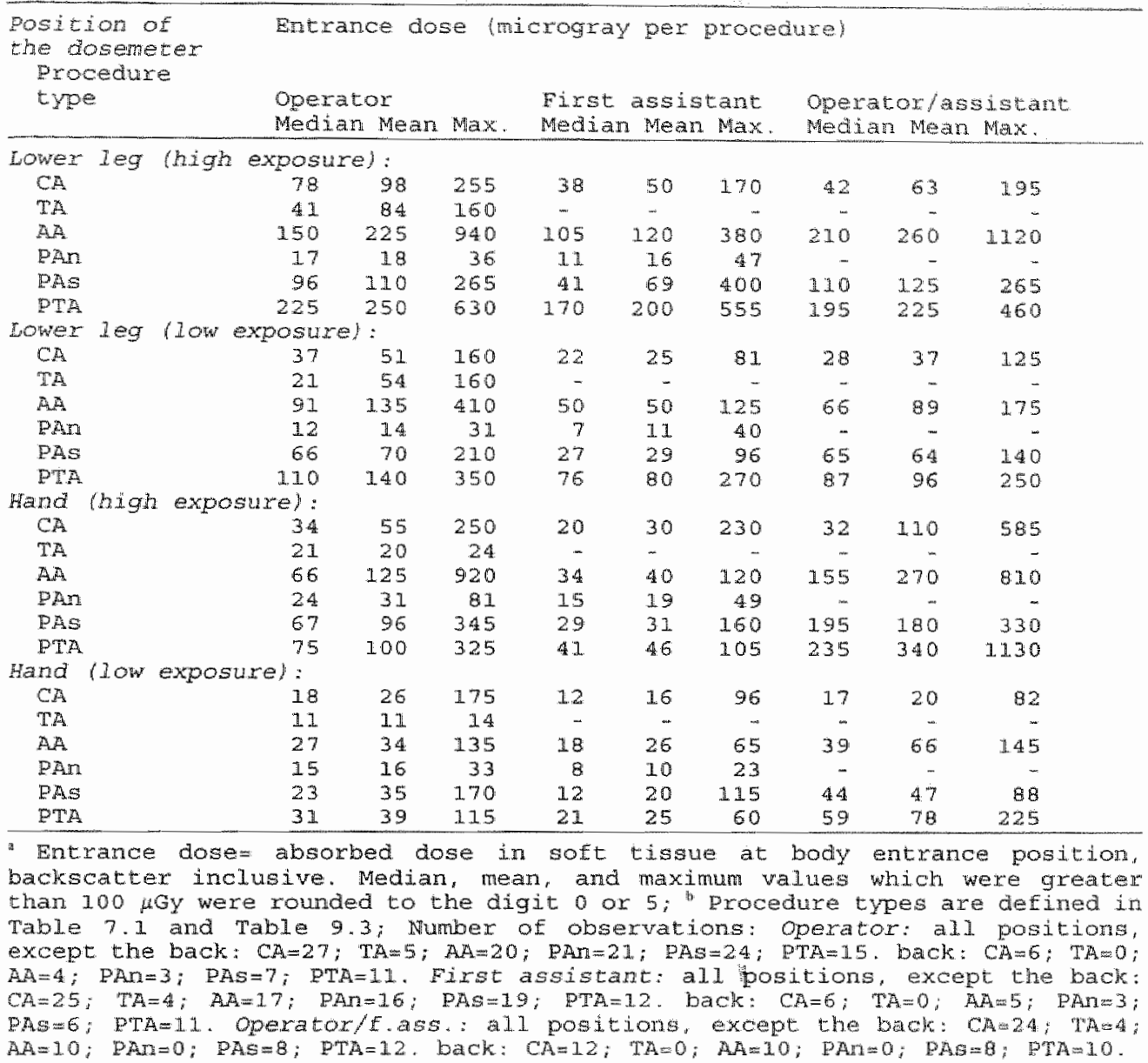

Comparison of various procedure types showed that abdominal arteriography procedures (AA) resulted in relatively high average exposures, followed by percutaneous transluminal angioplasty (P『A) and peripheral arteriography of both legs (PAs). Occupational exposures during cerebral arteriography (CA) and thoracic arteriography (TA) were relatively low. The lowest mean exposure was found for peripheral arteriography of one $\operatorname{leg}(\mathbf{P A n})$.

On average, exposures to operators were about a factor of two higher than for assistants. These findings correspond with visual observations that the effective distance of the assistant from the radiation source is larger than for the operator.

Dose measurements on the back of the trunk indicate that sometimes the back of the body was exposed. Visual observations showed that this exposure resulted from turning the back to the patient during viewing of fuoroscopy images displayed on a video monitor, positioned near the distal end of the patient table. Usually, the video monitor was 
placed in a way that allowed conventent viewing by the operator. The potential for exposures to the back was therefore higher for assistants than for operators.

\section{Dose measurements for the hands in the azM}

At the start of this study, three dose measurements were performed simultaneously at each hand: ring dosemeters were worn at the middle finger and the ring finger, and a collar dosemeter was worn on the wrist. Wrist dosemeters were used because of the ease of assembling, relatively high precision (each wrist dosemeter contained three TL-elements versus one TL-element in a ring dosemeter), and comfort (some persons did not appreciate ring dosemeters). It was anticipated that for assessment of the dose to the fingers, which could be directly exposed in the primary beam, the accuracy of wrist dosemeters could be lower than the accuracy of ring dosemeters.

Results:

Ratios of the ring finger dose by the middle finger dose were derived for the left hand, and the right hand of both the operator and the assistant. Mean ratios per subgroup varied between 1.08 and 1.21, with standard errors of $0.12 \quad(n=27)$ and $0.16 \quad(n=21)$ respectively. Although mean values were practically equal, some single dose combinations showed large differences (see Figures 9.1 and 9.2); middle finger/ring finger dose ratios varied between about 0.1 and 5 . No associations were found for differences between ring and middle finger doses and the dose level. The Spearman rank correlation coefficient derived for 112 pairs of doses to the middle finger and ring finger was equal to 0.85 .

Figure 9.2 shows the distribution of ratios in doses to the fingers by doses to the wrist. Generally, wrist doses were lower than finger doses. At high dose levels, the wrist dosemeter underestimated the dose to the fingers by about $40 \%$. Close to the X-ray beam the spatial dose gradient is quite steep. Therefore it was expected that the correlation between ring dosemeters and wrist dosemeters for the hand close to the $\mathrm{X}$-ray beam would be less than for the other hand. However, correlation analysis showed that this correlation was much better for the hand close to the $X$-ray beam $\left(r_{\text {Spearman }}=0.82, n=60\right.$ ) than for the other hand $\left(r_{\text {Spearman }}=0.59, n=60\right)$. This conclusion was obtained both for the operator and the assistant. A possible source of error, a relatively large number of inaccurate doses near the detection level, was examined and found to be insignificant. It was concluded from the observations described above that the dose to the hands could be estimated with one ring dosemeter for each hand. Because of their potential for underestimation of the dose, the use of wrist dosemeters was not continued. In the following parts of this study project, ring dosemeters were worn at the middle finger, with the TL-element placed at the dorsal side of the hand. 


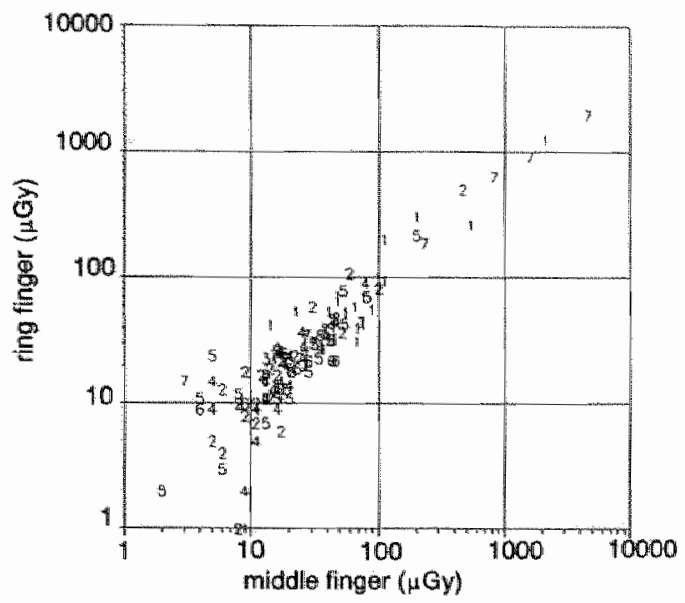

Figure 9.1 Comparison of "TI dose measurements on the middle finger and ring finger in wascular radiology (see also legend of Figure 9.2).

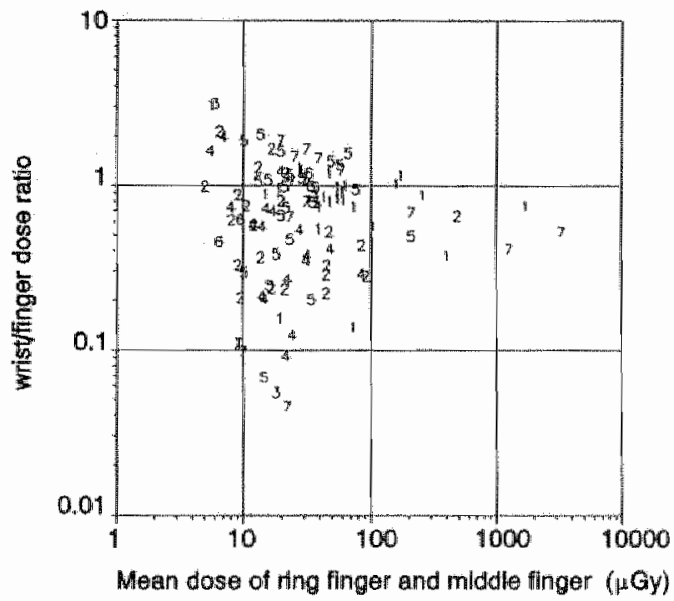

Figure 9.2 Ratio of wrist dose to finger dose as a function of the finger dose Numerical codes used in Figure 9.1 - 9.2:

1,2: Operator at the right side of the supine patient: $1=$ left hand, $2=$ right hand: 3: Operator, staying at the left side of the supine patient: left or right hand; 4,5: Assistant at the left side of the supine patient: 4=left hand, 5=right hand; 6 : Assistant, staying at the right side of the supine patient: left or right hand: 7: Dose results for other exposure conditions. 
Entrance dose measurements for the operator as a function of the height from the floor In addition to the standard dose measurements, the occupational exposure was determined as a function of the height from the floor. During 20 procedures, including arteriography procedures and interventional procedures, the operator was provided with four strips, each containing 26 dosemeters. These strips were attached, parallel to the vertical axis, at the front and at the left side of both the trunk and the left leg. Dose measurement were also used to derive side/front ratios. Features and calibration of these dosemeters were equal to those of the standard dosemeters. Measurements were carried out during procedures with the operator at the right side of the supine patient, with his left side exposed to scatter radiation.

Results of entrance dose measurements:

Results of dose measurements at the front and left side of the operator are given as a function of the height from the floor in Figure 9.3. Dose data, normalised to the dose at the front side, $35 \mathrm{~cm}$ above the floor (about $20 \mathrm{~cm}$ above the ankle), are given in Figure 9.4. Both figures show a relatively consistent picture. Up to about $80 \mathrm{~cm}$ from the floor, doses at different heights were relatively constant. From about $80 \mathrm{~cm}$ to $180 \mathrm{~cm}$ the dose level gradually decreased by about a factor of 5-10.
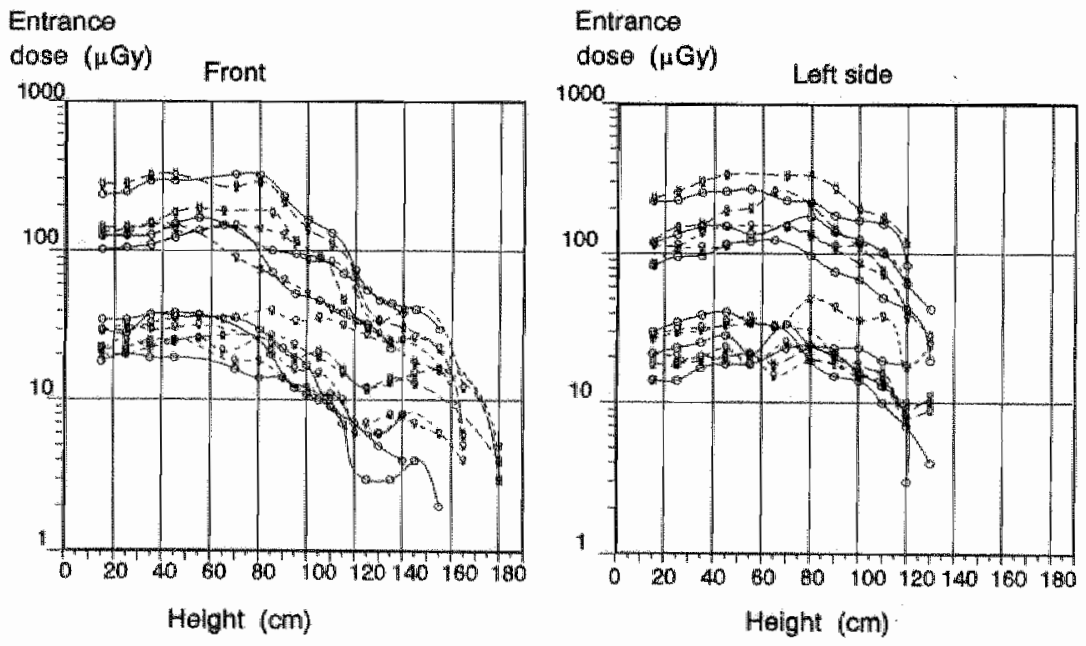

Figure 9.3 Entrance doses at the front and left side of the operator during warious procedures as a function of the height from the floor. 


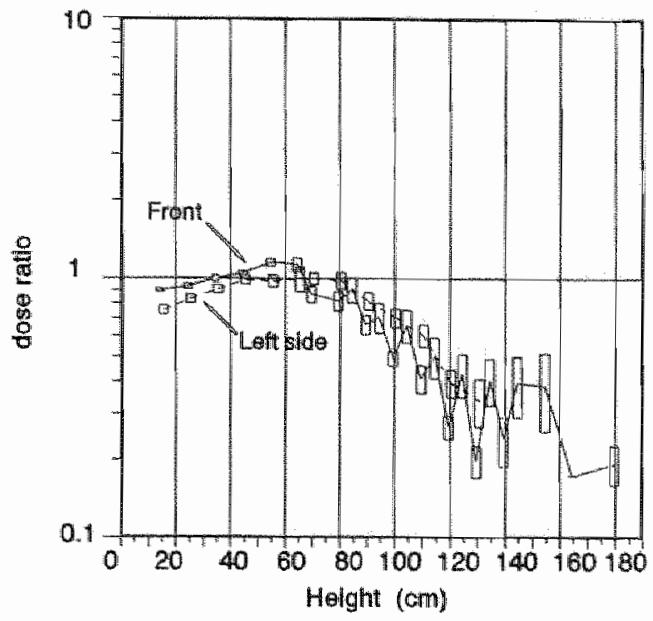

Figure 9.4 Mean entrance doses at the front and left side of the operator as a function of the height from the floor, normalised to the dose at the front of the lower $l \mathrm{eg}$ at $35 \mathrm{~cm}$ above the floor.

( - : mean dose; $\square$ : mean \pm standard error)

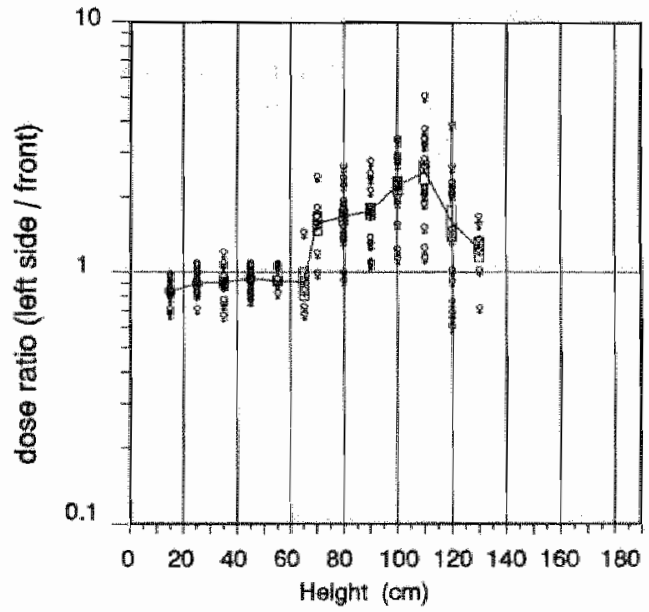

Figure 9.5 Ratios of entrance doses at the left side and doses at the front of the opperator as a function of the height from the floor.

(- - : mean dose; $\square$ : mean \pm standard error; $\&$ denotes ratios for single procedures)

Average ratios of the dose to the left side and the dose at the front at the same height, given in Figure 9.5, varied from about a factor of 0.8 to 2.5. Ratios derived for single procedures varied between 0.6 and 5 . Up to a height of about $70 \mathrm{~cm}$ the dose to the side 
was lower, over $70 \mathrm{~cm}$ height the dose to the side exceeded the front dose (ratio about 23).

Measurements for the neck have been compared with measurements for the forehead, thorax, left and right upper arm [K192]. Dose ratios were estimated to be for:

- operators:

- thorax : neck (thyroid) : forehead $=1: 0.7: 0.3$

- left upper arm : neck (thyroid) : right upper arm $=1: 0.4: 0.2$

- first assistants:

thorax : neck (thyroid) : forehead $=1: 1: 1$

left upper arm : neck (thyroid) : right upper arm $=0.3: 0.3: 1$.

\subsubsection{Entrance dose estimates for occupationally exposed persons in DW}

Results of dose measurements for operators, first assistants, and persons who performed both as operator and first assistant in the course of single procedures in the DW hospital are summarised in Table 9.5. Mean values were nearly always higher than median values, indicating skewed dose distributions. Mean/median-ratios were almost always within the range of 1 to 2 . Except for a small number of cases, maximum/median-ratios were less than 10. Dose levels over $1000 \mu \mathrm{Gy}$ were only found for the lower legs. Maximum doses for the highly exposed hand were all less than about $600 \mu \mathrm{Gy}$, to the other hand less than $150 \mu \mathrm{Gy}$. Similar to the exposure conditions in the azM, high doses to the lower leg are associated with undercouch $X$-ray tube applications.

Dose levels at the neck (thyroid) were higher than corresponding doses to the forehead. The dose to the most exposed upper arm was about a factor of two thigher than the dose to the neck, and about a factor of five higher than the dose to the other arm. The average ratio of doses to the leg close to the $X$-ray beam, and the other leg, was about a factor of two. Exposures 10 persons who performed both as operator and as first assistant in a single procedure generally exceeded the exposures to operators and first assistants in "normal" procedures. Relatively high exposures were found for PTA-procedures and for peripheral arteriography of both legs (PAs).

Two measurements for the operator showed high doses to the hands. In both procedures the entrance hand dose was estimated to be about $2100 \mu \mathrm{Gy}$. These results were assigned to exposures of the hand in the primary $\mathrm{X}$-ray beam (these data have been excluded from the statistical calculations).

Measurements for the neck have been compared with measurements for the forehead, and the left and right upper arm [KI93b]. Dose ratios were estimated to be:

- for operators:

- neck (thyroid) : forehead $=1: 0.5$

- left upper arm : neck (thyroid) : right upper arm $=1: 0.6: 0.3$

- for first assistants:

- neck (thyroid) : forehead $=1: 0.9$

- left upper arm : neck (thyroid) : right upper arm $=1: 0.7: 0.4$. 
Table 9.5 Bntrance dose estimates for oceupationaliy exposed persons in Dw position Entrance dose microgray per procecure of the

doseneter

procedure

Lype

operator

Median Mean Max.

Forehead:

CF $\quad 6 \quad 96$

$\mathrm{EA}$

TA

AD

Aniv

PAn

PAS

PTA

Thyroid:

$c$ A

$E x$

$T A$

AA

AMiv

PAM

DAS

PTA

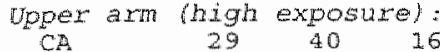

$\begin{array}{llll}\text { EA } & 110 & 11 & 29\end{array}$

Th

$A$ A

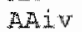

PAn

PAS

Pra

Upper

$\begin{array}{llll}C A & 2 & 7 & 65\end{array}$

$E A$

TI

An

A.Miv

PAn

PRS

PTA

Lowe

eg (hith exposure)

CA 4 is

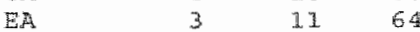

$\begin{array}{llll} & 6 & 6 & 16\end{array}$

A $24 \quad 32 \quad 68$

P到证 $\quad 32 \quad 29 \quad 37$

PAn 11 14 37

$\begin{array}{llll}\text { PAs } & 17 & 16 & 25\end{array}$

PTH $\quad 89 \quad 185 \quad 2250$

Lower leg (low expasure):

$\begin{array}{llll}C A & 2 & 13 & 270\end{array}$

EA

TA

A.A

ARiv

PAn

PAS

Pat

523

21.43

1727

$10 \quad 32$

1121

$110 \quad 940$

(continued on next page)

Eixet assistant

Median Mean Max.

Operator/ass

Median Mean Max

$\begin{array}{rrr}3 & 5 & 22 \\ 4 & 4 & 12 \\ - & - & - \\ 5 & 4 & 6 \\ - & - & - \\ - & - & - \\ 10 & 24 & 55 \\ 9 & 12 & 35\end{array}$

$\begin{array}{rrr}5 & 7 & 25 \\ 4 & 6 & 14 \\ - & - & - \\ 5 & 4 & 5 \\ - & - & - \\ - & - & - \\ 16 & 27 & 55 \\ 12 & 17 & 52\end{array}$

$48 \quad 45$

$4 \quad 5 \quad 21$

$\begin{array}{rrr}- & - & 5\end{array}$

$\begin{array}{lll}- & - & - \\ - & - & -\end{array}$

$20 \quad 30 \quad 56$

$14 \quad 25 \quad 165$

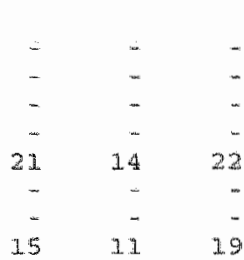

$\begin{array}{lll}1 & 3 & 20\end{array}$

2

7

5

2

$5 \quad 15 \quad 15$

$16 \%$

$\begin{array}{rrr}18 & -16\end{array}$

$6 \quad 12 \quad 24$

$29 \quad 63 \quad 315$

$\begin{array}{rrr}0 & 2 & 21 \\ 3 & 3 & 13 \\ - & - & - \\ - & - & 16 \\ - & - & - \\ 3 & 8 & 10 \\ 19 & 46 & 240\end{array}$
$21 \quad 22 \quad 43$

$61 \quad 51 \quad 90$

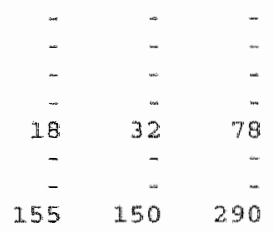

$13 \quad 13 \quad 25$ 


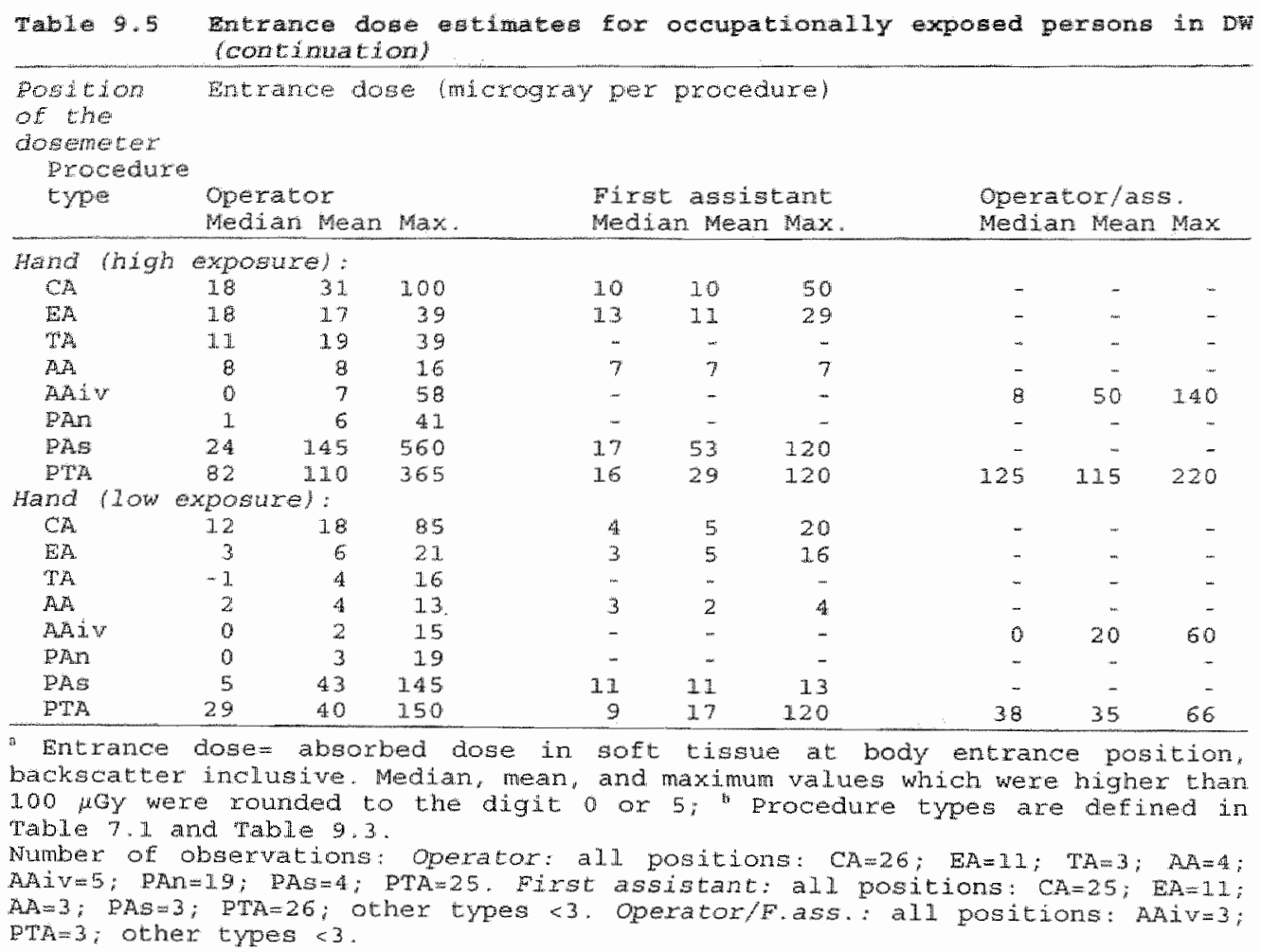




\subsubsection{Entrance dose estimates for occupationally exposed persons in MA}

Results of T1 dose measurements for operators and first assistants in the MA hospital are summarised in Table 9.6. The exposure type "operator/first assistant", as introduced for the azM hospital and DW hospital, did not occur in the MA hospital. Table 9.6 contains measurements for both undercouch and overcouch tube positions. At a glance it can be seen that dose levels for these exposure conditions differ considerably.

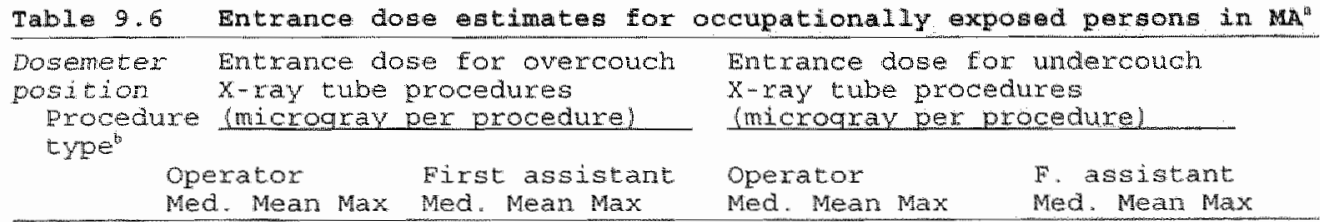

\begin{tabular}{|c|c|c|c|c|c|c|c|c|c|c|c|c|}
\hline \multicolumn{13}{|c|}{ Forehera } \\
\hline CAI & 18 & 20 & 76 & 8 & 8 & 20 & - & - & - & - & - & - \\
\hline $\mathrm{Cl}_{2}$ & 20 & 29 & 365 & 10 & 13 & 115 & 15 & 20 & 56 & 6 & 6 & 直钱 \\
\hline ER & 6 & $\vec{\jmath}$ & 12 & 3 & 5 & 11. & - & - & . & $\cdots$ & - & - \\
\hline$M A$ & 35 & 43 & 105 & 18 & 24 & 69 & 1.6 & 13 & 28 & 3 & 4 & 11 \\
\hline$A A B$ & 75 & 31.0 & 365 & 36 & 41 & 75 & $\infty$ & - & - & - & - & - \\
\hline $\mathrm{PTA}$ & 115 & 130 & 445 & 105 & 115 & 395 & 8 & 8 & 10 & 8 & 10 & 3.4 \\
\hline \multicolumn{13}{|c|}{ Thyroia } \\
\hline$C A 1$ & 52 & 51 & 115 & 8 & 8 & 16 & - & - & $\cdots$ & - & - & - \\
\hline $\mathbb{C A 2}$ & 70 & 82 & 520 & 8 & 13 & 150 & 24 & 27 & 71 & 3 & 5 & 17 \\
\hline $\mathbb{E}$ & 7 & 10 & 23 & 4 & 5 & 11 & - & - & $\cdots$ & - & - & - \\
\hline$M A A$ & 66 & 100 & 300 & 18 & 23 & 74 & 8 & 27 & 74 & 5 & 6 & 11 \\
\hline$A M B$ & 210 & 300 & 1120 & 42 & 40 & 74 & $=$ & $\infty$ & - & - & $\sim$ & - \\
\hline PT & 275 & 340 & 1220 & 140 & 150 & 610 & 1.8 & 21 & 28 & 12 & 13 & 17 \\
\hline \multirow{2}{*}{\multicolumn{13}{|c|}{$\begin{array}{l}\text { Upper am } \\
\text { hilgh exp) }\end{array}$}} \\
\hline & & & & & & & & & & & & \\
\hline $\mathrm{CA}_{1}$ & 80 & 88 & 185 & 11 & 12 & $\begin{array}{r}23 \\
250\end{array}$ & 53 & 34 & 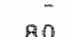 & 5 & 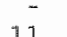 & $\omega$ \\
\hline CA2 & 120 & 140 & 865 & 10 & 19 & 25.0 & $\begin{array}{r}33 \\
-\end{array}$ & 34 & 80 & 3 & $d 1$ & 33 \\
\hline$E A$ & 13 & 32 & 99 & 5 & 7 & $\begin{array}{r}18 \\
15\end{array}$ & 28 & 52 & 125 & 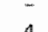 & 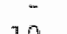 & - \\
\hline A. & 100 & 180 & 525 & 18 & 27 & $\begin{array}{l}115 \\
120\end{array}$ & $\begin{array}{r}28 \\
-\end{array}$ & 52 & 125 & 4 & 10 & 23 \\
\hline$A M B$ & 260 & 435 & 1580 & 47 & 56 & $\begin{array}{l}320 \\
055\end{array}$ & 48 & 53 & - & 4 & - & 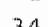 \\
\hline PTA & 425 & 590 & 2200 & 1.75 & 225 & 855 & 48 & 53 & 80 & 24 & 25 & 34 \\
\hline \multicolumn{13}{|c|}{$\begin{array}{l}\text { Wpper anm } \\
\text { (Dow exp) }\end{array}$} \\
\hline$C A 1$ & 17 & 17 & 43 & 4 & 4 & 8 & - & - & - & 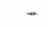 & - & . \\
\hline CA2 & 15 & 25 & 290 & 5 & 8 & 56 & 6 & 12 & 35 & 4 & 4 & 15 \\
\hline EA & 2 & 5 & 12 & 3 & 2 & 4 & - & - & $\omega$ & - & - & - \\
\hline $\operatorname{AAx}$ & 27 & 34 & 72 & 8 & 10 & 32 & 8 & 17 & 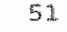 & 3 & 3 & 7 \\
\hline$M A B$ & 61 & 97 & 360 & 13 & 14 & 27 & - & - & $\approx$ & - & - & - \\
\hline PTA & 125 & 245 & 460 & 34 & 70 & 305 & 21 & 11 & 15 & 3 & 3 & 5 \\
\hline \multicolumn{13}{|l|}{ Back: } \\
\hline$C A 2$ & 3 & 4 & 7 & 1 & 1 & 2 & .. & - & - & - & $\omega$ & - \\
\hline$A D B$ & 3 & 3 & 5 & 1 & 1 & 2 & - & $\cdots$ & - & - & - & 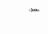 \\
\hline \multicolumn{13}{|c|}{$\begin{array}{l}\text { Abolomen } \\
\text { (on apron) }\end{array}$} \\
\hline $\mathrm{CA} 1$ & 17 & 18 & 55 & 3 & 3 & 10 & - & - & - & - & - & \\
\hline$C A 2$ & 20 & 23 & 87 & 2 & 3 & 8 & 24 & 30 & 200 & 3 & 5 & 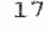 \\
\hline $\mathbb{E A}$ & 3 & 5 & 12 & - & - & - & - & - & - & $\cdots$ & $=$ & \\
\hline$M A$ & 24 & 37 & 105 & 5 & 7 & 16 & 24 & 56 & 3.55 & 2 & 6 & 22 \\
\hline PTA & 83 & 86 & 245 & 34 & 26 & 47 & 31 & 28 & 43 & 14 & 16 & 22 \\
\hline
\end{tabular}

cont inued on next pagel 


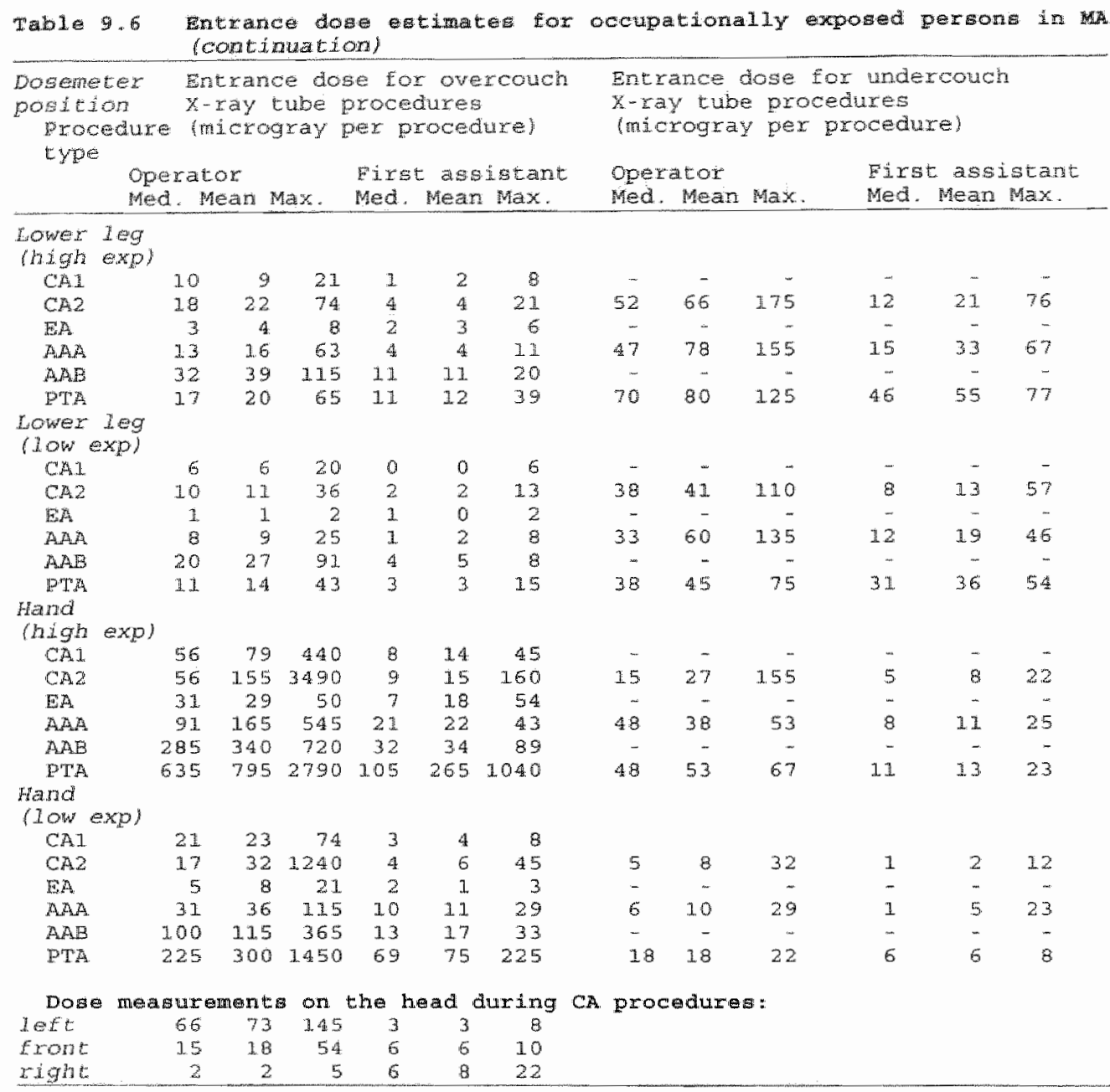

" Entrance dose absorbed dose im soft tissue at body entrance position, backscatter inclusive. Med. = median; Mean = arithmetic mean; Max. = maximum. Median, mean, and maximum values which were greater than 100 HGy were rounded to the digit or 5; procedure cypes axe defined in Table 7.3 and Table 9.3. Numbers of observations for the operator and for the first assistant

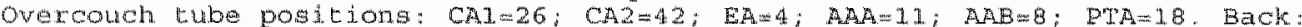

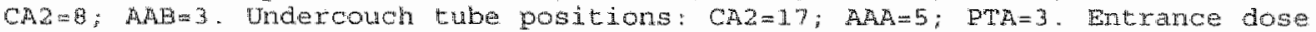
measurement fox the head were performed during 12 camprocedures.

Exposures to parts of the body above the abdominal region were significantly higher for overcouch tube positions than for undercouch tube positions. On the other hand, exposures to the leg were much lower for overcouch tube positions.

As shown in Table 9.6, significant exposures to the back were not found. 
In procedures with overcouch tube positions, exposures to the lands and the upper arm, close to the $X$-ray source (denoted as high exp), were relatively high. It is useful to note that mean doses to the hand and upper arm, close to the $X$ aray source, were very similar.

Additional dose measurements for the head of the operator showed that the mean dose of the highly exposed side was about a factor of four more than the mean dose to the front, and about a factor of 35 more than the dose to the other side. Dose ratios for the first assistant were small, about a factor of two to thee. Dose ratios front/left side and right side/left side were associated with the positions of the video display monitor, the operator and the radiation source. During viewing of the fluoroscopy image the face is turned away from the source, the exposure to the dosemeter on the forehead is consequently decreased. It should be noted that this effect is advantageous to reduce the dose to the eye lens. However, if dose measurements on the forehead are used in calculations of effective doses, results may underestimate actual exposures.

Measurements for the neck have been compared with measurements for the forehead, abdomen, left and right upper arm [KI93c]. Dose ratios were estimated to be for:

- operators:

- abdomen : neck (thyroid) : forehead $=0.4: 1: 0.4$

- left upper arm: neck (thyroidy: right upper arm $=1: 0.6: 0.2$.

- first assistants:

- abdomen : neck (thyroid) : forehead $=0.4: 1: 1$

- left upper arm : neck (thyroid) : right upper arm $=0.5: 0.8: 1$.

\subsubsection{Summary of entrance doses to occupationally exposed persons in the azM, DW and MA hospitals}

\section{Summary of occupational exposure conditions}

In a relatively large number of procedures, the catheter was inserted in the femoral artery (iliac region, above the femur head). During catheterisation, the operator (radiologist) stood next to the patient table, somewhere between the abdomen and the femoral region of the patient (distance between operator and field entrance position varied from about 30 to 150 $\mathrm{cm}$ ).

Since very often power driven injection systems were applied (see Chapter 4), occupationally exposed persons stayed behind protective barriers or at a distance of more than $2 \mathrm{~m}$ from the patient during conventional radiography and DSA-imaging.

Due to high dose rates (e.g. $10 \mathrm{mG} / \mathrm{min}$ ), incidental exposures to the primary beam could result in high local doses to the fingers. However, dose data showed that prolonged exposures of the hands in the primary beam did not occur, or had a very low frequency only.

Characteristics of supportive actions by the first assistant depended on the procedure type, on local protocols, and on the preferences of the operator. In general, the first assistant stayed at some greater distance from the patient than the operator. Depending on local routines, the first assistant stayed at the same side as the operator (DW) or opposite to the operator (azM, MA). Occupational exposures to first assistants during radiographic imaging was quite rare; most of the time they stood behind protective barriers or at a distance of at least $2 \mathrm{~m}$ from the patient, like the operator.

All personnel wore $0.5 \mathrm{~mm}$-thick lead-equivalent aprons. Although thyroid collars were available, almost nobody used them. Lead glasses were used very infrequently, lead gloves were never worn. 
Summary of typical entrance doses in vascular radiology

Taking account of the annual frequencies and the number of measurements performed for various procedure types, frequency correction factors were derived for the three hospitals separately. These factors were used to compute typical exposure levels for the body parts encompassed in this study. Results are given in Table 9.7

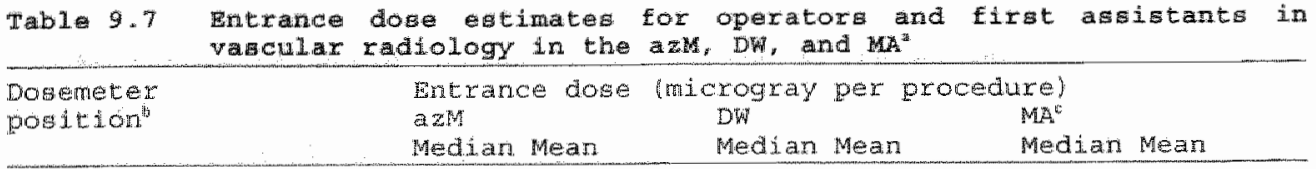

\section{OPERATCH}

- potehead

- Thyroid

- Upper arm (h. exp)

- Thorax

- Abdomen

- Lower leg (h. exp)

- lower leg (1. exp)

- Hand (h. exp)

- Hand (1. exp

FIRST ASSISTANT:

- Fonehead

- Thyroid

- Upper arm (h. exp)

- Upper arm (1. exp)

- Thoray

- Abdomern

- Lower leg (h. exp)

- lower leg (1. exp)

- Hand (h. exp)

- Hanc (1. exp)

" Annul number of procedures used for extrapolation of measurement results: $a Z M=380 ; D W=440 ; M A=360$. " $h$. exp" denotes upper arm, lower leg, and hand close to the radiation source, resulting in relatively high exposures. 1. exp" denotes coxesponding body parts far from the radiation source, resulting in relatively low expogumes, Entrance doses to the thorax, abdomen, and thyrold refer to doses on the apron and thyrolid collar; "Dose data for the MA howplal refer to overcouch tube positions, whereas an and pw data refer to undercouch tube positions.

\section{Conclusions:}

- Exposure conditions per procedure varied widely, resulting in a broad range of dose estimates for the body parts monitored in this study. Measurement results varied from less than $10 \mu \mathrm{Gy}$ to more than $3000 \mu \mathrm{Gy}$.

- The major part of the distributions of entrance doses, derived for specified positions on the body, appearedl to be skewed, with long tails at the high dose level sides. Most of these data could not be considered as samples from normal distributions. Therefore, evaluation of measurements required nonparametric statistical methods, which complicated the interpretation of the results.

- In undercouch tube systems, the entrance dose to the trunk, measured on the protective apron, averaged per procedure type, varied from less than 10 to $75 \mu$ Gy per procedure. The mean dose to the neck, head, and upper arms (these body parts were not protected by protective clothing) varied between about 1 and $130 \mu \mathrm{Gy}$. Procedure type averaged doses to the lower leg were estimated to be 20 to $250 \mu \mathrm{Gy}$. For overcouch tube exposure 
to the lower leg were estimated to be 20 to $250 \mu \mathrm{Gy}$. For overcouch tube exposure geometries, doses to the upper part of the body of occupationally exposed persons were signiticantly higher than for undercouch tube geometry. Measurement results clearly showed that the dose to the hands for an overcouch $\mathrm{X}$-ray tube system was much higher than for an undercouch system.

\subsubsection{Correlation of entrance doses in the azM, DW and MA hospitals with the X-ray output}

Using the distribution free Speamman rank correlation coefficient, $r_{s}$, entrance doses to various positions on the body of occupationally exposed persons were associated with the exposure to scattered X-rays. Exposure conditions were quantified with the dose-area product from fluoroscopy, DAP fu, and the fluoroscopy time, $t_{\text {nu }}$. As shown in Table 9.8, $r_{s}$-values for $D A P_{f u}$ and entrance dose exceed $r_{s}$-values for $t_{f t u}$ and entrance dose. It follows that DAP $P_{\text {gtu }}$ has more potential for predicting entrance doses than $t_{\text {flu. }}$. Table 9.8 also shows relatively high correlation coefficients for the lower legs. For undercouch tube positions (hospitals azM and DW), $r_{s}$-values for the lower legs even exceed $r_{s}$-values for other positions (except for DW, operator, neck). On the other hand, in overcouch tube positions (the MA hospital). correlations were stronger for measurement positions above the waist than for the legs. Considering the data presented in Table 9.8 , it is concluded that there is a readily correlation between $D A P_{f i z}$ and the entrance dose at various positions. This indicates that, if required, relationships between DAP Dhu $_{\text {and }}$ entrance doses could be useful for dose assessments. Since Table 9.8 was composed without any relation to the effective dose, it obviously does not contain differences in the efficiency of the various measurement positions with respect to the personal dosemeter. This subject will be addressed in Section 9.5.4. 
Table 9.8 Speaman rank correlation analyos for entrance dotes at various exposure to $X-x a y e$

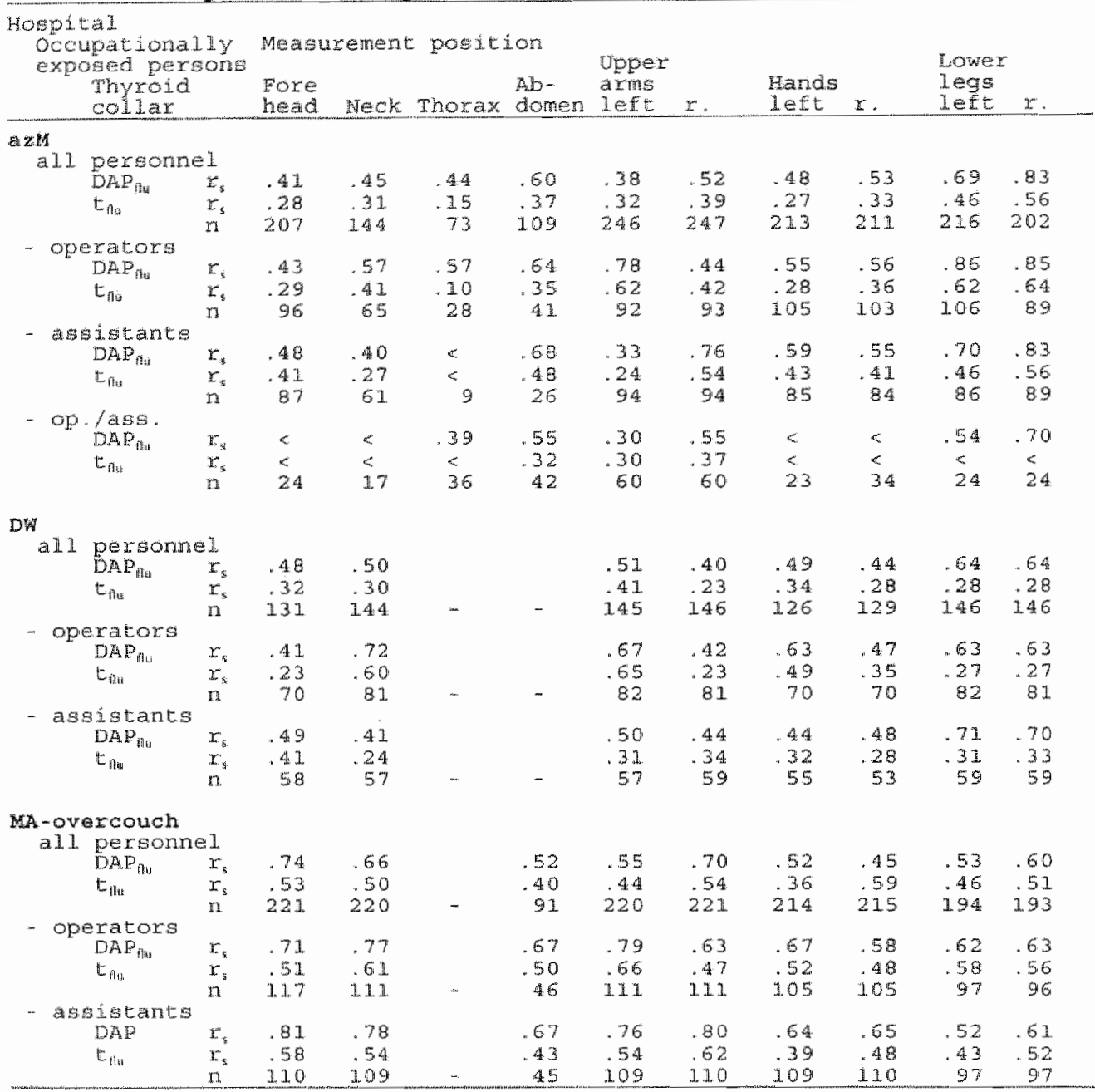

" wi" anotes the spearman rank correlation coefficient, n denotes the rumber of parted observations. Because of missing data the numbers of paired

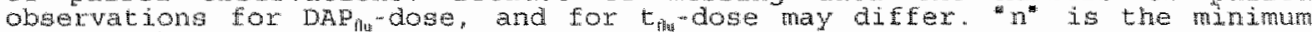
watue. indicates a probability $>0.05$ that $x_{a}=0$.

\subsubsection{Comparison of entrance doses in the azM, DW and MA hospitals with dose limits}

Mean entrance dose data presented in Table 9.7 were used to estimates for the occupational equivalent dose to the eye lens, thyroid, hands, and lower legs. As a first approach, it was assumed that all procedures were performed by the same operator and assistant. Mean doses to the procedures listed in Table 9.7 were also taken to be representative for other procedures performed in the angiography room. Annual doses to 
upper arm, hand, and lower leg were derived from the maximum value for the lef and right extremity. Because of the high radiation attenuation by the aprons, doses to the trunk were not included. It should be noted that mean entrance doses to assistants in azM and DW were based on fewer procedures than to operators (see Table 9.4 and 9.5). Because most of the procedures involved a team of at least two persons, annual frequencies derived for the operator have been applied for assistants as well. Generally, only radiologists and registrars were involwed as operator/assistant. Therefore, results obtained for operators/assistants have been assigned to the group of radiologists. As two operator/assistants were involved per procedure, the number of these procedures was multiplied by two. It is obvious that the final results (Table 9.9) will overestimate actual equivalent doses.

By comparing data presented in Table 9.9 with the currently used occupationally dose limits in the Netherlands (eye lens $150 \mathrm{mSv}$ per year, other organs and tissue $500 \mathrm{mSv}$ per year), it is easy to see that equivalent doses associated with radiological work in the angiography rooms in the hospitals azM, DW and MA were quite small. Even if in each angiography room all procedures were performed by one radiologist and one rechnologist, equivalent doses to these persons would be less than about $15 \%$ of the corresponding occupational dose limits.

Table 9.9 Estimates for annual equivalent doses associated with all procedures performed in the angiography rooms ${ }^{\mathrm{a}}$

\begin{tabular}{|c|c|c|c|c|c|c|c|c|c|c|}
\hline \multirow{3}{*}{ Hospital } & \multicolumn{5}{|c|}{ Operator } & \multicolumn{5}{|c|}{ First assistant } \\
\hline & \multirow{3}{*}{$\begin{array}{l}\text { No. } \\
{\left[a^{-1}\right]} \\
639\end{array}$} & \multirow{2}{*}{\multicolumn{3}{|c|}{$\begin{array}{l}\text { Equivalent dose }[\mathrm{mSv} \\
\text { lens thyroid hands }\end{array}$}} & \multirow{3}{*}{$\frac{\left.a^{1}\right]}{\text { legs }}$} & \multirow{3}{*}{$\begin{array}{l}\text { No. } \\
{\left[\begin{array}{l}\left.a^{-1}\right] \\
429\end{array}\right.}\end{array}$} & \multicolumn{4}{|c|}{ Equivalent dose $\left[\mathrm{mS} \mathrm{S} \cdot \mathrm{a}^{-1}\right]$} \\
\hline & & & & & & & lens & thys & lhands & $\operatorname{legs}$ \\
\hline $\mathrm{aZM}$ & & 5 & 13 & 46 & & & 2.6 & 3.9 & 13 & 33 \\
\hline DW & 766 & 12 & 19 & 49 & 29 & 680 & 11 & 13 & 31 & 16 \\
\hline $\mathrm{MA}$ & 360 & 15 & 40 & 77 & 5 & 360 & 10 & 12 & 19 & 2 \\
\hline
\end{tabular}

"No. denotes the number of exposures used to calculate the annual dose.

\subsection{Effectiveness of 0.5 -mm-thick lead-equivalent aprons in vascular radiolog ${ }^{1}$}

\subsubsection{Introduction}

Because of the highly nonuniform exposure conditions in vascular radiology, a reliable estimation of the effective dose for occupationally exposed persons requires a number of dose measurements at various locations on the body. The nonuniform occupational exposure is mainly associated with the relatively short distance to the radiation source (scattered radiation

1 This section is based on the publication: P.J. Kicken, A.J.J. Bos. Effectiveness of Lead Aprons in Vascular Radiology: Results of Clinical Measurements. Radiology. $1995 ; 197: 473-478$. Only editorial modifications were made. 
from the patient) and the attenuation of the scattered radiation by protective clothing and shielding. In order to estimate the radiation exposure to organs and tissues of the trunk, the radiation dose undemeath the protective clothing must be measured. As an alternative approach, these dose levels may be estimated by combining dose measurements obrained outside of the apron with physical data about the photon attenuation by the protective clothing. Because the radiation attenuation of lead aprons depends on the effective energy of the incident $X$-ray photons and geometric factors, the resulis of these model calculations should be verified with dose measurements obtained in clinical practice.

Various papers have been published about the occupational radiation exposure in diagnostic radiology [BO91, FA82, MC83, N193, TR87]. Recently, a number of studies have been performed to determine the relationship between the effective dose and the dosemeter reading from radiologists and technical staff [FA88, FA93, HU94, N194, RO94, WE89]. Most papers about occupational exposures in radiology do not include dose estimates for protected body regions under clinical conditions; instead, published data about $X$-ray transmission are usually used [FA82, FA88, FA93, HU94, N194, RO94, TR87] or other methods are applied [N193, WE89]. In some papers, unrealistically small attenuation factors for lead aprons have been used. McGuire et al. [MC83] applied a factor of 5, Tryhus et al. [TR87] a factor of 7-11.

In a study about occupational exposures in vascular radiology in a general hospital in the Netherlands, the total contribution of the dose equivalent of organs and tissues protected by a lead apron to the effective dose was derived for overcouch tube positions [KI93c]. By using transmission factors of 0.01 and 0.05 for the apron (no thyroid collar used), the total contribution of the doses of "protected tissues" (thorax, abdomen and thighs) was estimated to be $3 \%$ and $13 \%$ respectively. Transmission factors of 0.1 and 0.2 would have resulted in relative contributions of $23 \%$ and $38 \%$ respectively. These data indicate the need for reliable estimates of the radiation attenuation of aprons in clinical conditions.

In an additional study, the effectiveness of lead aprons of $0.5 \mathrm{~mm}$ lead-equivaltent in vascular radiology in the $a z M$ was determined. This section presents the results of three clinical thermoluminescent dosemeter (TLD) studies and measurements of tube high voltage.

\subsubsection{Materials and Methods}

Dose measurements were carried out for various types of vascular examinations (cerebral, thoracic, abdominal and peripheral angiography) and during interventional vascular radiology (abdominal and peripheral percutaneous transluminal angioplasty procedures) by using fluoroscopy, digital subtraction angiography, and conventional radiographic imaging systems. During fluoroscopy, the operator and assistant are close to the patient, whereas in digital subtraction angiography and conventional angjography, they stay behind protective barriers. In our institution, as is common in The Netherlands, radiologists and technical staff wear 0.5 mm-thick lead-equivallent semi-closed aprons (in our institution: Burlington Medical Supplies, Amesbury, Mass). Aprons were not of the so-called light-weight type.

\section{Phaniom study}

We used the angiographic $\mathrm{X}$-ray system to obtain empirical data about the radiation attenuation of the lead aprons as a function of the tube high voltage with dose measurements in the high voltage range 60 to $110 \mathrm{kV}$ (six measuring points at intervals of about $10 \mathrm{kV}$ ). A simple solid rectangular phantom constructed of acrylic (Lucite) $(24 \times 30 \times 30 \mathrm{~cm})$ was placed in the primary $X$-ray beam, $60 \mathrm{~cm}$ from the focus. The dose rate in the scattered radiation, perpendicular to the primary beam (broad-beam geometry), was measured with and without an apron between the phantom and the measuring device. The apron was placed approximately $10 \mathrm{~cm}$ to the side of the phantom. Dose measurements were carried out with a 
300-ml ionisation chamber (Babyline 81; Nardeux, Loches, France), at a distance of about $0.5 \mathrm{~cm}$ to the apron. The backsatter dose to TLDs placed under aprons worn by radiologists (backscatter from the body) was assessed with additional measurements. With use of a broadbeam geonetry, two series of dose measurements were carried out with a 30 -mi ionisation chamber (PM-30; Capintec, Pittsburgh, $\mathrm{Pa}$ ) positioned in the primary beam immediately behind the lead apron and connected to an electrometer (Exposure Rate Meter Model 192; Capintec) calibrated at the Dutch Standards Institute. The dose rate dependence [W A880] was experimentally checked to be absent in our exposure conditions. In the first series of measurements, the detector was essentially free-in-air. In the second series, the detector was half encapsulated by a backscatter phantom made of perspex, measuring $24 \times 30 \times 15 \mathrm{cn}^{3}$.

\section{Clinical study}

The clinical dosimetry study was carried out in three sessions. In the first session, TLDs of normal sensitivity were worn by radiology personnel for 1-4 weeks. In the second and third sessions, TIDS of high sensitivity were used. Dose data from the second session were obtained in single examinations, whereas those in the third session were obtained in one-week periods, thereby measuring the cumulated dose associated with a number of examinations. TLD measurements for single examinations were combined with real-time measurements of the rube high voltage, dose-area product and fluoroscopy time. All TLD measurements were corrected for environmental background radiation.

\section{First session}

In the first session, TLDs of normal sensitivity (TLD-100; Harshaw, Solon, III, USA; $3.2 x$ $\left.3.2 \times 0.9 \mathrm{~mm}^{3}\right)$ were worn by two radiologists. Each dosemeter consisted of a thin plastic sachet measuring $2.5 \times 5.0 \mathrm{~cm}^{2}$, each containing three thermoluminescent elements; the dosemeters did not contain additional filters or absorbers. The dosemeters were worn in the centre of the abdominal region: one dosemeter was worn on the outside of the apron and two were worn on the inside. No changes in the use and storage of aprons were introduced. Dosemeters were worn for 1-4 weeks. The back of one of the dosemeters worn inside the apron was shielded with a 1-mm-thick lead sheet. This "shield" was attached to prevent the exposure of this dosemeter to scattered radiation due to patient examinations when the apron was stored in the preparation room, which was located next to the angiography room. Background measurements in the preparation room were performed at two apron hanger systems.

TLDs were calibrated in batches, with each batch containing up to approximately 50 elements with a homogeneous response (thermoluminescent signal of each element differts less than $5 \%$ of the mean value). Calibration was performed essentially in free-in-air exposure conditions by using a diagnostic X-ray system (tube high voltage $73 \mathrm{kV}$; distance-to-focus, 92 $\mathrm{cm}$; total beam filtration, $2.8 \mathrm{~mm} \mathrm{Al}$, first half-value layer equal to $2.7 \mathrm{~mm}$ Al at $73 \mathrm{kV}$ ). The beam cross-section area at $92 \mathrm{~cm}$ from the focus (location of TLDs) was $20 \times 25 \mathrm{~cm}^{2}$. Kerma measurements were performed with the same $30-\mathrm{ml}$ ionisation chamber applied in radiation transmission measurements. Experimental results showed that the exposure variation over the field surface in the beam cross-section area occupied by TLDs and the ionisation chamber (heel-effect) was less than $5 \%$.

For background corrections the mean TL-signal of six randomly selected, unexposed TLDs was applied. The lower detection level (i.e. the dose level that results in a TL-signal equal 10 three times the standard deviation of that of background TL-elements) was calculated to be 10 $\mu \mathrm{Gy}$. 


\section{Second session}

Two dosemeters of high sensitivity were worn in the centre of the abdominal region, one on the inside and one on the outside of the apron. Dosemeters were worn by 14 radiologists and registrars during 27 procedures. Each dosemeter consisted of a thin plastic sachet measuring $2.5 \times 5.0 \mathrm{~cm}^{2}$, each containing two themoluminescent elements (GR-200A; Beijing Shiying Radiation Detector Works, Beijing, China; diameter, $4.5 \mathrm{~mm}$, thickness, $0.8 \mathrm{~mm}$ ). The dosemeters did not contain additional filters or absorbers. New sets of dosemeters were used at the start of each patient procedure.

Thermoluminescent elements were processed in batches. In order to reduce the contribution of background radiation, the time between annealing and readout was kept as short as possible. Background corrections were carried out by subtracting the mean TL-signal. of 10 randomly selected elements that were kept from X-ray exposures. TLDs used for background measurements were processed and stored in the same manner as those used for occupational dose measurements. Calibration was performed for individual TLD elements (in free-in-air exposure conditions) by using an $X$-ray beam with the following parameters (high voltage $60 \mathrm{kV}$; total beam filtration of $4 \mathrm{~mm}$ aluminum $+0.6 \mathrm{~mm}$ copper; first half-value layer at $60 \mathrm{kV}, 0.24 \mathrm{~mm}$ copper; focus-TLD-distance of $115 \mathrm{~cm}$ ). The lower detection level was calculated to be $1 \mu \mathrm{Gy}$.

Because doses measured under the apron were often less than the lower detection level, a subset of dose data above the detection level was used to estimate the upper level of the transmission factor. First, all procedures with dose levels over the apron less than $10 \mu \mathrm{Gy}$ were deleted from the data set. Then, doses under the apron less than the lower detection level $(1 \mu \mathrm{Gy}$ ) were set equal to 0.5 times the lower detection level (this correction is explained in the Discussion).

\section{Third session}

In the third session, two dosemeters were worn in the centre of the abdominal region, one under and one on the outside of the apron (the same type of dosemeters were applied as in session 2). The number of staff members wearing these aprons and the number of vascular procedures performed by these persons were not recorded. The back of the dosemeter on the inside was shielded with a 1 -mm-thick lead sheet (see session 1). To improve precision, each dosemeter contained four, in stead of two, TL-elements. Dosemeters were renewed at the beginning of a week. Consequently, the measured dose is equal to the sum of the contributions of single vascular procedures carried out in that week. The methods used to process the thermoluminescent elements and determine the lower detection level were the same as those used in session 2 .

\section{Real-time Recording System}

The $X$-ray system was equipped with a personal computer-based automated monitoring system that was developed for dosimetric studies during vascular radiology. Various system parameters were recorded in real time during fluoroscopy, digital subtraction angiography, and serial cut film angiography. This system is described in detail elsewhere [K192].

In this study, we recorded data about the dose-area product, fluoroscopy time, and tube high voltage during fluoroscopy. The dose-area product was measured with a flat transmission ionisation chamber positioned in the primary beam (Diamentor; PTW, Freiburg, Germany). The dose-area product meter was linked digitally with the real-time monitoring system.

The X-ray tube high voltage was sampled during fluoroscopy in 35 examinations with a sample frequency of about $3 \mathrm{~s}^{-1}$. The time averaged tube high voltage, the dose-area product, and the fluoroscopy time were determined for consecutive time intervals in which the monitored system parameters were constant (deviation from current averages less than $5 \%$ ). The number of recorded time intervals per procedure varied from about 50 to 250 . 
Four different weighing methods were applied to assess the mean $X$-ray tube high voltage per patient examination.

In method 1, the fluoroscopy time was applied for weighting as follows:

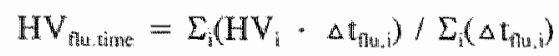

where $H V_{i}$ is the high voltage during fluoroscopy, as recorded in time interval $i$, and $\Delta t_{f u, i}$ is the duration of time interval i.

In method 2, the dose-area product was applied for weighting the tube high voltage. Dosearea product data were used because it has been shown that the occupational exposure to radiologists and staff is proportionally related to the dose-area product [K192a, K193c]. The dose-area product was applied for weighting as follows:

$$
\mathrm{HV}_{\text {dose-area }}=\Sigma_{\mathrm{i}}\left(\mathrm{DAP} \cdot \mathrm{HV}_{\mathrm{i}}\right) / \Sigma_{\mathrm{i}}(\mathrm{DAP})
$$

where $\mathrm{DAP}_{\mathrm{i}}$ is the dose-area product, and $\mathrm{HV}_{\mathrm{i}}$ is the high woltage recorded in time interval $\mathrm{i}$.

In method 3, the dose-area product, combined with a transmission factor for lead aprons (derived from phantom studies), was applied for weighting, as follows:

$$
H_{\text {dose area, weighted }}=\Sigma_{i}\left[D A P_{i} \cdot \operatorname{Tr}(H V)_{i} \cdot H V_{i}\right] / \Sigma_{i}\left[D A P_{i} \cdot \operatorname{Tr}(H V)_{i}\right]
$$

where $\mathrm{DAP}_{i}$ is the dose-area product for time interval $\mathrm{i}_{3} \mathrm{HV}_{\mathrm{i}}$ is the high voltage recorded in time interval $i$, and $\operatorname{Tr}(\mathrm{HV})_{i}$ the transmission of scattered radiation through 0.5 mm-thick lead-equivalent aprons; transmission is a function of the tube high voltage $\mathrm{HV}_{\text {; }}$.

In method 4 , it is assumed that in consecutive time intervals the entrance skin dose underneath the apron $\left(D_{\mathrm{skin}}\right)$ is equal to the entrance dose at the outside of the apron $\left(\mathrm{D}_{\text {approt }}\right)$ multiplied with the transmission factor $\operatorname{Tr}(\mathrm{HV})$. Backscatter and beam hardening are neglected. Furthermore it is assumed that $\mathrm{D}_{\text {apron }}$ and the dose-area product (DAP) are linearly related $\left(D_{\text {apron }}=c\right.$. DAP; $c=$ constant $)$. This method was used as the standard of reference. The total entrance skin dose in an examination, $D_{\text {skin, } \text { toal, was determined as }}$ follows:

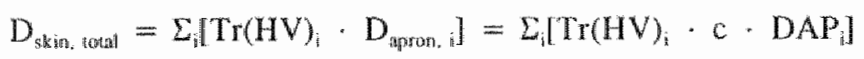

Introducing an effective transmission factor per examination $\mathrm{Tr}_{\text {cffr }}$, the total entrance skin dose may be calculated as follows:

$$
\mathrm{D}_{\text {skit, teal }}=\operatorname{Tr}_{\mathrm{eft}} \cdot \Sigma_{\mathrm{i}}(\mathrm{c} \cdot \mathrm{DAP})
$$

Combining Formulas (4) and (5) results in the following equation:

$$
\operatorname{Tr}_{\mathrm{eff}}=\Sigma_{i}\left[\operatorname{Tr}(\mathrm{HV})_{\mathrm{i}} \cdot \mathrm{DAP}\right] / \Sigma_{\mathrm{i}}\left[\mathrm{DAP} \mathrm{P}_{\mathrm{i}}\right]
$$

The callculated results for $\operatorname{Tr}_{\mathrm{eff}}(\mathrm{Eq}[6])$ and the mathematical rellationship between the radiation transmission and the tube high voltage $\operatorname{Tr}(H V)$, which was applied in method 3 , were used to derive the effective tube high voltage $H V_{\text {efr }}$. For this purpose, Equation (7) (given in the discussion) was solved analytically to estimate $\mathrm{HV}_{\text {efr }}$ for calculated values of $\mathrm{Tr}_{\mathrm{teff}}$. 


\subsubsection{Results}

Figure 9.6 presents transmission factors for a 0.5 -mm-thick lead equivalent apron as a function of tube high voltage. These factors were obtained from phantom studies. The transmission of the primary beam and the transmission reported by Rawlings et al. [RA90] have been included in Figure 9.6 as well. The transmission data reported by Rawlings and our data do not include backscatter from the body. In our phantom-based experiments, the backscatter contribution was estimated to be about $10 \%$ (range, $7 \%$ to $18 \%$ ).

Our phantom-based transmission factors, shown in Figure 9.6 , have been applied to calculate the weighted average tube high voltage per procedure according to method 3.

Statistics on TLD measurements from the first session are given in Table 9.10. These results refer to the integrated dose associated with various procedures performed in the measuring period. The uncovered TLDs at the outside of the apron have been corrected for contributions of scattered $X$-rays in the preparation room. The transmission factor (Tr) for consecutive measuring periods was calculated as the quotient of the dose of the TLD at the inside with 1 -mm-thick lead covering and the dose at the outside. The derived transmission factor $\mathrm{Tr}$ per measuring period varied from 0.0034 to 0.020 . The transmission factor was also derived from the sums of doses over and under the apron. From these figures, the overall transmission in the first session was calculated to be 0.0083 (attenuation factor $=120$ ).

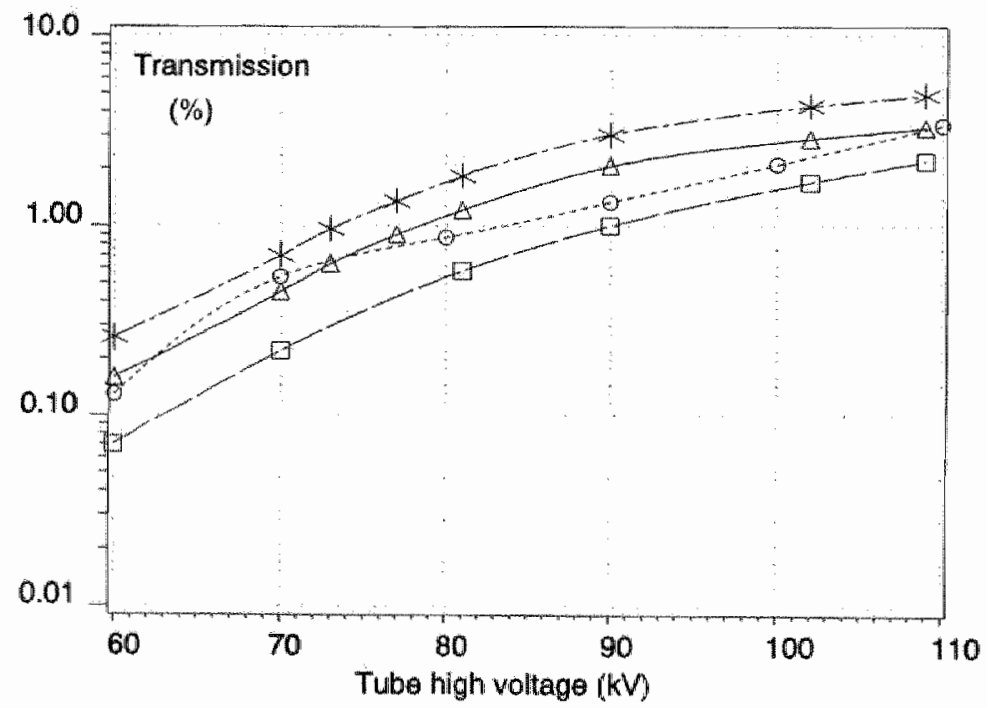

Figure 9.6 Reduction of $\mathrm{X}$-ray dose rates by 0.5 -mm-thick lead-equivalent aprons as a function of the tube high voltage.

- 1-a- transmission of radiation scattered $90^{\circ}$ (experimentally derived, using a 12-pulse voltage generator); $-\mathrm{O}-\mathrm{O}-$ transmission of radiation scattered $90^{\circ}$ by a wax phantom ( $\mathrm{X}$-ray beam, fully rectiffed unsmoothed voltage waveform, beam filtration not specified) in the study by Rawlings ef al. [RA90]; $-\Delta-\Delta-$ primary beam attenuation experimentally derived for a narrow beam geometry by using a 12-pulse voltage generator: $-X-X$ - primary beam attenuation experimentally derived for a broad beam geometry by using a 12-pulse voltage generator. 
Table 9.11 presents results from the two-element dosemeters (GR-200A) applied in single vascular procedures in session 2. In all, dose data were obtained from 53 vascular procedures. A subset of dose data above the detection level was used to estimate the upper level of the transmission factor.

Table 9.12 presents results of the four-element dosemeters (GR-200A) that were worn for 1 week in session 3. As in session 1 , these results refer to the cumulated dose of a number of vascular radiologic procedures. The total number of monitored procedures in session 3 was 50.

Statistics on tube high voltage during fluoroscopy, averaged per examination, are given in Table 9.13. Four different methods for calculating the high voltage were applied.

Table 9.10 Dose measuraments obtained with TLDs of normal sensitivity in sesion $1^{\mathrm{a}}$

\begin{tabular}{|c|c|c|c|c|c|c|}
\hline \multirow{2}{*}{$\begin{array}{l}\text { No. of } \\
\text { Expeximents } \\
\frac{1}{1}\end{array}$} & \multirow{2}{*}{$\begin{array}{l}\text { Dose } \\
\text { apron } \\
(\text { pey) }\end{array}$} & \multirow{2}{*}{$\begin{array}{l}\text { outside } \\
-(5)\end{array}$} & \multicolumn{2}{|c|}{$\begin{array}{l}\text { Dose inside apron (HGY) } \\
\text { With } 1 \text {-mm- without } 1 \text {-mm- } \\
\text { thick lead thick lead } \\
\text { covering }\end{array}$} & \multicolumn{2}{|c|}{$\begin{array}{l}\text { Backgrourd } \\
\text { Dose } \\
(4 \mathrm{C} y)\end{array}$} \\
\hline & & & $5(0.0)$ & $10(0.6)$ & 7 & 5 \\
\hline 2 & 654 & $(7)$ & $4\left(I_{n} .2\right)$ & $10(1.5)$ & 3 & 8 \\
\hline 3 & 894 & $(14)$ & $3(2.1)$ & $9(0.7)$ & $?$ & $: 10$ \\
\hline 4 & 6.6 & (19) & $13(0.6)$ & $16(2.6)$ & 6 & 5 \\
\hline 5 & 397 & (11) & $7(2.0)$ & $8(1.5)$ & 6 & 4 \\
\hline 6 & 460 & $(23)$ & 4. $(1,7\rangle$ & $5(0.6)$ & 0 & 8 \\
\hline 7 & 619 & 28 & $6(0.6)$ & $27(0.6)$ & 7 & 6 \\
\hline 8 & 1,774 & $(36)$ & $8(\pi, 0)$ & $1.5(1.7)$ & 8 & 9 \\
\hline Total & 6,051 & & 50 & 100 & 52 & $i 55$ \\
\hline
\end{tabular}

"Three dosemeters, each containing three thexmoluminescent elements (TLD-100), were worn in the abdominal region. One dosemeter was wom outside and two dosemeters inside the lead apron. Numbers in parentheses are sample standard deviations which were calculated from dose results from three thermoluminescent elements: background dose was measured at two hanger systems in the preparation xoom, which was located next to the angiography noom.

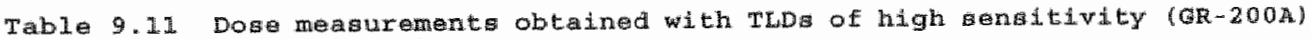
In sereion $2^{\text {a }}$

\begin{tabular}{|c|c|c|c|c|c|c|c|}
\hline $\begin{array}{l}\text { Dosemeter } \\
\text { posituion }\end{array}$ & $\begin{array}{l}\text { No. ot } \\
\text { vasoul } \\
\text { proc. }\end{array}$ & $\begin{array}{l}\text { Dose } \\
\text { min. }\end{array}$ & $\begin{array}{l}\frac{H y}{10 \mathrm{ch}} \\
\mathrm{perc}\end{array}$ & median & mean & $\begin{array}{l}90 \mathrm{~b} \\
\mathrm{PEC}\end{array}$ & $\max$ \\
\hline \multicolumn{8}{|l|}{ And data } \\
\hline Ower apron & 53 & 0.1 & 1.6 & 13 & 28 & 92 & 162 \\
\hline $\begin{array}{l}\text { Under apron } \\
\text { selected and } \\
\text { moditied dat }\end{array}$ & 53 & -1.5 & -0.5 & 0.0 & 0.1 & 0.6 & 4.7 \\
\hline Over apron & 29 & 11.1 & 13 & 27 & 49 & 126 & 162 \\
\hline Under apron & 29 & 0.5 & 0.5 & 0.5 & 0.7 & 1. 1 & 4.7 \\
\hline Ratio & 29 & 22 & 27 & 52 & 77 & 194 & 253 \\
\hline
\end{tabular}

" statistics have been derived, without application of a lower detection 1 imit, from the total data set, inclusive of negative values. Each dosemeter comtained two Twelements (GR-200A); brocedures with outside-apron dose levels less than $10 \mu \mathrm{G}$ have been deleted. Doses under the apron less than the detection level (1 $14 \mathrm{~Gy}$ ) were set equal to 0.5 times the detection 1 evel 10.5 HGy: "Ratio refer to the quotient of paired dose levels over the apron and dose levels under the apron. 


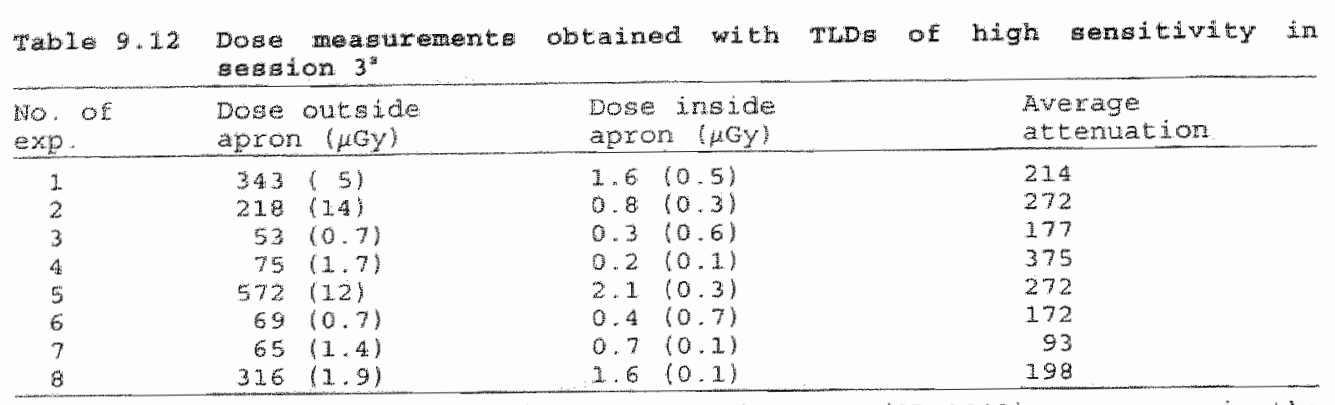

s Tuo doseneters, each containing four TL-elements (GR-200A) were worn in the abdominal region. one dosentet was worn outside the lead apron and one was worn inside. The measurement period was always egual to 1 week. Mumberg in parentheses are the standard errors of the dose estimate per dosemeter and were ciloulded from the four TLelements. The mean average attenuation was 222 (standard exrox, 30 ).

ith 9.13 Tube high voltage during fluoroseopy

\begin{tabular}{|c|c|c|c|c|c|c|c|}
\hline $\begin{array}{l}\text { weighting } \\
\text { method }\end{array}$ & $\begin{array}{l}\text { Mo. } \\
\text { of } \\
\text { Oroc. }\end{array}$ & $\begin{array}{l}\text { Tube } \\
\text { min. }\end{array}$ & $\begin{array}{c}\text { high vol tage } \\
\text { Joth } \\
\text { perc. }\end{array}$ & $\begin{array}{l}(\mathrm{kV}) \\
\text { median } \\
\end{array}$ & mean & $\begin{array}{l}\text { goth } \\
\text { perc. }\end{array}$ & $\max$ \\
\hline 1 & 35 & 66 & 69 & 72 & 75 & 86 & 91 \\
\hline 2 & 35 & 68 & 69 & 75 & 77 & 88 & 93 \\
\hline 3 & 35 & 70 & 70 & 79 & 80 & 90 & 96 \\
\hline 4 & 35 & 69 & 70 & 76 & 78 & 88 & 94 \\
\hline
\end{tabular}

seal-time measurements of the tube high woltage during flworoscopy wexe recorded in time intervals of variable length. These recordings were averaged pex examination by using four different weighting methods.

\subsubsection{Discussion}

\section{Radiation attenuation}

In the tube high voltage range of $60-110 \mathrm{kV}$, which is usually applied during fuoroscopy in vascular radiology, our phantom-based transmission factor varied between $0.07 \%$ and 2.2\% (see Figure 9.6). Transmission factors derived from a broadmeam geometry were about two to three times higher, depending on the tube high voltage. In our phantombased experiments, the backscatter contribution was experimentally determined to be about $10 \%$. Figure 9.6 clearly shows that backscatter contributions are less important than differences introduced by variation in X-ray beam geometry. Therefore, backscatter contributions ste negligible.

The results of the first session (Table 9.10) clearly demonstrates the protection provided by a lead apron. Table 9.10 indicates that, on average, there is good agreement in the estimated background dose due to scattered $\mathrm{X}$-ray radiation and the difference in doses for TLDs attached on the inside of the lead apron with and without a 1-mm-thick lead covering. The broad range of transmission factors may be associated with actual variances in exposure conditions as well as with (relatively large) errors in the estimated dose at the inside of the apron.

In the second session, measurements of the radiation attenuation in single examinations were performed to obtain information about the variance in the derived attenuation factor (Table 9.11). Table 9.11 indicates that dose levels underneath the lead apron for single examinations are too low to obtain easily interpretable data, even if TLDs of high 
In the second session, measurements of the radiation attenuation in single examinations were performed to obtain information about the variance in the derved attenuation factor (Table 9.11). Table 9.11 indicates that dose levels underneath the lead apron for single examinations are too low to obtain easily interpretable data, even if TLDs of high sensitivity (detection level, $1 \mu \mathrm{Gy}$ ) are applied (more than $90 \%$ of the measurement results obtained under the apron were below $0.6 \mu \mathrm{Gy}$ ). Because of very large relative uncertainties in the small doses under the apron, the average transmission factor is unreliable. The attenuation factor, derived from the summed doses of all results at the outside and inside the apron, was calculated to be 280 .

In order to estimate the transmission factor from data given in Table 9.11 , a subset of paired dose data was selected. Taking the lower detection level of $1 \mu$ Gy into account and the conclusion that the attenuation factor is probably greater than 10 (Figure 9.6), this subset was composed of doses on the outside of the apron of at least $10 \mu \mathrm{Gy}$. A dose of 0.5 times the lower detection level was assigned to the doses on the inside of the apron that were less than the lower detection level. This technique is used in the literature for censored data samples. Perkins et al. [PE90] have shown that "under the assumption of lognormality, this approach is quite reliable. The result obtained by Perkins et al. with this method was only $21 \%$ smaller than the more accurate (but also more elaborate) Cohen technique for estimating the mean. This simple method is therefore appropriate for our calculations. The average attenuation factor for this modified subset $(n=29)$ is 77 (range, 20-250). The quotient of the summed doses outside and inside the apron was 69 . The minimal level of the radiation attenuation, obtained by assigning the numerical value of lower detection level to doses less than the lower detection level, wh 63.

Results of dose measurements with TLDs of high sensitivity during a number of examinations (session 3) are presented in Table 9.12. In order to obtain a higher precision, each dosemeter contained four Tl-elements instead of two. The average attenuation has been calculated as the average value for dose quotients per measuring period as well as the quotient of the cumulated doses. Table 9.12 shows that both methods result in an average value of 222 . As a third method, a simple linear regression line with no zero intercept was fitted to the dose data obtained under the apron as a function of that measured over the apron in session 3 (method of least squares). The attenuation factor was calculated to be $236\left(n=8\right.$, standard error $\left.=18, R^{2}=96\right)$.

As TLDs of relatively low sensitivity were used in the first session and most measurements obtained in the second session refer to low dose levels, the transmission factor derived in session 3 is considered to be the most accurate one.

\section{Tube high voltage during fluoroscopy:}

Linear regression analysis on the transmission factor ( $\mathrm{Tr}$, given in percentages) and the tube high voltage ( $\mathrm{HV}$, given in kilovolts), obtained in the phantom study, resulted in the following simple mathematical equation:

$$
\mathrm{Tr}=15.5+0.267 \cdot \mathrm{HV}-4.06 \sqrt{\mathrm{HV}} \quad\left(\mathrm{n}=6, \mathrm{R}^{2}=0.999\right)
$$

This relation has been used in the calculations of the effective hube high voltage according to method 3. An analytical approach was used to derive the effective tube high woltage from estimated values for the transmission according to method 4.

Statistics on the tube high voltage for fluoroscopy in vascular radiology, measured in 35 examinations, are given in Table 9.13. Comparison of the results per patient 
examination for the four different calculation techniques shows a consistent picture: the time-weighted average high voltage is smaller than or equal to the dose-area productweighted average high voltage, which is smaller than the average high voltage computed with method 3 (weighted with dose-area product and the lead apron atrenuation factor; expressed as a function of high voltage). These results are quite logical when taking accotint of the superlinear relationship between high voltage and dose-area product per unit time and the decrease in attenuation at increasing high voltage. The average "weighted tube high voltage" was estimated to be between 75 and $80 \mathrm{kV}$, depending on the weighting technique applied. The median waried between 72 and $79 \mathrm{kV}$. In $90 \%$ of all examinations, the average tube high voltage was less than $90 \mathrm{kV}$.

On theoretical grounds, method 4 is thought to be more accurate than methods 1-3. Calculations of high voltage obtained according to method 1,2 , and 3 have been compared with the effective rube high woltage calculated according to method 4 . It was expected that the best approximation for effective tube high voltage was provided by method 3, followed by method 2 and (at some distance) 1 . However, it is concluded from both correlation analysis and linear regression analysis that method 2 (weighting with dose-area product) gives the best approximation for effective tube high voltage $(r=.90$, .99 and .95 for method 1,2, and 3 respectively; Spearman rank test). Linear regression coefficients for method 1,2 , and 3 were $1.03 \pm 0.006,1.01 \pm 0.002$, and $0.97 \pm 0.003$ respectively. On average, method 2 underestimates the effective tube high voltage by only about $1 \%\left(\mathrm{HV}_{\mathrm{eff}}=1.01 \pm 0.002 \cdot \mathrm{HV}_{\mathrm{DAP}} ; \mathrm{n}=35, \mathrm{R}^{2}=0.9999\right)$

On average, time-averaged estimates for the tube high voltage seem to underestimate the effective tube high voltage by $2.5 \mathrm{kV}$. We believe that if dose-area product data are not available, time-averaged values for high voltages are useful as well.

With real-time measurements, the average tube high woltage during fluoroscopic examinations in vascular radiology is estimated to be $78 \mathrm{kV}$ (rounded to $80 \mathrm{kV}$ ). By using the transmission data presented in Figure 9.6, this high voltage level would result in a transmission of about $0.5 \%$, corresponding to an attenuation factor of 200 ; Rawlings at al. [RA90] reported an attenuation factor of 125 .

\section{4 .5 Conclusion}

From real time measurements a typical value of $80 \mathrm{kV}$ was derived for the tube high voltage in fuoroscopy in vascular radiology. Comparison of different methods to calculate the average tube high voltage showed that the end result is relatively insensitive to the method applied. On the basis of tube high voltage settings and phantom-based derived ransmission data, the typical attenuation factor of 0.5 -mm-thick lead-equivalent aprons is estimated to be 200 . It is obvious that the average tube high voltage for other types of $\mathrm{X}$ ray systems or in examinations with significant differences in the $X$-ray beam direction may differ. As shown in Figure 9.6, in this case the attenuation factor will deviate as well. In a study of radiation dose in vascular radiology performed in two other Dutch hospitals with different $X$-ray systems [Kr93b, K193c], the same numerical value for the effecive tube high voltage was derived. Experimental determination of the attenuation factor of 0.5 -mm-thick lead-equivalent aprons in clinical practice is quite cumbersome, since most under-apron measurements result in doses below the detection level, even if TLDs of high sensitivity are used. Simple straightforward statistical methods are not applicable. TLD measurements obtained under and over atead apron in three different 
Sessions resulted in estimated attenuation factors ranging from 70 to 280 . Data from the most accurate measurements indicate a typical value of 220 . From both the attenuation factors (derived from clinical TLD dose measurements) and the data recorded on tube high woltage, it is concluded that a factor of 200 (transmission $0.5 \%$ ) may be used as a rypical value for the radiation attenuation factor for 0.5 -mm-thick lead equivalent aprons in vascular radiologic examinations performed at average tube high voltages of $80 \mathrm{kV}$.

The effeciveness of 0.5 -mm-thick lead aprons, determined with clinical measurements, agrees with estimates based on generating potential.

\subsection{Effective dose estimates for occupationally exposed persons}

\subsubsection{Intraduction}

By means of the results of dose measurements performed on the body (see Section 9.3), and taking the radiation attenuation by protective clothing into account, effective dose estimates were derived for operators and first assistants in the University Hospital Maastricht (azM), the De Wever Hospital Heerlen (DW), and the Maasland Hospital Sittard (MA).

During this study, two types of 0.5 -mm-thick lead-equivalent aprons were in use, semclosed and wrap-around aprons (see Section 4.6.2). Semi-closed aprons protect the front and both sides of the trunk; wrap-around aprons protect the front, both sides and the back. Considering effective dose calculations, the attenuation factor of these aprons was estimated to be 130 (see Section 6.5.2). This factor applies for a nube high voltage of 80 $\mathrm{kV}$, that was considered to be a typical value for vascular radiology [KI95], and includes a correction factor to allow for the increase of the effective photon energy. Thyroid collars and protective eye glasses were only used infrequently. Leaded gloves were not used at all. Additional physical shielding, attached to the X-ray carrier, the patient support table or to the ceiling were not provided.

Results of effective dose calculations for conventional 0.5 -mm-thick lead-equivallent aprons are discussed in Section 9.5.2. Also the contributions of doses to various regions to the effective dose will be reported. At the end of that subsection, the annual occupational effective dose, associated with procedures performed in the angiography suite, will be compared with established dose limits.

Additional effective dose calculations were performed for a range of attenuation factors for lead aprons. Calculabions and results are discussed in Section 9.5.3. The relationship between the effective dose and the X-ray ouput is discussed in Section 9.5.4. The correlation between entrance doses at various measurement locations and the effective dose will be addressed in Section 9.5.5. In that subsection the relationship between the effective dose and the entrance dose to the neck will be quantified.

\subsubsection{Estimates for the effective dose}

Occupational exposures in the azM

As shown in Table 9.14, mean effective doses to operators in the azM varied between 0.8 and $3.4 \mu \mathrm{S} v$ per procedure type. Occupational exposures during abdominal arteriography (AA) and percutaneous transluminal angioplasty procedures (PTA) were bigher than 
Maximum dose levels for the operator and assistant were associated with a long fluoroscopy time of $85 \mathrm{~min}$ (fluoroscopy time for operator/assistant was not available). Mean effective doses to the assistant waried between 0.4 and $1.5 \mu$ Sv per procedure type. Ratios of the mean effective dose for assistants by the mean effective dose for operators varied beween 0.33 and 0.75 . Mean effective doses to operator/assistants were similar to the effective dose to operators for cerebral arteriography (CA), abdominal arteriography (AA) and peripheral arteriography (PAs) procedures, whereas the effective dose to operator/assistants in thoracic arteriography (TA) procedures was less, and in PTA higher, than to operators.

Comparison of median and mean values showed that means were equal to or higher than medians, indicating skewed distributions with a small number of relatively high doses. The Shapiro-Wilk test [SA89] showed that 9 of the 17 effective dose distributions presented in Table 9.14 could not be considered as random samples from normal distributions (the associated probabilities of being normally distributed were less than $5 \%$ ).

Taking all procedures performed in the anglography room into account, the mean effective dose per standard procedure was estimated to be $2.2 \mu \mathrm{SV}$ for the operator and $1.2 \mu \mathrm{Sv}$ to the assistant. In more complex procedures and during training stages of registrars, characterised by task switching by the operator and the first assistant, the mean effective dose was $2.7 \mu \mathrm{SV}$.

Table 9.14 Effective dose for occupationally exposed persons in arteriography and interventional endowascular procedures in the aaM

\begin{tabular}{|c|c|c|c|c|c|c|c|c|c|}
\hline \multirow{3}{*}{$\begin{array}{l}\text { Procedure } \\
\text { type }\end{array}$} & \multicolumn{9}{|c|}{ Effecive dose ( $\mu S v$ per procedure) } \\
\hline & \multicolumn{3}{|c|}{ Operator } & \multicolumn{3}{|c|}{ First assistant } & \multicolumn{3}{|c|}{ Operator/F.assistant } \\
\hline & Median & Mean & Max. & Medi & Mean & Max. & Meduan & Mean & $\operatorname{Max}$ \\
\hline $\mathrm{CA}$ & 1.2 & 1.3 & 3.7 & 0.6 & 0.8 & 4.2 & 1.0 & 1.3 & 3.4 \\
\hline $\mathrm{TA}$ & 1.0 & 1.2 & 2.2 & 0.4 & 0.4 & 0.7 & 0.2 & 0.2 & 0.5 \\
\hline $\mathrm{AA}$ & 2.0 & 3.4 & 17 & 1.1 & 1.4 & 4.3 & 2.9 & 3.9 & 12 \\
\hline PAnn & 0.6 & 0.8 & 3.2 & 0.4 & 0.6 & 4.3 & - & - & - \\
\hline PAs & 1.5 & 1.7 & 4.3 & 0.6 & 0.7 & 1.4 & 1.7 & 1.9 & 3.2 \\
\hline $\mathrm{PTA}$ & 1.8 & 26 & 6.8 & 1.5 & 1.5 & 3.5 & 2.4 & 3.7 & 8.1 \\
\hline$a I^{\text {lis }}$ & 1.2 & 2.2 & 46 & 0.6 & 1.2 & 28 & 1.6 & 2.7 & 25 \\
\hline
\end{tabular}

"Procedure types are defined in Table 7.1 and Table 9.3.

Number of observations: Operator: $\mathrm{CA}=27 ; \mathrm{TA}=5 ; \mathrm{AA}=20 ; \mathrm{PAn}=21 ; \mathrm{PAs}=24 ; \mathrm{PTA}=15$. First assistant: $\mathrm{CA}=25 ; \mathrm{TA}=4 ; \mathrm{AA}=17 ; \mathrm{PAn}=16 ; \mathrm{PAs}=19 ; \mathrm{PTA}=12$. Operator $/$ ass: $\mathrm{CA}=24, \mathrm{TA}=4$; $A A=10 ; P A n=0 ; P A S=8 ; P T A=12$.

1) Taking the anmual frequency of each procedure type into account (see Table 9.3), statistics for "all procedures" were derived from measurements for operators $(n=140)$, first assistants $(n=114)$, and operator/assistants $(\mathrm{n}=69)$. Other procedures, such as percutaneous transhepatic cholangiography, were included too. In all, dose data were extrapolated to 429 procedures for operators, to 346 procedures for assistants. and to 105 procedures for operator/assistants.

\section{Occupational exposures in the DW hospital}

Table 9.15 shows that mean effective doses to operators in the DW hospital varied between 0.5 and $3.5 \mu \mathrm{Sw}$ per procedure type. During Seldinger procedures for peripheral arteriography (PAs), and during percutaneous transluminal angioplasty procedures (PTA), occupational exposures exceeded those in other procedures. Maximum vallues found for 
values were obtained in the same procedure with a long fuoroscopy time ( 32 min). Mean effective doses to the assistant varied between 0.4 and $1.6 \mu$ Sv per procedure (maximum $=$ $4.8 \mu \mathrm{Sv})$.

Depending on the procedure type, ratios of the mean effective dose for assistants by the mean effective dose for operators waried between 0.3 and 0.8 . Means were equal to or higher than medians, indicating non-normal dose distributions, with a few results on the high dose level sides.

Considering all procedures annually performed in the angiography room, the mean effective dose per standard procedure was estimated to be $1.5 \mu \mathrm{Sv}$ for the operator and $1.0 \mu \mathrm{Sv}$ to the assistant. In more complex procedures, characterised by task switching by operators and assistants, the mean occupational effective dose was $2.1 \mu \mathrm{Sv}$ per procedure.

\begin{tabular}{|c|c|c|c|c|c|c|c|c|c|}
\hline \multirow{3}{*}{$\begin{array}{l}\text { Procedure } \\
\text { type }\end{array}$} & \multicolumn{9}{|c|}{ Effective dose (hSV per procedure) } \\
\hline & \multicolumn{6}{|c|}{ operator First assistant } & \multicolumn{3}{|c|}{ Operatow/E.assistant } \\
\hline & Median & Mean & $\operatorname{Max}$ & Median & Mean & Max. & Median & Mear & Max. \\
\hline CA & 0.8 & 1. 3 & 8.3 & 0.3 & 0.4 & 1.5 & - & - & $\ldots$ \\
\hline EA & 0.4 & 0.5 & 1.6 & 0.3 & 0.4 & 0.9 & - & - & - \\
\hline TX & 0.5 & 0.8 & 1.9 & - & - & - & - & - & .. \\
\hline$A A$ & 1.0 & 1. 0 & 1.5 & 0.4 & 0.4 & 0.3 & - & - & - \\
\hline $\mathrm{AA}$ iv & 1.0 & $1 \cdot 1$ & 1.0 & - & - & - & 2. 4 & $2 \cdot 4$ & 3.5 \\
\hline $\mathrm{PAn}$ & 0.5 & 0.7 & 2.1 & - & - & - & - & - & $\ldots$ \\
\hline PAS & 2.1 & 3.2 & 0.1 & 1.0 & 1.6 & 3.2 & m & - & w \\
\hline PTA & 2.7 & 3.5 & 18 & 0.8 & 1,3 & 4.8 & 6.9 & 6.9 & a. 2 \\
\hline$a 11^{b}$ & 0.8 & 1.5 & 28 & 0.8 & 1.0 & 4.8 & 1.3 & 2.1 & 8.2 \\
\hline
\end{tabular}

- Procedure types are defined in Table 7.3 and Table 9.3. Mumber of
observations: Operator: $\quad C A=26 ; \quad E A=11 ; \quad T A=3 ; \quad A A=4 ; \quad A A 1 n=5 ; \quad P A n=19 ; \quad P A S=4 ;$

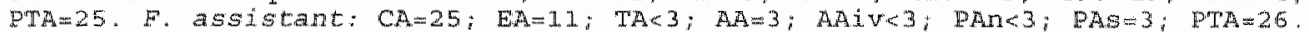

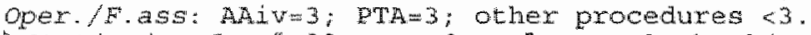

- Statistics for "al1 procedures" were derived by extrapolating 107 resulfu for the operator, 75 for the first assistant, and 8 for the operator/assistant co the annua Erequency of each procedure type (swe Table 9.3). Other procedures, such as cervical myelography, were included too. Dose data were extrapolated to 680 procedures for operators, to 454 procedures for assistants, and to 43 procedures for operator/assistants.

\section{Occupational exposures in the MA hospital}

During procedures with overcouch tube positions, mean effective doses to the operator varied between 0.8 and $22 \mu \mathrm{Sv}$ per procedure type (Table 9.16). Occupational exposures in selective abdominal arteriography (AAB) and percutaneous transluminal angioplasty procedures (PTA) were higher than in other procedures. The maximum effective dose to operators was $77 \mu \mathrm{Sv}$. Maximum values for the operators and assistants were obtained in the same procedure, with $45 \mathrm{~min}$ fluoroscopy time (the maximum value included in the data set). Mean effective doses to the assistant during overcouch tube exposure conditions varied between 0.3 and $8.7 \mu \mathrm{S} v$ per procedure type.

Ratios of mean effective doses for assistants by mean effective doses for operators varied between about 0.15 and 0.4 . Generally, mean/median-ratios per procedure type were within the range of 1 to 1.5 .

Taking all procedures performed in the angiography room into account, the mean effective dose per standard procedure was estimated to be $6.9 \mu \mathrm{S} v$ for the operator and $2.0 \mu \mathrm{Sw}$ for the assistant. 
In addition to the effective dose estimates for procedures performed in the angiography room, effective doses were derived for Seldinger catheterisations for peripheral arteriography (PAs) in an other X-ray room (overcouch $X$-ray rube sysiem). From dose data obtained in eight procedures, the mean effective dose to the operator was estimated to be $3.5 \mu S v$, to the assistant $0.4 \mu s v$.

In the second stage of this study in the MA hospital, effective doses were estimated for undercouch $X$-ray tube applications. In addition to the deliberate change to undercouch vube position, one extra video monitor was used for fluoroscopy viewing by the operator [K193c]. "This monitor was placed near the operator, across the patient table. The regular monitor, a ceiling mounted device, was positioned above the distal end of the patient table. The purpose of the extra monitor was to prevent the operator from turning his back to the X-ray source. From clinical observations it was assumed that by loosing sight of the $X$-ray source, the awareness of the presence of the source decreased, resulting in a reduction of the distance from the source.

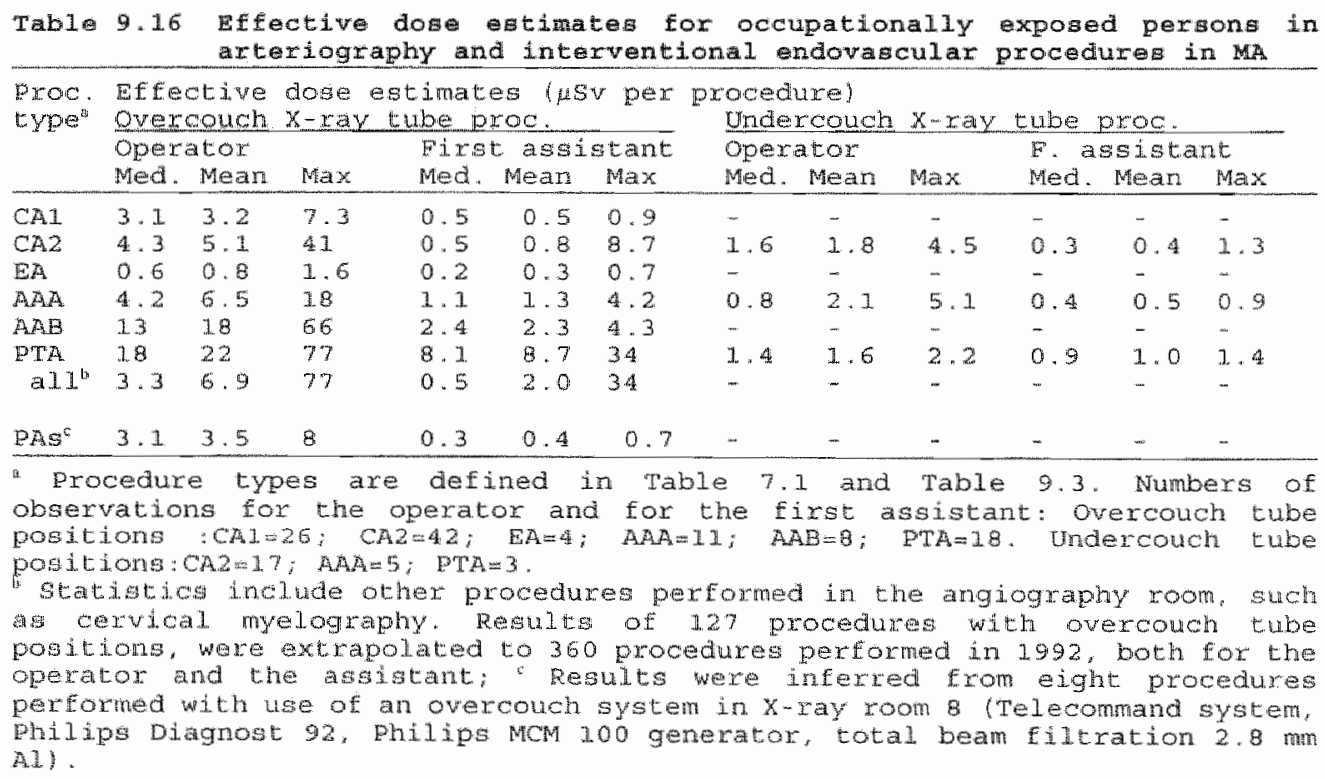

Dose estimates obtained in the first and second stage were compared in detail elsewhere [K193c]. Taking the X-ray output into account, which is characterised by the dose-area produch, it was concluded that, due to the deliberate changes in working and exposure conditions, the effective dose to the operator was decreased by a factor 3 to 8 , depending on the procedure type. For the assistant a reduction factor of 2 to 5 was obtained. Global comparison of mean effective dose estimates presented in Table 9.16 also shows that the occupational exposure in procedures with overcouch tube positions exceeded those in undercouch tube positions. Due to the changes discussed before, the mean effective dose no the operator was reduced from 5.1 to $1.8 \mu \mathrm{SW}$ in cerebral arteriography (CA2), from 
product, it was concluded that, due to the deliberate changes in working and exposure conditions, the effective dose to the operator was decreased by a factor 3 to 8 , depending on the procedure type. For the assistant a reduction factor of 2 to 5 was obtained. Global comparison of mean effective dose estimates presented in Table 9.16 also shows that the occupational exposure in procedures with overcouch tube positions exceeded those in undercouch tube positions. Due to the changes discussed before, the mean effective dose to the operator was reduced from 5.1 to $1.8 \mu \mathrm{Sv}$ in cercbral arteriography (CA2), from 6.5 to $2.1 \mu \mathrm{Sv}$ in abdominal arteriography (AAA), and from 22 to $1.6 \mu \mathrm{Sv}$ in percutaneous transluminal angioplasty (PTA) procedures. Mean effective doses to the assistant were reduced in a more or less similar way. Differences were found to be statistically significart $(\mathrm{p}<0.01)$. It is useful to note that high reduction factors $(6-8)$ were obtained in procedures with relatively high occupational exposures, selective abdominal arteriography $(\mathrm{AAB})$ and PTA [KT93c].

As described before, two types of changes were introduced simultaneously in the second stage (undercouch tube instead of overcouch tube, and an additional monitor). Because of limitations to the resources, the influence of each single factor on the occupational exposure could not be assessed. In simulated exposure conditions, we performed additional dose-rate measurements to estimate the dose to the neck of the operator as a function of the $X$-ray tube position. Cylindrical and rectangular perspex phantoms were applied to simulate the head and trunk of the patient. By rotating the $X$-ray tube from A $P$ to PA positions, the variation of the dose to the neck (assumed at about $50 \mathrm{~cm}$ above the abdominal region of our phantom, $25 \mathrm{~cm}$ lateral from the longitudinal axis) was studied. It was concluded from these measurements that, for tube voltage settings of about $80 \mathrm{kV}$, the dose tate to the neck will be about 3 to 10 times higher for overcouch than for undercouch tube positions. The variance in this ratio is mainly associated with variations in the angle of rotation. Taking these results and data by other investigators [FA82, BO91] into account, it was concluded that the major part of the dose reduction obtained in this study could be attributed to the change of $X$-ray tube position.

\section{Contributions of various regions to the effective dose}

Relative contributions of doses to various regions to the effective dose have been summarised in Table 9.17. Results are shown for the operators and the first assistants in the three hospitals separately. The effect of thyroid collars on the relative dose distributions has been demonstrated as well the attenuation factor of these collars was assumed to be 100 ). It should be noted again that dose measurements were performed on persons who did not wear a thyroid collar. It follows from Table 9.17 that the major part of the effective dose resulted from the nomprotected neck region. This statement holds for all persons and for each exposure condition considered in this study. By introducing a thyroid collar this contribution will decrease with a factor of 10 (see Table 9.17). The corresponding effective dose will decrease with a factor of 2 to 3 , depending on the exposure conditions. Table 9.17 also shows that, at least for undercouch tube positions, the dose contributions from the region "lower leg" are of significance. It follows that, after the introduction of thyroid collars, protection of the lower legs by using extended aprons can be considered as an additional option for further dose reduction. 


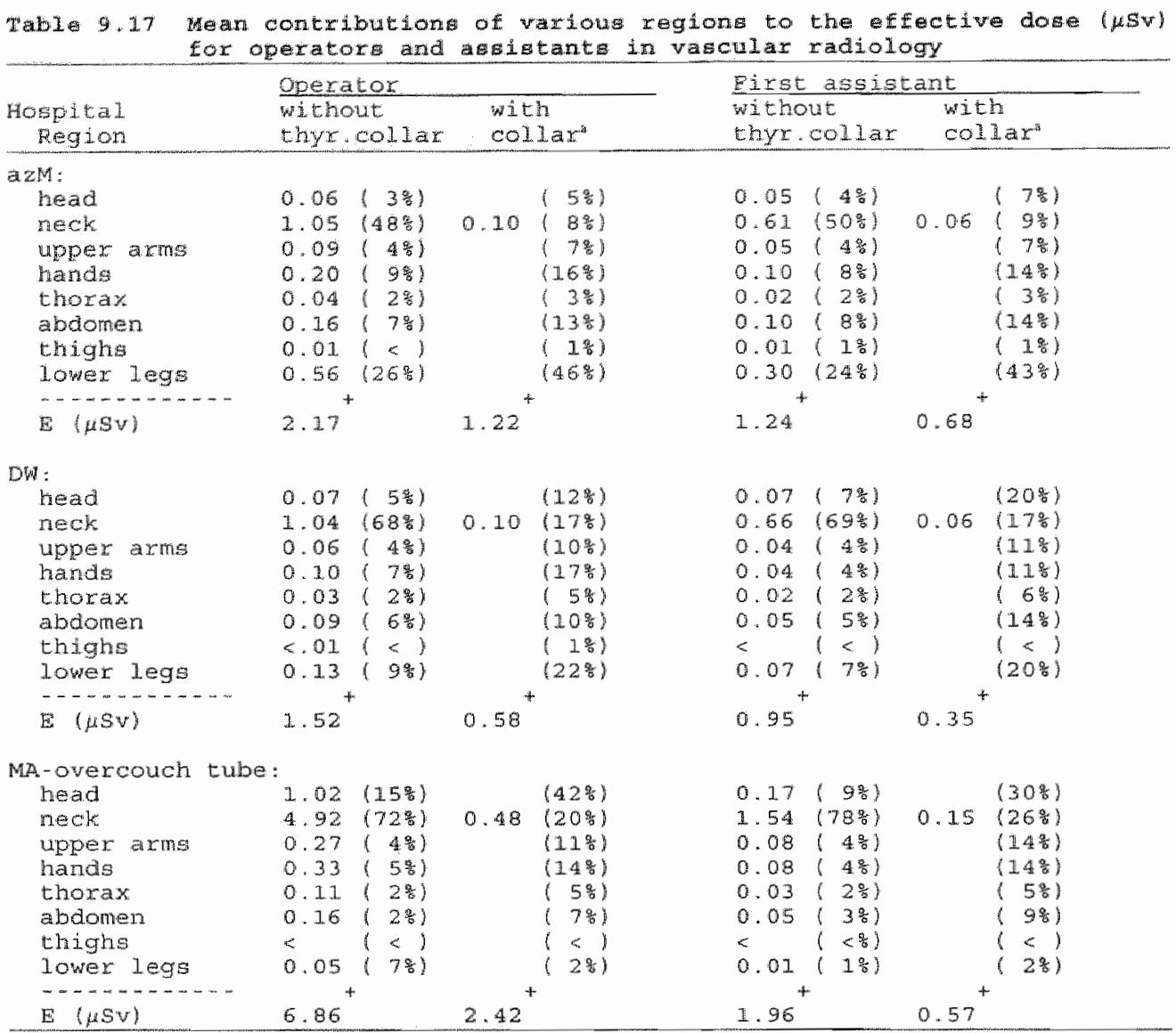

"Effective dose contributions from regions not protected by the thyroid collar are equal to corresponding dose data listed in the colum "without chyr. collar" ro lighlight the peduction of the dose to the neck by wearing a collar, dose data for other regions were not included in the column "with collit. Dose data were obtained for persons who did not wear thyroid collars regularly. Ateruation factor of thyroid collars was assumed to be 100 for the thyrold and 50 for all other tissues protected by the collar. Because of rounding errors, the sum of percent wallues does not always add up to 100 :

\section{Amual occupational effective doses in the hospitals azM, DW and MA}

Taking account of the annual frequency (Table 9.3) and the mean effective dose for various procedure types performed in the angiography rooms (Tables 9.14-9.16), estimates for the occupational effective dose 10 radiologists and technologists were derived. As a first approach, it was assumed that all procedures were performed by the same operator and assistant. Dose estimates for procedures not listed in the Tables 9.14-9.16 were taken into account as well. It should be noted that mean effective doses to assistants in azM and DW were based on fewer procedures than to operators (see Tables 9.14 and 9.15). Because most of the procedures involved a team of at least two persons, annual frequencies derived for the operator have been applied for assistants as well.

Generally, only radiologists and registrars were involved as operator/assistant. Therefore, results obtained for operators/assistants have been assigned to the group of radiologists. 
Generally, only radiologists and registrars were involved as operator/assistant. Therefore, results obtained for operators/assistants have been assigned to the group of ratiologists. As two operator/assistants were involved per procedure, the number of these procedures was multiplied by two.

The results are presented in Table 9.18. The ratio of effective dose by the currently used occupationally effective dose limit in the Netherlands ( $20 \mathrm{mSv}$ per year), are given in parentheses. These figures clearly show that effective doses associated with radiological work in the angiography rooms studied were relatively small. Even if in each anglography room all procedures were performed by one radiologist and one technologist, the effective dose to these persons would be less than about $10 \%$ of the occupational dose limit.

Table 9.18 Estimates for the annuall effective dose, $\mathbb{E}$, associated with all procedures performed in the angiography rooms ${ }^{a}$

\begin{tabular}{|c|c|c|c|c|c|c|c|c|}
\hline \multirow{3}{*}{$\begin{array}{l}\text { Hospital } \\
\mathrm{aZM}\end{array}$} & \multicolumn{5}{|c|}{ Operator } & \multicolumn{3}{|c|}{ First assistant } \\
\hline & \multirow{3}{*}{$\begin{array}{l}\text { No. } \\
{\left[\mathrm{a}^{-1}\right]}\end{array}$} & \multirow{3}{*}{$\begin{array}{l}E_{\text {mean }} \\
\llbracket 4 \mu \mathrm{Sv}\rfloor \\
429 \\
210\end{array}$} & \multicolumn{3}{|c|}{$\begin{array}{l}E_{\text {owil }} \\
{\left[\mu \mathrm{S} v \cdot \mathrm{a}^{-1}\right]}\end{array}$} & \multirow{3}{*}{$\begin{array}{l}\text { No. } \\
{\left[a^{1}\right]}\end{array}$} & \multirow{2}{*}{$\begin{array}{l}E_{\text {inean }} \\
{[\mu \mathrm{SV}]}\end{array}$} & \multirow{2}{*}{$\begin{array}{l}E_{\text {[wad }} \\
{\left[\mu S v-a^{1}\right]} \\
515(2.6 \%)\end{array}$} \\
\hline & & & 2.2 & 944 & & & & \\
\hline & & & 2.7 & $567\}$ & $15 \|(7.6 \%)$ & & & \\
\hline \multirow[t]{2}{*}{ DW } & & 680 & 1.5 & $1020\}$ & & 680 & 1.0 & $680(3.4 \%)$ \\
\hline & op/ass & 86 & 2.1 & $181\}$ & $1201(6.0 \%)$ & & & \\
\hline MA & op & 360 & 6.9 & & $2484(12 \%)$ & 360 & 2.0 & $720(3.6 \%)$ \\
\hline
\end{tabular}

"No. denotes the number of exposures; $\mathbb{E}_{\text {mean }}$ denotes the mean effective per procedure, weighted for the relative frequencies of various types; $\mathrm{E}_{\text {was }}$ denotes the anmual effective dose, derived by multiplying $\mathrm{E}_{\text {mean }}$ by No. Ratios of effective doses by currently applied dose limits in the Netherlands (20 nisv, $a^{-1}$ ) are given in parentheses; ${ }^{\circ} o p$ and op/ass refer to operators and to operator/assistants respectively.

\subsubsection{Effective dose reduction by protective clothing}

Quite regularly the question arises what type of apron should be used to optimise radiological protection. Aprons featuring a low radiation attenuation factor, or protecting only a small part of the body will not reduce the effective dose to a large extend. By increasing the mass of the radiation attenuation material, the effective dose will decrease as well. However, beyond a certain point, the additional protection will be insignificantly small. It follows that the loss of comfort of wearing, or the increased chance of back pain or injuries from heavy and large aprons, will not necessarily be compensated by a significant increase of health protection. Recently, optimisation of protection by aprons has been addressed by Marshall and Faulkner [MA95] and Niklason et al. [N193].

In this section we will discuss the relationships between the effective dose and the radiation attenuation by (1) conventional lead aprons, (2) conventional aprons plus thyroid collars, and (3) extended lead aprons which protect the trunk, neck (thyroid) and the llegs. Extended aprons were introduced because of the results presented in Table 9.17. The relationships were studied theoretically. In our effective dose calculations the decrease of the radiation dose behind the apron was dealt with by multiplying the entrance dose on the 
apron by an attenuation factor. This attenuation factor was stepwise changed from 1 (no protection to $100000(1,1.4,2.5,52,10 \mathrm{etc})$. In these model calculations, AP-exposuras to $80 \mathrm{kV}$ X-rays were assumed. Entrance doses and effective dose calculation models applied, are discussed in the sections 9.1-9.3. In all, results were obtained from 360 calculations, involving 15 different attenuation factors, 3 types of protective clothing (conventional apron, conventional apron plus thyroid collar, extended apron), 4 exposure sites (azM, DW, MA-overcouch mbe positions, MA-undercouch tube positions), and 2 persons (operator, first assistant). The numbers of procedures involved in these calculations are given in footnotes in Table 9.14-9.16. Effective doses, normalised to the effective dose to persons who did not wear protective clothing, are presented in Figure 9.7 .9 .9

Figure 9.7 presents relative effective doses for persons wearing a lead apron of conventional size, with no thyroid protection. Figure 9.7 clearly shows that the effectiveness of conventional aprons depends on both the radiation transmission by the apron and the exposure conditions. The highest differential increase of protection was obtained for attenuation factors between 1 and about 10. The protection factor, defined as the $E_{\text {nio apron }} / \mathrm{E}_{\text {ippon }}$-ratio, at an attenuation factor of 10 , was calculated to be 4.1 for exposures resulting from overcouch, and 5.6-6.3 for exposures from undercouch tube positions. For aprons featuring an aftenuation factor of 100 , the protection factor was estimated to be 6.0-6.1 for overcouch tube positions, and 10.5-13.6 for undercouch tube positions. The maximum protection factor (at an attenuation factor of 10000) was calculated to be 6.3-6.4 and 12-16 for overcouch and undercouch tube position respectively. It follows that aprons, loaded with additional material to obtain an attenuation factor that exceeds about 100, are quite ineffective.

Figure 9.8 depicts the relative effective dose to persons wearing a lead apron of conventional size, and an additional thyroid collar with an attenuation factor of 100 . In our effective dose calculations it was assumed that the thyroid was completely covered by the collar, whereas other tissues in the neck region, such as red marrow, skin, and oesophagus were only partly covered $(50 \%)$. Similar to the results presented in Figure 9.7, the data in Figure 9.8 show that the effectiveness of conventional aprons and thyroid collars depends on both the radiation transmission and on the exposure conditions. Comparison of Figure 9.7 and 9.8 shows that differences between overcouch tube and undercouch tube installations were smaller, if thyroid collars were to be used. The protection factor of aprons providing an attentation factor of 10 , combined with an additional thyroid collar, was estimated to be 6.6-7.1 for overcouch tube conditions, and 7.4-8.2 for undercouch tube positions. At an attenuation factor of 100 , the protection factor was estimated to be 15-18 for overcouch tube positions, and 20-29 for undercouch abe positions. The maximum protection factor (attenuation factor 10000) was calculated to be 17.22, and 26-40 for overcouch and undercouch tube position respectively. Again, it follows that aprons, loaded with additional material to obtain an attenuation factor that exceeds about 100 , are quite ineffective.

Figure 9.9 provides the relative effective dose for persons wearing an extended lead apron, featuring additional protection to the neck (thyroid), and the lower legs. In our calculations it was assumed that this apron provided the same radiation attenuation for tissues in the neck, in the lower legs, and in the trunk. For an attenuation factor of 10 , these aprons provide a protection factor of 7.4-8.1, and 8.9-9.3 for overcouch and undercouch nube positions respectively. For an attenuation factor of 100 , the 
Corresponding maximum values for the protection factor were found to be $26-38$, and 73 117 respectively.

The relative effectiveness of the protection measures described before, have been normalised to the effectiveness of conventional aprons. For each attenuation factor, ratios of effective doses associated with conventional aprons plus thyroid collars by effective doses for conventional aprons, and ratios of effective doses for extended aprons by effective doses for conventional aprons were calculated. Results, given in Figure 9.10, show that thyroid collars are quite effective. For example, for an attenuation factor for aprons of 100 , the effective dose ratio, $E_{\text {apron tediar }} / E_{\text {aproms }}$, was 0.33 to 0.6 . In other words, by using a thyroid collar the effective dose was decreased with about a factor of 2 . Figure 9.10 also shows that the effectiveness of thyroid collars decreases if the attenuation by the apron decreases. For instance, for an attenuation factor of 10 , the effective dose ratio varied between 0.52 and 0.80 . It also follows from Figure 9.10 that by extending the protective area to the leg region, the effective dose decreases. At an attenuation factor of 100, as used in this study, the additional protection provided by an extended apron, compared with a conventional apron would amount to about a factor of 3 to 5 . Generally speaking, the protection factor for extended aprons is about a factor of two higher than for conventional aprons plus thyroid collars.

By using the mean protection factor derived for conventional aprons (attenuation factor 130 ) as a reference point (overcouch tube: $6 x$; undercouch: $12 x$ ), corresponding attenuation factors for conventional aprons plus thyroid collars were calculated to be 20 for undercouch and 8.3 for overcouch tube positions. Corresponding attenuation factors for extended aprons were calculated to be 14 for undercouch and 7 for overcouch tube positions.

In conclusion, the relative effective dose to operators and assistants in vascular procedures depends both on the radiation attenuation by the lead apron, and on the exposure conditions. Aprons featuring an attenuation factor in the range of about 30 to 10000 appeared to result in about the same effective dose. For attenuation factors between about 1 and 30 , the effective dose increases more rapidly. The reduction of the effective dose, obtained by conventional aprons (no thyroid collar used) was calculated to be 6 to 14 . With use of a thyroid collar the reduction factor was 15 to 29 . It follows that thyroid collars can reduce the effective dose with about a factor of two. This result is similar to the effect of a thyroid collar on the effective dose found estimated by Niklason at al. [N193] and Marshall and Faulkner [MA95]. 


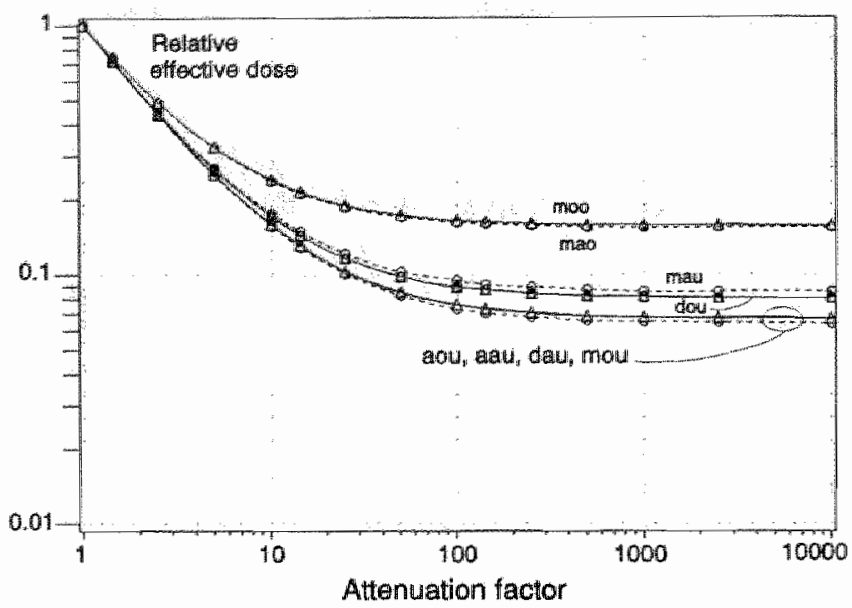

Figure 9.7 Relative effective dose for operators and assistants in vascular radiology as a function of the attenuation factor for lead aprons of conventional size (no thyroid protection). xyz:

$\mathrm{x}=\mathrm{a}$ : azM hospital; $\mathrm{x}=\mathrm{d}$ : $\mathrm{DW}$ hospital; $\mathrm{x}=\mathrm{m}$ : MA hospital

$y=a:$ assistant $(-\bigcirc-O--) ; y=0$ : operator $(-\Delta-\Delta-\Delta-)$.

$z=0$ : overcouch tube positions; $z=u$ : undercouch tube positions.

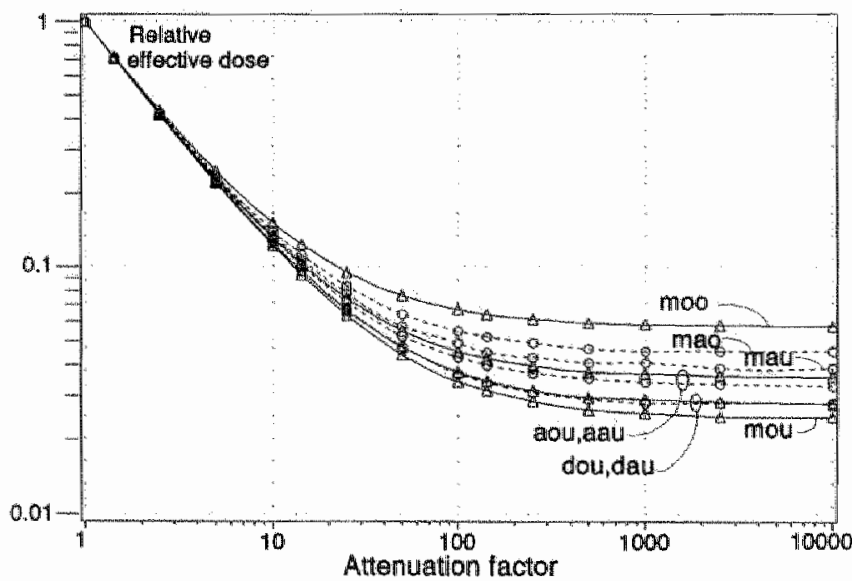

Figure 9.8 Relative effective dose of operators and assistants in vascular radiology, wearing conventional aprons plus thyroid collars (attenuation factor of collar, 100), as a function of the attenuation factor for lead aprons of conventional sizes (see Figure 9.7 for explanation of character codes). 


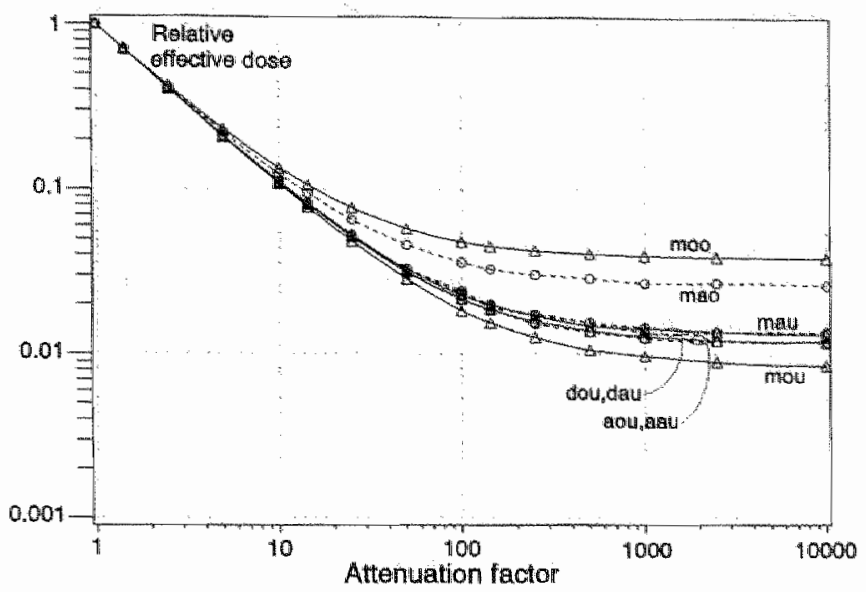

Figure 9.9 Relative effective dose of operators and assistants in vascular radiology as a function of the attenuation factor for extended lead aprons, protecting the neck region (thyroid) and lower legs.

(see Figure 9.7 for explanation of lines and character codes)

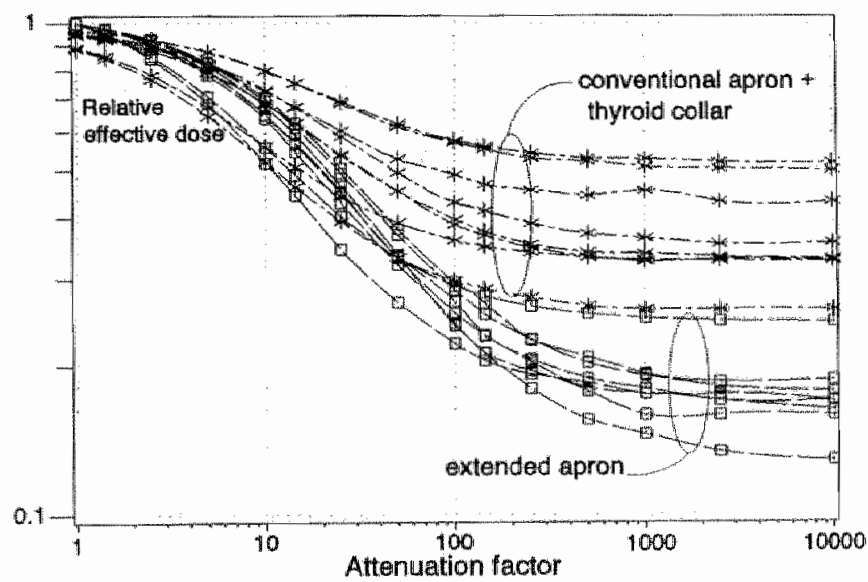

Figure 9.10 Effective doses to persons wearing a conventional apron plus thyroid collar, or wearing an extended apron, nomalised to the corresponding effective dose to persons wearing a conventional apron, as a function of the attenuation factor for lead aprons. 


\subsubsection{Relationships between occupational effective doses and the dose-area product}

The nonparametric Spearman rank correlation coefficient was used to associate the effective dose estimates for operators and first assistants with the workload of the X-ray system during occupational exposures. Because of information about the working conditions as provided in Section 4.6.2, the workload was characterised by the dose-area product during fluoroscopy. In addition, the correlation between the effective dose and the fluoroscopy time was examined. Since our data showed that the use of thyroid collars could be considered as quite effective, correlations between exposure variables were extended with the affective dose for persons wearing a conventional apron and a thyroid collar. Results of the correlation analysis are given in Table 9.19. Figures 9.11-9.14 depict the effective close to persons (no thyroid collar) and the dose-area product from fluoroscopy.

Table 9.19 clearly shows that the correlation between the effective dose and the dose-area product from fluoroscopy was quite high. Table 9.19 also indicates that the dose-area product has more potential as a determining parameter than the fluoroscopy time. Correlations between dose-area products and effective doses to persons with conventional aprons plus thyroid collars appeared to be similar to those for persons who wore conventional aprons only. It should be noted that correlation coefficients between effective doses and the total dose-area product per procedure (data not shown in Table 9.19) were higher than for the fluoroscopy time, but less than the dose-area product from lluoroscopy.

Table 9.19 Spearman rank correlation analyses for effective doses and fluoroscopy during vascular radiology

\begin{tabular}{|c|c|c|c|c|}
\hline \multicolumn{2}{|l|}{ Hospital } & \multicolumn{3}{|c|}{ Spearman rank correlation coefficients ${ }^{b}$} \\
\hline Parameter" & $\begin{array}{l}\text { Thyroid } \\
\text { collat }\end{array}$ & Operator & First assistant & All personnel \\
\hline \multicolumn{5}{|l|}{$a Z M$} \\
\hline \multirow[t]{2}{*}{ DAP P Pis: } & no & $0.79 \llbracket 115 \rrbracket$ & $0.77[94]$ & $0.71[269]$ \\
\hline & yes & $0.83[115]$ & $0.83[94]$ & $0.76[269]$ \\
\hline \multirow{2}{*}{$t_{p_{\mathrm{u}}}:$} & no & $0.58 \llbracket 111 \rrbracket$ & $0.51\lceil 94]$ & $0.49[265]$ \\
\hline & yes & $0.59[111]$ & $0.56[94]$ & $0.51[265]$ \\
\hline \multicolumn{5}{|l|}{$D W$} \\
\hline \multirow[t]{2}{*}{ DAP } & no & $0.77[82]$ & $0.66[59]$ & $0.66[147]$ \\
\hline & yes & $0.77[82]$ & $0.70[59]$ & $0.69[147]$ \\
\hline \multirow[t]{2}{*}{$t_{\text {finit }}:$} & no & $0.55[91]$ & $0.43[64]$ & $0.44[161]$ \\
\hline & yes & $0.53[91]$ & $0.42[64]$ & $0.43[161]$ \\
\hline \multicolumn{5}{|c|}{ MA-overconch } \\
\hline \multirow[t]{2}{*}{ DAP } & no & $0.77[111]$ & $0.78[111]$ & $0.65 \llbracket 222 \rrbracket$ \\
\hline & yes & $0.76[111]$ & $0.82[111]$ & $0.64[222]$ \\
\hline \multirow[t]{2}{*}{ lfflux $:$} & no & $0.60[120]$ & $0.55[120]$ & $0.49[240]$ \\
\hline & yes & $0.59[120]$ & $0.58[120]$ & $0.48[240]$ \\
\hline
\end{tabular}

"DAP ${ }_{\text {fu }}$ and $\mathrm{t}_{\text {gn }}$ denote the dose-areal product from fluoroscopy and the fluoroscopy time respectively; ${ }^{\mathrm{B}}$ The figures in brackets indicate the numbers of paired observations; "The column "All personnel" also comprises data about operator/assistants 
Taking advantage of the results of the correlation analyses, a simple linear regression model (method of least squares) was applied to determine the relationship between the effective dose and the dose-area product from fluoroscopy. As a DAP value of zero would have to correspond with an effective dose of zero, it was assumed at priot that the fitted line passed through the origin (i.e. that the intercept is zero). Interactively, in a multi-pass procedure, data points that appeared to have a large influence on the parameter estimates were deleted. As a measure of intluence, Cook's D was used [MO92, SA89]. Points fon which Cook's D was greater than unity were excluded. Results of various regression analyses are summarised in Table 9.20. Parameter estimates for the full data set were compared with those for the restricted data sets (excluding observations with Cook's $D>1)$. Ratios of the regression coefficient $B\left(B_{\text {resticted }} / B_{\text {ful dats }}\right)$ varied between 0.6 and 1.7 . It can be concluded from Table 9.20 that effective dose estimates for assistants $(\mu \mathrm{Sv})$ can be reasonably derived by multiplying the dose-area product from fluoroscopy $\left(\mathrm{Gy} \cdot \mathrm{cm}^{3}\right)$ by a factor of $0.07 \mu \mathrm{Sv} \cdot \mathrm{Gy}^{-1} \cdot \mathrm{cm}^{2}$ for undercouch tube positions, and by a factor of 0.25 $\mu \mathrm{Sv} \cdot \mathrm{G} \mathrm{y}^{-1} \cdot \mathrm{cm}^{-2}$ for overcouch ube positions. Derived relationships for operator with undercouch tube positions varied more widely than those for assistants. Nevertheless, the conversion factors for undercouch and for overcouch tube positions can be estimated to be $0.1-0.2 \mu \mathrm{Sv} \cdot \mathrm{Gy}^{-1} \cdot \mathrm{cm}^{-2}$, and $0.8 \mu \mathrm{Sv} \cdot \mathrm{Gy}^{-1} \cdot \mathrm{cm}^{-2}$ respectively.

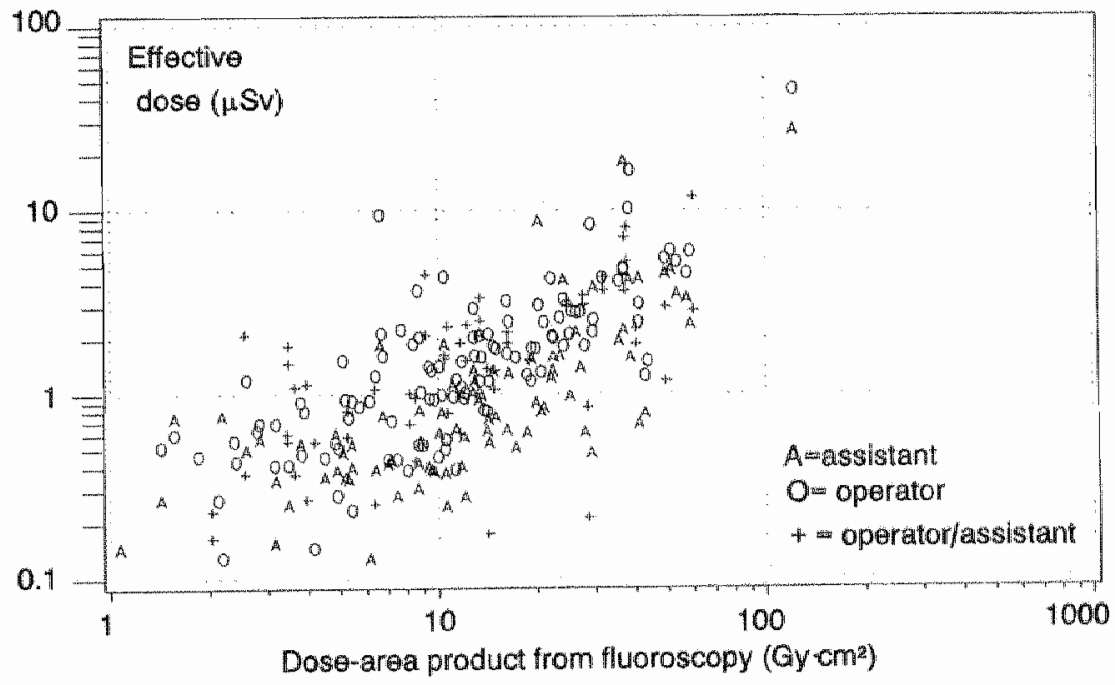

Figure 9.11 Efrective dose estimates for occupationally exposed persons and corresponding dostarea products from fluoroscopy in the axM hospital. 


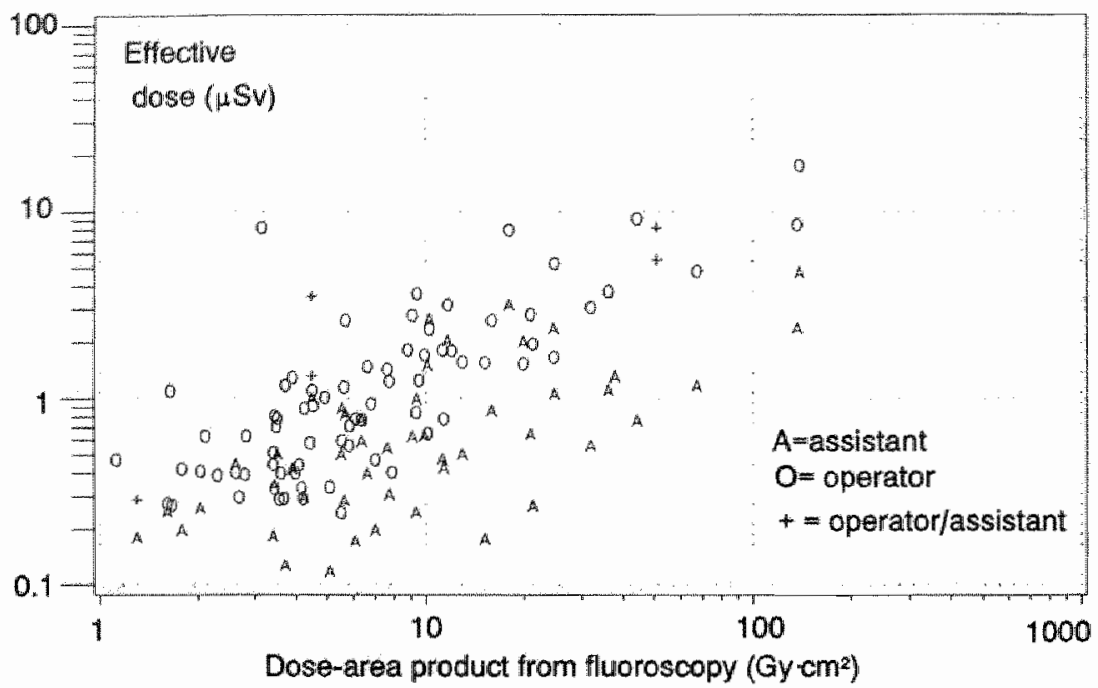

Figure 9.12 Effective dose estimates for occupationally exposed persons and corresponding dosearea products from fluoroscopy in the DW hospital.

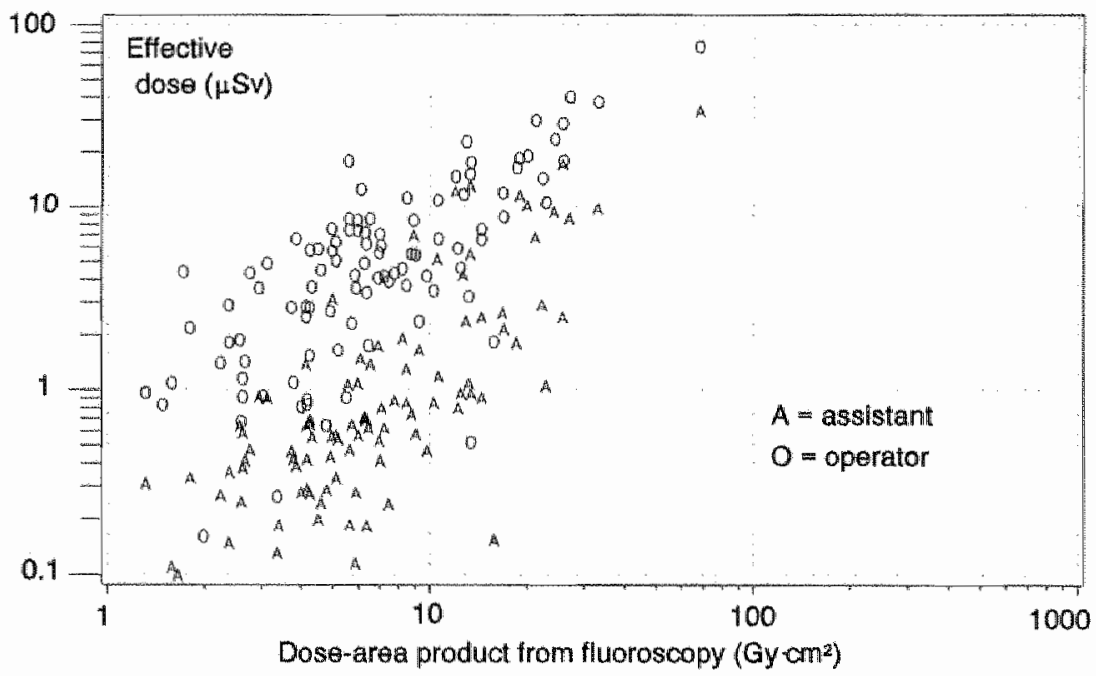

Figure 9.13 Effective dose estimates for occupationally exposed persons and corresponding dosearea products from fhoroscopy in the MA hospital. (overcouch tube positions) 


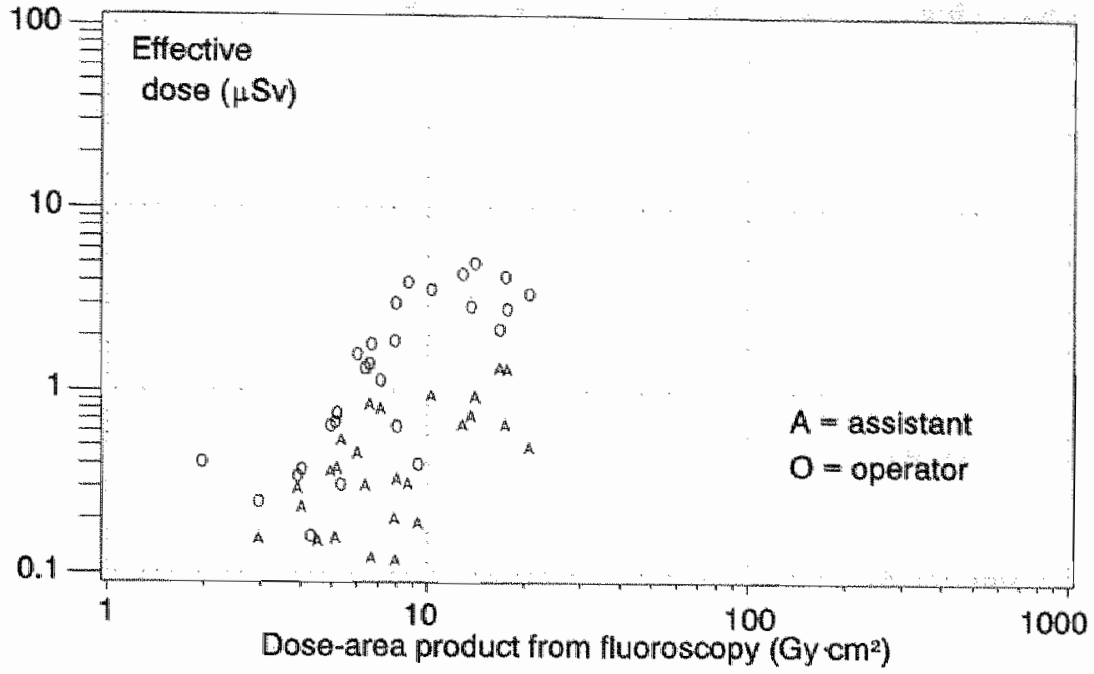

Figure 9.14 Effective dose estimates for occupationally exposed persons and corresponding dosearea products from fluoroscopy in the MA hospital. (undercouch tube positions)

Table 9.20 Linear regression analyses ${ }^{\mathrm{A}}$ for effective doses and the dose-area product fron fluoroscopy during vascullar radiology

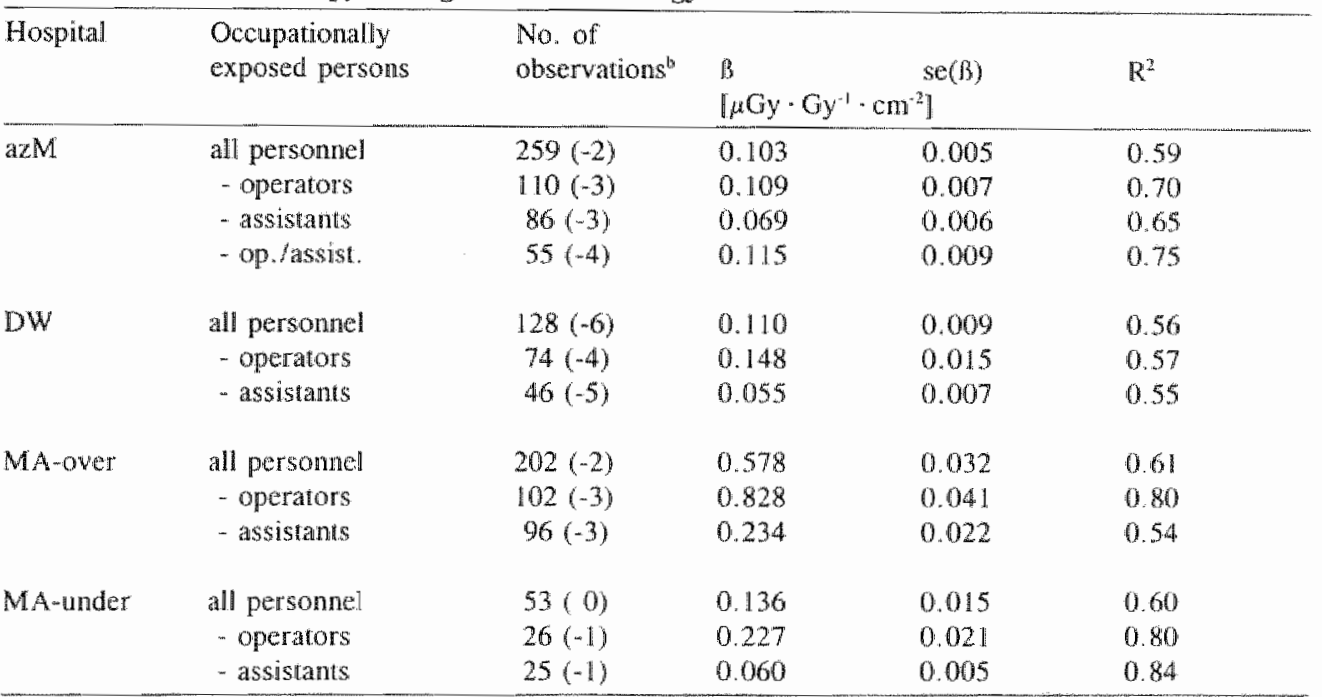

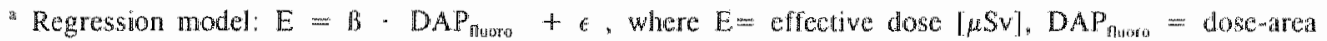
product from fluoroscopy $\left[\mathrm{Gy} \cdot \mathrm{cm}^{2}\right]$, and $\epsilon=$ a random error component. se(fi) and $\mathbb{R}^{2}$ denote the standaril error of $B$ and the coefficient of determination respectively: "Number of observations included in the regression analysis. The numbers of observations excluded from the calculations, because of a large influence on the parameter estimates (Cook's D>1), are given in parcntheses. 


\subsubsection{Relationships between occupational effective doses and entrance dose measurements performed at various positions on the body}

It is of interest to know which measurement positions provide dose information that highy correlates with the effective dose. These positions could be considered as appropriate for personal dosemeters, designated to exposed workers in vascular radiology.

The relationship between personnel dosemeter(s) readings and effective dose equivalent $\left(\mathrm{H}_{\mathrm{E}}\right)$ and effective dose (E) has been addressed in various papers [FA88, WE89, FA93, N193. HU94, N194, R094]. Faulkner and Harrison [FA88] estimated the neck dosemeter to read about 15 times higher than $\mathrm{H}_{\mathrm{E}}$ (0.5 $\mathrm{mm}$ lead apron, overcouch tube system, 90 $\mathrm{kV}$. It was recommended that, if one dosemeter was used, this dosemeter was positioned under the lead apron. Webster [WE89] recommended two dosemeters, one waist dosemeter under the apron and one neck dosemeter above the apron. According to Webster, $H_{E}$ could be assessed with the formula, $H_{\mathrm{F}}=1.5 \cdot \mathrm{D}_{\text {waisturuter apron }}+0.04 \cdot \mathrm{D}_{\text {neck }}$. Assuming an attenuation factor for 0.5 -mm lead-aprons of 200 (Section 9.4.5), and a figure of 2 for the $\mathrm{D}_{\text {waist, on aprom }} / \mathrm{D}_{\text {neck }}$-ratio (see Section 9.3$), \mathrm{H}_{\mathrm{E}}$ can be estimated to be $0.055 \cdot \mathrm{H}_{\text {neck. }}$. It follows that the neck dosemeter is 18 times higher than $\mathrm{H}_{\mathrm{g}}$. Faulkner and Harrison [FA93] estimated the $D_{\text {neak }} /$ E-ratio for $0.5 \mathrm{~mm}$ lead aprons (tube high voltage 70 $90 \mathrm{kV}$ ) to be $50-65$ for overcouch (linear interpolation results in 58 for $80 \mathrm{kV}$ ), and 32 for undercouch X-ray tube systems. Niklason et al. [N193] concluded that over-collar dosemeter measurement results were larger than the effective dose by a factor of 11 when no thyroid collars were used. Huyskens et al. [HU94] concluded that a reduction factor of 5 could be used to convert the unshielded dose at $10 \mathrm{~mm}$ tissue depth, measured at the front of the body, into an estimate for the effective dose. Calculations showed that the reduction factor was dependent on the size and fit of the apron and the exposure orientation. The authors stressed that a wide range of uncertainty for the reduction factor by aprons hampers the allocation of a generally applicable correction factor, emphasizing that single badge monitoring is often not sufficient. In order to estimate $\mathbb{E}$ for personnel not wearing a thyroid collar, Niklason et al. [N194] used the equation $\mathrm{E}=0.06 \cdot\left(\mathrm{H}_{0 \mathrm{~s}}-\mathrm{H}_{\mathrm{u}}\right)+$ $\mathrm{H}_{u}$, where $\mathrm{H}_{0 \mathrm{~s}}$ denotes the shallow close at the neck above the apron, and $\mathrm{H}_{u}$ denotes the under-apron dose. If the same factors as described before are applied (attenuation by apron, 200; neck/waist dose ratio, 2 ), this equation can be converted to $\mathbb{E}=0.07 \cdot \mathrm{H}_{0 \%}$. From this relationship, the $\mathrm{D}_{\text {meck }}$ /E-ratio is calculated to be 14 . By using data presented by Faukner and Marshall [FA93], Rosenstein and Webster [RO94] derived an empirical relationship. They concluded that $\mathrm{E}$ could be estimated by using the relationship, $\mathrm{E}=$ $0.5 \cdot \mathrm{D}_{\text {witst under apron }}+0.025 \cdot \mathrm{D}_{\text {nuck above spron }}$ If the factors mentioned before are used, this relationship results in a $D_{\text {neck }} / \mathrm{E}_{\text {- tatio }}$ of 33 .

In conclusion, $\mathrm{D}_{\text {neck }}$ E-ratios derived in various papers discussed before, made applicable to vascular radiology, vary between 5 and 60 .

By using Spearman rank correlation coefficients, we quantified associations of effective dose estimates for operators and assistants with the entrance doses obtained at various locations on the body. Calculations of correlation were extended to entrance doses and effective doses for persons wearing a conventional apron and a thyroid collar. Results of the correlation analyses are given in Table 9.21. It follows from Table 9.21 that all measurement points show a high correlation with the effective dose, both for persons with and without thyroid collars. If no other data are available, even the entrance doses to the 
hands could be useful to assess effective doses. Table 9.20 shows that the neck region provides the highest correlation. Generally, correlations for persons with and withour thyroid collars were simiar. Correlations for abdomen, hands and, especially, lower legs increased for undercouch tube positions (azM, DW). This change is obviously related to the increase of the relative contributions of these locations to the effective dose, due to a decrease of the contribution from the neck (see Table 9.17).

The relationship between the entrance dose to the neck and the effective dose for persons with conventional aprons (no thyroid collars) is depicted in the Figure 9.15-9.18.

The same approach as applied to determine the relationship between the effective dose and dose-area product was used to perform a simple linear regression analysis (no intercept) to quantify the relationship between the effective dose and the entrance dose to the neck. The results are summarised in Table 9.22. As indicated by Figure 9.15-9.18, and quantified by listed values for $\mathrm{R}^{2}$ (Table 9.22), a relatively high accuracy could be obtained. This was to be expected because of high contributions of the neck area to the effective dose (see Table 9.17 ).

If no thyroid collars are worn, the range of conversion factor to derive effective doses from entrance doses to the neck, is equal to 0.06 to $0.1 \mu \mathrm{S} v / \mu \mathrm{Gy}$, both for undercouch and overcouch tube positions. It can be derived from these results as a rule of thumb, that the $\mathrm{E} / \mathrm{D}_{\text {neck }}$-conversion factor is equal to $0.1 \mu \mathrm{Sv} / \mu \mathrm{Gy}$.

Conversion factors derived for personnel wearing aprons plus thyroid collars, varied between 0.02 and $0.06 \mu \mathrm{Sv} / \mu \mathrm{Gy}$. Taking into account that the reduction factor for thyroid collars was estimated to be two (see Section 9.5.3), it is concluded from these results as a rule of thumb, that the $E / D_{\text {meck }}$ on collat - conversion factor for staff wearing a thyroid collar is equal to $0.05 \mu \mathrm{S} v / \mu \mathrm{G} y$.

In conclusion, effective dose estimates for operators in vascular radiology performed with remotely controlled contrast medium injectors can be estimated by multiplying the dosearea product from fluoroscopy by a conversion factor of $0.2 \mu \mathrm{Sv} \cdot \mathrm{Gy}^{-1} \cdot \mathrm{cm}^{2}$ or 0.8 $\mu \mathrm{Sv} \cdot \mathrm{Gy}^{-1} \cdot \mathrm{cm}^{2}$ for undercouch or overcouch tube systems (Section 9.5.4). Corresponding conversion factors for assistant were estimaled to be three times lower. If the personnel dosemeter is worn in the neck region above the apron, the effective dose can be estimated by multiplying the entrance dose to the neck region by a factor of $0.1 \mu$ Sv/ $\mathrm{G} y$. If a thyroid collar is worn, a conversion factor of $0.05 \mu \mathrm{Sw} / \mu \mathrm{Gy}$ should be used. 


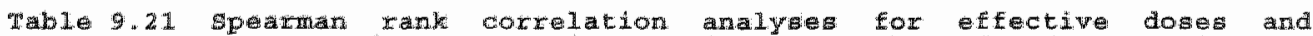
ontance doses at various positions on the body of occupationally wroosed perbonnel ${ }^{\text {t }}$

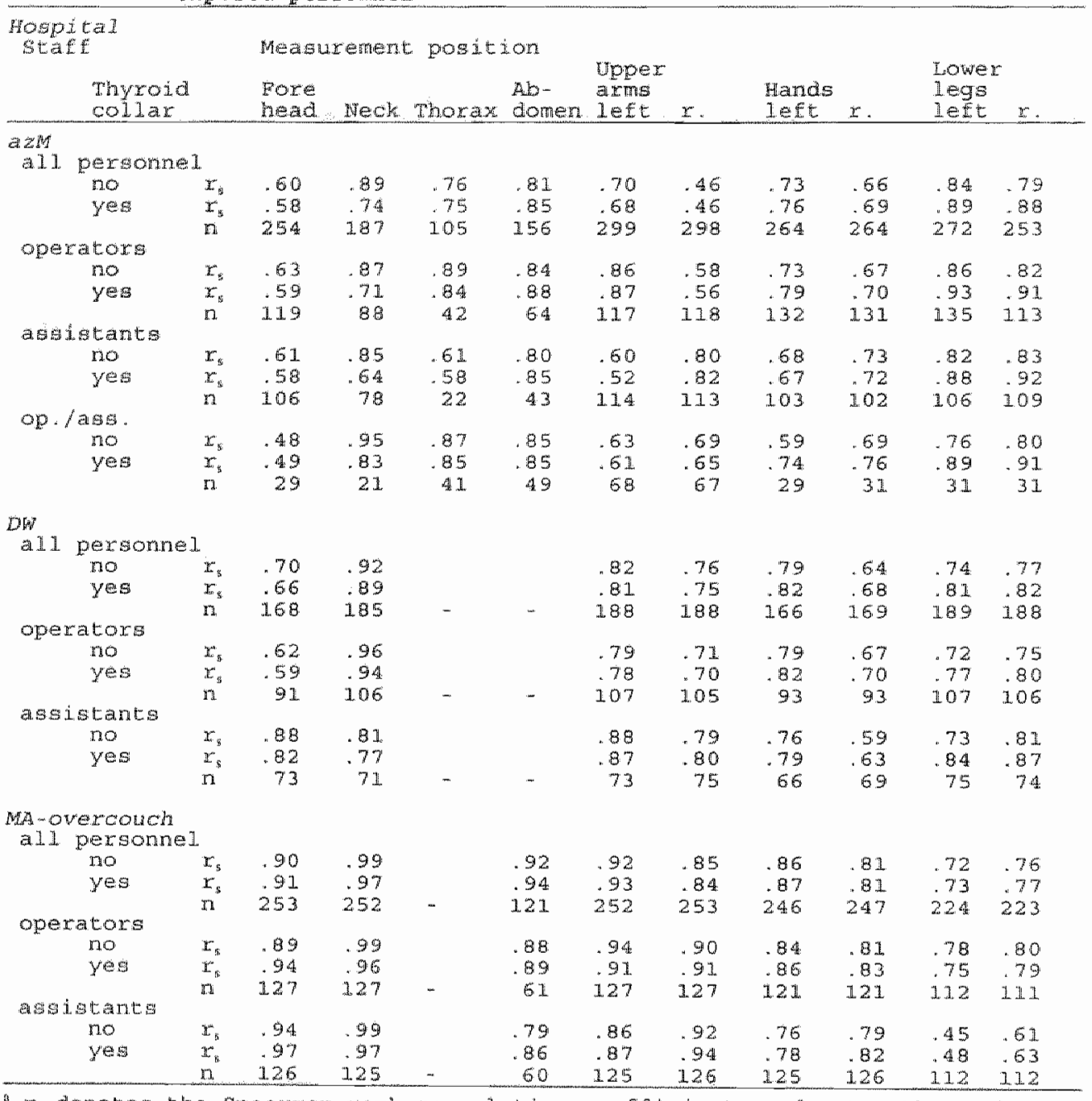

" $x_{\text {; }}$ denotes the Spearman rank correlation coefficient; a denotes the number of pairad observations. 


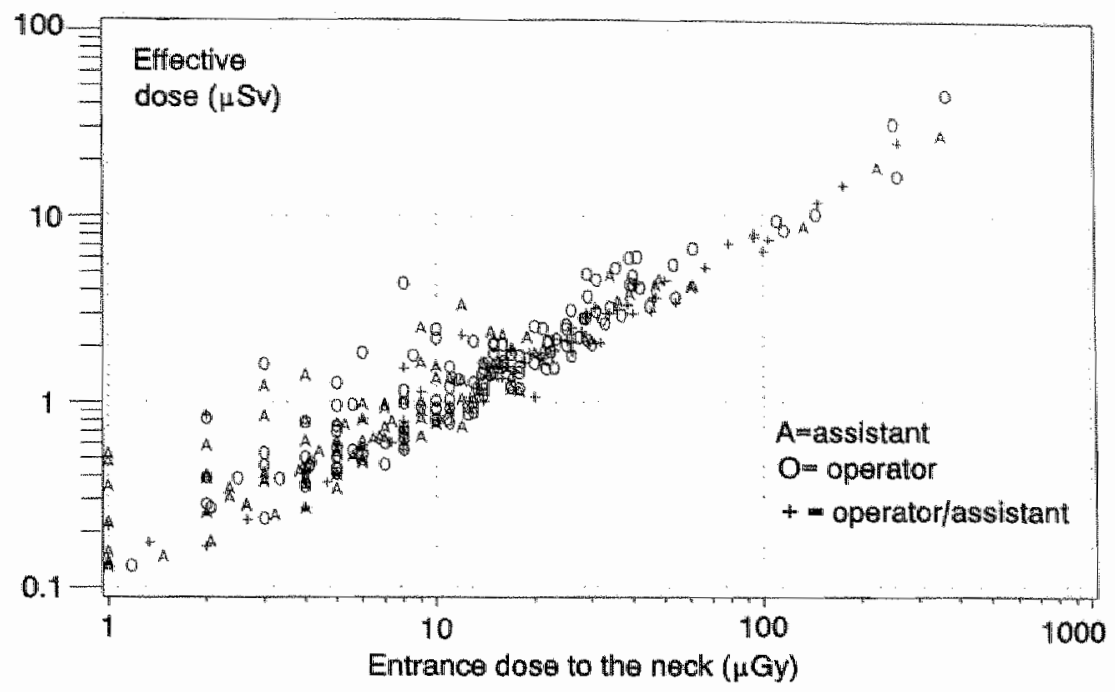

Figure 9.15 Entrance doses to the neck and effective dose estimates for occupationally exposed persons in the axM hospital.

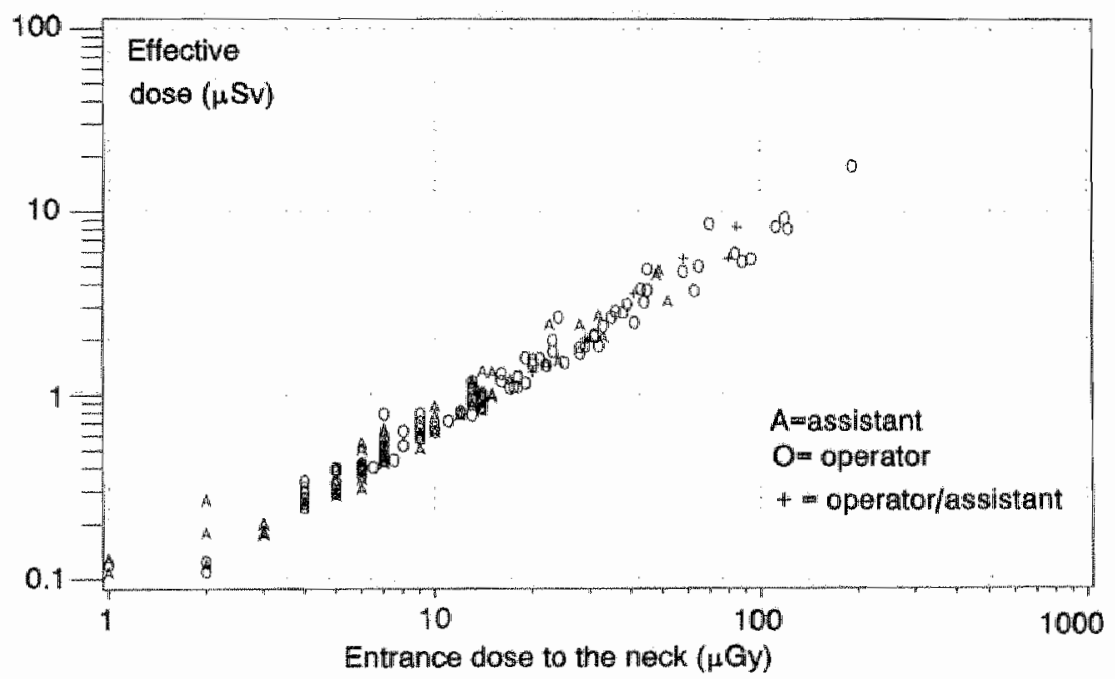

Figure 9.16 Entrance doses to the neck and effective dose estimates for occupationally exposed persons in the DW hospital. 


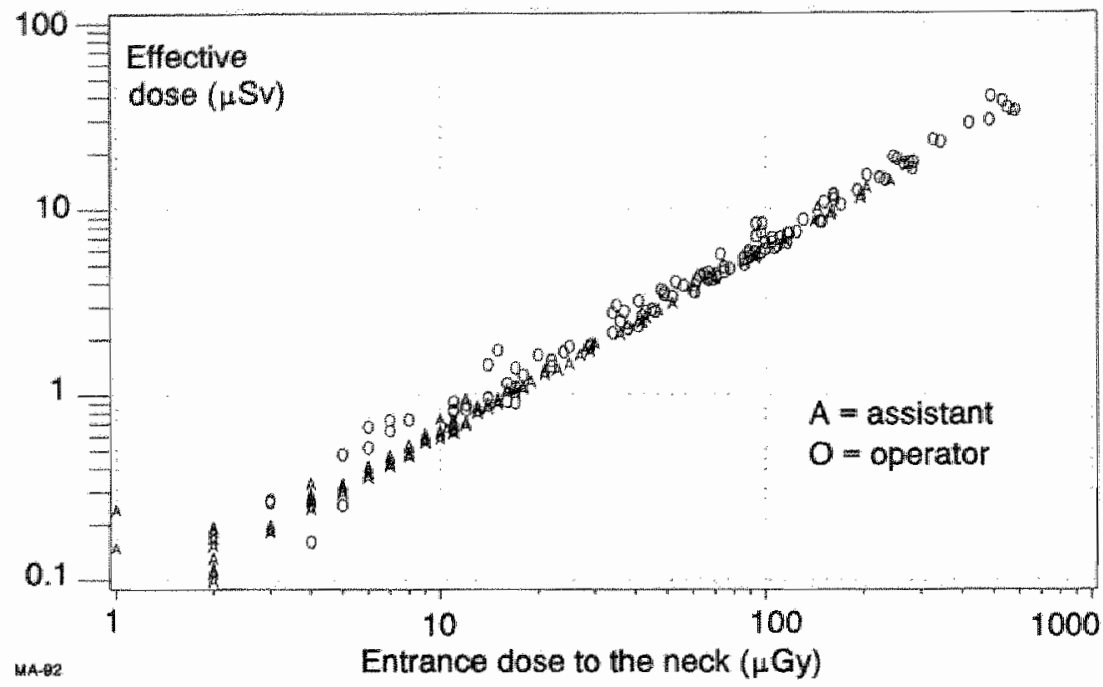

Figure 9.17 Entrance doses to the neck and effective dose estimates for occupationally exposed persons in the MA hospital. (overcouch rube positions)

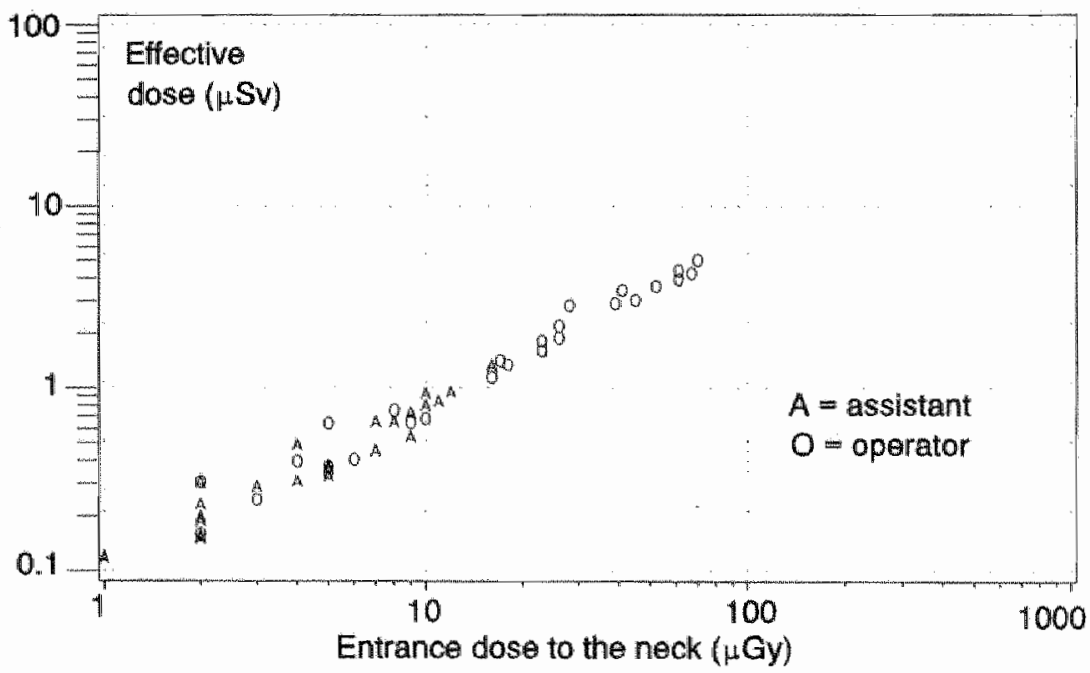

Figure 9.18 Entrance doses to the neck and effective dose estimates for occupationally exposed persons in the MA hospital. (undercouch tube positions) 
Table 9.22 Linear regression analyses for effective doses and the entrance dose to the areck for occupationally exposed persons

\begin{tabular}{|c|c|c|c|c|c|}
\hline Hospital & Staff & No. of obs & BuSv $\mu \mathrm{Gy}]$ & $\mathrm{se}(\mathrm{B})$ & $\mathrm{R}^{2}$ \\
\hline $\begin{array}{l}\text { No thyroid o } \\
\text { arM }\end{array}$ & $\begin{array}{l}a r \\
\text { all personnel } \\
\text { - operators } \\
\text { - assistants } \\
\text { - op./assist. }\end{array}$ & $\begin{aligned} 303 & (7) \\
127 & (9) \\
99 & (8) \\
63 & (4)\end{aligned}$ & $\begin{array}{l}0.085 \\
0.105 \\
0.103 \\
0.082\end{array}$ & $\begin{array}{l}0.001 \\
0.003 \\
0.003 \\
0.001\end{array}$ & $\begin{array}{l}0.94 \\
0.91 \\
0.91 \\
0.98\end{array}$ \\
\hline DW & $\begin{array}{l}\text { all personnel } \\
\text { - operators } \\
\text { - assistants } \\
\text { - op./assist }\end{array}$ & $\begin{array}{rr}173 & (12) \\
98 & (8) \\
66 & (6) \\
5 & (2)\end{array}$ & $\begin{array}{l}0.075 \\
0.074 \\
0.070 \\
0.088\end{array}$ & $\begin{array}{l}0.001 \\
0.001 \\
0.001 \\
0.005\end{array}$ & $\begin{array}{l}0.98 \\
0.99 \\
0.98 \\
0.98\end{array}$ \\
\hline $\mathrm{MA} \mathrm{A}_{\text {ewercostich }}$ & $\begin{array}{l}\text { all personnel } \\
\text { - operators } \\
\text { - assistants }\end{array}$ & $\begin{array}{rr}228 & (11) \\
104 & (17) \\
66 & (17)\end{array}$ & $\begin{array}{l}0.066 \\
0.066 \\
0.061\end{array}$ & $\begin{array}{l}<.001 \\
0.001 \\
<.001\end{array}$ & $\begin{array}{l}0.99 \\
0.99 \\
0.90\end{array}$ \\
\hline $\mathrm{MA}_{\text {uandercouncli }}$ & $\begin{array}{l}\text { all personnel } \\
\text { - operators } \\
\text { - assistants }\end{array}$ & $\begin{array}{ll}50 & (11) \\
27 & (0) \\
27 & (0) \\
\end{array}$ & $\begin{array}{l}0.076 \\
0.072 \\
0.082\end{array}$ & $\begin{array}{l}0.001 \\
0.002 \\
0.002\end{array}$ & $\begin{array}{l}0.99 \\
0.99 \\
0.98 \\
\end{array}$ \\
\hline $\begin{array}{l}\text { with thyroid } \\
\text { azM }\end{array}$ & $\begin{array}{l}\text { lar } \\
\text { all personnel } \\
\text { - operators } \\
\text { - assistants } \\
\text { - op. Lassist. }\end{array}$ & $\begin{aligned} 293 & (7) \\
126 & (9) \\
92 & (8) \\
61 & (4)\end{aligned}$ & $\begin{array}{l}0.041 \\
0.061 \\
0.059 \\
0.038\end{array}$ & $\begin{array}{l}0.001 \\
0.003 \\
0.003 \\
0.001\end{array}$ & $\begin{array}{l}0.79 \\
0.78 \\
0.76 \\
0.93\end{array}$ \\
\hline DW & $\begin{array}{l}\text { all personnel } \\
\text { - operators } \\
\text { - assistants } \\
\text { - op./assist. }\end{array}$ & $\begin{aligned} 140 & (11) \\
88 & (8) \\
46 & (3) \\
& \end{aligned}$ & $\begin{array}{l}0.031 \\
0.030 \\
0.031\end{array}$ & $\begin{array}{l}0.001 \\
0.001 \\
0.002\end{array}$ & $\begin{array}{l}0.91 \\
0.94 \\
0.85\end{array}$ \\
\hline $\mathrm{MA}_{\text {wwercousch }}$ & $\begin{array}{l}\text { all personnel } \\
\text { - operators } \\
\text { assistants }\end{array}$ & $\begin{array}{rr}201 & (13) \\
104 & (17) \\
80 & (15)\end{array}$ & $\begin{array}{l}0.022 \\
0.022 \\
0.017\end{array}$ & $\begin{array}{l}<.001 \\
0.001 \\
<.001\end{array}$ & $\begin{array}{l}0.94 \\
0.94 \\
0.98\end{array}$ \\
\hline 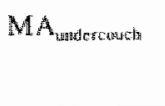 & $\begin{array}{l}\text { all personnel } \\
\text { - operaiors } \\
\text { - assistants }\end{array}$ & $\begin{array}{ll}43 & (4) \\
26 & (0) \\
21 & (0)\end{array}$ & $\begin{array}{l}0.032 \\
0.029 \\
0.038\end{array}$ & $\begin{array}{l}0.001 \\
0.002 \\
0.002\end{array}$ & $\begin{array}{l}0.94 \\
0.93 \\
0.93\end{array}$ \\
\hline
\end{tabular}

Regression model: $\mathrm{E}=B \cdot \mathrm{D}_{\text {teck }}+\varepsilon$, where $\mathrm{E}=$ effecive dose $[\mu \mathrm{SV}], \mathrm{D}_{\mathrm{weck}}=$ entrance dose to the neck region $[\mu \mathrm{G} y]$, and $\varepsilon=$ a random error component. $\operatorname{se}(B)$ and $\mathrm{R}^{2}$ denote the standard error of $B$ and the coefficient of determination respectively. Regression analysis was performed for $E>0.1 \mu \mathrm{SV}$, and $D_{\text {aresk }}>1$ $\mu G y ;{ }^{~ N o}$. of obs. = Number of observations included in the regression analysis. The numbers of observations excluded from the calculations, because of a large influence on the parameter estimates (Cook"s $D>1)$, are given in parentheses. 


\section{Chapter 10}

\section{Conclusions and recommendations for dose control}

\subsection{Introduction}

According to the National Radiological Protection Board [NR90], 87\% of the population dose from man-made sources in the United Kingdom is due to medical radiology. It was stated in their report that "it would not be unreasonable to suggest that at least $20 \%$ of the X-ray examinations are clinically unhelpful". It was also claimed that if a number of appropriate methods were applied, the dose reduction could amount to nearly one-half of the current annual collective population dose from medical X-rays in the UK. It is obvious that if these statements also apply to the Netherlands, quantitative data about radiation exposures and the quality of the medical information of radiodiagnostic procedures are of great interest for justification and optimisation.

Various studies of exposures in vascular radiology have been published. Most of these studies, however, provide information about the entrance dose only; estimates for the effective dose to patients have only been inferred by a very few investigators. As the stochastic health risks of $\mathrm{X}$-ray exposures should be assessed from effective doses rather than from entrance doses, the value of previously published data is restricted. This lack of data about effective doses is probably related to the complex nature of vascular imaging and endovascular radiology procedures. Generally, these procedures comprise many different diagnostic views with a large variation in setuings of technique parameters. The assessment of doses to organs that are involved in effective dose calculations, requires information about e.g. the position, direction, size and quality of the X-ray beam for all imaging modes applied. Consequently, a large number of observations of various technique parameters and many dose measurements are needed to estimate effective doses to patients reliably.

During fluoroscopy and sometimes during radiographic imaging, operators and assistants have to stay close to the patient. As most of the vascular procedures involve considerable fluoroscopy lime and multiple digital and/or radiographic images, these procedures can result in high occupational exposures. Although various studies of occupational exposures have been published, so far, estimates for the effective dose to staff are very scarse.

From measurement data collected in three hospitals, located in the south of the Netherlands, we quantified relewant radiation exposure conditions and doses both for the patient and staff during vascular radiology.

\subsection{The extent of vascular radiology in The Netherlands}

In a survey on vascular radiology in The Netherlands, data were collected for the year 1992 (Chapter 5). In all, vascular procedures were performed by about 360 radiologists, 
in 120 hospitals, comprising 136 angiography rooms. Of these hospitals. $68 \%$ applied DSA systems, $53 \%$ conventional angiography, and $34 \%$ spot film systems. The mean age of the $X$-ray equipments and the imaging systems was about 7 and 6 years respectively. A rellatively large number of angiography rooms applied $X$-ray tubes in overcouch nube positions $(38 \%)$.

The total numbers of patients anmually referted, were estimated to be 32100 for intraarterial arteriography, 8900 for intravenous DSA (IV-DSA) arteriography, and 5000 for interventional endovascular procedures. The total numbers of the annually pertormed radiological examinations were estimated to be 61200 for intra-arterial arteriography. 12900 for intravenous DSA arteriography, and 6000 for interventional endovascular radiology. It follows from these data that, on average, about 2 examinations were carried out per arteriography procedure and 1.2 examinations per interventional procedure, the exact value depending on the procedure type.

Using the figure of 7.4 million for the annual frequency of radiological examinations in 1991 [VA92], the frequencies of diagnostic vascular radiology and endovascular examinations, relative to all medical diagnostic $X$-ray examinations (dentistry exclusive), are culculated to be $1.1 \%$ and $0.08 \%$ respectively. It should be noted that the sum value of $1.2 \%$ exceeds the earlier nation-wide estimate of $0.23 \%$ [KE90].

\subsection{Results inferred for patients}

Detailed information about diagnostic views was used to estimarte effective doses to patients for three types of peripheral arteriography and for five types of abdominal arteriography procedures (Chapter 8). These estimations involved entrance doses or dosearea products and appropriate organ dose conversion coefficients for most relevant stages of the procedures. Sex-average estimates for the mean effective dose to patients were found to be similar to effective dose estimates inferred from less detailed DAP measurements and E/DAP-conversion factors, derived from general literature. Effective dose estimates for other procedures discussed were calculated from dose-area product measurements and appropriate conversion factors, found in literature. Estimates for mean effective doses, annual frequencies of various procedure types, and collective effective doses are summarised in Table 10.1.

The overall mean effective doses, calculated as the quotient of the collective dose divided by the frequency, for intra-arterial arteriography, IV-DSA and interventional endovascular procedures are estimated to be $4 \mathrm{mSv}, 6 \mathrm{mSv}$ and $12 \mathrm{mSv}$ respecively. The collective effective dose from arteriography and endovascular radiology in the Netherlands was estimated to be about $250 \mathrm{man}$ - sievert - year-y. A mean effective dose from diagnostic radiology of $0.44 \mathrm{mSv}$ per person [GE95] and a population size of 15 million people were used to estimate that the relative contribution of arteriography and endovascular procedures to the collective effective dose from radiodiagnostic procedures in the Netherlands was $3.8 \%$.

Effective doses to individual patients varied considerably. This variance was associated with intra- and interprocedure type variations, and with differences between hospitals. In all, the effective dose range was estimated to be about 0.1 to $40 \mathrm{mSv}$. If, at worst, the highest measured DAP-value $\left(250 \mathrm{~Gy} \cdot \mathrm{cm}^{2}\right)$ was associated with vascular imaging of a prone patient with overcouch $X$-ray tube positions, the maximum effective dose to the patient was estimated to be $75 \mathrm{mSv}$. 
On average, effective doses to female patients were higher than to males. Mean effective dose ratios (female/male) varied between 1.1 and 3.1 for abdominal arteriography, and between 0.9 and 1.6 for peripheral arteriography (Chapter 8 ).

In summary, effective dose estimates for patients referred for vascular radiology varied between about $0.1 \mathrm{mSv}$ and $40 \mathrm{mSv}$. Mean effective doses were estimated to be about 4 $\mathrm{mS} w$ for intra-arterial arteriography, $6 \mathrm{mSv}$ for IV-DSA, and $12 \mathrm{mSv}$ for interventional endovascular procedures.

Table 10.1 Effective dlose to patients in vascular radiology in the Netherlands

\begin{tabular}{|c|c|c|c|}
\hline Procedure type & $\begin{array}{l}\text { Mean effective } \\
\text { dose } \\
(\mathrm{mSv})\end{array}$ & $\begin{array}{l}\text { Annual } \\
\text { frequency } \\
\left(\mathrm{y}^{-1}\right)\end{array}$ & $\begin{array}{l}\text { Annual collective } \\
\text { effective dose } \\
\left(\text { Sv } \cdot y^{-1}\right)\end{array}$ \\
\hline \multicolumn{4}{|l|}{ Intra-arterial } \\
\hline Cerebral & 4.4 & 6334 & 28 \\
\hline Upper limbs & 3.2 & 1360 & 4.4 \\
\hline Thoracic & 3.7 & 1772 & 6.6 \\
\hline Abdominal & 8.1 & 3696 & 30 \\
\hline lliac/lower limbs & 3.5 & 16054 & 56 \\
\hline Abdominal, iliac legs & 5.8 & 1697 & 9.8 \\
\hline \multirow[t]{3}{*}{ Unspecified $^{ \pm}$} & 4.6 & 1175 & 5.4 \\
\hline & & $+\ldots-n$ & $+\ldots \ldots \ldots$ \\
\hline & & 32088 & 140 \\
\hline \multicolumn{4}{|l|}{ Intrawenous } \\
\hline \multicolumn{4}{|l|}{ DSA-arteriography } \\
\hline Cerebral & 1.5 & 2112 & 3.2 \\
\hline Thoracic & 3.3 & 1070 & 3.5 \\
\hline Abdominal. & 9.9 & 766 & 7.6 \\
\hline lliac/legs & 7.2 & 2139 & 15 \\
\hline Abdominal, iliac legs ${ }^{\circ}$ & 8.6 & 1791 & 15 \\
\hline \multirow[t]{3}{*}{ Unspecified ${ }^{d}$} & 5.5 & 1009 & 5.5 \\
\hline & & $+\cdots$ & $+\ldots . .$. \\
\hline & & 8887 & 50 \\
\hline \multicolumn{4}{|l|}{$\begin{array}{l}\text { Mrementional } \\
\text { procedures (PTA). }\end{array}$} \\
\hline Abdominal & 12.7 & 431 & 5.5 \\
\hline Peripheral & 12.3 & 2962 & 36 \\
\hline Abdominal, iliac legse & 12.5 & 915 & 11 \\
\hline \multirow[t]{3}{*}{ Unspecilfied } & 12.5 & 674 & 8.4 \\
\hline & & $+\ldots$ & $\frac{5}{3} \quad-\quad-2 \cdots \cdots$ \\
\hline & & 4982 & 61 \\
\hline TOTAL: & & & 251 \\
\hline
\end{tabular}

Mean effective doses tor specified procedure types were calculated from mean effective doses for subtypes $\left(\mathbb{E}_{i}\right)$, performed with undercouch tube systems, as presented in Table 7.9. 8.16 and 8.25. The number of observations per subtype $\left(\mathrm{N}_{\mathrm{i}}\right)$ was assumed to be representative for the total distribution. The relative frequency of overcouch procedures was estimated to be $38 \%$. Everchuch $_{\text {was assumed to be equal to }}$ two times $\mathrm{E}_{\text {tasdercuath }}$ " Data, taken from Table 5.2, refer to 1992.

- Unspecified data for the abdoninal and iliac/lower limbs regions. $E_{\text {mean }}$ was estimated to be $0.5 \cdot\left(E_{\text {atxtuner }}\right.$ $\left.+E_{\text {itachlusis }}\right)$. Unspecified data. $E_{\text {masan }}$ was assumed to be cqual to the average value for specified types. 


\subsection{Results inferred for occupationally exposed persons}

Entrance doses and effective doses to staff were estimated for various procedure rypes. Effective doses were estimated by means of entrance doses and appropriate organ dose conversion coefficients (DCCs). Entrance doses were determined for the forehead, neck, upper arms, hands, chest, abdomen and lower legs. It was inferred from measurements in clinical practice that $80 \mathrm{kV}$ could be considered as a typical value for the tube high voltage during occupational exposures. The corresponding radiation attenuation lactor of $0.5 \mathrm{~mm}$ lead-equivalent aprons was estimated to be 200 . However, taking the increase in effective photon energy behind the apron into account, an effective attenuation factor of 130 was applied in our effective dose calculations.

Mean effective doses per procedure type for operators varied between about 0.5 and $3.5 \mu \mathrm{Sv}$ for undercouch $\mathrm{X}$-ray tube positions and between about 0.5 and $20 \mu \mathrm{Sv}$ for overcouch tube positions. On average, effective doses to operators were about a factor of 1.5 higher for undercouch, and a factor of 3.5 higher for overcouch tube procedures, than corresponding doses to assistants. Maximum effective dose estimates per procedure found in this study were equal to $18 \mu \mathrm{Sv}$ for undercouch and $77 \mu \mathrm{Sv}$ for overcouch tube applications. It should be noted that non vascular interventional procedures performed in angiography rooms may even result in higher doses than vascular procedures. For instance, the overall maximum effective dose associated with an undercouch system was estimated to be $46 \mu \mathrm{Sv}$, whereas the corresponding maximum effective dose for vascular procedures was estimated to be $17 \mu \mathrm{Sv}$.

Taking the radiation attenuation by the aprons into account, the contributions of various regions (e.g. head, neck, limbs) to the effective dose were calculated. Substantial contributions were found to be associated with the unprotected neck region (thyroid), varying between $48 \%$ and $78 \%$. In one hospital, performing procedures with undercouch rube positions, the relative contribution from the lower legs was noticeably high (about $25 \%)$.

The collective occupational effective dose of radiodiagnostic $\mathrm{X}$-ray procedures in the Netherlands in 1990, not including candiology, was estimated to be approximately 0.3 man - sievert year ${ }^{-1}$. Using the same annual frequencies as reported in Table 10.1, and again assuming $38 \%$ overcouch procedures, the collective effective dose to operators and assistants from arteriography was estimated to be 0.11 man sievert - year ${ }^{-1}$. The collective effective dose of IV-DSA and from interventional endovascular radiology were estimated to be 0.008 man - sievert year ${ }^{-1}$, and 0.07 man - sievert year ${ }^{-1}$ respectively. It follows from these data that the total collective effective dose from vascular radiology amounts to 0.2 man-sievert - year ${ }^{-1}$, being equal to about $70 \%$ of the total occupational collective effective dose from radiology. These figures clearly indicate that, although the relative frequency is quite low, vascular radiology contributes substantialy to the occupational effective dose of staff.

Calculations showed that conventional aprons of $0.5 \mathrm{~mm}$ lead-equivalence reduce the effective dose to staff by a factor of 6 for overcouch tube, and by a factor of about 12 for undercouch tube positions. From additional calculations il was inferred that the effective dose is reduced with at least $50 \%$ by wearing a thyroid collar $(0.5 \mathrm{~mm}$ lead equivalent).

Regression analysis was used to derive the relationship between the effective dose and the dose-area product from fluoroscopy was derived. It was concluded that the effective dose can be estimated by multiplying the dose-area product from fluoroscopy by an appropriate conversion coefficient. Depending on the exposure conditions, estimated 
conversion coefficients for persons not wearing a thyroid collar, varied between 0.07 and $0.8 \mu \mathrm{Sv} \cdot \mathrm{Gy}^{2} \cdot \mathrm{cm}^{2}$. It follows from these data that, as a rule of thumb, a conversion coefficient of $1 \mu \mathrm{Sv} \cdot \mathrm{Gy}^{-1} \cdot \mathrm{cm}^{-2}$ can be used to estimate the occupational effective dose.

Regression analysis between the effective dose and the entrance dose to the neck showed that, if no thyroid collars are used, the effective dose can be estimated by muliplying the neck entrance dose (measured above the apron) by a conversion coefficient of $0.10 \mathrm{mSw} / \mathrm{mGy}$.

By using remolely triggered contrast medium injection system, personnel can stay behind protective shields during serial cut film radiography and DSA. Therefore, the major part of the occupational exposures is associated with fluoroscopy. If personnel would have to stay near the patient table during all imaging activities, effective doses would increase to about three times the current estimates.

In summary, as a result of the dose reduction provided by lead aprons, the wide-spread use of remotely controlled contrast medium injection systems, the preferential use of the $X$-ray tube in undercouch positions, and the apparent awareness to keep the hands from the $X$-ray field, both the entrance dose and the effective dose to staff in vascular radiology is relatively low. Overall means of the effective doses to the operator are estimated to be about $3 \mu \mathrm{S} v$ per intra-arterial arteriography procedure, $0.7 \mu \mathrm{Sv}$ per IV-DSA procedure, and $10 \mu \mathrm{Sw}$ per interventional endovascular procedure. Maximum occupational effective doses found for vascular radiology were about $20 \mu \mathrm{Sv}$ for undercouch and $80 \mu \mathrm{Sv}$ for overcouch tube systems.

\subsection{Recommendations for dose controll}

General applicable recommendations about the medical use of X-rays can be found elsewhere [e.g. BU94, IC90, NC89a, NC90, NR90, NR93]. The following recommendations, appropriate for vascular radiology, have been devised from observations and measurement results reported in this study.

1. Many hospitals in the Netherlands apply overcouch tube systems. This was not expected, since for some years now various investigators have published dosimetric studies, showing that overcouch tube positions are associated with higher effective doses than undercouch positions, both for the patient and staff. If overcouch tube systems were changed to undercouch tube positions, the effective dose to staff would decrease with a factor of 5 to 10. Effective doses to patients would decrease by about a factor of two. It is recommended that vascular radiology is performed more often with undercouch instead of overcouch tube systems.

2. Generally, $0.5-\mathrm{mm}$ lead-equivalent aprons were used. Aprons with no protection of the back are in use in approximately $50 \%$ of the hospitals. In order to prevent exposure to the unprotected back, special care should be taken in choosing appropriate positions for the fluoroscopy display unit.

3. From additional effective dose calculations for aprons with various lead thickness, it was derived that currently used semi-closed aprons of $0.5-\mathrm{mm}$ lead-equivalence, are sub-optimal. Aprons offering less lead-equivalent thickness, which protect a greater part of the body than the conventional aprons, especially the neck, would decrease the effective dose by at least a factor of two. Aprons that provide additional protection to 
the back of the trunk and the lower legs are the most effective. It is recommended that thinner lead aprons with a more effective size and fitting are used.

4. Standardisation of the use of lead thyroid collars has not been acheved yet. Only $30 \%$ of the hospitals use thyroid collars on a regular basis. Effective dose calculations showed that thyroid collars can reduce the effective dose to members of staft, who wear a conventional sized lead apron, by a factor of two. It is recommended that besides conventional aprons, thyroid collars are introduced and used on a larger scale.

5. Clinical observations and dose measurements showed that thyroid collars sometimes were worn too low to protect the thyroid. It is recommended that the use of thyroid collars is accompanied with an adequate instruction and supervision.

6. Although various studies have shown that the relationship between dosemeter readings and effective dose heavily depends on the location of the dosemeter, standardisation in the position of wearing personal dosemeters has not been accomplished. Therefore, as long as standardisation in wearing personal dosemeters has not been achieved and (national) dosimetry record keeping systems do not contain information on the dosemeter location, reliable effective dose estimates cannot be calculated from dosimetry data in these systems. Therefore, it is recommended that appropriate instructions are supplied to radiation protection officers who supervise the monitoring of occupationally exposed staff.

7. Personal dosemeters should be worn outside of the apron. A position near the neck, above the apron, not protected by a thyroid collar should be preferred. If problems are anticipated, the upper arm/shoulder should be considered as an alternative. Dosimetry characteristics should be laid down in a code of practise, made available to all workers.

8. Mean sizes of patients referred for vascular radiology differ from the mathematical phantoms currently applied in Monte Carlo organ dose calculations. On average. patients are taller (female $3 \mathrm{~cm}$, male $4 \mathrm{~cm}$ ) and heavier (female $8 \mathrm{~kg}$, male $4 \mathrm{~kg}$ ). It is recommended that a study will be undertaken to assess the need to up-date current phantoms.

9. The patient population referred for vascular radiology is quite old. Taking the dependence of radiation risks on age into account, it is recommended that the age distribution of these patients is taken into account in risk assessments, carried out to justify and optimise vascular radiodiagnostic procedures.

10. Generally, a large entrance field mode of an image intensifier requires a lower entrance dose value at the input screen than a small field mode, resulting in a lower dose both to the patient and staff. It is recommended that large entrance field modes of the image intensifier with a well-collimated $X$-ray beam are used as much as possible, provided that the lower spatial resolution does not have adverse effects on the medical result.

11. During all imaging modes, the $X$-ray beam should be collimated to the smallest field that is necessary to obtain the diagnostic information required. Using the berm collimating system is of utmost importance, especially if large image input screens are selected. As a rule of thumb, one may adopt a linear relationship between the beam cross section area and the effective dose, both to patients and staff.

12. Because digital imaging requires lower image entrance doses than conventional radiography, in the advent of the use of DSA systems it was assumed that the patient dose would decrease. Probably because there is no penalty in collecting many DSA 
frames, the numbers of DSA-frames produced exceed earlier expectations. Consequenty, the total dose from DSA appeared to be higher than expected. A study is recommended to develop technologies and procedures that require a smaller number of DSA-frames. It is also recommended that operators will be provided with information about dose conseguences of digital imaging.

13. In intra-arterial arteriography, fluoroscopy contributes substantially to the total dosearea product and hence to the dose to patient and staff. It is recommended that fluoroscopy should be kept to a minimum, and that it should be performed in an intermittent manner for short periods with as long intervals as possible, combined with memory facility of the fluoroscopy display unit (last image hold). As it can be expected that the more widespread use of pulsed $\mathrm{X}$-ray generators, allowing a lower fluoroscopy frame rate, will reduce the patient dose and the occupational dose, maintaining the same level of image quality, the consequences of the introduction of the systems should be studied. Taking advantage of the experience gained with the introduction of DSA systems, where the expectations about lower doses were not fullfilled, one should be aware of unexpected drawbacks.

14. Settings of tube high voltage and tube current for fluoroscopic control of manipulation of catheters, should be adapted to reduce the radiation dose, maintaining an adequate picture. This could be achieved by introducing a two settings system, with the system being programmed to start with the low dose and submaximal quality picture being programmed as the standard option. Manual setting of voltage and current should be avoided. Automatic control units can adapt these technique parameters faster and more reluably.

15. Taking operational aspects of the medical procedures into account, the influence of the (temporal) remowal of the antiscatter grid on the image quality and the dose to patient and staff, should be studied in more detail, both for fluoroscopic actions and DSA imaging.

16. Dose-area product meters should be used more frequently to obtain information about the usage of the X-ray system. Measurement results should be discussed periodically in appropriate consultation situations. It is recommended that some members of the staff are appointed to perform the tasks of routine data acquisition, data presentation and data evaluation.

17. The survey response showed that the annul number of angiographic and interventional endovascular procedures in some hospitals was quite small. It was derived that at least 48 hospitals performed on average less than one vascular procedure a week. The question arises if operators in these hospitals can maintain the skill and experience needed for these complex procedures. A study is recommended to the consequences of the concentration of vascular radiology in a smaller number of hospitals with the prospect of better medical results and probably a reduction of radiation exposures.

18. In those hospitals where contrast media are still injected manually, reduction of the occupational dose can be achieved by using a remotely controlled power driven injection system. 


\section{Appendix A}

\section{Thermoluminescence dosimetry}

\section{A.1. Introduction}

Thermoluminescence dosimetry is based on the physical phenomenon that various materials emit part of the absorbed ionising radiation energy as visible light upon lyeating the exposed material. This phenomenon is found in many insulators and semiconductors of natural and synthetic origin [MC81]. The process of light emission upon heating is called thermoluminescence (TL). Applications of thermoluminescence are found in solid state physics, archaeology, environmental studies, clinical dosimetry for medical therapeutic purposes, research in health physics, and last but not least in dosimetry for occupationally exposed persons.

By means of a photomultiplier, the low level of emitted light can be magnified and measured. The output signal of the photomultiplier, the TL-signal, nay be applied as a measure for the radiation dose. Heating of the TL-element may be performed with hot inert gas, a heating planchet, a hot funger or by laser light. The heating of the TL-element and determination of the TL-signal is called the readout procedure. The TL-signal is integrated in a defined temperature range. As an alternative, the amplitude of a TL-peak in the TL glow curve is determined. The first method, the so-called integrated method, is applied more often than the second method, the peak height method. Nowadays, computerised approaches can be found frequently in the literature [BO93, BO94, DE90, DE92, LO93a, PE91]. By means of numerical methods the TL-signal is decomposed in a number of single peaks. It is claimed that the precision of low dose measurements substantially improves [DE90]. After the heating cycle, the absorbed radiation energy is lost. Unless complex dose reassessment procedures are applied, the thermoluminescent signal from one exposure can be determined only once. However, TL-elements are reusable. This means that the processes of exposure and readout may be repeated many times. In order to prevent disturbance of the TL-signal by early exposures, the TLelement is "reset" before the exposure by heating it to a much higher temperature than applied in the readout cycle. This heating process is called annealing. The integrated value as well as the amplitude of the TL-signal depend on the TL-material, heating procedure, radiation type, energy of the radiation, the radiation intensity, exposure time, and background radiation level. Other factors which may influence the dose assessment performance are e.g. the annealing procedure, the annealing and radiation exposure history, the time lap between annealing and exposure, and the time between the exposure and readout procedure. Each type of thermoluminescence material has its own features, characterised by e.g. the wave length of the emitted light, form of the glow curve, optimal annealing characteristics, fading (ioss of TL-signal as a function of time after the radiation exposure), sensitivity and radjation energy dependence of sensitivity, decrease or increase of the TL-signal upon exposure to visible light and/or to ultra violet light, sensitivity to humidity and chemicals, supralinear response characteristics, and the lower detection level. 
Since TL-dosimetry is a relative dose measurement method, TL-elements have to be calibrated. This involves that a number of TL-elements are placed in a well defined enwironment in which the type and energy of the radiation are known. The radiation intensity, expressed in a dosmetric quantity, is measured or calculated to a high degree of accuracy. If the exposure time and or radiation intensity is varied, a relationship can be derived between the dosimetric quantity and the measured TL-signal. In the low dose range this relationship is generally quantified by linear regression.

Smal』 TL-elements designed for radiation dosimetry are called TLDs. In the literature the term TLD may refer to the bare element as well as to a group of elements encapsulated in a holder. Generally, dosemeters for personal dosimetry consist of a plastic holder, in which removable sets of TL-elements are placed. Most of the time additional filters are placed in the holder, in front of the TL-elements. As these filters result in differences in the attenuation of the incident radiation and thereby in different TL-signals of the TL-elements placed behind these filters, these dosemeters can provide insight in the radiation quality.

\section{A.2. Thermoluminescence dosimetry in vascular radiology}

Dose measurements have been carried out with commercially available extruded chips of LiF, doped with small quantities of magnesium and titanium (TLD-100, Harshaw). LiF is nearly tissue equivalent (photon effective atomic number $Z_{\text {LiF }}=8.2 ; Z_{\text {tissue }}=7.2$ ). The dependence of the sensitivity on photon energy is relatively low. In the photon energy range 10 to $120 \mathrm{keV}$, as encountered in diagnostic radiology, the maximum deviation of the TL-signal/dose ratio is about 1.3 to 1.4 at $20-30 \mathrm{keV}$ [OB81, MC81, NA93]. The TL response of $\mathrm{LiF}$ is proportional to the absorbed dose up to several gray [CH94, MC81, MO93]. The dose reading is practically independent of dose rate up to $10^{9} \mathrm{~Gy} / \mathrm{s}$ [OB81]. Studies into the fading characteristics of LiF have shown that appropriate pre-exposure annealing and read out procedures reduce the apparent fading of the "stored" TL-signal to a negligibly low level [MC81]. Indeed, our own experiments have confirmed that fading in measurement periods of three weeks or less is insignificant, for the TLD dose measurement system applied in this study. Background corrections were made by determining the average TL-signal from a subgroup of TLDs of the same reading cycle, as proposed by Zarand an Polgar [ZA83]. Reading out every TLD twice, resulting in an additional decrease in the variance of the background [ZA83], was considered but not put into practice.

In our study two types of dosemeters were used: (i) "body-dosemeters", dosemeters worn on the body, and (ii) "ringdosemeters", dosemeters worn on the hands. Each "bodydosemeter" comprised two TLD-100 elements, dust-proof sealed in thin sachets with dimensions of $5 \times 2.5 \mathrm{~cm}^{2}$. The backing material consisted of a strip of thin sterilisation paper, covered with a layer of dry glue. A thin polyester/polyethylene foil was used as front cover (12 $\mu \mathrm{m}$ polyester; $50 \mu \mathrm{m}$ polyethylene). The front cover and backing material were mutually attached at the four sides by heating. Each ringdosemeter contained one TLD-100 element. The TLD was placed in a plastic ring and covered, dust-proof and waterproof, by a piece of paper $\left(80 \mathrm{~g} / \mathrm{m}^{2}\right)$ and a thin, aluminized, plastic foil $(50 \mu \mathrm{m})$, fixed to the ring by means of a layer of dry glue. In order to maintain sterile working conditions, ringdosemeters were immersed in alcohol during five minutes before clinical applications. 
TLDs were read out by means of a manual TLD-reader Harshaw 4000B. Harshaw. Solon, USA), featuring planchet heating and a programmable temperature control unit. As the peak height method is dependent on the heating rate, while the integrated TL-signal is independent of it [NA93], we applied the integral method in our sudy. The readoui cycle comprised a pre-read out temperature of $150^{\circ} \mathrm{C}(5 \mathrm{~s})$, followed by a TL-acquisition period, in which the temperature increased $\left(25^{\circ} \mathrm{C} / \mathrm{s}\right)$ to $230^{\circ} \mathrm{C}$, this temperature level was maintained during $10 \mathrm{~s}$. In order to reduce the background level of TL-signals, the heating chamber was flushed with nitrogen gas at room temperature $(0.8 \mathrm{l} / \mathrm{min})$. TL-signals were collected for evaluation purposes in a IBM-compatible personal computer (PC). All TLsignals were visualised on the PC display unit. TL glow curves which deviated significantly from the average picture were discarded from the data-set.

\section{Selection of TLDS}

At the start of the study more than one thousand TL-elements were cycled five times through the annealing procedure (see below). Next, these dosemeters were exposed to a radiation dose of $2 \mathrm{mGy}$ and subsequently read out. All dosemeters within the range $-5 \%$ to $+5 \%$ of the arithmetic mean were selected. After repeating this process one more ime, approximately 500 TLDs were selected for further applications. The annealing process, readout process, calibration procedure and the applications were documented in detail to obtain a very high degree of repeatability.

By means of the selected TLDs, calibration procedures and background subtraction were performed batchwise. Compared with individually calibrated TLD procedures, the administrative tasks and probability of errors in using calibration factors for groups of TLDs, were significantly reduced. The loss of precision was regarded acceptable.

\section{Annealing}

Annealing was carried out for batches of about 100 TLDs, placed on an aluminium holder and covered by a thin aluminium capping. As shown in Table A.1, the annealing process involved six steps.

Table A.

Annealing of TLD-100

(1) Maintain temperature of the empty oven at $400^{\circ} \mathrm{C}$ doring 30 minutes before starting TLD annealing.

(2) Perform high temperature annealing of TLDS:

(3) Cooling TLDs to room temperature:

Temp. $=400^{\circ} \mathrm{C}$. Than $=60 \mathrm{~min}$ : mediutn $=$ air.

Forced, fast cooling by placing the batch whith TLelements, outside of the oven, between wo aluminim plates (dimension $30 \times 30 \times 2 \mathrm{~cm}$; room temperature).

(4) Maintaining the oven temperature at $105^{\circ} \mathrm{C}$ during 15 mimutes.

(5) Performing low temp. annealing:

(6) Cooling TLDs to ambient temperature:

Temp $=105^{\circ} \mathrm{C} ;$ Time $=90 \mathrm{~min}$.

Unforced cooling down to ambient liemperature in open air. 
Every step was carried out with special attention to reproducibility. If one step failed to meet the prescribed criteria, the total procedure was repeated from the beginning. Step 3 especially was considered to be of importance [MA84].

It should be noted that low temperature annealing at $105^{\circ} \mathrm{C}$ during 90 minutes deviates from the usually applied procedure $\left(80^{\circ} \mathrm{C}\right.$ during 24 hours). Our own experiments with several combinations of temperature and time showed that $90 \mathrm{~min}$ at $105^{\circ} \mathrm{C}$ was an adequate alternative, provided that temperature and time were kept within narrow margins. Maximal deviations allowed in our procedure were: temperature $\pm 5^{\circ} \mathrm{C}$, time \pm 5 minutes). This alternative method was applied in our study to reduce the preparation time and to maintain a high throughput.

\section{Calibration}

It was known that TLD dosemeters would be attached to lead aprons, bony body parts (skull, fingers) as well as to body parts with substantial tissue volumes (trunk, upper legs, neck). These locations have very different backscatter characteristics. For example, the response of TLDs placed on a massive volume, such as the trunk is about $30 \%$ higher than the response of TLDs, placed free in air. Therefore, TLD dosemeters have been callibrated free in air; and backscatter corrections have been carried out in the dose calculation algorithms. Calibration exposures were performed for "body-dosemeters", only. The derived calibration factor was assigned without additional modifications to ring dosemeters.

In order to ensure high reliability of dose measurements, the calibration procedure was performed for each batchwise application of TLDs. After annealing the batch of TLelements, two subgroups of TL-elements (each containing six TL-elements) were set apart. These TL-elements were taken randomly from the batch. The first group was stored in the dosimetry room. This group was used to estimate the background TL-signal of non exposed TL elements. The background signal ( $\mathrm{TL}_{\text {background }}$ ) includes the TL-signal introduced by natural radiation, caused by radioactivity in the building materials, terrestrial radiation, and cosmogenic radiation. About three days after annealing, the second group of TL-elements was exposed for calibration purposes.

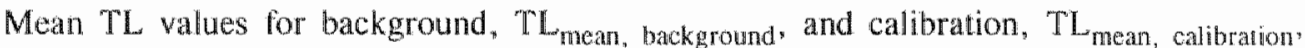
were determined in the same readout batch process in which the TL-signal of occupationally exposed TL-elements were determined. Usually, the readout process was performed one week after the annealing procedure.

If the calibration is performed with high energy photon sources, LiF TLDs can overrespond in the diagnostic range of X-ray photons by as much as $40 \%$. In order to minimise the systematic error introduced by the energy dependence of the response of $\mathrm{LiF}$, calibration exposures were performed in an X-ray radiation field (Polymobil, Siemens, Erlangen, Germany; high frequency voltage generator) each time simultaneously quantified by measurement of the air kerma, free in air $\left(\mathrm{K}_{\text {calibration }}\right)$, with an ionisation chamber. Calibration exposures of TL elements were carried out essentially free in air, with the TL elements placed in the centre of an X-ray field. The characteristics are summarised in Table A.2. To improve the reliability, a test exposure was performed at the start of each calibration procedure (exposure criterion: $\mathrm{K}_{\mathrm{air}}$ within range 1.9 to $2.0 \mathrm{mGy}$ ). 
The constancy of the ionisation dose measurement system was checked each week by means of a ${ }^{90} \mathrm{Sr} /{ }^{90} \mathrm{Y}$ radiation source, temporally fixed to the chamber in a specially developed device.

\section{Table A.2 Characteristics of the calibration exposures for TLD-100}

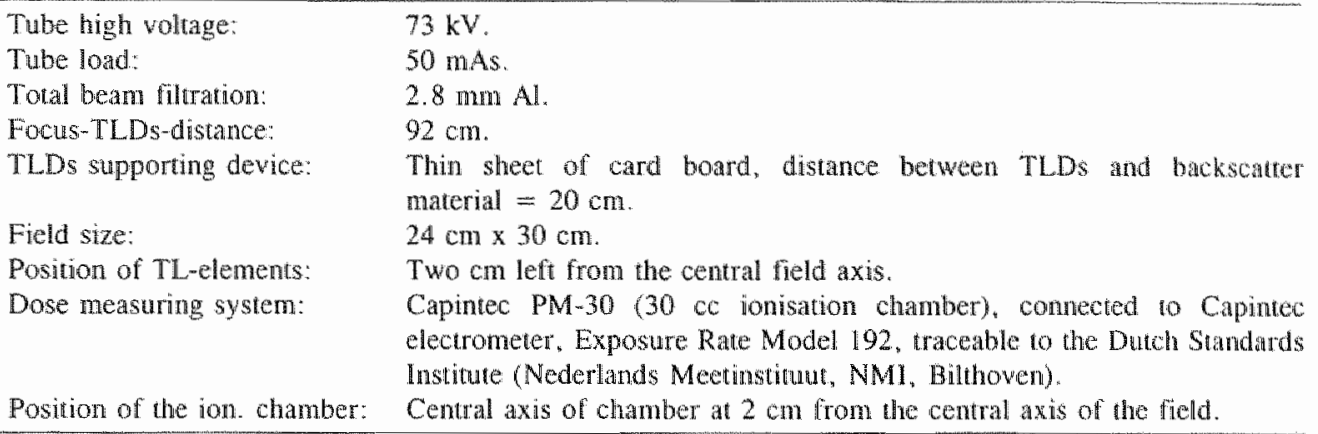

Directional dependence of the TLD-response has been studied by various investigators [OB81, W191]. In nonperpendicular exposures, TL-readings per unit dose may decrease about $25 \%$, depending on photon energy and irradiation angle. We made no corrections in our dose measurements. In the calibration exposure, all TLDs were placed with their square faces perpendicular to the centrall beam axis.

In the diagnostic dose range, the relationship of TL-signal versus radiation dose is linear. Therefore, the following simple relationship could be applied:

$$
\text { TL mean, calibration }=c \cdot \mathrm{K}_{\text {calibration }}+\mathrm{TL}_{\text {mean, background }}
$$

where $c$ is the callibration factor (TL-response per unit of dose).

In order to estimate the air kerma of the applied $T L$-elements $\left(K_{\text {exp }}\right.$ ) the following relationship was used:

$$
K_{\exp }=1 / \mathrm{c} \cdot\left(T L_{\text {exp }}-T L_{\text {background }}\right)
$$

with and $\mathrm{TL}_{\text {background }}$ derived in the calibration process. 


\section{Appendix B}

\section{Distribution of red marrow in peripheral bones}

Data concerning the distribution of red marrow in peripheral bones are controversial. Since the tissue weighting factor of red marrow is relatively height ( $w_{\text {red marrow }}=0.12$; see Table 2.1), the distribution could have a serious impact on dose estimates. Therefore, a literature review was undertaken. Conclusions are drawn both for patients and personnel.

\section{B.1. Literature data}

In anthropomorphic models, applied in Monte Carlo organ dose calculations, the distribution of red marrow in human bones is generally derived from data provided in ICRP Publication 23 [IC75] or as published by Cristy [CR80, CR81]. According to ICRP Publication 23, red marrow in adults is limited mainly to the bones in the trunk and head, and to the proximal ends of humerus and femur. In the anthropomorphic phantoms ADAM and EVA, used in this study, the active red marrow is localised in small cavities in all bones, except the lower arm bones and the lower legs bones [KR86].

【CRP Publication 23 comprises scientific information as available in the 1960 s and early 1970s. In a review paper on bone marrow imaging in 1988 by Vogler [VO88], age related distributions of marrow were discussed. Comparison of Voglers data, with information provided in ICRP Publication 23, showed that no major changes were mentioned. In 1988, the lack of red marrow in the adult distal femur was confirmed in an investigation by Deutsch [DE88], in which only ten out of 1400 patients $(0.7 \%)$ showed haematopoietic marrow in the long bones in the knee region. A study into age-related marrow in the femur of 77 subjects by Moore et al. [MO90] confirmed that after birth, the conversion of red to yellow marrow started from the distal end of the femur, followed by the epiphysis and midshaft of the long bones. The adult pattern, showing red marrow in the proximal metaphysis, only, was seen at an age of 24 years. A study by Zawin and Jaramillo [ZA93a] into marrow in the humerus in 91 patients, with no malignancies or bone marrow abnormalities, concluded that the general patterns of the conversion of red to yellow marrow in the humerus were quite similar to those reported in [MO90] for the femur. In subjects older than 15 years, all of the humeral marrow was fatty, except for the proximal metaphysis.

These findings deviate from the distribution of red marrow, shown in a schematic drawing in a textbook on medical X-ray examinations, published in 1979 [SH79]. In this drawing, red marrow occurs in both distal and proximal ends of the long bones in the upper and lower limbs, and in bones in the ankle and hands. More recently, two other groups found evidence for high prevalences of red marrow in the distal femur. Shelloc et al. [SH92] estimated the prevalence of active marrow in the distal femur to be $30 \%$ (22/74) for healthy adults and $15 \%(8 / 54)$ for patients with knee disorders. In a group of 
marathon runners the prevalence was estimated to be high as $45 \%$ (10/23). In all persons examined, no red marrow was detected in the epiphysis and the proximal tibia. Shellock postulated that the high prevalence in marathon runners was a response to "sports anaemia", commonly found in aerobically trained athletes. Lang et al. [LA93], also concluded that haematopoietic marrow in the adult distal femur, in the absence of haematopoietic abnormalities, is relatively high, especially in women of menstruating age. Out of 51 patients, active marrow was found in $56 \%(13 / 23)$ of female patients, and in $18 \%(5 / 28)$ of male patients. The prevalence of red marrow in the distall femur was related to residual red marrow areas, and/or marrow reconversion, probably caused by anaemia. These findings, quite dissimilar to the data presented in ICRP Publication 23 , were explained by superiority of modern $\mathrm{MR}$ imaging over anatomic macrosectioning, as used in the past. Lang explained deviations in results of the other two studies by Deutsch and Shellock, with differences in the red marrow classification procedures (Deutsch), as well as with differences in the MR imaging technique (Deutsch, Shellock).

\section{B.2. Summary/conclusion}

After the introduction of MR imaging, three studies [DE88, MO90, ZA93a] confirmed the data presented in ICRP Publication 23. Two studies [LA93, SH92] deviated, indicating that the prewallence of red marrow in the knee region is much higher than determined in the past. Deviations were explained by high sensitivity of well defined windowed MR imaging. Data on positive prevalence of red marrow in lower arms, hands, lower legs and ankle/feet were not found. New estimates for the mass of red marrow in humerus and femur were not found either.

It is concluded that, for the time being, new findings probably do not warrant modifications in Monte Carlo anthropomorphic phantoms. In occupational exposure conditions, however, large differences occur in radiation intensities incident on body parts, protected by a lead apron, compared to unprotected body parts. Therefore, a comparison of the results of two calculations of effective dose estimates (one with and one without red marrow in distal bones) could be useful to assess the inaccuracy introduced by incomplete modelling of the red marrow distribution. 


\section{Appendix C}

\section{Lead aprons}

Generally, a lead apron consists of one, two or three thin leaded rubber or vinyl sheets with nylon outer coverings (thin sheets are used to provide flexibility and handling ease). An apron usually protects the front and sides of the torso of the body and the thighs. Some types have a large neckhole and protect only a relatively small area of the upper part of the thorax. In a so-called wrap-around apron incident radiation on the back side is attemuated as well. Some specially destgned aprons provide (partially) protection to the thyroid.

The lead equivalent thickness of aprons varies between 0.25 to $0.50 \mathrm{~mm}(1 \mathrm{~mm}$ lead equivalent has been mentioned as well). In general, wrap-around aprons provide more attenuation at the front side (e.g. $0.5 \mathrm{~mm} \mathrm{~Pb}$-eq) than at the back side (e.g. $0.25 \mathrm{~mm} \mathrm{~Pb}$ eq). Wrap-around aprons may provide in a vertical section in the front of $\downarrow \mathrm{mm} \mathrm{Pb}$ equivalent by overlapping of the left and right parts of the apron. Depending on the design of the apron and the size of the person, this section varies between a few centimetres and about $20 \mathrm{~cm}$, thereby covering the main part of the front side.

The radiation attenuation of an apron depends on the energy of the incident (scattered) photon radiation as well as on the lead equivalent thickness. The energy of the scattered photons depends in the first place on the energy of the X-ray photons in the primary beam, and secondly on the scatter angle. Consequently, the attenuation factor of an apron depends on the tube high voltage and the beam filtration. With a high voltage range of approximately $50 \mathrm{kV}$ to $120 \mathrm{kV}$, the radiation attenuation factor of an apron varies between approximately 1000 and 10 .

The weight of the apron may become awkward in interventional procedures with prolonged fluoroscopic actions and may to some extent be a limiting factor in work performance.

The effective dose to persons wearing an apron depends on the radiation dose to organs and tissues protected by an apron and thyroid collar and the radiation dose to unprotected tissues. The body areas that are not protected by the apron include the head, neck, arms, hand, lower legs and feet. Depending on the design and the fitting of the apron. the protection of the side of the thorax, particularly the female breast may be poor.

Aprons with large armhole openings especially provide relatively less protection in lateral exposure conditions for the operator, a situation which frequently occurs in vascular imaging procedures. A thyroid collar protects the thyroid. The oesophagus, bone surface and red marrow contents of the cervical spine, skin and muscle of the neck area are partly protected as well. 


\section{Appendix D}

\section{Effective dose to the patient as a function of the $\mathrm{X}$-ray beam direction}

Because of differences in radiosensitivity of internal organs and tissues, the effective dose (E) depends on the exposure direction. As angiography involves a large number of different views and reduction of the number of views in the dosimetric calculations would be of advantage, we have investigated the influence of the beam drection on $E$. This issue has been addressed by various authors [IC88, KE80, RE94, YA94a]. Shrimpton et al. [SH86] estimated the AP/PA-ratio for abdominal films to be two. Gray et al. [GR94] reported AP/PA-ratios for abdominal radiography equal to 1.7-1.8. Data presented by Petonssi et al. [PE95] for large film sizes $\left(40 \times 40 \mathrm{~cm}^{2}\right)$ were used to derive AP/PA-ratios of 1.7. Marshal et al. [MA94] concluded that effective doses resulting from PA abdominal projections are between two and five times lower than those from the corresponding AP projections. Huda and Bissessor [HU90a] found AP/PA-ratios of about unity for the abdomen, 1.8 for the chest and 1.2 for the head. The dissimilarity of these findings for the abdominal region with other workers is probably due to inaccurate modelling of the human anatomy in their mathematical phantom [MA94].

The XDOSE software package [LE94] was used to derive estimates for the effective dose, associated with perpendicular and oblique views in $X$-ray imaging. On the assumption that dose-area products for two identical, but reversed views (AP versus PA, L LAT versus R LAT, etc) are alike, ratios have been calculated for effective dose estimates, normalised to unit dose-area product $(\mathrm{HV}=80 \mathrm{kV}$, total filtration $=4 \mathrm{~mm} \mathrm{Al})$. The results for AP versus PA views are given in Table D.1.

Table D.1 Effective dose for AP and PA vicws for a hermaphrodite adulf phantom", normalised to dose-area product.

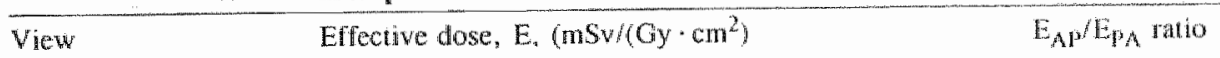

\begin{tabular}{llll} 
& AP & PA & \\
\hline Head & 0.043 & 0.033 & 1.3 \\
Chest & 0.241 & 0.153 & 1.6 \\
Heart & 0.153 & 0.170 & 0.9 \\
Upper stomach & 0.562 & 0.257 & 2.2 \\
Stomach & 0.445 & 0.192 & 2.3 \\
Kidneys & 0.252 & 0.151 & 1.7 \\
Small intestine & 0.237 & 0.185 & 1.3 \\
Abdomen & 0.235 & 0.147 & 1.6 \\
\hline
\end{tabular}

XDOSE (NRPB-SR262, 1994),[LE94, HA94]. Tube high volage $=80 \mathrm{kV}$; Tolal beam filtration $=4$ $\mathrm{mm} \mathrm{Al} . \mathrm{AP}=$ anterior-posierior $\mathrm{view} ; \mathrm{PA}=$ posterior-anterior wiew. 
It is conchuded that effective doses, associated with $A P$ views $\left(\mathrm{E}_{\mathrm{AP}}\right.$ ) are higher than with $P A$ views $\left(E_{P A}\right): E_{A p} / E_{P A}$ ratios vary between 0.9 and 2.3 . Allowances for the patient support table have not been made. Incorporating the table in the dose calculations would yield an increased $\mathrm{E}_{\mathrm{AP}} / \mathrm{E}_{\mathrm{P} A \mathrm{~A}}$ ratio.

Effective doses for left and right oblique views, presented in Table D.2, indicate that views of the lower trunk, with $X$-rays entering the left side of the body (R LAT, RAO, $R P O)$ result in higher effective dose values; ratios of right to left for this region vary between 0.4 and 0.8 . The ratio of the effective doses of $A P$ views of the right and left hips is equal to 0.6 (not shown in Table D.2). Right/left ratios of effective doses for oblique views in the upper part of the body are about unity $(0.8$ to 1$)$, indicating that effective doses for this region, associated with lateral views, are insensitive to the beam direction. This finding indicates that dose assessments for complex examinations of the upper trunk, can be carried out by taking the dose of left oblique views equal to the dose of corresponding right oblique views. Dose estimates for oblique lower trunk views, with the X-ray beam entering the right side (L LAT, LAO, LPO) can be derived if dose estimates for R LAT, RAO and RPO views are multiplied with an appropriate correction factor (about 0.7).

Table D.2 Effective dose for various oblique views for a hermaphrodite adult phantom ${ }^{\text {a }}$ normalised to dose-area prodluct.

\begin{tabular}{|c|c|c|c|}
\hline \multirow[t]{2}{*}{ View $^{b}$} & \multicolumn{2}{|c|}{$\begin{array}{l}\text { Effective dose, } \mathrm{E} \text {, for views } \\
\text { with } \mathrm{X} \text {-rays entering from aside } \\
\left(\mathrm{mSv} /\left(\mathrm{Gy} \cdot \mathrm{cm}^{2}\right)\right)\end{array}$} & \multirow[t]{2}{*}{$\underset{\text { ratio }}{\mathrm{E}_{\text {righit }} / \mathrm{E}_{\mathrm{left}}}$} \\
\hline & Right side ${ }^{c}$ & Left side ${ }^{d}$ & \\
\hline Head (L LAT, R LAT) & 0.040 & 0.040 & 1.0 \\
\hline Throat (L LAT, R LAT) & 0.142 & 0.142 & 1.0 \\
\hline Cervical spine (L LAT, R LAT) & 0.041 & 0.045 & 0.9 \\
\hline Chest (L LAT, R LAT) & 0.104 & 0.128 & 0.8 \\
\hline Oesophagus (LAO,RAO) & 0.151 & 0.152 & 1.0 \\
\hline Heart (L LAT, R LAT") & 0.203 & 0.209 & 1.0 \\
\hline Heart (LAO, RAO) & 0.205 & 0.230 & 0.9 \\
\hline Thoracic spine (LAO, RAO) & 0.111 & 0.121 & 0.9 \\
\hline Stomach (LAO,RAO) & 0.162 & $0.2 \| 1$ & 0.8 \\
\hline Colon (LAO.RAO) & 0.085 & 0.109 & 0.8 \\
\hline Lumbar spine (L LAT, R LAT) & 0.084 & 0.136 & 0.6 \\
\hline Lumbar spine (LPO, RPO) & 0.112 & 0.280 & 0.4 \\
\hline Lumbo-sacral joint (L LAT, $\mathbb{R}$ LAT) & 0.073 & 0.105 & 0.7 \\
\hline
\end{tabular}

a XDOSE (NRPB-SR262, 1994) [LE94, HA94]. Tube high voltage $=80 \mathrm{kV}$, Total beam filtration $=4 \mathrm{~mm}$ Al; "Convention of views [LE94]: L LAT: X-rays enter right side of the body and form an image on the left side. $R L A T$ : $X$-rays enter left side of the body and form an image on the right side. $L A O$ : Left anterior oblique: $X$-rays enter right rear side and form an image on the left front side. $R A O: X$-rays enter left rear side and form an image on the right fron side. $L P O$ : Left posterior oblique: $\mathrm{X}$-rays enter right front side and form an image on the left rear side. RPO: X-rays enter left front side and form an image on the right rear side; "Right side: This column comprises L LAT, LAO and LPO views. "Left side: This column comprises R LAT, RAO and RPO views. 


\section{References}

AS91 Ashmore JP, Sont WN, Davies BF. Analysis of medicall workers dose reconds from the Canadian national dose registry. Radiation Protection Dosimetry. 1991; 36(2/4):79-83.

BE84 Beentjes $L$ B. Glas JA. An estimate of the somatically effective dose from diagnostic radiology in the Netherlands during 1976-1980. Heallth Physics. 1984;47(2):299-304.

BE85 Beninson D, Sowby D. Age and sex dependent weighting factors for medical irradiation. Radiation Protection Dosimetry. 1985; 11(1):57-60.

BE90 BEIR-V, Committee on the Biological Effects of llonizing Radiations. Health effects of exposure to low levels of ionizing radiation. Washington DC (US), National Academy Press; 1990.

BE90a Beentes LB. Timmermans CWM. Age and sex specific radiographic examination frequency in the Netherlands. Br J Radiol 1990; 63: 691-697.

BE91 Bennett BG. Exposures from medical radiation world-wide. Radiation Protection Dosimetry. $1991 ; 36(2 / 4): 237-242$.

BE91a Beentjes LB, Timmermans CWM. Patient doses in the Netherlands. Rad Prot Dosimetry 1991: 36: 265 268.

BE9lb Berthelsen B, Cederblad A. Radiation doses to patients and personnel involved in embolization of intracerebral arteriovenous malformations. Acta Radiologica. 1991;32(6):492-497.

B076 Boer den JA, Mohr H. Distribution of scattered radiation around the Cardio Diagnost. Medicamundi. 1976;21(2):121-128.

BOS1 Boone JM, Levin DC. Radiation exposure to angiographers under different fluoroscopic imaging conditions. Radiology. 1991:180:861-865.

BO93 Bos AJJ, Piters TM, Gomez Ros $\ M_{4}$, Delgado A. An intercomparison of glow curve analysis compuer programs: 1. Synthetic glow curves. Radiation Protection Dosimetry. 1993:47(1-4):473477 .

Bo94 Bos AJJ, Piters TM, Gomez Ros JM, Delgado A. An intercomparison of glow curve analysis compuer programs: Il. Measured glow curves. Radiation Protection Dosimetry. 1994;51(4):257. 264.

BR86 Briesmeister J. MCNP. A general Monte Carlo code for neutron and photon transpon, version 3A. Los Alamos, NM: Los Alamos National Laboratory; LA-7396-M, Rev. 2. 1986.

BR88 Britton CA, Wholey MH. Radiation exposure of personnel during digital sublraction angiography. Cardiowascular Interventional Radiology. 1988:11:108-110.

BR9l Briesmeister J. MCNP-4 newsletter. Los Alamos, NM: Los Alamos National Laboratory, 1991.

BR95 Broerse JJ. Personal communication. 1995.

BU89 Bushong SC. Personnel monioring in diagnostic radiology revisited-again!. Heallth Phys 1989; 56: $565-566$.

BU94 Bushberg JT, et al. The essential of physics of medical imaging. Williams \& Wilkins, Ballimore (USA), 1994.

CA63 Carlsson C. Determination of the integral absorbed dose from exposure measurements. Acta Radiologica Therapy Physics Biology. 1963:1:433-458.

CA65 Carlsson C. Integral absorbed doses in roentgen diagnostic procedures. Acla Radiologica Therapy Physics Biology. 1965;3:311-326.

CA86 Carlsson GA, Carlsson CA. Relations between effective dose equivalent and mean absorbed dose (energy imparted) to patients in diagnostic radiology. Phys. Med. Biol. 1986;31(8):911-921.

CA86a Carmody RF, et al. Digital subtraction angiography update 1986. Inwestigative Radiology. 1986:21:899-905.

CA88. Casselden PA. Ocular lens dose in cerebral vascular imaging. The British Journal of Radiology. 1988:61:202-204. 
CA95 Castellano A et al. Assessment of organ radiation doses and associated with digital bifernoral arteriography. The British Journal of Radiology. 1995;68:502-507.

CH80 Chopp M et al. Clinical dosimetry during cerebral arteriography. Neuroradiology. 1980;20:79-81.

$\mathrm{CH} 82$ Christensen $\mathrm{P}$, Botter Jensen $\mathrm{L}$, Majborn $\mathrm{B}$. Thermoluminescence dosimetry applied to radiation protection. Int. I. Appl. Rad. Isot. 1982:33:1035-1050.

CH94 Chen R, Mckeever WS. Characterization of monlinearities in the dose dependence of thermoluminescence. Radiation Measurements. 1994:23(4):667-673.

C088 Contento $G$ et al. A comparison of diagnostic radiology practice and patient exposure in Britain, France and lady. The British Joumal of Radiology. 1988;61:143-152.

CR80 Cristy $M$. Mathenatical phantoms representing children of various ages for use in estimates of internal dose. Oak Ridge National Laboratory, NUREG/CR-1159. 1980.

CR80a Cruikshank JG et al. Finger doses received by Radiologist during Chiba Needle Percuntaneous Cholangiography (Technical note). British Journal of Radiology. 1980;53:584-585.

CR81 Cristy M. Active bone marrow distribution as a function of age in humans. Phys. Med. Biol. $1981: 26: 389$.

CU90 Curry T. Christensen's physics of diagnostic radiology- 4th edition. Lea\& Febiger, Malwern (USA). 1990.

DA88 Dawson P. Digital subtraction angiography - a critical analysis. Clinical Radiology. 1988; 39:474477.

DE88 Deutsch AL et al. Incidental detection of hernatopoietic lyperplasia on routine knee mr imaging. American Journal of Radiology. 1988;152:333-335

DE90 Delgado A, Gomez Ros JM. A simple method for glow curve analysis improving TLD-100 performance in the dose region below $100 \mu$ Gy. Radiation Protection Dosimetry. 1990;34(14):357-360.

DE92 Delgado A, Gomez Ros JM, Muniz JL, Portillo JC. Application of glow curve analysis methods to improve TLD-100 dose reassessment performance. Health Physics. 1992;62(3):228-234.

DR85 Driscoll CMH, McWhan A, Richards DJ. A comparative study of the sensitivity and fading characteristics of thermoluminescent LiF chips (technicall note). Rad. Prot. Dos. 1985:11(2):119121.

DR90 Drexler $G$, Panzer $W$, Widenmann $L$, Williams $G$, Zankl M. The Calculation of Dose from Extermal Photon Exposures Using Reference Human Phantoms and Monte Carlo Methodts. Part III: Organ Dases in X-ray Diagnosis. GSF-Bericht 11/90, Munchen (Germany). 1990

DR93 Drexler G, Panzer W, Petoussi N, Zankl M. Effective dose- how effective for parients?. Radiat Environ Biophys. 1993;32:209-219.

DR93a Drexler G, Panzer W, Stieve FE. Widenmann L, Zankl M. Die Bestimmung von Organdosen in der Röngendiagnostik. Hoflman GmbH Verlag Berlin, 1993.

EC84 European Communites, Richnlijn van de Raad van 3 september 1984 tot vaststelling van fundamentele matregelen met betrekking tot de stralingsbescherming van personen die medischi worden onderzoch of behandeld. Publikatieblad van de Europese Gemeenschappen Nr. L 265 (84/466/Euratom). 1984.

FA82 Faulkner K. Moores BM. An assessment of the radiation dose received by staff using fuoroscopic equipment. British Journal of Radiology 1982;55:272-276.

FA88 Faulkner K. Harrison RM. Estimation of Effective Dose Equivalent to Staff in Diagnostic Radiology. Phys. Med. Biol. 1988:33(1):93-91.

FA93 Faulkner K, Marshall NW. The relationship of effective dose to personnel and monitor reading for simulated thoroscopic urradiation conditions. Health Physics, 1993; 64: 502-508.

FE91 Felmlee JP et al. Hand dose measurements in interventional radiology (Operational topics). Health Physics. 1991:60(2):265-267.

FE92 Feygelman VM, Huda W, Peters KR. Effective dose equivalents to patients undergoing cerebral angiography. American Journal of Neuroradiology. 1992;13:845-849.

F195 Fisher $\mathrm{H}$ et al. Die strahlenexposition des Radiologen bei Angiographien: Dosismessungen ausserhalb der Bleischürze. Fortschr. Röntgenstr. 1995;162(2):152-156.

Fo79 Forster D, Mohr H. Radiation protection at urological fluoroscopy working stations. Medicamundi. 1979;24,2:54-58. 


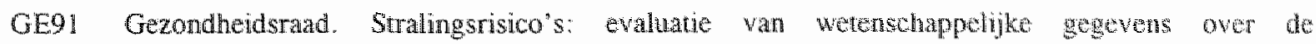

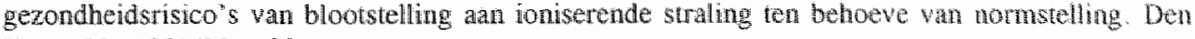
Hang. No 1991/22:1991.

GE92 Geleins I et all. Amber and conventiongl chest radiography: comparison of adiation dose and image qualicy. Rádiology, 1992;185:719-723.

GE94 Gelejus I el al. Comparison of cwo methods for assessing patient dost from computed romography. British Jourmal of Radiology, 1994:67:360-365.

GE94a Geneeskndig Adresboek $93 / 94$ Nederand, Nigh Periodieken B.V. Schedam, The Netherlands [1.Dutch].

GE95 Geleijns J. Patient dosimetry in diagnostic radiology, chest examinations and computed tomography. Thesis. Uniwersity of Leiden. 1995.

GR8 G Gray IE et al. Normalized organ doses for various diagnostic radiological procedures. American Journal of Radiology. 198: :137:463-470.

GR85 Greening IR. Fundamentals of radiation dosimetry. Medical Physics Handbooks no 15 (sec. ed.). Adam Hilger Ltu, Bristol (UK); 1985 .

GR94 Gray $\mathrm{N}$ at al. A patient dose survey for three common diagnostic radiographic axaminations using a dose-area product meter. Australasian Physical \& Engineering. 1994;17(2):79-83.

Gu81 Gustafsson M, Lunderquist A. Persomel exposure to radiation at some angiographic procedures. Radiology. 1981; $140: 807-8 \| 1$.

HA83 Harrison RM et al. A survey of radiation doses to patients in five common diagnostic examinations. The British Joumal of Radiology. 1986;56:383-395.

HA94 Hart D, Jones DG, Wall BF. Normalised organ doses for medical X-ray examinalions calculated using Monte Carlo techniques. National Radiological Protection Board. NRPB Report SR262. Chilton (UK). 1994

HA94a Hart D, Wall BF. Estimation of the effective dose from dosearea product measurements for barium meals and bariom enemas. The British Joumal of Radiology. 1994:67:485-489.

HE87 Health Physics. Special Issue on Radiation Hormesis. Health Physics. 1987,52(5):521-678.

HE94 Hemelaar J. Occupational dosimetry (personal communications). 1994.

HO91 Howe D et al. Patient effective dose equivalent from sellected arteriograms. Presentation, 36 h. annual meeting of the Health Society (July 21-26, 1991), Sheraton, Washington. 1991 .

HU89 Huda $W$ et al. Radiation dose and detriment from chest $X$-ray examinations. Phys. Med. Biol. $1989 ; 34(10): 1477-1492$.

HU90 Huda W. Bews J. Population irradiation factors (PIFs) - in diagnostic medical dosimetry. Health Physics. 1990;59(3);345-347.

HU90a Huda W, Bissessur K. Effective dose equivalents, $H_{\mathrm{E}}$, in radiology. Medical Physics. $1990 ; 17(6): 998-1003$.

HU9 Huda W. Mclellan J. Mclellan $Y$. How will the new detintion of "effective dosc" modify estimates of dose in diagnostic radiology? J. Radiol. Prot. 1991;11(4):241-247.

HU94 Huyskens CJ. Franken Y. Hummel WA. Guidance on personal dosimetry for occupational exposure in interventional radiology. I Radiol Prot 1994:14:229-234.

IC55 ICRP, International Commission on Radiological Protection. Recommendations of the International Commission on Radiological Protection. British Journal of Radiology, supplement 6. 1955 .

IC59 ICRP. International Commission on Radiological Protection. Recomnendations of the International Commission on Radiologicall Protection: Report of Committee II on permissible dose for internal radiation, ICRP Publication 2. Pergamon Press, London. 1959.

IC62 ICRU, International Commission on Radiation Units and Measurements. Radiation Quantilics and Units, ICRU Report 10a, National Bureau of Standards Handbook 84. U.S. Govermment Printing Office, Washington, D.C. (USA); 1962

IC75 ICRP. International Commission on Radiological Protection. Report of the task group on reference man. ICRP Publication 23. Pergamon Press. Oxford (UK). 1975.

IC77 ICRP, International Commission on Radiological Protecion. Recommendations of the International Commission on Radiological Protection. ICRP Publication 26. Pergamon Press, Oxford (UK). $\$ 977$. 
1C78 ICRP, International Commission on Radiological Protection. Statement from the 1978 Stockholm meeting of the International Commission on Radiological Prosection. ICRP Publication 28. Pergamon Press, Oxiord; 1978

IC80 ICRU, International Commission on Radiation Units and Measurements. Radiation Quantities and Units, ICRU Report 33. JCRU, Bethesda (USA): 1980.

IC84 ICRP. International Commission on Radiological Protoction. Nonstochastic effects of ionizing radiation, ICRP Publication 41. Pergamon Press, Oxford: 1984.

IC85 ICRU, International Commission on Radiation Unils and Measurements. Determination of dose equivalents from extemal radiation sources, ICRU Report 39. ICRU, Bethesda (USA); 1985.

1 IC88 ICRU, International Commission on Radiation Units and Measurements. Determination of dose equivalents from external radiation sources- part 2, ICRU Report 43. ICRU, Bethesda (USA); 1988.

IC89 ICRP, International Commission on Radiological Protection. Optimization and Decision-Making in Radiological Protecion, ICRP Publication 55. Pergamon Press, Oxford; 1989.

IC90 ICRP, International Commission on Radiological Protection. Radiological protection of the worker in medicine and dentistry. ICRP Publication 57. Perganon Press, Oxford, UK. 1990.

IC91 ICRP, International Commission on Radiological Protection, 1990 Recommendations of the International Commission on Radiological Protection. ICRP publication 60. Pergamon Press, Oxford (UK). 1991.

IC9la ICRP. International Commission on Radiological Protection. Risks Associated with ionising radiation. Arnals of the ICRP. Pergamon Press, Oxford; 1991:22(1).

IC9lb ICRP, International Commission on Radiological Protection. The biological basis for dose linnitation in the skin, ICRP Publication 59. Pergamon Press, 1991.

$1 \mathrm{C} 92$ ICRU, International Commission on Radiation Unirs and Measurements. Measurement of dose equivalents from external photon and electron radiations, ICRU Report 47. ICRU, Bethesda (USA); 1982 .

IC92a ICRU International Commission on Radiation Units and Measurements. Phantoms and computational models in therapy, diagnosis and protection. ICRU-Report 48. Bethesda (USA). 1992.

IC92b ICRU, International Commission on Radiation Units and Measurements. Photon, electron, proton and neutron interaction data for body tissues. ICRU-Report 46. Bethesda (USA). 1992.

IC920 International Commission on Radiological Protection. Radiological Protection in Biomedical Research. Publication 62. Pergamon Press. Oxford (UK). 1992.

IC93 ICRU, International Commission on Radiation Units and Measurements. Radiation Quantities and Units in Radiation Protection Dosimetry. ICRU Report 51. ICRU, Bethesda (USA); 1993.

JE90 Jeans WD. Review article: the development and use of digital subtraction angiography. The British Journal of Radiology. 1990;63:161-168.

1085 Jones $\mathrm{DG}$. Wall BF. Organ Doses from Medical $X$-ray Examinations Calculated Using Monte Carllo Techniques. NRPB-Report 186. National Radiological Protection Board. Chilton (UK). 1985.

J087 Johnsrude IS, Jackson DC, Dumick NR. A practical approach to angiography (sec. ed.). Little Brown and Company, Boston. 1987.

KA78 Kase KR, Nelson WR. Concepts of Radiation Dosinetry. Pergamon Press. New York, 1978.

KA90 Kanal E. Shellock FG. Talagala $\mathbb{L}$. Safety considerations in MR imaging. Radiology. $1990 ; 176: 593-606$.

KE80 Kereiakes JG. Rosenstein M. Handbook of Radiation Doses in Nwclear Medicine and Diagnostic X-Ray, CRC Press, USA (1980).

KA82 Kauffmann GW. Flemming K, Friedburg H. Schattenberg S. Einflusse der strahlenbelastung in der rontgendiagnostik. Radiologe. 1982:22:235-240.

KE90 Kempen RJ van. Pattern of Diagnostic Procedures in Radiology in The Netherlands. Rad Prot Dosimeiry 1990; 36: 257-259.

K188 Kicken PJH. Stralingsbelasting van radiologen en rontgenlaboranten bij CT-scanning en angioonderzoken (1987). Internal report SBD/CZ 6785. SBD, University of Technology Eindhoven. 1988.

KI88a Kicken PJH et al. Radiation exposure during cardiac catheterization procedures. Proceedings of IRPA-7 Congress, Sidney. 1988. 
K191 Kicken PJ. Walstra R. Kenerink GJ. Computational Dosimerry for Angiography of Aoriolliac and Peripheral Vessels, (input data for Monte Carlo computations). University Hospical of Matastricht, report fys204 (1991).

K192 Kicken PJH, Kenerink GJ, Vaessen PJ, Ackermans JJ. An sutonated measurement system for characterisation of parient exposure during angiography. Rad Prot Dosimetry 1992:44(1/4):165169.

Klig2a Kicken PH. Occupational exposure in vascular radiology in the University Hospital Maastricht The Netherlands. Internal report 1992, fys.281 (in Dutch)

K193 Kicken PJH. Occupational exposures in angiography and interventional radiology in the University Hospital Maastricht, part 2. Imternal report 1993 . fys.390 (in dutch).

K193b Kicken PJH. Occupational exposure in vascular radiology in the De Wever Hospital Heerlen The Netherlands. Internal report 1993, fys. 353 (in Dutch).

K193c Kicken PJH. Occupational exposure in vascular radiology in the Maasland Hospital Sittard The Netherlands. Internal report 1993, fys.371 \& fys.380 (in Dutch).

K195 Kicken PJH, Kemerink GJ. Engelshoven JMA van. Vascular radiology in the Nethertands in 1992: a quantitative approach. European Journal of Radiology. 1995;19:212-219.

KR86 Kramer R, Zankl M, Williams G, Drexler G. The Calculation of Dose from External Photon Exposures Using Reference Human Phantoms and Monte Carlo Methods. Part I: The Male (Adam) and Female (Eva) Adult Mathematical Phantoms. GSF-Bericht S-885. Munchen (Germany). 1986.

LA78 Lackner K, Ewen K, Felix R. Die Strahlenexposition des Untersuchers bei Angiography. Fortschr. Röntgenstr. 1978;128:86-90.

LA85 Law J. Doses to head and arms of radiologists during fluoroscopy (short communication). The British Journal of Radiology. 1985;58:187 188 .

LA90 Laubenberger $T$. Techniek der medizinischen radiologie, Deutscher Arzte-Veriag Kön (Germany). 1990.

LA93 Lang PH et al. Hematopoietic bone marrow in the adult knee: spin-echo and opposed-phase gradient-echo mr imaging. Skeletal Radiology. 1993;22:95-103.

LA89 Law $J$ et al. Radiation dose to urological surgeons during $X$-ray fluoroscopy for percutancons stone extraction. British Journal of Radiology. 1989:62:185-187.

LE86 Lee KR et al. Intraarterial digital subtraction arteriographic evaluation of extremity numours: comparsson with conventional arteriography. Radiology $1986 ; 158: 255-258$.

LE92 Le Heron J. Effective dose in diagnostic radiology. Journal of Radiological Protection. 1992;12:111-112.

LE92a Le Heron J. Estimation of effective dose to the patient during medical X-ray examinations from measurements of the dose-area product. Physics in Medicine and Biology, 1992;37:2117-2126.

LE94 Le Heron JC. XDOSE: a user"s guide. National Radiation Laboratory. Ministry of Heallh. Christchurch (New Zealand). 1994.

L192 Lindskoug. BA. The reference man in dagnostic radiology dosimety. The British loumal of Radiology, 1992:65:43:-437.

LO86 Lowe F et al. Montoring radiation exposure to medical personnel during percutaneous nephrolithotomy. Urology. 1986:28:221-226.

LO93 Loken MK. Feinendegen LE. Radiation Hormesis, its emerging significance in medical practice. Investigative Radiology. $1993: 28(5): 446-450$.

LO93: Lowry KA, Lee Y, Gorbics SJ, Johnson TL. Method for the rapid deconvulation of thermoluminescence glow curves. Radiation Protection Dosimetry. 1993:47(1-4):493-496.

MA84 Marshall TO, Inst P. Accuracy and precision in thermoluninescence dosimetry. The Hospial Physicists Association, Practical Apects of Thermoluminesce Dosimetry (editor AP Hufion). HPA, London (UK). 1984.

MA88 Maccia C. Beneditinni M. Lefaure C. Doses to patients from diagnostic radiology in France. Health Physics. 198:854(4):397-408

MA92 Marshall NW. Fanlkner $K$. The dependence of the seattered radiation dose to personnel on technique factors in diagnostic radiology. The Brilish Journal of Radiology, 1992;65:44-49.

MA93 Mansson LG, Wallstrom $E$, Mattsson $S$. Relations between effecive dose, effecife dosc equivalent, area-kerma product, and energy imparted in chest radiography. Radiation Protoction Dosimetry, 1993:49(4):421-431 
MA94. Marshall WW et all. A comparison of radiation dose in examination of the abdomen using different radiological imaging techniques. The British Journal of Radiology. 1994:67:478-484.

MA95 Marsliall NW. Faulkner K. Optimization of personnel shielding in interventional radiology. Procerdings of a BIR-CEC Meeting held on 6 December 1993, Radiation Protection in Interventional Radiology. BIR, London. 1995

MA95a Marshall WW, Noble J, Faulkner K. Patsent and staff dosimetry in neuroradiological procedures. The British Journal of Radiology. 1955:68:495-501.

MC8. Mckinlay AF. Thermoluminescence dosinnetry. Medical Physics Handbooks 5. Adam Hilger Lid, Bristol, UK. 1981

MC83 MCGuire EL. Baker ML. Vandergif JF. Evaluation of radiation exposures to personnel in nuoroscopic $x$-ray facilities. Healih Physics 1983;45:975-980.

MC90 Mcparland BI, Nosil I. Burry B. A survey of xadiation exposures received by the staff at two cardiac catheterization laboratories. The British Journal of Radiology. 1990:63:885-888.

MO80 Moller P. Fehrentz. Dosismessungen an patienten. Therapiewoche. 1980; 30:3434-3440.

M090 Moore SG. Dawson KL. Red and yellow marrow in the femur: age-related changes in appearance at nur imaging. Radiology. 1990;175:219-223.

MO92 Montgomery DC, Peck EA. Introduction to linear regression analysis (2nd ed). Willey \& Sons. Inc. New York. 1992.

M092 Moore B et al. The relationship between back pain and lead apron use in radiologists. American Journal of Radiology. 1992;158:191-193.

M093 Moscovitch M, Taylor PL, Rodgers JE, MCRae DA. An algorthm for supralinearity correction applied to radiation therapy thermoluminescence dosimetry. Radiation Protection Dosimetry. $1993: 47(1-4): 505 \% 508$

M095 Morrison GD, Underwood AC. Entrance doses during lateral lumbar spine and antero-posterior abdornen examinations: generator waveform dependence. The British Journal of Radiology. $1995: 68: 491 \times 494$.

MU89 Mustafa AA, Janeczek J. Organ doses from cardiac and carotid digital subtraction angiography. The Britisin Journal of Radiology. 1989;62:838-842.

NA93 Nariyama $N$ et al. Responses of LiF TLDs to $10-40 \mathrm{keV}$ monoenergetic photons from synchrotron radiation. Radiation Protection Dosimetry. 1993;49(4):451-457.

NC83 NCRP, National Council on Radiation Protection and Measurements. Biological effects of ultrasound: Mechanisns and clinical umplications. National Council on Radiation Protection and Measurements. NCRP Report No. 74. Bethesda (USA). 1983.

NC89 NCRP, National Council on Radiation Protection and Measurements, Medical X-ray, electron bean and ganma-ray protection for energies up to $50 \mathrm{MeV}$. NCRP Report No. 102. NCRP. Bethesda (US). 1989.

NCB9; NCRP. National Council on Radiation Protection and Measurements. Radiation Protection for Medical and Allied Health Personnel. NCRP Report No. 105. NCRP. Bethesda (US). 1989.

NC90 NCRP. National Council on Radiation Protection and Measurements. Implementation of the Principles of As Low as Reasonably Achievable (ALARA) for Medical and Dental Personnel. NCRP report No. 107. NCRP, Bethesda (USA); 1990.

NC91 NCRP, National Council on Radiation Protection and Measurements. Conceptual basis for calculations of absorbed-dose distributions. NCRP report No 108. NCRP. Bethesda (USA); 1991.

NC92 NCRP. National Council on Radiation Protection and Measurements. Exposure criteria for medical diagnostic ultrasound: 1. Criteria based on thermal mechanisms. National Council on Radiation Protection and Measurements. NCRP Report No. 113. Bethesda (USA). 1992.

NH91 NHMRC. Safery Guidelines for magnetic resonance diagnostic facilities. National Health and medical research council. Radiation Health Series No. 34. Canberta. (Australia). 1991.

N193 Niklason LT, Marx. MV, Chan HP. Interventional radiologists: occuppational radiation doses and risks. Radiology. 1993; 187:729-733.

N194 Niklason LT, Marx MV, Chan HP. The estimation of occupational effective dose in diagnostic radiology with two dosimeters. Health Physics 1994;67:611-615.

NR90 NRPB. Patient dose reduction in diagnostic radiology. Documents of the NRPB. Chilton, UK. $1990 ; 1(3)$ 
NR91 NRPB. Board statement on clinical magnetic resonance diagnostic procodures. Nanional Radiological Protection Board. Documents of the NRPB. $1991,2(1)$

NR93 NRPB. Occupational, public and medical exposure. Documents of the NRPB. Chilton, UK. $1993: 4(2)$.

OB81 Oberhofer M, Scharman A (ediors). Applied Thermoluminescence dosimetry. 1spra course 1979. Adarm Hilger Lud. Bristol (UK), 1991.

PA82 Pavlicek W, et al. Patient doses during digital subtraction angiograply of the carotid anteries: comparison with conventional angiography. Radiology. 1982; 145:683-685.

PA83 Paix $D$. Backscatter from diagnostic $x$ rays from metals. Communications in Medical Physics. 1983:10(1):112-113.

PA83a Passariello $R$ ef al. Radiation exposure of the patient in conventional and digital intravenous angiography. Ann Radiol. 1983;26(7):548-550.

PA87 Padovani $R$ et al. Patient doses and risks from diagnostic radiology in North-east ltaly. The British Journal of Radiology. 1987:60:155-165.

PA91 Prat TA, Sweeney $\ K$. Occupational exposure in the national health service- the north westem region. Radiation Protection Dosimetry. 1991:36(2/4):225-227.

PA92 Page JE. Walker WJ Complications artributable to the formation of the track in patients undergoing percutaneous nephrolithomoty. Clinical Radiology. 1992;45:20-22

PE90 Perkins JL, Cutter GN, Cleveland MS. Estimating the mean, variance, and confidence limits from censored (<limil of detection), lognormally distributed exposure data. Am. Ind. Hyg. Assoc. J. $1990 ; 51: 416-419$.

PE91 Perks CA. Marshall M. Techniques for thermoluminescence glow curve analysis. Radiation Protection Dosimetry. 199; 38:(4):261-269.

PE93 Persliden J, Sandborg M. Conversion factors between energy imparted to the patient and air collission kerna integrated over beam area in pediatrie radiology. Ack Radiologica 1993;34:92. 98.

PE95 Petoussi-Henss, Panzer W. Zankl M, Drexler G. Dose-area product and body dose. Radiation Protection Dosimetry. 1995;57(1-4):363-366.

PH155 Philips Medical Systems. Diagnost Arc U Product data. Philips Medical Systems Best (Netherlands). 1985.

PH85a Philips Medical Systems. Diagnost Arc U, operator's manual. Philips Medical Systems Best (Netherlands). 1985.

PH86 Philips Medical Systems. Digital Subtraction Angiography. Philips Medical Systems Best (Netherlands). 1986.

PL86 Plunket MB, Gray JE. Kispent DB. Radiation exposure from conventional and digital subtraction angiography of cerebral wessels. American Journal of Neuroradiology. 1986;7:665-668.

P093 Poel LCJ van der. Centraal Orgaan Tarieven Gezondheidszorg, PO Box 3017, 3502 GA Urecht. document 5621/1500/93/I. February 151993 [Dutch].

PR81 Pradhan AS. Thermoluminescence dosimetry and its applications. Rad. Prot. Dos, 1981;1(3):153167.

PY78 Pychlau P. Messen des flachendosisproduktes in R.cm². Röntgenpraxis. 1978:31(5):115-119.

PY94 Pychlau P. Dose-area product meter calibration and use. Measurement Assurance in Dosimetry. Proceedings of a symposium in Vienna in 1993. IAEA, Viemna 1994.

RA90 Rawlings DJ. Faulkner $\mathrm{K}$, Harrison RM. Broad-beam transmission data in lead for scatnered radiation produced at diagnostic energies (short conmunication). Br I Radiology 1990;64:69-71.

RA90a Ramsdale ML, Walker WJ, Horton PW. Extremity doses during interventional radiology. Clinical Radiology. 1990;41;34;6.

RE94 Reece WD, Poston JW, XU XG. Determining the effective dose equivalent for external photon radiation: calculational results for beam and point source geometries. Radiation Protection Dosimetry. $2994: 55(1): 5-21$.

R172 Riley R et al. Exposure of Radiologists during Special Procedures. Radiology. 1972;104:679-683.

RO78 Rosenbaum AE, Anold BA. Postero-anterior radiography: a method for reduction of eye dose (technical note). Radiology. 1978:129:812.

RO91 Roberts PJ, Temperton DH. Occupational exposures in UK hospitals. Radiation Protection Dosimetry. 1991:36(2/4):229-232. 
R094 Rosenstein M. Webster EW. Effectwe dose to personnel wearing protective aprons during furoroscopy and interventionall radiology (correspondence). Health Physics 1994; 67:88-89.

R095 Röngen WC. On a new kind of rays (preliminary communication). Nature 1896;53:274-276. (Originally published in Germany: Sitzungberichte der Wurzburger Physikmed Gesellschaft. $1895,17: 132-141)$.

SA75 Santen $B C$, at. Exposure to the radiologist to scattered radiation during angiography. Radiology. 1975:115:447-450.

SA89 SAS Institute Inc, SAS procedures Guides, SAS/STAT User"s Guide, release 6.03, 1989.

SC94 Schultz FW, Gelejins J, Zoetelief J. Calculation of dose conversion factors for PA chest radiography of adults with relatively high-energy X-ray spectrum. British Journal of Radiology. $1994 ; 67: 775-785$.

SC94a Schulk FW, Jansen JThM, van Unmik JG, Geleijns J, Teeuwisse W, Broerse JJ, Zoetelief J. Calculated factors to convert dose-area product into organ dose for $x$-ray examinations of colon and stomach of adults: dependence on phantoms used. Proceedings of the 10th antrual symposium of the Belgian Association of Hospital Physicists. Dexember 9-10, 1994.

SC95 Schultz FW, Geleijns J. Zoetelief J. Effective doses for different techniques used for PA chest radiography. Proc. of workshop Grado, Italy, Sept. 29- Oct. 1, 1993. Radiation Protection Dosimetry 1995:57:371-376.

SC95a Schultz FW. Personal communication.

SE87 Seuntjes J, Thierens H, van de Plaetsen A, Segaert O. Conversion factor for $x$-ray beam qualities, specified by peak tube potential and HVL value. Phys. Med. Biol. 1987;32(5):595-603.

SE92 Serwomaa A, Ranuiko S, Ermakov I. Assessment of effective dose in $\mathrm{x}$ ray imaging in view of the proposed ICRP risk factors. Radiation Protection Dosimerry. 1992;43(1/4):225-227.

SH79 Schinz HR et al (editors). Lehrbuch der röntgendiagnostik. Band II/Teill 1. Georg Thicme Verlag. Stuttgart (Germany). 1979.

SH82 Shrimpton $P C$, Wall BF. An evaluation of the Diamentor transmission ionisation chamber in indicating exposurc-area product $\left(R \mathrm{~cm}^{2}\right)$ during diagnostic radiological examinations. Phys. Med. Biol. 1982:27(6):871-878

SH84 Shrimpton PC, Wall BF, Jones DG, Fisher ES. The measurement of energy imparted to patients during diagmostic x-ray examinations using the Diamentor exposure-area product meter. Phys. Med. Biol, $1984 ; 29(10): 1199-1208$

SH86 Shrimpton $P C$, et al. A national survey of patients undergoing a selection of routine $X$-ray examinations in English hospitals, National Radiological Protection Board Report R200. Chilton $(\mathrm{UK}) ; 1986$.

SH92 Shellock FG er at. Hematopoietic bone marrow hyperplasia: high prevalence on mr images of the knee in asymptomatic marathon runners. American Journal of Radiology. 1992;158:335-338.

S188 Siegel S. Castellan NJ. Nonparametric statistics for the behavioral sciences (second edition). McGraw-Hill Book Company Singapore. 1988.

ST93 Steele HR, Temperton DH. Patient doses received during digital subraction angiography (Technical note). The British Journal of Radiology. 1993;66:452-456.

TA.89 Taylor LS. 80 Years of quantities and units personal reminiscence (part I): from a variety of radiation units to the international standard. ICRU News. $1989 ; 1: 6-14$.

TA89a Taylor C. Cowen AR, Wilson U. Patient absorbed dose in digital subtraction angiography. BIR Report 20. British Institute of Radiology, London. 1989:200-202.

TH88 Thijssen MAO, et al. Quality analysis of DSA equipment. Neuroradiology. 1988;30:561-568.

T192 Timmernans C. Beentjes L. Stralingsbelasting van de Nederlandse Bevolking I.g.v. de medische roepassing wan ioniserende straling, VROM rapport nr 54. VROM distributiecentrum, Zoetermeer: 1992.

TR87 Tryhus M. Metter FA, Kelsey C. The radiologist and angiographic procedures: absorbed radiation dose. Invest Radiology 1987;22:747-750.

rs9o TSuno MM, Gang Jian Shu. Posteranterior versus anteroposterior lumbar spine radiology. Journal of Manipulative and Physiological Therapeutics. 1990;13(3):144-151.

UN82 United Nations Scientific Committee on the effects of atomic radliation. Ionizing radiation: Sources and biological effects. UNSCEAR 1982 Report to the General Assembly, with annexes. United Nations. New York: 1982. 
UN86 United Nations Scientific Comminee on the effects of alomic radiation. Genetio and somatic effects of ionizing radiation. UNSCEAR 1986 Report to the General Assembly, whth annexes. United Nations, New York; 1986.

UN88 United Nations Scientific Committee on the effects of atomic radianion. Sources, effects and risks of ionizing radiation. UNSCEAR 1988 Report to the General Assembly, with annexes. United Nations, New York; 1988.

UN93 United Nations Scientific Committee on the Effects of Atomic Radiation. Sources and effects of ionizing radiation. UNSCEAR 1993 Report to the General Assembly, with amnexes. United Nations, New York; 1993.

UN94 United Nations Scienific Committee on the Effects of Atomic Ratiation. Sources and effects of ionizing radiation. UNSCEAR 1994 Report to the General Assembly, with annexes, United Nations, New York; 1994.

US70 US Department of Health, Education, and Weltare. Radiological Health Handbook (edition 1970 ).

VA91 Vaas LH, Blauwber RO, Leenhouts HP. Radiation sources, doses and dose distributions in the Netherlands. Radiation Protection Dosimetry. 1991;36(2/4):89-92.

VA92 Valois de JC. Radiodiagnostiek in Nederland. Medisch Contacr 1992; 47: 1383-1384 [Dutch].

VE89 Veit R et al. Tomographic anthropomorphic models, part I: construction technique and description of models of an 8 week old baby and a 7 year old child. Institut fur Strahtenschutz. GSF-Bericht3/89. Munchen (Germany). 1989.

VE9H Vehmas $T$, et al. Radiation exposure during percutaneouls nephrostomy. Fortschr. Röntgenstr. $1991 ; 154,3: 238-241$.

VE92 Vehmas $T$. Tikkanen $H$. Measuring radiation exposure during percutaneous drainages: can shoulder dosemeters be used to estimate finger doses? The British Journal of Radiology. $1992 ; 66: 1007-1010$.

VE93 Vehmas T. What factors infuence radiologists" finger doses during percutaneous drainages under fluoroscopic Guidance? Health Physics. 1993;65(2):161-163.

VE93a Veit $R$, Zankl $M$. Variation of organ doses in paediatric radiology due to patient diameter, calculated with phantoms of warying voxel size. Radiation Protection Dosimetry. 1993;1/3,353356.

V088 Vogter JB, Murphy WA. Bone marrow imaging. Radjology. 1988;168:679-693.

WA88 Wall BF, Russell JGB. The application of cost-tility analysis to radiological protection in diagnostic radiology. Journal of Radiological Protection. 1988;8(4):221-229.

WA88a Wall BF, Harrison RM, Spiers FW (editors). Patient dosimetry techniques in diagnostic radiology. The Institute of Physical Sciences in Medicine, Report No. 53. York (UK). 1988.

WA88b Wall BF, Russel JGB. Quantification of radiation harm from diagnostic X-rays. The Institute of Physical Sciences in Medicine. Report No. 55. York (UK). 1988: 7-18.

WA88c Wagner LK et al. Energy and rate dependence of diagnostic x-ray exposure meters. Med. Phys. $1988 ; 15(5): 749-753$.

WA89 Wall BF. Quality control of dose-area product meters. British Institute of Radiology. BIR Report 18. London. 1989; 140-142.

WA89a Wall BF, Shrimpton. Patient expasure criteria. The Brilish Institute of Radiology. BIR Report 20. London. 1989:239m241.

WE89 Webster EW. Effective dose equivalem for exposure with protective aprons [correspondence]. Health Physics 1989; 56: 568-569.

WE93 Webster EW. Hormesis and tadiation protection. Investigative Radiology. 1993:28(5):451 -453.

WH90 Whitehouse GH, Worthington BS. Techniques in diagnostic imaging (sec. editiona). Blackwell Scientific Publications. Oxford. 1990.

WI91 Will W. Energy independent measurement of photon individual dose equivalents with LiF derectors behind combined filters. Radiation Protection Dosimetry. 1991;1:55-58.

W192 Winsen van J, et al. Stralingsbelasting van werkers in Nederland. NVS-Nicuws. Matastricht (Netherlands). $1992: 17(4): 8,13$.

Wo89 Workman A, Cowen AR. A review of automatic exposure control of conventionall and digital systems. BIR Report 18, Technical and physical parameters for quality assurance in medical diagnostic radiology. Alden Press, Oxford. 1989.

WY95 Wyngaarden KE van, Pauwels EKJ. Hormesis: are low doses of ionizing radiation harmful or beneficial?. Eur I Nucl Med. 1995:22(5):481-486. 
YA94 Yamaguchi $Y$. Age-dependent effective doses for external photons. Radiation Protection Dosimeiry. 1994;55(2):123-129.

YA94a Yamaguchi $Y$. Journal of nuclear science and rechnology. 1994;31(7):716-725.

ZA8.3 Zarand P. Polgar I. On the background subtractio in 'low-dose' measurements using thermoluminescence dosemeters. Phys. Med. Biol. 1983; 28(2):161-168.

ZA92 Zankl M, Petoussi $\mathrm{N}$, Drexler G, Effective dose and effective dose equivalent- The impact of the new ICRP Definition for external photon irradiation. Health Physics. 1992;62(5):395-399.

ZA93 Zankl M. Compuiationall models employed for dose assessment in diagnostic radiology. Radiation Protection Dosimetry. $1993 ; 1 / 3 ; 339-344$.

ZA93a Zawin $J K$, Jaramillo $D$. Conversion of bone marrow in the humerus, sternum and clavicle: changes with agc on mri images. Radiology. 1993;188:159-164.

ZA95 ZankJ M, Drexler $G$. An analysis of the equivalent dose calculation for the remainder tissues. Health Physics. 1995; 69(3):346 -355.

ZA95a Zankl M. Personal communication. 1995. 


\section{Samenvatting}

Röntgentoestellen worden op grote schaal toegepast bij medische diagnostiek en interventies. In het totaal van de radiologische verrichtingen in Nederland nemen angiografie en vasculaire interventie met relatieve frequenties van respectievelijk $1,1 \%$ en $0,8 \%$ een bescheiden plaats in. De tot 1990 gepubliceerde gegevens indiceerden echter dat de individuele strallingsdoses van patiënten en personeel bij deze stralingstoepassingen aanzienlijk hoger konden zijn dan bij standaard röntgenonderzoeken. Ook lieten deze gegevens grote variaties zien in de dosisschattingen. Teneinde meer imzicht te krijgen in de stralingsdoses en de mogelijke maatregelen voor dosisbeperking werd in drie ziekenhuizen een studie uitgevoerd.

In het proefschrift is een beschrijwing gegeven van de methode en resultaten van de schatting van de stralingsdoses van zowel patiènten alsmede van catheteriseurs en assistenten. Tevens is de samenhang tussen enkele (dosis)gegevens onderzocht en zijn aanbevelingen gegeven voor de bepaling van de beroepsmatige blootstelling en voor stralingsbescherming van patiënten en personeel.

Bij de schatting van de patièntdoses werd gebruik gemakt van een geautomatiseerd meetsysteem dat elektronisch werd gekoppeld aan het röntgensysteem. Hiermee werd bij meer dan 1000 patiënten tijdsafhankelijke informatie verkregen over relevante toestelparameters zoals buisspanning, veldgrootte, afbeeldingstechniek (doorlichten, radiografie, digitale subtractie angiografie), aantal afbeeldingen en doorlichtijd. Met een in de primaire röntgenbundel geplaatste vlakke transmissie ionisatiekamer werd continu het dosis*oppervlakte produkt (DAP) geregistreerd. Berekeningen van de effectieve dosis voor de patiënt werden uitgevoerd m.b.v. zogenaamde orgaandosisconversiecoëfficiënten, die voor geselecteerde diagnostische projecties de verhouding weergeven tussen de orgaandosis en de intreedosis of de orgaandosis en DAP. De in de literatuur gevonden conversiecoëfficiënten werden door Monte Carlo dosisberekeningen bij TNO (Rijswijk) en GSF (München) uitgebreid. De doses voor het personeel werden geschat met thermoluminescentie dosimeters. Bij meer dan 350 patientonderzoeken werden dosimeters gedragen werden op diverse plaatsen op het lichaam ( 0. a. voorhoofd, handen, onderbenen, borst en hals). Evenals bij de patienten werd woor schatting van de effectieve doses wan het personeel gebruik gemaakt van dosisconversiecoëfficiënten. De resultaten hebben betrekking op meerdere typen angiografie en vasculaire interventie.

De effectieve dosis van de patiënt varieerde tussen $0, \mathbb{l}$ en $40 \mathrm{mSv}$ per onderzoek. De gemiddelde effectieve dosis per patiëntonderzoek werd geschat op $4 \mathrm{mSv}$ voor intraarteriële arteriografie, op $6 \mathrm{mSv}$ voor intraveneuze DSA en op $12 \mathrm{mSv}$ voor vasculatre interventie radiologie. De relatieve bijdrage van arteriografie en vasculaire interventie in de collectieve effectieve dosis door radiologie werd geschat op $4 \%$.

De per behandelingstype gemiddelde effectieve dosis van de catheteriseur varieerde iussen 0,5 en $3,5 \mu \mathrm{Sv}$ bij gebruik van toestellen met de röntgenbuis onder de patiëntafel en tussen 0,5 en $20 \mu \mathrm{Sv}$ voor boventafelbuissystemen. Voor ondertafelbuissystemen was de 
effectieve dosis van de assistent gemiddeld een factor 1.5 kleiner dan voor de catheteriseur; bij boventafelbuissystemen was deze verhouding gelijk aan 3,5. De relatieve bijdrage van vasculaire onderzoeken en interventies in de beroepshalve ontvangen effectieve dosis door radiodiagnostiek werd geschat op circa $70 \%$. Met modelberekeningen werd afgeleid dat de effectieve dosis met een factor twee kan worden verminderd door een schildklierkraag te dragen. Uit statistisch onderzoek bleek dat de effectieve dosis van de catheteriseur kan worden geschat door DAP doorlichien te vermenigvuldigen met een conversiefactor, die afhankelijk van de blootstellingscondities varieert tussen 0,07 en 0,8 $\mu \mathrm{Sv} \cdot \mathrm{Gy}^{-1} \cdot \mathrm{cm}^{-2}$; als vuistregel kan de omrekenfactor $1 \mu \mathrm{Sv} \cdot \mathrm{Gy} y^{-1} \cdot \mathrm{cm}^{-2}$ worden gehanteerd. Wanneer de beroepshalve blootstelling wordt bepaald m.b.v. een intreedosismeting in de halsstreek kan de effectieve dosis worden geschat door dit meetresultaat te vermenigvuldigen met een conversiecoëfficiënt van $0,1 \mathrm{mSv} \cdot \mathrm{mGy}^{-1}$.

Samenvattend wordt gesteld dat uit deze studie blijkt dat zowel de medische alsmede de beroepshalve ontvangen stralingsbelasting bij arteriografie en vasculaire interventie radiologie, bij een goede werktechniek, niet onrustbarend hoog zijn. Hoewel voor digitale afbeelding een lagere stralingsintensiteit benodigd is dan voor radiografie, blijkt in de praktijk dat de stralingsdosis per patiëntonderzoek bij gebruik van digitalle systemen hoger kan zijn. Dit wordt vooral veroorzaakt door de grote aantallen afbeeldingen die worden geproduceerd. Het verdient dan ook aanbeveling om (werk)methoden te ontwikkelen om het aantal digitale afbeeldingen te beperken. In combinatie met het stimuleren van het gebruik van röntgensystemen met een ondertafelbuis en het toepassen van elektrische contrastvloeistofinjectiesystemen, het beperken van de doorlichttijd en veldgrootte, en het vergroten van de stralingsbeschermingskennis bij de uitwoerenden zijn er goede mogelijkheden om de stralingsdosis van zowel de patiënt als de medewerker, met behoud van de medisch diagnostische kwaliteit, nog verder te beperken. 


\section{Acknowledgement}

Dit proefschrift is gebaseerd op onderzoek bij de afdeling Radiodiagnostiek van het Academisch Ziekenhuis te Maastricht (azM). Bij dit onderzoek waren ook betrokken de afdeling Radiodiagnostiek van het Maasland Ziekenhuis te Sittard, de afdeling Radiodiagnostiek van het De Wever Ziekenhuis te Heerlen, TNO, Centrum voor Stralingsbescherming en Dosimetrie te Rijswijk, GSF-Institut für Strahlenschutz te München, en het IRI/Technische Universiteit Delft. Bij de uitvoering van de thermoluminescentie dosimetrie werd gebruik gemaakt wan de faciliteiten van het gemeenschappelijk Dosimetriecentrum van het azM, de Rijks Universiteit Limburg en het De Wever Ziekenhuis.

Het onderzoek werd financieel ondersteund door het Ministerie van Sociale Zaken en Werkgelegenheid, het Ministerie van Welzijn, Volksgezondheid en Cultuur, en de afdeling Radiodiagnostiek (azM).

Wetenschappelijk onderzoek in een klinische ongeving kan uitsluitend plaatsvinden wanneer het betrokken (para)medisch en ondersteunend personeel oog heeft voor de problematiek van dit onderzoek. In de drie ziekenhuizen waar dit onderzoek is uitgevoerd werd in ruime mate aan deze randwoorwaarde voldaan. De medewerking van het Maasland Ziekenhuis en het De Wever Ziekenhuis is zonder meer uitstekend te noemen.

In dit onderzoek hebben velen wetenschappelijk, technisch of mental ondersteuning geboden. Zonder anderen te kort te willen doen, wil ik enkele personen nadrukkelijk bedanken.

Prof. dr. J.M.A. van Engelshoven. Zeer geachte eerste promotor, beste Jos. Ik heb het zeer op prijs gesteld dat je mijn promotor wilde zijn. Jouw medische inbreng, andach yoor hoofdlijnen en kritische benadering van strallingsdosimetrische informatie en stralingsheschermingsaspecten hebben grote invloed gehad op de beschrijving van de studie-opzet en conclusies. Dat het proefschrift uiteindelijk is afgerond is voor een belangrijk deel te danken aan de beperkingen die je, vanuit een pragmatische benadering. aan de eindopdracht hebt meegegeven. Je adviezen hebben een belangrijke bijdrage geleverd aan de uiteindelijke worm van dit proefschrift. Ik ben je dankbaar voor de gelegenheid die je mij hebt geboden on dit onderzoek binnen je afdeling te kunnen uitvoeren.

Prof. dr. J.J. Broerse. Zeer geache tweede promotor, beste Johan. Een betere tweede promotor voor dit onderzoek had ik mij niet kumnen wensen. Jouw inzicht in wetenschappelijk onderzoek in de stralingsclosimetrie en verslaglegging is van groot belang geweest voor dit proefschrift. Je hebt ongetwijfeld meerdere correctie-potloodjes versieten in je pogingen om vraagstellingen, onderzoekopzet, resultaten en conclusies helder en correct geformuleerd te doen krijgen. Jouw kritische kanttekeningen en onze discussies over hoofdlijnen en punten en komma"s heb ik erg gewardeerd. 
Dr. G.J. Kemerink, klinisch fysicus Radiodiagnostiek azM Zeer geachte co-promotor, beste Gerrit. Jouw begeleiding en fysische inbreng zijn zeer belangrijk geweest voor de realisatie van nagenoeg alle onderdelen van dit project. Je wetenschappelijke benadering, maar ook je collegiale houding heb ik als zeer positief en stimulerend ervaren. Jouw kennis wan elektronica, fysica en stralingsdosimetrie waren van onschatbare waarde. Zonder mankeren wist je de zwakke plekken in methoden en werkwijzen bloot te leggen, zodat onnodig onderzoek kon worden voorkomen. Bovendien droeg je met grote regelmaat oplossingen aan voor gesignaleerde problemen. In de afrondende fase heb je veel tijd besteed aan het bewerken van ruwe teksten. Heel veel dank.

De beoordelingscommissie bestaande uit prof. dr. A. Hasman (voorzitter), prof. dr. P.J.E.H.M. Kitslaar, dr. L.B. Beentjes en dr. J. Zoetelief, wil ik graag danken voor de tijd om dit proefschrift aan een kritisch onderzoek te onderwerpen.

Mevr. M. Frantzen, medewerkster Dosimetriecentrum azM. Beste Marij, zonder jouw inspanningen zouden de vele metingen ongetwijfeld aanzienlijk minder uitgebreid en betrouwbaar zijn uitgevoerd. Met je paramedische achtergrond en je opgewekt humeur was je in deze studie de ideale partner om 'handen en voeten' te geven aan variabele gedachten over opzet en uitvoering van vele verschillende (dosis)metingen. Ik denk met veel plezier terug aan onze goede samenwerking.

Mevr. H. Nelissen, coördinerend radiodiagnostisch laborant vaatkamer azM. Beste Hetty, jij hebt ondanks de hoge werkdruk vele uren vrijgemaakt om mij in de gelegenheid te stellen de benodigde experimenten en metingen in de vaatkamer te laten uitvoeren. Zonder jouw 'colleges' over angiografie en je ondersteuning bij de evaluatie van de geregistreerde gegevens was het onderzoek aanzienlijk stroever verlopen. Hetty en andere laboranten die bijdragen hebben geleverd, zeer veel dank voor jullie inzet.

Dr. R. Walstra en drs. D. Koster, werkzaam als radioloog in het azM gedurende respectievelijk de begin- en eindfase van het onderzoek. Beste Robert en Dick, met jullie hulp heb ik een klein beetje inzicht gekregen in de techniek van angiografie. Mijn dank hiervoor. Robert in het bijzonder ook dank yoor je commentaar op de concepten.

Dr. F. Schulz en Dr. J. Zoetelief van TNO, CSD. Beste Frank, door jouw Monte Carlo berekeningen is de kwaliteit van de schattingen van de effectieve dosis aanzienlijk toegenomen. Beste Hans, dankzij jouw bereidwillige opstelling heb ik gebruik kunnen maken van jullie faciliteiten.

Dr. A. Bos van het IRI/TU Delft. Beste Adri, onze gezamenlijke inspanningen om met hoog gevoelige thermoluminescentie dosimeters metingen uit te voeren aan catheteriseurs en assistenten in de klinische praktijk hebben succes gehad. Mijn dank voor de beschikbaar gestelde diensten en discussie bij de evaluatie van de resultaten.

Ir. J. Hemelaar, Technische Universiteit Eindhoven. Beste Jos, jouw commentaar op concepten van teksten is zeer waardevol geweest. Ik verwacht dat we onze discussies over scheve verdelingen opnieuw kunnen gaan oppakken. 
Ms. M. Zankl, GSF-Institut für Strahlenschutz. Dear Ms. Zankl, I am grateful to you for sharing your time and computer resources with me in order to provide organ dose conversion coefficients for patient dosimetry in vascular radiology. It was a great support. Many thanks for your discussion on dosimetric topics and your collaboration.

Van de anderen die niet met name zijn genoemd wil ik nog in het bijzonder bedanken:

Drs. G.O. Veldhuyzen van Zante (radioloog), Dr. Ph.J. De Korte (radioloog), J. Slot, I. Mertens en J. Laumen van het De Weverziekenhus te Heerlen.

Drs. C. Kamps (radioloog), Drs. D. Touw (klimisch fysicus), H. Mentink en C. Hintzen van het Maasland Ziekenhuis te Sittard.

Peter Vaessen (HTS-afstudeerstage), Robert Peperkamp (HIO-stage), Richard Renkens (HIO-stage), Martin Jäkhel (RL-stage).

An Mordant, Christianne Schiffer, en Edith, Marcel, Ria, Mia, Peter, allen van de afdeling Radiodiagnostiek azM.

In de persoon van Evert Klein dank ik alle vrienden en kennissen die mij moreel ondersteund hebben bij de realisatie van dit proefschrift.

Tenslotte, maar zeker niet op de laatste plaats hoort hier ook een woord van dank aan mijn echtgenote en kinderen. Binnen de huiselijke kring hebben zij mij de afgelopen jaren regelmatig ontzien en gesteund bij het langdurig verblijf in de studeerkamer. Paulette, Thomas en Cécile, jullie verdienen de meeste dank, ik draag het proefschrift dan ook graag aan jullie op. 


\section{Curriculum vitae}

5 juli 1952 Geboren te Simpelveld

$1964-1969 \quad$ R.K. HBS te Kerkrade

1969-1977 Studie chemische technologie aan de Technische Universiteit Eindhoven

1978- 1990 Wetenschappelijk assistent/ambtenaar bij de Stralingsbeschermingsdienst, Technische Uniwersiteit Eindhoven

1979

1981

Opleiding stralingsdeskundige (niveaw 3 )

$1990-1993$

Opleiding stralingsdeskundige (niveau 2)

Fysicus/wetenschappelijk onderzoeker bij de afdeling Radiodiagnostiek van het Academisch Ziekenhuis Mastricht

1991. - heden

Bestuurslid Nederlandse Vereniging woor Stralingshygyene (secretaris)

1994 - heden Algemeen stralingsdeskundige bij de Dr. Daniel den Hoed Kliniek, Academisch Ziekenhuis Rotterdam, Erasmus Universiteit Rotterdam. 